\title{
UC-NRLF
}

||||||||||||||||||||||||||||||||||||||||||||||||||||

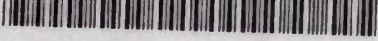

B 4 49ᄅ 334 


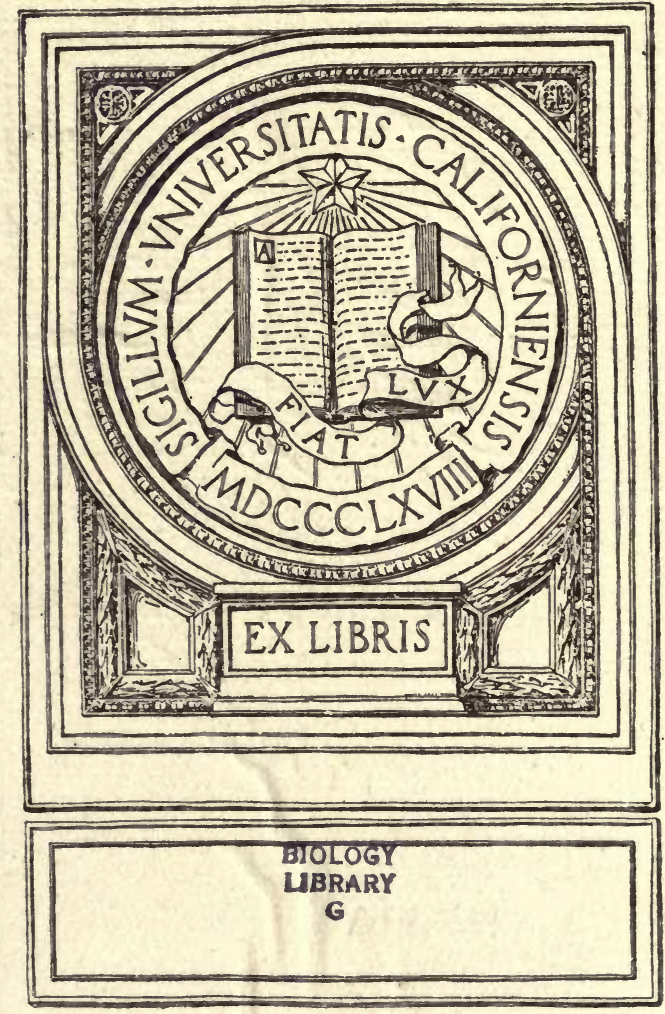









\section{PRINCIPLES OF}

\section{MICROBIOLOGY}

A TREATISE ON BACTERIA, FUNGI and PROTOZOA PATHOGENIC for DOMESTICATED ANIMALS

BY

VERANUS ALVA MOORE, B.S., M.D., V.M.D.

Professor of Comparative Pathology, Bacteriology and Meat Inspection, New York State Veterinary

College at Cornell University, and

Director of the College

ONE HUNDRED AND ONE ILLUSTRATIONS

ITHACA, N. Y.

CARPENTER \& COMPANY

1912 


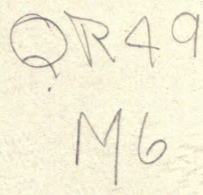

BIOLOGY LIBRARY

\section{COPYRIGHT IgI2}

BY

CARPENTER \& COMPANY

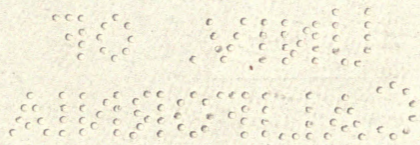




\section{TO ALL THE STUDENTS}

WHO HAVE STUDIED IN MY LABORATORY AND BY THEIR INTEREST HAVE STIMULATED ME TO RENEWED EFFORT TO MEET THE NEEDS OF BEGINNERS IN THE STUDY OF MICROBIOLOGY THIS VOLUME IS APPRECIATIVELY DEDICATED. 


\section{PREFATORY NOTE.}

This volume has been prepared as a text-book for veterinary students beginning the study of microbiology. It is not exhaustive but rather elementary in character. In its preparation, the purpose has been to point out the place and rôle of microörganisms in nature; to give the methods for their study and identification; to indicate the relation of certain species to animal diseases; to give a description of the more important species pathogenic for animals; and a brief discussion of the reaction of the tissues to microbian invasion and the theories of immunity. Each of these topies has a voluminous literature but the undergraduate can familiarize himself with a few of the essential facts and principles only. In recognition of this, the purpose has been to give a few of the more important facts and to explain briefly the essential principles and theories of infection. In order that the volume may be of further aid as a key to the entire subject, numerous references to the literature are given where the student can obtain at first hand the results of original research. Further, a list of text and reference books on the subject is appended.

This volume is the outgrowth of a lecture course which has accompanied the laboratory work in bacteriology and protozoology. I have endeavored to choose the material that will be of most help to the student of animal diseases and to avoid as much as possible matters of controversy. I wish to acknowledge my indebtedness for assistance derived from the various text books, reports and current literature on this subject. For reading copy and other assistance I wish to thank Drs. S. H. Burnett and C. P. Fitch of this department. 


\section{TABLE OF CONTENTS.}

List of Illustrations........................ vii

List of text and reference books................. $\mathrm{x}$

CHAPTER I.

Page

Historical Sketch $\ldots \ldots \ldots \ldots \ldots \ldots \ldots \ldots \ldots \ldots \ldots \ldots \ldots \ldots$

CHAPTER II.

Bacteria and their Place in Nature................ 8

CHAPTER III.

Morphology of Bacteria....................... 16

CHAPTER IV.

Classification of Bacteria and the Identification of Species.... 29

CHAPTER V.

Bacteriological Apparatus...................... 52

CHAPTER VI.

Sterilization and Disinfection...................... 64

CHAPTER VII.

The Preparation of Media for the Cultivation of Bacteria......

CHAPTER VIII.

The Isolation and Cultivation of Bacteria $\ldots \ldots \ldots \ldots \ldots \ldots .97$

CHAPTER IX.

The Examination of Cultures..................... 108

CHAPTER $\mathrm{X}$.

The Microscopic Examination of Bacteria and Stains Employed 120

CHAPTER XI.

Vital Activities of Bacteria........................ 140

CHAPTER XII.

The Relation of Bacteria to Disease.................. 156 
CHAPTER XIII.

The Use of Animals in Bacteriological Examinations and Inves-

tígations

CHAPTER XIV.

The Bacteriology of Water and Milk.

CHAPTER XV.

Coccaceae. Genus Streptococcus and its Species Pathogenic for Animals

CHAPTER XVI.

Coccaceae. Genus Micrococcus and its Species Pathogenic for Animals

CHAPTER XVII.

Bacteriaceae. Genus Bacterium and its Species Pathogenic for Animals

\section{CHAPTER XVIII.}

Bacteriaceae. Genus Bacillus and its Species Pathogenic for Animals

CHAPTER XIX.

Bacteriaceae. Genus Pseudomonas Migula

CHAPTER XX.

Higher Bacteria and Fungi Pathogenic for Animals

CHAPTER XXI.

Protozoa, their Classification and Species Pathogenic for Animals

CHAPTER XXII.

Epizootic Diseases of Undetermined Etiology (Filterable Viruses)

CHAPTER XXIII.

Specific Bacterial Products, Tissue Reactions and Immunity...

CHAPTER XXIV.

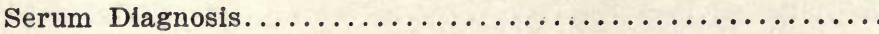

CHAPTER XXV.

Immunity and Vaccine Therapy $\ldots \ldots \ldots \ldots \ldots \ldots \ldots \ldots$ 


\section{LIST OF ILLUSTRATIONS IN TEXT.}

1. Bacteria from van Leeuwenhoek .............. Page

2. Higher bacteria ......................... 17

3. Morphology of the genus Micrococcus............. 17

4. Morphology of the genus Streptococcus............ 18

5. Morphology of the genus Bacillus............... 18

6. Morphology of the genus Bacterium .............. 18

7. Different varieties of spirilla .................... 18

8. Arrangement of flagella..................... 21

9. Sporulation and germination of spores........... 24

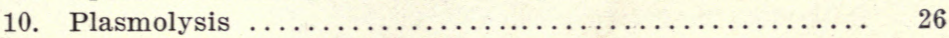

11. Migula's classification of lower bacteria........... 30

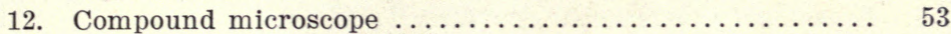

13. Forceps used for handling cover-glasses............ 54

14. Slides for studying living bacteria.............. 54

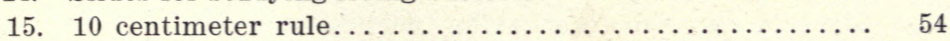

16. Bottles for holding balsam and reagent............ 55

17. Test tubes for culture media .................. 55

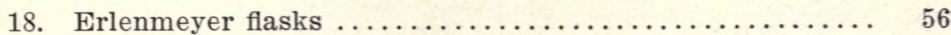

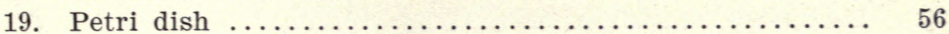

20. Platinum wires and loops for making cultures....... 57

21. Novy's apparatus for plate cultures............. 57

22. Wright's device ............................ 58

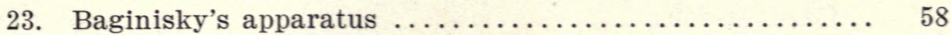

24. Apparatus for cultivating anaerobes............ 59

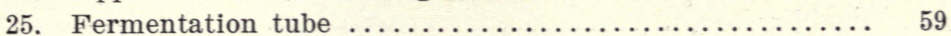

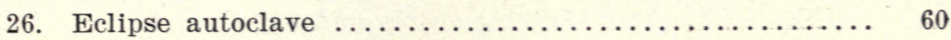

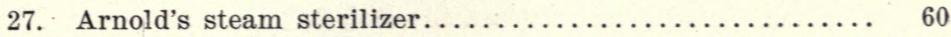

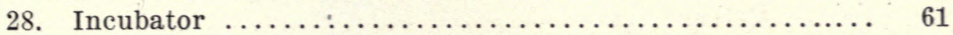

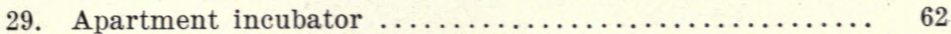

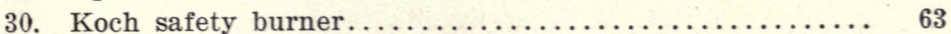

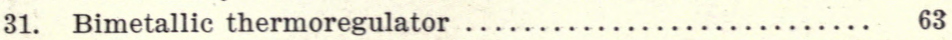

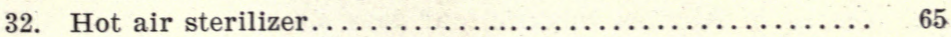

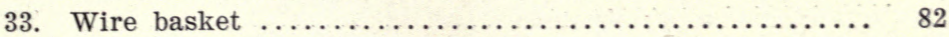

34. Block for holding test tubes.................... 100

35. Types of colonies........................... 110

36. Structure of colonies......................... 111

37. Character of borders of colonies................ 112

38. Jeffers' plate for counting colonies of bacteria......... 113 
39. Characters of surface elevation................ 114

40. Characters of growth in depth of media............ 115

41. Types of liquefaction in gelatin stab cultures......... 115

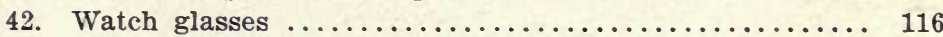

43. Cover-glass preparation of market milk............ 181

44. Chart showing germicidal action of milk........... 182

45. Six forms of streptococci.................. 194

46. Streptococcus pyogenes ................... 197

47. Streptococcus of mastitis..................... 204

48. Micrococcus pyogenes aureus................. $20 \mathrm{~s}$

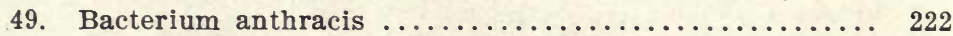

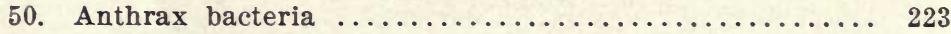

51. Anthrax bacteria ........................ 223

51. Anthrax bacteria on agar plate culture............ 224

52. Colony on agar of anthrax bacteria.............. 224

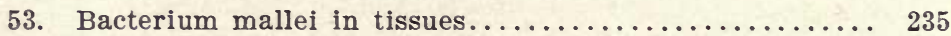

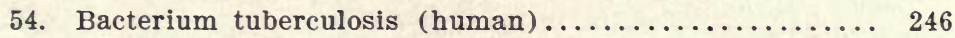

55. Bacterium tuberculosis (bovine) ................ 246

56. Photograph showing tubercle bacteria in milk........ 247

57. Cultures of tubercle bacteria................. 249

58. Glycerin agar culture of avian tubercle bacteria....... 260

59. Avian tubercle bacteria..................... 261

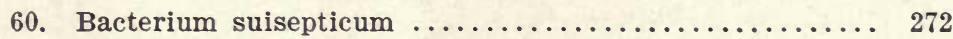

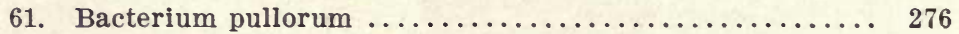

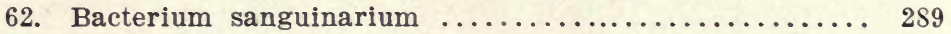

63. Bacterium lactis acidi..................... 301

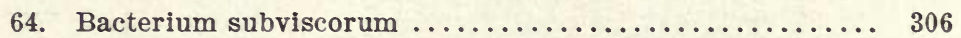

65. Resemblance in morphology of bacteria belonging to different species ........................ 310

66. Bacillus suipestifer in a smear preparation........... 317

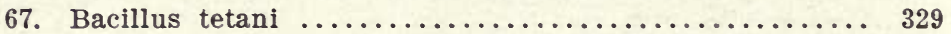

68. Bacillus of blackleg showing spores and flagella........ 336

69. Bacillus of malignant oedema showing flagella and spores 340

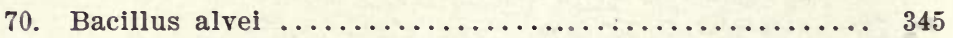

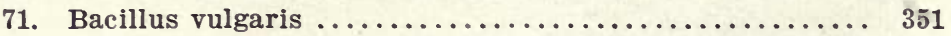

72. Bacillus vulgaris showing flagella from agar culture 12

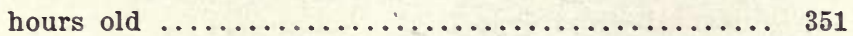

73. Colony of Bacillus vulgaris four days old.......... 352

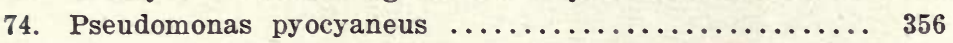

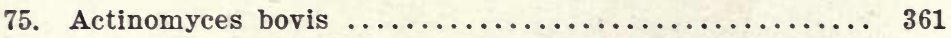

76. Actinomyces bovis. Section of actinomycotic tissue showing small clumps of the fungus.............. 361

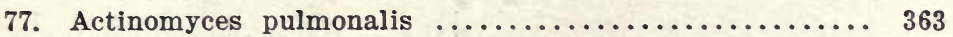

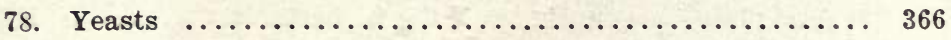


79. Aspergillus fumigatus $\ldots \ldots \ldots \ldots \ldots \ldots \ldots \ldots \ldots \ldots \ldots \ldots$

80. Trichophyton tonsurans from a calf............... 370

81. Ameba meleagridis ....................... 382

82. Piroplasma bigeminum in the red blood corpuscles..... 385

83. Blood in a capillary of the heart showing Piroplasma bigeminum in the red corpuscles............... 385 ,

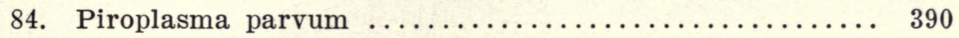

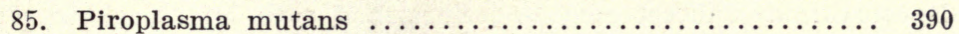

86. Trypanosoma Evansi from rat's blood.............. 397

87. Trypanosoma equiperdum from guinea pig.......... 399

88. Trypanosoma Brucei from rat's blood............... 401

89. Trypanosoma Brucei in blood of a rat............. 401

90. Trypanosoma equinum from blood of a mouse......... 403

91. Trypanosoma Americanum .................... 404

92. Treponema anserina from the blood of a goose........ 407

93. Spirochaetes from the lesions in the diseased skin of a pig . ................................ 410

94. Various stages in the flexions and transverse divisions of Treponema gallinarum .................... 411

95. Life cycle of Treponema gallinarum illustrated diagrammatieally $\ldots \ldots \ldots \ldots \ldots \ldots \ldots \ldots \ldots \ldots \ldots \ldots, 412$

96. Negri bodies in nerve cells ................... 419

97. Sarcocysts in muscle....................... 426

98. Coccidium oviforme from a rabbit's liver............ 429

99. Coccidium oviforme in the section of a rabbit's liver.... 430

100. Diagrams illustrating the production of antitoxin and

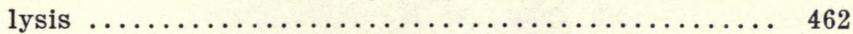

101. Complement fixation with glanders.............. 476 


\section{LIST OF TEXT AND REFERENCE BOOKS.}

Аввотт, A. C.-The Principles of Bacteriology.

ABEL, R.-Handbook of Bacteriology.

Baumgarten.-Jahresbericht u. d. Fortsch. d. path. Mikroorganismen. BowhilL, T.-Manual of Bacteriological Technique and Special Bacteriology.

BUCHANAN, R. E.-Veterinary Bacteriology.

Calkins, G. N.-Protozoology.

Chester, F. D.-A Manual of Determinative Bacteriology.

Cons, H. W.-Bacteria in Milk and its Products.

Crookshank, E. M.-A Text-book of Bacteriology.

Curtis, H. J.-The Essentials of Practical Bacteriology.

Doyer, E. ANd Roussel, G.-Atlas de Microbiologie.

Eisenberg, J.-Bacteriological Diagnosis.

EMerY, W. D.-Clinical Bacteriology and Haematology.

Erre, J. W. H.-The Elements of Bacteriological Technique.

Fischer, A.-The Structure and Functions of Bacteria.

FluegGe, C.-Die Mikroörganismen. 2 vols.

Fraenkel, C.-Text-book of Bacteriology.

Fraenkel, C. And Pfeiffer, R.-Mikrophotographischer Atlas der Bakterienkunde.

Frankland, P. ANd G. C.-Micro-Organisms in Water.

Frost, W. D. And McCampbell, E. F.-A Text-book of General Bacteriology.

Gedoelst, L.-Traité de Microbiologie.

HeIM, L.-Lehrbuch der bakteriologischen Untersuchung und Diagnostik.

Herter, C. A.-The Common Bacterial Infections of the Digestive Tract.

Herzog, M.-A Text-book on Disease-producing Microorganisms.

Hewlett, R. T.-A Manual of Bacteriology.

Hiss, P. H. ANd Zinsser, H.-A Text-book of Bacteriology.

Hueppe, F.-The Principles of Bacteriology.

Jordan, E. O.-A Text-book of General Bacteriology.

Jorgensen, A.-Micro-Organisms and Fermentation. 
Kolle, W. And Wassermann, A.-Handbuch der pathogenen Mikroorganismen. 4 vols.

Lehmann, K. B. and Neumann, R.-Atlas and Principles of Bacteriology. 2 vols.

Mace, E.-Traité Pratique de Bacteriologie.

McFarland, J.-A Text-book upon the Pathogenic Bacteria.

Marshall, C. E.-Microbiology.

Matzuschita, T.-Bacteriologische Diagnostik.

Migula, W.-System der Bakterien. 2 vols.

Mosselman and Lienaux.-Manual of Veterinary Bacteriology.

MuiR, R. AND RITchie, J.-Manual of Bacteriology.

Newman, G.-Bacteriology and the Public Health.

Park, W. H. AND Williams, A.-Pathogenic Bacteria and Protozoa.

Pearmain, T. H. and Moor, C. G.-Applied Bacteriology.

Sмrтн, E. F.-Bacteria in Relation to Plant Diseases. 2 vols.

SternberG, G. M.-A Manual of Bacteriology.

SternberG, G. M.-A Text-book of Bacteriology.

Swithinbank AND Newman-Bacteriology of Milk.

Thoinot, L. H. And Masselin, E. J.-Précis de Microbie.

WILliams, H. U.-A Manual of Bacteriology.

Woodhead, G. S.-Bacteria and their Products.

Wurtz, R.-Précis de Bactériologie clinique. 



\section{CHAPTER I.}

\section{HISTORICAL SKETCH.}

It has been said that "The history of the world is the biography of great men." It ean be stated likewise that the essential facts in the history of mierobiology are in the records of a few great leaders in the study of mieroorganisms. While it is true that many discoveries have been made and important details have been supplied by men of less reputation, the actual principles that have distinguished the seiences of bacteriology and protozoology have been recorded by eomparatively few men. It is in the work of such men that the various steps in the evolution of the subject are to be found. No one can read the findings of Davaine, Pasteur, Sir Joseph Lister, Hueppe, Koch, Weleh, Theobald Smith, Roux, von Behring, Metehnikoff and Ehrlich without experiencing the thrill that comes with the introduction of new facts and better methods. Their diseoveries have already overthrown many of the errors that were entertained concerning natural phenomena and changed the attitude of the people toward many phases of nature's eeonomy. This change brought about in popular conception as well as in scientific theories made it possible to study microorganisms in their relation to the higher forms of life. Bacteriology as a seience began with the work of Davaine, Pasteur and others about fifty years ago. At first progress was slow because both methods and apparatus had to be developed. This is illustrated in the history, of anthrax. In 1849, Pollander saw the bacterium of this disease in the blood of infected animals but it was not until 1876, twenty-seven years later, that Koch obtained it in pure culture.

Historically, the first record of the diseovery of bacteria was made in 1683 by Anton van Leeuwenhoek, a Dutch 
naturalist and pioneer in the world of the infinitely little. By the aid of home-made lenses of wonderful efficiency, he found in the saliva from the human mouth minute organisms to which he gave the name animalcula on account of their power of movement.

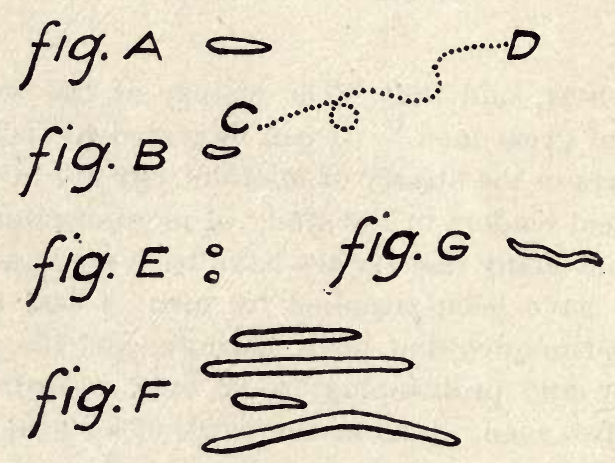

Fig. 1. Oldest known figures of genuine bacteria (Bacteria of the mouth) from v. Leeuwenhoek. A and $\mathrm{F}$ represent Bacillus buccalis maximus. B is perhaps Vibrio buccalis; its movements were followed by $v$. Leeuwenhoek from $C$ to $D$. $E$ is a species of coccus and G no doubt Spirillum sputigenum (Fischer).

In the description ${ }^{1}$ and in the figures he gives curved and straight forms; long and short rods are plainly recognizable. They constitute the first reliable record of bacteria, the study of which in later times has revolutionized medicine and expanded into a new science.

After van Leeuwenhoek, the study of these lower forms was given up, because of the difficulty of observing them with the simple microscope. The discovery of the compound microscope marked a great advance in the study of microorganisms. Müller ${ }^{2}$ was the first to apply this dis-

${ }^{1}$ van Leeuwenhoek. Arcana naturae detecta. The figure dates from the year 1683, and is taken from a new edition of the Arcana published in 1722 (vol. ii, p. 40).

${ }^{2}$ Müller. Vermium terrestrium et fluviatilium Historia, 1774, and Animalcula infusoria fluviatilia et marina, 1786. 
covery in the description and classification of the lower organisms. He succeeded in arranging in order the confused throng of microscopic beings.

Müller divided the bacteria into two classes, Monas and Vibrio, names which are still used. The species of the genus Monas, only incompletely described, can scarcely be recognized; two of the ten species which he includes are evidently short bacteria. In the genus Vibrio he described thirty-one species, six of which are undoubtedly true bacteria.

Lamarck $^{2}$, Bruguière ${ }^{3}$, and Bory de Saint-Vincent ${ }^{4}$ confined themselves to reproducing; either intact or with slight modifications, the principles laid down by Müller which remained as law for nearly a half century.

Ehrenberg, using better instruments, made great pro. gress in the study of microscopic life. In his great work on Infusoria ${ }^{5}$ are found results far superior to those of the workers before his time. He made the new class Vibrionia which he spoke of as "small filiform beings without external organs, united in chains or filiform series through an incomplete spontaneous division." Since that time bacteria have never drifted entirely out of sight.

Dujardin ${ }^{6}$ followed the ideas of Ehrenberg with only slight modifications. He gave new and interesting details on the development of bacteria in different media and the manner of obtaining and studying them.

The results obtained at that time were of great importance; some of them were repeatedly confirmed and are still to be found in the best works of today. The achromatic microscope, which was being brought to perfection, allowed

${ }^{2}$ Lamarck. Histoire des animaux sans vertebres. Paris, 18151819 ; et 2e edition par Deshayes et Milne-Edwards. Paris, 1835-1845.

${ }^{3}$ Bruguière. Encyclopedie methodique. Paris, 1824.

${ }^{4}$ Bory de Saint-Vincent. Encyclopedie methodique. Paris, 1824.

${ }^{5}$ Die Infusionstierchen als vollkommene Organismen. Berlin 1833. 1841.

${ }^{6}$ Dujardin. Histoire naturelle des Zoophytes Infusoires, Paris 
the experiments made by such workers as Dujardin to advance to a successful conclusion.

Until about 1850, the appearance of these organisms, animalcula as they were then called, in liquids such as meat broth was considered as a mere chance phenomenon. At the same time very appreciable changes were observed in the liquid in question, but no one supposed that there existed between the two orders of facts such a close relation as cause and effect.

To Pasteur belongs the great honor of having established beyond a doubt the close connection or causal relation between fermentative changes in certain liquids and the development within them of bacteria. In his work on fermentation of milk he laid the foundation for the physiological study of microorganisms. ${ }^{7}$ What he had shown by this fermentation he applied to others and made a succession of scientific studies and experiments the results of which have perhaps never been surpassed.

Pasteur introduced the physiology of bacteria, and Davaine pointed to the significance of their pathological powers. Pasteur's studies on the disease of the silk worm were the first to be made on the cause of an infectious disease, although Pollander, Davaine and others had observed rod-shaped bodies in the blood of animals dead of anthrax.

It was not, however, until about 1870 that the subject was taken up by pathologists, who from that time to this have contributed more than any others to the upbuilding of the science of bacteriology. With the publication of Robert Koch's first studies on anthrax began the activity of numerous investigators, whose incessant industry has furthered our knowledge of these minute organisms and has accumulated a vast literature. Before this period of expansion and rapid growth, bacteria had been studied chiefly by botanists of whom Cohn and Nägeli were most active. Their work

${ }^{7}$ Pasteur. Mémoire sur la fermentation appelée lactique (Ann. de chim. et de phys., 2e serie, LII, p. 404). 
had been both physiological and structural, and it is on the foundation which they laid that the science in its modern form has been built up. For the fundamental labors of the earlier years, the student is referred to Löffler's lectures on the history of bacteriology. ${ }^{8}$

The first important work in bacteriology was the establishment by Pasteur of the relation of bacteria to fermentation. This was followed by demonstrating the "Germ theory" of disease first suggested by Henle in 1821. The introduction of cotton plugs to remove bacteria from air by Schroeder and von Dusch in 1854 ; the sterilization of culture media by heat, perfected by Pasteur, Koch and others; the demonstration of the transmissibility by inoculation of anthrax by Davaine (1863) and of tuberculosis by Villemin (1865); the application in surgery of germicidal substances by Sir Joseph Lister, in 1875; the publication of the work on wound infectious diseases by Koch in 1878; the introduction of the aniline dyes for staining bacteria by. Weigert in 1877; and the introduction of solid culture media by Koch in 1881, are among the more important of the early discoveries in bacteriology.

The first observers, Müller, Ehrenberg and Dujardin, regarded bacteria as part of the animal kingdom. The motility of some known species was, in their opinion, a characteristic which the plant kingdom must necessarily lack. Later, when Davaine had proved, from his study of the bacteria of anthrax, the absolute immotility of certain species in the whole cycle of their existence, species which could in no other way be distinguished from their neighbors, ideas on the subject of bacteria underwent a complete change. Davaine $^{9}$ placed the Algae in the class with the Oscillaria, and included in it the Beggiatoas or Sulfurairer. Raben-

${ }^{8}$ Löffler. Vorlesungen über die geschichtliche Entwickelung der Lehre von den Bakterien. Part I, up to the year 1878 (all that has appeared), Leipzig 1887.

'Davaine. Récherches sur les Vibrioniens (C. R. de l'Acad. des Sc., 1864). Voy aussi "l'Oeuvre de Davaine." 
horst ${ }^{7}$ shared this opinion and classed them with the Oscillaria. Since that time most naturalists have placed them as the lowest class of the vegetable kingdom. Haeckel ${ }^{8}$ relegated bacteria to the Protista, beside the Monas; Pasteur regarded them as Infusoria. De Bary ${ }^{1}$, Balbiani ${ }^{2}$, Künstler $^{3}$, and Bütschli ${ }^{4}$ placed them with the Flagellates.

The name Bacteria was proposed by Cohn in 1872 . The term Microbe, introduced by Sëdillot in 1878, belongs not only to the bacteria but also to the Yeasts, Moulds, and Protozoa; the same is true of the popular term Microorganism.

In protozoology the discovery of the malarial plasmodium by Laveran in 1880; of the piroplasma of Texas fever and its transmission by means of the cattle tick by Smith and Kilborne in 1889; and the discovery of the trypanosomes that are the cause of certain diseases of animals, laid the foundation for the enormous amount of work that has been done in determining the existing relation between protozoa and certain diseases in animals and in man.

The earlier work in bacteriology and parasitic protozoology had for its purpose the finding of the cause of the different infectious diseases.

The discovery of tuberculin by Koch in 1890, and the production of antitoxin in the blood of animals infected with certain bacteria such as those of diphtheria and tetanus by von Behring, Roux and others, led to investigations concerning tissue resistance and reaction to microorganisms and alien substances of a protoplasmic nature. This resulted in the development of the present theories of immunity as

${ }^{7}$ Rabenhorst. Flora europaea Algarum, 1865.

${ }^{8}$ Haeckel. Le Regne des Protistes, 1879.

${ }^{1}$ De Bary. Morphologie und Biologie der Pilze, Mycetozoen und Bacterien, 1884.

${ }^{2}$ Balbiani. Jour de micr., 1886 et suiv.

${ }^{3}$ Künstler. De la position systematique des Bacteriacees (Jour. de micr., 1885).

${ }^{4}$ Bütschli. Ueber den Bau der Bacterien und verwandter Organismen, 1890. 
set forth by Metchnikoff and Ehrlich and vaccine therapy which at the present moment is attracting much attention.

Although the methods that have been introduced for the study of specific etiology have resulted in finding the cause of a very large number of infectious diseases, they have not been sufficient to demonstrate the etiology of epizootic hog cholera, rinderpest, foot and mouth disease, dog distemper and other important plagues of the domesticated animals. Many of these diseases have been found to be due to agents that will pass through the Berkefeld or Chamberland filters and consequently the causes of these maladies. are spoken of as filterable viruses. 


\section{CHAPTER II.}

\section{BACTERIA AND THEIR PLACE IN NATURE.}

Bacteria. Bacteria are minute unicellular, living organisms generally accepted as belonging to the vegetable kingdom.* They are placed among the lowest of the Thallophytes. Naegeli called them "fission fungi" or Schizomycetes, because they usually reproduce by transverse division or fission. Under favorable conditions they multiply very rapidly. Bacteria do not possess chlorophyl. Their structure seems to be very simple but their functional activities are exceedingly varied. Although microscopic, they differ in size, form and properties to such an extent that several families, many genera, and hundreds of species have already been recognized and described. The part of biology which deals with the distribution, morpho-

* The relation of bacteria to the animal kingdom on one side and to the vegetable kingdom on the other has been contested by several workers. The question is often asked, Are bacteria animals or plants? As Fischer has so admirably pointed out, "The terms 'animal' and 'plant' are collective terms invented by laymen to describe familiar living things, insects and elephants, mosses and oak trees, and they date from a time when such minute beings as bacteria were quite unknown. It is therefore as superfluous as it is futile to attempt, as many have done, to detect the distinguishing characters of the 'animal' and the 'vegetable' kingdoms among organisms for which these terms were never intended. For this reason Haeckel and others have proposed to establish a third domain, that of the Protista, which shall include all those forms in which differentiation has not been pronounced on the lines of either animal or plant development. The n'w group would take up Radiolarians, Flagellata, and Infusoria from the animal side, and the Cyanophyceae as well as some low forms of Algae and Fungi from the plants. The border line between protista on the one hand and plants and animals on the other, is, it must be confessed, artificial. To these protista; which embrace approximately all those forms of life we commonly call microorganisms or microbes, the bacteria belong." 
logy, classification and function of bacteria is called Bacteriology.

Distribution of bacteria in nature. Bacteria exist nearly everywhere in external nature. Their home is in the soil, in water, in milk, on the skin of man and animals, and on certain of their mucous membranes, especially those of the alimentary tract. They are not usually found within the tissues of healthy plants, or in the blood and tissues of healthy animals, ${ }^{1}$ and but rarely on certain of the mucous membranes, such as those of the lungs, kidneys and bladder. Occasionally they are carried through the skin or they pass through the mucous membranes of the digestive tract after which they may be found for a short time in the blood and living tissues of the body. ${ }^{2}$

When considering the distribution of bacteria, it is necessary to discriminate first of all between actively growing bacteria and latent forms. Highly resistant bacterial spores, and the hardly less resistant dried vegetative forms of some species, occur very generally upon the earth's surface and upon the animals, plants, and inanimate objects that cover it. They are, in short, ubiquitous. But living bacteria in active growth or multiplication occur only where the life conditions necessary for their multiplication are

${ }^{1}$ Ford (Transactions of the Asso. of Am. Physicians, Vol. XV (1900) p. 389) found that at least $80 \%$ of the livers and kidneys of healthy normal animals contain bacteria which will develop on culture media if allowed to incubate for a sufficiently long time after removal from the body. He states that other observers have obtained negative results because they rejected their cultures too soon. Among the bacteria isolated Ford obtained streptococci, M. pyogenes, Paracolon, B. Mesentericus, vulgatus, fuscus, B. proteus, B. coli and others.

${ }^{2}$ Nocard (Compt rendu de la Soc. de Biol., Vol. XLVII (1895) found bacteria in the blood of horses when it was drawn at certain times relative to feeding, but not at other times. Ravenel (Jour. of Med. Research, Vol. X (1904) p. 460) verified previous observations that the tubercle bacterium would pass through the mucous membrane of the intestine when taken in connection with fat. 
fulfilled, namely, in places where there are moisture, the required temperature, proper gaseous environment, and a suitable supply of food. These conditions are found in ponds. or rivers contaminated with organic matter, such as dead plants or animals, and in soils containing more or less moisture together with organic matter. In the habitations of man and beast they are found in the various foods, such as milk and other dairy products, stale meat and cooked vegetables when not properly refrigerated, and in moist places. in stables and yards for animals. In the animal body they are found on the mucous membrane of the digestive tract, especially of the mouth, and the small and large intestines. There are, however, great differences in the conditions of life and nutrition required by the different species and varieties. Bacteria have been reported to multiply in a temperature ranging from $0^{\circ}$ to $75^{\circ} \mathrm{C}$. Some are able to live in water containing a slight amount of organic substance and others in purely organic matter, such as decomposing vegetables and animal tissues. For some bacteria free oxygen is necessary for their multiplication, and the growth of others is promptly stopped by its presence.

The bacteriological analyses of soils, water, milk, mucus from the mouth and intestines of living animals, and decomposing plants and animals, show great differences in the number and varieties of bacteria present. This is accounted for in part by the difference in the food supply furnished by these different substances for the organisms, and in part by the selective power of the bacteria themselves. These facts are very important, as they furnish us with certain data that explain somewhat the existence of bacterial floras. Thus in pure spring water there are very few bacteria, while in water contaminated by soil drainage many organisms arepresent, often including many species. In uncontaminated, freshly drawn milk, there are certain species of bacteria that come from the milk ducts of the udder where they have become localized and multiply. Again certain species: inhabit the deep layers of the skin including the ducts: 
of the sweat glands. In like manner the mucous membrane of the intestine harbors certain species of bacteria. In a soil that is richly fertilized with organic matter a still greater variety of bacteria is found. The difference in the species that are found in these different substances and places is so pronounced that they are spoken of with considerable definiteness as the bacterial flora of these particular substances or places such for example as the bacterial flora of spring water, of milk, of the skin, and of the intestine. It must be understood that other bacteria are frequently present and that all the species of these different flora are never present in any individual case.

When reference is made to a bacterial flora it is important to distinguish between the organisms which become localized and multiply in a given place and which constitute its flora and the bacteria which are brought to the place by accident. Thus, in the intestine, the bacteria of the contents brought there with the food must be distinguished from those that inhabit the mucous membrane and which appear in cultures made from the scrapings of the mucosa after the contents have been washed off with sterile water.*

* For a study of the bacteria of the digestive tract the student is referred to the work by Herter (Bacterial infections of the digestive tract, MacMillan Co., 1907). Bullard (Am. Med. Vol. IV (1902) p. 546.) showed that the $B$. coli invasion of the intestine of rabbits depended largely upon their environment. Löber ( $A m$. Med. Vol. VII (1904) p. 152) found that the intestinal flora of fish from Cayuga Lake did not contain $B$. coli but $B$. proteus were quite common. Ward (Bulletin 178, Cornell Agric. Exp. Station, 1900) found certain species of bacteria throughout the udder. In the 19 specimens examined there was great uniformity in the species revealed. Bacteria not commonly present in the udder may occasionally gain entrance and remain for a shorter or longer time. King (Amer. Med. Vol. $X$ (1905) p. 400) found the bacterial flora of the intestinal mucosa of the fowl to be quite constant and to consist of about 50 species. He found the flora in the different fowls to vary somewhat according to the conditions under which they had been kept. He also studied the flora of the conjunctiva and found that it consisted of a few species distributed between the genera bacterium and micrococcus. 
From the localized habitat of these species, such as the intestine for Bacillus coli, large numbers of individuals are carried to other places where they multiply if the life conditions are suitable, or perish if they are not. The colon bacilli which normally multiply in the intestinal tract and are expelled with the contents, continue to multiply if by ehance they are brought into a suitable environment. If, however, they are under conditions unfavorable for their multiplication they soon die. This is equally true of the disease-producing forms which are eliminated from infected individuals.

Among bacteria, there are a few species that have acquired, if they did not possess it in the beginning, the power to live and multiply in the living tissues of the body. These are spoken of as the parasitic or paratrophic (Fischer) bacteria. They are also spoken of as pathogenic bacteria. However, but a small percentage of the species that thrive on the different mucosae or in the deep layers of the skin are capable under usual conditions of producing morbid changes. The majority of bacteria have for their source of food supply dead organic matter either of animal or plant origin. Such organisms ean not exist in living tissues. These are designated as saprophytic or metatrophic (Fischer) bacteria.

The role of bacteria in nature. Bacteria play a very important part in nature's economy. Through their functional activities the highly complicated tissues of plants and animals are resolved into simple compounds such as carbonic acid $\left(\mathrm{CO}_{2}\right)$, water $\left(\mathrm{H}_{2} \mathrm{O}\right)$ and ammonia $\left(\mathrm{NH}_{3}\right)$, in which form they may be appropriated as nourishment by the more highly organized plants. In this way they are able to remove as scavengers dead organic matter by converting it into food necessary for the life of higher vegetation. This is important, as chlorophyl plants do not possess the power to obtain their carbon and nitrogen directly from such highly organized substances as serve for the nutrition of bacteria. As the production of the simple compounds by 
the animal world is not sufficient to meet the demands of the chlorophyl plants, the importance of the part played by bacteria in preparing food that can be assimilated by higher plants can not be overestimated. The continuance on the earth of the higher forms of life is, when reduced to its last analysis, dependent upon the activities of microscopic organisms. In addition to the preparation of organic matter for plant food by the saprophytic bacteria, there are other species which live in the soil and in the roots of certain leguminous plants that are able to take the free nitrogen from the air and store it up in the roots of plants for their nourishment.*

In their work as scavengers, bacteria are undoubtedly more or less assisted by other low forms of vegetation, such as yeasts, moulds and possibly other fungi. The part, if any, played by minute forms of animal life is not clearly defined.

Divisions of Bacteriology. When the study of bacteria is considered in a broad sense, bacteriology divides itself very naturally into several quite distinct lines.

1. The study of the bacteria in the soil and their relations to plant life constitutes what is now recognized as agricultural bacteriology.

* There are in nature, according to Fischer, five sources of nitrogen open to plants and animals:

"1. The atmosphere ( 79 per cent. by volume of free nitrogen).

2. The nitrates of the soil and the traces of nitrous acid formed in the air during thunderstorms.

3. Ammonia, which occurs in minute quantities in the air, and is set free abundantly by the putrefaction and decay of dead organisms.

4. Animal excreta, which contain nitrogen compounds of many kinds, even down to ammonia; and

5. The tissues of plants and animals.

The first three of the above-named sources are useless to animals, for they obtain their nitrogen from plants only, either directly (herbivora), or indirectly through other animals (carnivora). To. plants, on the other hand, n'trogen seemed until comparatively recently to be available only in one of these three forms. Vegetable 
2. The consideration of the bacteria in milk and their relations to dairy products such as pure milk, butter and cheese forms a very distinct line of investigation, already possessed of an extensive literature, known as dairy bacteriology.

3. The study of the bacteria that are useful in the arts, those found to be advantageous in the manufacture of, or more or less destructive to, certain food preparations, such for example as canned vegetables, has somewhat closely circumscribed what is known as industrial bacteriology.

4. The inquiries into the causes of plant diseases have shown that many of the ills of our flowers, fruits and vegetables are due to the invasion by certain bacteria. We have thus a distinct line of bacteriology in the study of plant pathology.

5. A certain number of bacteria that are more or less parasitic for animals and man and which when multiplying within or upon the tissues of the body produce serious physiological disturbances or morbid ehanges in the tissues constitute another very important part of bacteriology. As it was the discovery of the bacteria capable of producing disease in man and animals that first brought bacteriology into general recognition, the term bacteriology usually sug-

physiologists had come to the conclusion that in nature the nitrates of the soil were the one and only form in which nitrogen was taken up by plants. For although it was known that experimental plants could be induced to take up ammonia salts and even gaseous ammonia, it was evident that ammonia was not a common source of nitrogen in nature. And, finally, the atmosphere, the greatest storehouse of nitrogen, seemed closed to plants. These views, however, were overturned by detailed investigations into the nutrition of the Leguminosae. That the Leguminosae could grow in soil poor in nitrogen and thrive thereon, even without nitrogenous manuring, had long been known, and it has now been demonstrated that they take up nitrogen from the air and convey it to the soil. This enrichment is particularly evident when the plants are ploughed in. All other plants, all our cereals and food crops, are, as regards the soil, merely consumers of nitrogen, since they are unable to take it up in any form but that of the nitrates of the soil." 
gests a treatise on bacteria pathogenic for man and animals.

A further analysis of the powers of the disease producing forms, reveals the interesting fact that these organisms may be divided according to their pathogenesis into three quite distinct groups, namely :

(1) Those that are restricted in their pathogenesis to the human species.

(2) Those that are restricted in their pathogenesis to certain species of the lower animals.

(3) Those that are pathogenic for man and one or more species of the lower animals.

This classification has reference to natural infection. A number of bacteria that in the natural course of events attack but one species of animals or man, are capable of causing tissue disturbances in other species when they are brought into their tissues. Thus the bacterium of glanders naturally affects the equine family only, but it is pathogenic for guinea pigs when these animals are inoculated with the organism.

Human bacteriology therefore deals with the life history and properties of the bacteria that produce disease in man. Animal bacteriology includes a study of the species of bacteria that are the cause of diseases in the lower animals. Each necessarily overlaps the other and experimentally the use of animals plays an important part in the study of all pathogenic bacteria.

The lower bacteria have, within certain limits, a uniform structure, and the fundamental methods employed in their study are the same. The principles of bacteriology, therefore, have a general application in the study of all bacteria, but for the more exact determination of the properties of different species or groups of organisms, such for example as the nitrifying bacteria, special methods are necessary. 


\section{CHAPTER III.}

\section{MORPHOLOGY OF BACTERIA.}

General grouping. The minuteness of bacteria renders investigation into their structure somewhat difficult. When they are examined microscopically in the fresh or living condition they appear as colorless, refractive bodies of different shapes and sizes. According to their morphology, bacteria are divided into two groups, viz., the lower and higher forms.

Lower bacteria. The lower bacteria consist of unicellular, spherical, rod-shaped, thread, or spiral forms, rarely more than three to five microns* in length. The largest forms met with in animals do not exceed ten microns in length and perhaps 2.0 microns in thickness. The smallest are 0.5 micron long and 0.1 to 0.2 micron in width. They are divided into three distinct classes, namely, the spherical, the rod-shaped, and the spiral forms. They are rarely branched. Lower bacteria reproduce in the vegetative form by fission or transverse division.

Higher bacteria. The higher bacteria are characterized by quite definite branched or unbranched filaments. In most cases the filaments are cut transversely at regular intervals by septa into short rod-shaped or curved elements. Some have a definite membrane or sheath common to all the elements in the filament. In certain cases the free ends only seem to be endowed with reproductive function. They develop bodies known as conidia. In this group belong the Chlamydobacteriaceae and the Beggiatoa.

The most striking features in the development of the

$* A$ micron $=.001$ of a millimeter $=1 / 25000$ of an inch. It is: the unit for microscopic measurements. 
higher bacteria are the long filaments made up of shorter segments and the whole surrounded by a sheath, the occasional branching of the filaments, and in some cases, the setting apart of certain elements (conidia) for the purpose of reproduction. The distinctive morphological characters of the genera of the higher bacteria are given under the

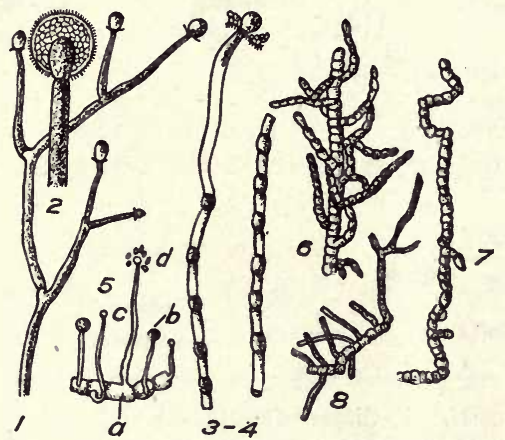

Fig. 2. Higher bacteria: 1, branched filament carrying spores; 2 , cross section of spore highly magnified; 3 and 4, spore building; 5 , developing and bursting spores; 6 and 7 , branching and sprouting spores. (After Tavel.)

chlamydobacteria in Migula's classification. There is not a uniform agreement among authors regarding the generic characters. These organisms are, however, of much less importance pathologically than the lower bacteria.

Morphology of the lower bacteria. The vegetative form of all the lower bacteria consists of single cells. In form they differ to such a degree that three basic forms or types are recognized, namely, the spherical (coccus), the rod-

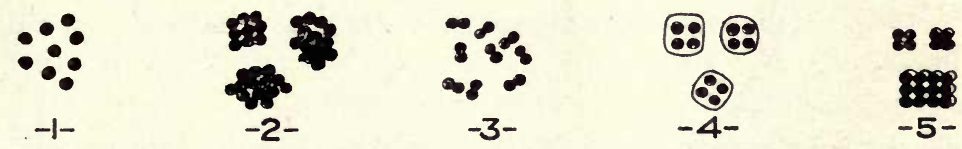

Fig. 3. Spherical forms. 1, micrococci; 2, micrococci clumped (staphylococci); 3 , micrococci in pairs (diplococci); 4, tetracocci (micrococci, not separated after division); 5, in packets (sarcina). 
shaped (bacterium and bacillus), and the spiral (spirillum). Although these forms vary considerably it is ordinarily not difficult to determine to which type a given organism belongs. These forms, within well defined limits, are constant when under conditions favorable to growth. The micro-
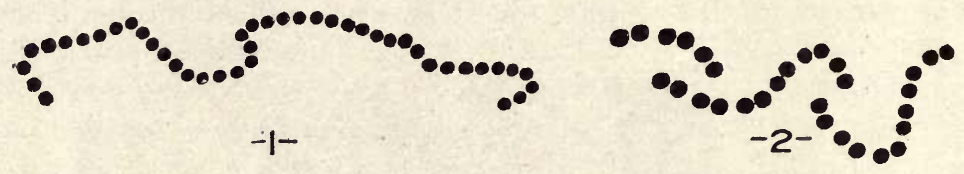

Fig. 4. Streptococci (micrococci in chains). 1, long slender chains;.2, shorter chains in which the segments appear in pairs.

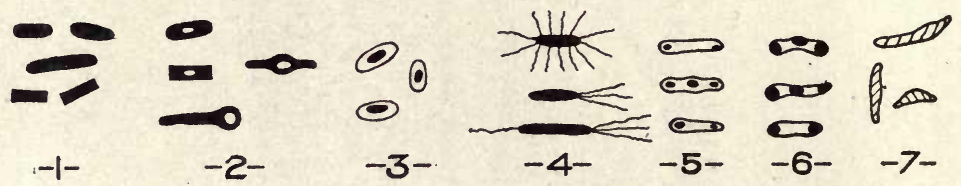

Fig. 5. Bacilli. 1, different shaped rods; 2, showing spores; 3, capsules; 4, flagella; 5 and 6 , granules; 7 , involution forms.

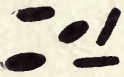

$-1-$

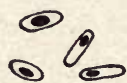

$-2-$

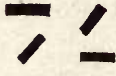

$-3-$

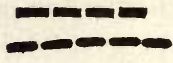

$-4-$

Fig. 6. Bacterium. 1, different forms; 2, spores; 3, square at rends; 4 , united in short chains.

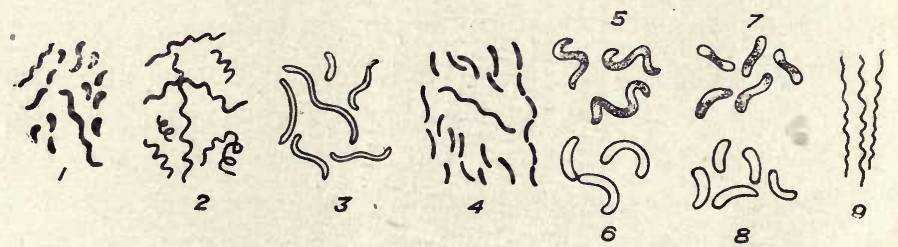

Fig. 7. Spirilla. The figures show different varieties of spiral forms.

cocei produce micrococei; bacilli produce bacilli; and spirilla produce spirilla. Although these types are constant, there is found on examining cultures of any of them while in the 
active process of multiplication that there is considerable variation in the form and size of the individual organisms. The variation is explained by the fact that the form of the bacterial cells at full development differs from that which they possess just after or just before they have divided. As the spherical organism develops preparatory to its division it becomes elongated and appears as a short oval rod just prior to division. A short rod becomes in the same way, at the moment of its division, two organisms, the longitudinal diameter of each of which may be even a trifle less than its transverse diameter, when, on a superficial examination, they might be mistaken for micrococci.

Certain species of bacteria have a greater or less tendency to "emain more or less loosely attached after division has taken place. This is on account of the capsule-like envelope which surrounds the organisms. This hanging together may cause the organisms to appear as an aggregation or clump of bacteria as in the case of the staphylococcus or they may be attached so closely end to end that the two or more may appear almost as a single rod or filament, or again as in the streptococcus the individual elements appear as a chain.

Structurally all bacterial cells belonging to the lower bacteria have (1) a cell wall and (2) a cell content (cytoplasm, central body or nucleus) or, after Fischer, a protoplasmic outer layer and a central fluid. In addition to these, some species have eapsules, others spores, and others flagella. Many species contain granules (metachromatic bodies). Plasmolysis often causes a concentration of the cytoplasm suggesting granules or spores.

Cell wall. When bacteria are examined microscopically in a living condition in salt solution or bouillon, they appear as colorless, refractive bodies with or without spores. When stained preparations of these bacteria are examined, they appear to have a rather indefinite cell membrane or wall which surrounds a central protoplasm or cell substance. 
This outer layer or membrane is thought by some to be a much more eoncentrated substance than the central portion but otherwise the same. With possibly a few exceptions, it is not known to contain céllulose.

The presence of the so-called shadow forms which appear as empty capsules and, with species that produce spores, the frequent appearance of a well-outlined cell body after the vegetative form has degenerated in the course of the formation of spores, strengthens the assumption that there is a well-defined cell membrane or wall.

Cell contents. According to Fischer ${ }^{1}$ the cell contents are composed of a substance similar to the membrane or cell wall except that it is not so dense. Bütschli ${ }^{2}$ claims to have demonstrated within this entoplasmic substance a reticular meshwork, between the spaces of which lie granules of chromophilic or nuclear material. Zettnow ${ }^{3}$ states that the contents contain a nucleus, or a substance equivalent to the nucleus of the more highly developed cells, lying within a net-work of protoplasm. Other observers ${ }^{4}$ have confirmed this opinion. Zettnow originally thought the greater part of the organism was of a nuclear nature. The nuclear substance takes the chromatin stain and is often so abundant that the structure holding it is covered up. Whether or not

${ }^{1}$ Fischer. The Structure and Functions of Bacteria. Oxford, 1900.

${ }^{2}$ Bütschli. loc. cit.

${ }^{3}$ Zeit. f. Hyg., Bd. XXIV (1897).

'Nakanishi. Münch. Med. Wochenschrf., Bd. VI (1900).

The method of Nakanishi is carried out as follows: Thoroughly cleansed slides are covered with a saturated aqueous solution of methylene blue. This is spread over the slide in an even film and allowed to dry. After drying, the film on the slide should be transparent and sky-blue in color. The microorganisms to be examined are then emulsified in warm water, or are taken from the fluid media, and dropped upon a cover slip. This is placed, face downward, upon the blue ground of the slide. In this way, bacteria are stained without fixation. Nakanishi claims that by this method the entoplasm is stained blue, while the nuclear material appears of a reddish or purplish hue. 
any of the lower bacteria contain true nuclei does not seem to be positively determined.

Capsule. Many bacteriologists believe that all of the lower bacteria are surrounded by a gelatinous like substance or envelope which is designated a capsule. The eapsule, in the form in which it is recognized, consists of an inner somewhat dense portion immediately surrounding the body of the organism and gradually becoming thinner in the outer zone. This capsule is not colored by the ordinary staining processes. In stained preparations of bacteria having pronounced capsules such as Micococcus lanceolatus and Bacillus viscosus, the bodies of the bacteria are stained

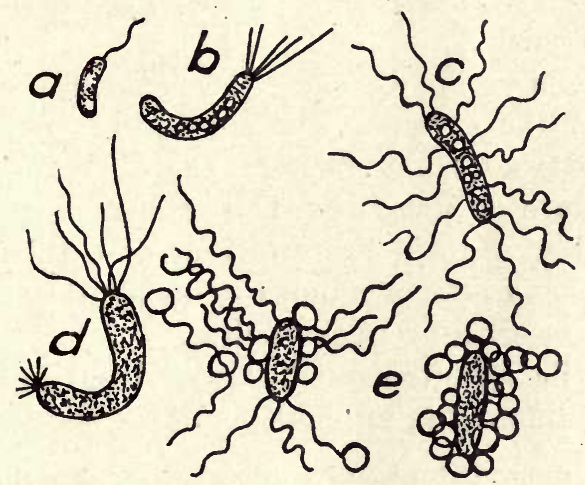

Fig. 8. Figures illustrating the different arrangement of flagella. a, b, and d polar; c and e peritrichial.

and surrounded by a zone which is unstained. The thickness and form of the capsule vary in different species. Its demonstration is frequently of much assistance in making a rapid diagnosis. This is especially true with Micrococcus lanceolatus in preparations made from a pneumonic lung of an infected rabbit and in some of the higher forms such as Saccharomycosis farciminosis, the cause of epizootic lymphangitis in horses. It is of further interest to note that the capsule can rarely be detected about bacteria excepting when they grow in the animal body or in smear prepara- 
tions made in a drop of serum. ${ }^{1}$ It is quite generally believed that there is a thin capsular substance surrounding all bacteria and that it represents a swelling of the ectoplasmic zone of the organism.

Flagella. Flagella are fine hair-like appendages varying in length from a few to many microns, radiating from the bodies of the motile bacteria. They are the organs of locomotion or motility. They are distributed over the entire body or they may occur singly or as tufts at one or both ends of the organism. The polar flagella are said to appear on the bacteria shortly before division. Like the capsules, they require a special stain. They were observed on some of the larger saprophytic bacteria in fresh preparations by Dallinger and Drysdale. ${ }^{2}$

The flagella seem to come either from the cell wall or ectoplasma or the capsular like substance. In cultures of bacteria possessing many flagella there frequently occur bundles of more or less twisted, detached flagella. It has been stated that certain bacteria may lose their power of producing flagella after a number of generations. ${ }^{3}$ This has not been the observation of the writer.

The flagella were thought by Tavel ${ }^{4}$ and Luksch ${ }^{5}$ to be of value in differentiating closely related species. Messea ${ }^{\circ}$

${ }^{1}$ Hiss has somewhat recently (Journal of Experimental Medicine, Vol. VII (1905) p. 223) called attention to this method of demonstrating capsules although it has long been followed in certain laboratories.

2Dallinger and Drysdale, Monthly Microscopical Journal, London, Vol. XIV (1875) p. 175.

Also, Journal of the Royal Microscopical Society, Vol. I, p. 175.

${ }^{3}$ As possibly bearing on this point, the writer isolated an organism from a pig which possessed all the physiologic and pathogenic properties of Bacillus suipestifer but it did not possess flagella and was not motile. Dr. Theobald Smith has also published a description of a like organism.

* Tavel, La semaine Med., 1892, p. 52.

${ }^{\cdot 5}$ Luksch, Centralb. f. Bakt., Vol. XII (1892) p. 427.

${ }^{6}$ Messea, Rivista d'igiene e sanita public, No. 14 (1889) p. 513. 
proposed a classification of bacteria based upon the number and arrangement of the flagella.

Spores. Spores are small spherical or oval highly refractive bodies which develop in the body substance of certain species of bacteria. There is no difference in the protoplasm of the spores, however, from that of the contents of the organisms. They contain all of the proteins of the parent cell and when developed are surrounded by a thin substance inside the otherwise empty shell or cell wall of the organism. This cell wall softens or dissolves and the spore is then set free. Free spores are frequently observed in 24 hour cultures when the growth occurs under favorable conditions. Usually, however, they are not set free until they are much older. They are characterized by their power to resist injurious influences, such as heat, dessication and disinfectants. The spores of different species of bacteria differ in the degree of their resisting power. Bacteria produce endospores. Arthrospores do not appear to exist among. any of the bacteria. To observe the form of the spores of any species it is well to employ a streak culture on agar or potato, which should be kept at the temperature best suited to the growth of the organism. After 12 hours and at short. intervals thereafter specimens of the culture should be examined in a hanging drop preparation, and if round or oval strongly refractive bodies are observed within the bacteria, they should be stained for spores. Individual bacteria rarely contain more than one spore each; more than two have not been observed. The formation of spores has been determined in a few spirals, in many rod-shaped bacteria, but not in micrococci. The vast majority of bacteria do not produce spores. The conditions of spore formation are not fully understood.

According to Fischer, motile bacteria always come to a state of rest or immobility previous to spore formation. Several species first become elongated. The anthrax bacterium does this, and a description of the method of its production of spores may serve as an illustration of the process. 
In the beginning the protoplasm of the elongated filaments is homogeneous, but after a time it becomes turbid and finely granular. These fine granules are then replaced by a smaller number of coarser granules, which are finally amalgamated into a spherical or oval refractive body. This is the spore. For a time the spores are retained in a linear position by the cell membrane of the bacterium, but this is later dissolved or broken and the spores are set free. Spores are not formed in every individual organism. This species loses its property of forming spores when grown under a high temperature $\left(43^{\circ} \mathrm{C}\right.$. $)$.

Types of spore formation. The following are the most important types of spore formation: (1) the spores lying in the interior of single, undistended organisms; (2) the spores lying in the interior of a chain of undistended organisms; (3) the spore lying at the extremity of the organism much
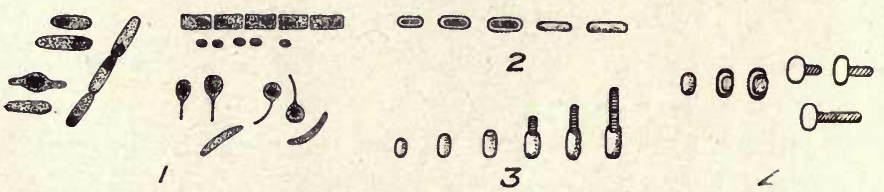

Fig. 9. Sporulation and germination of spores. 1, formation of spores; 2, direct germination; 3 , polar germination; 4, equatorial germination. Highly magnified.

enlarged at that end-the so-called "head spore"; and (4) the spore lying centrally in the interior of an organism which is much enlarged in its central portion, giving it a spindle shape.

Spores may be considered as the resting stage or form of the bacteria which produce them, i. e., the spores are enabled to remain alive under life conditions that would destroy the vegetative forms.

Spore germination. When the spores are brought under favorable life conditions they absorb moisture and germinate. This process is not the same for all species. In 
germination the first change observed is that the spore swells up and lengthens, due probably to the absorption of moisture. As the spore enlarges it becomes less refractive and dull in appearance. It then gives rise to a young organism in one of three ways.

1. Direct germination, in which the spore gradually changes by elongating and growing directly into an organism. In this case no shell or spore wall is thrown off, although it may possibly be softened and dissolved during the process of conversion.

Usually in spore germination the spore wall splits open at some one place on the surface and through the opening thus produced a young form makes its appearance. When the opening in the spore wall is at the end of the elongated spore it is spoken of as polar and when in the middle it is designated equatorial.

2. Polar germination. In this form the elongated spore opens at one pole and the young cell grows out of the spore wall. The long axis of the new organism is parallel to the long axis of the spore. The anthrax spore germinates in this way.

3. Equatorial germination. In this form the lengthened spore opens as a result of a split across the middle. In some species the spore wall is completely divided and the two walls are pushed asunder by the young spore. In the case of Bacillus subtilis the cleft is incomplete. In such instances the young rod-shaped organism leaves the spore wall either by doubling up and assuming a horse shoe form or it rotates and passes out at right angles to the axis of the spore.

Conditions necessary for spore germination. In the germination of spores in disease producing bacteria it is necessary to have in addition to a suitable culture medium or soil, proper temperature. The process takes place slowly in a low temperature and more rapidly in a temperature nearer that of the animal body. 
Granules. In the place of spores there very often appear in the bodies of certain species of bacteria, especially the rod-shaped forms, minute, or larger, more or less irregular granules. In the unstained organism they are light refracting. In stained preparations they appear as deeply stained irregular masses, known as metachromatic granules. They have a strong affinity for dyes, thereby staning more rapidly and deeply than the rest of the organism and they are decolorized with great difficulty. In certain bacteria, such as that of diphtheria, they are practically constant, which gives them much value in diagnosis. Besides these, there are often present other concentrated masses of protoplasm. In stained preparations of bacteria there appear very frequently small irregular areas which do not take the stain and which are referred to as vacuoles.

Plasmolysis. When living bacteria are placed in a solution containing an osmotic substance, such as in a $2.5 \%$

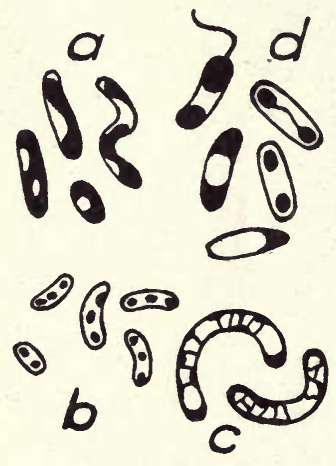

Fig. 10. Plasmolysis. Figures showing different forms of condensed body contents. solution of saltpeter or a $1 \%$ solution of salt, the osmotic pressure of the outside solution overcomes the normal pressure of the bacterial contents. Under such conditions a current is established into the body of the bacterium. The protoplasm of the organism as a result retracts from the cell wall. This is shown by the dense masses of protoplasm arranged at the poles or irregularly placed within the bacteria. The clear areas appear as vacuoles.

Reproduction in lower bacteria. The lower bacteria reproduce by cell division or fission. Bacteria multiply under favorable life conditions only. The young organisms elongate until they reach the size of the adult when over the. center of the long axis thus formed there will appear a slight 
indentation in the cell wall which increases in extent until the division is complete and there exist two individuals.

Ordinarily these new or daughter cells completely separate from one another after division, but occasionally they remain together for a shorter or longer time in the form of pairs, chains or clumps. Under certain conditions of nutrition long threads or filaments are formed. When these are cultivated under more favorable life conditions they break up into short fragments. When the culture media are exhausted or nearly so, the rod-shaped forms often divide without the usual elongation, resulting in a mass of coccus-like forms ; but when these are brought under favorable life conditions they assume their original shape. It is now thought. that in the reproduction of bacteria the division starts from the protoplasmic layer, the central portion being passively divided. This has been used as an argument against the true nucleus. The time required for the complete process of division in most species of bacteria under favorable conditions is from 15 to 30 minutes. According to investigations by Buchner ${ }^{1}$ spirilla double in number under. most favorable conditions in 20 minutes.

Although elongation in the greater diameter and transverse division is the rule for most bacteria, there are certain groups, such as the sarcina, which divide more or less regularly in three planes and instead of becoming separated from each other there is a tendency for the segmentation to be incomplete, and the organisms to remain together in masses: In other groups, such as the micrococei, the division takes place in two planes. When these are held together we have tetrads. The rod-shaped bacteria have not been observed to divide longitudinally.

Longevity of bacteria. The duration of life of individual bacteria is theoretically unlimited, since from each organism by the process of fission two new ones are produced. The life of these organisms, therefore, has, because

${ }^{\star}$ Buchner, Centralb. f. Bakt., Bd. II (1887) p. 1. 
of their method of reproduction, unlimited possibility. Practically, however, in experimental work the results are quite different. It has been pointed out by many investigators that in cultures in bouillon, for instance, the number of individuals that will multiply becomes very much reduced in number after a limited time. It is known that the rapidity of death of bacteria in cultures depends upon the nature and quantity of the medium as well as upon the vital forces of the individual organisms that differ with the species. Some cultures of bacteria die in a few days while others will live for weeks or even months. The same variation holds when these bacteria are put in extraneous substances such as in the soil or water.

Involution forms. When bacteria are cultivated under somewhat unfavorable conditions, or when grown for a long time on artificial media, without being transferred, there frequently occurs a variation in the form and size of the organism. These are referred to as involution or degeneration forms. Such forms have been described most frequently in cases of diphtheria. They are, however, now and then detected in cultures of practically all species. With certain organisms, such as the bacterium of tuberculosis ${ }^{1}$ and diphtheria ${ }^{2}$, branched forms have been described. These, however, are to be differentiated from the involution forms.

Pleomorphism. The early observers of bacteria did not recognize distinct genera and species among them. Some of those observers recognized a pleomorphism or mutability of shape. For instance they did not believe that a micrococcus necessarily always remained a micrococcus but that it could change into a bacillus, a vibrio, and later return to the spherical form of the micrococcus. Pleomorphism is no longer recognized in bacteriology. The subject matter of the whole discussion by the earlier writers may be summed up in pleogeny or mutability of function and pleomorphism or mutability of shape. We now recognize the definite taxonomic value of such terms as micrococeus, bacillus, spirillum, and the like.

${ }^{1}$ Wolbach and Ernst, Jour. of Med. Research, Vol. X (1903)

p. 313. ${ }^{2}$ Hill. Annual Rept. of the Boston Board of Health, 1901. 


\section{CHAPTER IV.}

\section{CLASSIFICATION OF BACTERIA AND THE IDENTIFICATION OF SPECIES.}

Classification. Bacteria are classified into families and genera by means of their morphology. The species are determined by their physiologic, biochemic or pathogenic properties.

A number of methods or systems have been followed by different writers in their classifications. As the form and method of reproduction are the most constant features in the morphology of bacteria they have been used as the basis of most of the classifications. There are, however, a number of elements in the morphology, such as the production of spores and the presence of flagella, that have been used more or less for that purpose. As an illustration of the latter we have Messea's classification of bacteria which is based on the presence and distribution of the flagella on the bodies of the organisms. As illustrations of the earlier classification, those of Cohn ${ }^{1}$, Ehrenberg ${ }^{2}$, Zoph $^{3}$, De Bary ${ }^{4}$ and Baumgarten $^{5}$ may be mentioned. Cohn divided bacteria into four genera or classes, represented by the following genera: Micrococcus, Bacterium, Bacillus and Vibrio, Spirillum and Spirochaeta. Ehrenberg placed all bacteria in four genera, namely: Bacterium, Vibrio, Spirillum and Spirochaete. Dujardin ${ }^{6}$ placed all bacteria in three genera: Bacterium, Vibrio, and Spirillum.

${ }^{1}$ Cohn. Beitr. f. Biol. der Pflanzen, Pt: I and II, 1882.

${ }^{2}$ Ehrenberg. Die Infusionstierchen als vollkommene Organismen, 1838.

${ }^{3}$ Zoph, Zur Morphologie der Spaltpflanzen, Leipzig, 1882.

${ }^{4}$ De Bary. Vergleichende Morphologie und Biologie der Pilze, Mycetozoen und Bacterien (1884); Vorlesunger über Bacterien, II Aufl. (1887).

${ }^{5}$ Baumgarten. Lehrbuch der pathologischen Mykologie, 1890.

${ }^{6}$ Dujardin. loc. cit. 
These two authors placed the bacteria among the infusoria. Zoph divided bacteria into four groups, namely: the Coccaceae five genera, Bacteriaceae six genera, Leptitricheae four genera, and Cladotricheae one genus. De Bary divided them into two groups, one producing endospores, the other arthrospores. Baumgarten divided bacteria into two groups, (1) the monomorphous and (2) the pleomorphous. The first contained the micrococci, bacilli and spirilla; the second the higher forms. Messea ${ }^{7}$, who classified bacteria after their flagella, divided them into the

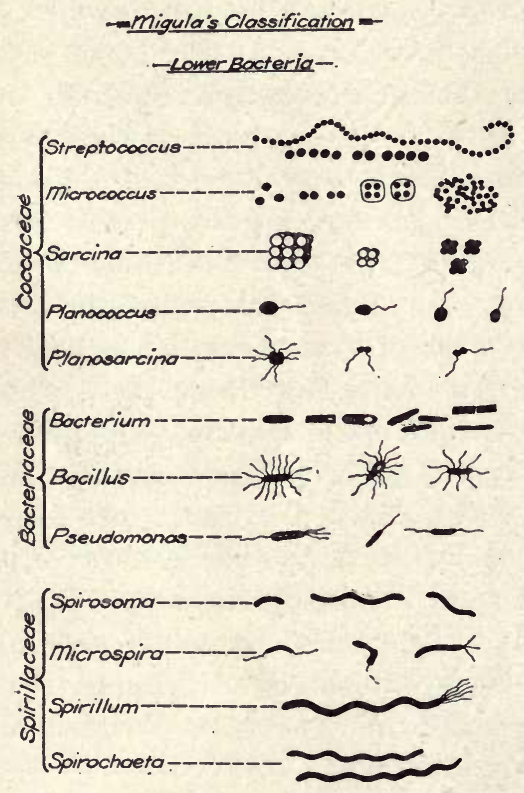

Fig. 11. A diagrammatic scheme of Migula's classification of lower bacteria.

satisfactory when considered from the point of view of animal pathology, because it introduces so few new

${ }^{7}$ Messea. loc. cit.

${ }^{8}$ Migula. Die natürlichen Pflanzenfamilien, 1896.

I. Gymnobacteriaall bacteria without flagella.

II Trichobacteriaall bacteria with flagella (motile).

1. Monotricha-bacteria with one flagellum at one pole.

2. Lophotricha-bacteria with a bunch of flagella at one pole.

3. Amphitricha-bacteria with flagella at each pole.

4. Peritricha-bacteria with flagella diffused over the body.

Of the numerous more recent classification the one by Migula ${ }^{8}$ seems to be the simplest and most 
genera and changes very few of those in more common use. Possibly the greatest objection to this classification is the use of the generic term bacterium to include a number of species of pathogenic bacteria heretofore recognized as bacilli.*

\section{MIGULA'S CLASSIFICATION OF BACTERIA.}

Families.

I. Cells globose in a free state, not elongating in any direction before division into 1,2 , or 3 planes 1 . Coccaceae. II. Cells cylindrical, longer or shorter, and only dividing in one plane, and elongating to about twice the normal length before the division.

a. Cells straight, rod-shaped, without sheath, non-motile, or motile by means of flagella

2. Bacteriaceae.

b. Cells crooked, without sheath

3. Spirillaceae.

c. Cells enclosed in a sheath

4. Chlamydobacteriaceae.

\section{COCCACEAE.}

Cells without organs of motion.
a. Division in one plane
b. Division in two planes
c. Division in three planes

Cells with organs of motion.

a. Division in two planes

b. Division in three planes

1. Streptococcus.

2. Mierococeus.

3. Sarcina.

* The different meanings attached to the words Bacillus and Bacterium deserve notice. In two of the more recent systems of classification the senses in which they are used have little in common. Lehrmann and Neumann apply the word Bacterium to all rodshaped forms in which spores are unknown (a point in regard to which any day may bring a change in our knowledge), the genus Bacillus embracing those in which spores have been found. Of the manner of ciliation no notice is taken. Migula, on the other hand, uses the term Bacterium for all non-motile rods, and Bacillus for peritrichous species, the remaining motile forms, both lophotrichous, monotrichous and amphitrichous, constituting a new genus, Pseudomonas. 
2. BACTERIACEAE.

Cells without organs of motion

1. Bacterium.

Cells with organs of motion (flagella).

a. Flagella distributed over the whole body 2. Bacillus.

b. Flagella polar

3. Pseudomonas.

3. SPIRILLACEAE.

Cells rigid, not snake-like or flexuous.

a. Cells without organs of motion

1. Spirosoma.

b. Cells with organs of motion (flagella).

1. Cells with 1 , very rarely 2 to 3 , polar flagella

2. Microspira.

2. Cells with polar flagella-tufts Cells flexuous

3. Spirillum.

4. Spirochaeta.

4. CHLAMYDOBACTERIACEAE (higher bacteria).

Cell contents without granules of sulphur.

a. Cell threads unbranched.

I. Cell division always in one plane 1. Streptothrix.

II. Cell division in three planes previous to the formation of gonidia.

1. Cells surrounded by a very delicate, scarcely visible sheath (marine)

2. Phragmidiothrix.

2. Sheath clearly visible (in fresh water)

b. Cell threads branched

3. Crenothrix.

Cell contents containing sulphur granules

4. Cladothrix.

5. Thiothrix.

\section{BEGGIATOACEAE.}

Thread like bacteria without a sheath, motility due to an undulating movement. Sulphur granules are not present.

Fischer* in a series of studies on the introduction of general bacteriology, has proposed a classification in which he has introduced a number of sub-families and new genera.

* Fischer. Vorlesungen über Bakterien, Leipsig (1897) translated by A. C. Jones, The Structure and Functions of Bacteria, Oxford, 1900 , p. 32 . 


\section{FISCHER'S CLASSIFICATION OF BACTERIA.}

ORDER 1. HAPLOBACTERINAE.

Vegetative phase unicellular, spherical, cylindrical, or spirally twisted; isolated or united in chains or clusters.

FAMILY 1. COCCACEAE.

Vegetative cell spherical.

SUB-FAMILY 1. ALLOCOCCACEAE.

Planes of fission without definite sequence; no pronounced colonies or growth-forms, cells isolated or in short chains or irregular clusters.

Genus Micrococcus Cohn. Non-motile. Includes most cocci, the pathological 'staphylococei,' ete.

Genus Planococcus Migula. Motile.

SUB-FAMILY 2. HOMOCOCCACEAE.

Planes of fission in definite sequence.

Genus sarcina Goodsir. Three planes of division at right angles to each other. Cubical colonies, non-motile.

Genus Planosarcina Migula. Similar to Sarcina, but monotrichous, eiliate, and motile.

Genus PEDIococcus Lindner. Two planes of fission alternate and at right angles. Micrococcus tetragenous, Thiopedia (a sulphur organism), and probably some species usually termed micrococcus.

Genus streptococcus Billroth. Planes of fission parallel, giving rise to chains. The pathological Streptococci and Leuconostoc.

\section{FAMILY 2. BACILLACEAE.}

Vegetative cell straight, cylindrical, ellipsoidal, or eggshaped; very short forms difficult to distinguish from cocci. Fission always transverse.

SUB-FAMILY 1. BACILLEAE.

Spore-forming rods eylindrical, unchanged. 
Genus Bacillus Cohn. Non-motile. B. anthracis, B. diphtheriae, etc.

Genus bactrinium A. Fischer. Motile, monotrichous, with terminal cilium. Includes provisionally all monotrichous rods whose spores are as yet unknown, e. g., Bac. pyocyaneous.

Genus Bactrillum A. Fischer. Motile, with lophotrichous ciliation. Includes provisionally Bac. cyanogenus, and many other sporeless forms.

Genus BACtridium A. Fischer. Motile, peritrichous, in some spores as yet unknown. Very numerous representatives, e. g., B. subtilis, B. megatherium, B. vulgaris (old genus Proteus), B. typhi, and B. coli.

\section{SUB-FAMILY 2. CLOSTRIDIEAE.}

Rods spindle-shaped during sporulation.

Genus Clostridium Prazmowski. Motile, peritrichous; includes some of the butyric bacteria. Genera with monotrichous and lophotrichous ciliation are unknown as yet.

\section{SUB-FAMILY 3. PLECTRIDIE.AE.}

Rods drum-stick-shaped during sporulation.

Genus Plectridium A. Fischer. Motile, peritrichous. Some butyric bacteria, the parasite of tetanus and a methane ferment.

FAMILY 3. SPIRILLACEAE.

Vegetative cell cylindrical but spirally twisted. Fission always transverse.

Genus viBRı Müller and Löffler. Very slightly curved rods 'comma' shaped; motile, monotrichous. Vibrio cholerae asiaticae and numerous other vibrios of fresh and salt water.

Genus SPIRILlum Ehrenberg. Cylindrical cells twisted in an open spiral; motile, lophotrichous. Spirillum undula, Sp. rubrum. 
Genus. SPirochaete Ehrenberg. Cells long and attenuated, spirally twisted with numerous turns; cilia unknown; the cell membrane is perhaps yielding. Spirochaete Obermaieri (remittent fever).

\section{ORDER 2. TRICHOBACTERINAE.}

Vegetative phase an unbranched or branched filament or chain of cells, the individual members of which break off as swarm-spores (gonidia).

FAMILY 1. TRICHOBACTERIACEAE.

(a) Filaments non-motile, rigid, enclosed in a sheath.

Genus CRenothrix Cohn. Filaments unbranched and devoid of sulphur granules.

Genus тніотнRix Winogradsky. The same, but containing sulphur granules.

Genus Cladothrix Cohn. Filaments branched, false dichotomy (includes Sphaerotilus).

(b) Filaments motile, with oscillating and gliding movements, and devoid of a sheath.

Genus beggiaton Trevisan. Containing sulphur.

Grouping of bacteria according to their habitat and properties. Bacteria are often referred to by names indicative of their habitat or some property which they possess or the nature of their special activities. The more commonly used of these group names are as follows :

Saprophytic bacteria. These are bacteria which normally live on dead organic matter and which do not possess the power of multiplying in living tissues. They are the organisms ordinarily found in the soil, decaying vegetation or decomposing animal tissues.

Parasitic bacteria. These are bacteria which have their natural habitat on or in the living body. As the line of demarcation between pathogenesis and parasitism is not 
always closely drawn the term "parasitic" bacteria is often used synonymously with "pathogenic" bacteria.

Pathogenic bacteria. These are bacteria capable of living in the tissues of animals and as a result of their presence and multiplication produce more or less disturbance in the animal economy. This disturbance is the disease which they produce.

Kruse * in his discussion of saprophytic and pathogenic bacteria has divided them in the following manner:

I. Saprophytes (not infectious bacteria).

1. not toxic bacteria.

2. toxic bacteria.

II. Parasites (infectious or virulent bacteria).

1. Bacteria which cause local infection.

a. slight growth, strong toxin formation.

b. strong growth in the depths of the tissue.

c. strong growth on the surface.

2. Bacteria which eause general infection.

a. by continuous growth in the tissues.

b. by metastasis.

c. septicemia.

Zymogenic bacteria. These are bacteria which cause fermentation of the carbohydrates.

Saprogenic bacteria. These are bacteria which cause putrefaction and decomposition of organic matter, usually animal tissue.

Chromogenic bacteria. These are bacteria which produce pigment in the growth itself on a solid medium or impart color to the medium in or on which they are multiplying.

Photogenic bacteria. These are bacteria which cause phosphorescence.

Aerogenic bacteria. These are bacteria which produce gas as the result of the fermentation of the substance in which they are growing.

* Kruse. In Flügge's Die Mikroorganismen. Bd. I, p. 276. 
Nitrifying bacteria. These are the organisms which take nitrogen out of the air for plant food.

Aerobic and anaerobic bacteria. Bacteria are also named according to their gaseous environmental requirements. Certain bacteria will not grow in the presence of oxygen (atmosphere), and consequently they must be cultivated in a medium from which the air has been excluded, or in the presence of some neutral gas such as hydrogen. While certain bacteria, like those of symptomatic anthrax, tetanus, and malignant oedema, require the absence of oxygen, others, like Bacillus subtilis, will not multiply without it. There are, however, a large number of bacteria which are able to multiply independently of the presence or absence of this element. In reference to oxygen requirements bacteria are grouped as follows :

Obligatory aërobic bacteria require oxygen.

Obligatory anaërobic bacteria require the absence of oxygen.

Facultative aërobic bacteria grow best in the absence of oxygen, but will grow in the presence of air.

Facultative anaërobic bacteria grow best in the presence of oxygen, but will grow in its absence.

Bacteria are also known by special names according to the temperature best adapted for their multiplication. These are:

Psychrophilic bacteria. These are bacteria that require a low temperature (15-20 degrees C.) for their multiplication.

Mesaphilic bacteria. These are bacteria that require a medium temperature (15-37 degrees C.) for their multiplieation. Several saprophytic and nearly all known pathogenic bacteria are in this group.

Thermophilic bacteria. These are bacteria that will multiply in a high temperature (40-60 degrees C.). 


\section{IDENTIFICATION OF SPECIES.}

The identification of species. The student of bacteriology soon learns that there are a large number of species. of bacteria and that in external nature they exist together in greater or less numbers. With organisms so small and of such simple structure the differentiation of one species from another often becomes a difficult task. The work that has been done in identifying species of bacteria shows that the family and genera are determined by the morphology of the organism, and its species by its cultural manifestations, biochemic properties or pathogenesis. Thus in identifying a culture of Bacillus coli the family Bacteriaceae to which it belongs is determined because morphologically it is rodshaped. The genus Bacillus to which it belongs is ascertained from its motility and peritrichial flagella. The species is determined from the character of its growth in and upon culture media, such as bouillon, gelatin, and agar, its power to ferment the sugars, to coagulate milk, etc. It is ordinarily not difficult to determine from the microscopic examination the family and genus, but to determine the species is often a more difficult task, unless the organism possesses some distinctive biological or pathogenic property. Bacteriologists, however, are not fully agreed as to what constitutes specific characters or to what extent variation in the cultural or physiological properties may be accepted. The very close resemblance in the growth of many bacteria belonging to the same genus has made it difficult in many cases to identify the species.

Formerly many bacteria were given specific names but the nature of their growth on a very few media was recorded. There are therefore many species on record whose identifying descriptions are restricted to their growth on gelatin, agar and in bouillon. More than that, it is very difficult in many cases to determine to which of several species an organism belongs because of the close resemblance if not identity of the brief descriptions given. This condition, which 
is very confusing, could not well have been avoided in the earlier stages of descriptive bacteriological work and before differential media were employed. There are, however, many species which possess well defined properties or pathogenic powers by which they ean be positively identified.

In analysing a substance like milk or sewage one encounters many bacteria that are very difficult to identify by comparing the description of their cultural characters with the very brief identifying descriptions recorded in the several manuals ${ }^{1}$ that have been written for this purpose.

In order to bring about a more uniform description of species for purposes of records and identification the Society of American Bacteriologists have recommended a chart for recording descriptions of the growth and morphology of bacteria and a decimal system for grouping species or varieties. This chart is very helpful in recording descriptions for subsequent reference.

There are many bacteria that resemble well defined species so closely that they must be considered varieties of it. Such species and their varieties are frequently referred to as a group, such for example as the "colon group." In most quantitative analyses no attempt is made to identify the species, other than well defined and important ones, beyond the placing of them in the group to which they belong.

The procedure to follow in identifying species is first to determine the morphology and the cultural and bio-chemic properties and pathogenesis of the organism in question and then to compare them by the use of manuals or other literature with the descriptions of the species already described and named. If the organism can not be identified it may be placed, temporarily at least, in some group of bacteria or if in the judgment of the worker it is sufficiently distinct it may be recorded and named as a new species.

\footnotetext{
${ }^{1}$ Chester, A Manual of determinative Bacteriology.

${ }^{2}$ Fluegge, Die Mikroorganismen.

${ }^{3}$ T. Matzuschita, Bacteriologische Diagnostik.

* Migula, System der Bakterien.
} 
In practical bacteriological analyses, usually no attempt is made to identify all the species present but to ascertain the number of individual bacteria or the presence of bacteria belonging to groups known to contain species that are of special significance. In examining organs for purposes of diagnosis the effort is to find the specific organisms present and to isolate and identify them. It is also desirable to ascertain when possible other species if they are present in the tissues. Although the known pathogenic bacteria have their properties sufficiently described to make their identification possible, there are many bacteria that can live for a certain time on tissues and which may appear to have a causal relation to the lesions but are not so readily identified. These bacteria when found should be either identified, placed in a definite group, or failing in these, described as a new species.

\section{DESCRIPTIVE CHART-SOCIETY OF AMERICAN BACTERIOLOGISTS *}

Prepared by F. D. Chester, F. P. Gorham, Erwin F. Smith, Committee on Methods of Identification of Bacterial Species. Endorsed by the Society for general use at the Annual Meeting, Dec. 31, 1907.

\section{GLOSSARY OF TERMS.}

AGAR HANGING BLOCK, a small block of nutrient agar cut from a poured plate, and placed on a cover-glass, the surface next the glass having been first touched with a loop from a young fluid culture or with a dilution from the same. It is examined upside down, the same as a hanging drop.

AMEBOID, assuming various shapes like an ameba.

AMORPHOUS, without visible differentiation in structure.

ARBORESCENT, a branched, tree-like growth.

BEADED, in stab or stroke, disjointed or semi-confluent colonies along the line of inoculation.

BRIEF, a few days, a week.

* This chart can be procured from the Secretary of the Soc. of Am. Bacteriologists. It is very convenient for recording descriptive characters of bacteria. 
BRITTLE, growth dry, friable under the platinum needle.

BULLATE, growth rising in convex prominences, like a blistered surface.

BUTYROUS, growth of a butter-like consistency.

CHAINS,

Short chains, composed of 2 to 8 elements.

Long chains, composed of more than 8 elements.

CILIATE, having fine, hair-like extensions like cilia.

CLOUDY, said of fluid cultures which do not contain pseudozoogloeae.

COAGULATION, the separation of casein from whey in milk. This may take place quickly or slowly, and as the result either of the formation of an acid or of a lab ferment.

CONTOURED, an irregular, smoothly undulating surface, like that of a relief map.

CONVEX, surface the segment of a circle, but flattened.

COPROPHYL, dung bacteria.

CORIACEOUS, growth tough, leathery, not yielding to the platinum needle.

CRATERIFORM, round, depressed, due to the liquefaction of the medium.

CRETACEOUS, growth opaque and white, chalky.

CURLED, composed of parallel chains in wavy strands, as in anthrax colonies.

DIASTASIC ACTION, same as DIASTATIC, conversion of starch into water-soluble substances by diastase.

ECHINULATE, in agar stroke a growth along line of inoculation, with toothed or pointed margins; in stab cultures growth beset with pointed outgrowths.

EFFUSE, growth thin, veily, unusually spreading.

ENTIRE, smooth, having a margin destitute of teeth or notches. EROSE, border irregularly toothed.

FILAMENTOUS, growth composed of long, irregularly placed or interwoven filaments.

FILIFORM, in stroke or stab cultures a uniform growth along line of inoculation.

FIMBRIATE, border fringed with slender processes, larger than filaments.

FLOCCOSE, growth composed of short curved chains, variously oriented.

FLOCCULENT, said of fluids which contain pseudozoogloeae, i. e., small adherent masses of bacteria of various shapes and floating in the culture fluid.

FLUORESCENT, having one color by transmitted light and another by reflected light. 
GRAM'S STAIN, a method of differential bleaching after gentian violet, methyl violet, etc. The + mark is to be given only when the bacteria are deep blue or remain blue after counterstaining with Bismark brown.

GRUMOSE, clotted.

INFUNDIBULIFORM, form of a funnel or inverted cone.

IRIDESCENT, like mother-of-pearl. The effect of very thin films.

LACERATE, having the margin cut into irregular segments as if torn.

LOBATE, border deeply undulate, producing lobes (see undulate).

LONG, many weeks, or months.

MAXIMUM TEMPERATURE, temperature above which growth does not take place.

MEDIUM, several weeks.

MEMBRANOUS, growth thin, coherent, like a membrane.

MINIMUM TEMPERATURE, temperature below which growth does not take place.

MYCELIOID, colonies having the radiately filamentous appearance of mold colonies.

NAPIFORM, liquefaction with the form of a turnip.

NITROGEN REQUIREMENTS, the necessary nitrogenous food. This is determined by adding to nitrogen-free media the nitrogen compound to be tested.

OPALESCENT, resembling the color of an opal.

OPTIMUM TEMPERATURE, temperature at which growth is most. rapid.

PELLICLE, in fluid bacterial growth either forming a continuous or an interrupted sheet over the fluid.

PEPTONIZED, said of curds dissolved by trypsin.

-PERSISTENT, many weeks, or months.

PLUMOSE, a fleecy or feathery growth.

PSEUDOZOOGLOEAE, clumps of bacteria, not dissolving readily in: water, arising from imperfect separation, or more or less fusion of the components, but not having the degree of compactness and gelatinization seen in zoogloeae.

PULVINATE, in the form of a cushion, decidedly convex.

PUNCTIFORM, very minute colonies, at the limit of natural vision. RAISED, growth thick, with abrupt or terraced edges.

RAPID, developing in 24 to 48 hours.

REPAND, wrinkled.

RHIZOID, growth of an irregular branched or root-like character, as in B. mycoides.

RING, same as RIM, growth at the upper margin of a liquid culture, adhering more or less closely to the glass. 
SACCATE, liquefaction the shape of an elongated sack, tubular, cylindrical.

SCUM, floating islands of bacteria, an interrupted pellicle or bacterial membrane.

SHORT, applied to time, a few days, a week.

SLOW, requiring 5 or 6 days or more for development.

SPORANGIA, cells containing endospores.

SPREADING, growth extending much beyond the line of inoculation, i. e., several millimeters or more.

STRATIFORM, liquefying to the walls of the tube at the top and then proceeding downwards horizontally.

THERMAL DEATH-POINT, the degree of heat required to kill young fluid cultures of an organism exposed for 10 minutes (in thin-walled test tubes of a diameter not exceeding $20 \mathrm{~mm}$.) in the thermal water-bath. The water must be kept agitated so that the temperature shall be uniform during the exposure. TRANSIENT, a few days.

TURBID, cloudy with flocculent particles; cloudy plus flocculence.

UMBONATE, having a button-like, raised center.

UNDULATE, border wavy, with shallow sinuses.

VERMIFORM-CONTOURED, growth like a mass of worms, or intestinal coils.

VERRUCOSE, growth wart-like, with wart-like prominences.

VILLOUS, growth beset with hair-like extensions.

VISCID, growth follows the needle when touched and withdrawn, sediment on shaking rises as a coherent swirl.

ZOOGLOEAE, firm gelatinous masses of bacteria, one of the most typical examples of which is the streptococcus mesenterioides. of sugar vats (Leuconostoc mesenterioides), the bacterial chains being surrounded by an enormously thickened firm covering, inside of which there may be one or many groups of the bacteria.

\section{NOTES.}

(1) For decimal system of group numbers see Table 1. This will be found useful as a quick method of showing close relationships inside the genus, but is not a sufficient characterization of any organism.

(2) The morphological characters shall be determined and described from growths obtained upon at least one solid medium (nutrient agar) and in at least one liquid medium (nutrient broth). Growths at $37^{\circ} \mathrm{C}$ shall be in general not older than 24 to 48 hours, and growths at $20^{\circ} \mathrm{C}$ not older than 48 to 72 hours. To secure uniformity in cultures, in all cases preliminary cultivation shall be 
practiced as described in the revised Report of the Committee on Standard Methods of the Laboratory Section of the American Public Health Association, 1905.

(3) The observation of cultural and bio-chemical features shall cover a period of at least 15 days and frequently longer, and shall be made according to the revised Standard Methods above referred to. All media shall be made according to the same Standard Methods.

(4) Gelatin stab cultures shall be held for 6 weeks to determine liquefaction.

(5) Ammonia and indol tests shall be made at end of 10th day, nitrite tests at end of 5 th day.

(6) Titrate with $\mathrm{N}$ NaOH, using phenolphthalein as an indicator: make titrations at same times from blank. The difference gives the amount of acid produced.

The titration should be done after boiling to drive off any $\mathrm{CO}_{2}$ present in the culture.

(7) Generic nomenclature shall begin with the year 1872 (Cohn's first important paper).

Species nomenclature shall begin with the year 1880 (Koch's discovery of the poured plate method for the separation of organisms).

(8) Chromogenesis shall be recorded in standard color terms.

\section{TABLE I.}

\section{A NUMERICAL SYSTEM OF RECORDING THE SALIENT CHARACTERS OF AN ORGANISM (GROUP NUMBER)}

$\begin{aligned} 100 . & \text { Endospores produced } \\ 200 . & \text { Endospores not produced } \\ 10 . & \text { Aerobic (Strict) } \\ 20 . & \text { Facultative anaerobic } \\ 30 . & \text { Anaerobic (Strict) } \\ 1 . & \text { Gelatin liquefied } \\ 2 . & \text { Gelatin not liquefied } \\ 0.1 & \text { Acid and gas from dextrose } \\ 0.2 & \text { Acid without gas from dextrose } \\ 0.3 & \text { No acid from dextrose } \\ 0.4 & \text { Acid and gas from lactose } \\ .01 & \text { Acid without gas from lactose } \\ .02 & \text { No acid from lactose } \\ .03 & \text { No growth with lactose } \\ .04 & \end{aligned}$




$\begin{array}{ll}.001 & \text { Acid and gas from saccharose } \\ .002 & \text { Acid without gas from saccharose } \\ .003 & \text { No acid from saccharose } \\ .004 & \text { No growth with saccharose } \\ .0001 & \text { Nitrates reduced with evolution of gas } \\ .0002 & \text { Nitrates not reduced } \\ .0003 & \text { Nitrates reduced without gas formation } \\ .00001 & \text { Fluorescent } \\ .00002 & \text { Violet chromogens } \\ .00003 & \text { Blue " } \\ .00004 & \text { Green " } \\ .00005 & \text { Yellow " } \\ .00006 & \text { Orange } \\ .00007 & \text { Red } \\ .00008 & \text { Brown } \\ .00009 & \text { Pink } \\ .00000 & \text { Non-chromogenic } \\ .000001 & \text { Diastasic action on potato starch, strong } \\ .000002 & \text { Diastasic action on potato starch, feeble } \\ .000003 & \text { Diastasic action on potato starch, absent } \\ .0000001 & \text { Acid and gas from glycerine } \\ .0000002 & \text { Acid without gas from glycerine } \\ .0000003 & \text { No acid from glycerine } \\ .0000004 & \text { No growth with glycerine } \\ \text { The }\end{array}$

The genus according to the system of Migula is given its proper symbol which precedes the number thus: ( $\left.{ }^{i}\right)$

Bacillus COLI (Esch.) Mig. becomes B. 222.111102 Bacillus Alcaligenes Petr. “ Pseudomonas Campestris (Pam.) Sm. “ “ Ps. 211.333151 BACTERIUM SUICIDA Mig. Bact. 222.232203

Source

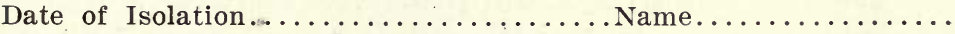

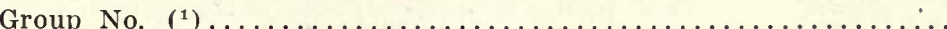

DETAILED FEATURES.

NOTE-Underscore required terms. Observe notes and glossary of terms on preceding pages.

I. MORPHOLOGY $\left({ }^{2}\right)$

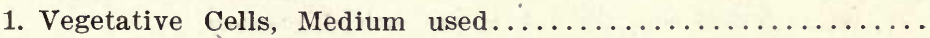

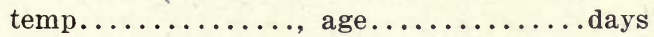

Form, round, short rods, long rods, short chains, long chains, filaments, commas, short spirals, long spirals, clostridium, cuneate, clavate, curved. 


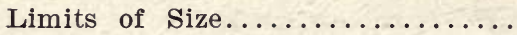

Size of Majority

Ends, rounded, truncate, concave.

Agar

Hanging-Block

Orientation (grouping).........

Chains (No. of elements).......

Short chains, long chains

Orientation of Chains, parallel, irregular.

2. Sporangia, medium used............ temp..........., age............. days

Form, elliptical, short rods, spindled, clavate, drumsticks.

Limits of Size........... Size of Majority...........

Agar

Hanging-Block

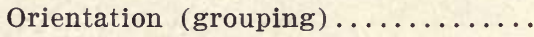

Chains (No. of elements) ..........

Orientation of Chains, parallel, irregular.

Location of Endospores, central, polar.

3. Endospores.

Form, rounded, elliptical, elongated.

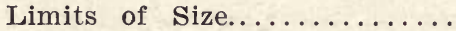

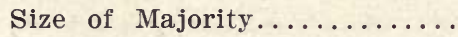

Wall, thick, thin.

Sporangium wall, adherent, not adherent.

Germination, equatorial, oblique, polar, bipolar, by stretching.

4. Flagella No.........Attachment polar, bipolar, peritrichiate.

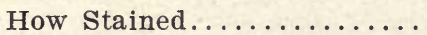

5. Capsules, present on...........

6. Zoogloea, Pseudozoogloea.

7. Involution Forms, on............ days at... ${ }^{\circ} \mathbf{C}$.

8. Staining Reactions.

1:10 watery fuchsin, gentian violet, carbol fuchsin.

Loeffler's alkaline methylene blue.

Special Stains.

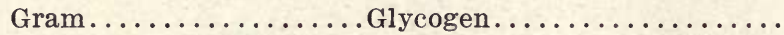

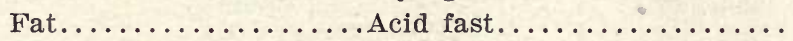

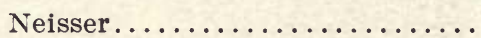

\section{CULTURAL FEATURES $\left({ }^{3}\right)$}

1. Agar Stroke.

Growth, invisible, scanty, moderate, abundant.

Form of growth, filiform, echinulate, beaded, spreading, plumose, arborescent, rhizoid.

Elevation of growth, flat, effuse, raised, convex.

Lustre, glistening, dull, cretaceous.

Topography, smooth, contoured, rugose, verrucose.

Optical Characters, opaque, translucent, opalescent, iridescent.

Chromogenesis $\left({ }^{8}\right) \ldots \ldots \ldots \ldots \ldots \ldots$ 


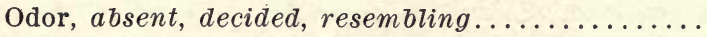

Consistency, slimy, butyrous, viscid, membranous, coriaceous, brittle.

Medium grayed, browned, reddened, blued, greened.

2. Potato.

Growth,scanty, moderate, abundant, transient, persistent.

Form of growth, filiform, echinulate, beaded, spreading, plumose, arborescent, rhizoid.

Elevation of growth, flat, effuse, raised, convex.

Lustre, glistening, dull, cretaceous.

Topography, smooth, contoured, rugose, verrucose.

Chromogenesis $\left({ }^{8}\right) \ldots \ldots \ldots$. Pigment in water insoluble, soluble; other solvents.

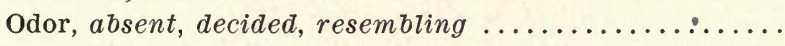

Consistency, slimy, butyrous, viscid, membranous, coriaceous, brittle.

Medium grayed, browned, reddened, blued, greened.

3. Loeffler's Blood Serum.

Stroke invisible, scanty, moderate, abundant. Form of growth, filiform, echinulate, beaded, spreading, plumose, arborescent, rhizoid.

Elevation of growth flat, effuse, raised, convex.

Lustre, glistening, dull, cretaceous.

Topography, smooth, contoured, rugose, verrucose.

Chromogenesis $\left({ }^{8}\right) \ldots \ldots \ldots \ldots$.

Medium grayed, browned, reddened, blued, greened.

Liquefaction begins in ........d, complete in........d.

4. Agar Stab.

Growth uniform, best at top, best at bottom; surface growth scanty, abundant; restricted, wide-spread.

Line of puncture, filiform, beaded, papillate, villous, plumose, arborescent; liquefaction.

5. Gelatin Stab.

Growth uniform, best at top, best at bottom.

Line of puncture, filiform beaded, papillate, villous, plumose, arborescent.

Liquefaction, crateriform, napiform, infundibuliform, saccate, stratiform; begins in ..........d, complete in.......d.

Medium fluorescent, browned............

6. Nutrient Broth.

Surface growth, ring, pellicle, flocculent, membranous, none.

Clouding slight, moderate, strong; transient, persistent; none; fluid turbid.

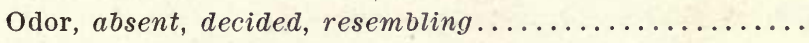


Sediment, compact, flocculent, granular, flaky, viscid on agitation, abundant, scant.

7. Milk.

Clearing without coagulation.

Coagulation prompt, delayed, absent.

Extrusion of whey begins in......... days.

Coagulum slowly peptonized, rapidly peptonized.

Peptonization begins on ........d, complete on...........

Reaction, $1 \mathrm{~d} . \ldots ., 2 \mathrm{~d} \ldots \ldots, 4 \mathrm{~d} \ldots . ., 10 \mathrm{~d} . . ., 20 \mathrm{~d} . . .$.

Consistency, slimy, viscid, unchanged.

Medium browned, reddened, blued, greened.

Lab ferment, present, absent.

8. Litmus Milk.

Acid, alkaline, acid then alkaline, no change.

Prompt reduction, no reduction, partial slow reduction.

9. Gelatin Colonies.

Growth slow, rapid.

Form, punctiform, round, irregular, ameboid, mycelioid, filamentous, rhizoid.

Elevation, flat, effuse, raised, convex, pulvinate, crateriform (liquefying).

Edge, entire, undulate, lobate, erose, lacerate, fimbriate, filamentous, floccose, curled.

Liquefaction, cup, saucer, spreading.

10. Agar Colonies.

Growth slow, rapid, (temperature.........)

Form, punctiform, round, irregular, ameboid, mycelioid, filamentous, rhizoid.

Surface smooth, rough, concentrically ringed, radiate, striate.

Elèvation, flat, effuse, raised, convex, pulvinate, umbonate.

Edge, entire, undulate, lobate, erose, lacerate, fimbriate, floccose, curled.

Internal structure, amorphous, finely-, coarsely- granular, grumose, filamentous, floccose, curled.

11. Starch Jelly.

Growth, scanty, copious.

Diastasic action, absent, feeble, profound.

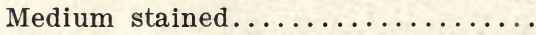

12. Silicate Jelly (Fermi's Solution).

Growth copious, scanty, absent.

Medium stained...............

13. Cohn's Solution.

Growth copious, scanty, absent.

Medium fluorescent, nonfluorescent. 
14. Uschinsky's Solution.

Growth copious, scanty, absent.

Fluid viscid, not viscid.

15. Sodium Chloride in Bouillon.

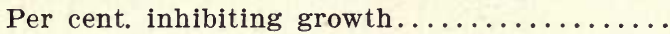

16. Growth in Bouillon over Chloroform, unrestrained, feeble, absent.

17. Nitrogen. Obtained from peptone, asparagin, glycocoll, urea, ammonia salts, nitrogen.

18. Best media for long-continued growth $\ldots \ldots \ldots \ldots \ldots \ldots \ldots$

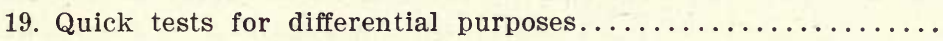

III. PHYSICAL AND BIOCHEMICAL FEATURES.

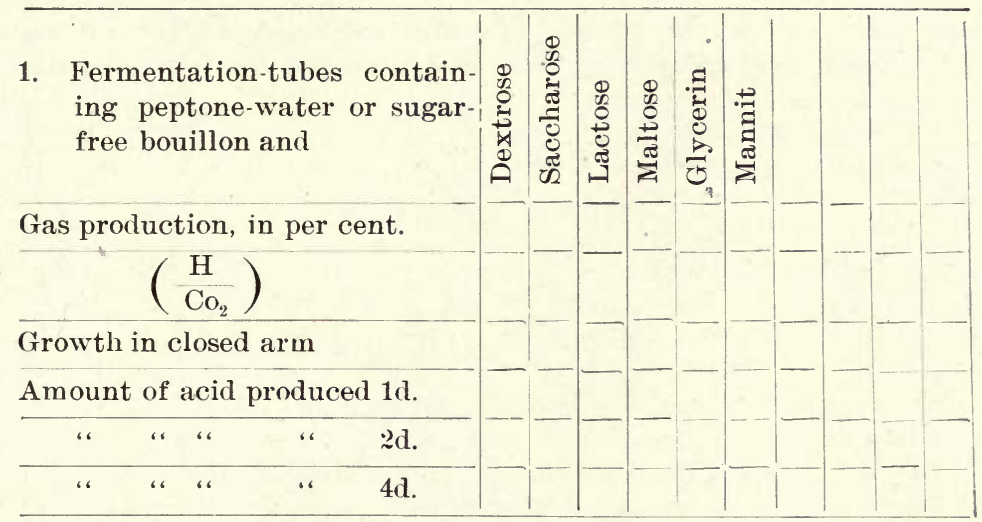

2. Ammonia production, feeble, moderate, strong, absent, masked by acids.

3. Nitrates in nitrate broth.

Reduced, not reduced.

Presence of nitrites.

.ammonia..........

" " nitrates.......... free nitrogen.......

4. Indol production, feeble, moderate, strong.

5. Toleration of acids: great, medium, slight.

Acids tested................

6. Toleration of $\mathrm{NaOH}$ : great, medium, slight.

7. Optimum reaction for growth in bouillon, stated in terms of

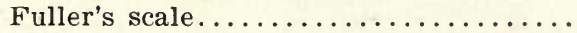

8. Vitality on culture media: brief, moderate, long. 
9. Tempcrature relations:

Thermal death-point (10 minutes exposure in nutrient broth when this is adapted to growth of organism) .........

Optimum temporature for growth. . . . C. : or best growth at $\left.15^{\circ} \mathrm{C}, 20^{\circ} \mathrm{C}, 25^{\circ} \mathrm{C}, 30^{\circ} \mathrm{C}, 37^{\circ} \mathrm{C}, 41\right)^{\circ} \mathrm{C}, 50^{\circ} \mathrm{C}, 60^{\circ} \mathrm{C}$.

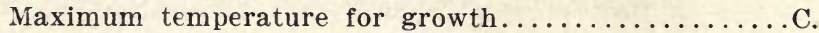

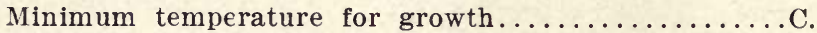

10. Killed readily by drying; resistant to drying.

11. Per cent. killed by freezing (salt and crushed ice or liquid air)

12. Sunlight: Exposure on ice in thinly sown agar plates: onehalf plate covered (time 15 minutes), sensitive, not sensitive.

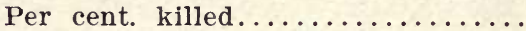

13. Acids produced

14. Alkalies produced

15. Alcohols

16. Ferments: pepsin, trypsin, diastase, invertase, pectase, cytase, tyrosinase, oxidase, peroxidase, lipase, catalase, glucase, galatase, lab, etc.

17. Crystals formed:

18. Effect of germicides:

\begin{tabular}{|c|c|c|c|c|c|}
\hline Substance & Method used & 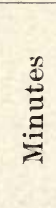 & 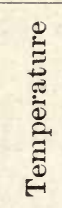 & 象密 & 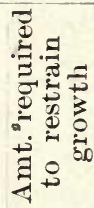 \\
\hline & 1 & & & 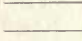 & \\
\hline & - & - & & & \\
\hline & 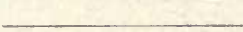 & 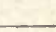 & 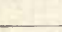 & 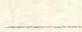 & \\
\hline & $x=$ & & & & \\
\hline & 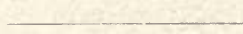 & & & & \\
\hline & - n & 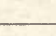 & $\ldots$ & & \\
\hline 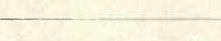 & 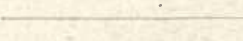 & & & -8 & \\
\hline & & & & & \\
\hline
\end{tabular}

IV. PATHOGENICITY.

1. Pathogenic to Animals.

Insects, crustaceans, fishes, reptiles, birds, mice, rats, guinea pigs, rabbits, alogs, cats, sheep, goats, cattle, horses, monkeys,

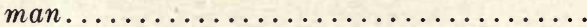

2. Pathogenic to Plants: 
3. Toxins, soluble, endotoxins.

4. Non-toxin forming.

5. Immunity bactericidal.

6. Immunity non-bactericidal.

7. Loss of virulence on culture media: prompt, gradual, not ob. served in......................

\section{BRIEF CHARACTERIZATION.}

Mark + or O, and when two terms occur on a line erase the one which does not apply unless both apply.

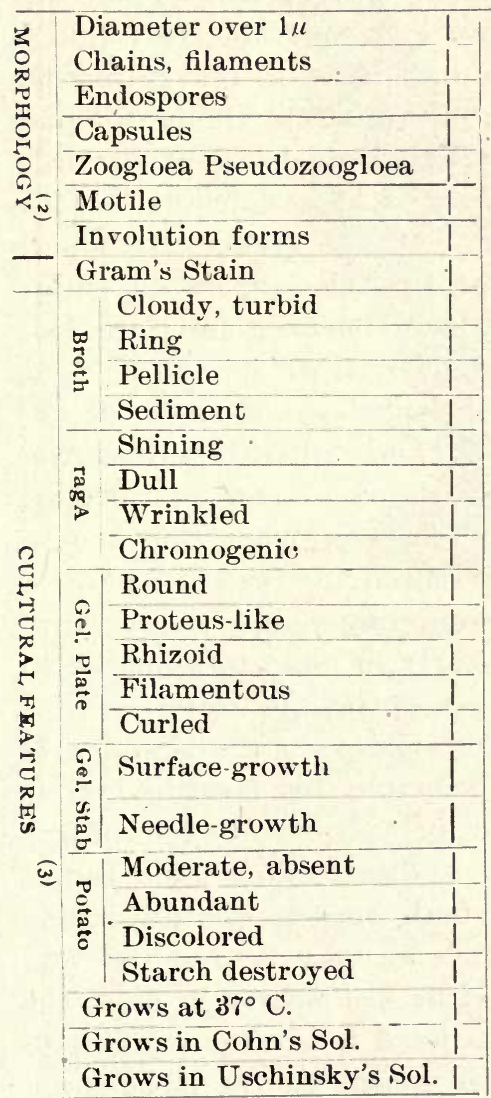

\begin{tabular}{|c|c|}
\hline & Gelatin (4) \\
\hline & Blood-serum \\
\hline & Casein \\
\hline & Agar, maunan \\
\hline & Acid curd \\
\hline & Rennet curd \\
\hline & $\bar{\pi}$ Casein peptonized \\
\hline & Indol (5) \\
\hline & Hydrogen sulphide \\
\hline & Ammonia (5) \\
\hline & Nitrates reduced $(5)$ \\
\hline & Fluorescent \\
\hline & Luminous \\
\hline & Animal pathogen,epizoon \\
\hline & Plant pathogen,epiphyte \\
\hline & Soil \\
\hline & Milk \\
\hline & Fresh water \\
\hline & Salt water \\
\hline & Sewage \\
\hline & Iron bacterium \\
\hline & Sulphur bacterium \\
\hline
\end{tabular}




\section{CHAPTER V.}

\section{BACTERIOLOGICAL APPARATUS.}

Apparatus used in the study of bacteria. In the study of bacteria, apparatus by which certain conditions may be secured is necessary. In different laboratories and in different lines of bacteriological work considerable variation is found in the equipment. It is important to recognize that much of the apparatus has been especially designed for particular use and convenience, but that much of the essential work in the practical application of bacteriological knowledge can be done without many of the special appliances usually employed in the laboratory. The apparatus, equipment and material for the study of bacteria fall into four groups, according to the purpose for which it is to be used, namely: for (1) studying the morphology of bacteria; (2) making culture media, isolating and cultivating bacteria; (3) special determinations and analyses; and (4) making toxins, antitoxins, vaccines, etc. The equipment that is most commonly used and which is essential for these purposes is briefly described below. In equipping a laboratory, however, it is important to keep clearly in mind the purpose of the apparatus and to recognize the principle involved in its use. In the application of bacteriology in the practice of medicine and surgery it is the principle that must be heeded rather than any particular form of equipment. The practitioner, for example, frequently wishes to do certain things in the field of bacteriology but finds himself wanting in the particular appliances with which he may be familiar and which are usually employed. If he has clearly in mind the principle involved in the task at hand it is often possible to substitute some ordinary kitchen utensil for the more specifically designed equipment and to obtain satisfactorily the desired results. 
Apparatus for the study of bacteria. As bacteria are very small, it is necessary in order to study their morphology to have a compound microscope with a sub-stage condenser,

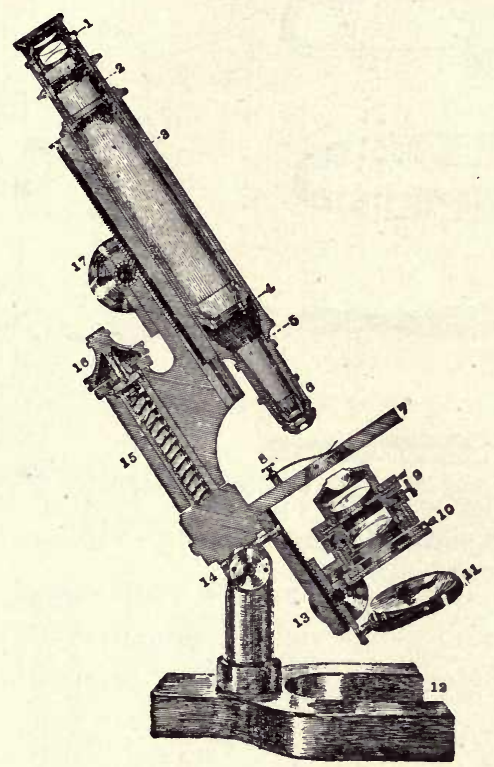

THE MICROSCOPE IN SECTION.

1. Positive ocular.

2. Draw-tulse.

3. Main tube or body.

4-5. Society screws in the

draw-tube and body.

6. Objective in positiou

7. Stage.

8. Spring for holding slides.

9. Sub-stage condenser.

Io. Iris diaphragm.
I1. Plane and concave mirror.

I 2. Horse-shoe base.

13. Rack and pinion for condenser.

14. Flexible pillar.

15. Spiral spring of fine

adjustment.

16. Fine adjustment.

17. Coarse adjustment.

From Gage, the Microscope and Microscopical Methods,

Fig. 12. A compound microscope.

oil immersion objective and suitable eye-pieces. There are many accessories that are often very desirable and occasionally necessary. The accompanying diagram illustrates a microscope suitable for this purpose, showing the essential parts. 
In addition to the microscope, slides, cover-glasses and cover-glass forceps are necessary. For examining living
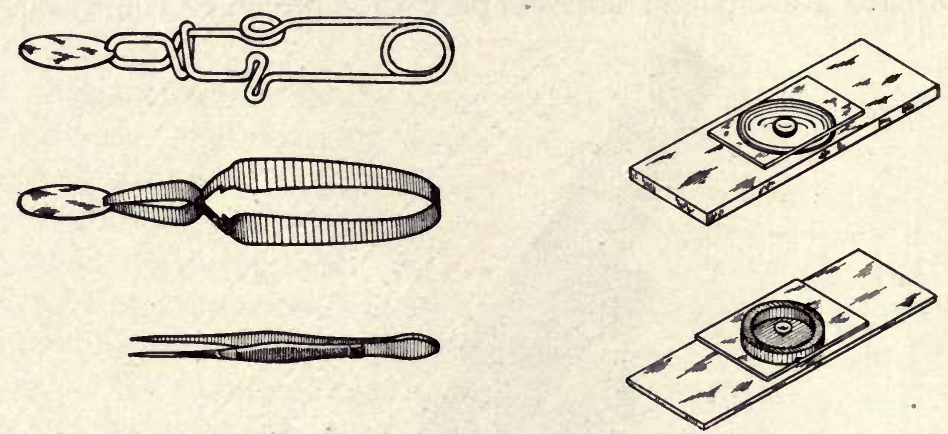

Fig. 14. Slides for

Fig. 13. Varieties of forceps used for handling cover-glasses. studying living bacteria with cover-glasses in place.

bacteria it is necessary to have a culture cell, or better, an ordinary glass slide on which is cemented a glass ring about $1.2 \mathrm{~cm}$. in diameter and 1 to $3 \mathrm{~mm}$.* in thickness. To stain

* Fig. 15.

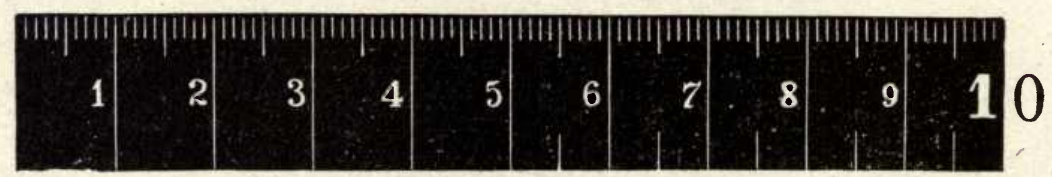

10 CENTIMETER RULE

The upper edge is in millimeters, the lower in centimeters, and half centimeters.

\section{THE METTRIC SYSTEM}

UNITS.

THE METER FOR \{ IENGTH. .

THE GRAM FOR \{ WEIGHT. . . \{

THE LITER FOR \{ CAPACITY. :
The most commonly used divisions and multiples. Centimeter (cm.), 0.01 Meter; Millimeter (mm.), 0.001 Meter: Micron $(\mu) 0.001$ Millimeter; the Micron is the unit in Micrometry. Kilometer, 1000 Meters; used in measuring roads and other long distances.

Milligram (mg.), 0.001. Gram.

Kilogram, 1000 Grams, used for ordinary masses, like groceries, etc. Cubic Centimeter (cc.), 0.001 Liter. This is more common than the correct form, Milliliter.

Divisions of the Units are indicated by the Latin prefixes: deci, 0.1 ; centi, 0.01: milli, 0.001 ; micro, one millionth $(0.000001)$ of any unit.

Multiples are designated by the Greek prefixes: deka, 10 times; hecto, 100 times: kilo, 1000 times; myria, 10,000 times; mega, one million $(1,000,000)$ times any unit. 
bacteria one needs aniline dyes, such as basic fuchsin, methylene blue and others, together with small bottles and
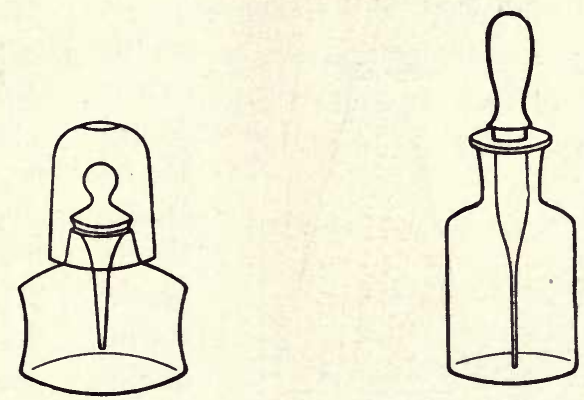

Fig. 16. Bottles for holding balsam and reagent.

droppers to contain the properly prepared solutions of these dyes.

Apparatus needed for making culture media and isolating bacteria. For these purposes a large variety of test
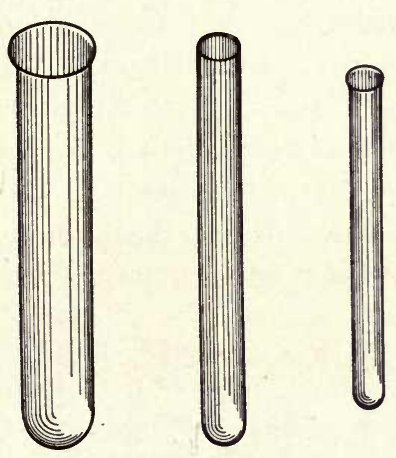

Fig. 17. Large and smaller test tubes for culture media. The middle size is used most for cultures, the largest for storing media for plate cultures, and the smallest for serum agglutination work. tubes and flasks is lemployed. For the ordinary work, culture media can be conveniently stored in Erlenmeyer flasks of 500 cc. capacity. Larger or smaller ones may be used if desired. For many cultures the media are distributed in small and larger test tubes. There is a considerable variety of tubes used for this purpose. The ordinary test tubes, from 8 to $12 \mathrm{~mm}$. in diameter and from 10 to $15 \mathrm{~cm}$. in length, are quite commonly employed. A tube known as the "Board of Health" tube which is made of heavier glass about $8 \mathrm{~mm}$. in diameter and $12 \mathrm{~cm}$. in length and is.without a lip is found 
to be very satisfactory. Such tubes are used for the ordinary agar, gellatin and bouillon cultures. Larger tubes 10 to $12 \mathrm{~mm}$. in diameter and 10 to $12 \mathrm{~cm}$. in length are com-
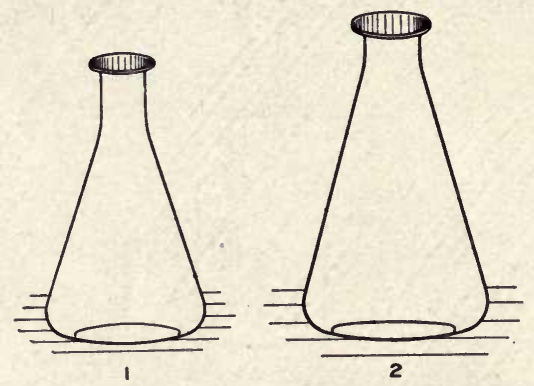

Fig. 18. Erlenmeyer flasks, showing cifferent sizes and shapes ; 1,250 cc. ; 2, 500 cc. capacity.

monly employed for storing agar and gelatin. For plate cultures, Petri dishes are usually employed instead of the Koch plate formerly used. They are simply round, double glass dishes. For inoculating media or making cultures, platinum wires or loops attached to glass rods are employed. A gas burner or alcohol lamp is used for sterilizing the needle or loop. For determining the quantity of gas produced by the growth of certain bacteria, the fermentation tube of which there are several forms is used. The more convenient size holds from 15 to 20 ce. The open bulb should have a capacity of fully three-quarters that of the closed branch. A large variety of apparatus has been devised to meet the requirements of the different methods for cultivating bacteria in the absence of atmospheric oxygen.

In the preparation of culture media agate iron basins and cups varying in size from 0.5 to 2.0 liters have been employed. Scales for weighing the peptone etc.; litmus paper; one or more burettes and small dishes, porcelain, for titrating

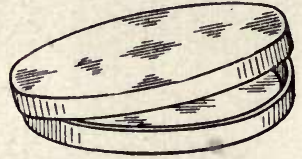

Fig. 19. Petri dish with cover tipped. the media; steam and hot water cookers; water baths; steam sterilizers; and autoclave for sterilizing media under superheated steam are also necessary. A large variety of autoclaves, steam sterilizers and water baths have been made. In some laboratories the autoclave 
is used almost entirely for sterilizing media etc., while in others it is employed very little and in its place streaming steam sterilizers or large water baths are substituted. Temperatures slightly above that of boiling water $\left(100^{\circ} \mathrm{C}\right.$.) may be obtained by using instead of an expensive autoclave a water-bath containing a solution of calcium chloride or some other salt.

Most bacteria that are pathogenic for animals are culti-

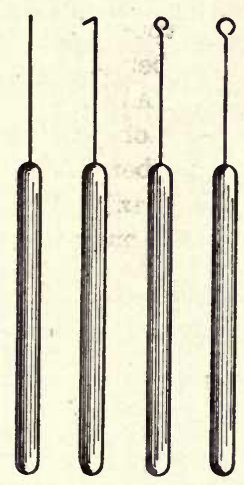

Fig. 20.

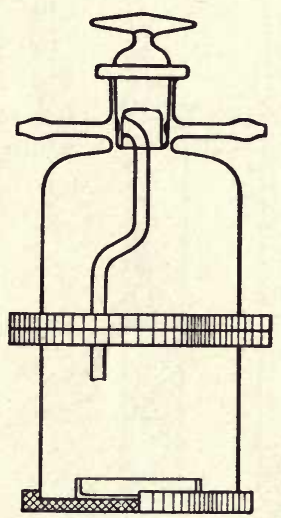

Fig. 21.

Fig. 20. Platinum wires and loops of different forms and sizes used for making cultures.

Fig. 21. Novy's apparatus for plate cultures in a vacuum or in the presence of hydrogen. In this case hydrogen is introduced through the glass tube and after the atmosphere has been replaced by hydrogen the entrance and exit are closed by turning the stopper. Novy has designed a somewhat similar apparatus for culture tubes.

vated at a temperature of about $37^{\circ} \mathrm{C}$. For this purpose an incubator is necessary. Incubators are constructed on different plans, the chamber of some being surrounded by water jackets and others being kept at a constant temperature by means of a circulation of heated air through metal pipes. In some laboratories a small room is kept at the body temperature and used in place of an incubator. An apartment incubator for use when a number of individuals are at work 
as in a student laboratory is very convenient. For heatingincubators, gas burners are usually employed and those with an automatic cut off or safety burners are most desirable. The temperature of the incubator is regulated by means

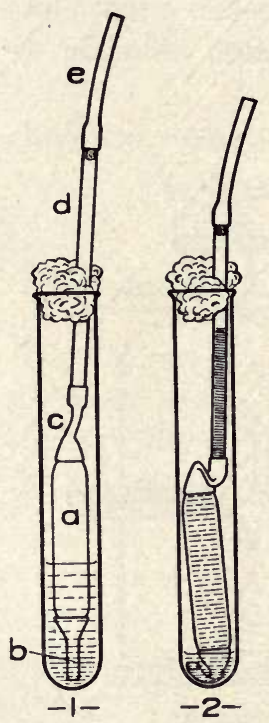

Fig. 22.

Fig. 22. Wright's device. The apparatus consists of a system of glass and rubber tubes. standing in an ordinary test tube. (A), is a glass tube somewhat constricted at each end; (B), (C), and (E) are short pieces of rubber tubing; glass tube (D) carries in its upper extremity a small cotton plug. The test tube contains. some culture fluid as indicated in 1.

Fig. 23. Baginisky's apparatus. It consists of a large metal plate, the circumference of which is covered with a thick rubberring. A bell jar is inverted over the plate and rests on the layer of rubber. Over the bell jar is placed a metal plate similar to that which forms the bottom of the apparatus. The bottom part contains four projections in which are hinged metal rods, the outer ends of these rods fit into similar projections in the cover plate. By means. of these four metal rods the upper and the lower metal plates are. tightly pressed against the bell jar, closing the apparatus hermetically. On opposite sides the bell jar contains small lateral tubes by means of which hydrogen is introduced and air driven out.

of a thermostat. There are many varieties of thermoregulators; some are controlled by the use of alcohol and ether, others by mercury and still others use a metallic bar thecontraction and expansion of which controls the flow of gas. 
When incubators are heated by electricity, the temperature is controlled by electric thermostats. When gas is used, the metallic bar regulators seem to give the best results and to require the least attention.

Special apparatus. The special apparatus necessary depends upon the kind of work that is being done. In the

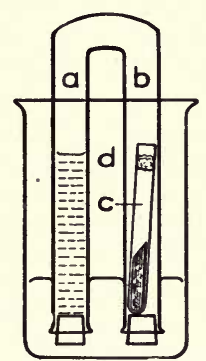

Fig. 24.

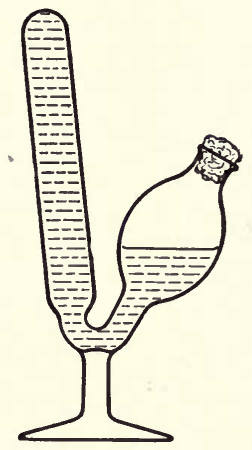

Fig. 25.

Fig. 24. An apparatus used by Erwin F. Smith for cultivating anaerobes. Into one end of a large $U$ tube place about three grams of dry pyrogallic acid and three grams of sodium hydrate. Close this end with a rubber stopper and pour about $15 \mathrm{cc}$. of water into the other end (b) holding the $U$ tube so that the water all escapes into the branch (a) containing the reagents. Now insert in the second branch (b) a small test tube (c) containing the inoculated medium and a loose cotton plug. Close this end of the $U$ tube with a rubber stopper and stand the $U$ tube in a beaker (d) containing mercury or glycerin. Good results were obtained by this method.

Fig. 25. Fermentation tube. This tube was introduced by Theobald Smith for the study of anaerobic bacteria. Strictly anaerobes multiply in the closed branch only.

bacteriological examination of liquids or semi-solids, it is frequently desirable to centrifuge the material. For this, a centrifuge is required. The size is to be determined by the nature of the work to be done. In the study of toxins, bacterial filtrates and the like, it is necessary to have filter- 
ing apparatus such as the Chamberland or Berkefeld bougies that will remove bacteria. There is a large variety of these on the market and one must determine the size and kind best adapted for the work in hand. The Berkefeld bougies are made from infusorial earth and are more porous than the Pasteur filter or Chamberland bougies. They are

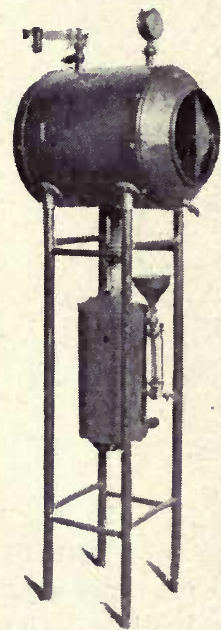

Fig. 26.

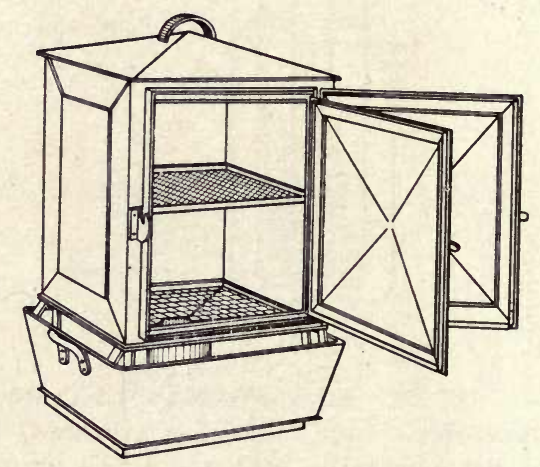

Fig, 27.

Fig. 26. Eclipse autoclave for rapid sterilization under steam pressure.

Fig. 27. Arnold's steam sterilizer. (Board of Health pattern.)

graded according to the fineness of the pores as A., B., C., ete.

In making plate cultures, it is necessary to have accurately levelled shelves on which to stand the plates or to use a levelling apparatus. This is very important where the exact number of colonies is to be determined.

There is a large variety of pipettes, graduates, beakers, dessicators, etc., that are useful in special kinds of work.

Apparatus for making vaccines. For this work, in addition to the ordinary apparatus, especially designed 
tubes, pipettes, centrifuges, shaking apparatus, apparatus for heating the cultures to a definite temperature and other devices have been placed on the market. As already mentioned, it is important to understand that various uses of

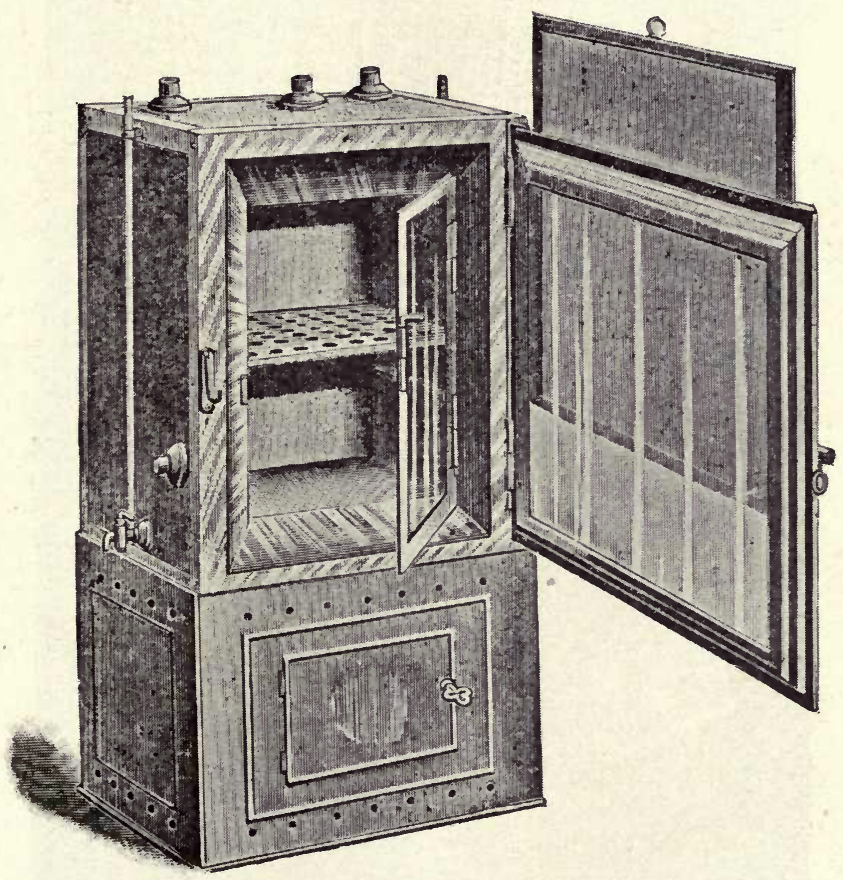

Fig. 2s. Incubator.

the different apparatus, and to appreciate the fact that most of it has been designed for special purposes and the other for convenience. In selecting equipment for bacteriological work, difficulties will be minimized if as simple and noncomplicated appliances as possible are chosen. In the application of bacteriological knowledge in the practice of veterinary medicine, as in other fields, it is the principle that must be applied and for this, special apparatus is not always neces- 


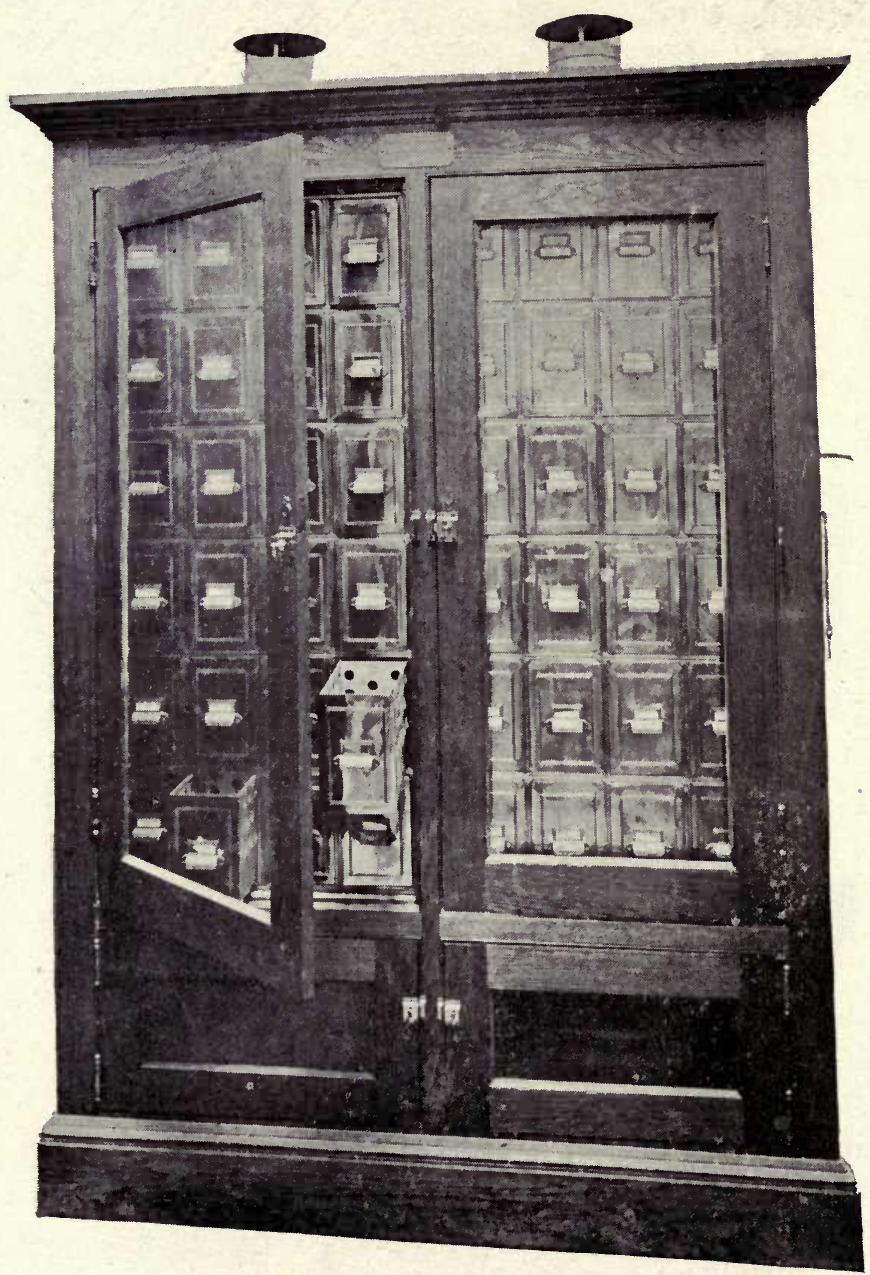

Fig. 29. Apartment incubator. 
sary. The amount of equipment required by the practitioner to do such bacteriological work as is necessary to be done immediately is not large. This is gratifying, for it is desirable to take into actual practice as many methods for accurate determinations as possible.

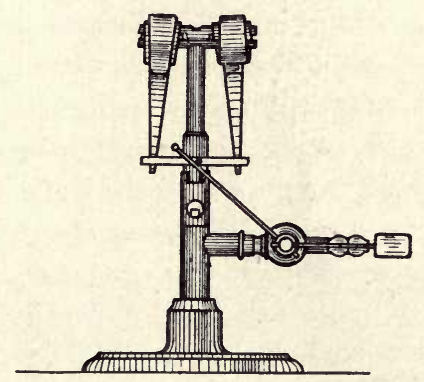

Fig. 30. Koch safety burner for heating incubators.

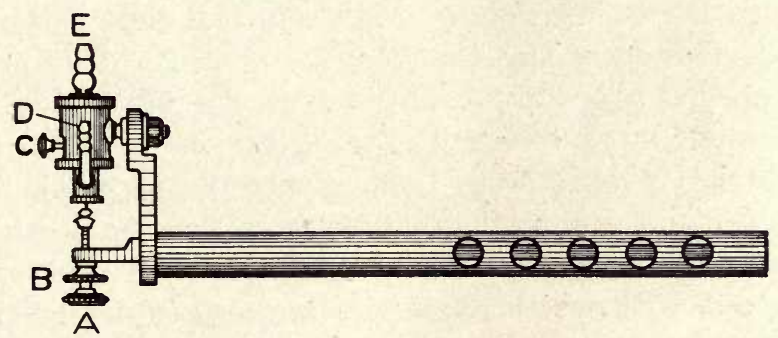

Fig. 31. American make of the Roux bimetallic thermoregulator. 


\section{CHAPTER VI.}

\section{STERILIZATION AND DISINFECTION.}

Sterilization. This is the killing of all living things in or upon the object or substance sterilized. The application of sterilization is of the greatest importance in bacteriological work as well as in the practical application of bacteriology in medicine, surgery and sanitary science generally. In order to procure sterilized substances or media a number of procedures are employed. In general it may be stated that sterilization is produced by the application of heat, certain chemicals as disinfectants and in certain instances by filtration. Where it can be used, heat is the most effective agent in securing this condition, although chemicals are sometimes necessary. In order to know that an article is sterilized it is necessary to apply sufficient heat to kill any and all microorganisms that may be present. This may be accomplished by a very high temperature for a short time or a lower temperature for a longer period. Some bacteria are killed by a much lower temperature or with weaker solutions of disinfectants than others. In specific work it is necessary to know the thermal death point of each species of bacteria with which one is dealing and to determine the strength of the commonly used disinfectants that is necessary to kill them. In sterilizing any substance or article it is necessary to bear in mind the effect of the agent used upon the substance as well as the expense and possible convenience in applying it.

Methods of sterilization. As already stated a number of methods are not only possible but necessary in order to. sterilize different articles. The more important of these methods are as follows:

1. Dry heat. Dry heat at a temperature of $135^{\circ} \mathrm{C}$. for one hour is destructive to all bacteria except perhaps 
the spores of certain species. Dry heat is applied by the use of the direct flame and by heated air chambers.

(a) Direct flame. In laboratory work the direct flame of a gas burner or of an alcohol lamp is used to sterilize certain articles, such as platinum needles for making cultures and sometimes for instruments used for making cultures at post mortem and occasionally instruments used for slight operations. The method consists in holding the instrument in the flame until it is heated sufficiently to kill all organisms that may be upon it. In practice this is usually deter-

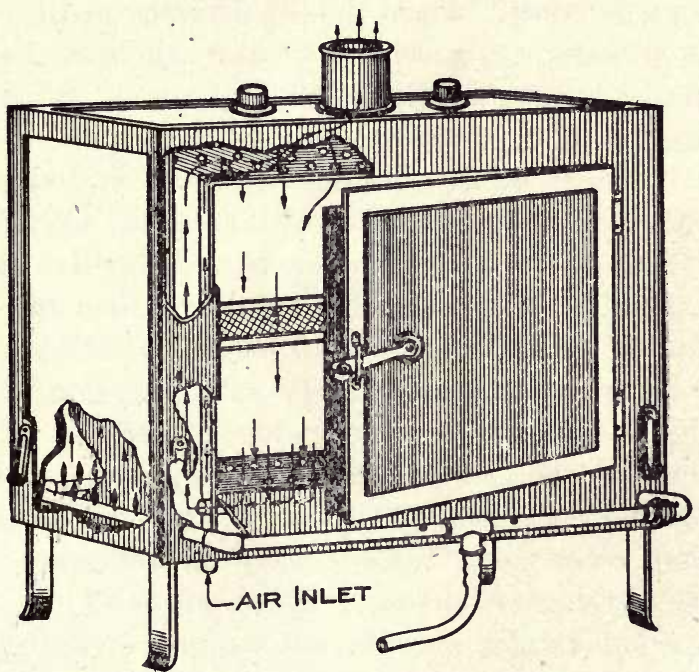

Fig. 32. Hot air sterilizer, Lautenschlager pattern. These ovens can be heated to a temperature of $150^{\circ} \mathrm{C}$ in about 20 minutes.

mined with small articles like the platinum wire or loop by the red or white heat of the metal.

(b) Hot air. Many articles can not be sterilized in the direct flame but can be by the application of air heated to the temperature of $135^{\circ}$ to $170^{\circ} \mathrm{C}$. for from one to two hours. This is accomplished by means of the hot air sterilizer, which is a metal chest heated by means of a gas flame. In using it the material or apparatus to be sterilized is placed 
in the sterilizer, the door tightly closed, and the gas lit. When the desired temperature is attained it is held there by an automatic gas regulator or by adjusting the amount of gas fed to the flame. Ordinarily this high temperature is maintained for an hour. This method is used very largely for sterilizing glassware. It is sometimes used for sterilizing instruments and other articles.

2. Moist heat. In the presence of moisture bacteria are destroyed at a much lower temperature than they are in dry air. Moist heat is applied by the use of the water bath. Articles to be sterilized are placed directly in the water, or if liquid, in retainers set in the water, such as glass tubes, or flasks; or by the application of streaming steam; or the use of steam under pressure.

(a) Water bath. Boiling in water destroys very quickly the vegetative form of all bacteria. Certain spores such as those of Bacterium anthracis and Bacillus subtilis require boiling for a considerable length of time for their destruction. If articles that are to be sterilized by boiling in a water bath are not completely submerged in the water, the water bath should be tightly closed. As most of the nonspore bearing bacteria are killed at a temperature much below the boiling point, it is possible to sterilize substances at a temperature of $60^{\circ} \mathrm{C}$. if they do not contain resisting spore bearing organisms. This method is often used in sterilizing substances that do not contain spore-bearing organisms and which would be injured if they were heated to the boiling point. Most non-spore bearing bacteria are killed when held at a temperature of $60^{\circ} \mathrm{C}$. for 20 minutes in the presence of moisture. Some of the pathogenic forms, like streptococei, are killed at a lower temperature.

(b) Streaming steam. Articles to be sterilized by this method are placed in some receptacle into which steam may flow. The Arnold sterilizer is the most common form of apparatus in which to apply steam. The temperature ranges from $98^{\circ}$ to $102^{\circ} \mathrm{C}$. This will kill all non-spore bearing bacteria in from 10 to 20 minutes. It is used in the lab- 
oratory largely for sterilizing culture media. It is sometimes used for sterilizing surgical dressings and certain glassware that might be injured by the high temperature in dry air.

(c) Dry steam or steam under pressure. This is obtained in the autoclave or steam chest. A pressure of from 10 to 20 pounds or more is employed. It is used frequently in making and sterilizing certain eulture media. There are, however, certain objections to the use of such a high temperature in the preparation of most media, especially those in which bouillon forms the essential nutritive portion. Sterilizers of this kind are used for sterilizing certain apparatus, instruments and surgical dressings. They are largely employed, however, for sterilizing or disinfecting clothing and bedding after known infection. It is necessary to have the steam under pressure in order to give it sufficient penetrating power.

3. Chemicals. Certain chemicals which possess high germicidal action may be used for disinfecting eertain articles such as harnesses, halters and instruments. Chemicals are also employed to sterilize or disinfect the field of operation. Ordinarily when chemicals are employed the process is called disinfection. In using chemicals to sterilize any substance the effect of the chemical upon said substance should be known. Solutions of the chemical sufficiently strong to kill the organisms must be used.

4. Filters. Filters are sometimes used to remove all bacteria from certain fluids used in the laboratory. This method is sometimes employed for sterilizing water. In order to sterilize a liquid by means of a filter it is necessary to have a filter through which bacteria will not pass, to have this filter sterilized, and the filtrate must pass directly into a sterilized flask or other receptacle. The filters that can be used for this purpose are the Chamberland (Pasteur), Kitasato, and the Berkefeld bougies. There are different grades of these but none of them can be continuously used for a very long time without resterilization as the bacteria will 
grow through them.* Few if any of the other domestic filters are capable of removing bacteria from liquids.

Fractional or discontinuous sterilization. It has been stated that spores are not destroyed promptly in all cases by the application of heat even at $100^{\circ} \mathrm{C}$. It has also been stated that heating a substance at a lower temperature for a longer time will, in the absence of spores, sterilize, as well as heating to a higher temperature for a shorter time. If spores are present,or organisms more resistant to heat, it is not sufficient to heat a substance once. Fractional sterilization consists in heating substances in a water bath or steamer at a temperature of from $60^{\circ}$ to $100^{\circ} \mathrm{C}$. according to the requirements of the substance for from 10 to $30 \mathrm{~min}$ utes each day for three or more consecutive days. The reason for this is that the first heating destroys all the bacteria in the vegetative stage; by allowing the substance to stand over night the spores of the more resistant bacteria will begin to germinate or multiply, when the second heating will destroy them. The same holds for the third heating.

The practical application of sterilization. There is perhaps a no more important lesson for the laboratory worker who is to become a practitioner of medicine to learn in bacteriology than the one regarding sterilization. The necessity of a knowledge of sterilization and the means by which it can be produced has many practical bearings.

1. In the laboratory. In bacteriological work it is of the greatest importance that all culture media and instruments used in making cultures should be sterile. In order to have these sterile it is necessary to understand the methods by which this condition can be brought about without injury to the various substances. Likewise, all jars and bottles used for collecting material for a bacteriological examination should be sterile. If one understands that the principle of sterilization consists simply in the application of p. 628 .

* Smith and Moore. Centralbl. f. Bakteriology, Bd. XII (1892) 
heat, whether moist or dry, or chemicals of a germicidal power, it is possible under almost all circumstances by one method or the other to sterilize the necessary instruments or retainers.

2. In surgery. The application of sterilization in surgery consists in the sterilization or disinfection of the field of operation, the hands of the operator, and all instruments and dressings used in the operation. In case of injury where infection may have taken place, the wound should be disinfected. For this purpose chemicals are used. The thermo cautery is occasionally used by practitioners in place of chemical disinfection, as it not only destroys the organisms but also promotes granulation.

3. In medicine. Many of the digestive troubles due to fermentation respond to the administration of medicines that have a germicidal action. Many skin disturbances are caused by infection and respond readily to the application of proper sterilizing solutions or disinfectants. Many local lesions, such as tonsilitis and foci of inflammation on the mucous membranes, especially of the mouth, are benefited by the use of such solutions. In man, the preservation of the reeth is enhanced by the use of germicidal tooth washes.

4. In sanitary work. It is of the first importance in cases of infectious disease to see that all excreta are disinfected or sterilized in order to prevent the spread of the virus. Stables or pens that have contained such diseased animals should be thoroughly disinfected before they are again occupied. More attention is gencrally paid to the sterilization of clothing, bedding and apartments in case of infectious diseases in man than is accorded to the blankets, harnesses, stables or pens of domestic animals under like conditions; but it is of equal importance in order to prevent the spread of animal diseases that the same care be exereised in these matters. 
Disinfection. . Disinfection ${ }^{1}$ is the destruction of all infecting organisms such as bacteria, fungi and protozoa, but not necessarily all of the bacteria present. When applied to the disinfection of cars or stables in which animals suffering from protozoan diseases such as Texas fever have been kept it implies the destruction of the insect which carries the microorganism.

Disinfection has a wide range of application. It is used by the surgeon to prepare the field of operation, his hands, instruments, and dressings and by the practitioner or the sanitarian in the cleansing of cars, stables and pens in which animals suffering from infectious diseases have been kept.

A large amount of work has been done to determine the exact germicidal value of many chemicals as well as the rapidity of the action of such natural germ destroyers as sunlight and drying. The recorded results are not uniform. A study of the germicidal action of various substances on different species of bacteria requires a careful consideration of the following facts: (1) the variation in the vital resisting power of different species or organisms; (2) the resisting power of the same species varies under different conditions such as the young actively growing cultures and old cultures; (3) the medium in which the bacteria exist influences to a considerable extent the action of the disinfectants; (4) the temperature under which the disinfectant acts influences the rapidity and certainty of its action; and (5) the inhibiting or antiseptic action ${ }^{-}$of the disinfectant must not be confused with germicidal action.

There is often confusion in the use of certain terms referring to the prevention of growth and the destruction of

${ }^{1}$ For a more extended study of the various disinfectants and their application, the student is referred to the following list of works on this subject in which will be found many references to specific tests and studies.

S. Rideal, Disinfection and Disinfectants, London.

A. G. Young, Disinfectants and Disinfection, Augusta.

M. J. Rosenau, Disinfection and Disinfectants, Philadelphia.

H. M. Bracken, Disinfection and Disinfectants, Chicago. 
bacteria. It is important, therefore, to have clearly in mind the following terms and their definitions.

Antiseptic. An antiseptic is a chemical substance which inhibits the multiplication of bacteria but does not necessarily kill the individual bacteria present. Most if not all disinfectants in solutions too weak to disinfect act as antiseptics.

Germicide. A germicide is a chemical substance or physical agent that will kill microorganisms.

Asepsis. A substance is aseptic when it is free from. pathogenic or septic bacteria. An aseptic operation, for instance, means that the operation is performed in the absence. of infecting bacteria, that is, after proper disinfection of the field of operation, the hands of the operator and the sterilization of the instruments and dressings.

Deodorant. Deodorants are substances which have the property of absorbing the unpleasant odors that are emitted from matter undergoing decomposition. These substances must not be mistaken for true disinfectants.

Disinfectants. A large number of substances have been used as disinfectants. In the choice of a disinfectant several factors are to be considered. (1) In regard to the disinfectant itself. It is important to choose those agents that arestable and uniform such for example as acids, alcohols or stable chemical substances such as corrosive sublimate. Certain of the compounds of substances in themselves valuable arefound not to be uniform in their germicidal action. (2) The effect upon the substance to be disinfected. Here great care is to be exercised. Mercuric chloride so highly recommended in surgery because of its non-irritating properties and reliability can not be used to disinfect instruments or metal articles because of its corrosive nature. (3) Facility of use and cost. After the reliability of the germicidal action and effect upon the objects to be disinfected are determined, a further choice lies in the facility with which it can be applied and its cost. In practical disinfection, one must employ solutions stronger than the minimum strength found to be germi- 
cidal with young cultures. The disinfectants may be grouped according to the condition in which they are applied as (1) natural agents, (2) chemical solutions and (3) gases.

The natural germicidal agents are sunlight and drying.

The more commonly used disinfectants are bichloride of mereury, carbolic acid (phenol), sulphur, calcium compounds, formalin and the cresols. Formaldehyde and sulphur are used in the form of gases. There are, however, many other preparations that are used, among which are equal parts of sulphuric and crude carbolic acid.

\section{Bichloride of mercury $\left(\mathrm{HgCl}_{2}\right)$ (Corrosive sublimate).} This is a white crystalline mass. It will dissolve in 16 parts of cold water and 3 parts of hot water. As a germicide, bichloride of mercury acts in solution by combining chemically with the microprotein of the organisms. This requires direct contact between the microorganisms and the solution in which a certain length of time and concentration of the solution are necessary. Koch, ${ }^{1}$ Sternberg ${ }^{2}$ and many others have found this to be a very powerful germicide. Its efficiency depends, however, upon the nature of the medium in which the bacteria are when subjected to its influence. For ordinary disinfection an aqueous solution of 1 to 1000 is used. The addition of a small quantity of common salt is desirable to avoid erystallization. Sixty grains of corrosive sublimate and two tablespoonfuls of common salt to one gallon of hot water make a solution of 1 to 1000 . When it is employed to disinfect substances containing albuminous matter such as sputum or feces it must be used in excess as a chemical combination takes place between the mercuric chlonide and the albuminous matter present. Behring ${ }^{3}$ found that this solution would kill vegetating anthrax bacteria in dilution of 1 to 500,000 . It must not be kept in metal retairers but in those of glass or wood.

${ }^{1}$ Koch. Mitt. a. d. Kais. Ge؟urdheit, Bd. I (1881) p. 269. Translated in Recent essays New Sydenham Society 1886.

${ }^{2}$ Sternberg. Disinfection and Disinfectants, 1888, p. 41.

${ }^{3}$ Behring. Bekampfung der Infectionskrankheiten. Bd. II (1894) p. 43. 
It is not very penetrating and when employed to disinfect the skin it must have considerable time (several hours) to act. The alcoholic solutions are much more penetrating. As it is very poisonous great care must be exercised in its use and in properly labeling all bottles containing it.

Carbolic acid $\left(\mathrm{C}_{6} \mathrm{H}_{5} \mathbf{O H}\right)$ (Phenol). Pure carbolic acid erystallizes in long colorless needles. At ordinary temperature it is soluble in about 16 parts of cold water. A saturated solution contains from 6 to 7 per cent of the acid. Its value as a disinfectant is increased by the fact that it acts in the presence of albuminous substances. For disinfection it is commonly used in solutions of from 3 to 5 per cent. In these strengths it it destructive to all non-spore bearing bacteria. It is not reliable for the destruction of spores and consequently should not be used in the disinfection for anthrax, tetanus, malignant edema and black leg bacteria. Carbolic acid is much more penetrating than watery solutions of corrosive sublimate and for that reason it is more valuable for skin disinfection preparatory to operation. Dorset ${ }^{1}$ sums up the advantages and disadvantages of carbolic acid as follows. The advantages are :

(1) It is reasonably effective for destroying nonsporebearing bacteria.

(2) Its action is only slightly interfered with by albuminous substances.

(3) It does not destroy metals or fabrics in a 5 per cent solution.

(4) It is readily available at all pharmacies.

The following disadvantages may be mentioned:

(1) It can not be depended upon to destroy the spores of such bacteria as anthrax and malignant edema.

(2) It is expensive (the pure phenol costs approximately 7.5 cents per pound).

Tricresol. Tricresol is a mixture of ortho-meta- and para-cresols. It is a clear pinkish colored syrupy liquid. A

\footnotetext{
${ }^{1}$ Dorset. Farmers' Bulletin No. 345, U. S. Dept. Agric. 1908.
} 
2.5 per cent solution in water can be obtained. It is considered to be less poisonous than carbolic acid and about three times as powerful as a disinfectant. It seems to. be the most efficient of the cresols. It is usually employed in about a one per cent solution. It is much more rapidly destructive to spores than carbolic acid. The cresols are not very soluble in water. Harrington states that ereolin (contains 10\% cresols: and a small quantity of carbolic acid), and lysol (contains $50 \%$ cresols with neutral potash soap) are very efficient as disinfectants. There are many other preparations. containing cresols that are on the market and recommended as disinfectants.

Calcium compounds. The use of lime was early resorted to as a disinfectant. The milk of lime and lime water are the most valuable forms.

Milk of lime is prepared by adding 1 quart of freshly slacked lime to from 4 to 5 quarts of water. Air slacked lime is of little or no value as a disinfectant. When surfaces are thoroughly covered and brushed with this mixture most of the bacteria are destroyed. If it does not kill them outright it imprisons them so that they perish. It is much used for disinfecting stables and pens. Lime water is a very good disinfectant for non spore-bearing bacteria.

Chlorinated lime, which is prepared by passing nascent chlorin gas over moist calcium hydrate, should contain not less than $35 \%$ of available chlorin. It is prepared for use by mixing $6 \mathrm{oz}$. of the lime with a gallon of water. It is frequently applied as a dry powder for the disinfection of excreta, yards, etc. It is also a powerful deodorant.

Formalin. When applied in solution one part of formalin to ten parts of water is used. This is equal in its disinfecting powers to a $5 \%$ solution earbolic acid (phenol). On account of its irritating effect it is rarely used in solution but it is applied as a gas.

Formaldehyde gas. This is the most widely used general disinfectant. It can not, however, be used unless the room to be disinfected ean be sealed tight. For this reason it is of 
less value in disinfecting barns, stables and the like than in houses. The gas must be liberated rapidly in large quantities and there should be moisture present. Formaldehyde is used as a spray in the strength of 1 part of formalin to 10 of water. It is, however, more usually employed in the gaseous state. Formaldehyde gas may be obtained in the following ways. (1) By heating formalin (40 per cent aqueous solution of formaldehyde) in an autoclave under pressure or (2) in a retort without pressure (3) By adding formalin to potassium permanganate and (4) By heating paraform. In producingformaldehyde gas for disinfection purposes a large volume of gas should be evolved in a very short time. There are on the market several forms of apparatus for generating formaldehyde gas. Formaldehyde gas may be generated from a lamp by a dehydrogenation of the vapor of wood alcohol in passing it mixed with air over incandescent platinum. The followingreaction takes place.

$$
\mathrm{CH}_{3} \mathrm{OH}+\mathrm{O}=\mathrm{HCOH}+\mathrm{H}_{2} \mathrm{O}
$$

methyl alcohol oxygen formaldehyde water.

Formaldehyde is more commonly used as a disinfectant by liberating it from solid forms into which it ean be condensed. The gas is a complex unstable body and failures in its use as a disinfectant are attributable to an imperfect knowledge of its properties and methods of production.

Formaldehyde ( $\mathrm{HCOH})$ exists in at least three isomeric states; (1) formic aldehyde is a gas at ordinary temperatures, colorless and possessing a slight odor and having a very irritating effect upon the mucous membranes especially those of the nose and conjunctiva. At a temperature of about $-20^{\circ} \mathrm{C}$. the gas polymerizes into paraformaldehyde which is known commercially as paraform, (2) Paraform is a white substance soluble in both water and alcohol. It consists chemically of two molecules of formaldehyde. It is this substance which it is supposed constitutes the commercial solutions of formaldehyde known as formalin, formol, etc. (3) Trioxymethylene is formed by the union of three molecules of formaldehyde. It is a white powder giving off a strong odor of the gas. It is 
slightly soluble in water and alcohol. To summarize, formaldehyde exists in three states.

$\mathrm{CH}_{2} \mathrm{O}$
$\mathrm{CH}_{2} \mathrm{O}$

$\mathrm{CH}_{2} \mathrm{O}$

$\mathrm{CH}_{2} \mathrm{O}$
$\mathrm{CH}_{2} \mathrm{O}$

$\mathrm{CH}_{2} \mathrm{O}$

Formaldehyde gas. Paraformaldehyde. Trioxymethylene. Paraform.

Paraform is obtained in the market and is put up by certain manufacturers in the form of paraform eandles, in such quantities that one candle liberates gas sufficient for $1,000 \mathrm{cu}$. ft. of space. When used the room or stable must be tightly sealed.

Formaldehyde is used practically by saturating sheets or blankets with formalin and suspending them in the room, using at the rate of $10 \mathrm{oz}$. of formalin for each $1,000 \mathrm{cu}$. $\mathrm{ft}$. of space.

Sulphuric and crude carbolic acids. This consists of a mixture of these acids. It is quite corrosive and care should be taken to protect the eyes and the hands from accidental splashing:

\section{Crude sulphuric acid $1 / 2$ gallon. Crude carbolic acid - $1 / 2$ gallon.}

These two substances should be mixed in wooden tubs or glass vessels. The sulphuric acid is very slowly added to the carbolic acid. During the mixing a large amount of heat is developed. The disinfecting power is heightened if the amount of heat is kept down by placing the tub or demijohn containing the carbolic acid in cold water, while the sulphuric acid is being added. The resulting mixture is added to water in the ratio of 1 to 20 . One gallon of mixed acid will thus furnish 20 gallons of a strong disinfecting solution having a slightly milky appearance. The mixture should be applied to the walls and floors of the pens, saturating them with it.

Sulphur. Sulphur is one of the oldest disinfectants. Sulphur dioxide gas $\left(\mathrm{SO}_{2}\right)$ has been extensively used for the 
disinfection of hospitals, ships and living apartments. It is an active germicide when in sufficient quantities in the presence of moisture, and with which it combines to form sulphurous acid $\left(\mathrm{H}_{2} \mathrm{SO}_{3}\right)$. It is not thought to be very active in the dry state. It has been determined that $\mathrm{SO}_{2}$ as a disinfectant when present in at least 4 volumes per cent in the presence of moisture and an exposure of 8 hours is very satisfactory. Four pounds of sulphur burned for each 1,000 cu. ft. will give an excess of the gas. In using it, the room should be tightly closed and steam should be given off. Some of the modern burners for sulphur are arranged so that the heat used for burning sulphur will be utilized for heating water thus liberating steam.

As previously stated, many substances have been used as disinfectants. Regarding these, Park ${ }^{1}$ has given the following table of antiseptic values, which he states are approximately correct and represent the percentage of the disinfectant necessary to be added to the fluid containing considerable organic matter in order to prevent further bacterial growth. Solutions of half these strengths will in most cases inhibit the growth of most of the organisms.

\section{ANTISEPTIC VALUES OF DIFFERENT SUBSTANCES}

$\begin{array}{llll}\text { Disinfectant } & \text { Dilution } & \text { Disinfectant } & \text { Dilution } \\ \text { Alum } & 1: 222 & \text { Mercuric chloride } & 1: 14,300 \\ \text { Aluminum acetate } & 1: 6000 & \text { Mercuric iodide } & 1: 40,000 \\ \text { Ammonium chloride } & 1: 9 & \text { Potassium bromide } & 1: 10 \\ \text { Boric acid } & 1: 143 & \text { Potassium iodide } & 1: 10 \\ \text { Calcium chloride } & 1: 25 & \text { Potassium permanganate } 1: 300 \\ \text { Calcium hypochlorie } & 1: 1000 & \text { Pure formaldehyde } & 1: 25,000 \\ \text { Carbolic acid } & 1: 333 & \text { Quinine sulphate } & 1: 800 \\ \text { Chloral hydrate } & 1: 107 & \text { Silver nitrate } & 1: 12,500 \\ \text { Cupric sulphate } & 1: 2000 & \text { Sodium borate } & 1: 14 \\ \text { Ferrous sulphate } & 1: 200 & \text { Sodium chloride } & 1: 6 \\ \text { Formaldehyde (40\%) } & 1: 10,000 & \text { Zinc chloride } & 1: 500 \\ \text { Hydrogen peroxide } & 1: 20,000 & \text { Zinc sulphate } & 1: 20\end{array}$

${ }^{1}$ Park. Pathogenic Bacteria and Protozoa, p. 108. 
Practical disinfection. In disinfecting stables, pens and the like it is necessary first to remove all litter, which should be burned or thoroughly soaked with a disinfectant and secondly, the floors and walls should be thoroughly cleaned to insure its free access, after which the germicide can be applied. "The thorough scrubbing of the floors and walls with a hot soda solution will greatly enhance the efficiency of the disinfectant. All cracks and crevices' should be soaked to the bottom with the disinfectant if a liquid is used and if a gas is chosen, they should be cleaned to enable its free access. Jaeger ${ }^{1}$ has called attention to the necessity of knowing the disinfecting power of the agent used for the specific organism to be destroyed. The failure to recognize this principle accounts for many failures in practical disinfection.

${ }^{1}$ Jaeger. Arbeiten a. d. Kais. Gesundheitsamt, Bd. V (1889). 


\section{CHAPTER VII.}

\section{THE PREPARATION OF MEDIA FOR THE CULTIVATION OF BACTERIA.}

Preparation of retainers. In order to study the properties characteristic of the different species of bacteria it is necessary to cultivate them under artificial conditions. The successful cultivation of bacteria, especially the pathogenic species, requires close adherence to several fundamental procedures. For the purpose of cultivation and the study of the properties of the individual species and strains of bacteria, certain culture media are necessary and in their preparation certain preliminary work is necessary.

Before using the test tubes and flasks for receiving the media they must be thoroughly cleaned. It is also important that they be sterile. The test tubes and flasks must be plugged with cotton.* Absorbent cotton with a long fibre is best adapted to this purpose. Common cotton can not be used satisfactorily unless it is previously degreased. Test tubes ean ordinarily be cleaned by washing them with a strong alkali soap and water, using the best tube brush. They must be thoroughly rinsed, preferably in hot water, and drained. Petri dishes and flasks must also be cleaned in this way.

* It is important in opening and closing cultures for purposes of exanination to have tubes closed with well made plugs. For this purpose absorbent cotton is used. Rolls of it are cut in short segments of from 5 to $7 \mathrm{~cm}$. in length. A piece of this narrow strip of sufficient length to give cotton enough for the plug is torn off. The quantity varies, of course, with the size of the mouth of the tube or flask, but a little experience will enable one to estimate the quantity quite accurately. The edges of the piece of cotton torn off are turned in and it is rolled up to form a firm plug which should snugly fit the neck of the tube or flask. It should be inserted into the tube for about $3 \mathrm{~cm}$. and the end should be nearly flat and smooth. The projecting part should be about the same 'ength, of equal firmness and project over the lip of the tube if it has one. 
Fermentation tubes usually require a cleaning mixture because of the inability to use the test tube brush.*

The above has reference to the cleaning of new or empty glassware; but it is necessary to use again the glassware and consequently the tubes and Petri dishes containing eultures must be dealt with. The tubes, flasks and Petri dishes eontaining cultures should be placed in a water bath, covered with water to which a little salsoda is added and boiled for at least 20 minutes. The tubes can then be emptied of their contents and again boiled in clean soap and water after which they are treated as in the beginning. Cultures of spore-bearing pathogenic bacteria such as anthrax should be sterilized by heating them in an autoclave at a temperature not less than $110^{\circ} \mathrm{C}$. for at least a half hour in order to kill the spores.

Culture media and their preparation. In the cultivation of bacteria it is necessary to have a medium or soil in which they can multiply. A large number of natural substances and compounds are used. Like the higher plants. bacteria are somewhat selective in the choice of media in which to grow. In their artificial cultivation it is necessary therefore to simulate as nearly as possible the natural requirements of the organism. In the preparation of media it is well to keep in mind that they must contain nourishment in an available form and in suitable quantities for the bacteria and that their chemical reaction must be right, as bac-

* It is sometimes desirable to use the cleaning mixture. In this case after the tubes are washed with soap and water they are filled with the cleaning mixture and stood in a glass jar (aquarium). After it has acted for from 10 to 20 minutes, it is poured wack from the tubes into the bottle originally containing it. The tubes are then to be thoroughly rinsed, and dried as before.

Formula for chromic acid cleaning mixture. Dissolve 80 grams of potassium dichromate $\left(\mathrm{K}_{2} \mathrm{Cr}_{2} \mathrm{O}_{7}\right)$ in $300 \mathrm{cc}$. of warm water; when all of the $\mathrm{K}_{2} \mathrm{Cr}_{2} \mathrm{O}_{7}$ is dissolved and the solution cooled, add to it slowly with constant stirring $460 \mathrm{cc}$. of concentrated sulphuric acid. A lead lined iron kettle is the best receptacle in which to mix the ingredients. Store the mixture in a glass-stoppered bottle. The liquid will be quite thick with small crystals. When the crystals are used up tne liquid should be discarded. 
teria will not grow if the media are too acid or too alkaline. Ordinarily a reaction +1.5 to phenolphthalein $*$ is suitable for the pathogenic species except perhaps Bact. mallei. The media must be sterile and when possible it is desirable to have them clear.

As the species of bacteria are determined largely from their cultural characters on the different media, it is necessary to have a considerable variety of media in order to procure a range for their biochemic and physiologic properties. Some of these have been designated as differential media, that is, by their use certain species may be identified. Some species of bacteria require for their multiplication certain kinds of media such as blood serum, or glycerinated agar. These are recognized as special media.

The more commonly used media have for their base the aqueous extract of meat, usually beef or veal, and peptone. In addition to these, certain vegetables such as potatoes are often used as well as such substances as milk, eggs, blood serum and ascitic fluid. A large variety of media have been used for the determination of certain properties of bacteria.

\section{LIQUID MEDIA.}

The more common of these are the different bouillons and milk. Bouillon is the liquid medium most commonly em-

* Titraticn of bouillon. Take 5 cc. of bouillon and place in a porcelain $€$ vaporating dish with about $45 \mathrm{cc}$. of water. Boil for three minutes. Add $1 \mathrm{cc}$. of a solution of phenolphthalein. Stir and add to the solution in the evaporating dish enough of a $\mathrm{N} / 20$ $\mathrm{NaOH}$ solution from a burette to give it a clear, bright pink color. This amount then of $\mathrm{N} / 20 \mathrm{NaOH}$ solution is required to neutralize 5 cc. of the bouillon. A provisional standard reaction of +1.5 to phenolphthalein has bcen adopted. This would be slightly alkaline to litmus. In order to bring the entire amount of bouillon to the desired reaction $(+1.5)$, subtract 1.5 from the amount of $N / 20$ $\mathrm{NaOH}$ solution drawn from the burette and multiply the difference by the number of cc. of bouillon divided by 100 . The product, if plus, represents the amount of $\mathrm{N} / 1 \mathrm{NaOH}$ to be added; if minus, the amount of N/1 HCL to be added. After mixing, test the reaction again in the same way and add alkali or acid if needed. For greater accuracy further tests should be made. 
ployed in cultivating bacteria. It is practically a beef tea containing peptone and salt. There are several methods reeommended for making it. It may be made directly from simple meat infusion or from meat extract. When meat extract is used, the bouillon does not seem to be a favorable culture fluid for certain bacteria. As the extracts are not uniiorm in the quantities of the various salts, it is impossible to make bouillons of a uniform composition fron them. Bouillon is used as the nutritive base in preparing agar and gelatin.

Preparation of bouillon. In preparing bouillon the following method has been found to be very satisfactory. Take 500 grams of lean beef, remove all fat, and grind it in a sausage machine or have it minced at the butcher shop. Place the minced meat in an agate-iron dish, add 1000 cc. ( 2 parts water to one of meat) of clear boiled water, cooled to $65^{\circ} \mathrm{C}$., and stir thoroughly with a glass rod. Then macerate it, with

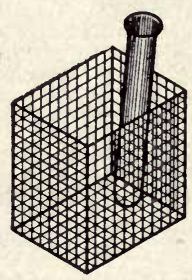

Fig. 33. Wire basket for holding tubes. frequent stirring, in a water bath at a temperature of $60^{\circ} \mathrm{C}$. for one hour after the temperature of the meat and water reaches that of the water outside or, to save time, at a temperature of $65^{\circ} \mathrm{C}$. for 30 minutes. Remove the meat by straining the liquid through a piece of cheese cloth. For this a stout iron meat press is desirable. Boil the strained meat infusion for 20 minutes. Cool to harden the fat, and filter through filter paper. The filtrate should equal in quantity the amount of water used; if it does not, add enough distilled or clear boiled water to make up that amount. To this meat infusion add 1\% peptone (white peptone free from sugar) and $1 / 2 \%$ sodium chloride. Add enough of a normal solution of sodium hydrate to give the liquid a faintly alkaline reaction when litmus is added as an indicator. It is simpler to titrate. The infusion is then boiled in a water bath for three quarters of an hour and filtered hot. The filtrate should be perfectly clear. The color will vary according to the amount 
of blood pigment in the meat used, and according, to the length of time it is steamed or boiled, i. e., according to the amount of material precipitated out. After filtering, distribute the bouillon in tubes and flasks and stand them in a wire basket for sterilization. Sterilize them by boiling in a closed water bath or steaming in the Arnold's steam sterilizer for 30 minutes, ${ }^{*}$ the time to be computed from the time the water boils or the temperature in the steamer reaches $99^{\circ}$. The flasks of bouillon should be boiled or steamed for 20 minutes on each of the two succeeding days (certain anaërobic bacteria may not be destroyed by this treatment). When they have cooled the outside of the tubes should be carefully wiped with a moist cloth and placed in an incubator for twenty-four to forty-eight hours. Then carefully examine them, and if any of the tubes are contaminated, that is, if the liquid is clouded or has a membrane on the surface, they must be rejected. Label the others and store.

Preparation of sugar free bouillon. Bouillon prepared by the ordinary method usually contains small quantities of muscle sugar. To eliminate this the following method has been recommended. ${ }^{1}$ Beef infusion is inoculated in the evening with a rich fluid culture of some acid-producing organism (B. coli) and placed in the incubator. The next morning the white of an egg is added, and the infusion is boiled and filtered. Peptone and salt are added as usual. It is boiled, filtered again, distributed in tubes or flasks, as desired, and sterilized and distributed in flasks the same as bouillon.

Glycerin bouillon. After filtration, 3 to 5 per cent of glycerine is added to the peptone bouillon and sterilized. This medium is used especially for the growth of tuborcle bacteria in which case it is titrated to +1.3 to phenopthalein.

${ }^{1}$ Smith. Jour. Exper. Med., Vol. II. (1897) p. 543.

* Media can be quickly sterilized by means of the autoclave where the temperature is raised from $110^{\circ}$ to $115^{\circ} \mathrm{C}$. While this method is quick and convenient, the high temperature seems to be detrimental to media for the growth of certain pathogenic bacteria. The autoclave, however, is quite extensively used. 
Preparation of acid glycerin bouillon. This is prepared either as ordinary bouillon or as a sugar free bouillon, with the omission of the alkali and the addition of $5 \%$ c. p. glycerin.

Preparation of glucose bouillon. Take the desired quantity of sugar-free peptonized bouillon and add $1 \%$ of pure grape sugar (glucose). After it is dissolved and thoroughly disseminated through the bouillon by stirring or pouring, distribute the bouillon in fermentation tubes, filling completely the closed branch and the open bulb about half full. It is often used in small test tubes. Sterilize by discontinuous steaming for 20 minutes each day for 3 consecutive days. The tubes should be wiped, labeled and stored until needed for use.

Preparation of lactose bouillon. This is prepared by adding $1 \%$ of pure lactose (milk sugar) to the peptonized sugar-free bouillon. It is necessary that the bouillon used does not contain muscle sugar. After adding the lactose, which has been dissolved and thoroughly mixed in a few cubic centimeters of the bouillon, distribute in fermentation tubes and small test tubes, sterilize, label and store.

Preparation of saccharose bovillon. This is peptonized sugar-free bouillon to which $1 \%$ pure saccharose (cane sugar) has been added. It is prepared from bouillon free from muscle sugar in the same manner as lactose bouillon.

Calcium carbonate broth. This medium has been recommended for obtaining mass cultures of streptococei. It is prepared by taking 100 ce. of bouillon and adding $1 \%$ powdered calcium carbonate and $1 \%$ of glucose. It is recommended to sterilize the calcium carbonate in a hot air sterilizer before adding it to the bouillon.

Peptone solution (Dunham's). This is a 1 or 2 per cent solution of peptone in tap or distilled water to which 0.5 per cent of sodium chloride is added. The peptone and sodium chloride are dissolved by heating. The fluid is filtered, placed in tubes and sterilized. The reaction is slightly alkaline to litmus which is suitable for the growth of most bacteria. It can be altered or standardized if desired. 
Serum bouillon media (Marmorek's media).

1. IIuman serum, 2 parts; nutrient bouillon, 1 part.

2. Ascitic or pleuritic fluid, 1 part; nutrient bouillon, 2 parts.

3. Horse serum, 1 to 2 parts; nutrient bouillon, 1 to 2 parts.

These media were first used extensively by Marmorek in cultivating streptococei. The ascitic fluid bouillon has been found by Williams to be of great use in enriching cultures of diphtheria bacteria. It is also the best medium for the growth of pneumococci, streptococei, and many other pathogenic bacteria.

Serum-water media (Hiss' serum media). When diluted with 2 to 10 parts of water, many sera can be steamed without coagulating.

1. Ox serum, 1 part; distilled water, 2 parts; normal sodium hydrate, 0.1 per cent.

2. The same, with inulin 1 per cent substituted for the sodium hydrate.

For the sterilization of undiluted fluid serum and of ascitic and pleuritic fluids, it is requisite that it be exposed to a temperature of from $62^{\circ}$ to $66^{\circ} \mathrm{C}$. for one hour on each of six consecutive days. The best apparatus for obtaining and maintaining this temperature (about $65^{\circ}$ C.) is a small and well-regulated incubator or chamber surrounded by a water space, into which the tubes and flasks containing serum are to be put each day, and in which they are to be left for the prescribed time after having been warmed to the desired temperature:

Serum may be preserved by placing it in flasks which, after the addition of 5 per cent chloroform, are sealed. When it is to be used it is poured into sterilized culture (test) tubes and sterilized by exactly the same methods as are employed in sterilizing fresh serum. The chloroform, being volatile, tends to disappear at ordinary temperatures, but is quickly and surely driven off at the temperatures used in the sterilization. 
Serum may be sterilized, when great care is used, by passing it through a well-tested Pasteur filter, under pressure. When so treated the filtrate is very clear and light colored.

Preparation of milk for a culture medium. It is better that the cream be removed from the milk before it is used. To do this the fresh milk is placed in a beaker and set in the ice box for from 10 to 15 hours. Then earefully remove the cream. Fresh separated milk can be used with advantage. It is well to filter the milk through a thin layer of absorbent cotton to remove any masses of cream that may be left. The reaction should be tested, and if strongly acid, should be rejected or made $1.5 \%$ acid to phenolphthalein by the addition of $\mathrm{N} / 10$ sodium hydrate. Distribute the skimmed milk in small test tubes ( 5 ce. in each) and sterilize by discontinuous steaming. Wipe, label, and store.

Preparation of litmus milk for a culture medium. This is prepared the same as the milk medium, with the addition of enough of an aqueous solution of litmus to impart a decidedly blue color to the milk. Sterilize, wipe, label, and store the same as the milk.

Litmus media. When it is desirable to determine whether bacteria produce in their growth acid or alkali from one or more of the constituents of the media litmus is frequently added. To prepare the litmus solution take the lump litmus, powder finely, and boil with distilled water so that a saturated solution is obtained. Filter and then boil for thirty minutes on two successive days. The litmus solution is added to the neutral media in sufficient quantity to give the desired depth of color. The less heating that is done after mixing the better the results. Merck's purified litmus in 1 per cent aqueous solution should be used in careful work.

Petrusky's litmus whey (as modified by Durham). Fresh milk is slightly warmed and clotted by means of essence of rennet. The whey is strained off and the elot is hung up to drain in a piece of muslin. The whey, which is somewhat turbid, is then cautiously neutralized with 4 per cent citric acid 
solution, neutral litmus being used as an indicator. When it gives a good neutral violet color with the litmus it is heated at $100^{\circ} \mathrm{C}$. for one hour; thereby nearly all of the proteid is coagulated. It is filtered clear, and neutral litmus is added to a color convenient for observation.

Teutral red. This dye is added to the peptone and bouillon-sugar media to the amount of 1 to 5 per cent of a concentrated solution. Its reduction * by the growth of bacteria is a valuable aid in the differentiation of certain species.

Preparation of nitrate bouillon. Take peptonized bouillon 200 ce. Add potassium nitrate 1 gram (0.5\%). Dissolve the nitrate in the bouillon, put in tubes, and sterilize the same as bouillon.

The nitrate of sodium or ammonium may be substituted for that of potassium. The salt may be added in the proportion of from 0.1 to $1 \%$ to meet special demands.

* Test for nitrites. Twenty-five cubic centimeters of distilled water are added to one-half gram (more or less) of pure potato starch and the fluid boiled. One cubic centimeter or more of this starch-water and $1 \mathrm{cc}$. of freshly prepared potassium-iodide water (1 : 250) are now put into the culture fluid, to which are then added a few drops of strong sulphuric-acid water $(2: 1)$. If any appreciable quantity of nitrite is present the culture immediately becomes blue-black from the liberation of free iodine, which acts upon the starch. Old potassium iodide water should never be used without first testing carefully, as it usually contains some free iodine. It is always best to first make a trial test without the bacteria. Commercial starch frequently contains products of bacterial decomposition and starch prepared aseptically should be substituted.

A test for ammonia gas. For this Nessler's reagent may be used.

Nessler's reagent. Dissolve 50 grams potassium iodide in a minimum quantity of cold water. Add a saturated solution of mercuric chloride until a slight but permanent precipitate persists. Add 400 cc. of 50 per cent solution of potassium hydrate, made by dissolving the potassium hydrate and allowing it to clarify by sedimentation before using. Dilute to one liter, allow to settle and decant. This solution should give the required color with ammonia within five minutes after addition, and should not precipitate with small amounts of ammonia within two hours. 
Uschinsky's Proteid-Free Medium. ${ }^{1}$ To one liter of distilled water add:

$\begin{array}{lrl}\text { Asparagin } & 3.4 \text { grams } \\ \text { Ammonium lactate } & 10.0 & \text { "6 } \\ \text { Sodium chloride } & 5.0 & \text { ، } \\ \text { Magnesium sulphate } & 0.2 & \text { "6 } \\ \text { Calcium chloride } & 0.1 & \text { "6 } \\ \text { Potassium phosphate } & 1.0 & \text { " }\end{array}$

When these substances are thoroughly dissolved, add $40 \mathrm{ec}$. of glycerin. Tube and sterilize.

\section{Cohn's Solution.}

1. Weigh out and mix

Acid potassium phosphate

5.00 grams

Tribasic ealcium phosphate

0.50 gram

Magnesium phosphate

5.00 grams

Ammonium tartrate

and dissolve in distilled water

10.00 grams

1000 ec.

2. Tube or flask and sterilize.

Synthetic media. In the eultivation of bacteria it has been shown that certain of them will grow in media composed largely of various inorganic compounds. Many such synthetic media have been proposed especially for the cultivation of bacteria where a chemical analysis has to be made either of the organisms themselves or to determine the effect of their multiplication on the medium. A large amount of work has been done on this subject by Gorham and his students. The formulae for a few of the more simple nutrient solutions are appended. The one of Uschinsky has been used somewhat extensively.

Uschinsky's solution. Mix the following substances, distribute in tubes. Sterilize.

${ }^{1}$ Ushinsky. Cent. f. Bakt., Bd. XIV (1893) p. 316. 
Water,

1000 ec.

Glycerin, 30 to 40 grams

Sodium chloride, 5 to 7 grams

Calcium chloride, 0.1 gram

Magnesium sulphate, 0.2 to 0.4 grams

Dipotassium phosphate,

Ammonium lactate,

Sodium asparaginate,

2.5 to 3 grams

6 to 7 grams

3 to 4 grams

Instead of this complicated solution, one may employ many simpler ones; for example, such as is recommended by Voges and C. Fränkel, ${ }^{1}$ which is as follows:

Water

1 liter

Sodium chloride

5 grams

Neutral commercial sodium phosphate

2 grams

Ammonium lactate

6 grams

Asparagin

4 grams

A substitute for Loeffler's bloodserum in the diagnosis of diphtheria. Gorham recommends the following proteidfree medium which in the liquid form had been found by Hadley to be favorable for the growth and toxin production of Bact. diphtheriae. It was used in combination with agar as a substitute for Loeffler's bloodserum. It is as follows:

$\begin{array}{ll}\text { Glycerin } & 3.40 \text { parts } \\ \text { Sodium chloride } & 0.60 \text { “" } \\ \text { Calcium chloride } & 0.08 \text { ، } \\ \text { Magnesium sulphate } & 0.32 \text { “" } \\ \text { Dipotassium phosphate } & 0.23 \text { “" } \\ \text { Ammonium lactate } & 0.75 \text { “" } \\ \text { Ferric phosphate } & 0.08 \text { “ } \\ \text { Glycocoll } & 0.10 \text { “" }\end{array}$

Distilled water to make 100 parts, 1.5 per cent agar, reaction made +1 with sodium hydrate.

It was found possible to make a diagnosis from swabbings on this medium in less than 15 hours.

The organisms were of about the same types as on the

${ }^{1}$ Voges and Fränkel. Hyg. Rundschau, 1894, p. 769. 
Loeffler's blood serum though there was some indication that the granular types were more common on the synthetic medium than on the blood serum.

Bile medium. This medium described by Conradi ${ }^{1}$ has: been recommended by Buxton and Coleman for the cultivation of bacteria from the blood. It is prepared as follows :

$\begin{array}{lr}\text { Ox bile } & 900 \mathrm{cc} . \\ \text { Glycerin } & 100 \mathrm{cc} . \\ \text { Peptone } & 20 \text { grams }\end{array}$

Mix, distribute in small flasks, putting about 100 ec. in each, and sterilize by fractional sterilization.

Solid media. The solid media are employed to isolate different species and to study the character of the growth, especially of individual colonies of bacteria. The usual solid. media are agar and gelatin. The striking difference between the two is that gelatin liquefies at body temperature whereas agar is not liquefied below the boiling point. For this reason gelatin is not used for the cultivation of bacteria at a high (body) temperature. There are several methods for the preparation of these media. The simplest is the addition of the gelatin or agar to bouillon. In these media the essential nutritive part is in the bouillon, the agar and gelatin being used for the purpose of solidifying the media. Agar itself is usually neutral in reaction but the gelatin is often decidedly acid. There is considerable variation in the reaction of different brands of gelatin. Other solid media, such as blood serum, egg and potato, are used to a considerable extent.

The preparation of nutrient agar. Weigh out 12 grams. of agar and cut it into small pieces with a pair of scissors. Put the finely cut agar into an agate-iron dish, add $300 \mathrm{cc}$. of distilled water, and boil over a gas flame, with constant stirring to prevent scorching, until the agar becomes a thick, homogeneous substance. Then add 1000 cc. of bouillon. ${ }^{2}$ Place the dish containing the mixed agar and bouillon in a:

${ }^{1}$ Conradi. Deut. med. Woch., Bd. XXXII (1906).

${ }^{2}$ Moore. Am. Monthly Microscopical Journal, May 1890, p. 115. 
closed water bath and boil for 20 minutes, then cool it to a. temperature between 45 and $50^{\circ} \mathrm{C}$., add the white of three eggs and thoroughly mix in the liquid agar. This is easily accomplished by pouring it a number of times from one beaker to another. It is well to add a small quantity of Coignet Fils wine clarifier. When the egg albumen is dissolved, the agar is returned to the water bath and boiled vigorously until the white of the egg is firmly coagulated. This usually takes about 30 minutes. The rapidity and completeness with which the coagulation takes place depends somewhat upon the reaction. If too alkaline, a firm coagulation is not formed. Filter the agar immediately, while hot, through ordinary filter paper which has been moistened with boiling water. A layer of moistened absorbent cotton can be used in place of the paper. A hot-water funnel is recommended by some but we have not found it necessary. Distribute the filtrate in small and large tubes or flasks, as desired. Sterilize, label and store the agar in the same manner as the bouillon.

Preparation of glycerine agar. Take the desired quantity of the agar previously prepared and add $5 \%$ of pure glycerin. Thoroughly mix it with the agar, after which distribute in tubes. Sterilize, label and store as ordinary agar.

Preparation of acid agar. This is prepared in the same manner as ordinary agar, by using acid bouillon. ${ }^{1}$

The preparation of nutrient gelatin. Take a flask of bouillon containing $1000 \mathrm{cc}$. and pour it into a small agate iron dish, add 100 grams of sheet gelatin and heat, with frequent stirring, in a water bath, until the gelatin is dissolved. Allow it to cool to a temperature between $45^{\circ}$ and $50^{\circ} \mathrm{C}$. and then add the white of three eggs and mix it thoroughly by stirring, or, better, by pouring the gelatin many times from one flask or beaker to another. After the egg albumen is completely diffused, return the liquid gelatin to the large covered water bath and boil until the egg albumen is firmly

${ }^{1}$ Acid bouillon is bouillon that has not been neutralized by $\mathrm{NaOH}$ solution. For accuracy it should be titrated to the acidity required. 
coagulated. This takes about 30 minutes. It is important not to boil the gelatin longer than is necessary for the coagulation of the albumen. It is now ready for filtering which must be done while the gelatin is hot. Filter through properly folded but ordinary paper, first moistened with boiling water. Distribute the filtrate as desired. In pouring the gelatin into the tube, use a small beaker or graduate, and see that the gelatin does not touch the sides of the upper part of the tube. Stand the tubes in a wire basket and sterilize in a water bath or steam sterilizer.

Blood-serum media. Blood serum may be sterilized by fractional sterilization and remain fluid, or it may be rendered solid by the application of a higher degree of heat in sterilizing it. The blood is obtained from an ox, horse, sheep, dog, or rabbit and collected in jars, flasks or tubes. When it is to be used in a fluid state it should be drawn in an aseptic manner into a flask from a vein by means of a sterile cannula and rubber tube. When it is to be solidified, less care is necessary. It is here sufficient to eatch the blood from the cut artery or vein in sterile jars or tubes. To facilitate clotting it is well to have in the jar or tube something for the clot to contract around.

Preparation of Loeffler's blood serum. This consists of 1 part neutral bouillon (prepared from meat) containing $1 \%$ grape sugar and 3 parts liquid blood serum. Mix and distribute in sterile test tubes, incline, and solidify the same as blood serum. The temperature should be about $75^{\circ} \mathrm{C}$., and the exposure will be necessarily longer than for the pure blood serum. When it is to be used for the cultivation of diphtheria organisms it can be set at a much higher temperature $\left(80^{\circ}\right.$ to $100^{\circ} \mathrm{C}$.). Label and store.

Blood serum for tubercle bacteria (Smith). ${ }^{1}$ Dog's serum is used. The dog is bled under chloroform and the blood drawn from a femoral artery under aseptic conditions, through sterile tubes directly into sterile flasks. The serum

${ }^{1}$ Smith. Jour. Exp. Med., Vol. III (1898) p. 451. 
is drawn from the clots with sterile pipettes and either distributed at once into tubes or else stored with 0.25 to $0.3 \%$ chloroform added. Discontinued sterilization is rendered unnecessary. The temperature required to produce a sufficiently firm and yet not too hard and dry serum is for the $\operatorname{dog} 75^{\circ}$ to $76^{\circ} \mathrm{C}$. For horse serum it is from $4^{\circ}$ to $5^{\circ}$ lower. The serum is set in a thermostat into which a large dish of water is always placed to forestall any abstraction of moisture from the serum. About three hours are required for the coagulation. When serum containing chloroform is to be coagulated, the tubes should be placed for an hour or longer in a water bath at $55^{\circ}$ to $60^{\circ} \mathrm{C}$., or under the receiver of an air pump, to drive off the antiseptic. This procedure dispenses with all sterilization excepting that going on during the coagulation of the serum. It prevents the gradual formation of membranes of salts, which, remaining on the surface during coagulation, form a film unsuited for bacteria. Tubes of coagulated serum should be kept in a cold closed space where the opportunities for evaporation are slight. They should always be kept inclined.

The ordinary cotton-plugged test tubes are not used, because of the rapid drying, but a tube is used which has a ground glass cap fitted over it. This cap contracts into a narrow tube plugged with glass wool. This plug is not disturbed. The tube is cleaned, filled and inoculated by removing the eap.

Agar-gelatin-serum. This medium was introduced by Bang ${ }^{1}$ and Stribolt for the investigation of certain anaërobic bacteria. After having liquefied the agar-gelatin (that is to say, $3 / 4$ per cent agar and 5 per cent gelatin) the liquid is cooled to $45^{\circ} \mathrm{C}$., and it is then mixed with about half its volume of liquid sterile serum. The serum should be added just before the medium is to be used.*

'Bang. The Jour. of Compar. Path. and Therap., Vol. X (1897) p. 125 .

* A tube of the liquid medium is inoculated with a loopful of the matcrial from the first, a sccond tube is inoculated with 2 to 3 
Silicate Jelly (Winogradski).-For the cultivation of nitrifying bacteria.

1. Weigh out and mix, Ammonium sulphate

0.40 gram

Magnesium sulphate

0.05 gram

Calcium chloride

0.01 gram

Distilled water

50 ec.

Label-Solution A.

2. Weigh out and mix, Potassium phosphate 0.10 grams

Sodium carbonate

0.60 gram

Dissolve in distilled water

$50 \mathrm{ce}$.

Label-Solution B.

3. Weigh out silicic acid

Dissolve in distilled water

3.4 grams

100 ce.

4. Pour the silicic solution into a large porcelain basin.

5. Mix equal quantities of the solutions $\mathrm{A}$ and $\mathrm{B}$; then add successively small quantities of the mixed salts to the silicic acid solution, stirring continuously with a glass rod, until a jelly of sufficiently firm consistency has been formed.

6. Spread a layer of this jelly over the bottom of each of several large capsules or "plates."

7. Sterilize in the steamer for twenty minutes on each of three consecutive days.

Fermi's solution. For many purposes Fermi's solution is a good one to add to the dialyzed jelly. This is made as follows, for this purpose: Freshly-boiled distilled water, 100 ; magnesium sulphate, 0.2 ; monopotassium phosphate, 1.0 ; ammonium phosphate, 10.0. Dissolve. Then add glycerin, 45.0 .

loopfuls, and from the second a third tube is inoculated. The test tubes are then immediately cooled and solidified in a stream of water. This mixture of serum and gelatin-agar remains transparent, and permits accurate observation of the isolated developing colonies, as well as the starting of fresh colonies from them. The solid medium also serves very well for the preparation of stab cultures by means of a glass needle. This medium was first employed by Bang and Stribolt in the study of the organism of contagious abortion. 
Nutrient starch-jelly for study of diastasic action. ${ }^{1}$ One gram of starch is rubbed up with a sterile glass rod in $10 \mathrm{cc}$. of the sterile nutrient fluid (Uschinsky's solution) placed in a slanting position, in test tubes, and solidified in a blood-serum oven or in the top of a steamer with the vents left open. There should be several heatings of two hours each to insure sterilization. The temperature should not exceed $93^{\circ} \mathrm{C}$. nor fall much below $85^{\circ} \mathrm{C}$. Sterilization is rendered much easier if the starch is prepared in a cleanly way. The only difficulty experienced is in the formation of a thin film of semiopaque solidified starch on the walls of the tubes above the slant. This often cracks off, however, during the heatings, and is largely obviated by placing the tubes in a slanting position before the starch is rubbed up in the fluid, taking care to soil the walls above the slant surface as little as possible during the operation.

Hiss's medium for differentiating colon-typhoid colonies.

Plate culture. The composition of this medium is as follows :

$\begin{array}{lrl}\text { Agar } & 15 \text { grams } \\ \text { Gelatin } & 15 \text { grams } \\ \text { Liebig's meat extract } & 5 \text { grams } \\ \text { Sodium chloride } & 5 \text { grams } \\ \text { Dextrose } & 10 \text { grams } \\ \text { Distilled water } & 1000 \text { ce. }\end{array}$

The agar is thoroughly dissolved in 1,000 ce. of distilled water, either over a free flame or in the autoclave. When the agar is melted, the gelatin, meat extract and salt are added and dissolved by further heating. Any loss in weight is then adjusted by the addition of water. No titration or adjustment is necessary. The medium should be cleared, in the usual way, with the white of two eggs, and filtered through cotton. To the cleared medium is added one per cent of dextrose, and the medium tubed, about 8 ce. to each tube, and sterilized.

${ }^{1}$ See Proc. Am. Asso. Adv. Sci., 1898, p. 411, or Centralb. f. Bakt., Bd. V, p. 102. 
Dorset's egg medium. ${ }^{1}$ The whole egg is preferable. Carefully break the shell of the required number $(3,6$, or more) of fresh eggs, drop the entire contents into a sterile beaker, and carefully stir with a sterile glass rod, care being taken to avoid air bubbles. After the egg is well mixed it is poured into test tubes (6 to $10 \mathrm{ec}$. in each) and sterilized by heating, preferably in a serum water bath, at $70^{\circ} \mathrm{C}$. for from 4 to 5 hours each day for 2 days. After sterilization the tubes should be sealed. Before using, add a few drops of sterile water, or better perhaps, of $5 \%$ glycerin or of glucose to afford sufficient moisture. This medium is used largely at the present time for the cultivation of tubercle bacteria.

${ }^{1}$ Dorset. Am. Med., April 5, 1902. 


\section{CHAPTER VIII.}

\section{THE ISOLATION AND CULTIVATION OF BACTERIA.}

Cultivating bacteria. As bacteria are ommipresent in external nature, it is difficult to procure any material such as soil, water, etc., which does not contain several species or varieties of these organisms. The isolation of bacteria means the separating of the different kinds of organisms so that there is but one species of bacteria present which can be cultivated on different media and the nature of its growth determined.

The cultivation of bacteria is much like that of garden plants. In the growth of lettuce, for example, to determine the nature of the developed plant all other plants and weeds that grow up immediately around it are removed. So in isolating and cultivating the bacillus of tetanus from the soil it is first necessary to get it separated from all other bacteria.

The growth of Bacillus tetani alone in a tube of bouillon would be a pure bouillon culture of that organism.

Requirements of bacteria. In the artificial cultivation of bacteria, or in their multiplication in nature, a number of factors are necessary, such as food, moisture, temperature, and to a certain extent, light. The extent of their development and their effect upon the culture medium, host, or surroundings depend upon and vary with these biological requirements or life conditions.

Frood supply. The food for bacteria must be of such a nature and in such a condition that the bacteria can assimilate it. As a rule, they require organic matter, although some species can thrive on inorganic elements and compounds. Again, the food must be of suitable chemical reaction. For most bacteria it must contain nitrogen. Some species require carbo-hydrates. Unless the food is in a suitable condition the bacteria can not multiply. This is an im- 
portant fact to be observed, in general sanitary work as well as in the laboratory study of bacteria.

Moisture. The presence of water is necessary for the continuous growth of bacteria. The amount of drying that bacteria will stand varies with the species. As a rule, the vegetative forms do not endure long but spores will resist drying for a considerable length of time.

Temperature. For each species of bacteria there is a temperature at which it grows best. There is also a maximum temperature which is usually but a few degrees above the optimum and a minimum which is usually many degrees below. Most pathogenic bacteria develop best at a temperature of from $35-37^{\circ} \mathrm{C}$; ; many of them will grow at a temperature of from $40-43^{\circ} \mathrm{C}$. and at a minimum of $14^{\circ} \mathrm{C}$. There are a few species that favor the extreme temperatures.

Relation of gaseous environment. The relation of bacteria to the oxygen of the air is very important. Some species will not grow in its absence while others will not multiply in its presence. Because of this requirement, bacteria are divided into the obligatory and facultative aerobes and anaerobes.

Light. Direct sunlight will hinder bacterial development and if continued it will destroy the vitality of the organisms. Diffused light is also injurious. Dark places are more favorable for bacterial growth. A strong electric light is said to be as fatal as sunlight, but the X-rays seem to be without germicidal action.

Cultivation. The eultivation of bacteria means their growth on artificial media such as gelatin, agar, or in bouillon, milk or other substances.

A colony. A colony is a mass of bacteria that has developed on a solid medium from a single individual organism. Thus if a colon bacillus is planted on the surface or in the depth of agar it will multiply in 24 to 36 hours, and will exhibit a mass of organisms visible to the unaided eye, and when examined under a low magnification will show certain definite markings. 
A mixed or impure colony. This is a growth in which two or more individual organisms of different species multiply together on a solid medium giving a visible growth suggesting in many instances that produced by a single individual. Mixed colonies frequently occur and give rise to much confusion in the further study of the organism. When, however, the two or more organisms develop a growth differing in color or any other obvious character they are readily detected; but with two organisms which have a similar appearing growth on the medium, it is difficult and sometimes impossible to know that the colony is impure without further study.

A culture of bacteria. A culture is the growth or multiplication of organisms on some nutrient medium. It usually refers to. it in a tube or other retainer for media.

A pure culture. This is the growth or multiplication of a single species of bacteria upon a medium that was sterile before inoculation.

A mixed or impure culture. This is the growth or multiplication of two or more species together in a single medium. Thus the bacillus of typhoid and the colon bacillus growing together in a tube of bouillon would be an impure bouillon culture.

Procuring pure cultures. A pure culture of an organism is obtained by inoculating media from pure colonies or from a substance containing but one species of bacteria. Thus glanders nodules in the lungs or other organs are not likely. to have bacteria within them other than Bact. mallei.

Making bouillon cultures. In making this culture, carefully remove the plug from the tube of bouillon by first twisting it around to detach any adhesions and then pull it straight out. Pass the open end of the tilted tube quickly through the gas flame. The plug, which has in the meantime been carefully held, is partially replaced and the tube returned to its stand. Treat the tube containing the culture in the same manner. Then place the two tubes side by side between the thumb and forefinger of the left hand, palm 
facing upward, and grasp them about the middle of the upper half. Sterilize the platinum loop by passing it through the gas flame, eare being taken that the handle is also flamed for a distance of at least $15 \mathrm{~cm}$. Then carefully remove the plugs from the tubes and hold them between the fingers in such a manner that the tube ends, projecting outward, will not touch anything during the inoculating process. Insert the wire loop carefully into the culture and transfer a loop-

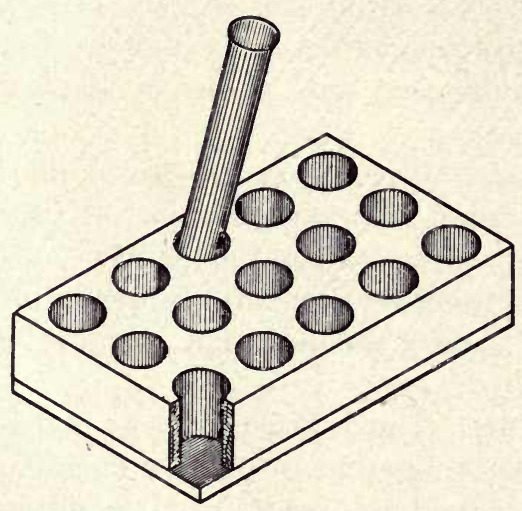

Fig. 34. A convenient block for holding test tubes.

ful of the culture to the tube of bouillon and gently rinse. The loop is then withdrawn, the plugs replaced in their respective tubes, and the loop flamed and put aside. Label the freshly inoculated tube with the name of the organism, source, and date.

In inoculating tubes of bouillon from a colony, a platinum wire with the end slightly bent is preferable to a loop. In inoculating bouillon from tissues, a platinum spatula is heated in a gas flame to a red heat and the surface of the organ is scorched. With a pair of flamed (sterile) fine forceps an opening through the scorched surface is made and a bit of tissue underneath is crushed. With the platinum loop take up a loopful of the crushed tissue.

Inoculating tubes of agar and gelatin. Ordinarily the agar is inclined or slanted in the tube before it is inoculated. In this case it is spoken of as inclined or slant agar. Occasionally the agar is inoculated without inclining it. Cultures made in this manner are spoken of as "stab" or "stick" cultures. (a) Inclined or slant agar. Stand tubes of agar in a wire basket in a water bath and boil it until the agar is 
liquefied. Lay the tubes on a tray, the top resting on the side of the tray so that the surface of the agar will be about $5 \mathrm{~cm}$. long, and allow it to cool. In placing the tubes the label should be up. When the agar has set it is ready for use. It is inoculated precisely as the bouillon, excepting that the loopful of culture is drawn over the inclined surface instead of being thrust into the medium as in the bouillon. Label and place it in the incubator. On the following day there should be a growth of the inoculated organism on the surface of the agar. (b) Stick or stab cultures. These are made with a platinum needle in agar that has not been slanted. The impregnated platinum needle is pushed down through the center of the agar. In all other respects this culture is made like the slant-agar culture.

Gelatin cultures. Tube cultures in gelatin are usually made without inclining the gelatin, i. e., stick cultures. The tube of gelatin is inoculated in the same manner as the stick culture in agar. Gelatin cultures are not placed in the incubator, but must be kept at room temperature. The growth will appear along the needle track usually in from one to four days.

Inoculation of other media. When media in fermentation tubes, or in other retainers, are inoculated, the same precautions to avoid contamination should be observed.

Apparatus and methods for isolating bacteria. The more common methods for isolating bacteria and procuring pure cultures of each species present or of the species desired are plate cultures and animal inoculation. Formerly, dilutions in liquid cultures were employed. Certain species can be obtained in pure culture by adding antisepties to liquid eultures in sufficient quantity to prevent the growth of all organisms excepting the species in question. Sometimes it is possible to isolate certain species by inoculating media or material containing them with other bacteria and growing the cultures at a high temperature $\left(40^{\circ}\right.$ to $42^{\circ} \mathrm{C}$.), or by heating the cultures sufficiently to destroy the vegetative forms but not to injure the spores of the species in question. 
(See Kitasato's method for isolating B. tetani.) In the study of pathogenic bacteria the methods usually employed are plate cultures and animal inoculation.

Plate cultures. Plate eultures consist of liquefied gelatin or agar which has been inoculated with the material in question and poured on glass plates or in Petri dishes. Each organism present in this medium is enabled to develop or multiply by itself, forming a colony. Formerly, glass plates were employed for this purpose and covered with sterile bell-jars. This was followed by the Esmarch rolls. ${ }^{1}$ Later Petri substituted the covered round glass dish which bears his name. They are made in several sizes.

Making plate cultures. Take 3 large tubes of agar or gelatin and liquefy them. Then cool by standing the tubes with a thermometer in a cup of water at a temperature of about $45^{\circ} \mathrm{C}$. When the temperature of the agar reaches that of the water and the temperature of the whole has lowered to $40^{\circ} \mathrm{C}$. it is ready for use. For convenience in labeling, number the tubes 1,2 , and 3 .

Place 3 sterilized Petri dishes on the leveling tripod and adjust it by means of a spirit level. If shelves are properly adjusted the leveling tripod is not necessary. With the wire loop proceed by the same method as followed in making tube cultures. Take one loopful of the bouillon culture, place it in tube 1 and mix by carefully shaking. Flame the wire and transfer 2 loopfuls from tube 1 to tube 2 and mix as before. Again flame the loop and transfer 3 loopfuls from tube 2 to tube 3 and mix as with tubes 1 and 2. After the tubes are inoculated, pour the agar into the Petri dishes. In doing this remove the plug, carefully flame the mouth of the tube, and after quickly cooling, raise with the left hand the edge of the cover on one side of the Petri dish sufficiently to allow of inserting the mouth of the tube. After the agar is poured out of the tube replace the cover immediately. Label and number the Petri dishes to correspond with the dilutions

1 Esmarch. Zeit. f. Hygiene, Bd. I (1886) p. 293. 
in the tubes. Place the label near the edge of the cover. Wax pencils for marking glass may be used instead of the gummed label. In making the dilutions it is important that the wire loop should be flamed after making each transfer.

Instead of inoculating the liquid media the material to be inoculated is sometimes drawn by means of a platinum wire over the surface of the medium after it is solidified in the Petri dish. These are spoken of as streaked cultures.

Inoculating animals. With the pathogenic bacteria such as those of swine plague it is often easier to inoculate subcutaneously a susceptible experimental animal with the medium containing the organism. By this method the saprophytic bacteria which might grow vigorously on the media are destroyed in the tissues of the animal, but the pathogenic species will in proper time kill the animal. From the organs of the dead animal the organism can be recovered on suitable media usually in pure culture. In certain cases, such as tuberculosis, it is almost necessary to make inoculations in this way and to procure the culture on suitable media from the organs of the diseased animal. In tetanus, especially when this organism is to be isolated from soil containing it, it is necessary to inoculate a susceptible animal such as a guinea pig in order to procure a pure culture.

\section{THE CULTIVATION OF ANAËROBIC BACTERIA.}

Certain bacteria, such as the bacilli of tetanus and black leg, can thrive in the absence of oxygen only. These bacteria will grow on the same kind of media as the aerobes providing the atmospheric oxygen is removed. Various methods have been introduced involving many devices for the cultivation of these organisms. Notwithstanding this fact our knowledge of the anaërobic bacteria is as yet very limited. While rapid progress has been made along the line of the aerobic species, a comparatively small number of the anaërobic bacteria have been carefully studied and identified. The principles underlying the various methods that 
have been proposed for the study of these bacteria consist in growing them under the following conditions:

(1) In a vacuum, (2) by replacing the air with inert gases, (3) by the absorption of oxygen, (4) by the reduction of oxygen, (5) by expulsion of atmospheric oxygen by means of various physical principles and mechanical appliances, and (6) by the combined application of two or more of the above methods.

It should be borne in mind that the many methods which have been introduced with specially devised apparatus for the cultivation of anaërobic bacteria were introduced for certain specific purposes. In order to obtain satisfactory results, it is necessary that the methods employed for this work should be chosen in accordance with the purpose of their respective inventors. In order to facilitate the selection of methods the following classification has been made:

1. The methods for the determination of the presence of anaërobic bacteria in a given substance.

2. Methods for isolating anaërobic bacteria.

3. Methods for growing pure cultures of anaërobes on different media.

4. Methods for the propagation of pure cultures and for the preservation of stock cultures.

5. Methods for the preparation of toxins.

Although the number of methods for cultivating these organisms is very large, for ordinary work with pathogenic anaërobic bacteria the following methods have proved to be quite satisfactory.

Liborius $^{1}$ recommended the following method: Pour into a test tube, Erlenmeyer flask, or deep Petri dish a sufficient quantity of nutrient gelatin or agar to form a layer of from 5 to $10 \mathrm{~cm}$. deep. Bcil the medium for at least five minutes to expel the air, cool down to a temperature of about $40^{\circ} \mathrm{C}$., inoculate the medium, distributing the inoculating material well through it. Care must be taken not to shake

${ }^{1}$ Liborius. Zeit. f. Hygiene, Bd. I (1886) p. 115. 
the tube or flask; after inoculation cool rapidly by standing the apparatus in cold water until the medium is set. In this way a large number of isolated colonies usually develop, which are either distributed all through the medium, or appear only in the higher zone, or inhabit exclusively the lower layers. The sharply marked distribution of the colonies over the different zones, their size and other characteristics permit a fairly accurate estimate of their relative want of oxygen. The inoculation is made with a long, firm platinum wire, which has previously been brought into contact with the culture material, or a long eapillary pipette may be used, into which the culture has been introduced by suction. This simple method, which is very effective even in the case of the strictest anaërobes, is being used successfully in many laboratories.

Often a layer of sterile medium is poured on top of the inoculated layer after the latter has solidified. In order to gain access to the colonies the tube is broken. Sanfelice recommends warming the bottom of the tube and shaking the column of agar out into a sterile glass dish, where it can be cut into slices, the colonies examined and subcultures made.

Smith found the fermentation tube to be an apparatus of considerable antiquity and of unknown origin. He says: “'In Detmer's Pflanzenphysiogischem Practicum I find it figured as Kühnesches Gährungsgefäss. More recently it has been adapted by Eichorn for the quantitative determination of sugar in urine and by Doremus for that of urea in the same fluid." Smith, ${ }^{1}$ in 1889 , first conceived the value and made practical application of this tube with reference to anaerobioses and gas-formation among bacteria. With regard to its construction Smith says: "In the construction of this simple bit of apparatus several points must be borne in mind. The bulb should be large enough to receive all the fluid contained in the closed branch. Moistening the plug

${ }^{1}$ Smith. Centralb. f. Bakt., Bd. VII (1890) p. 502. 
imperils the purity of the culture. If the bulb is sufficiently large this difficulty will not arise. The connecting tube should not be too small, for then the filling and emptying of the closed branch becomes very tedious. Nor should it be too large, otherwise the anaërobic properties of the fluid in the closed branch may be less effective. Lastly, the angle formed by the two branches of the tube must not be too acute, otherwise the tube must be tilted so much during the transference of the fluid from the tube to the closed branch that there is danger of its moistening the plug or even running out of the bulb.".

Method. Heat the fermentation tube containing peptonized sterile glucose bouillon in the steam sterilizer, cool, and inoculate it with the culture in question. In case of a pure anaërobic culture the growth will take place in the closed bulb and the line of demarcation between the turbid, teeming liquid of the closed branch and that of the bulb and connecting tube is sharply drawn.

Baginisky constructed an apparatus that appears to be simple in construction and easy to manipulate. (Fig. 23.)

Method. Place the inoculated Petri dishes upon the bottom plate of the apparatus. Invert the bell jar and seal the apparatus by serewing the upper and lower plates firmly against the bell jar. Introduce hydrogen at the upper lateral tube, the air will escape through the other. When all the air is driven out, which is determined by the hydrogen tube test, seal first the exit, then the entrance of gas and place the apparatus in the incubator. A very satisfactory way is to run the hydrogen through continuously until the cultures are grown.

This apparatus is also well suited for a large number of tube cultures in hydrogen atmosphere.

Novy ${ }^{1}$ has devised very convenient jars for cultivating bacteria in tubes and plates in an atmosphere of hydrogen. There is a large number of methods and appliances deseribed

${ }^{1}$ Novy. Centralb. f. Bakt., Bd. XIV (1893) p. 581. 
for the cultivation of anaërobic bacteria. Hunziker ${ }^{2}$ has reviewed the methods and illustrated most of the apparatus suggested for studying this class of bacteria.

Buchner's Method. Use two test tubes of different sizes, drop into the large tube a small wire support on which the small tube is subsequently placed. The small test tube contains the inoculated medium and is closed with a loose cotton plug. Put into the large test tube one gram of dry pyrogallic acid and then ten ec. of a one-tenth solution of potassium hydroxid (1 part liquor kali caust. to 10 parts of water). Then quickly lower the small culture tube and close the latter hermetically with a new, elastic, well fitting, paraffined rubber stopper. Shake well. Buchner observed that the above stated amount of pyrogallic acid and potassium hydroxid will completely absorb the oxygen in a tube with a cubic content of $100 \mathrm{cc}$. in 24 hours at incubator temperature. At lower temperature, as for instance in the refrigerator, the absorption of oxygen is much slower. Frequent shaking hastens the absorption.

${ }^{2}$ Hunziker. Jour. of Applied Microscopy and Laboratory Methods, Vol. V (1902) p. 1694. 


\section{CHAPTER IX.}

\section{THE EXAMINATION OF CULTURES.}

The study of cultures. The examination of eultures of bacteria consists in a careful study of the appearance of the growth in or upon the medium; its effect upon the medium, such as the liquefying of gelatin, the imparting of pigment, coagulation of the casein in milk; and the microscopic examination of the bacteria themselves. The time at which the cultures are to be examined varies with the medium used, the temperature at which the cultures were grown, and the organisms themselves. The more common pathogenic bacteria will have completed their growth under favorable eircumstances in from 24 to 36 hours. However, certain streptococei will have developed their characteristic colonies in from 10 to 16 hours; while the bacteria of glanders and tubereulosis will require a much longer time. When one examines pure cultures, the work is a matter of simple description; but in making bacteriological analyses where the number of species is unknown the process is more difficult. In such examinations it is often desirable to determine the number of bacteria present, in case of quantitative work the number of different species. In most quantitative work and in procuring pure cultures of the species in question, plate cultures are used.

The examination of plate cultures. It is on the plate culture that one is able to obtain the characteristic growth of the colony. When the colonies are developed the plates should be examined first by the unaided eye, making note of the general character and number of the colonies. In an impure culture the variety of colonies should be noted. In such cases it is very important that the examination be made early, before the colonies of bacteria that are more vigorous in their growth or have a pronounced tendency to spread on 
the surface of the medium have overgrown the more delicate or less vigorously growing ones. It is important also to note the difference between the colonies on the surface, in the depth of the medium, and at the bottom. In case of gelatin plates it is necessary to watch them carefully in order to detect the early appearance of liquefying colonies. The examination of plate cultures, therefore, consists in determining the character of the different colonies, their action upon the medium, the rapidity of their development, and in case of quantitative analysis, the number and variety of colonies. This is nearly always required in the analysis of milk, water, feces or other substances. In describing the colonies, Chester's ${ }^{1}$ terminology is valuable.

\section{Chester's terminology for description of colonies.}

1. Form of colonies. Plate culture.

Punctiform: dimensions too slight for defining form by naked eye, minute, raised, semispherical.

Round: of a more or less circular outline.

Irregular.

Elliptical.

Fusiform: spindle-shaped, tapering at each end.

Cochleate: spiral or twisted like a snail shell.

A moboid: very irregular, streaming.

Mycelioid: a filamentous colony with the radiate character of a mold.

Filamentous: an irregular mass of loosely woven filaments.

Floccose: of a densely woolly structure.

Rhizoid: of an irregular branched, rootlike character, as in Bact. mycoides.

Conglomerate: an aggregate of colonies of similar size and form.

Toruloid: an aggregate of colonies like the budding of the yeast plant.

Rosulate: shaped like a rosette.

2. Detailed character of surface.

Smooth: surface even, without any of the following distinctive characters.

Alveolate: marked by depressions separated by thin walls, so as to resemble a honeycomb.

Punctate: dotted with yunctures like pin pricks.

${ }^{1}$ Chester. A Manual of Determinative Bacteriology. 1901. 
Bullate: like a blistered surface, rising in convex prominences, rather coarse.

Vesicular: more or less covered with minute vesicles, due to gas formation; more minute than bullate.

Verrucose: wartlike, bearing wartlike prominences.

Squamose: scaly, covered with scales.

Echinate: beset with pointed prominences.

Papillate: beset with nipple- or mamma-like processes.

Rugose: short, irregular folds, due to shrinkage of surface growth.

Corrugated: in long folds, due to shrinkage.

Contoured: an irregular but smoothly undulating surface, like the surface of a relief map.

Rimose: abounding in chinks, clefts, or cracks.
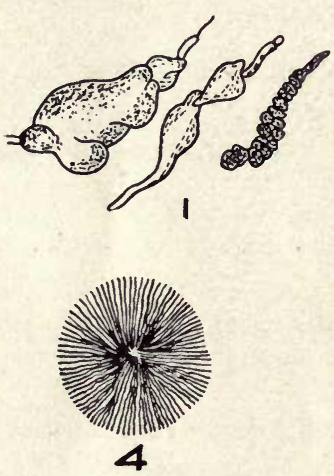

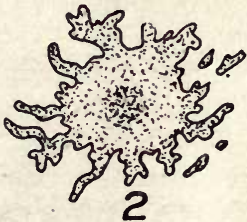

5
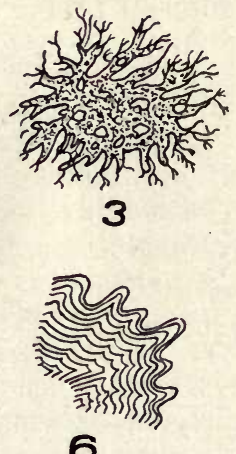

Fig. 35. Types of colonies: 1, cochleate; 2, amœboid; 3, rhizoid; 4 , mycelioid; 5 , filamentous; 6 , curled structure.

3. Internal structure of colony (microscopic).

Amorphous: without definite structure as below specified.

Hyaline: clear and colorless.

Homogeneous: structure uniform throughout all parts of the colony.

Homochromous: color uniform throughout.

Granulations or blotchings.

Finely granular.

Coarsely granular.

Grumose: coarser than the preceding, a clotted appearance, particles in clustered grains.

Moruloid: having the character of a morula segmented, by which the colony is divided into more or less regular segments. 
Clouded: having a pale छround, with ill-defined patches of a deeper tint.

4. Colony marking or striping (surface).

Reticulate: in the form of a network like the veins of a leaf.

Areolate: divided into rather irregular or angular spaces by more or less definite boundaries.

Gyrose: marked by wavy lines indefinitely placed.

Marmorated: showing faint, irregular stripes, or traversed by veinlike markings as in marble.

Rivulose: marked by lines, like the rivers of a map.

Rimose: showing chinks, cracks, or clefts.

Filamentous: as already defined.

Floccose: composed of filaments densely placed.

Curled: filaments in paradlel strands, like locks or ringlets, as in agar colonies of Bact. anthracis.

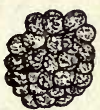

1

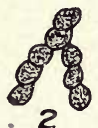

2
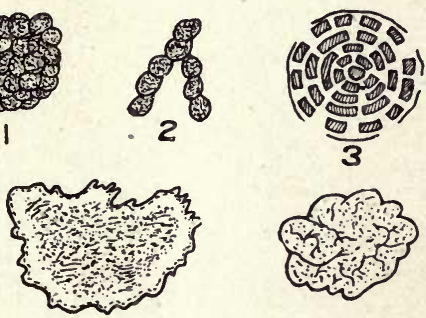

6

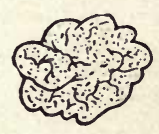

7
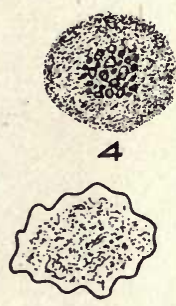

8
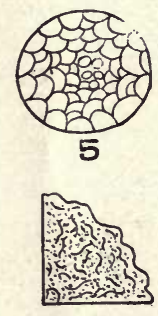

9

Fig. 36. Structure of colonies: 1, conglomerate colony; 2, toruloid colony; 3 , alveolate structure; 4 , grumose in center; 5 , moruloid; 6 , clouded; 7 , reticulate; 8 , marmorated; 9 , gyrose.

5. Edges of colonies.

Entire: without toothing or division.

Undulate: wavy.

Repand: like the border of an open umbrella.

Erose: as if gnawed, irregularly toothed.

Lobate.

Lobulate: minutely lobate.

Auriculate: with earlike lobes.

Lacerate: irregularly cleft, as if torn.

Fimbriate: fringed.

Ciliate: hairlike extensions, radiately placed.

Tufted.

Filamentous: as already defined.

Curled: as already defined. 
6. Optical characters (after Shuttleworth).

Transparent: transmitting light.

Vitreous: transparent and colorless.

Oleaginous: transparent and yellow; olive to linseed oil colored. Resinous: transparent and brown, varnish or resin colored.

Translucent: faintly transparent.

Porcelaneous: translucent and white.

opalescent: translucent, grayish white by reflected light, smoky brown by transmitted light.

Nacreous: translucent, grayish white, with pearly luster.

Sebaceous: translucent, yellowish or grayish white.

Butyrous: translucent and yellow.

Ceraceous: translucent and wax colored.

opaque.

Cretaceous: opaque and white, chalky; dull, without luster.

Dull: without luster.

Glistening: shining.

Fluorescent.

Iridescent.
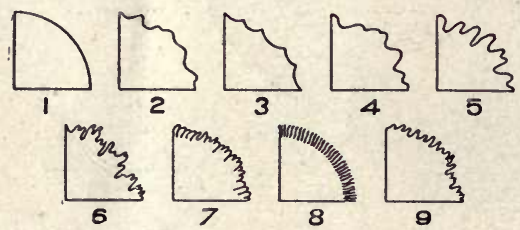

Fig. 37. Character of borders of colonies: 1 , entire; 2 , undulate: 3 , repand; 4 , lobatelobulate; 5 , auriculate; 6 , lacerate; 7 , fimbriate; 8 , ciliate; 9 , erose.

In the study of colonies it is necessary to observe their general appearance, color, ${ }^{1}$ and whether they are well isolated or run together (confluent), observing the shape and character of the edges. They should be examined with a low power lens in order to determine any special markings which may be characteristic.

Estimating the number of colonies on plates. If the number of colonies is not large (not exceeding 100), they may be counted and the exact number recorded. When the number is larger it is more convenient to divide the total area into smaller areas and count the number of colonies in

'Saccardo, Chromotaxia seu Nomenclatur Colorum. This is a very helpful color chart for descriptions. 


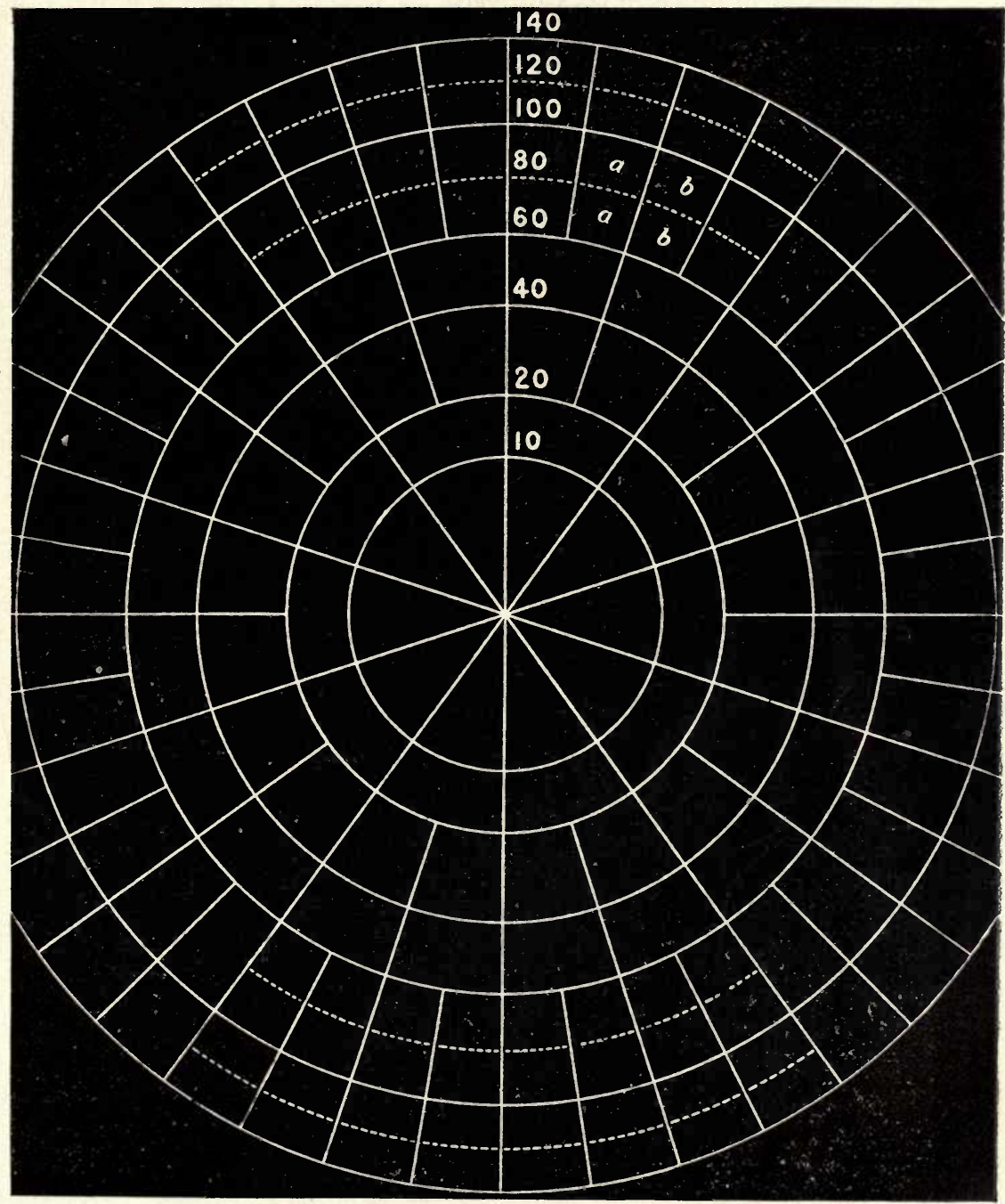

Fig. 38. Jeffers' plate for counting colonies of bacteria in Petri dishes. The area of each section is one square centimeter. 
each of several (20 to 40 ) of the small areas, and ascertain the average number on one area from which the number of colonies on the plate can be approximately determined.

For dividing the area of the plate into smaller, equal areas, it is convenient to use Wolffhügel's counting apparatus. This was devised more particularly for square or oblong plates (Koch). In counting the colonies on the Petri dishes Parkes' ${ }^{2}$ scheme modified by Jeffers ${ }^{3}$ is more suitable. It consists of a disk about $20 \mathrm{~cm}$. in diameter, divided into areas of a square centimeter each. Place the Petri dish over the disk, taking care that it is centered.

Count the number of colonies in several (10 to 40) of the areas and multiply the mean number by the number of areas covered. This product gives the approximate number of colonies on the plate.

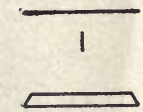

2

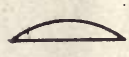

3

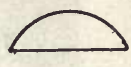

4

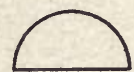

5

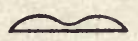

6

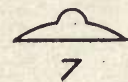

Fig. 39. Characters of surface elevation: 1 , flat; 2 , raised; 3 , convex; 4 , pulvinate; 5 , capitate; 6 , umbilicate; 7 , umbonate.

Fixamination of cultures in test tubes on solid media. In examining the growth of the organism on slant agar the extent of its development (whether feeble, moderate or vigorous), color, form, and surface appearance (whether glistening or of a dull appearance), should be observed. The character of the growth in the condensation water which forms at the bottom of the inclined surface should be noted. In stab cultures the appearance of the growth both on the surface and along the needle track should be noted. In

${ }^{2}$ Parkes, Journal of Pathology and Bacteriology, Vol. IV, p. 173.

${ }^{3}$ Jeffers, Journal of Applied Microscopy, Vol. I, No. 3, 1898. 
gelatin the same observation should be made and also whether liquefaction has taken place and if so to what extent and in what form. For this purpose, Chester has introduced a terminology in descriptive bacteriology which has the advantage of being definite and-concise, while at the same time it is sufficiently elastic to fit the varying forms of growth. It applies to the surface growth, to the growth along the needle track in the depth of the media, and to colonies on plate cultures.

1. Surface elevation. General character of surface growth as a whole.

Flat: thin, leafy, spreading over the surface.
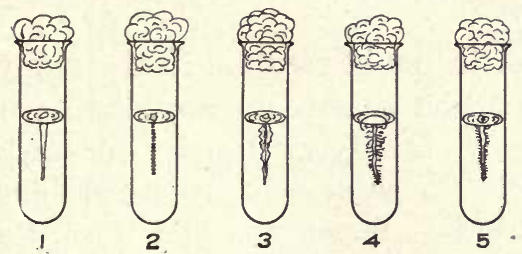

Fig. 40. Characters of growth in depth of media: 1 , filiform; 2 , beaded; 3 , tuberculateechinulate; 4, arborescent; 5, villous.

Fig. 41. Types of liquefaction in gelatin stab cultures: 1 , crateriform; 2, napiform; 3 , saccate; 4, infundibuliform; 5, stratiform.
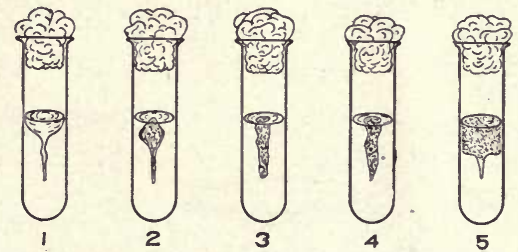

Effused: spread over the surface as a thin, veilly layer, more delicate than the preceding.

Raised: growth thick, with abrupt terraced edges.

Convex: surface the segment of a circle, but very flatly convex. Pulvinate: surface the segment of a circle, but decidedly convex. Capitate: surface hemispherical.

2. Gelatin stab cultures. Nonliquefying line of puncture.

Filiform: uniform growth, without special character.

Nodose: consisting of closely aggregated colonies.

Beaded: consisting of loosely placed or disjointed colonies.

Papillate: beset with papillate extensions.

Echinate: beset with acicular extensions.

Tillous: beset with short, undivided, hairlike extensions. 
Plumose: a delicate feathery growth.

Arborescent: branched, or treelike, beset with branched hairlike extensions.

3. Gelatin stab culture. Liquefying line of puncture.

Crateriform: a saucer-shaped liquefaction of the gelatin.

Saccate: shape of an elongated sack, tubular, cylindrical.

Infundibuliform: shape of a funnel, conical.

Napiform: shape of a turnip.

Fusiform: outline of a parsnip, narrow at either end, broadest below the surface.

Stratiform: liquefaction extending to the walls of the tube and downward horizontally.

In the examination of cultures on potato, blood serum, egg media, and other solid substances the same observations should be made.

Examination of cultures in liquid media. In the study of bouillon cultures it is important to note the appearance of the liquid, whether uniformly, faintly or heavily clouded, turbid, or clear with flocculent masses held in suspension; whether or not there is a surface membrane and if so, its character, whether viscid, friable or flocculent. The reaction of the culture should also be determined. ${ }^{1}$ The viscidity of
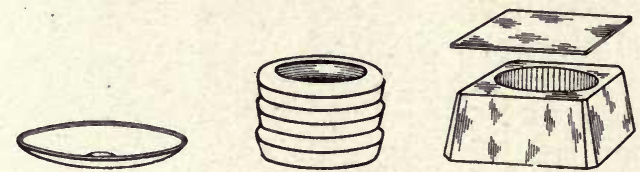

Fig. 42. Various forms of watch glasses (crystal, Syracuse and solid.)

the liquid and especially of the sediment is determined by inserting a platinum loop into it and earefully withdrawing it. If the sediment is viscid, by gently shaking the tube it will rise up, appearing as a somewhat twisted, tenacious cone with its apex reaching to or near the surface. If friable, the sediment will break and become disseminated throughout the liquid. Milk cultures should be examined to

${ }^{1}$ This is accomplished by placing a small piece of each of the red and blue litmus papers in a solid watch glass. With the platinum loop carefully place a drop of the culture on each piece of paper. 
determine what change has taken place. The most usual change is the coagulation of the casein, giving a firm, solid coagulum. Some organisms precipitate the casein. The amount of clear serum over the coagulum should be noted. Some organisms, like $B$. suipestifer, saponify the milk, giving it a brownish, translucent appearance in old cultures. The examination of bouillon cultures containing sugars in fermentation tubes includes the determination of the extent of the growth in the open and closed parts of the tube, the presence or absence of gas, the rapidity with which it is produced, and the reaction of the liquid. After the gas production is completed, it is desirable to determine the quantity and its approximate composition.

Determination of the quantity of gas. It is desirable to determine the quantity of gas collected in the closed branch in terms of the capacity of the tube. To do this, measure the length of the closed branch and the length of that portion of the tube filled with gas. Thus, if the length of the tube is $10 \mathrm{~cm}$. and the length of the portion filled with gas is $3 \mathrm{~cm}$., the gas fills three-tenths of the branch. This cannot be determined unitil the gas formation has ceased, which sometimes requires several ( 4 to 6 ) days. The closed branch of the fermentation tube should be straight and the connecting part of the tube should be narrow. If the tube stands too long before the quantity of gas is determined, some of it is liable to be absorbed. To determine the ratio of $\mathrm{CO}_{2}$ to $\mathrm{H}$ in the gas produced remove the plug from the fermentation tube and fill the open bulb with a $2 \%$ solution of caustic soda. Place the thumb tightly over the open end of the tube and tip it up so that the gas will pass through the liquid and come into the open bulb. It is then returned. This should be repeated several times. Remove the thumb when the open bulb is full, and the liquid will rush up into the closed branch to fill the space occupied by the $\mathrm{CO}_{2}$ which has been absorbed by the caustic soda. Measure the portion of the tube first occupied with gas and now filled with the liquid. This will indicate the quantity of $\mathrm{CO}_{2}$. The remainder of the gas is $\mathrm{H}$. 
(There are also traces of other gases.) Its explosive property can be tested by filling the open bulb with water, covering it with the thumb and again bringing the gas to the open bulb, holding it close to a flame, and removing the thumb. A distinct explosion will be heard.

The ratio of $\mathrm{CO}_{2}$ to $\mathrm{H}$ can be determined from the measurements. Thus if the total amount of gas in the closed branch $=5 \mathrm{~cm}$., and the amount absorbed $\left(\mathrm{CO}_{2}\right)=2 \mathrm{~cm}$., the remaining gas, or $3 \mathrm{~cm} .,=\mathrm{H}$. The ratio of $\mathrm{CO}_{2}$ to $\mathrm{H}$ is, therefore, as $2: 3$, or $\mathrm{CO}_{2}: \mathrm{H}:: 2: 3$.

2. To determine the effect of the bacteria on the medium.

(a) Fermentation of sugars producing acid with or without gas. The gas consists largely of $\mathrm{CO}_{2}$ and $\mathrm{H}$. More $\mathrm{CO}_{2}$ is formed when alcohol is produced. $\mathrm{C}_{6} \mathrm{H}_{12} \mathrm{O}_{6}$ (Glucose) plus bacteria equal $2 \mathrm{C}_{2} \mathrm{H}_{6} \mathrm{O}$ (Alcohol) plus $2 \mathrm{CO}_{2}$.

More $\mathrm{H}$ is formed when butyric acid is produced.

$\mathrm{C}_{6} \mathrm{H}_{12} \mathrm{O}_{6}$ plus bacteria equal $\mathrm{C}_{4} \mathrm{H}_{8} \mathrm{O}_{2}$ (Butyric acid) plus $2 \mathrm{CO}_{2}$ plus $2 \mathrm{H}_{2}$.

No gas is formed when lactic acid is produced.

$\mathrm{C}_{6} \mathrm{H}_{12} \mathrm{O}_{6}$ plus bacteria equal $2 \mathrm{C}_{3} \mathrm{H}_{6} \mathrm{O}_{3}$ (Lactic acid):

When acid is produced in milk casein is coagulated. In fermentation of the nitrogenous bodies alkalies are produced, as $\mathrm{CO}\left(\mathrm{NH}_{2}\right)_{2}$ (Urea) plus $\mathrm{H}_{2} \mathrm{O}$ plus bacteria equal $\mathrm{CO}_{2}$ plus $2 \mathrm{NH}_{3}$.

When alkalies are produced fats are saponified.

(b) Peptonizing. This is manifested in the liquefaction of gelatin or blood serum.

In the examination of cultures they should be earefully observed from day to day for the purpose of noting any changes that may take place. Usually they are fully developed and the changes completed within a few days. It is of the greatest importance that the changes in the cultural characters and manifestations of the different species be carefully determined, for it is by these changes that the different species and varieties of bacteria are determined. As bacteria lose certain of their properties, such as the power 
to liquefy gelatin, by continued cultivation, cultures must be lept under observation for a considerable time. For exainple, $B$. suipestifer produces no change in the appearance of milk for at least two weeks after which it begins to saponify. This very distinctive character can not be determined in a few days. Again, the composition of the culture medium may be such as to modify the appearance of the growth. In identifying species or describing new ones great care should be exercised in accurately determining the cultural characters and pathogenesis of the organisms. 


\section{CHAPTER X.}

\section{THE MICROSCOPIC EXAMINATION OF BACTERIA AND STAINS EMPLOYED.}

The examination of bacteria from cultures. Because of the minute size of bacteria it is necessary in the study of their morphology to use a compound microseope with the high power (oil immersion) objective and substage condenser. The successful study of bacteria therefore requires one to be familiar with the use of the microscope.*

Bacteria are examined microscopically in the living, unstained condition and in fixed and stained preparations.

In the fresh state they are examined in what is known as hanging drop preparations. These are prepared from liquid and solid media cultures.

(a) From a bouillon culture. Place a clean cover-glass on a tray. With the platinum loop remove a drop of the liquid culture and place it on the middle of the cover-glass. With a pair of fine forceps invert the cover-glass over the glass ring fixed to a slide for this purpose. The surface of the ring should previously be moistened with liquid vaseline to prevent the cover-glass from sliding and to keep the preparation from drying out. Examine with the oil immersion objective.

(b) From cultures on solid media. On account of the very large number of bacteria in the growth on solid media it is necessary to separate them in a clear liquid. This is done by taking a cover glass as before and placing a loopful of bouillon or sterilized water on the center. Touch the surface growth very gently with the end of the platinum

* A course in microscopy or in the technique of the microscope should precede the study of bacteriology. Those who are obliged to acquire this knowledge outside of regular instruction in the subject are referred to "The Microscope" by S. H. Gaze, Comstock Publishing Company, Ithaca, N. Y. 
needle and carefully rinse it in the drop of liquid on the cover-glass. From this point the examination is the same as with the liquid culture. Upon examination, if the bacteria are so numerous that the individual organisms cannot be clearly distinguished from each other, the preparation should be rejected and another one made, using a smaller quantity of the growth. After examination, the cover glasses should be placed at once in a strong disinfectant.

In the examination of bacteria in these preparations one can determine the shape of the individual bacteria and also whether or not they are single or appear in pairs, clumps or in short or longer chains. It is also possible to determine whether or not they are motile or possessed of a distinct capsule. In the examination of the hanging drop preparation it is desirable to move the slide so that one studies the organism at the edge of the drop. Many details in the morphology of bacteria can not be determined in these preparations. Thus the flagella and usually the capsule are not in evidence on bacteria possessing them unless they are specially stained. It should be noted that certain species of bacteria take the stain less readily and more unevenly than others.

The hanging block culture. In order to study the morphology and the manner of multiplication of bacteria to better advantage than in the hanging drop, Hill ${ }^{1}$ devised the following procedure: "Melted nutrient agar is poured into a Petri dish to a depth of about one-eighth to one-quarter of an inch. When cool, a block is cut out about one-quarter of an inch square. The block is placed under surface down on a slide and protected from dust. A suspension of the growth to be examined is then made in sterile bouillon and spread over the upper surface of the block. The slide and block are then put in the incubator for ten minutes to dry slightly. A clean cover-slip is now placed on the agar block in such a way as to avoid large air bubbles. The slide is then removed. With the aid of a platinum loop, a drop or

${ }^{x}$ Hill. Jour. of Medical Research, Vol. VII (1902) p. 202. 
two of melted agar is run along each side of the block to fill any angles between it and the cover-glass. After drying in the incubator for five minutes it is placed over a hollow slideand sealed with paraffin."

Film or cover-glass preparations. These are made from cultures of different kinds and also from other material containing bacteria, such as animal tissues, milk and the like. The following procedure may be recommended for making cover-glass preparations: (a) From bouillon cultures. Place two clean cover-glasses on the tray. With the loop remove a drop of the bouillon culture and spread it in a thin layer over about two-thirds of the surface of the cover-glasses. One loopful will ordinarily make from 2 to 4 preparations. Allow the liquid to dry on the cover-glasses in the air and, when dry, fix the bacteria to them by passing them, film upward, three times through the middle of the upper half of the gas flame. Each passage (complete circle) should not occupy more than one second. After fixing they are ready for staining. (b) From cultures on solid media. Place the coverglasses on a tray, and on the center of each put a drop of sterile water or bouillon. Touch the surface growth of the culture with the end of the needle and then gently rinse it in the liquid on the covers. Spread the liquid on the covers as before. From this point the procedure is the same as that for preparations made from a bouillon culture. (c) From tissues. With a pair of fine forceps take up a bit of tissue from the freshly cut liver, spleen, or kidney, and rub it gently over the surface of a clean cover-glass, care being taken that the film or tissue is thin. Allow this to dry in the air, after which pass the cover-glass, film up, three times through the flame to fix the tissue to the glass. It can be stained the same as the cover-glass preparations from the cultures. When carbol fuchsin is used for staining, the preparation should be wet before applying the stain. These are often spoken of as smear preparations.

In making these preparations from blood, hold a coverglass by the edge and with the platinum loop place a drop of 
blood on the cover-glass near the edge. Take a thick, square cover-glass by the edge, rest it on the first above the drop of blood, hold it at an angle of about $20^{\circ}$ from it, and draw it down over the first, thus spreading the blood in a very thin, even film over the surface. If the film is thick, the preparation should be rejected and another made. Some prefer slides to cover-glasses for this purpose. (d) From milk cultures. Spread as thin a film of the milk culture as possible on the cover-glass and allow it to dry in the air. Immerse the preparation in a watch glass or other receptacle containing a few cubic centimeters of ether and absolute alcohol in equal parts, which dissolves out the fat and fixes the film to the cover-glass at the same time. Then remove and, after the ether and alcohol have evaporated, stain as usual. The amount of albumen in the milk will usually cause a heavy background, which will require decolorizing with alcohol or weak acetic acid. (e). From pus. Spread as thin a film of the pus as possible on the cover-glass. (Slides may be used if preferred.) This can be readily done by drawing the edge of a square cover-glass or slide over the surface of another cover-glass or slide on which a bit of the pus has been placed. (f) From sputum. These are usually made for the examination of tubercle bacteria, streptococci and the organisms associated with pneumonia. Select the little yellowish-colored masses, if present, remove them by means of fine forceps or platinum loop, and spread them on the coverglass in a thin layer. If the sputum is homogeneous, make the preparations the same as from cultures, using a small loopfuI of the liquid. If the sputum is viscid, it is necessary to use the forceps to spread the film on the cover-glass. When dry, the films are fixed by passing the preparations through the flame, after which they are ready to be stained. Slides may be used instead of cover-glasses. Good results follow by dissolving the sputum in a weak solution of antiformin, centrifuging, and examining the sediment for tubercle bacteria.

Staining bacteria in cover-glass preparations. (a) With alkaline methylene blue. With the pipette place a few 
drops of the staining solution on the film side of the fixed preparation, which is either held horizontally with the fine forceps or left resting on the tray or piece of filter paper. Allow the stain to act for 2 or 3 minutes with old stains, which act more quickly than those freshly prepared; then carefully rinse it off in water, holding the cover firmly by one edge with the forceps. After thoroughly rinsing, place the preparation, film downward, on a clean slide and dry the upper surface with a piece of filter paper. It is now ready for the microscopic examination. Use first the dry lens (1-8 in. obj.) and then the oil-immersion objective. If the specimen is a good one and it is desirable to preserve it, wipe off the drop of oil with a piece of lens paper and run a drop of distilled water under the cover-glass, which will float it, when it can be easily removed with the forceps. Place it on the tray, film upward, and when dry, mount it in a neutral or slightly alkaline Canada balsam.*

(b) With carbol fuchsin. Moisten the film side of the cover-glass with water (using the pipette); then cover it with the stain and allow it to act for from 10 to 30 seconds. Then rinse it thoroughly in water, after which cover it with $0.1 \%$ solution of acetic acid or strong (95\%) alcohol. Allow this to act for from 2 to 5 seconds, and again thoroughly rinse in water and examine as above.

Upon examination the preparation should be free from deposits or stained background. The bacteria should, as a rule, be isolated and distinct; unless they are, the preparations are not satisfactory.

Staining bacteria in tissues. Occasionally it is important to examine the bacteria in the tissues themselves. In such cases the tissues should be taken soon after death, to prevent as much as possible post mortem changes. Selected pieces can be cut on the freezing microtome but the best results are

* To neutralize balsam, add some pure sodium carbonate to it and allow it to stand for about a month in a warm place, shaking it from time to time. Then allow the sodium carbonate to settle. The clear supernatant balsam will be found to be slightly alkaline. 
obtained when the tissues are fixed and imbedded in paraffin and eut in thin sections.

From the properly selected areas small portions, not more than 5 to $10 \mathrm{~mm}$. in thickness, are cut and placed in absolute alcohol for 8 to 10 hours if less than one-eighth inch thick, and longer if thicker. For the larger pieces, it is better to change the alcohol after twenty-four hours. The pieces of tissue should be kept from falling to the bottom, as the higher layers of alcohol remain nearer absolute. If along with the bacteria one wishes to study the finer structure of the tissue he should employ formalin or corrosive sublimate. The tissue is put in formalin 4 to 10 per cent solution for from three to twenty-four hours, and then in alcohol. Corrosive sublimate as a saturated solution in 0.75 per cent sodium chloride solution is also an excellent fixative agent. Dissolve the sublimate in the salt solution by heat and then allow it to cool, when the separation of crystals will show that saturation is complete. Many prefer Zenker's * solution to the saturated corrosive sublimate as a fixative. The tissues should then be placed in pieces of gauze or copper wire baskets, ${ }^{1}$ and left in running water for from twelve to twenty-four hours, according to the size of the pieces, to wash out the excess of sublimate. They are then placed for twenty-four hours in each of the following strengths of alcohol, 67, 82, and 95 per cent, and absolute alcohol for a few hours. The latter is not a necessity. They are then ready to be prepared for cutting according to the usual histological methods. The paraffin sections of tissue having been prepared and eut, they are ready

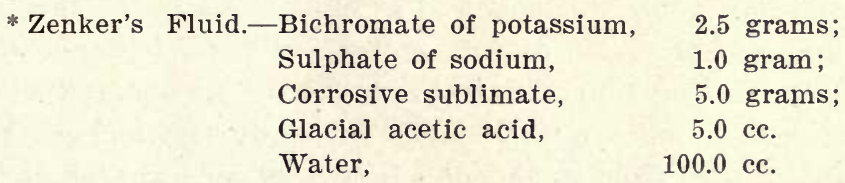

Dissolve the corrosive sublimate and the bichromate of potassium in the water with the aid of heat.

${ }^{1}$ See Gage, “The Microscope," 1908, p. 286, for washing apparatus for tissues. 
for staining after the paraffin has been removed by benzine, and the benzine removed by immersing in $95 \%$ alcohol. Bacteria are best shown, however, in tissues with fixation by absolute alcohol or formalin.

Staining with Loeffler's methylene blue. The hydrated sections are placed in Loeffler's methylene blue solution for 5 to 30 minutes, and then for a few seconds in a 1 per cent solution of acetic acid.* They are then washed quickly in water after which they are transferred to $95 \%$ alcohol and then to absolute alcohol, cleared in xylol, and mounted in Canada balsam. The number of seconds during which the preparation remains in the acetic acid must be tested by trials: The bacteria appear stained a dark blue, the nuclei of the cells blue, and the cell bodies light blue.

Thionin solution, carbol-fuchsin and gentian violet can be used instead of Loeffler's methylene blue. Gram's method, using a 3 per cent hydrochloric acid in alcohol as a tissue decolorizer and allowing it to act for ten seconds, is valuable in certain cases.

Dyes used in staining bacteria. The cell body or protoplasm of bacteria reacts to stains very much as nuclear chromatin. There is, however, much variation in the intensity with which they take the coloring matter. The best stains for bacteria are the basic aniline dyes which are compounds derived from the coal tar product aniline. The aniline dyes which are used for staining purposes are divided into two groups, according as the staining property depends upon the basic or acid portion of the molecule. The former contain the amido groups and are spoken of as nuclear stains. They color the nuclear chromatin of both animal cells and bacteria. The latter or acid portion contain the hydroxyl groups and do not stain bacteria but are used chiefly for contrast coloring. They are often mentioned in staining tissues as general stains. The

* In place of acetic acid the following solution is thought by some to be better. Distilled water $100 \mathrm{cc}$, conc. sulphuric acid 20 drops, oxalic acid $5 \%$ solution 10 drops. 
basic dyes are generally employed as salts of hydrochloric acid; while the acid dyes occur as sodium of potassium salts. EHRLICH'S CLASSIFICATION OF THE ANILINE DYES.*

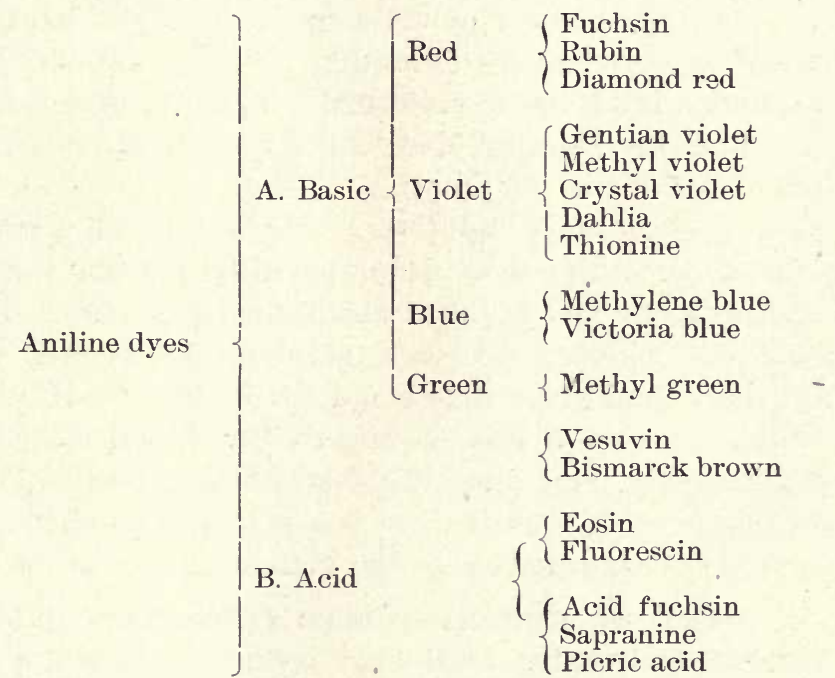

Of the aniline stains the violet and red are the most intense in action. With them it is easy to overstain the specimen. Of the blues, methylene blue is one of the best for many purposes, especially the differentiation of structure, and it is difficult to overstain with it.

These dyes are more or less crystalline powders and while some are definite chemical compounds, others are mixtures. For this reason various brands are met with on the market and exact duplication of stains is not always possible. In purchasing these dyes one can procure the crystalline or powder form from which the various solutions are prepared. If desired, the staining solutions can be procured from the dealers. Bacteriologists as a rule use Grübler stains. In addition to the appended formulae for preparing the ordinary staining solutions, there are special staining processes for certain species, such for example, as the tubercle bacterium; and

* Quoted by Thoinot and Masselin. Precis de Microbie, 1896, p. 166. 
still others for staining certain parts in the structure of the bacteria, such as the flagella on the motile forms, the spores in the spore-bearing organisms, and the capsules when present. There are a large number of these special methods but those ordinarily employed are as follows :

Formulae for staining solutions. In the preparation of nearly all of the staining solutions the saturated alcoholic solution of the dye is employed.

Saturated alcoholic solutions. The saturated alcoholic solutions of the aniline dyes are prepared by pouring the dye into a clean bottle and filling it about one-fourth full. Then fill the bottle with strong ( $95 \%$ or absolute) alcohol, cork tightly, shake, and allow it to stand for 24 hours. If at the end of that time the dye is entirely dissolved, add more dye, shake thoroughly, and allow it to stand for another day. Repeat this procedure until there is a permanent sediment of undissolved coloring matter in the bottom of the bottle.

ALKALINE METHYLENE BLUE (LOEFFLER)

Saturated alcoholic solution of methylene blue 6 ec.

Caustic potash (1\% solution) 0.2 ce.

Distilled water

$20 \mathrm{ce}$.

CARBOL FUCHSIN (ZIEHL'S SOLUTION)

Fuchsin (dry)

1 gram

Alcohol (absolute)

$10 \mathrm{cc}$.

Carbolic acid ( $5 \%$ solution)

100 ce.

Dissolve the fuchsin in the alcohol, after which add the carbolic acid solution. Instead of using the dry fuchsin and alcohol, 11 ce. of a saturated alcoholic solution of fuchsin may be used. If the mixture is not clear, add more of the saturated alcoholic solution of fuchsin drop by drop until when viewed through the pipette by transmitted light the liquid is perfectly clear.

ANILINE GENTIAN VIOLET (EHRLICH-WEIGERT)

Saturated alcoholic solution of gentian violet $11 \mathrm{cc}$.

Absolute alcohol

$10 \mathrm{ce}$.

Aniline water

100 ec. 


\section{CARBOLIC GENTIAN VIOLET (NICOLLE)}

Gentian violet (saturated alcoholic solution) $10 \mathrm{cc}$.

- Carbolic acid (1\% solution)

100 ec.

Mix and filter before storing.

Aqueous solutions. Aqueous solutions of methyl violet, gentian violet, fuchsin, and the other aniline dyes are prepared by adding 1 ec. of the saturated alcoholic solution of the desired dye to 20 ce. of distilled water. This will impart a decided color to the liquid, so that in a pipette it will be barely trasparent.

The true aqueous solutions are made by dissolving the dyes in water, but these are weak and not so effective as those prepared from the alcoholic solutions. These solutions deteriorate in a short time. The carbol fuchsin and alkaline methylene blue will keep a little longer, but they require filtering occasionally.

STAINS FOR SPECIAL PURPOSES.

Gram's method of staining bacteria. Stain the coverglass preparations in gentian violet aniline water, or in a saturated alcoholic solution of gentian violet in $5 \%$ carbolic acid in the proportion of 1 to 20 for from 5 to 7 minutes. Rinse in water and transfer them to a watch glass containing Gram's solution until the color becomes quite black. This requires from 1 to 2 minutes; then place the preparations in a watch glass containing alcohol and allow them to remain there until the color has almost entirely disappeared, or has become a pale gray. Rinse in water and examine at once, or allow them to dry and mount in balsam. (Sections of tissues: must be dehydrated and cleared before mounting.)

\section{GRAM'S SOLUTION}

Iodine

Potassium iodide

Distilled water
1 gram

2 grams

300 ec.

Certain bacteria stain deeply and retain the coloring matter when treated by this method, while others are decolorized by the alcohol. On this account some investigators 
consider it an important aid in the differentiation of certain bacteria.

Paltauf (Proceedings N. Y. Pathological Society, Oct. 1909 ) recommends the use of a staining solution composed of from 3 to 5 ce. of aniline oil, 90 cc. of distilled water and 7 ec. absolute alcohol in place of aniline water.

BACTERIA WHICH DO AND DO NOT STAIN ACCORDING TO GRAM.

GRAM POSITIVE

Str. of apoplectiform septi- Bact. abortionis cemia.

Str. capsulatus gallinarum.

Microcoecus pyogenes.

Bact. acidi lactici.

" anthracis.

$"$ astheniae.

“. bulgaricus.

“ caseous lymphadenitis.

" diphtheriae group.

" of leprosy.

" rhusiopathiae.

" subviscorum.

« truttae.

" tuberculosis.

B. alvei.

B. tetani.

B. Chauvaei.

B. subtilis.

\section{GRAM NEGATIVE}

"، aerogenes.

“ cholerae gallinarum.

“ cuniculicidum.

“" pullorum.

“ sanguinarium (?).

“ suisepticum.

" mallei.

B. coli.

" enteritidis.

“ dysenteriae group.

" of malignant oedema.

" mucosus capsulatus.

" oedematis.

" proteus.

" suipestifer.

“ typhosus group.

B. vulgaris.

Ps. pyocyaneus.

Spirilla cholerae and allied forms.

Gram-Weigert ${ }^{1}$ method of staining bacteria. This is a valuable stain for Gram positive bacteria in sections. The sections are stained 4 to 5 minutes in lithium carmine* Dehydrate in $95 \%$ alcohol, stain in aniline-gentian violet for 10 to 15 minutes, wash in tap water and place sections in Lu-

${ }^{1}$ Weigert. Fort. de Med., Bd. V (1887) p. 228.

* Formula for lithium carmine:

Carmine 3.5 grams.

Sat. aqueous solution lithium carbonate $100 \mathrm{cc}$.

Thymol a small crystal for preservation. 
gol's solution (iodine 1 , potassium iodide 2, water 100) for one minute, rinse in water, blot to remove excess of water, dehydrate in aniline oil (or better aniline oil 2 parts and xylene 1 part) clear in xylol and mount in balsam.

Staining spores. Make a cover-glass preparation, dry, and flame as already described. Take the preparation by the edge with the fine forceps, " cover the film surface with carbol fuchsin, and hold the preparation over the gas flame until steam is given off; then remove it for a few seconds and heat again. Repeat the heating three or four times. After the stain has acted for from 3 to 5 minutes, rinse the preparation in water and decolorize it by immersing it in a watch glass containing about 3 ce. of $1 \%$ solution of sulphuric acid or $95 \%$ alcohol. After about one-half minute remove the preparation and rinse it thoroughly in water. If it is not decolorized, repeat the bleaching process. This removes the coloring matter from the bodies of the bacteria, but leaves it in the spores. After thoroughly washing the preparation, counterstain it with a saturated aqueous solution of methylene blue for about 30 seconds, rinse in water, and examine. The spores should be stained red (with the fuchsin) and the rest of the organism should be colored blue.

Moeller's method is designed still further to favor the penetration of the coloring matter through the spore membrane. The prepared cover-slip is held for two minutes in chloroform, then washed off in water, then placed from onehalf to three minutes in a 5 per cent solution of chromic acid, again washed in water, and stained in dilute (1 to 10) carbol fuchsin, heated slowly over flame until steam is given off, for 3 to 5 minutes. The staining fluid is then washed off and the preparation decolorized in a 3 per cent solution of hydrochloric acid or a 5 per cent solution of sulphuric acid. Wash and stain for a minute in aqueous methylene blue. The spores will be red and the body of the bacteria blue. Different spores vary greatly in the readiness with which they take up the dyes, and we have, therefore, to experiment with each species 
to ascertain the length of time they should be exposd to the maceration of the chromic acid. Even under the best conditions it is almost impossible to stain some spores.

Staining capsules. Many methods of demonstrating the capsules have been devised. The glacial acetic method, as described by Welch, is as follows: 1 . Cover the preparation with glacial acetic acid for a few seconds. 2. Drain off and replace with aniline gentian violet solution; this is to be repeatedly added until all the acid is replaced. 3. Wash in 1 to 2 per cent solution of sodium ehloride and mount in the same.

Hiss' copper sulphate method. The organisms are grown, if possible, on ascitic fluid or serum media. Spread the organisms on the cover-glass by mixing them with a drop of serum, or, better, a drop of one of the diluted serum media. Dry in the air and fix by heat.

The capsules are stained in a 5 to 10 per cent aqueous solution of gentian violet or fuchsin ( 5 ce. saturated alcoholic solution gentian violet or basic fuchsin to 95 ce. distilled water). The stain is placed on the dried and fixed coverglass preparation and gently heated for a few seconds until steam arises. The dye is washed off with a 20 per cent solution of copper sulphate (crystals). The preparation is then placed between filter-paper and thoroughly dried.

Staining flagella. ${ }^{1}$ Johnson and Mack have modified Loeffler's method with very satisfactory results. The process which they recommend and which we have used with success is as follows:

Make a culture of the organism to be stained on slant agar and incubate for from 18 to 24 hours. Prepare a tube with 6 to $8 \mathrm{cc}$. of sterile water, and keep it in the incubator until it is of the same temperature. With a sterile platinum loop scrape away some of the growth from the agar surface, using eare not to remove any of the agar, and rinse it off carefully in the tube of water previously prepared for this

${ }^{1}$ Johnson and Mack. Am. Med., Vol. VII (1903) p. 754. 
purpose. 'There should be enough to impart to the water a faint cloudiness. This should be done in a warm room and with considerable care. Replace this tube in the incubator and the bacilli will distribute themselves quite evenly through the water, but any clumps or masses settle to the bottom. The tube is left in the incubator for from 2 to 3 days before preparing the films. Place a tray of properly prepared coverglasses in the incubator to warm them; then, still in the warm room, with a platinum loop put a drop or two from the tube on each cover. Replace the tray in the incubator until the water has evaporated, when the films are ready to stain. The films require no fixing other than by the mordant. The small amount of organic matter in films prepared in this way gives but little background when stained. Different mordants and staining solutions may be used. Those of Loeffler or Pitfield give the most uniform and satisfactory results.

\section{LOEFFLER'S MORDANT}

Twenty per cent aqueous solution tannic acid $10 \mathrm{cc}$.

Saturated aqueous solution iron sulphate 5 ce.

Saturated alcoholic solution basic fuchsin $1 \mathrm{cc}$. Mix, let stand two or three hours, and filter.

Tannic acid solution should be freshly prepared, but the iron sulphate solution is better if it stands until it begins to turn brownish by oxidation, but it should not be too old. If when this mordant is used it gives a precipitate, filter again. When properly prepared it should have much the same color as a solution of hematoxylin.

LOEFFLER'S STAIN (ZIEHL'S CARBOL FUCHSIN)

Saturated alcoholic solution basic fuchsin $31 \mathrm{cc}$.

Five per cent carbolic acid 20 ce.

If not clear, add fuchsin solution drop by drop until it clears, then filter.

Loeffler's Method. ${ }^{1}$ Place 2 loopfuls of sterilized distilled water or normal salt solution on the center of the cover-

\footnotetext{
${ }^{1}$ Loeffler. Centralbl. f. Bakteriologie, Bd. VI (1889) p. 209.
} 
glass. Gently touch the surface growth on the agar culture with the end of the platinum needle and immerse it in the water on the cover-glass without spreading the drop. The impregnated needle should carry bacteria enough for 3 or 4 preparations. Then place the tray of cover-glasses in the incubator to dry. The bacteria become disseminated throughout the water by means of their power of locomotion. When dry they are ready for the staining treatment.

The bacteria are fixed to the cover-glass by holding them, film upward, between the thumb and forefinger, over a gas flame for about a minute. They are then treated with Loeffler's mordant.

Place the fixed cover-glass preparation in a large test tube, cover it with mordant, and carefully heat over a gas flame or in a water bath until steam is given off. Allow the mordant to act for from 3 to 5 minutes. Then remove the cover-glass with a bent wire loop and fine forceps and thoroughly rinse it in water. Then place it in a similar tube and cover with carbol fuchsin for staining. Heat this as the mordant was heated and allow the stain to act for from 5 to 10 minutes. Remove the cover-glass as before and thoroughly rinse in water. If the stain is too deep, decolorize by rinsing the preparation for a few seconds in alcohol and again in water. It is then ready for the microscopic examination in water, or it may be allowed to dry and then be mounted in balsam. If the first preparation fails, add 2 drops of a $10 \%$ solution of sulphuric acid to the mordant.

The flagella should appear as fine, hairlike appendages radiating from the bacteria.

Van Ermengem's ${ }^{2}$ method. The films are prepared as described above. Three solutions are necessary.

$$
\text { SOLUTION A (FIXING BATH) }
$$

Osmic acid, $2 \%$ solution

1 part

Tannin, 10 to $25 \%$ solution

2 parts

${ }^{2}$ Van Ermengem. Ref. Centralb. f. Bakteriologie, Bd. XV (1894) No. 24 , p. 969 . 
Place the films in this for 1 hour at room temperature or heat in an oven for 5 to 15 minutes at $55^{\circ} \mathrm{C}$. Wash the preparation with distilled water, then with absolute alcohol for from 3 to 4 minutes, and again very thoroughly in distilled water. It is now ready to treat with Solution B.

\section{SOLUTION B (SENSITIZING BATH)}

This is another solution of silver nitrate in distilled water. Allow the films to be in this for from 2 to 3 minutes. Then without washing transfer to Solution C.

SOLUTION C (REDUCING AND STRENGTHENING BATH)

Gallic acid

Tannin

Fused potassium acetate

Distilled water
5 grams:

3 grams

10 grams. 350 ce.

Keep in this for from 1 to $1 \frac{1}{2}$ minutes. Wash, dry, and mount. It is an advantage to use a fresh supply of Solution C for each preparation, a small quantity being sufficient. If overbrowned, the background will be too deeply stained; if underbrowned, the flagella will be too faint.

The use of mordants and decolorizing agents. In films of blood and pus, and in tissue sections, the tissue elements: may be stained to such an extent as to obscure the bacteria. Hence many methods have been devised to use substances which, while increasing the staining power, tend to fix the stain in the bacteria and further to treat the preparations with substances which decolorize the overstained tissue to a greater or less extent, while leaving the bacteria stained. The staining capacity of a solution may be increased by (a) the addition of substances such as carbolic acid, aniline oil, or metallic salts, all of which probably act as mordants; (b) by the addition of weak alkaline solution, especially of caustic potash or ammonium carbonate; (c) by the employment of heat; (d) by long duration of the staining process.

Staining acid fast bacteria. The tubercle bacterium is 
the most important of this group. The Ziehl-Neelson method ${ }^{1}$ is the one most used. Thin smears of the suspected material are made on cover-glasses or slides, fixed by heat and stained in carbol-fuchsin solution. The slides or cover-glasses may be flooded with the stain, and gently heated over a flame until steam is given off, or else the cover-glass may be inverted upon the surface of the staining fluid, in a porcelain dish or watchglass, and this heated until it steams. The heat is continued for three to five minutes. Decolorize with either five per cent nitric acid, 10\% sulphuric acid, or 3\% hydrochloric acid for three to five seconds. A 3\% hydrochloric acid in $95 \%$ alcohol is an excellent decolorizer. It has been recommended as being of value in differentiating tubercle bacteria from other acid fast organisms. It should not be used therefore in staining saprophytic acid fast organisms. The treatment with the acid is continued until subsequent washing with water will give only a faint pink color to the preparation.

If the stain is for tubercle bacteria, after treating with the acid wash with $95 \%$ alcohol until no further color can be removed. If, after prolonged washing with alcohol, a red color still remains in very thick places only upon the smear, it may be disregarded. If a counter stain is desired wash the preparation in water and stain with Loeffler's methylene blue from 10 to 30 seconds. Again rinse in water, dry and mount. By this method the tubercle bacteria are colored red, other bacteria and cellular elements which may be present are stained blue.

Gabbett ${ }^{2}$ has devised a rapid method in which the decolorization and counterstaining are accomplished by one solution. The specimen is prepared and stained with carbol fuchsin as in the preceding method. It is then immersed for one minute directly in the following solution:

Methylene blue

2 grams

Sulphuric acid 25 per cent (sp. grav. 1018) 100 ce.

${ }^{1}$ Ziehl. Deut. med. Woch., 1882, p. 451.

Neelson. Deut. med. Woch., 1882.

${ }^{2}$ Gabbett. Lancet, 1887 - i, p. 757 . 
It is then rinsed in water, and examined or dried and mounted.

The differentiation between tubercle bacteria and saprophytic acid fast organisms. The method of differentiating tubercle bacteria from other members of the acid fast group devised by Fontes and recommended by the Committee on Standard Methods for the Bacteriological Diagnosis of Tuberculosis ${ }^{3}$ of the laboratory section of the American Public Health Association is as follows:

(a) Stain the preparation by the ordinary carbol fuchsin method. (b) Wash in tap water. (c) Stain about two minutes with carbol crystal violet (carbol gentian violet gave better results). (d) Treat with lugol solution until no more metallic mirrors are found. (Decolorization is more easily affected if at this point the preparation is blotted thoroughly.) (e) Treat with aceton-alcohol (equal parts of aceton and alcohol until the stain ceases to wash out). (f) Rinse thoroughly in distilled water and counterstain with methylene blue.

Peterson ${ }^{4}$ found that it was impossible to differentiate between tubercle bacteria and non pathogenic acid fast organisms that frequently appear in the feces and milk of cattle by any of the known methods of decoloration.

Staining spirochaetes. For this purpose Giemsa's stain is quite generally used. The method of Giemsa ${ }^{5}$ is really a modification of the Romanowsky method. It is widely applicable, being of great value in the staining of the spirochaetes, especially Treponema pallida, Vincent's spirilla, protozoa, and Negri bodies. The stain has been modified several times by its originator, the following being the formula given by him in 1904. The substance referred to as azur II and purchasable under that name, consists of pure methylenazur chloralhydrate combined with an equal quantity of methylene blue chloralhydrate. The substance referred to as azur II-eosin is a combination of this substance with eosin.

${ }^{3}$ Jour. of the Am. Public Health Asso., Vol. I (1911) p. 273.

" Peterson. Rept. of the N. Y. State Veterinary College, 1909-1910, p. 65.

'Giemsa. Centralbl. f. Bakt., Bd. XXXVII (1904) p. 308. 
The staining fluid is made up as follows:
Azur II-eosin
3 grams
Azur II
8 grams

This mixture is thoroughly dried over sulphuric acid in a desiccator, finely powdered, and rubbed through a fine sieve. It is then dissolved in 250 grams of C. P. glycerin (Merck), at $60^{\circ} \mathrm{C}$. To this is added methyl alcohol (Kahlbaum) 250 ce. previously warmed to $60^{\circ} \mathrm{C}$. This mixture is well shaken and allowed to stand at room temperature for twenty-four hours. The mixture is then ready for use.

When used, 10 ce. of distilled water are poured into a test tube and one to two drops of a one per cent potassium carbonate solution are added. Ten drops of the staining solution described above (one drop to the cc.) are mixed with this slightly alkaline water. The preparation which is to be stained is fixed in methyl alcohol, dried, and covered with the diluted staining solution. For the staining of protozoa and exudates containing bacteria, ten to fifteen minutes are sufficient. For the staining of Negri bodies or Treponema pallida, one or more hours of staining should be employed. After staining, wash in running tap water, blot, dry and mount.

Stains for blood preparations. These are often valuable for certain bacteriological examinations and in studying the blood in cases of infection.

Jenner's stain. ${ }^{6}$ Jenner's stain is one of the most rapid and easy to manipulate of the many methods in use and stains each of the several kinds of granules in the leucocytes. It is recommended for ordinary examinations. The staining fluid is a five-tenths per cent solution of the dye (Gruebler's) in pure methyl alcohol (Merck's). This acts as both fixing and staining fluid. The smear, previously unfixed, simply dried in the air, is flooded with the staining fluid which is allowed to act two or three minutes, when it is washed in distilled water until the better spread portions have a pinkish tint, which usually requires about ten seconds. The water

- Jenner. Lancet, 1899 , i. p. 370. 
should then be shaken and blown vigorously from the specimen which is then dried rapidly in the air. As soon as it is thoroughly dry it may be examined using a two $\mathrm{mm}$. (1/12 in.) oil immersion objective. It is not necessary to place a coverglass on the specimen, as the index of refraction of homogeneous oil is the same as that of glass. If a dry objective should be used a cover-glass would be necessary; but as high a magnification as that given by a two $\mathrm{mm}$. (1/12 in.) objective is needed. The stained films keep as well without being covered as when mounted in balsam. Immersion oil may be removed from the film by dropping on chloroform or xylene.

With Jenner's stain the red corpuseles should have a pinkish or terra cotta tint; nuclei, blue; the fine granules of polymorphonuclears, pinkish; eosinophile granules, deeply stained pinkish; basophile granules, deeply stained dark violet. Bacteria are well stained blue.

Wright's stain. ${ }^{7}$ The staining fluid may be obtained ready for use from dealers in microscopical supplies. It is a solution in pure methyl alcohol of eosinate of polychrome methylene blue. The unfixed film which has dried in the air is covered with the stain which is allowed to act one minute. Then an equal number of drops of distilled water is added. This is allowed to act two or three minutes longer when the specimen is washed with distilled water until the better spread portions have a pinkish or orange tint. A few seconds will usually suffice, but it may take one to three minutes. The excess of water is shaken and blown vigorously from the specimen which is then dried in the air. When it is dry examine with the two $\mathrm{mm}$. (1/12 in.) oil immersion objective.

Wright's stain is excellent, staining the several kinds of granules well. The red corpuscles should have a pinkish or terra cotta tint; nuclei, blue; the fine granules of polymorphonuclears, pinkish; eosinophile granules, reddish; basophile granules, a deep royal purple. This stain also stains bacteria well. Wright's is preferable to Jenner's stain for staining the protozoa found in the blood.

${ }^{7}$ Wright. Jour. Med. Research, Vol. VII (1902) p. 138. 


\section{CHAPTER XI.}

\section{VITAL ACTIVITIES OF BACTERIA.}

Range of activities. The study of bacteria reveals their many interesting properties and numerous and important natural phenomena dependent upon their activities. The activities of bacteria fall quite naturally into two classes, first, the power they possess of doing things themselves such as motility, light and pigment production, toxin elaboration, etc., and secondly, their effect upon other substances or things such as the decomposition of proteid substances, the fermentation of sugars with the production of acids with or without gas, the absorption of nitrogen from the air, and many other actions of great importance to the animal world. We too often look upon bacteria as agents of destruction without appreciating that it is because of their activities that higher animal life is possible. In a text of this kind there is space to refer to but very few of the services which these minute organisms render.

The production of specific poisons such as toxins and the reactionary bodies or antibodies thrown off by the tissues themselves as the result of stimulation by the toxins has become such an important part of the subject that it is discussed in a separate chapter, restricting the present statements to a brief mention of the more general activities of these microorganisms.

Motility. When certain bacteria are examined microscopically in the living condition they are observed to present pronounced independent motion. The movements of these forms vary in character and are described as rotary, undulatory, sinuous, wobbling, and the like. Some are very active while others move sluggishly. It has been proved that the motile organisms possess flagella and as already stated a classification of bacteria was proposed by Messea based on the number and arrangement of these filaments. In many cases in a hanging drop preparation it is difficult to 
decide whether an organism possesses active independent movement or is exhibiting pronounced Brownian or molecular motion, i. e., the dancing and tremor exhibited by finely divided inorganic particles. Actual motility of an organism is determined by its passing from one place in the field to another. A number of organisms that are non-motile have been described as possessing motility. Thus, Bact. mallei, which exhibits very pronounced dancing movements, was first described as being motile. The degree of activity exhibited by certain bacteria varies according to the age of the culture and the media. Such organisms as B. tetani and the bacillus of black leg while exhibiting active motility in the vegetative stage do not usually show such motion after spores develop. It has been reported by one observer at least that the degree of motility is influenced by the temperature at which the organisms are grown. Ferrier ${ }^{1}$ has shown that the motility of $B$. coli almost ceases and that the flagella are not present when this organism is cultivated at its maximum temperature, i. e., at $43^{\circ} \mathrm{C}$. His explanation is that the flagella under the influence of the heat form a protective coat for the bacilli.

Pigment production. So far as known the production of pigment has no connection with the pathogenesis or virulence of bacteria, although the pathogenic bacteria contain a very few pigment producing organisms. Pigment production, however, is an interesting phenomenon and of value in the identification of certain species. 'The pigments have not until recently been studied to any extent chemically. Numerous experiments have been made to determine the cause of the variation in the chromogenic function of bacteria. All unfavorable life conditions such as improper media, too low or too high a temperature, tend to decrease the production of pigment. $B$. prodigiosus produces little or no pigment when grown at $30^{\circ} \mathrm{C}$. Ps. pyocyaneus does not produce pigment when grown under anaërobic conditions. Several varieties of pigment are produced.

${ }^{1}$ Ferrier. Archiv de Med. Exp. et d'Anat. Path., Tome VII (1895) p. 58 . 
(1) Red and yellow pigments. Schneider studied twentyseven red and yellow pigment forming bacteria, nearly all of which produced coloring matter soluble in alcohol and insoluble in water. The larger majority of them were colored blue-green with sulphuric acid and red or orange with a solution of potash. They varied in their chemical composition and in their spectra. They may be classified, for the most part, among that large group of pigments common to both the animal and vegetable kingdoms known as lipochromes, and to which belong the pigments of fat, yolk of egg, the carotin of carrots, turnips, etc. (2) Violet pigments. Certain bacteria produce violet pigments, insoluble in water, ether, benzol and chloroform, but soluble in alcohol. (3) Blue pigments. Ps. pyocyaneus produces the blue pyocyanin. It is stated that it is also produced by the so-called fluorescent bacteria, along with a pigment named bacteriofluorescein. In cultures, the fluorescence is at first blue; later, as the cultures become alkaline, it is green. (4) Fluorescent pigments. The fluorescent pigments which occur in the cultures of very many bacteria are identical, according to the recent investigations of K. Thumm. ${ }^{1}$. The pigment which is called bacteriofluorescein, when dry, is lemon-yellow and amorphous. It is soluble in water and dilute alcohol, insoluble in strong alcohol, ether, and earbon bisulphid. The aqueous solution of this pigment, when concentrated, is orange; when diluted, pale yellow. The solution, when acid in reaction, presents no fluorescence; when neutral, a blue; and when alkaline, a green fluorescence. In the culture the fluorescence is at first blue, and later, because of the ammonia produced by the bacteria, it becomes green. The pigment is not sensitive to oxidizing agents. Phosphoric acid and magnesium appear to be essential for the production of bacteriofluorescein. ${ }^{2}$

The beautiful blue crystalline pigment, pyocyanin, $\mathrm{C}_{14} \mathrm{H}_{14} \mathrm{O}$, can be easily extracted from cultures of Ps. pyo-

${ }^{1}$ Thumm. Arbeiten aus dem bakteriologischen Institut der techn. Hochschule zu Karlsruhe, Bd. I, p. 291.

${ }^{2}$ Jordan. Botanical Gazette, Vol. XXVII, p. 19. 
cyaneus with chloroform, and separated from the bacteriofluorescein.

Phosphorescent bacteria. Certain bacteria have the property of emitting light when grown on solid culture media. These organisms are quite widely distributed in sea-water and are observed in salt fish. They have been frequently isolated and studied. The giving off of light is a property of living bacteria. It is not usually due to oxidation of any photogenic substances eliminated by them, although such a substance has been reported. Agents which are injurious to the life of the bacteria affect this property. A filtrate of the cultures has proven to be non-phosphorescent. Phosphorescent bacteria are best grown with free access of oxygen in a culture medium prepared by boiling fish in sea-water (or water containing 3 per cent sea-salt), to which 1 per cent peptone, 1 per cent glycerin, and 0.5 per cent asparagin are added. Even in this medium the power of emitting light is soon lost unless the organisms are frequently transplanted to fresh media.

Chemotaxis. This is the attraction or repulsion of bacteria by chemical substances and was first described by Strahl and Pheiffer. Some chemical substances seem to exert a peculiar attraction for bacteria. The bacterial proteins are, according to Buchner, especially active in this respect. Other chemical substances repel them (negative chemotaxis). Moreover all species are not affected alike, for the same substance may attract some bacteria and repel others. Oxygen, for example, attracts aerobic and repels anaërobic bacteria, and for each variety there is a definite proportion of oxygen which most strongly attracts. The chemotactic properties of substances are tested by pushing the open end of a fine capillary tube, filled with the substance to be tested, into the edge of a drop of culture fluid containing bacteria and examining the hanging drop under the microscope. In this way one can observe whether the bacteria crowd about the tube opening or are repelled from it. Peptone and urea show positive chemotaxis for nearly all bacteria, while alcohol and many of the metallic salts possess a negative chemotaxis. 
Production of heat. The production of heat by bacteria is so slight that it does not attract attention. Fermenting cultures, according to careful tests, develop a small amount of heat. The increase of temperature in organic substances when stored in a moist condition, such as tobaceo, hay, manure, etc., is partly due to the action of bacteria.

Chemical action. The changes which substances undergo that are being decomposed depend first, on the chemical nature of the bodies involved and the conditions under which they exist, and secondly, on the varieties of bacteria present. Knowledge of these chemical changes is incomplete. Chemists have as yet only enumerated some of the final substances evolved, and described, in a few cases, the manner in which they are produced. Bacteria are able to construet their body substance out of various kinds of nutrient materials and also to produce fermentation products, and they are able to do these things either analytically or synthetically with almost equal ease. This ambidextrous metabolic power exists, according to Hueppe, among bacteria to an extent as yet unknown in other living things.

Hueppe has clearly set forth several groups of phenomena in the building up of the bacteria bodies. "(1) Polymerization, a sort of doubling up of a single compound; (2) synthesis, a union of different kinds of simple compounds into one or more complex substances; (3) formation of anhydride, by which new substances arise from a compound through the loss of water; and (4) reduction or loss of oxygen, which is brought about especially by the entrance of hydrogen into the molecule. The breaking down of organic bodies of complicated molecular structure into simpler combinations takes place, on the other hand, through the loosening of the bonds of polymerization, through hydration or entrance of water into the molecule, and through oxidation. The chemical changes are greatly influenced by the presence or absence of oxygen.",

In the presence of oxygen some of the decomposition products that are formed by the attack of the anaërobic bac- 
teria are further decomposed and oxidized by the aërobes; they are thereby rendered, as a rule, inert and consequently harmless. Some bacteria have adapted themselves to the exclusive use of oxygen in combination, using those compounds from which oxygen can be obtained, and others, the obligatory aërobes, are able to live only in the presence of free oxygen. The facts of anaërobiosis are of great importance to technical biology and to pathology. Three types of chemical activity are recognized.

1. "The bacteria develop their tissues.

2. "The bacteria produce and liberate ferments or enzymes which tend to make the food stuff in their neighborhood more assimilable.

3. "The bacteria assimilate food and liberate it changed to other material. These changes may be due to ferments retained in the cells."

Fermentation. Fermentation refers to the splitting up or cleavage of a carbohydrate. This power is possessed by a number of bacteria and yeasts. The variation in the action on carbohydrates is of considerable value in differentiating species. In this connection it has been found that the specific carbohydrate-splitting powers of bacteria are practically constant through many generations. The cleavage process seems to be due to a process of hydrolysis. The ferments causing the different fermentations have been named by adding the suffix "ase" to the converted carbohydrate to indicate the enzyme. Thus there are ferments known as amylase, cellulase, lactase, invertase, etc.

Some writers refer all forms of decomposition due to bacteria to fermentation, referring to the putrefactive fermentation of albuminous substances; others limit the term to the process when accompanied by the production of gas; others, again, take fermentation to mean only the decomposition of carbo-hydrates, with or without gas-production.

Park defines fermentation "as a chemical decomposition of an organic compound, induced by the life processes of 
living organisms (organized ferments), or by chemical substances thrown off from the bacteria (unorganized or chemical ferments or enzymes). In the first the action is due to the life processes necessary for the growth of the organisms producing the ferment, as in the formation of acetic acid from alcohol by the action of the vinegar plant, and in the second the enzyme, either within or outside of the organism and having no direct connection with the growth of the organism, causes a structural change without losing its identity, as in digestion. E. Buchner ${ }^{1}$ Las shown that even in those cases of fermentation in which formerly it was believed the organized cell itself was necessarily concerned, the cell protoplasm squeezed from its capsule is able to cause the same changes as the organized cells. This brings fermentation by unorganized and organized ferments very closely together, the one being a substance thrown off by the cell, the other a substance ordinarily retained in the cell. The increase of both ceases with the death of the bacteria producing them. These renzymes, even when present in the most minute quantities, have the power of splitting up or decomposing complex organic compounds into simpler, more easily soluble and diffusible molecules. The changes thus made may greatly aid in rendering the foodstuff suitable for bacterial growth. We can only speak of chemical ferments when it can be demonstrated that the fermentation continues in the absence of all living bacteria. This may be accomplished by the addition of disinfectants, - carbolic acid, chloroform, ether, etc.,- to the cultures or by filtration."

Properties of ferments. Ferments are non-dialyzable. They withstand moderate dry heat, but are usually destroyed in aqueous solutions at a temperature over $70^{\circ} \mathrm{C}$. They are injured by acids, especially the inorganic ones, but are resistant to all alkalies. A simple example of bacterial fermentation of carbohydrates produced by an enzyme is that of grape sugar :

${ }^{1}$ Buchner. Berichte d. Deutsch. chem. Gesellsch., Bd. XXX, 117-124 and 1110-1113. 


$$
\begin{aligned}
& \mathrm{C}_{6} \mathrm{H}_{12} \mathrm{O}_{6}=2 \mathrm{C}_{2} \mathrm{H}_{6} \mathrm{O}+2 \mathrm{CO}_{2} \\
& \text { Grape-sugar } 2 \text { alcohol } 2 \text { carbon dioxide. } \\
& \text { Or, } \quad \mathrm{C}_{6} \mathrm{H}_{12} \mathrm{O}_{6}=2 \mathrm{C}_{3} \mathrm{H}_{6} \mathrm{O}_{3} \\
& \text { Grape-sugar } \quad 2 \text { lactic acid } \\
& \text { Or, } \quad \mathrm{C}_{6} \mathrm{H}_{12} \mathrm{O}_{6}=3 \mathrm{C}_{2} \mathrm{H}_{4} \mathrm{O}_{2} \\
& \text { Grape-sugar } 3 \text { acetic acid }
\end{aligned}
$$

Oxidizing fermentation, as in the production of acetic acid from alcohol, is less commonly encountered. Here the energy is acquired not by the decomposition but by the oxidation of the alcohol.

The proteolytic ferments, which are somewhat analogous to trypsin-being capable of changing albuminous bodies into soluble and diffusible substances-are very widely distributed. The liquefaction of gelatin, which is chemically allied to albumin, is due to the presence of a proteolytic ferment or trypsin. The production of proteolytic ferments by different cultures of the same varieties of bacteria varies considerably. Even among the freely liquefying bacteria, such as the cholera spirillum and $M$. pyogenes, poorly liquefying varieties have been found repeatedly. These observations have detracted considerably from the value of the property of liquefying gelatin as a positive means of identifying bacteria. Nearly all conditions which are unfavorable to the growth of bacteria seem to interfere more or less with their liquefying power.

Certain bitter tasting products of decomposition are formed by liquefying bacteria in media containing proteid, as, for example, in milk. Certain bacteria also produce diastatic ferments which convert starch into sugar.

Inverting ferments are of very frequent occurrence. Among bacteria these ferments withstand a temperature of $100^{\circ} \mathrm{C}$. for more than an hour.

Rennet-like ferments or substances having the power of coagulating milk with neutral reaction, independent of acids, are occasionally found among bacteria. $B$. prodigiosus, for instance, in from one to two days coagulates to a solid mass 
milk which has been seterilized at $55^{\circ}$ or $60^{\circ} \mathrm{C}$. It has been asserted that these ferments may be present in all species of bacteria which coagulate milk, even though the organisms also act upon the sugars with the production of acid.

Fermentation yields products that inhibit the action of the ferments. Fermentation ceases when it reaches a certain point. Different kinds of fermentation are named according to the products. Thus acetic fermentation yields acetic acid; alcoholic or vinous fermentation produces alcohol; ammoniacal yields ammonia; amylic yields amylic alcohol; butyric yields butyric acid; lactic yields lactic acid; and the like.

Aerobic bacteria produce alkaline products from albuminous substances in culture media free from sugar. Many species of bacteria produce acids in the presence of sugars, which explains the fact that neutral or slightly alkaline broth often becomes acid in young cultures from the fermentation of the sugar contained in the meat used for making the media. When the sugar is used up the reaction often becomes alkaline due to the action on the proteid. The substances producing the alkalinity in cultures are chiefly ammonia, amine, and the ammonium bases.

The conversion of urea into the carbonate of ammonia affords an example of the production of alkaline substances by bacteria:

$$
\mathrm{CO}\left(\mathrm{NH}_{2}\right)_{2}+2 \mathrm{H}_{2} \mathrm{O}=\mathrm{CO}_{2}\left(\mathrm{NH}_{4}\right)_{2} \text {. }
$$

Urea 2 water ammonium earbonate.

Ptomains. Nencki, Brieger, Vaughan and others have succeeded in obtaining organic bases of a definite chemical composition out of putrefying substances such as meat, fish, old cheese and milk. Some of these were found to exert a poisonous effect upon animals, while others were harmless. The ptomains may be present in the decomposing animal body hence the name ptomain. They may be formed also in the living animal body, and, if not made harmless by oxidation, may act as self-poisons or leucomains. The ptomains are described by Vaughan as cleavage products. 
Many ptomains such as cadaverin and cholin are quite well understood. By the oxidation of cholin there can be produced the highly toxic musearin, found by Schmeideberg in a poisonous toadstool and by Brieger in certain decomposing substances :

$$
\underset{\text { Cholin }}{\mathrm{C}_{5} \mathrm{H}_{15} \mathrm{NO}_{2}}+\mathrm{O}=\underset{\text { Muscarin }}{\mathrm{C}_{5} \mathrm{H}_{15}} \mathrm{NO}_{3}
$$

The ptomain tyrotoxicon was obtained from cheese, milk, and ice eream by Vaughan and Novy.

Since the name ptomain was given to the poisonous products resulting from bacterial growth before these substances were chemically understood the term is often wrongly applied to all poisons found in food. Thus the physical disturbance following the consumption of decomposing meat, cheese or milk due to true toxins or even living bacteria is almost always referred to as ptomain poisoning. (See meat poisoning bacteria.) It is, with our present knowledge of the subject, very difficult if not impossible to distinguish between the two causes.

Pyocyanin $\left(\mathrm{C}_{14} \mathrm{H}_{14} \mathrm{~N}_{2} \mathrm{O}\right)$. This produces the color in blue or blue-green pus, and is said to be a ptomainic pigment. Similar bodies of a basic nature may be found in the intestinal contents as the products of bacterial decomposition. Some of these are poisons which may be absorbed. It is believed that the symptoms designated as coma and tetany may be aseribed to the absorption of substances of this nature.

Sulphuretted hydrogen $\left(\mathrm{H}_{2} \mathrm{~S}\right)$. Sulphuretted hydrogen is a very common product of bacterial action upon albuminous substances or putrescent material containing free sulphates or sulphites. Its presence is determined by pasting a piece of paper moistened with lead acetate inside the neck of the flask containing the culture, closing the mouth with a cotton wool stopper, and over this again an India-rubber cap (black rubber free from sulphur). The paper is colored at first brownish and later black; repeated observation is necessary, as the color sometimes disappears towards the end of the reaction. 
Apparently negative results should not be rashly accepted as conclusive.

Reduction power of bacteria. All bacteria seem to possess the property of converting sulphur into sulphuretted hydrogen in the presence of nascent hydrogen. The following processes depend also in part upon the action of nascent hydrogen. The reduction of blue litmus pigments, methylene blue and indigo to colorless substances frequently occurs in the deeper layers of the culture. The surface layer in contact with the air often shows no change. By agitation the access of air restores the color but at the same time, if acid has been formed, the litmus pigment is turned red. The ability to reduce litmus seems to be more commonly present among the liquefying bacteria.

The reduction of nitrates to nitrites and ammonia. ${ }^{1}$ The first of these properties seems to pertain to a great many bacteria. In a number of bacteria studied by Rubner only one failed to produce nitrite. Certain bacteria produce other substances as the result of their growth. As these are formed during the decomposition of albumins they are present in the digestive tract. The best known of these substances and

${ }^{1}$ The test for nitrites may be made as follows: Two bouillon tubes containing nitrates are inoculated, and, along with two uninoculated tubes, are allowed to remain in the incubator several days; then to the cultures and control test is added a small quantity of colorless iodide of starch solution (thin starch paste containing 0.5 per cent potassium iodide) and a few drops of pure sulphuric acid. The control tubes remain colorless or become gradually slightly blue, while if nitrites are present a dark-blue or brown-red coloration is produced.

The demonstration of ammonia may be made by the addition of Nessler's reagent to culture media free from sugar. In bouillon, if ammonia is present, Nessler's reagent is almost immediately reduced to black mercurous oxide. A strip of paper saturated with the reagent can also be suspended over the bouillon tube, or this can be distilled at a low temperature and with the addition of magnesium oxide and the distillate treated with Nessler's reagent. A yellow to red coloration indicates the presence of ammonia. Controls are necessary. 
those of most value for identifying species are indol, skatol, phenol, and tyrosin. The results of careful investigations have only been recorded relative to the occurrence of indol ${ }^{1}$ and phenol.

Decomposition of fats. Pure fat is not a suitable culture medium for bacteria. The rancidity of butter is brought about (1) as the result of a purely chemical decomposition r,f the butter by the oxygen of the air under the influence of sunlight, and (2) through the formation of lactic acid froin the milk-sugar left in the butter. Fats are, however, attacked by bacteria when mixed with gelatin and used as culture media, with the production of acid.

Putrefaction. By putrefaction is commonly understood the decomposition due to bacteria which results in the production of malodorous substances. Technically putrefaction depends upon the decomposition of complex organic compounds, albuminous substances due largely if not entirely to anaërobic: bacteria.

${ }^{1}$ Demonstration of indol and phenol according to Lehmann and Neuman is as follows: Indol. To a bouillon culture, which should, if possible, be not under eight days old and tree from sugar, is added half its volume of 10 per cent sulphuric acid. If in heating to about $80^{\circ} \mathrm{C}$. a pink or bluish-pink coloration is immediately produced it indicates the presence of both indol and the nitrites, the abovedescribed nitroso-indol reaction requiring the presence of both these substances for its successful operation. This is the so-called "cholera-red reaction" of the cholera spirillum and once thought to be diagnostic of it. As a rule, however, the addition of sulphuric acid alone is not sufficient, and a little nitrite must be added; this may be done later, the culture being first warmed without nitrite, when, if there is no reaction or a doubtful one, 1 to $2 \mathrm{cc}$. of 0.005 per cent solution of sodium nitrite is added until the maximum reaction is obtained. The addition of strong solutions of nitrite colors the acid liquid brownish-yellow and ruins the test. Phenol. The culture in sugar-free bouillon receives the addition of about one-fifth its volume of hydrochloric acid and is then distilled. The distillate gives a flocculent precipitate when treated with bromin water. If carefully neutralized with calcium carbonate, the addition of neutral very dilute chlorid of iron gives a violet color. 
Nitrifying bacteria. According to recent observations, sitrification is produced by a small group of bacteria which are cultivated with difficulty. Hellriegal and Welfarth and many other investigators in this field have succeeded in demenstrating that there are certain bacteria which possess the power of taking nitrogen from the air and making it available for plant food. In this process, there appear to be two distinct species present in the soil, one of which oxidizes ammonia to nitrites and the other converts nitrites to nitrates.

Conversion of nitrous and nitric acids into free oxygen. Barrie and Stulzer seem to be the first who accurately described the nitrate-fermenting bacteria. In their investigation they isolated from horse manure two bacteria, neither of which was alone capable of producing nitrogen from nitrates but which together in the presence of oxygen decomposed nitrates. Later $\mathrm{a}^{\circ}$ second de-nitrifying bacillus was found, $B$. denitrificans $I I$, which would produce nitrogen from nitrates.

Nitrogen combinations. Bacillus radiocola, isolated by Beyerinck, has the power of assimilating nitrogen from the air. This bacillus is found in the small root nodules of various leguminous plants (peas, clover, etc.) and can be obtained in cultures from the nodules on the roots of these plants. Different varieties are said to exist in different species of legumes, each kind of legume apparently having a special kind of bacteria adapted to it, as every variety is not capable of producing nodules in all legumes. There are certain "neutral", varieties, however, existing free in the soil and not adapted to any special legume, and these seem to be able to form nodules in the different species.

Production of acids. Many bacteria are able to form free acids in culture media containing sugar. Acid is formed in ordinary bouillon because of the presence of dextrose which usually occurs in small quantities in the meat. According to Theobald Smith, all anaërobic or facultative anaërobic bacteria form acids from sugar; the strict aërobic species do not, or so slowly that the acid is concealed by the almost simultaneous 
production of alkali. The formation of acid occurs sometimes with and sometimes without the production of gas. Excessive acid production may cause the death of the bacteria from the increase in the acidity of the medium. If after the sugar is consumed not enough acid has been formed to kill the bacteria, or inhibit their multiplication, the acid may be neutralized gradually and in the end become alkaline due to the production of alkalies.

Of the acids produced by the action of bacteria on sugar the most important is lactic acid. There are usually if not always traces of formic acid, acetic acid, proprionic acid and butyric acid. Not infrequently some ethyl-alcohol and aldehyde or acetone are formed. Occasionally no lactic acid is present, and only the other acids are formed. Various bacteria, as yet incompletely studied, seem to possess the property of producing butyric acid and butyl alcohol from carbohydrates. A few bacteria seem to have the power of decomposing cellulose.

Formation of gas from carbohydrates. In the decomposition of sugar by bacteria gas is not formed, so long as pure lactic acid or acetic acid is produced.

$$
\begin{aligned}
& \mathrm{C}_{6} \mathrm{H}_{12} \mathrm{O}_{6}+\left\{\begin{array}{l}
\text { action of } \\
\text { bacteria }
\end{array}=\quad 2 \mathrm{C}_{3} \mathrm{H}_{6} \mathrm{O}_{3} .\right. \\
& \text { Dextrose } \\
& \text { Lactic acid. }
\end{aligned}
$$

A large number of the acid-producing species produce more or less gas consisting chiefly of $\mathrm{CO}_{2}$ and $\mathrm{H}$. Traces of other gases are reported. In sugar free media nitrogen is the only gas produced in visible quantities. Marsh gas is seldom formed by bacteria, with the exception of those decomposing cellulose. Grimbert ${ }^{1}$ ascribed the greater production of $\mathrm{CO}_{2}$ to a greater formation of alcohol and the more abundant production of $\mathrm{H}$ to a greater formation of acid in accordance with the following formulae:

${ }^{1}$ Grimbert. Ann. de l'Inst. Pasteur, Vol. VII (1893) p. 353. 
$\mathrm{C}_{6} \mathrm{H}_{12} \mathrm{O}_{6}+\left\{\begin{array}{l}\text { action } \\ \text { of bac }- \\ \text { teria }\end{array}=\mathrm{C}_{4} \mathrm{H}_{8} \mathrm{O}_{2}+2 \mathrm{CO}_{2}+4 \mathrm{H} \therefore \mathrm{H} / \mathrm{CO}_{2}=50 / 50\right.$ (Glucose) Butyric acid

$\mathrm{C}_{6} \mathrm{H}_{12} \mathrm{O}_{6}+\left\{\begin{array}{l}\text { action } \\ \text { of bac. }=\mathrm{C}_{4} \mathrm{H}_{10} \mathrm{O}+2 \mathrm{CO}_{2}+\mathrm{H}_{2} \mathrm{O} \cdot \therefore \mathrm{H} / \mathrm{CO}_{2}=0 / 100 .\end{array}\right.$ (Butyl alcohol)

The percentage of $\mathrm{CO}_{2}$ and $\mathrm{H}$ in the gases formed by many bacteria especially the colon group vary, but for each species a ratio between $\mathrm{H}$ and $\mathrm{CO}_{2}$ is fairly constant. Smith ${ }^{1}$ considered the gas formation and gas production as important factors in identifying species.

In order to test the production of a gas, a culture medium composed of glucose-agar containing about 1 per cent grapesugar may be used. At the end of one to twelve hours in the incubator (or twenty-four hours room temperature) the agar will contain a greater or less number of gas bubbles. For the determination of the quantity and kind of gas produced by a given microorganism the fermentation tube recommended by Theobald Smith is the best. This is a bent tube, constricted greatly at its lowest portion, supported upon a glass base. The tube is filled with a bouillon containing $1 \%$ glucose (or other sugar) which has been sterilized in the steam sterilizer. It is inoculated with a culture of the organism in question, and observations made:

1. If there is a turbidity produced in the open bulb it indicates the presence of an aërobic species; if this clouding occurs only in the closed arm, while the open bulb remains clear, it is an anaërobic species.

2. The quantity of gas produced daily should be marked on the upright arm; if the tube is graduated a note of it is taken and the percentage calculated on the fourth to sixth day after gas production has ceased.

3. A rough analysis of the gas produced may be made as follows: Having designated by a mark on the tube the

${ }^{1}$ Smith. Wilder Quarter Century Book, 1893, p. 187. 
total quantity. of gas produced, the open bulb is completely filled with a $10 \%$ solution of $\mathrm{NaOH}$, the mouth tightly closed with the thumb, and the mixture thoroughly shaken. After a minute or two all the gas is allowed to rise to the top of the closed arm by inclining and turning the tube, and then, removing the thumb, the volume of gas left after the union of the $\mathrm{NaOH}$ with the $\mathrm{CO}_{2}$ is noted. The remainder is for the greater part nitrogen, hydrogen, and marsh-gas. If it is desired to test for the presence of hydrogen, the open end of the tube is again filled with water, the thumb is again placed over the opening and the gas collected under it. As the thumb is removed a lighted match or gas flame is brought into contact with the gas. If hydrogen is present a slight explosion occurs. Hill has devised a tube for collecting the gas in the top of the closed arm by having a ground glass stopper substituted for the sealed end.

Numerous results have been obtained from the conversion of the fatty acids and their salts into other fatty acids by bacteria. As a rule, the lime salts of lactic, malic, tartaric, and citric acids have been employed, these being converted into various acids by the action of bacteria, such as butyric, proprionic, valerianic, and acetic acids; also succinic acid, ethyl-alcohol, and more rarely, formic acid have been produced. The gases formed were chiefly $\mathrm{CO}_{2}$ and $\mathrm{H}$. Thus Pasteur found that certain anaërobic bacteria convert lactate of lime into butyric acid. 


\section{CHAPTER XII.}

\section{THE RELATION OF BACTERIA TO DISEASE.}

The action of bacteria on living tissues. It has been stated that bacteria are divided into two distinct groups: one saprophytic or those living on dead organic matter, and the other pathogenic or those which live in the tissues of living plants and animals. The bacteria that acquire, if they did not originally possess it, the ability to live and multiply in living tissues produce as a result of their multiplication changes of more or less significance in the tissues of the host. Smith ${ }^{1}$ has pointed out that certain bacteria which have acquired the habit of parasitism in animal tissues elaborate a poisonous toxin which primarily appears to be for the purpose of assisting the bacteria to overcome the resisting forces of the living tissues but which perhaps unintentionally on the part of the organism poisons their host. Bacteria which have already attained a high degree of efficiency of parasitism, such for instance as those of tuberculosis and leprosy, are able to live and to multiply in the tissues in opposition to the resisting forces of their host. In these cases the diseases they produce are due largely to the destruction of the tissues, while in the former case the symptoms and often fatal results are due to the immediate effects of the toxins themselves.

Smith has explained the general phenomenon of infection to be that the tendency of all invading microorganisms in their evolution toward a more highly parasitic state is to act solely on the defensive while securing opportunity for multiplication and escape to another host. By tendency is meant a general slow movement through long periods of time. The following data are in its favor:

1. "The production of diffusible toxins survives parasitism indefinitely, and is readily brought about in cultures.

\footnotetext{
${ }^{1}$ Smith. American Medicine, Vol. VIII (1904) p. 711.
} 
2. "Where toxin-producing bacteria have become adapted to a definite species, as in diphtheria, the toxin itself acts upon a number of different species. In other words, the parasitic relation is far more specialized than the chief pathogenic product.

3. "No strictly invasive bacteria have yet been found producing diffusible toxins which appear to be of any real significance in the disease process.

4. "Those which produce such toxins are not strictly invasive bacteria.

5. "The injury due to invasive bacteria is known to be due to the disintegration of bacteria and the setting free of poisons locked up in the bodies of the microbes.

6. "Pathogenic bacteria manifest less biochemic activity than the related saprophytic forms.

7. "The hemolytic and leukocidic toxins of bacterial filtrates may be due to autolysis of the bacteria. Jordan has shown that hemolysis is at least in part due to a change in the reaction of the culture fluid."

Three possible fates await the invaders. 1. They are largely destroyed within the body. 2. They are excreted, or discharged through various channels. 3. They remain indefinitely in the body after the disease is over to be eventually destroyed or eliminated.

Theoretically, the blood and organs of healthy animals are free from bacteria. It has been found, however, that often solitary streptococei, tubercle bacteria, etc., are present in the healthy body, circulating in the lymph and blood stream or localized in the lymph glands. These may and often do become fixed at points of least resistance from which places they multiply and extend further into the body. Perez found, in a systematic examination of healthy bodies, that the lymph glands only contain bacteria, but here the bacterial flora was very rich. In dead animals, after sixteen to twenty hours at room temperature or after five to six hours in the incubator, bacteria are found in the blood and organs (Trombetta). having for the greater part wandered from the intestine. In 
the most frequent artificial method of infection, i. e., subcutaneous injection, the bacteria are taken up through the lymph-stream, and in part are held back in the lymph-glands, where their virulence is weakened and where they may be killed; but if the organisms are strongly "pathogenic" they resist total destruction, and soon begin to multiply. Joest and his associates have found tubercle bacteria in a large number of apparently healthy lymphatic glands.

Infection. Infection takes place when microorganisms ean remain alive and multiply after they have been introduced into the tissues, or when they become localized on the surface of a mucous membrane, multiply and in so doing elaborate a poisonous toxin which is absorbed and which acts injuriously upon the host.

Specific infection. This refers to the entrance in or upon the body tissues of the organism of one of the specific diseases such as anthrax, glanders or tuberculosis. The bacteria belonging to this group cause rather definite tissue reactions so that the lesions produced by each of them are more or less characteristic. This makes it possible when the disease takes its usual form to predict with considerable certainty the etiological factor.

Wound infection. This term is applied to the entrance of bacteria into wounds and their multiplication there. The wounds may be either accidental or surgical in origin. Many bacteria are able, when introduced into the tissues, to produce local inflammation, leading to suppuration or exudates of different kinds. It is not ordinarily possible to predict from the lesions the species of bacteria causing the disturbance.

Cause of variation in the form of infectious diseases. The infectious diseases vary in their manifestation with the variation in the degree of resistance (immunity) of the individual affected or variation in the virulence of the infecting organism. This condition may be expressed in the following formula: ${ }^{1}$

${ }^{1}$ Smith and Moore, Bulletin No. 6, Bureau of Animal Ind., 1894. 
$D=\frac{V}{R} \quad \begin{aligned} & \text { D equals the form of disease (acute, chronic, } \\ & \text { local, general, etc.), } V \text { equals the virulence of } \\ & \text { the organism and } R \text { equals the resistance of the }\end{aligned}$ host. $\mathrm{D}$ changes as $\mathrm{V}$ or $\mathrm{R}$ varies. The species, race, individual peculiarities, age, life conditions, etc., and channels of infection must also be taken into account in explaining variations.

Determination of pathogenic species. In order to prove that a bacterium is the cause of an infectious disease, Koch insisted that the following conditions should be fulfilled. These are often referred to as Koch's dicta.

1. The organism must be obtained in pure culture from the organs of the infected individual.

2. The organism must be cultivated for a number of generations in artificial media.

3. Healthy animals must be inoculated with a pure culture after passing through several generations and the disease produced.

4. Pure cultures of the organism must be obtained from the lesions in the inoculated animal.

These requirements do not apply to all of the disease producing microorganisms especially the higher bacteria and fungi or to those produced by protozoa.

Distribution of pathogenic bacteria. A few species of pathogenic bacteria seem to exist normally as simple parasites on certain mucosae of the healthy individual such as are found in the upper air passages of most of the domesticated animals. ${ }^{1}$ Others are able to live in the soil, such as the bacilli of tetanus and black leg. The evidence seems to indicate that $B$. tetani has its normal habitat in the intestines of horses, cattle and perhaps other animals. Others appear to exist in infected individuals only. It is necessary to learn the life history of each species of disease producing bacteriaits normal habitat, its means of dissemination, the method of its invasion and its resistance to destructive agents, such as sunlight, drying and disinfectants.

${ }^{1}$ Moore, Bulletin No. 3, Bureau of Animal Ind. 1893. 
Channels of infection. Pathogenic bacteria gain access to the body tissues through a variety of channels, the most common of which are: (1) The digestive tract. In drinking water, as the bacteria of water-borne diseases, and in milk. Other foods frequently serve as vehicles by which infectious agents are carried into the body. Foods chemically changed by the action of bacteria and made unfit for use and which may cause poisoning are to be differentiated from infection. The cause of the disturbance in these cases is either bacterial products or cleavage products due to the splitting up of the food substance into other compounds. (2) The respiratory tract. Pathogenic bacteria may gain entrance through the air passages. There are many who believe that tuberculosis is most frequently contracted in this manner. People become infected with anthrax (wool storers' disease) by inhaling the spores of the anthrax organism. (3) The gencrative organs. This ean happen when the disease is located in the organs of reproduction and the virus is being eliminated. The venereal diseases are illustrations of this means of infection. Other diseases, such as tuberculosis, are rarely transmitted through this channel. (4) Through wounds of the skin and mucous membrane. In addition to the common wound infections $B$. tetani usually gains entrance in this way. Anthrax is transmitted in this manner, especially in the form known as malignant pustule. Nearly if not all infectious diseases can be transmitted through wounds. The bites of insects. This is practically the same as by wounds. As insects play such an important part in the dissemination of many of the important diseases such as Texas fever, the transmission by means of insects is very important and liable not to be included 'with wound infections.

Bacteria escape from the infected body. Pathogenic bacteria are disseminated from the infected individual in various ways.

1. They escape through the excreta when the disease is of such a nature that the bacteria are given off into the channels of excretion. Tubercle bacteria appear in the feces 
when the tuberculous focus is in the wall of the intestine and is discharging into it, or when the animal is swallowing expectoration eoming from the lungs in which there are open tuberculous lesions. In cases of anthrax, the bacteria escape with the excreta after the organisms grow or come through the mucous membranes.

2. They escape with the secretions where the diseased focus is discharging into the ducts of secreting glands.

3. They escape with the pus from abscesses that are discharging externally.

4. When present, they escape with the blood taken by insects.

5. They are disseminated by dogs, foxes, buzzards and other animals that serve as scavengers by eating the flesh and organs of dead infected animals.

Resistance of bacteria to external influences. An important feature in the spread of pathogenic bacteria is their power to live after leaving the infected individual and before. there is opportunity to gain entrance to healthy ones. The prevention of infectious diseases centers itself largely in the control of the channels of dissemination and the channels through which the disease producing bacteria gain entrance to the body.

Bacteria of wound infection. There is a large number of bacteria that are able to produce more or less disturbance by way of exciting an inflammatory process when they are introduced into the animal tissues. As a rule these bacteria are pyogenic micrococei and streptococei but occasionally other species are found. These organisms gain entrance through wounds either accidental or surgical in origin. The character of the lesion does not indicate the species of bacteria producing it, as much depends upon the virulence of the organism and the resistance of the host. The serous and fibrinous exudates and the active spreading inflammations are more liable to be caused by streptococei than by $M$. pyogenes. The occasional isolation of other bacteria that are very active. in the production of spreading inflammations suggests the 
necessity for further study of wound infection bacteria. The lesions produced are to be classified according to the nature of the exudate along the lines laid down in general pathology.

Cattle are less susceptible to wound infection than horses. Swine, dogs and eats are quite resistant. Fowls rarely suffer from ordinary wound infection. While these species are less :susceptible they occasionally become infected so that rigid precautionary measures should always be observed. This renders a knowledge of disinfectants and the adoption of effective methods of applying them of much practical importance. 


\section{CHAPTER XIII.}

\section{THE USE OF ANIMALS IN BACTERIOLOGICAL EXAMINA- TIONS AND INVESTIGATIONS.}

Experimental animals. In the laboratory for the study of infectious diseases experimental animals constitute a very important part of the essential reagents. By experimental animals is meant in this connection guinea pigs, rabbits, white, field and house mice, and pigeons. Other species, especially the carnivora, are sometimes employed. The use of these animals is rendered imperative because there are at present no other means for determining certain facts relative to the disease producing power of microorganisms other than the actual test of the virus upon the animal body. It is important to keep in mind, however, that because a certain species of bacteria proves fatal to a guinea pig, it can not be assumed that it is pathogenic for other species of animals. The conclusion can not be drawn that because one species of animals succumbs to a given organism this organism will prove fatal to other species of animals. Many errors relative to the identity of certain diseases affecting man and the lower animals have been made because the results of the inoculation of a given animal with the bacteria from different sources have given apparently identical results. This is illustrated in the case of human and bovine tuberculosis in which guinea pigs being equally susceptible to the virus from both sources led the earlier workers in bacteriology to assume that tubercle bacteria from cases of tuberculosis in man and in cattle were identical. Animals are used in bacteriological work for a large number of purposes. Some of the purposes for which their use is imperative are appended.

1. As a culture medium - a form of plate culture where the specific organism will not grow outside of the living body or when it is impossible to isolate the organism in an artificial medium. Again, when certain pathogenic bacteria, such as 
those of tetanus, tuberculosis or glanders, are present in small numbers and in contaminated material, it is necessary to inoculate them into the susceptible guinea pig from whose tissues pure eultures may be procured after the disease has developed. By this means septicemia hemorrhagica and the bacillus of hog cholera, and in fact nearly all of the pathogenic bacteria affecting animals, may be obtained in pure culture by this method where it would be quite impossible to succeed by other means.

2. To determine the pathogenesis and virulence of bacteria. In the investigation of animal diseases, it frequently happens that pure cultures of some microorganism may be procured from certain diseased processes and because of its association with such lesions may be suspected of standing in a causal relation to the disease. In order to determine whether such relation actually exists, it is necessary to inoculate these organisms into animals. It sometimes happens that one procures a culture of some species of bacteria, such as Bacterium septicemiae hemorrhagicae, but does not know whether or not it is virulent. While it is known that this species is pathogenic one can not tell without actual inoculation into susceptible animals whether or not the organisms in this particular culture are virulent. In order, therefore, to determine whether a given organism is pathogenic or not and to determine its degree of virulence it is necessary to inoculate animals.

3. To modify the virulence. In the investigation of animal diseases it is sometimes necessary to modify the virulence of pathogenic organisms. This can be done in many instances by a continuous series of inoculations. Thus an organism like Bacterium septicemiae hemorrhagicae remaining for a certain length of time in the tissues of a partially immunized animal becomes attenuated. In these cases, especially with the septicemia hemorrhagica bacteria, it is possible to restore the original virulence by passing the organism through a series of susceptible animals such as rabbits.

4. To differentiate species. Animals are sometimes used, and necessarily so, to differentiate between species or varieties 
of bacteria which are quite distinct but which in their morphological and cultural characters are very similar, such as is found in anthrax and anthrax-like bacteria. By injecting these into the proper animals it is possible to distinguish the one from the other by means of the pathogenesis.

5. To produce antitoxin. To produce antitoxin, bactericidal or agglutinating sera, animals are necessary. In the production of the antitoxins used in medicine the larger animals, of course, are employed; but for much of the experimental work smaller animals are used.

6. To test the antitoxic strength of sera. The experimental animals, largely guinea pigs, are the reagents for testing the strength of toxins and the therapeutic value of the antitoxins. They are also used for testing tuberculin and mallein.

7. For purposes of demonstration and in teaching. It is necessary in demonstrating the various properties of bacteria to use animals for purpose of instruction.

While it is unfortunate that it is necessary to employ animals in bacteriological investigation, there is at the present time no other means by which the very important results for both man and dumb ereation can be obtained.

Methods of inoculating animals. The methods of inoculating animals vary according to the different facts about which definite knowledge is desired.

1. Cutaneous. This consists in rubbing the culture or the substance containing the virus into the abraded skin.

2. Subcutaneous. The bacteria are injected by means of a hypodermic needle or by placing them in a pocket in the connective tissue under the skin. When cultures are used they are either injected under the skin with a hypodermic syringe or placed under the skin by means of the platinum loop. When infected material, such as glandered tissue, is used it may be crushed, ground up in sterile salt solution or bouillon and injected with a hypodermic syringe or a piece of the tissue may be placed under the skin and held there by means of a suture.

3. Intravenous. The bacteria are injected by means of a hypodermic needle into a vein. In case rabbits are employed 
it is usually easy to pass a needle directly into one of the superficial ear veins. With large animals the jugular vein is selected.

4. Intraorbital. Into the anterior chamber of the eye by means of a small hypodermic needle.

5. Into the body cavities. The peritoneal and less often the pleural cavities are used for bacterial injection. The hypodermic needle is usually employed, less often a glass tube drawn out to a fine point. The needle or the pointed glass tube is gently pushed through the abdominal wall, moved about to ensure its freedom from the intestines, and the fluid injected. The hypodermic needle should be inserted perpendicular to the abdominal wall.

6. By inhalation. This method consists in compelling animals to inhale infected spray or dust.

7. Into the trachea. This consists in inoculating either directly into the lumen of the trachea by means of a hypodermic needle or by making an incision into the trachea and then introducing the material.

8. By ingestion. This consists in feeding animals the infected material.

9. Subdural. This consists in injecting the material beneath the dura. In most instances it is necessary to trephine the skull, removing the button of bone, or to bore a hole through the skull by means of a small sharp instrument such as an awl, when by use of the needle the substance may be injected. With rabbits it is possible to introduce a hypodermic needle back of the ear through the skull into the dura without trephining. This method is used most largely in the inoculation for rabies.

10. Intramuscular. This is the injection of the suspected material or culture into the muscle.

In making inoculations it is important that the instruments be sterilized and the field of operation properly disinfected.

The use of anesthetics. If an anesthetic is given ether is safer for small animals than chloroform. Local anes- 
thetics can be used in many cases. An anesthetic should be given when the suffering from the operation is severe, or greater than the disagreeable effects of the ether, or when the operation is difficult to perform.

Restraining animals for inoculation. In making inoculations guinea pigs are held, as a rule, by an assistant who holds in one hand the forelegs and in the other the hind legs. The animal should rest flatly upon the table in order to avoid injury to the back from wrenching. Rabbits can be held in the same manner or it may be better to avoid injury by using some holder.

Mice, which are usually inoculated subcutaneously in the body at the root of the tail, may be placed in a mouse holder. A convenient substitute is to grasp the tail in a pair of laboratory tongs, and then, while allowing it to hang head downward in a jar, a glass plate is pushed across the top until only space for its tail and rump is left. In this position it is easy to make the subcutaneous injection with the hypodermic needle.

All these methods must be carried out with the greatest eare as to cleanliness. The hair should be clipped and the skin at the point of injection disinfected. The operator must be careful not to infect himself or his surroundings. After the inoculations are made the animals should be given the best of care, unless, for special purposes, we want to study them under unusual conditions. For food, rabbits and guinea pigs require only carrots and hay. Other food may be given but green or fresh vegetables must accompany grain or dry hay. The autopsy should be made at the earliest moment possible after death before post mortem changes occur. If delay is unavoidable, the animals should be placed immediately after death in a cold place. In making cultures from the dead bodies the greatest care should be taken to avoid contamination. The skin should be moistened with a disinfectant such as a 5 per cent solution of carbolic acid. All instruments are sterilized by boiling in water or a 3 per cent soda solution for five minutes. Change of knives, scissors: 
and forceps should be made as frequently as they become infected. When organs are examined the portions of the surfase through which an incision is to be made must be sterilized, if there is danger that the surrounding cavity is infected, by searing it with a spatula which has been heated to a white heat. Tissues if removed from the body should be placed immediately under cover to avoid contamination. Sterile deep Petri plates are useful for this purpose.

When it is necessary to transport tissues some distance they should be wrapped in cloths moistened in mercuric bichloride or placed in sterile retainers and sent to the point of destination as soon as possible. They should also be kept cool by packing the vessel containing them in a pail of ice.

Animals rarely show the same gross lesions as man when both suffer from the same disease. The cell changes are similar, and, also, so far as we can test them, the curative or immunizing effects of protective serums when administered in proper doses.

Animal inoculations for purposes of diagnosis. For simple diagnostic work with animal tests the guinea pig and rabbit are most usually employed. Other species, however, are not excluded. In-preparing the animal for inoculation the hair should be removed over the area of operation by the use of scissors, and the skin washed and disinfected. A $5 \%$ solution of carbolic acid or a solution of corrosive sublimate, 1 to 1000 , may be used. The incision should be made with a sharp knife. Liquid material is usually injected with a hypodermic syringe. An anesthetic should be given whenever the pain inflicted is to be long continued or excessively 'severe. The place of inoculation should be chosen where a local swelling, infiltration of tissue, or abscess would not interfere with the animal's locomotion. 
SPECIFIC DISEASES FOR WHICH ANIMAL INOCULATIONS ARE MOST COMMONLY RESORTED TO FOR DIAGNOSTIC PURPOSES.

Tuberculosis. Guinea pigs are preferable, although rabbits may be used in cases of bovine tuberculosis. With tuberculous tissues either one of two methods may be employed. (1) A sinall piece (about the size of a pea or bean) of the tissue may be inserted under the skin by first making an incision with a sharp sealpel through the skin and superficial fascia and then with a pair of fine forceps inserting the bit of tissue well under the skin and closing the opening with one or more sutures. (2) The tissue may be crushed in a mortar and thoroughly ground with a few eubic centimeters of sterile water or bouillon and then injected with a hypodermic syringe. Suspected milk may be injected directly into the abdominal cavity. If the material contained living tubercle, the death of the animal follows in from three weeks to four months. Usually the lymphatic glands of the groin and axilla are enlarged if the inoculation was subcutaneous. If a guinea pig is used, the liver, spleen, lungs and kidneys are liable, in the order named, to be affected; if a rabbit, the lungs are often the first of the visceral organs to be attacked. Rabbits should not be used if the material to be inoculated is of human origin.

Glanders. Male guinea pigs should be used. The material usually consists of the nasal discharge from the suspected glandered horse, bits of scrapings from the ulcers, or pieces of affected tissue. The method to be followed is precisely the same as with the subcutaneous injection of tuberculous material. In these cases there is liable to be a local swelling and abscess. The first indication of glanders noticed is usually orchitis. The lymphatic glands in the groin are also enlarged. After the orchitis becomes well marked the guinea pig may be chloroformed and examined. Pure cultures of the specific organism ean be obtained in most cases from the suppurating focus in the testicle. The spleen is 
usually enlarged and sprinkled with grayish nodules. Other organs may be involved.

Rabies. When inoculations are necessary to make a diagnosis, a rabbit, guinea pig or dog is injected beneath the dura with a bit of the brain or spinal cord of the suspected rabid animal. The guinea pig is reported by some to respond more promptly, but in our experience the subdural inoculation of rabbits has been the most reliable. The subdural method is, briefly stated, as follows:

The brain of the suspected animal is removed with aseptic precautions as soon as possible after death. A small piece of the brain or spinal cord is placed in a sterile mortar and thoroughly ground with a few cubic centimeters of sterilized water or bouillon. This forms the suspension to be injected. The hands of the operator and all instruments are carefully disinfected. The rabbit is etherized, the hair clipped from the head between the eyes and ears, and the skin thoroughly washed and disinfected. A longitudinal incision is then made, the skin and subcutaneous tissue held back by means of a tenaculum, a crucial incision is made in the periosteum on one side of the median line to avoid hemorrhage from the longitudinal sinus, and the four corners of the periosteum reflected or pushed back. By the aid of a trephine a small button of bone is easily removed, leaving the dura mater exposed. With a hypodermic syringe a drop or more of the rabid brain suspension is injected beneath the dura, the periosteum is replaced, the skin carefully sutured and disinfected, and the rabbit returned to its cage. As soon as the influence of the anesthetic has passed off, the rabbit shows no appearance of discomfort. If the operation is performed in the forenoon, the animal partakes of its evening meal with the usual relish. The inoculation wound heals rapidly and the rabbit exhibits every appearance of being in perfect health until the beginning of the specific symptoms, which occurs ordinarily in from 12 to 30 days, usually in 17 to 20 days, after the inoculation. Occasionally the symptoms appear earlier than 
15 days and in some cases the rabbits are not attacked for from 1 to 3 months.

The symptoms following the inoculations are quite uniform, the only pronounced difference being in the length of time the rabbits live after the initial manifestation of the disease. The fact should be clearly stated that rabbits do not ordinarily become furious. In some instances they are somewhat nervous for a day or two preceding the paralysis. There appears to be a marked hyperæsthesia. Usually the first indieation of the disease is a partial paralysis of one or both hind limbs. This gradually advances until the rabbits are completely prostrated, the only evidence of life being a slight respiratory movement. The head occupies different positions. In some it is drawn back as in tetanus; in others it is drawn down with the nose near the forelegs; and in still others it is extended as if the animal were sleeping. The period of this complete paralysis varies from a few hours to a few days, but ordinarily it does not exceed 24 hours. Although the animals are unable to move voluntarily, there is usually a reflex action of the limbs until a very short time before death.

During the period of incubation the temperature of the rabbits remains normal. As the time approaches for the first symptoms to appear there has been in the animals tested an elevation of temperature of from 1 to 2 degrees, which continued for a variable length of time, but rarely longer than 2 days. This is followed by a gradual or usually a more rapid drop to the subnormal, which continues to the end.

Swine plague. Rabbits are most susceptible. Inoculate subcutaneously with a bit of the pneumonic tissue, either in a solid piece or in a suspension in bouillon hypodermically. In case of virulent swine-plague bacteria, the rabbit will die in from 16 to 36 hours from septicemia. Pure cultures can be obtained from the blood, spleen, liver, or kidney. Stained cover-glass preparations from these organs show a greater or less number of polar-stained bacteria.

In case of a more attenuated virus the rabbit will live from a few days to several weeks and possibly months. In 
these cases there are usually marked local cell infiltrations, with inflammation of one or more of the serous membranes and possibly metastatic abscesses.

Hog cholera. Experimental animals are not susceptible to the filterable virus of hog cholera. It is often necessary to inoculate a pig with the blood of the hog suspected of being affected with hog cholera. A pig inoculated with from 1 to 2 ce. of blood develops the disease in about ten days. The disease of hogs due to Bacillus suipestifer can be diagnosed by inoculating rabbits subcutaneously with a small quantity of crushed spleen or liver or with 0.1 to 0.2 ce. of a pure bouillon culture of the organism. The rabbit will die in from 5 to 10 days with a much enlarged spleen and frequently with areas of coagulation necrosis in the liver. With attenuated organisms the lesions are modified and the time extended.

Anthrax. Mice or guinea pigs should be used. They are inoculated subcutaneously. They die of septicemia usually in from 24 to 72 hours. It is not always necessary to resort to animal inoculation with this disease. Occasionally, however, it is a very necessary procedure in making a positive diagnosis.

Diphtheria. Guinea pigs are nearly always used. In certain rare cases of mixed cultures taken directly from the suspected throat it is desirable to inoculate one or more guinea pigs to determine whether the suspected organism present is a virulent Klebs-Loeffler bacterium. In these cases a suspension of the growth on the serum may be injected. The guinea pig dies usually in from 36 to 80 hours. The lesions produced have been described by Park as follows:

"At the seat of inoculation there is a grayish focus surrounded by an area of congestion; the subcutaneous tissues for some distance around are odematous; the adjacent lymph nodes are swollen; and the serous cavities, especially the pleural and the pericardial, frequently contain an excess of fluid, usually clear, but at times turbid; the lungs are generally congested. In the organs are found numerous smaller and larger masses of necrotic cells, which are permeated by 
leucocytes. The heart and voluntary muscle fibres usually show degenerative changes. Occasionally there is fatty degeneration of the liver and kidneys. The number of leucocytes in the blood is increased. From the area surrounding the point of inoculation, virulent bacilli may be obtained, but in the internal organs they are only occasionally found, unless an enormous number of bacilli have been injected. Paralysis, commencing usually in the posterior extremities, and then gradually extending to other portions of the body and causing death by paralysis of the heart or respiratory organs, is also produced in many eases in which the inoculated animals do not succumb to a too rapid intoxication." 


\section{CHAPTER XIV.}

\section{THE BACTERIOLOGY OF WATER AND MILK.}

Bacteria in water. Water in streams and wells receiving surface drainage contains a variable number of bacteria. When water comes from great depths in the earth it usually is bacteria free. Water in springs and streams in an uninhabited country contains few bacteria while that in wells and streams in thickly inhabited districts is often teeming with microorganisms. A few species are said to live (multiply) in pure spring water which seems to be their normal habitat. The bacteria found in water may be divided arbitrarily according to their source into three classes.

1. Water bacteria. These include bacteria having their normal habitat in water.

2. Soil bacteria. These include the bacteria that are washed into the water from the soil.

3. Fecal bacteria. These include the bacteria that have their normal habitat in the intestine and which gain access to water from the excreta of man and beast.

Each of these groups of bacteria is characterized by certain species. The "water bacteria" are of no pathogenic significance. They will not multiply at the usual incubator temperature. The "soil bacteria" contain a large number of organisms which may be found, especially after heavy rains, in stream and well water. The "fecal group" of bacteria is characterized by $B$. coli and B. lactis aerogenes. In addition, water may contain important pathogenic species such as Bact. anthracis when animals that have died of that disease are left near the banks of streams or have been thrown into them. Frankland ${ }^{1}$ enumerates about 225 species of bacteria that have been isolated from water.

Jordan ${ }^{2}$ divided the bacteria isolated from surface water

${ }^{1}$ Frankland. Microorganisms in water. London, 1894.

${ }^{2}$ Jordan. The Jour. of Hygiene, Vol. III (1903) p. 1. 
into seventeen groups each dominated by a certain species. He does not believe it practicable to extend water analyses beyond the identifying of the group in which the organism belongs and the identification of the important and well defined species. For these organisms the methods described in this volume are sufficient but for the differentiation of many water bacteria it is necessary to employ special media and methods. The groups into which water bacteria may be divided as suggested by Jordan are as follows:

Group I B. coli communis.

Group II B. lactis aerogenes.

Group III B. proteus.

Group IV $B$. enteritidis.

Group V B. fluorescens liquefaciens.

Group VI B. fluorescens non-liquefaciens.

Group VII B. subtilis.

Group VIII Non-gas forming, non-fluorescent, non-sporeforming bacilli which liquefy gelatin and acidify milk.

Group IX Similar to Group VIII, save that the mill is rendered alkaline.

Group X Similar to Group VIII, save that gelatin is not liquefied.

Group XI Similar to Group IX, save that gelatin is not liquefied.

Group XII Similar to Group XI, save that the reaction of milk is not altered.

Group XIII Chromogenic bacilli not included in the above groups.

Group XIV Chromogenic staphylococei.

Group XV Non-chromogenic staphylococei.

Group XVI Sarcinae.

Group XVII Streptococci.

Pure water is not a favorable medium for the multiplication of bacteria unless it be those in class I. The individuals of most species die quite rapidly in water. However, a few persist for a long time. 
Objects of water analysis. Water is analyzed bacteriologically to determine: (1) the number of bacteria per cubic centimeter and (2) the kinds of bacteria. In addition to the soil, water and fecal organisms certain pathogenic bacteria may be present. These are largely the bacteria that produce intestinal disorders, the most common of which are the bacillus of typhoid fever, the microspira of Asiatic cholera and Pseudomonas pyocyaneus. Sometimes those of other diseases such as anthrax may gain access to water. Water is often the channel through which many pathogenic bacteria gain entrance to the human and animal body.

Methods of water analysis. In making water analyses great care must be taken in carrying out the details in: (1) collecting the samples and (2) the water must be collected in clean, sterile vessels such as sterilized bottles. Various devices are used for collecting it at different levels. The culture media to be used and the time for observing cultures before counting colonies are important. The media and methods vary according to the conditions and specific purpose of the examination.

Chamot and Redfield ${ }^{3}$ recommend the following respecting cultures, temperatures and time for examination. They give many other media for the determination of special properties and identification of species.

"Gelatin plates at $20^{\circ} \mathrm{C}$. in air. At least two with 1 ce. each; two with $0.1 \mathrm{cc}$. each and if the water is believed to be very bad, two with 0.01 ec. each."

"Agar plates kept at $20^{\circ} \mathrm{C}$. At least two with 1 ce. each, two with 0.1 ce. each.

"Agar plates kept at $38^{\circ} \mathrm{C}$. Two with 1 ce. each; two with 0.1 ec. each.

"Agar lactose litmus, incubated at $38^{\circ} \mathrm{C}$. Two tubes with 1 ce. each; two tubes with 0.1 ce. each. This consists in adding from 3 to 5 drops of sterile litmus solution to the warm liquefied lactose agar just before pouring into the Petri dishes.

${ }^{3}$ Chamot and Redfield. Analysis of Water for Household and Municipal Purposes. Ithaca, 1911. 
(Agar esculin bile salt at $38^{\circ} \mathrm{C}$. Two with 1 ce. each; one with $10 \mathrm{cc}$. in large dish.)

Fermentation tubes.

"Dextrose-peptone. Ten tubes with 1 ce. each; five tubes with 0.1 ce. each. A $2 \%$ dextrose solution in water, $3 \%$ white peptone (Witte) and $0.5 \%$ potassium chloride with a reaction 1.5 and 1.0 per cent.

"Lactose-peptone. Ten tubes with 1 cc. each; five tubes with 0.1 ce. each. Same as dextrose peptone by substituting lactose for dextrose.

"Dextrose-peptone to which five drops of 5 per cent phenol are added. ${ }^{1}$ Ten with 1 ec. each, five with 2 ec. each. Incubate at $42^{\circ} \mathrm{C}$.

"The colonies on agar plates incubated at $37^{\circ} \mathrm{C}$. to $38^{\circ} \mathrm{C}$. should be counted at the end of twenty-four hours, and again after forty-eight hours.

"The colonies on gelatin and agar plates at $20^{\circ} \mathrm{C}$. should be counted after forty-eight hours' standing and if possible again after seventy-two hours. When the number of colonies developing upon a plate are few it is the best plan to allow the plates to remain as long as possible in the incubator before making the final counts in order that slow growing species may become apparent and that all the species present may develop" sufficiently to exhibit their characteristic appearances."

The methods of making culture media and cultures in water analyses recommended by the Committee on Water Analysis of the Laboratory Section, American Public Health Association, $1905^{4}$ are considered as standard. They are generally followed in work of this kind.

The interpretation of the bacterial findings. The species common to water and soil are not known to be possessed of any direct sanitary significance. The fecal bacteria are represented largely by $B$. coli, $B$. aerogenes and streptococci. The presence of these species shows that the conditions are favor-

${ }^{1}$ Method of Vincent. Macé. Traitré de Bacteriologie, edition, p. 711 .

"Supplement of the Journal of Infectious Diseases, 1905, p. 1. 
able for infection, if individuals suffering with intestinal disease are present on the water shed. There seems to be no rule that can be followed for interpreting the findings generally, as each case must be determined on its merits.

In water analysis it is often necessary to determine the presence or absence of organisms detrimental to the water other than the cause of specific diseases. The veterinarian is interested in water analysis largely from the "disease producing" point of view and consequently he is most anxious about the presence of pathogenic bacteria or those indicating dangerous contamination. The work of Whipple is quite helpful in determining the higher forms of life often found in water.

Fungi and animal parasites. In addition to disease producing bacteria, many fungi and animal parasites gain entrance to the animal body through water.

Purification of water. Water is purified by (1) sedimentation, (2) filtration,-(a) sand filters, (b) mechanical filters,-and (3) by filtering through ordinary filters to remove the dirt and boiling to destroy the bacteria.

\section{BACTERIOLOGÝ OF MILK.}

Bacteria in milk. It was formerly supposed that freshly drawn milk was bacteria free. Bacteriological examinations have proved, however, that it is practically impossible to obtain milk free from bacteria. Leopold Schultz ${ }^{1}$ was among the first who carefully eonducted experiments relative to bacteria in freshly drawn milk. He found that the fore-milk usually contained numerous bacteria (97,200 per ce.) while that taken near the middle of the milking contained many less $(9,000$ per ce. $)$ and milk drawn at the close contained comparatively few (500 to 600 per ce.). Gernhardt ${ }^{2}$ investigated this subject but obtained quite different results, in that he found that the milk drawn at the close of milking often contained enormous numbers of bacteria $(7,000,000)$. He

${ }^{1}$ Schultz. Archiv f. Hygiene, Bd. XIV (1892).

${ }^{2}$ Gernhardt. Inaug. Dis. Jurjew, 1893. 
explained the large number on the supposition that clumps or colonies of bacteria had been washed from the teat where they had multiplied into the milk. Rotch ${ }^{3}$ presented a paper giving the results of experiments to determine the number of bacteria in freshly drawn milk. The fore-milk and the milk drawn near the close of milking were taken, and also the milk drawn through a sterile cannula passed into the milk duct nearly if not quite through the teat. His findings were that practically sterile milk could be obtained by rejecting the first or fore-milk from each teat. Moore ${ }^{4}$ examined milk from each quarter of the udder of nine cows. He found from a very few (0 to 10$)$ bacteria in a cubic centimeter to 8,400 per cc. in the first milk and as many as 2,400 in the last. Plate cultures made from the last milk from several quarters remained sterile. In all, 20 apparently different species were isolated.

Source of bacteria in milk. Bacteria gain entrance to milk from two sources. (1) From the ducts of the teat and udder. The bacteria that become localized in the udder itself are usually restricted to micrococci and occasionally streptococci. ${ }^{5}$ Rarely other bacteria become temporarily localized in the udder.* The species vary according to the environment and care of the cows. In case of disease affecting the general system or localized in the udder such as anthrax and tuberculosis the bacteria causing them may also appear in the milk.

${ }^{3}$ Rotch. Trans. Asso. of American Phys., Vol. IX (1894) p. 185.

${ }^{4}$ Moore. Annual report B. A. I., U. S. Dept. Agric., 1895-6, p. 261.

${ }^{5}$ Moore. Trans. of the Society for the promotion of agricultural sciences, 1899 , p. 110.

Reed and Ward. Am. Medicine, Vol. VII (1903) p. 256.

Ward. Cornell Univ. Agric. Exp. Station, Bulletin No. 178, 1900 .

* Moore and Ward found a bacillus belonging to the colon group that had invaded the udders of a large percentage of the cows in a dairy. This bacillus caused a bad taint to the cheese made from the milk. The udders were washed with a disinfectant and the stable thoroughly cleansed and disinfected at short intervals. After some months the bacillus was eliminated from all the udders. (Bulletin No. 158 Cornell Univ. Exp. Station, 1899.) 
(2) From external contamination. The more common of these sources are the dirt that falls from the skin of the flank and udder into the pail during the process of milking; the dirt from the hands and clothing of the milker; improperly cleansed milk utensils; and the dust and dirt that fall into the milking utensils before and after milking or carried by flies and other insects.

Kinds of bacteria in milk. The bacteria present in milk are (1) Non-pathogenic bacteria. These are the usual organisms that come from the udder and those that are brought in with the dirt from without. They vary in genera and species according to the conditions.

(2) Pathogenic organisms. These are disease producing microbes that get into the milk direct from the diseased udder; such as the bacterium of tuberculosis, anthrax, and the virus of foot and mouth disease, and secondly those that are introduced from without such as the organisms of diphtheria and typhoid fever. These latter gain access to the milk either from the hands and clothing of those suffering from the disease or having the care of the sick, or with infected water used in washing the utensils or by means of flies. The attendants may be "carriers" and consequently responsible for the infection of the milk.*

Number of bacteria in milk. The methods of determining the number of bacteria in milk are similar to those used in other quantitative analyses. Ordinarily the milk is diluted with sterile salt solution from 1 to 10 to 1 to 1000 or higher. From these dilutions plate cultures are made with definite quantities. The media commonly used for this work are gelatin and agar.

The number of bacteria in mixed milk varies from a few hundred to many millions per cubic centimeter. The variation

* The bacilli "carriers" or people who have recovered from the acute attack of the disease but who still harbor the organisms present a most difficult problem for the milk and dairy inspectors to solve. It is believed by some sanitarians that to reduce the danger of infection from this origin all market milk should be pasteurized. 
in number depends largely upon the care of the cows and the precautions taken in handling the milk. Certified milk sold in New York City must not contain over 30,000 bacteria per cubic centimeter. Park ${ }^{6}$ states that the milk dipped and sold at the groceries sometimes contained as high as $80,000,000$ bacteria per cubic centimeter.

Species of bacteria in milk. Conn, Esten and Stocking ${ }^{7}$ in their classification and description of dairy bacteria have given 145 species that have been isolated from milk. They

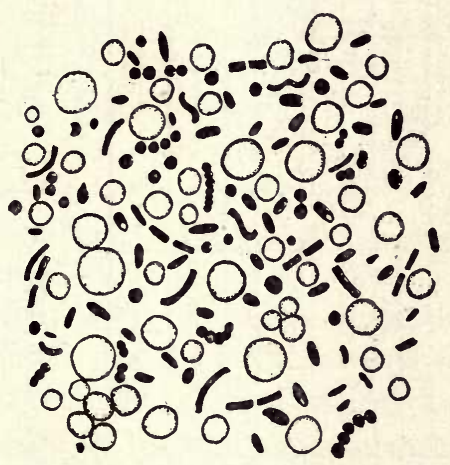

Fig. 43. Cover-glass preparation of market milk. The light bodies are fat globules and the dark ones are various bacteria.

point out, as did Jordan for water bacteria, the difficulty of identifying species. Several of those they describe are considered type species possessing a greater or less number of varieties. Thus Bact. lactis acidi, the common cause of souring of milk, seems to have many varieties.

Milk sometimes becomes very bitter owing to the products of certain bacteria multiplying in it. Weigmann, Conn and Freudenreich have isolated and studied a number of such species. A "blue" color is a peculiar condition of milk caused by a single species of bacteria (Pseudomonas syncyanea), although it possesses a number of varieties. Slimy or ropy milk is another of the many undesirable conditions brought about

${ }^{6}$ Park. The New York University Bulletin of the Medical Science, Vol. I (1891) p. 1.

${ }^{7}$ Conn, Esten and Stocking. Report of the Storrs (Connecticut) Agricultural Experiment Station, 1906. 


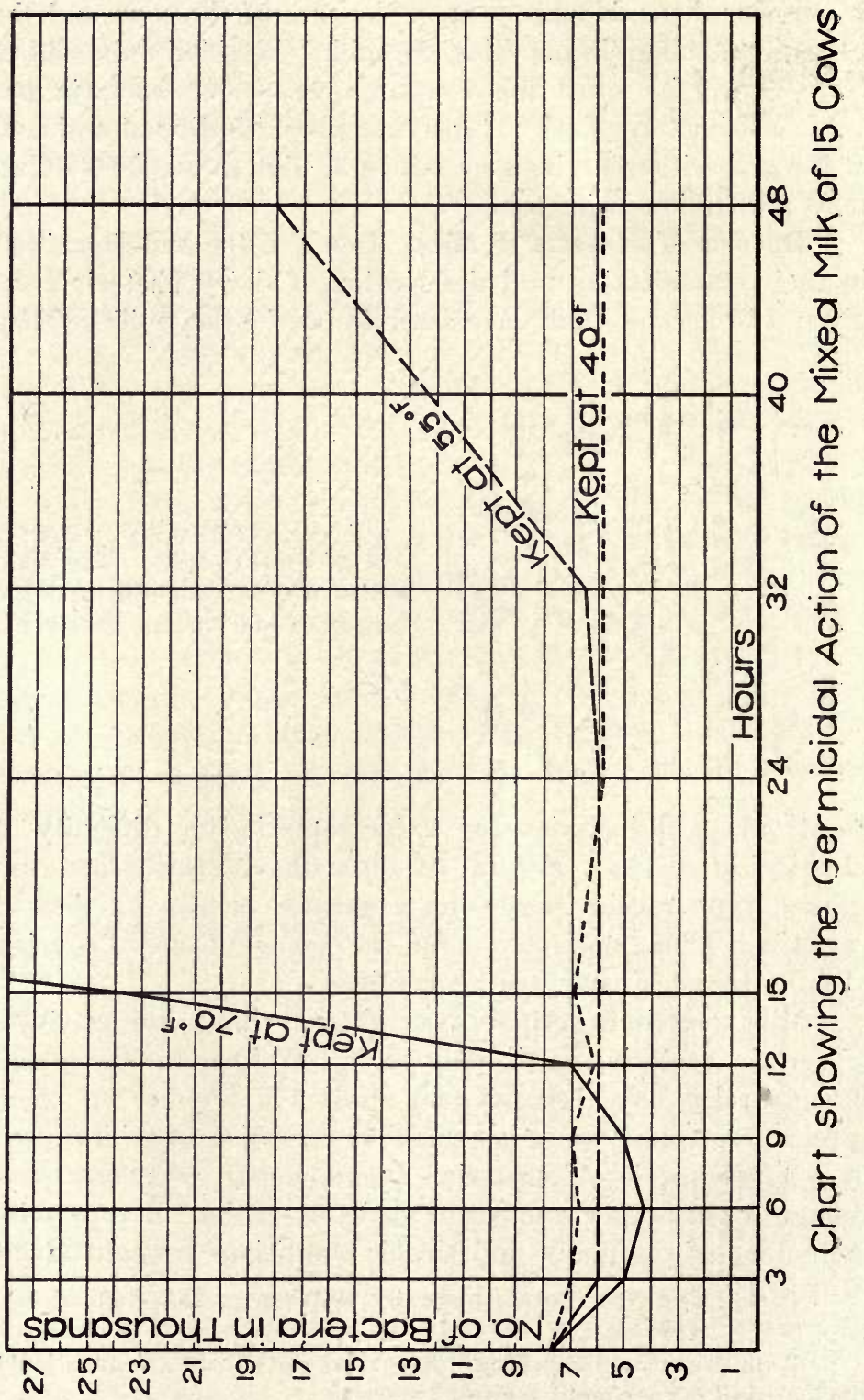


by microorganisms. The cause of this particular trouble seems to be due to one species, Bacillus subviscorum, described by Adametz. The organism causing this trouble exists, according to the investigations of Adametz $^{8}$ and Ward, ${ }^{9}$ in water from which it accidentally, or through carelessness in cleansing the milk pails and cans, gains entrance to the milk. To eliminate the trouble which it causes it is simply necessary to actually scald the pails, strainers and cans used in retaining and handling the milk.

Hunziker ${ }^{10}$ made a careful study of the germicidal action of milk (1) from individual cows, (2) mixed milk of the entịre dairy, and (3) the influence of different temperatures upon this action. A sample of the milk from each cow was divided into three parts, placed in sterile flasks, one of which was kept at each of the temperatures of $40^{\circ}, 55^{\circ}$ and $70^{\circ} \mathrm{F}$., respectively. Agar plate cultures were made immediately after milking, and at intervals of three hours until 48 hours had elapsed. Fifteen cows were thus tested. The first two, May and Ida, were milked in the ordinary way into separate pails, no special precautions being taken to prevent contamination from without. The samples of the milk from the other cows were obtained under rigid precautions against particles of dust or other contaminations. The teats, the udder and the parts immediately surrounding the latter were carefully washed with a 1-1000 solution of corrosive sublimate and then dried with a clean towel. From the moistened udders the milk was drawn into sterile flasks, which were held in a nearly horizontal position to prevent microorganisms from falling into them. About the same quantity of milk was taken from each teat. A tabulated summary of this experiment is appended.

${ }^{8}$ Landwirthschaftliche Jahrbücher, 1891, p. 185. Earlier and less complete reference to this organism are to be found in the Milch Zeitung, 1889, No. 48, p. 941. 1899.

${ }^{9}$ Ward. Bulletin No. 165, Cornell Univ. Agric. Exp. Station,

${ }^{10}$ Hunziker. Bulletin No. 197, Cornell Univ. Agric. Exp. Station, 1901. 
I. NUMBER OF BACTERIA IN I CC. OF MILK KEPT AT $40^{\circ} \mathrm{F}$.

\begin{tabular}{|c|c|c|c|c|c|c|c|c|c|}
\hline $\begin{array}{c}\text { NAME OF } \\
\text { COW. }\end{array}$ & $\begin{array}{c}\text { Cow } \\
\text { warm. }\end{array}$ & $\begin{array}{c}\text { After } \\
3 \\
\text { hours. }\end{array}$ & $\begin{array}{c}\text { After } \\
6 \\
\text { hours. }\end{array}$ & $\begin{array}{c}\text { After } \\
9 \\
\text { hours. }\end{array}$ & $\begin{array}{l}\text { After } \\
12 \\
\text { hours }\end{array}$ & $\begin{array}{c}\text { After } \\
\text { I5 } \\
\text { hours. }\end{array}$ & $\begin{array}{c}\text { After } \\
24 \\
\text { hours. }\end{array}$ & $\begin{array}{c}\text { After } \\
3^{32} \\
\text { hours. }\end{array}$ & $\begin{array}{c}\text { After } \\
48 \\
\text { hours. }\end{array}$ \\
\hline May_-_._- & 1,212 & $1,08 c$ & $I, 220$ & 1,040 & 1,020 & I, 120 & 1,360 & 1,040 & 400 \\
\hline Ida & 35,560 & 35,600 & 27,040 & 33,900 & 27,040 & 32,960 & 28,820 & 28,540 & 26,320 \\
\hline May..... & 440 & 400 & 340 & 340 & 320 & 220 & 120 & 100 & 240 \\
\hline Ida & 5,120 & 4,400 & 4,260 & 3,620 & 3,700 & 3,900 & 4,000 & $3,9 c 0$ & 3,840 \\
\hline Hilda.....-.- & 1,715 & 2,100 & 2,140 & 2,380 & 2,510 & 2,060 & 2,090 & 1,720 & 1,920 \\
\hline Peach ... & 2,330 & 2,500 & 2,270 & 2,400 & 2,320 & 2,300 & 1,880 & 1,880 & 1,560 \\
\hline Clover.- & 37,199 & 28,930 & 30,060 & 30,400 & 27,940 & 25,940 & 27,390 & 27,850 & 29,770 \\
\hline Kose & 500 & 540 & 370 & 600 & 510 & 470 & 240 & 321 & 310 \\
\hline Julia & $I, 345$ & $\mathbf{I}, \mathbf{1} 70$ & 1,070 & I, I 20 & 870 & 1,120 & 990 & $1,06 c$ & 1,080 \\
\hline Pansy ....... & 3,850 & 3,630 & 2,870 & 3,$0 ; 0$ & 2,880 & 2,750 & 2,000 & 2,560 & 2,170 \\
\hline Rita & 1,086 & 1,000 & 730 & 920 & 1,060 & 860 & 940 & 1,000 & $\mathrm{I}, \mathrm{COO}$ \\
\hline Vina & 3,150 & 2,430 & 2,270 & 2,660 & 2,380 & 2,490 & 2,130 & I, 880 & 2,040 \\
\hline Chloe & 1,706 & 1,390 & 1,560 & 1,550 & 1,600 & 1,640 & I, 730 & 1,630 & 1,260 \\
\hline Stella & $\mathrm{I}, 195$ & 960 & 960 & 1,220 & 1,060 & 1,000 & 1,320 & 970 & 1,230 \\
\hline Dena & 4.980 & 3,690 & 3,840 & 3,870 & 2,670 & 3,810 & 2.750 & I, 290 & 720 \\
\hline Average & 6,759 & 5,988 & 5,417 & 5,929 & 5,188 & 5,531 & 5,174 & 5,067 & 4,917 \\
\hline
\end{tabular}

II. NUMBER OF BACTERIA IN I CC. OF MILK KePt AT $55^{\circ}$ F.

\begin{tabular}{|c|c|c|c|c|c|c|c|c|c|}
\hline $\begin{array}{c}\text { NAMF, OF } \\
\text { COW }\end{array}$ & $\begin{array}{l}\text { Cow } \\
\text { warm. }\end{array}$ & $\begin{array}{l}\text { After } \\
3 \\
\text { hours. }\end{array}$ & $\begin{array}{c}\text { After } \\
6 \\
\text { hours. }\end{array}$ & $\begin{array}{l}\text { After } \\
9 \\
\text { hours. }\end{array}$ & $\begin{array}{c}\text { After } \\
\text { I } 2 \\
\text { hours. }\end{array}$ & $\begin{array}{l}\text { After } \\
\text { I } 5 \\
\text { hours. }\end{array}$ & $\begin{array}{c}\text { After } \\
24 \\
\text { hours. }\end{array}$ & $\begin{array}{l}\text { After } \\
3^{2} \\
\text { hours. }\end{array}$ & $\begin{array}{c}\text { After } \\
48 \\
\text { hours. }\end{array}$ \\
\hline May _.....-.- & I, 2 I 2 & 1,260 & 1,400 & 1,500 & 1,460 & 1,360 & I,080 & 3,500 & 17,740 \\
\hline Ida & 35.560 & 25,440 & 25,740 & 26,040 & 26,780 & 24.460 & 23,420 & 22,040 & 20,040 \\
\hline May......... & 440 & 320 & 300 & 140 & 220 & 240 & 340 & 340 & 240 \\
\hline Ida $=\ldots$ & 5,120 & 3,900 & 3,460 & 2,980 & 2,800 & 2,920 & 2,260 & 3,220 & 3,240 \\
\hline Hilda & 1,715 & 2,390 & 2,190 & 2,180 & $2.55^{\circ}$ & 2,460 & 2,290 & 2,560 & 5,540 \\
\hline Peach & 2.330 & 2,510 & 2,540 & 1,940 & 2,150 & 1,970 & 2,170 & 2,740 & $2 I, 800$ \\
\hline Clover & 37,199 & 28,340 & 26,070 & 29,640 & 28,670 & $27, \mathrm{C} 40$ & 24,980 & 27,320 & 28, I I \\
\hline Rose - - & 500 & 600 & - 360 & 460 & 400 & 410 & 460 & 500 & 1,740 \\
\hline Julia & 1.345 & 1,080 & 990 & 980 & $\mathrm{I}, 400$ & 1,080 & I, oso & 3, IIO & 68,800 \\
\hline Pansy - & 3.850 & 3,130 & 3,2 so & 3.240 & 2,410 & 2,970 & 3.140 & 3,050 & 7,200 \\
\hline Rita & 1,086 & 860 & $\mathrm{I}, 090$ & 970 & $I, 000$ & 930 & 780 & I, I 20 & 1,630 \\
\hline Vina & 3,150 & 2,520 & 2,550 & 2,960 & 2.730 & 2,810 & 2.730 & 2,830 & 84,000 \\
\hline Chloe - & 1,706 & 1,540 & 2.170 & 1,780 & $1,6.50$ & 1,720 & 2.000 & 2,460 & 2,520 \\
\hline Stella & $\mathrm{I}, 195$ & I, 000 & 1,150 & 1,320 & 1,210 & 1,180 & $I, 440$ & 1,530 & 5,490 \\
\hline Deva & 4,980 & 3,730 & 3,860 & 3,540 & 4120 & 4,230 & 3.910 & 4,670 & I 1,860 \\
\hline Average.-- & 6,759 & $5,24 I$ & 5,143 & $5,3 I I$ & 5,370 & 5,052 & 4,872 & $5,399]$ & 18,663 \\
\hline
\end{tabular}

III. NuMber OF BACTERIA in I CC. OF MILK KePt AT $70^{\circ}$ F.

\begin{tabular}{|c|c|c|c|c|c|c|c|c|}
\hline $\begin{array}{c}\text { NAME } \\
\text { OF } \\
\text { COW. }\end{array}$ & $\begin{array}{c}\text { Cow } \\
\text { warm. }\end{array}$ & $\begin{array}{l}\text { After } \\
3 \\
\text { hours. }\end{array}$ & $\begin{array}{c}\text { After } \\
6 \\
\text { hours. }\end{array}$ & $\begin{array}{c}\text { After } \\
9 \\
\text { hours. }\end{array}$ & $\begin{array}{l}\text { After } \\
\text { I } 2 \\
\text { hours. }\end{array}$ & $\begin{array}{l}\text { After } \\
\text { I5 } \\
\text { hours. }\end{array}$ & $\begin{array}{l}\text { After } \\
24 \\
\text { hours. }\end{array}$ & $\begin{array}{l}\text { After } \\
32 \\
\text { hours. }\end{array}$ \\
\hline May _.......... & I,2I 2 & $I, 000$ & 1,340 & 1,860 & 3,460 & 3,460 & 64,000 & 800,000 \\
\hline Ida & 35,560 & 18,260 & 12,100 & 9.020 & 7,820 & 6,720 & $80, c 00$ & 416,000 \\
\hline May & 440 & 440 & 280 & 280 & $44^{\circ}$ & I1, 540 & 303,600 & - \\
\hline$I d a$ & 5,210 & 3,560 & 2,120 & I, 880 & 1,800 & I, 240 & 4,960 & 58,400 \\
\hline Hilda & 1,715 & 2,280 & 2,110 & 10,200 & 26,860 & 192,000 & $1,527,000$ & $-\ldots-\ldots$ \\
\hline Peach & 2,330 & 2,230 & 2,110 & $2,5 \% 0$ & 8,870 & 26,940 & 420,000 & - - - - - \\
\hline Clover............... & 37.199 & 20,200 & 15,390 & $13,82 \mathrm{C}$ & I 2,5 so & 16,050 & $5 \mathrm{I}, 200$ & 204,000 \\
\hline Rose & 500 & 400 & 420 & 830 & 980 & 1,950 & 13,250 & $\ldots$ \\
\hline Julia _... & $\mathbf{I}, 345$ & 1,000 & $\mathbf{I}, 000$ & 1,200 & 5,600 & 17,720 & $\mathrm{I}, 600,000$ & 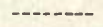 \\
\hline Pansy & 3,850 & 3,290 & 5,470 & 6.340 & 5,000 & I0,620 & $1,600,000$ & $-\ldots-n$ \\
\hline Rita & 1,086 & 1,170 & 1,230 & 1,320 & 1,200 & 1,120 & 29,680 & 26,400 \\
\hline Vina & 3,150 & 2,240 & 2,520 & 2,890 & 3.040 & 33.140 & $2,144,000$ & $----n$ \\
\hline Chloe & I,706 & 1,440 & 1,410 & 1,930 & 10,340 & 9.770 & 192,000 & $2,800,000$ \\
\hline Stella & I, I95 & $I, 040$ & 1,060 & 1,300 & 3,460 & 7,840 & 640,000 & $---\infty$ \\
\hline Dena & 4,980 & 4,440 & 2,600 & 3.750 & 3,660 & 57,40 & 180,000 & $6,400,000$ \\
\hline A verage - - & 6,759 & 4,200 & 3,411 & 3,947 & $6,34 \mathrm{I}$ & 23,495 & 589.980 & -- \\
\hline
\end{tabular}


An analysis of the results reveals several interesting facts, namely: (1) that there is a great difference in the number of bacteria in the freshly drawn milk of different cows; (2) there is no increase in the number of bacteria in the milk for about six hours after it is drawn when kept at a temperature of either $40^{\circ}, 55^{\circ}$ or $70^{\circ} \mathrm{F}$.; (3) there is an actual, but usually not large, decrease in the number of bacteria in the milk for the first six hours after it is drawn; (4) the decrease in the number of bacteria, that is the germicidal action, is greatest in the milk kept at $70^{\circ} \mathrm{F}$.; (5) the decrease in the number of bacteria is much greater in the milk of certain cows than it is in that from others; (6) the germicidal action is in the beginning more effective in the milk kept at $70^{\circ} \mathrm{F}$.; and (7) the germicidal action of the mixed milk is not sufficient to render it of any practical value in preserving milk for more than from six to nine hours. It is clear that milk cooled and kept at $40^{\circ}$ to $55^{\circ} \mathrm{F}$. remains unchanged for a much longer time than when a temperature of $70^{\circ} \mathrm{F}$. is maintained. At these low temperatures the number of bacteria continues to decrease for a longer time. It is important to note that frequently the number of bacteria begins to increase in the milk kept at $55^{\circ} \mathrm{F}$. after about 48 hours, but when the temperature is reduced to $40^{\circ} \mathrm{F}$. they do not.

Although for the first few hours the germicidal power is more active in milk kept at $70^{\circ} \mathrm{F}$., it has not been determined, but probably it is true, that in the milk kept at the lower temperatures it continues to act, but in a less degree, for a much longer time. For this reason it is very important to cool market milk to at least $55^{\circ} \mathrm{F}$. as quickly as possible after it is drawn, and to keep it at that temperature until it is delivered. If the milk is not to be consumed within 48 hours it is safer to keep it at a lower $\left(40^{\circ} \mathrm{F}\right.$.) temperature.

The difficulties involved in procuring in our large cities milk reasonably free from bacteria do not rest entirely with the producer. The method of transportation is quite as important. Milk may be produced under the best of conditions, and cooled at once to the required temperature at which it is 
delivered for transportation. If, however, its temperature is: allowed to rise to $60^{\circ} \mathrm{F}$. or above during the time it is in transit, the bacteria present will multiply, producing acids and by-products, so that when delivered the milk may have becomemarkedly, if not seriously, changed. As care of the milk required in the course of transportation is simply to have it put in clean cans and kept at a low temperature, there is no reason why milk cannot be shipped hundreds of miles and be delivered in a perfectly sweet and wholesome condition. The details of the methods for keeping it at a low temperature must, of course, be worked out by shippers generally as they have successfully been by some milk companies. The only requisite that the consumers need demand in the transportation is that the low temperature be maintained.

Significance of bacteria in milk. The significance of bacteria may be summarized as follows: (1) The non-pathogenic bacteria cause various changes in milk such as the lactic and butyric fermentation, bitter milk, ropy milk, etc. Sometimes certain species of bacteria become localized in the udder from which they get into the milk where they cause disagreeable taints or odors in the milk itself or in its products. Some of these may produce morbid conditions indirectly by the action of their by-products. (2) The pathogenic bacteria if present will produce their respective diseases in the susceptible consumer. The danger from external contamination is shown from the fact that there were reported in 1895, 138 epidemics of typhoid, 74 of scarlatina and 28 of diphtheria that were traced to milk supplies. ${ }^{11}$ Tubercle bacteria that escape with the milk from cows which have tuberculous udders often infect calves and pigs. The feeding of separated milk from creameries receiving infected milk is one of the most important methods of spreading tuberculosis among cattle. ${ }^{12}$. It is also . the source of much tuberculosis among swine.

${ }^{11}$ Busey and Kober. Report of the Commissioner of the District of Columbia, 1895.

${ }^{12}$ Russell. Bulletin No. 143, Univ. of Wis. Agric. Exp. Station,. 1907. 
The elimination of danger from infection. The danger from bacteria in milk may be eliminated by (1) having the milk produced under absolutely healthy conditions-cleanliness, healthy animals, and healthy attendants, and (2) sterilizing or pasteurizing the milk before it is used.

1. Sterilization. This is accomplished by boiling, although chemicals are sometimes used. Heating, however, is the more preferable: There are certain serious objections raised to the use of boiled milk, such for example as (a) the casein is rendered more indigestible; (b) the taste and odor are disagreeably altered; (c) a large part of the $\mathrm{CO}_{2}$ is driven off, resulting in a change of phosphates and a precipitation of casein and magnesium carbonates; (d) many of the fat globules coalesce; and (e) the lact-albumin is coagulated, giving: rise to the albuminous film or skin which forms on the surface of boiled milk.

The objection to the use of chemicals is their possible deleterious effect upon the body. The chemicals most often used are: soda, borax, boracic acid, salicylic acid, quick lime, and formalin.

2. Pasteurization. This consists in heating the milk at a temperature high enough and for a time sufficient to destroy the objectional bacteria. In some cases it sterilizes the milk but in others it does not. The process consists of two parts, (1) heating the milk usually from $60^{\circ}$ to $65^{\circ} \mathrm{C}$. for $20 \mathrm{~min}$ utes, and (2) the cooling of the milk as quickly as possible after heating it to a temperature of about $15^{\circ} \mathrm{C}$. and keeping it cool.

Foreign matter in milk. In addition to dirt from extraneous sources that may be in milk it must be remembered that milk as it comes from the cow usually contains leucocytes or pus corpuscles in considerable numbers. Market milk occasionally contains blood itself coming from some injured or diseased udder. The leucocytes in large numbers are objectionable, as they seem to interfere with the digestion of the 
consumer, especially very young children. Where these are the cause of difficulty they may be removed by filtering the milk through absorbent cotton thus giving great relief to the patient.*

* For a study of leucocytes in milk and other questions relating to pure milk the student is referred to the following works:

Swithinbank and Newman. Bacteriology of Milk.

Ward. Pure milk and the Public Health.

Campbell. Leucocytes in milk, methods of determination and the effect of heat upon their number. Bulletin No. 117, U. S. Bureau of Animal Industry, 1909.

Doane. Leucocytes in Milk and their Significance. Bulletin No. 102, Maryland Agric. Exp. Station, 1905.

Moore. Bacteria in Milk. N. Y. State Dept. of Agric., 1902.

Bergey. The Source and Nature of Bacteria in Milk. Bulletin No. 125, Dept. of Agric., Commonwealth of Pennsylvania, 1904.

Bergey. The Cellular and Bacterial Content of Cow's Milk at different Periods of Lactation. Univ. of Pennsylvania Medical Bulletin, 1904.

Various authors. Milk and its Relation to the Public Health. Bulletin No. 56, Hygienic Laboratory, Public Health and MarineHospital Service of the United States, p. 1-757. 


\section{CHAPTER XV.}

COCCACEAE.

\section{GENUS STREPTOCOCCUS AND ITS SPECIES PATHOGENIC FOR ANIMALS.}

General discussion of the genus Streptococcus. The genus streptococcus is based according to Migula on its method of reproduction or division. Streptococei are chains of spherical bacteria that divide in one plane perpendicular to the long axis of the chain. The segments do not separate but are held together presumably within a capsule in short or longer chains, although the divisions seem to be complete. According to older and more commonly encountered classifications, a streptococcus is simply a number of micrococci (spherical bacteria) united in the form of a chain. In some of the supposedly different species the segments are oblong and vary in size. Frequently, however, the segments vary in size and form in the same chain.

History. The streptococei were among the first bacteria that were carefully studied. In 1874 , Billroth ${ }^{1}$ published a monograph on septic coccabacteria in which this genus was described. The fundamental studies on wound infections by Koch ${ }^{2}$ were followed, in 1881 , by the work of Ogston ${ }^{3}$ who was the first to differentiate between the irregularly grouped staphylococei and the chain-cocei.

Pure cultures of streptococci were first obtained by Fehleisen ${ }^{4}$ in 1883 and by Rosenbach ${ }^{5}$ in 1884 . The thorough and systematic researches of the last-named authors, together

${ }^{1}$ Billroth. Untersuchungen über die Vegetationsformen der Coccabacteria septica. Berlin, 1874.

${ }^{2}$ Koch. Untersuchungen über Wundinfektion, u. s. w. 1878.

${ }^{3}$ Ogston. Brit. Med. Jour., 1881.

${ }^{4}$ Fehleisen. Aetiol. d. Erysipelas. Berlin, 1883.

${ }^{5}$ Rosenbach. Mikroors. bei Wundinfektion, u. s. w. Wiesbaden, 1884 . 
with those of Passet, ${ }^{6}$ were of special influence in placing our knowledge of the pathogenic properties of streptococci upon a scientific basis.

Gordon ${ }^{7}$ pointed out that streptococci could be separated into well defined groups by a study of their fermentative action in various carbo-hydrate media. Andrews and Horder ${ }^{8}$ founded a rational classification on the fermentation reactions of the streptococei and in 1910 Winslow and Palmer ${ }^{9}$ pointed out certain differences in the intestinal streptococei of the horse, cow and man. They showed that the streptococei from man and horse fermented dextrose more or less vigorously, but those from man produced more acid than those from the horse. The streptococci from the bovine species exhibited two distinct and clearly marked types, one forming a considerable amount of acid approaching those from the horse, the other forming no acid at all. Moore ${ }^{1}$ studied 28 cultures of streptococei isolated from tissues in the investigation of animal diseases. When compared on different media they were found to differ often but slightly one from another.

Classification of streptococci. A few investigators have tried to eliminate the confusion concerning species by classifying streptococei according to distinct morphologic characters and pathogenic properties. Of these classifications the following may be mentioned:

The classification of von Lingelsheim. ${ }^{2}$ This author divides all streptococei into two groups or species, namely :-

(a) Streptococcus brevis - which is non-pathogenic.

(b) Streptococcus longus - which is pathogenic.

This is a combination of pathogenesis and morphology

${ }^{6}$ Passet. Untersuchungen über die eitrigen Phlegm., u. s. w. Berlin, 1885.

${ }^{7}$ Gordon. 33rd. Annual Rept. of Local Govt. Board, containing report of the medical officer, p. 384-388.

${ }^{8}$ Andrews and Horder. Lancet, Vol. CLXXI (1906) p. 708.

'Winslow and Palmer. Journal of Infectious Diseases, Vol. VII (1910) p. 1.

${ }^{1}$ Moore. Bulletin No. 3, B. A. I., U. S. Dept. Agric., 1893.

${ }^{2}$ Von Lingelsheim. Zeit. f. Hygiene, Bd. X (1891) p. 331. 
which the author thought applicable to the entire genus. He worked very largely, however, with the streptococei from the human mouth and throat.

The classification of Kurth..$^{3}$ Kurth worked largely with the streptococei from cases of scarlatina. His system is practically the same as that of von Lingelsheim, with the exception that he does not include pathogenesis as necessarily belonging to either group. The divisions are as follows:

(a) Streptococcus rigidi-Streptococei growing in short ehains, imparting a uniform turbidity to bouillon.

(b) Streptococcus flexuosi-Streptococci which grow in long interlacing chains forming floceuli in bouillon, leaving the liquid clear.

The classification of Pasquale. ${ }^{4}$ Pasquale worked with thirty-three streptococei, including nearly all of the then known species. His work was quite exhaustive, but he had to deal with cultures of various generations. He divides them into four groups, as follows:

(a) Short saphrophytic streptococci.

(b) Long non-virulent streptococci.

(c) Long pathogenic streptococei.

(d) Short highly infectious streptococei.

Group (d) pertains largely to bacteria which are no longer recognized as streptococei, for example, the diplococcus (Micrococcus lanceolatus) of pneumonia. It is now known that streptococci which grow in short chains are often virulent. This is especially true of the pyogenic forms.

Classification of Andrews and Horder. These authors divide the genus into seven main types or species.

1. Streptococcus equinus. This type of streptococeus appears to be characteristic of the herbivora. It is abundant in horse dung and is the commonest form in the air of London. It forms chains of medium length, grows feebly; if at all, at

${ }^{3}$ Kurth. Arbeiten a.d. Kaiserlichen Gesundheitsamte, Bd. VII (1891) p. 389.

"Pasquale. Beiträge zur path. Anat. u. zur allgemeinen Pathologie, Bd. XII (1893) p. 433. 
20 degrees, and ferments saccharose and the glucosides (salicin and coniferin), but not lactose, raffinose, inulin, or mannite. It fails to clot milk or to reduce neutral red.

2. Streptococcus mitis. This type is found most commonly in human saliva and feces, but it is not as a rule associated with disease. It is short-chained, grows well on gelatin at 20 degrees, and acidifies milk without clotting. It ferments lactose as well as saccharose and salicin, but gives a negative reaction to the other tests.

3. Streptococcus pyogenes. This type represents the highest parasitic development of the group, being rarely found except in association with definite pathological conditions. It occurs in long chains, usually growing in woolly masses at the bottom of a clear broth. It grows well on gelatin at 20 degrees. It is actively hemolytic, but does not form hydrogen sulphide in broth cultures. It strongly acidifies milk, but never clots it, nor does it reduce neutral red. The usual positive reactions with Gordon's tests are saccharose, lactose, and salicin. It is highly pathogenic for animals.

4. Streptococcus salivarius. This type is the commonest form in the mouth, although it is also found elsewhere. It is a short-chained form which usually renders broth uniformly turbid. Its growth on gelatin at 20 degrees is variable. It clots milk and reduces neutral red and ferments saccharose, lactose, and raffinose.

5. Streptococcus anginosus. This type is a pathogenic long-chained form, allied in other respects to Str. salivarius, and bearing to it much the same relation which Str. pyogenes bears to Str. mitis. It occurs most commonly in cases of scarlatina and other forms of sore throat. It is long-chained and produces a flocculent deposit in broth. It generally fails to grow on gelatin at 20 degrees, and is markedly hemolytic. Like Str. salivarius, on the other hand, it clots milk, reduces neutral red, and forms acid in saccharose, lactose and raffinose.

6. Streptococcus faecalis. This type is specially characteristic of the human intestine. It is short-chained and renders broth uniformly turbid. It grows readily at 20 degrees 
and forms sulphuretted hydrogen in broth cultures. It has no hemolytic power and little virulence, but produces a positive reaction to all of Gordon's tests except raffinose and inulin. That is, it elots milk, reduces neutral red, and ferments saccharose, lactose, salicin, coniferin, and mannite. The mannite reaction is specially characteristic of this intestinal type.

7. Streptococcus gracilis (Escherich, Lehmann and Neumann). Small coccus occuring in chains. Ferments lactose and coagulates milk. May ferment salicin and mannite. Liquefies gelatin, actively.

It is evident that a natural and acceptable classification of streptococci has not been made and probably can not be until further facts concerning them are known.

Distribution of streptococci. It has been pointed out in many publications that streptococei are quite widely distributed in nature. The results of the bacteriologic examinations of normal mucous membranes show that they are frequently included in the bacterial flora of the mouth, throat, nares, intestines, vagina, and in a few cases they have been found in the bronchioles of the horse and rabbit. They are also present in greater or less numbers on the skin, especially in the deeper layers, presumably in the ducts of the sweat and sebaceous glands and along the hair shafts and follicles. They exist in soil and in water, and occasionally these forms are quite as delicate in their morphology and equally as sensitive to the influence of environment as those isolated from normal or diseased animal tissues. In view of this wide distribution, the presence of a streptococcus in any abnormal condition can not be considered necessarily a specific infection from a previous case of the same kind. In many affections where the specific organism has been demonstrated, such for example as diphtheria and tuberculosis, streptococci frequently appear in the lesions. In these cases, they are considered as accidental invaders, although in some of these maladies, such as tubereulosis, they are believed to be of more or less secondary importance. When, however, the specific cause of the disease is not positively known, and streptococei which possess certain 
pathogenic powers for experimental animals are constantly present and seem to stand in a causal relation to the disease, the pathologist is confronted with a puzzling problem in trying to determine the source and the etiological importance of the organism in hand. In cases of infection leading at once to septicemia, peritonitis or suppuration, the explanation is more

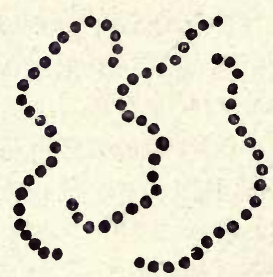

1.

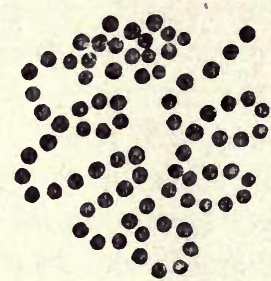

4.

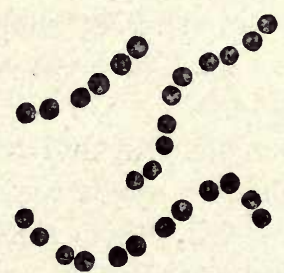

2.

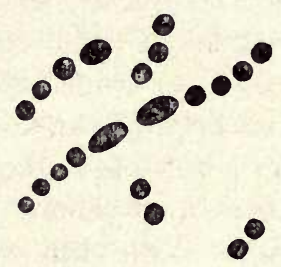

5.

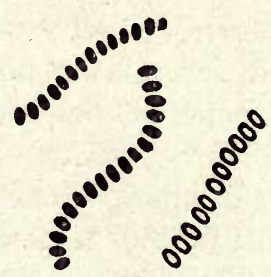

3.

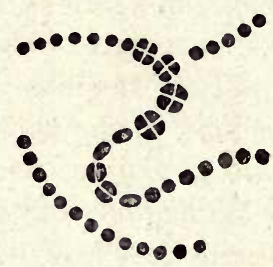

6.

Fig. 45. Six forms of streptococci. 1. Long chains consisting of small segments arranged with equal spaces between them. 2. Long and shorter chains in which the segments are arranged in pairs. The size of the individual segments is considerable larger than those in the long chains. 3. Short and longer chains where the segments are oval with the long diameter perpendicular to the long axis of the chain. 4. Long interlacing chains. 5. Short and longer chains with one or more segments very much larger than the others. 6. Chains showing divisions in two planes. This form of division has been observed in a few cases. The dividing in two planes is an exception which is not satisfactorily explained. $\times$ about 1000 .

simple than in the epizootic diseases, such as Brustseuche, where the constant presence of streptococei in the lesions can be quite as easily explained on the ground of their invasions of the parts affected from a normal habitat as on the hypothesis 
of a specific infection. Migula describes about 80 species of which very few are pathogenic for animals.

Morphology and biologic properties of streptococci. The individual streptococcus is a spherical microorganism measuring from 0.5 micron to 1 micron in diameter. Since the line of cleavage of cocci, when in chains, is perpendicular to the long axis of the chain, adjacent cocei often show slight flattening of the contiguous surfaces, forming, as it were, a series of diplococci arranged end to end.

Streptococei are easily stained by the usual aniline dyes. Stained by the method of Gram, the pyogenic streptococci are not decolorized and invariably retain the gentian-violet. Certain species found in stools and deseribed as Gram-negative are rare and are non-pathogenic. Others of the "Streptococcus brevis" variety, and purely saprophytic, may stain irregularly by the Gram method.

Cultivation. The pyogenic streptococci are readily cultivated on all the richer artificial media. While meat extractpeptone media may suffice for certain strains, it is usually better to employ those which have the beef or veal infusion for a base. For the cultivation of more delicate strains of streptococci, especially when taken directly from the animal body, it is well to add to the media animal albumin in the form of whole blood, blood serum, or ascitic or pleural transudates. Glucose, added in the proportion of one to two per cent, likewise renders media more favorable for streptococcus cultivation. Prolonged cultivation of all species upon artificial media renders them less fastidious as to cultural requirements. The most favorable reaction of media for streptococcus cultivation is moderate alkalinity (two-tenths to five-tenths per cent alkalinity to phenolphthalein). Growth may be obtained with many strains, however, in neutral media or even in those slightly acid. Growth ceases at a temperature of $45^{\circ} \mathrm{C}$. Many streptococei will develop slowly at room temperature. While the free access of oxygen furnishes the most suitable environment for most races of streptococci, complete anaërobiosis does not prevent the development of most species in favorable 
media. Perrone isolated a strictly anaërobic streptococcus from the human intestinal tract. ${ }^{1}$

In alkaline bouillon at $37.5^{\circ} \mathrm{C}$, pyogenic streptococei grow rapidly, form long and tortuous chains, and have a tendency to form flakes which rapidly sink to the bottom.

Resistance. Streptococei on ordinary culture media, without transplantation and kept at room temperature, usually die out within ten days to two weeks. Many of the cultures die out in from two to three days. According to Hiss * they may be kept alive for much longer periods by the use of the calcium-carbonate-glucose bouillon, if the cultures are thoroughly shaken and the powdered marble thoroughly mixed with the bouillon from time to time. Preservation at low temperatures $(1$ to $2 \circ \mathrm{C}$.) in the ice chest considerably prolongs the life of cultures. Virulence is preserved longest by frequent transplantation upon albuminous media. In sputum or animal excreta, streptococei may remain alive for several weeks.

Streptococei are killed by exposure to a temperature of $54^{\circ} \mathrm{C}$. for ten minutes. ${ }^{2}$ Low temperatures, and even freezing, do not destroy some races. Some species seem to resist a temperature somewhat higher than $54^{\circ} \mathrm{C}$.

The action of various chemical disinfectants has been thoroughly investigated by v. Lingelsheim, ${ }^{3}$ who reports among others the following results: Carbolic acid 1:200 kills streptococei in fifteen minutes. In the same time, bichloride of mercury is efficient in a dilution of $1: 1,500$; lysol in a dilution of $1: 200$; peroxide of hydrogen $1: 35$; sulphuric acid $1: 150$ and hydrochloric acid $1: 150$. Inhibition is exerted by carbolic acid 1:550; and by bichloride of mercury 1:65,000. Exposure to direct sunlight kills streptococei in a few hours.

${ }^{1}$ Perrone. Ann. de l'Inst. Pasteur, Vol. XIX (1905) p. 367.

* Hiss, loc cit.

${ }^{2}$ Sternberg. Textbook of Bacteriology, 2d. ed., 1901. Hartmann Arch. f. Hyg., Bd. VII (1887) p. 83.

${ }^{3}$ v. Lingelsheim. Beit. z. Exper. Therap., Abt. I (1899) p. 1. 
STREPTOCOCCUS PYOGENES ROSENBACH.

Synonyms. Streptococcus erysipelatos Rosenbach; Str. conglomeratus Kurth; Str. longus v. Lingelsheim; Str. septopyaemicus Biondi.

Place in nature. This streptococcus is the cause of a large number of acute and also chronic inflammations. The streptococcus of erysipelas and the one described by Pruden in human diphtheria are identical. Its distribution in nature is not fully understood except that it is quite common about hos-

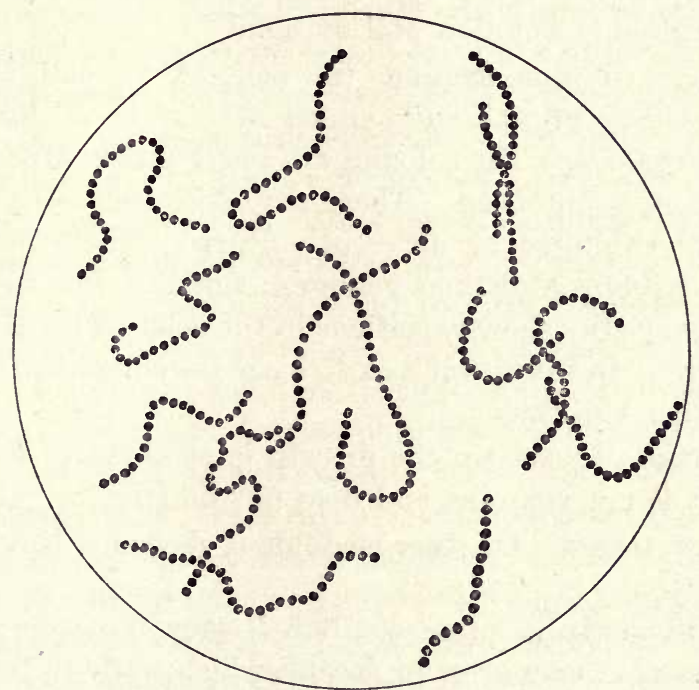

Fig. 46. Streptococcus pyogenes. Drawing made from a cover-glass preparation from a bouillon culture. $\times$ about 1000.

pitals and it has been reported to have been isolated from the soil. Streptococei are frequently found on the skin, on the mucosa of the digestive tract, and on certain other mucous membranes of the body that resemble it very closely. As the virulence of this streptococeus varies according to its environment it is possible that the streptococei living on the mucosa may be closely related to, if not identical with it. It is frequently associated with other lesions of the throat and lungs 
and it is considered of much importance as a secondary invader in cases of pulmonary tuberculosis.

Morphology. This streptococcus grows in quite long chains in bouillon. The individual segments are from 0.5 to $1.0 \mu$ in diameter. ${ }^{1}$ In smear preparations of pus they often appear in short chains. Considerable variation in size is recorded.

Staining. It stains readily with the usual aniline dyes. It is positive to the Gram stain.

Cultivation. It grows readily in the ordinary alkaline media, especially bouillon and on agar.

Agar. On this medium the colonies present a central convex nuclear growth surrounded by a zone of thin almost iridescent growth. The colonies are small, rarely attaining the diameter of a pin head. There are, however, quite marked differences exhibited by different cultures. The growth oceasionally develops a distinct yellowish tint in a few days. The different varieties show variations in the color of the growth on solid media. In the writer's experience the colonies are usually of a greyish white color.

Gelatin. In gelatin the growth is confined to the needle tract. It is not vigorous and does not liquefy the medium.

Blood serum. On this medium it develops tiny grayish colonies.

Bouillon. In alkaline bouillon it may impart a uniform cloudiness or it may grow in flocculi which settle to the bottom or sides of the tube. As a rule the long chained streptococei grow in floceulent masses. A little ascitic fluid added to the bouillon causes a more abundant growth. It ferments dextrose, lactose and saccharose in bouillon, producing acid but no gas.

Milk. Milk is often coagulated after a few days.

Life conditions and properties. This streptococeus is aërobic and facultative anaërobic. It is sensitive to changes 1901.

${ }^{1}$ Lehmann and Neumann. Atlas and Principles of Bacteriology, 
in its environment. The most favorable temperature for its multiplication is from 30 to $37^{\circ} \mathrm{C}$. but it grows somewhat slowly and feebly at the room temperature. Most pathogenic streptococci give rise to hemolytic substances. This is readily determined by the method given by Park. "If 1 cc. of fresh or defibrinated blood is added to 6 ce. of melted agar at 40 to $45^{\circ} \mathrm{C}$., well shaken, inoculated with characteristic streptococci and poured in a Petri dish there will appear in twelve to twenty-four hours tiny colonies surrounded by clear zones of about 5 to $8 \mathrm{~mm}$. in diameter." It possesses little pigment producing power. On albuminous media it is reported to produce toxins soluble in water and precipitated by alcohol.

Resistance. This is not very great. When dried in blood or pus, however, some individuals may live for several months at room temperature and longer in an ice-chest. In gelatin and agar cultures they live for from one week to three months. In order to keep streptococci alive and virulent, it is best to transplant them frequently and to keep them in serum or ascitic fluid bouillon in small, sealed glass tubes in the icechest. This streptococcus is destroyed at $54^{\circ} \mathrm{C}$. in ten minutes. It is killed by weak solutions of corrosive sublimate (1-2500), carbolic acid (1-300) and creolin (1-130) in a few minutes.

Pathogenesis. This streptococcus is often found in pus from abscesses and exudates following wound infection. It is fatal for white mice and often rabbits succumb to it. It tends to lose its virulence by continuous cultivation.

A large number of streptococei have been studied from different lesions, such as erysipelas, acute abscesses, septicemia, cellulitis, etc. These have been described under different names, but the conclusion seems to be warranted that the slight differences existing between them are acquired and nonpermanent variations of organisms derived from the same species. Certain differences have been found in S. pyogenes isolated from man and from cattle. It is generally considered that the streptococei associated with acute inflammatory processes should be grouped under S. pyogenes. Moore ${ }^{1}$ de-

${ }^{1}$ Moore. Am. Vet. Review, Vol. XXIII (1900) p. 687. 
scribed a serious outbreak of foot rot and erysipelatous inflammation in the limbs of cattle due to this organism.

\section{STREPTOCOCCUS EQUI SCHUTZ.}

Synonyms. Streptococcus coryzae contagiosae equorum Eisenberg.

Place in nature. This streptococcus was described by Schütz, ${ }^{2}$ Sand and Jensen, ${ }^{3}$ Poels ${ }^{4}$ and Lupke ${ }^{5}$ independently as the cause of strangles. It is generally accepted that the organism described by these different authors belongs to the same species. This streptococcus can not be differentiated with certainty from $S$. pyogenes.

\section{STREPTOCOCCUS OF APOPLECTIFORM SEPTICEMIA IN FOWLS NORGAARD AND MOHLER.}

Place in nature. Nörgaard and Mohler ${ }^{6}$ described briefly a streptococcus which appeared to be the cause of a fatal disease in chickens designated by them as apoplectiform septicemia. It has been found in one outbreak in New York State where nearly every fowl in the flock died.

Morphology. A streptococcus composed of chains of variable length. Individual chains vary from 0.6 to $0.8 \mathrm{mi}-$ crons in diameter. In tissues they appear as short chains in from 2 to 8 segments, while in bouillon they are much longer. Irregular segments are occasionally observed. Mohler states that the division sometimes occurs longitudinally to the axis of the chain and sometimes a perpendicular division occurs in the same individual.

Staining: The streptococcus stains readily with aniline dyes and also by Gram's and Gram Weigert's methods.

Cultivation. This streptococcus is an aërobe and a facul-

${ }^{2}$ Schütz. Archiv. f. Thierheilk., Bd. XIV (1888) p. 172.

${ }^{3}$ Sand and Jensen. Deutsche Zeitschrift f. Thiermed., Bd. XIII (1888) p. 437.

${ }^{4}$ Poels. Fortschritt der Med., Bd. VI (1888) p. 4.

${ }^{5}$ Lupke. Centralb. f. Bakt., u. s. w., Bd. V (1889) p. 44.

- Mohler. Bulletin No. 36, B. A. I., U. S. Dept. Agric., 1902. 
tative anaërobe. It grows in slightly acid, neutral or alkaline media. The most favorable temperature is about $38^{\circ} \mathrm{C}$. It will not grow at $41^{\circ} \mathrm{C}$.

Agar. On agar the growth appears as small shiny grayish colonies about $1.5 \mathrm{~mm}$. in diameter. They consist of a darker center surrounded by an irregular pale bluish zone. In the depth of the agar the growth appears as grayish white colonies with slightly fimbriated borders. The growth is more vigorous on glycerine-agar and serum-gelatin-agar.

Gelatin. On gelatin, the growth is not noticeable until the fourth or fifth day, when minute grayish white colonies are observed. These colonies are never larger than a pin head and have a fimbriated border. The gelatin is not liquefied.

Potato: It does not grow on potato.

Bouillon. In alkaline bouillon, growth appears in 24 hours, in the form of long chains which appear as fine flocculi in the liquid at the bottom and along the sides of the tube, leaving the medium clear. After the growth settles, the sediment is not viscid, and upon shaking breaks up into small masses. Some cultures impart a more uniform cloudiness to the medium. In dextrose bouillon, the growth is more vigorous than in simple peptonized bouillon and the reaction becomes acid. A similar reaction takes place in saccharose and lactose bouillon.

Milk. It produces no visible change in milk. In litmus milk the blue coloration changes to a pale pink in the course of a few days. In the writer's experience coagulation has not taken place.

Life conditions and properties. It is aërobic and facultative anaërobic. It does not produce indol. Toxins have not been described.

Resistance. It is destroyed at $60^{\circ} \mathrm{C}$. in 15 minutes. Mohler found it would not develop after 11 minutes exposure to that temperature. It is killed with weak solutions of earbolic acid $(1 \%)$ and corrosive sublimate (1-2000) in from two to three minutes. Creolin in a 1 per cent solution is destructive. 
Pathogenesis. It is fatal to rabbits when inoculated intravenously or into the abdominal cavity with 0.5 cc. of a bouillon culture in from 2 to 3 days. In one case fowls inoculated intravenously with a small dose ( 0.1 to 0.3 ce.) died within 48 hours. Magnusson ${ }^{4}$ has described a new disease of fowls in Europe due to a streptococcus. He has identified it as apoplectiform septicemia.

STREPTOCOCCUS OF INFECTIOUS PNEUMONIA OF HORSES.

Place in nature. In 1887, Schüt $z^{1}$ described microorganisms which he isolated from the tissues of horses suffering from infectious pneumonia or Brustseuche. He described them as small oval bacteria which appeared as diplococei, and in the cultures as short chains. They stained with methylene blue and other basic aniline dyes, but were not stained by the Gram method. A number of investigators described organisms somewhat similar to that found by Schütz. Hell ${ }^{2}$ was unable to differentiate the bacteria of Brustseuche from the pyogenic streptococci. He believed that the organism described by Schütz was the specific cause of Brustseuche. The earlier literature on this organism does not give its cultural characters sufficiently to differentiate it from other streptococei found in lesions in the horse.

In 1897, the writer isolated from the lungs of two of three fatal cases of this disease which occurred in an outbreak in Ithaca a streptococcus in pure culture which possessed morphological and cultural characters of the Streptococcus pyogenes. * Pfeiler, ${ }^{3}$ after studying 24 cases of Brustseuche, concludes that the diplo-streptococeus of Schüt is the cause of the disease. While there are strong indications that the organ-

"Magnusson. Centralbl. f. Bakt., Bd. LVI (1910) p. 411.

${ }^{1}$ Schütz. Virchow's Archiv, Vol. CVII (1887) p. 356.

${ }^{2}$ Hell. Quoted by Friedberger u. Fröhner.

* Evidence of the cocco-bacillus of Lignières either in cultures or in stained sections of the tissues was not found.

${ }^{3}$ Pfeiler. Zeit. f. Infektionskrankheiten u. Hyg. der Haustiere, Bd. VIII (1910) p. 155. 
ism discovered by Schütz is the specific cause, at present the evidence is not absolute that such is the case.

STREPTOCOCCUS CAPSULATUS GALLINARUM.

Place in nature. This streptococcus was described by Dennmann and Manegold as the cause of sleeping sickness of hens.

Morphology. This streptococcus grows in long chains. The individual segments are from 0.3 to 0.5 microns in diameter. Its capsule can be readily detected according to its discoverers by the use of carbol methylene blue applied to preparations of blood from the infected fowls.

Staining. It stains with the ordinary aniline dyes and is Gram positive.

Cultivation. This organism grows best on blood serum and in milk. It will develop, however, on agar gelatin and in bouillon. The addition of from 4 to 6 per cent glycerine or 1 per cent sugar tends to increase the growth. It should be incubated at the blood temperature. It is aërobic and facultative anaërobic. It does not liquefy gelatin. In saccharose bouillon it produces acid and little indol. It elaborates a poisonous toxin. It is destroyed in a 3 per cent solution of carbolic acid or lysol in from 3 to 5 minutes.

Pathogenesis. It is reported to produce a disease in pigeons, rabbits, white and gray mice, causing death in from 10 to 16 days with lesions similar to those of septicemia hemorrhagica.

THE STREPTOCOCCUS OF THE GRANULAR VENEREAL DISEASE OF CATTLE.

Place in nature. Ostertag ${ }^{1}$ describes a streptococcus as the probable cause of granular venereal disease in cattle (infectious granular vaginitis). It was found in the mucous or purulent substance covering the mucous membrane of the vulva and vagina as a diplococcus or in short chains. In sec-

${ }^{1}$ Ostertag. Monatshefte f. prakt. Thierheilk., Bd. XII (1901) p. 533. 
tions of the vagina it was found between the epithelial cells. It stained readily with Loeffler's methylene blue. It was found associated with Micrococcus pyogenes and $B$. coli. It grew sparingly or more vigorously on the usual culture media.

We have made very careful bacteriological examinations of the genital tract of many cattle and found repeatedly streptococci which did not differ from the one described by Ostertag so far as one is able to ascertain from his description. We have made several inoculations in calves but have failed to produce the disease.

\section{STREPTOCOCCI OF MASTITIS.}

Kitt described a streptococeus as the cause of an infectious mastitis in cattle. He designated it Streptococcus agilactae. Gouillebeau described Streptococcus contagiosi as the probable

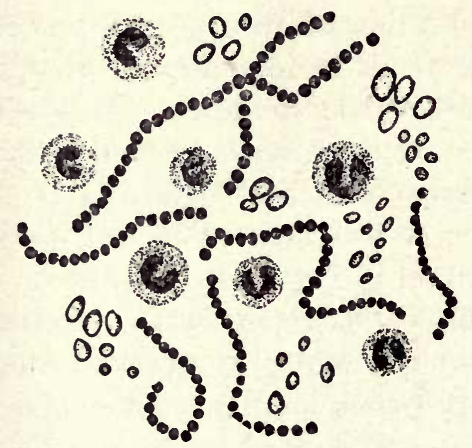

Fig. 47. Streptococcus of mastitis (much enlarged).

cause of this inflammation. The descriptions which these authors give are not sufficient for positive identification. Dubois $^{2}$ describes an acute streptococcic mastitis and Reed and Ward ${ }^{3}$ discuss the streptococei in the normal udder and one which produced acute mastitis. It is not possible, how-

${ }^{2}$ Dubois. Jour. of Comp. Path. and Therap., Vol. XVII (1904) p. 159 .

${ }^{3}$ Reed and Ward. Amer. Medicine, Vol. VII (1903) p. 256. 
ever, to determine the species of these streptococei. Gilruth ${ }^{4}$ mentions a streptococcus as the cause of a very serious mastitis of cows. He found that while it is generally a chronic disease, occasionally a very acute state of inflammation is seen. He states that cases are not altogether rare where death from generalized septicemia has followed the very acute form of the disease.

OTHER STREPTOCOCCI.

The literature contains many statements concerning the presence of streptococei in various local lesions and also associated with the lesions in certain infectious diseases. We have found streptococei repeatedly in the lesions of dog distemper but have not been able to find them in all cases. The descriptions that have been published of streptococci isolated from morbid tissues have, as a rule, not been sufficiently complete to differentiate them or to justify naming them as new species. At present, therefore, we can only say that streptococci have been found in a great variety of lesions. It is possible that further investigations will show that certain of these bear a causal relation to the morbid tissues in which they were found.

${ }^{4}$ Gilruth. Bulletin No. 13, New Zealand Dept. of Agric., Wellington, 1908. 


\section{CHAPTER XVI.}

\section{COCCACEAE.}

GENUS MICROCOCCUS AND ITS SPECIES PATHOGENIC FOR ANIMALS.

General discussion of the genus micrococcus. The genus micrococcus includes the spherical bacteria that divide in two planes. It includes those forms described by the earlier writers as micrococci, that is, single spherical organisms; diplococci, where they are united in pairs; tetracocci, where they appear in fours; and staphylococci, where they appear in clumps or masses. This genus contains a large number of species, more than 200 having been described. They are largely saprophytes. There are but few species known to be important in the production of disease in animals. Several of the infectious diseases of man, however, are due to organisms belonging to this genus. In animals, the micrococci of most importance are those associated with wound infection and which are commonly called pyogenic micrococci.

History. Historically, micrococei were first described by Billroth, Koch, Rosenbach, ${ }^{1}$ Pasteur, ${ }^{2}$ Ogston, and others who were engaged in studying wound infection bacteria. The group of micrococei that grow in clumps were found to be the most common cause of wound infection and consequently those forms described in older classifications as staphylococci (so called from their growth in irregular grape-like clusters) were found to be the most common and apparently the most important of the micrococci. Two varieties of these were recognized, namely, Micrococcus pyogenes, varieties albus and citreus, referring to the color of the growth of the colonies on solid media.

The Botryococcus ascoformans Bollinger or $M$. botryogenes Rabe appears to be identified with $M$. pyogenes.

${ }^{1}$ Loc. cit.

${ }^{2}$ Pasteur. Comp. Rend. de l'Acad. des Sci., Vol. CX (1880) p. 1033. 
Distribution of micrococci. The micrococei are widely distributed in nature. In certain flora such as that of the cow's udder they are the predominating forms. Ward ${ }^{1}$ describes seven micrococei isolated from this flora. Conn, Esten and Stocking ${ }^{2}$ describe 22 species in their classification of dairy bacteria. They are present in variable numbers on the mucous membranes of the digestive tract and also on the skin. The pyogenic coeci are numerous about stables and hospitals where suppurating wounds are common. They are frequently found on the hands of those engaged in the dressing of such eases. There is not in general the close resemblance between the micrococei that there is between the streptococci.

MICROCOCCUS PYOGENES (ROSENBACH) MIGULA.

Synonyms. Staphylococcus pyogenes aureus Rosenbach, grape-coceus, pus coccus.

Place in nature. This microorganism is one of the most frequent causes of abscesses, wound infection and suppuration. It is quite widely distributed in nature. It has been reported from various external sources, and the skin and mucosae of man and animals.

Morphology. It is a spherical coceus having an average diameter of about $0.8 \mu$ but varying within the extreme limits of 0.4 to $1.2 \mu$. Any considerable variation from the average size, however, is rare. The perfectly spherical forms do not appear when two or more are grouped together, unseparated after cell division. In this case, adjacent cocei are slightly flattened along their contiguous surfaces. In smears from cultures or pus, it may appear singly, in pairs, or in irregular grape-like clusters. Occasionally, short chains of three or four may be seen. In very young liquid cultures it often appears as a diplococcus.

Staining. Micrococcus pyogenes stains with all the usual basic dyes, and less intensely, with some of the acid dyes. It stains after Gram's method. This method of staining is excel-

${ }^{1}$ Ward. Bulletin No. 78, Cornell Univ. Exp. Station, 1900.

${ }^{2}$ Conn, Esten and Stocking. Loc. cit. 
lently adapted for the demonstration of these organisms in sections of tissue.

Cultivation. This organism grows readily on the usual laboratory media. The optimum temperature for its growth is about $35^{\circ} \mathrm{C}$. although it develops at temperatures as low as $15^{\circ} \mathrm{C}$. and as high as $40^{\circ} \mathrm{C}$. It is an aërobe and facultative anaërobe. It grows readily in an atmosphere of hydrogen.

Micrococcus pyogenes develops most favorably upon media having a slightly alkaline reaction. Moderately inereased alkalinity or acidity of the media does not inhibit growth.

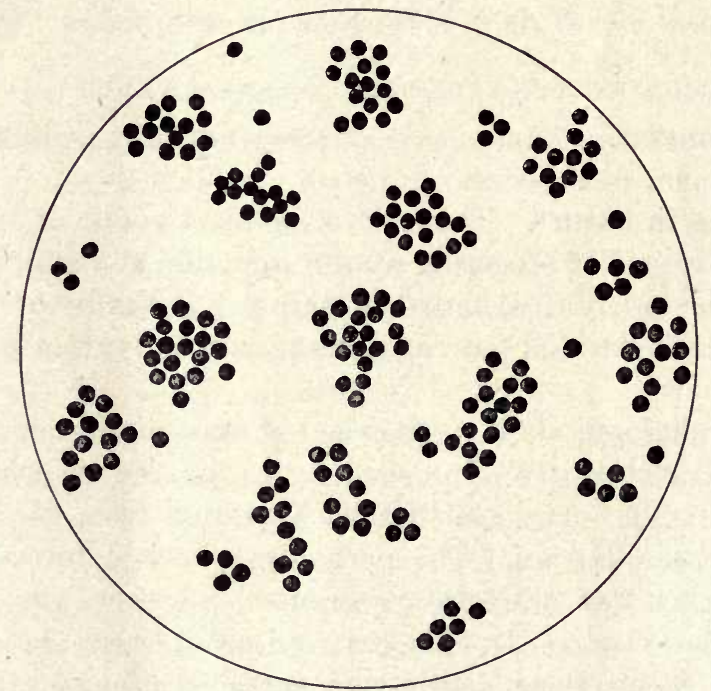

Fig. 48. Micrococcus pyogenes aureus. Drawing from a cover-glass preparation of a bouillon culture. Highly magnified.

Agar. On slant agar the growth is rapid and moderately fleshy. At first it is of a grayish-white, but later develops a glistening golden yellow color.

Gelatin. On gelatin plates, growth oceurs readily at room temperature. Within 36 to 48 hours, small, shining, pin-head shaped colonies appear, at first grayish-white, and later assuming a yellowish hue, which intensifies into a light brown 
and often a bronze color as the colony grows older. The intensity of the color differs considerably in various races of micrococci. Usually shallow, saucer-shaped depressions are formed about the colonies after forty-eight hours or more due to liquefaction of the gelatin. The zones of liquefied gelatin grow larger as the colonies develop until finally the gelatin is all liquefied. The colonies agre round and rise from the surface of the medium like a segment of a sphere. In gelatin stab cultures in tubes, liquefaction leads to the formation of a funnel shaped depression, with final complete liquefaction of the medium and sedimentation of the bacteria.

Potato. On potato, growth is abundant, rather dry and usually deeply pigmented.

Blood serum. Upon coagulated animal sera, rapid growth takes place and eventually slight liquefaction of the medium is said to occur.

Bouillon. In bouillon growth is rapid, leading to a general, even clouding of the medium, and giving rise, after 48 or more hours, to the formation of a thin surface pellicle. As growth increases, the bacteria sink to the bottom, forming a heavy, mucoid sediment. The odor of old cultures is often peculiarly acrid, not unlike weak butyric acid. In bouillon containing sugars, dextrose, lactose or saccharose-lactic, butyric, and formic acids are produced. There is no gas formation. In proteid media free from sugars, it produces an alkali.

Milk. In milk, it causes coagulation usually within three or four days, with the formation of lactic and butyric acids.

Life conditions and properties. Micrococcus pyogenes is a hardy organism growing readily on ordinary media. It produces a ferment-like body which is spoken of as "gelatinase" and which ean be obtained apart from the organism by the filtration of cultures. ${ }^{1}$ It is an extremely thermolabile body. It reduces nitrates and produces indol. Its reducing

${ }^{1}$ Loeb. Centralbl. f. Bakt., Bd. XXXII (1902) p. 776. 
action is shown by decolorization in eultures of litmus, methylene-blue and rosanalin. ${ }^{2}$

Resistance. Although it does not form spores Micrococcus pyogenes is more resistant to heat than many other purely vegetative forms. The thermal death point given for Micrococcus pyogenes by Sternberg ${ }^{3}$ lies between $56^{\circ}$ and $58^{\circ} \mathrm{C}$., the time of exposure beging ten minutes. The same author states that when in a completely dried state, it is still more resistant, a temperature of from $90^{\circ}$ to $100^{\circ} \mathrm{C}$. being required for its destruction. Against low temperatures, Micrococcus pyogenes is extremely resistant, repeated freezing often failing to sterilize cultures. Park states that 30 per cent of the organisms remained alive after being frozen for 30 minutes in liquid air. They are destroyed by corrosive sublimate in solution of $1-1000$ and in a 3 per cent carbolic acid solution in from 10 to 15 minutes.

Pathogenesis. This organism is found in a large number of abscesses, suppurating lesions, and occasionally in general sepsis, in a number of species of animals. It is one of the most important of the wound-infecting organisms. It is not the cause of any of the recognized specific infectious diseases. The susceptibility of animals to it varies greatly, depending upon resistance of the individual and virulence of the organism. Generally speaking, animals are less susceptible than man. Of the laboratory animals, the rabbit is most susceptible. Guinea pigs are more resistant. The subcutaneous inoculation usually results in the production of a local abscess. In case the animal is somewhat resistant, the inflammatory process may extend somewhat. When inoculated intravenously, sepsis and occasionally a pyemic condition follows. Occasionally, deep seated abscesses containing this organism are found. We have two specimens of suppuration beneath the endocardium in cattle associated with this organism.

Hemolysis. Kraus ${ }^{4}$ has reported a hemolytic action of

${ }^{2}$ Mueller. Centralbl. f. Bakt., Bd. XXVI (1899) p. 801.

${ }^{3}$ Sternberg. Loc. cit.

*Kraus. Wien klin. Wochenschrift, Vol. III, 1900. 
M. pyogenes growing on blood-agar plate cultures. Neisser and Wechsberg found that the hemolytic substance could be found in filtrates of bouillon culture. The quantity produced varied to a large extent in different strains of the organism and, it has been asserted, bears some relation to the virulence of the particular organism. It is further stated that the culture medium most favorable for the formation of these substances is alkaline beef bouillon. The hemolysin is said by some to be destroyed by heat at $56^{\circ} \mathrm{C}$. and others claim that a higher temperature is required.

Micrococcus pyogenes variety albus (Rosenbach) and $M$. pyogenes variety citreus (Passet) are practically identical with M. pyogenes excepting in the color of the growth on solid media. They do not appear, however, quite so frequently and as a rule they do not seem to possess as uniform virulence as M. pyogenes variety aureus.

\section{MICROCOCCUS CAPRINUS.}

Place in nature. This micrococcus was described by Mohler and Washburn ${ }^{1}$ in the organs of goats that had died of the disease known as "Takosis."

Morphology. This organism is spherical or oval, with a diameter of 0.8 to $1.0 \mu$ when grown in bouillon cultures. It frequently appears in pairs and in short chains with a diameter transverse to the chain, longer than the longitudinal diameter. It exhibits considerable variation in size. In older cultures there is a greater tendency to form chains. They exhibit quite pronounced Brownian movement.

Staining. It stains indistinctly with Loeffler's methylene blue and the standard aqueous aniline dyes, with the exception of gentian violet. It stains readily with carboliuchsin.

Cultivation. It is an aërobe and facultative anaërobe. It grows in both slightly alkaline and acid media. Its most favorable temperature is about $35^{\circ} \mathrm{C}$.

${ }^{1}$ Mohler and Washburn. Bulletin No. 45, B. A. I., U. S. Dept. Agric., 1903. 
Agar. On agar, after 24 hours, a white glistening granular growth of confluent colonies appears. It reaches its maximum growth on the fourth day with a somewhat granular surface and irregular wavy margin. On agar plates these appear as smooth, whitish, flatly convex, ceraceous colonies, about $1.5 \mathrm{~mm}$. in diameter. By transmitted light, they present a whitish center and a pearly margin. Colonies in the depth of the agar are slightly brownish with an irregular outline. They may be either round or lentil shaped but are always minute. There is no distinguishing difference in the growth of this organism on glycerin or on serum gelatin agar.

Gelatin. It grows somewhat slowly in gelatin, evidences of growth not appearing until the second day. The colonies are more minute than on agar and the growth that appears on the surface, though similar in consistency, is likewise thinner and less profuse than on agar. It does not liquefy gelatin until several generations have been grown on artificial media. With cultures that have been passed through several generations, the surface growth in the tube cultures on the fourth or fifth day begins to sink in the medium, after which liquefaction is very rapid, and within two or three days it may reach the bottom of the tube. The surrounding gelatin is then attacked and the whole mass becomes fluid with a white pellicle on the surface. In gelatin plates, liquefaction does not begin until the fourth or fifth day and sometimes later.

Potato. On this medium, inoculated from a vigorous bouillon culture, growth is somewhat feeble and ceases on the third day.

Blood serum. On dog serum, the organism forms a narrow compact line of whitish color with edges slightly elevated above the level of the body of the growth. The water of condensation becomes clouded. After 7 or 8 days, the color assumes a brownish tint.

Bouillon. In bouillon at $37^{\circ} \mathrm{C}$. the liquid becomes cloudy after 10 hours, and continues to increase for about 24 hours. At this time there may be a deposit of organisms at the bottom of the tube. The sediment is pearl gray in color and upon 
agitation rises slowly in the shape of a twisted ropy coherent mass. A delicate marginal ring on the side of the tube is usually present. No pellicle forms. The reaction in bouillon becomes decidedly acid after some days. In bouillon containing 1 per cent lactose, dextrose or saccharose, the growth is rapid, but gas is not formed. The closed bulb becomes uniformly cloudy. The liquid becomes strongly acid.

Milk. In milk, it grows rapidly. The milk becomes firmly coagulated in from three to four days. The coagulum becomes partially peptonized and a transparent odorless whey is collected about the coagulated mass. Litmus milk is changed to a delicate pink on the third day.

Life conditions and properties. There is evidence of phenol when Weyl-Lewandowski's ${ }^{1}$ test for phenol is used.

Resistance. This organism is destroyed at a temperature of from 58 to $60^{\circ} \mathrm{C}$. after 10 minutes. It is destroyed by a solution of 1 to 1000 bichloride of mercury in about $1 / 2$ minute. Formalin in strength of 2 per cent destroys it in less than a minute.

Pathogenesis. This organism which is the cause of takosis, a contagious disease of goats, is characterized by emaciation. Mohler found that it was pathogenic also to mice, guinea pigs and to a certain extent for rabbits. He also found that a certain number of the goats inoculated and fed with this organism developed the disease.

\section{MICROCOCCI PATHOGENIC FOR MAN.}

Several micrococci attack man. M. pyogenes (Staph. pyogenes aureus) is a very important pyogenic and wound infecting organism for man. The micrococei of specific etiological importance in the human species are: $M$. catarrhalis, supposed to be the eause of a nasal eatarrh; $M$. gonorrhoea, the cause of gonorrhoea; $M$. intracellularis meningitis, the cause of cerebro-spinal meningitis; $M$. lanceolatus, the cause of lobar pneumonia; M. tetragenus, occasionally found in acute abscesses; and $M$. melitensis, the cause of Malta fever.

${ }^{1}$ Lewandowski. Deut. med. Woch., Bd. XVI (1890) p. 1186. 
With the exception of $M$. pyogenes these micrococei are not known to be of significance in the cause of naturally contracted diseases in lower animals.

OTHER MICROCOCCI.

Micrococci resembling more or less $M$. pyogenes or its: varieties have been found in many lesions either alone or associated with other bacteria. The descriptions of some of these are so brief that it is impossible to identify them. In the study of animal diseases numerous micrococei are liable to occur in the cultures but usually they are secondary invaders. 


\section{CHAPTER XVII.}

\section{BACTERIACEAE.}

\section{GENUS BACT'ERIUM AND ITS SPECIES PATHOGENIC FOR}

ANIMALS.

General discussion of the genus Bacterium. In Migula's: classification the genus bacterium includes all the non-motile rod-shaped bacteria. The genus is based morphologically on the absence of organs of locomotion, or flagella. In some of the earlier classifications, the genus Bacterium was based on the absence of spores and many non-motile, spore-bearing, rodshaped bacteria were called bacilli. Several of the more common pathogenic organisms such as Bacterium anthracis, Bacterium mallei and others belonging to this genus were described according to the older classifications as belonging to the genus Bacillus. The genus Bacterium as defined by Migula contains a large number of the more important pathogenic species.

History. The genus Bacterium was introduced by Ehrenberg ${ }^{1}$ in 1828. In the different classifications of bacteria since his time it has been used with different meanings. In the more recent systems the sense in which the term is used is quite different. Lehmann and Neumann apply the name bacterium to all rod-shaped bacteria in which spores are unknown. Migula ${ }^{2}$ uses the term bacterium for all non-motile rods, disregarding the production of spores. Fischer does not use this genus in his classification.

As already stated, Migula's system seems to lend itself to the classification of pathogenic bacteria much better than others for the reason that it has less genera and consequently changes the generic names of a smaller number of species.

${ }^{1}$ Ehrenberg. Abhandlungen der Akademie der Wissenschaften, 1829 , p. 15.

${ }^{2}$ Migula, loc cit. 
Distribution. The species belonging to this genus are widely distributed in external nature. Migula describes about 380 species, a number of which were found in the intestines of domesticated animals. They exist, however, in soil and water as well as in the animal body. There are undoubtedly many descriptions not included in Migula's list. From the point of view of pathology, this genus contains a number of groups of organisms that are of the highest importance and which still require a large amount of study before their relation one to another can be accurately determined. The two most important groups are the acid fast or acid proof organisms, and the septicemia hemorrhagica group, both of which appear to contain species that range in their relation to disease producing power from unquestioned saprophytes to highly virulent pathogenic forms.

\section{BACTERIUM ABORTIONIS BANG.}

Synonyms. Bacillus abortus; Bacillus of contagious abortion in cattle, Bang. ${ }^{3}$

Place in nature. This organism is supposed to be the cause of infectious abortion in cattle. It was discovered by Bang in Denmark, who described it as an anaërobe. Later it was isolated and described by M'Fadyean and Stockman ${ }^{4}$ and $\mathrm{McNeal}^{5}$ who were able to cultivate it in the presence of oxygen. There are those who feel that this organism has not been satisfactorily demonstrated as the cause of abortion. Nowak ${ }^{-}$ confirmed the work of Bang and placed great confidence in the etiological relation of this organism to the disease. Nowak's contribution to our knowledge of this subject was in the dis-

${ }^{3}$ Bang. Zeitsch. f. Tiermedizin, Bd. I (1897) Heft 1; also Jour. Comp. Path. and Therap., Vol. X (1897) p. 125.

'M'Fadyean and Stockman. Report of the Departmental Committee appointed by the Board of Agric. and Fisheries to inquire into epizoötic abortion. London, 1909.

- McNeal. Jour. of Inf. Diseases, Vol. VII (1910) p. 469.

- Nowak. Ann. de l'Inst. Pasteur, Vol. XXII (1908) p. 541: 
covery of a particular plate method * for the isolation of the abortion organism from contaminated material. MacNeal and Kerr ${ }^{7}$ verified Nowak's findings and also isolated the organism by inoculating the material subcutaneously into pregnant guinea pigs, recovering the organism from the uterus after abortion. The natural habitat of this organism outside of the animal body is not known.

Morphology. This organism appears as ovals or short rods with rounded ends. They are observed in preparations from the uterine exudate singly, in small clumps or in more dense masses. In some preparations they appear as clumps of agglutinated bacteria. They vary from 0.6 to $2.5 \mu$ in length and are about $0.8 \mu$ in thickness.

Staining. It stains readily but somewhat irregularly with alkaline methylene blue and with dilute carbol fuchsin. It is negative to Gram's stain.

Cultivation. Bacterium abortionis was originally isolated and cultivated artificially by Bang and Stribolt in agargelatin-raw serum. This medium was inoculated while it was

* For this purpose ordinary agar is melted and cooled to $50^{\circ} \mathrm{C}$., then mixed with about one-fourth its volume of naturally sterile blood serum, and poured into sterile Petri dishes where it is allowed to solidify. The piece of the placenta or other material from the abortion is now streaked over several of these plates in succession, according to the usual bacteriological technic for obtaining streak dilution cultures. The plates are then placed at $37^{\circ} \mathrm{C}$. for 24 hours to allow contaminating aërobic bacteria to develop. Parts of the plate surface free from colonies are now marked with a wax pencil, as it is upon these areas that the growth of the abortion bacillus may subsequently appear if it is present. The plates are next put into a glass jar or desiccator together with a culture of the common hay bacillus, B. subtilis. About $1 \mathrm{sq}$. $\mathrm{cm}$. of culture surface of the latter organism should be allowed for each $15 \mathrm{cc}$. air capacity of the jar. The jar is now closed and placed at $37^{\circ} \mathrm{C}$. for three days, at the end of which time the transparent colonies of the abortion bacillus will have developed, if it is present. The growth of the $B$. subtilis culture serves to absorb the oxygen in the jar to just the partial pressure required for the development of the abortion organism.

${ }^{7}$ MacNeal and Kerr. Jour. of Inf. Diseases, Vol. VII (1910) p. 469. 
still liquid and colonies developed within the medium. Later M'Fadyean and Stockman found that very small isolated greyish speck-like colonies would appear in the thin film of medium on the surface. It was also found that it grew on the surface of ordinary agar but quite slowly. It will grow also in an atmosphere of pure oxygen.

Agar. When agar is inoculated with the natural material the growth is very slow often requiring ten days for its appearance. The isolated colonies are at first of a greyish color and later they become brownish. M'Fadyean and Stockman state that on agar the colonies first appear like very minute dew drops on the surface and later they develop into a delicate bottle-green tint and still later become a brownish tint. Dense masses of the bacteria collect in the water of condensation. Glycerine added to the agar does not increase the growth. In agar tubes inoculated after the Liborius method the colonies may appear under the surface. In plate cultures the growth seems to be more uncertain.

Gelatin. It does not grow on gelatin.

Potato. Potatoes are not satisfactory for obtaining original cultures but they are excellent for subcultures. On this medium the organism gives at the beginning a honeyyellow transparent looking viscous growth. It requires from 5 to 8 days for it to appear. With continued incubation the growth slowly increases in thickness, becomes opaque, and deepens in color, passing from the original yellow, through a ruddy tint, to a brown or chocolate one. M'Fadyean and Stockman called attention to the resemblance of the growth of this organism on potato to that of glanders. It is differentiated from it by its slow growth. They consider the growth on potato the most distinctive of the cultural characteristics.

Agar-gelatin-raw serum (Stribolt's medium). Bang found that in this medium the organism was practically anaërobic as determined by the deep inoculation (Liborius' method). M'Fadyean and Stockman describe the growth as follows: "When the Stribolt medium was sown with exudate 
very small isolated gray specks would appear in the film of medium on the surface at the circumference of the tubes, and a gray circular cloud appeared immediately below the surface and very soon spread to the top, especially if some of the fluid parts of the medium had been expressed in the cooling process. Not infrequently, also, the growth appeared to begin in the surface liquid. Such growths became distinctly visible after two days' incubation. Distinct colonies only appeared in the deeper part of the medium, that is to say, at the site of and below the grayish ring, after a week, and sometimes longer. The distance below the surface at which these colonies appeared varied considerably in different cases. A few isolated ones were occasionally found half an inch and even more below the surface, that is to say, in what might be called the anaërobic zones of the tubes.

"We were able eventually to convince ourselves that these occasional colonies were not impurities, although the appearance of a larger number of colonies in this situation may be taken as proof positive that the culture is impure.

"The majority of the sub-surface colonies appeared in the zone comprised between $1 / 8$ and $1 / 2$ inch below the surface. The number varied from one or two to hundreds; usually they were very numerous. In some cases we found a lower zone of colonies about $1 / 4$ of an inch from the surface, and an upper layer of small gray isolated colonies so near the top that they raised the surface of the medium and finally burst through the thin solid film and spread over the top.

"On most of the tubes which grew at all, as has been previously mentioned, there was a visible growth after two days' incubation, but in a number of cases we have seen the tubes require ten days' incubation before a growth became visible. The latter appeared almost invariably at about $1 / 4$ inch below the surface of the medium.

"The colonies vary in size from a pin point to the head of a large pin. The smaller ones are grayish in color, but as they increase in size, the center becomes of a distinct rusty 
brown. They approach the circular in outline, and in many cases the margins are dentated. Perhaps the most distinct characteristic of the abortion bacillus grown in this way is the appearance of the larger colonies above described showing the brownish center, gray rim and dentated edges."

Bouillon. The three strains studied impart a very faint cloudiness to the liquid. A small quantity of grayish viscid sediment forms in the bottom of the tube. In glycerine bouillon the growth is more vigorous. The strains studied show a growth in the open bulb of the fermentation tubes but not in the closed arm. The reaction is not changed in bouillon containing dextrose, lactose or saccharose.

Milk. Milk is not changed in its appearance.

Life conditions and properties. This organism seems to grow best at a temperature of about $37^{\circ} \mathrm{C}$. It was first described by Bang as an anaërobe but the English strain and likewise those isolated by MacNeal and in this laboratory in America grow in the presence of atmospheric oxygen. There seems to be an endotoxin product that gives rise to an elevation in temperature shortly after the injection of cultures.

M'Fadyean and Stockman prepared an "abortin" which consisted of the liquid in which the organism was grown for 4 to 6 weeks, heated to $99^{\circ} \mathrm{C}$. and filtered. With this filtrate they tested infected cattle and found that a reaction somewhat similar to that following the injection of tuberculin in tuberculous cattle was obtained in cases of infection. This suggests a soluble toxin of some kind. The same authors describe a method of determining infected cattle by the "complement fixation test" which indicates the production of specific antibodies.

Sven Wall ${ }^{8}$ reports excellent results in the diagnosis of animals affected with the abortion bacterium by means of the agglutination test and with the method of "fixation of complement." He reports testing it on a very large number of cattle. Holth ${ }^{9}$ describes the morphology and cultural charac-

- Wall. Zeit. f. Infek....der Haustiere, Bd. X (1911) p. 132.

'Holth. Zeit. f. Infek....der Haustiere, Bd. X (1911) p. 207. 
ters of this organism and also emphasizes the value of the agglutination test in detecting animals infected with this organism.

Resistance. Bact. abortionis is destroyed by heat at $60^{\circ} \mathrm{C}$. for a short time and by the usual disinfectants. It seems to be eliminated from the body of the infected cow in about six weeks after abortion.

Pathogenesis. M'Fadyean and Stockman state that they "have no hesitation in stating that we believe that at least 99 per cent of the outbreaks of cattle abortion which assume epizoötic characters are due to infection by the bacillus of cattle abortion, and that the fact of a cow having aborted on a premises formerly believed to be clean is a sufficient reason for suspecting that the disease has been introduced."

We have produced abortion in guinea pigs by the subcutaneous injection of cultures of this organism. Also pregnant cows injected in the jugular vein with pure cultures aborted and the organism was obtained from the uterus. The time required was from 40 to 120 days.

\section{BACTERIUM ANTHRACIS (KOCH) MIGULA.}

Synonyms. Bacillus anthracis Koch.

Place in nature. Bacterium anthracis is the cause of anthrax, a destructive infectious disease especially of the herbivora. Cattle and sheep suffer most, although horses, hogs, goats, guinea pigs and rabbits are susceptible. It also affects man, usually eausing local lesions which are often fatal. The disease is known in the human species as malignant pustule, wool-sorters' disease and rag-pickers' disease. Anthrax was formerly very prevalent on the continent of Europe as well as in India, Persia and Siberia. It has appeared in many places in the United States.*

Bacterium anthracis was first observed in 1849 by Pol-

* The literature shows that it has been reported from about 25 of the states. In 1910 (Report of the N. Y. State Vet. College) it appeared in ten localities in New York State. 
lender ${ }^{1}$ who. happened to examine the blood of a cow that had died from anthrax. The same observation was made independently by Brauell ${ }^{2}$ and Davaine. ${ }^{3}$. The organism did not receive special attention until Davaine published his further researches in 1863. Until this time, many ridiculed the theory of these little rods being the cause of the disease. Considerable interest is attached to this organism historically, as it was the first bacterium that was demonstrated as bearing a definite etiological relation to an infectious disease of animals. It has been stated that Bacterium anthracis laid as it were the corner stone of modern bacteriology.

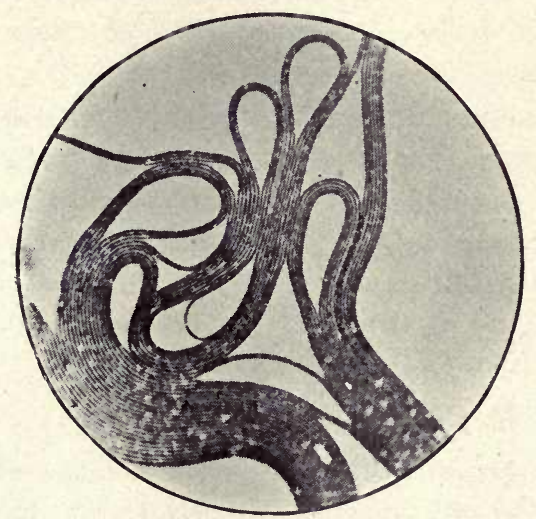

Fig. 49. Bacterium anthracis. Impression preparation from,a gelatin colony.

Morphology. The anthrax bacterium is a straight rod, 5 to $10 \mu$ in length, and from 1.0 to $2.5 \mu$ in width. In preparations made from the blood of an infected animal, the bacteria are usually single or in pairs. Grown on artificial media they form skeins of long threads. The ends are square cut. When in pairs or short chains the ends are often depressed so that the corners are sharp and the.ends of the bacteria touch each other only at these points, leaving in consequence an oval space between the ends of the organisms. On artificial media the anthrax bacteria form spores. The spore, one in each bacterium, appears as a small, highly refractile spot in the center of the individual bacterium. As this enlarges, the body of the bacterium around

${ }^{1}$ Pollender. Vierteljahrschar Ger. Med., Bd. VIII (1855).

${ }^{2}$ Brauell. Virchow's Archiv, Bd. II (1857).

${ }^{3}$ Davaine. Compt rendu de l'Acad. des Sci., Vol. LVII (1863). 
it gradually undergoes granular degenration and loses its staining eapacity. ${ }^{4}$ Oxygen is necessary for their formation and they are consequently not found in the blood or tissue of infected subjects. The spores are located in the middle of the organisms and they are distinctly oval. In preparations from animal tissues, especially the blood, a capsule is observed surrounding the organism. This is never seen in preparations from the ordinary culture medium. Its pres-

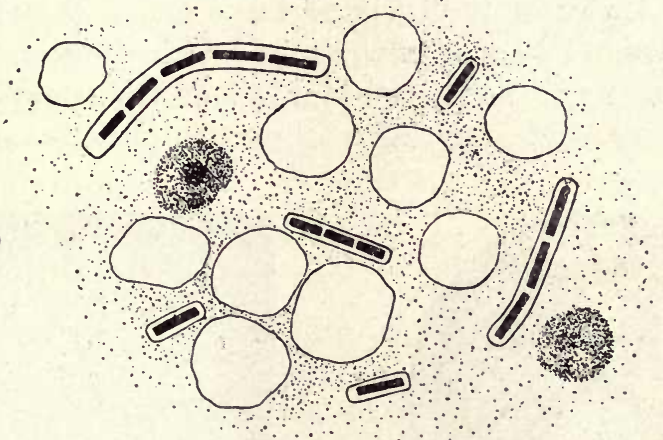

Fig. 50. Anthrax bacteria in a cover-glass preparation of blood, showing short chains and capsules.

ence has been recorded by some observers when the organism was cultivated in fluid blood serum. In blood from infected animals the organisms frequently appear in short chains. In these cases the capsule surrounds the entire chain.

Staining. They stain readily with the usual aniline dyes and with gentian violet and fuchsin in aqueous solution. The spores are difficult to stain but may be demonstrated by any of the usual methods for staining spores. The organisms retain the stain when treated by the Gram method. A differential stain has been described by M'Fadyean ${ }^{5}$ which he considers of much practical value.

${ }^{4}$ Behring. Zeit. f. Hyg., Bd. VI and VII, 1889; Deut. med. Woch., 1889.

${ }^{5}$ M'Fadyean. Jour. Comp. Path. and Therap., Vol. XVI (1903) p. 35 . 
Cultivation. The anthrax bacterium is an aërobic, facultative anaërobic organism. While it may develop slowly and sparsely under anaërobic conditions, free oxygen is required to permit its luxuriant and characteristic growth.

The optimum temperature for its cultivation is about $37.5^{\circ} \mathrm{C}$. It is not, however, delicately susceptible to moderate variations of temperature and growth is not entirely checked until temperatures as low as $12^{\circ} \mathrm{C}$. or as high as $45^{\circ} \mathrm{C}$. are reached. By continuous cultivation at a temperature near either the higher or the lower of these limits, it may become well adapted to the new environment and attain a luxuriant growth. It may be cultivated on all of the usual artificial media. It grows in hay infusion and on various other vege-

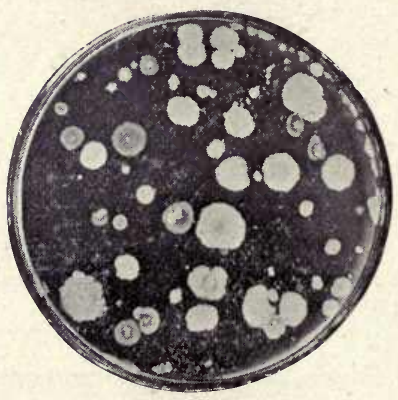

Fig. 51.

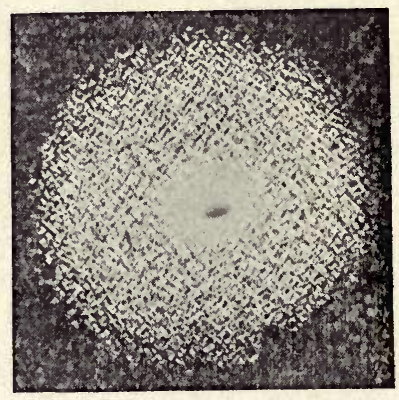

Fig. 52.

Fig. 51. Photograph of colonies of anthrax bacteria on agar plate culture. (Reduced one-half.)

Fig. 52. Photograph of a colony on agar of anthrax bacteria. $\times 6$.

table media. A neutral or slightly alkaline medium is the most favorable for its growth.

Agar. On agar plates, growth at $37.5^{\circ} \mathrm{C}$. is vigorous and colonies appear within twelve to twenty-four hours. They are irregular in outline, slightly wrinkled, and give under the microscope a characteristic tangled-thread appearance. The colonies are slightly glistening and tough in consistency.

On inclined agar, the colonies usually become confluent, 
the entire surface soon being covered by a grayish, tough pellicle which has a tendency to come away in thin strips or strands.

Gelatin. On gelatin plates, colonies develop within twenty-four to forty-eight hours as opaque, white disks, pinhead in size, irregularly round and rather flat. As the colonies increase in size their outlines become less regular and under the microscope they are seen to be made up of a hair-like tangle of threads spreading in thin wavy layers from a more compact central knot. The microseopic appearance of these colonies has been aptly described as resembling a "Medusa" head. Fragments of a colony examined on a slide with a higher power show the individual threads to be made up of parallel chains of bacteria.

After a day or two of further growth, the gelatin about the colonies becomes liquefied.

In gelatin stab cultures the growth appears at first as a thin white line along the course of the puncture. From this, growth proceeds in thin spicules or filaments diverging from the stab, more abundant near the top than toward the bottom, owing to more active growth in well oxygenated environment. Liquefaction begins at the top, at first a shallow depression filled with an opaque mixture of bacteria and liquid gelatin. Later the bacteria sink to the bottom of the flat depression, leaving a clear supernatant fluid of peptonized gelatin.

Potato. On potato, growth is rapid, white, and rather dry. Sporulation upon potato is rapid and marked, and the medium is favorable for the study of this phase of development.

Bouillon. In bouillon the growth takes place rapidly. Usually an initial pellicle forms at the top where the oxygen supply is greatest. Simultaneously with this, a slimy sediment appears at the bottom of the tube, due to the sinking of the bacteria. Apart from isolated flakes and threads the intervening broth is clear. When gently shaken the growth in the 
upper part of the tube appears as a tough, stringy, fluffy mass. A general clouding of the liquid is produced only by vigcrous shaking.

Milk. Milk is slowly acidified and slowly coagulated. This action is chiefly upon the casein; very few, if any, changes are produced either in the sugars or in the fats of the milk. The acids formed are, according to Iwanow, ${ }^{6}$ chiefly formic, acetic, and caporic.

Life conditions and properties. The anthrax bacterium is aërobic and facultative anaërobic. In the animal body it oceasionally forms capsules. In artificial cultures in the presence of oxygen, it sooner or later invariably forms spores. The spores appear after the culture has reached its maximum of development. Sporulation never occurs in the animal body, probably because of the absence of sufficient free oxygen. Spores are formed most extensively ${ }^{\top}$ at temperatures ranging from $20^{\circ}$ to $30^{\circ} \mathrm{C}$. Spore formation ceases below $18^{\circ} \mathrm{C}$. and above $42^{\circ} \mathrm{C}$. For different strains these figures may vary slightly, as has been shown by the results of various observers. Spores appear most rapidly and regularly upon agar and potato media.

If anthrax bacteria are cultivated for prolonged periods upon media containing hydrochloric or rosalic acid or weak solutions of carbolic acid, ${ }^{8}$ cultures may be obtained which do not develop spores and which seem permanently to have lost the power to produce them without losing their virulence to the same degree. Similar results may be obtained by continuous cultivation at temperatures above $42^{\circ} \mathrm{C}$. By this procedure, however, its virulence is diminished or entirely lost.

Pathogenesis. Of the experimental animals, white and field mice and guinea pigs are most susceptible. The Algerian sheep shows a marked resistance, while the European variety is highly susceptible. The gray rat is much more resistant

${ }^{6}$ Iwanow. Ann. de l'Institut Pasteur, 1892.

'Koch, loc. cit.

${ }^{8}$ Chamberland et Roux. Compt rendu de l'Acad. des Sci., Vol. XCVI (1882). 
than the white rat. Dogs, hogs, cats, birds, and the coldblooded animals are relatively insusceptible. For man the bacterium is definitely pathogenic, though less so than for some of the animals mentioned above.

Experimental infection in susceptible animals is most easily accomplished by subcutaneous injections. As a rule the inoculated animals appear perfectly well and comfortable until a few hours before death, when they suddenly become visibly very ill, rapidly go into collapse, and die. The duration of the disease, from the time of infection to death, depends to some extent upon the resistance of the infected. individual. In guinea pigs and mice it is usually twenty-four to forty-eight hours. The quantity of infectious material introduced, on the other hand, has little bearing upon the final outcome; a few bacteria, or even a single bacterium, may bring about fatal results. Barber ${ }^{9}$ found that in one instance a single bacterium was sufficient to kill a mouse, indicating that a sublethal dose does not exist for very susceptible animals. $\mathrm{He}$ states that fresh virulent material from the mouse has for mice about 100 times the infectivity of material grown in the first agar or bouillon culture.

Although the bacteria are not demonstrable in the blood until just before death, they nevertheless invade the blood and lymph streams immediately after inoculation, and are conveyed by these to all the organs. This has been demonstrated clearly by experiments where inoculations into the tail or ear were immediately followed by amputation of the inoculated parts without preventing the fatal general infection. The bacteria are probably not able at first to multiply in the blood, but find the point of inoculation or less resistant organs more favorable. When the resistance of the infected subject is overcome, they enter the circulation and multiply within it. The bacteria are found in large numbers in the blood and in the capillaries of all the organs at the time of death.

- Barber. Jour. of Inf. Diseases, Vol. VI (1909) p. 634. 
The mode of action of Bacterium anthracis is as yet not clearly determined. It has been asserted that death is brought about to a large extent by purely mechanical means, such as capillary obstruction. A true extracellular toxin or endotoxin has not been demonstrated for the anthrax bacterium. It is a matter of record that neither culture filtrates nor dead bacteria have any noticeable toxic effect upon test animals, and they do not exert an appreciable immunizing action.

Spontaneous infection of animals takes place largely by way of the alimentary canal, the bacteria being taken in with the food. The bacteria are swallowed as spores, and therefore resist the acid gastric juice. In the intestines they develop into the vegetative form, multiply, and gradually invade the system. The large majority of cattle infections are of this type. Direct subcutaneous infection may also occur spontaneously when small punctures and abrasions about the mouth are made by the sharp spicules of the hay, straw, or other varieties of fodder.

Infection by inhalation is probably rare among animals. Transmission among animals is usually by the agency of the excreta or unburned carcasses of infected animals. The bacteria escaping from the body are deposited upon the earth, which forms a suitable place for sporulation. The spores may then remain in the immediate vicinity, or may be scattered by rain and wind over a considerable area. The danger from buried carcasses, at first suspected by Pasteur, is probably very slight owing to the fact that the bacteria can not sporulate in the anaërobic environment to which the buryingprocess subjects them. The disease in cattle and sheep is usually acute, death following within one or two days. The mortality is extremely high.

In man the disease is usually acquired by cutaneous inoculation or by inhalation and through the alimentary tract. M'Fadyean ${ }^{10}$ found anthrax bacteria in the milk that had

${ }^{10}$ M'Fadyean. Jour. of Comp. Path. and Therap., Vol. XXII (1909) p. 148. 
been drawn post mortem from three cows that had died from anthrax. Moore ${ }^{11}$ found the anthrax organism in the milk of a cow at the time of her death but failed to find it in the milk of cows in advanced stages of the disease.

Bacteria resembling Bacterium anthracis. Several spe- . cies of bacteria resembling more or less closely Bacterium anthracis have been described. The accompanying table by Fitch ${ }^{12}$ summarizes the anthrax-like bacteria that may be mistaken for Bacterium anthracis in making a diagnosis.

Vaccine. Pasteur found that when susceptible animals were inoculated with an attenuated culture of Bact. anthracis immunity was established. He attenuated the organism by cultivating it at a temperature of from $42^{\circ}$ to $43^{\circ} \mathrm{C}$. The method of vaccinating, or of securing active immunity against anthrax, in animals is as follows: Two anthrax cultures of varying degrees of attenuation are used as vaccines. The first vaccine is a culture which has lost its virulence for guineapigs and rabbits and is potent only for mice. The second vaccine is a culture which is still definitely virulent for mice and guinea-pigs, but not potent for rabbits. Forty-eight-hour bouillon cultures of these attenuated organisms grown at $37.5^{\circ} \mathrm{C}$. constitute the vaccine actually employed. Vaccine is subcutaneously injected into eattle in doses of 0.25 cc.; sheep are given about half the quantity. After twelve days have elapsed similar quantities of Vaccine II are injected.

Active immunization of small laboratory animals is very difficult, but can be accomplished by careful treatment with extremely attenuated cultures.

${ }^{11}$ Moore. Rept. of the N. Y. State Dept. of Agric., 1897.

${ }^{12}$ Fitch. Report N. Y. State Vet. College, 1910, p. 200. 


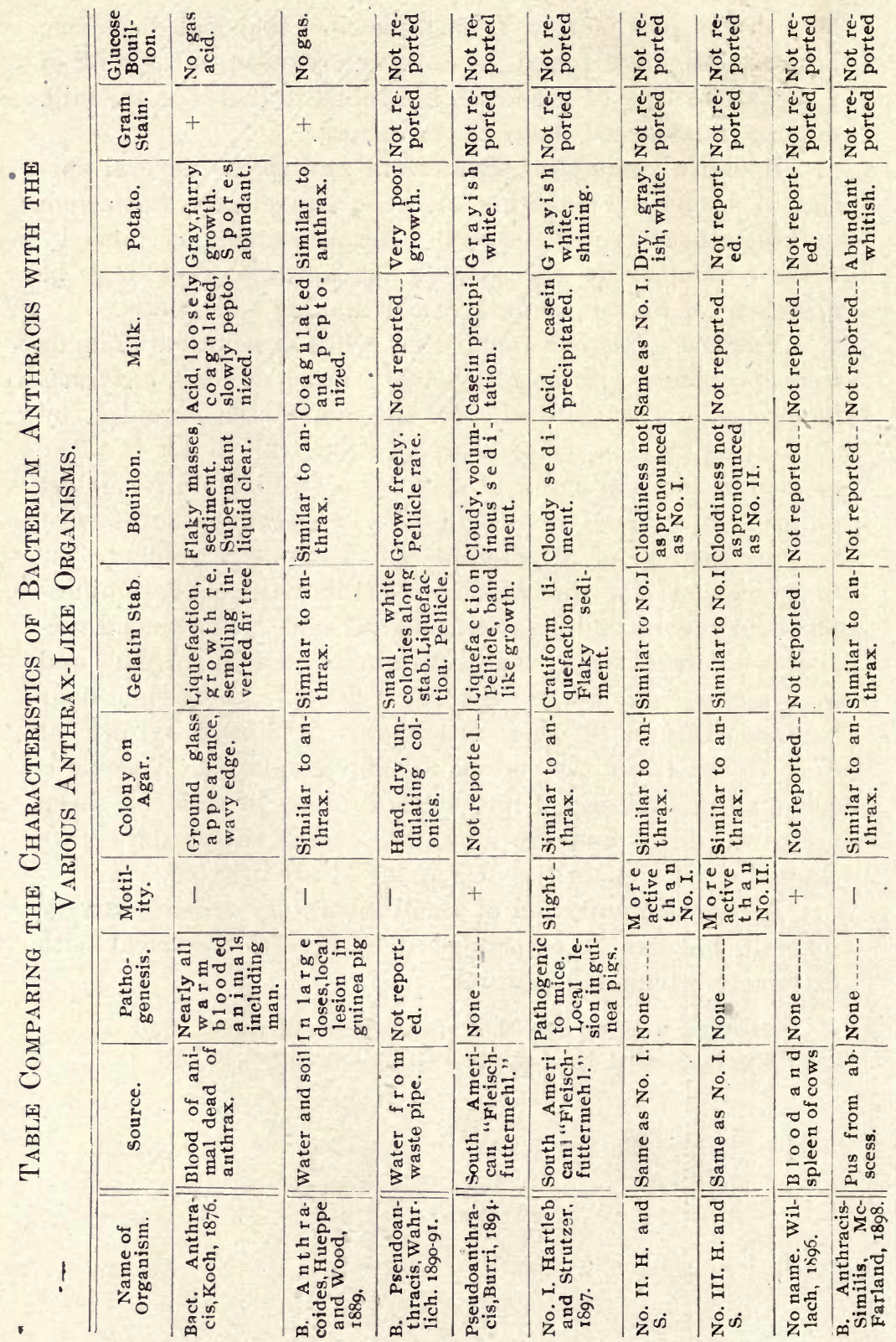




\begin{tabular}{|c|c|c|c|c|c|c|c|c|c|c|c|}
\hline 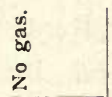 & 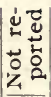 & 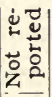 & 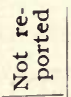 & 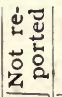 & 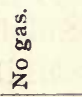 & 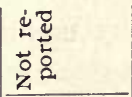 & 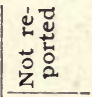 & 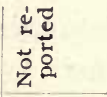 & 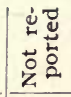 & 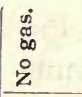 & 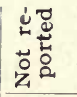 \\
\hline+ & 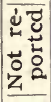 & 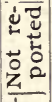 & 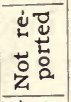 & 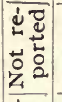 & + & + & + & + & 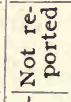 & + & + \\
\hline 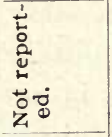 & 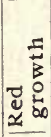 & 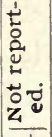 & 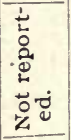 & 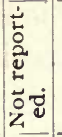 & 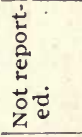 & 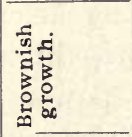 & 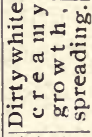 & 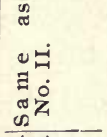 & 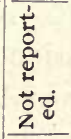 & 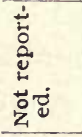 & 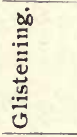 \\
\hline 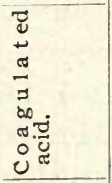 & 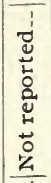 & 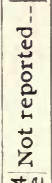 & 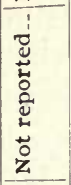 & 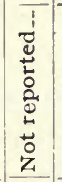 & $\begin{array}{l}1 \\
0 \\
0 \\
0 \\
0 \\
0 \\
0 \\
0 \\
0 \\
0\end{array}$ & 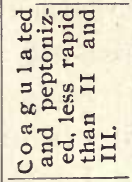 & 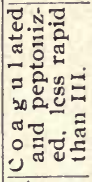 & 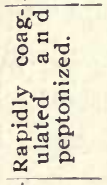 & 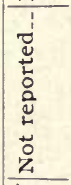 & 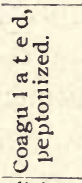 & 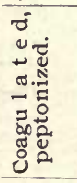 \\
\hline 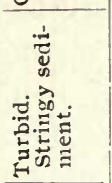 & 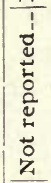 & 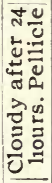 & 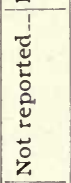 & 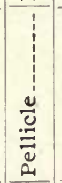 & 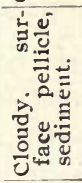 & 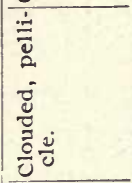 & 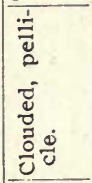 & 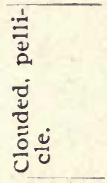 & 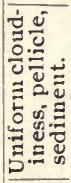 & 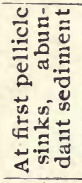 & 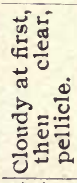 \\
\hline 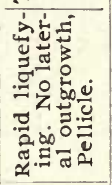 & 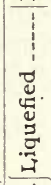 & 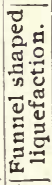 & 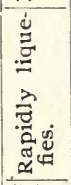 & 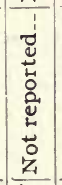 & 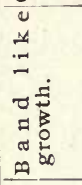 & 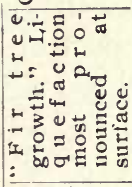 & 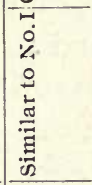 & 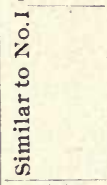 & 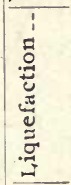 & 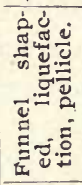 & 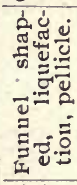 \\
\hline 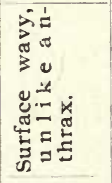 & 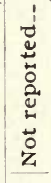 & 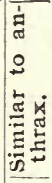 & 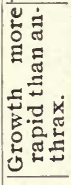 & 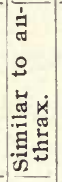 & 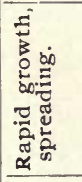 & 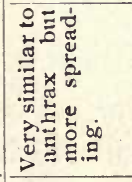 & 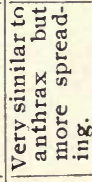 & 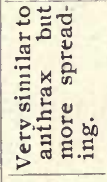 & 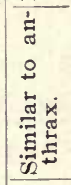 & 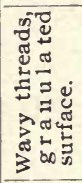 & 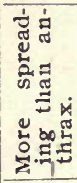 \\
\hline+ & + & + & +1 & + & + & $\frac{1}{\frac{1}{60}}$ & 它苛 & 尊 & + & + & + \\
\hline 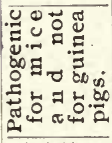 & $\begin{array}{l}0 \\
0 \\
u \\
0 \\
0 \\
0 \\
0 \\
0\end{array}$ & \begin{tabular}{r}
$\vdots$ \\
$\vdots$ \\
$\vdots$ \\
$z$ \\
$z$ \\
\cline { 1 - 1 }
\end{tabular} & 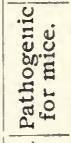 & ¿ & $\begin{array}{l}0 \\
\text { こ̇ } \\
z \\
\end{array}$ & 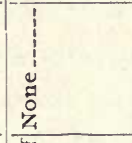 & $\begin{array}{l}0 \\
\ddot{z} \\
z\end{array}$ & 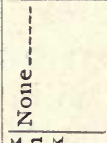 & $\begin{array}{l}\stackrel{0}{Z} \\
\mathrm{z} \\
\end{array}$ & $\begin{array}{l}0 \\
0 \\
z \\
\end{array}$ & $\begin{array}{l}0 \\
0 \\
0\end{array}$ \\
\hline 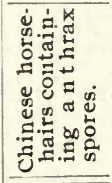 & 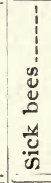 & 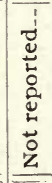 & $\begin{array}{l}\overline{0} \\
\dot{3}\end{array}$ & 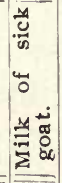 & 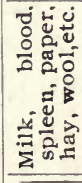 & 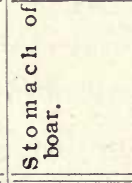 & 资 & 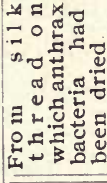 & 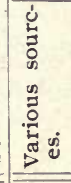 & $\begin{array}{l}1 \\
\vdots \\
5 \\
3 \\
3\end{array}$ & 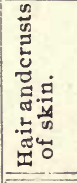 \\
\hline 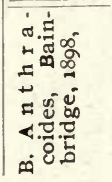 & 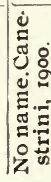 & 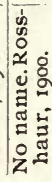 & 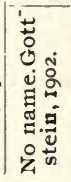 & 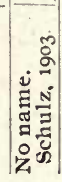 & 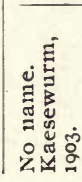 & 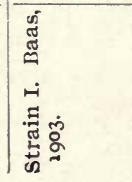 & 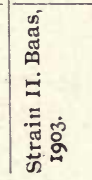 & 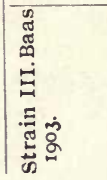 & 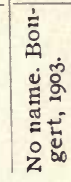 & 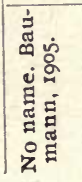 & 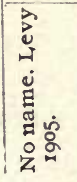 \\
\hline
\end{tabular}


Passive immunization by means of the serum of actively immune animals was first successfully accomplished by Sclavo. ${ }^{13}$ This method has been especially investigated and practically applied by Sobernheim. ${ }^{14}$ The serum used is produced by actively immunizing sheep. It is necessary to carry immunization to an extremely high degree in order to obtain any appreciable protective power in the serum. This is accomplished by preliminary treatment with attenuated vaccines, followed by gradually increasing doses of virulent cultures. Treatment continued at intervals of two weeks, for two to three months, usually produces an effective serum. Horses and cattle may also be used for the process, but they are believed by Sobernheim to give less active sera than sheep. Bleeding is done about three weeks after the last injection. The sera are stable and easily preserved. Horses have also been used to produce the serum. Injections of 20 to 25 ce. of the serum have been found to protect animals from anthrax and to confer an immunity lasting at times for two months. Animals already infected are said to be saved by treatment with 25 to 100 ce. of the serum.

\section{BACTERIUM ASTHENIAE DAWSON.}

Place in nature. Bacterium astheniae was discovered by Dawson ${ }^{1}$ in 1898. He considered it the cause of the disease in fowls known as "going light." It was isolated from the contents of the duodenum and it is not known that it has a habitat in external nature.

Morphology. A bacterium with blunt ends, varying in size according to the medium on which it is grown, from $1 \mu$ to $1.4 \mu$ long and about $0.5 \mu$ wide. It often occurs in pairs.

Staining. It does not stain in acid or alkaline methylene blue, carbol fuchsin, or in any alcoholic solutions of the various

${ }^{13}$ Sclavo. Centralbl. f. Bakt., Bd. XVIII (1895) p. 744.

${ }^{14}$ Sobernheim. Zeit. f. Hyg., Bd. XXV (1897) p. 301 ; Bd. XXXI (1899) p. 89.

${ }^{1}$ Dawson. Annual Report B. A. I., U. S. Dept. Agric., 1898, p. 329. 
aniline dyes. It stains well in aqueous solutions of fuchsin, methylene blue, Bismarck brown and night blue. It takes the Gram stain.

Cultivation. It grows readily on the ordinary culture media.

Agar. A luxuriant white opaque growth, with slightly wavy margins, occurs along the line of inoculation. It attains the maximum growth in about 24 hours.

Gelatin. At $20^{\circ}$ to $25^{\circ} \mathrm{C}$. growth occurs both on the surface and along the line of inoculation. Around the place of entrance is a spreading, brownish, deeply dentated growth. Along the needle track the growth appears as small, yellowish, closely packed colonies. On gelatin plates in twenty-four hours colonies $11 / 2 \mathrm{~mm}$. in diameter appear. The border is raised on a level with the rest of the colony. There is a papillated center. The colony has a yellowish color. The submerged colonies are yellowish and have irregularly lobulated margins with well-defined edges.

Potato. On this medium in three days there occurs a yellowish creamy growth, spreading around the base of the potato cylinder. Along the line of inoculation gas-containing blisters indicate its property of fermenting starch. Some of these have burst, causing crater-like depressions in the growth. The odor is pungent and disagreeable.

Bouillon. The medium becomes densely turbid in 24 hours. A ring of deposit which is easily broken is found at the surface of the liquid. The odor resembles that in cultures of the swine plague organism. The reaction is slightly acid. In acid bouillon, the organism flourishes well, causing a dense turbidity with a floating pellicle and a ring of deposit around the tube at the level of the liquid. The culture has a putrefactive odor and is of a yellowish green color. On the third day considerable white deposit occurs. In a $1 \%$ glucose bouillon, fermentation begins the first day and is completed on the third. The reaction becomes strongly acid. Growth occurs throughout the tube. It has a sour odor. The gas formula is 
$\mathrm{H}, 3$ parts ; $\mathrm{CO}_{2}, 2$ parts. In lactose bouillon there is less gas. Thirty-five em. was the total amount of gas produced. The formula is $\mathrm{H}$, two parts, and $\mathrm{CO}_{2}$, one part. . In saceharose bouillon, the amount of gas produced is much less than in lactose. The formula is $\mathrm{H}, 3$ parts and $\mathrm{CO}_{2}, 2$ parts.

Milk. Milk is firmly coagulated within 24 hours. The whey is perfectly clear, highly acid and odorless.

Life conditions and properties. It is an aërobe and a facultative anaërobe. It will grow at a temperature of $49^{\circ} \mathrm{C}$. It multiplies slightly at $50^{\circ} \mathrm{C}$.

Resistance. Bacterium astheniae is killed when immersed for a short time in thin walled tubes in water at $60^{\circ} \mathrm{C}$. It resists freezing for 24 hours. It resisted drying on cover-glasses. exposed to diffuse light for 12 days.

Pathogenesis. Rabbits inoculated intra-abdominally with 0.5 ec. of a bouillon eulture die within 24 hours.

\section{BACTERIUM MALLEI (LOEFFLER) MIGULA.}

\section{Synonyms. Bacillus mallei Loeffler.}

Place in nature. Bacterium mallei is the cause of an important infectious disease of horses and the horse kind known as glanders. Man is also suseeptible. Bact. mallei is a parasitic organism not known to exist in nature except in the tissues of glandered animals, and on material such as mangers, pastures, watering troughs, ete., contaminated with the discharges of the glandered animal. Bacterium mallei was discovered by Loeffler and Schütz ${ }^{1}$ in 1882 .

Morphology. Bacterium mallei is a small short rod with rounded ends. It varies in size from 1.5 to $4 \mu$ in length and in thickness from 0.5 to $0.75 \mu$. There is considerable variation in the size of different individuals in the same culture. They are usually straight, but sometimes they show a slight eurvature. Spores have not been discovered. When found in tissues, this organism appears quite often in small elumps, but

${ }^{1}$ Loeffler. Deut. med. Woch., Dec. 1882, translated by Ogilvie and published in a volume of recent essays on bacteria in relation to. disease, New Sydenham Society, 1886, p. 387. 
usually they are single or in short chains. Involution forms that are short and contain vacuoles are found in old cultures.

Staining. It stains with alkaline methylene blue somewhat irregularly. Granular, deeply stained areas, alternating with faintly stained or entirely unstained portions, often appear. This is quite characteristic and of some value in makinga diagnosis in a microscopic examination of smears from glandered lesions. The irregular staining may be due to a

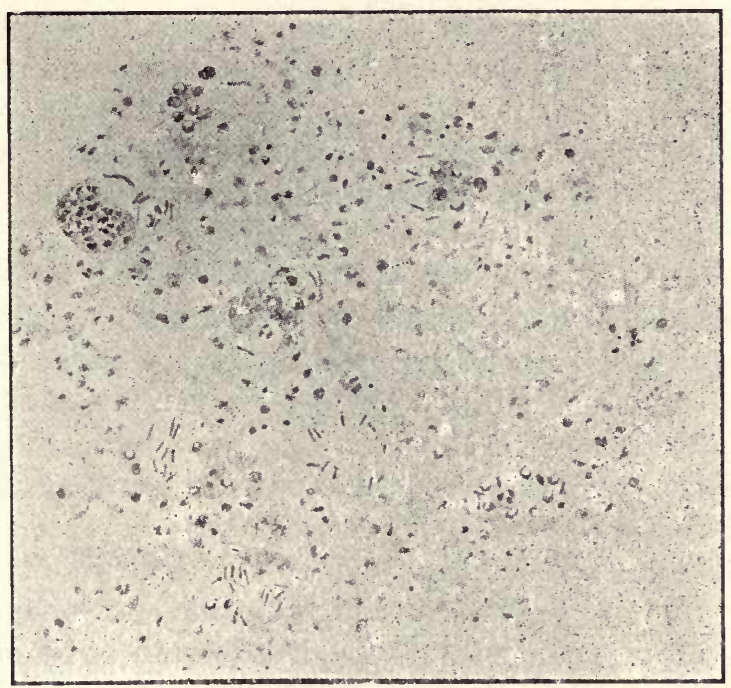

Fig. 53. Bacterium mallei in tissues (Ewing).

degeneration of the body content, a preparatory stage for sporulation, or a condition of the normal protoplasmic eomposition of the organism. It stains quite evenly with carbol fuchsin. It does not take the Gram stain.

Cultivation. This organism grows best on acid glycerine agar, titrated to +2.5 to phenolphthalein, potato and acid glycerine bouillon. After it has been under cultivation for a few generations it grows quite readily on nearly all of the ordinary media prepared from meat infusions. Sometimes it 
will grow on these media when inoculated directly from glanders tissue. Its most characteristic growth seems to appear on potato. In isolating this organism from glandered organs acid-glycerine-agar and potato are the culture media that give the most constant and satisfactory results.

Agar. On agar, yellowish white, at first transparent, but later somewhat opaque colonies, appear after twenty-four hours. The colonies are round, with an even margin, and under low magnification the surface is seen to be finely granular. In older cultures, the colonies become more or less yellow. These characteristics are more pronounced on acid-glycerineagar.

Gelatin. On this medium it grows slowly at room temperature. The growth is of a grayish white color and becomes abundant. The gelatin is not liquefied.

Potato. Potatoes that are too acid should not be used. On those that are less so, the growth is quite vigorous and within forty-eight hours covers the surface with a yellowish, transparent, slimy layer. It grows darker until it becomes a deep reddish brown hue.

Serum. Upon serum it develops small, clear, transparent, drop-like colonies.

Bouillon. In bouillon the liquid becomes uniformly cloudy. A ropy viscid sediment is formed. A slimy pellicle appears after some days. The culture liquid becomes darker by standing. In acid glycerine bouillon, growth is more vigorous, but otherwise does not differ from that in bouillon. It does not act on the sugars.

Milk. Milk is coagulated very slowly with the production of acid.

Life conditions and properties. Bacterium mallei is aërobic. It exhibits Brownian movement to such a marked degree that the mistake of considering it motile has frequently been made. Its most favorable temperature for cultivation is $37^{\circ} \mathrm{C}$. Development takes place slowly, at room temperature and ceases at a temperature of $43^{\circ} \mathrm{C}$. It imparts to the liquid in which it grows a specific toxin-a substance which consti- 
tutes the active principle of mallein. The toxin, or mallein, belongs to the class of endotoxins. The toxic products have been invariably obtained by extraction of dead bacilli. ${ }^{2}$ Mallein differs from many other bacterial poisons in being extremely resistant. It withstands temperatures of $120^{\circ} \mathrm{C}$. and prolonged storage without noticeable loss of strength. In its physiological action on healthy animals, mallein is not a powerful poison. It can be given in considerable doses without causing death. Mallein may be obtained by a variety of methods. Helman and Kalnig, the discoverers of this toxin, used filtered aqueous and glycerin extracts of potato cultures.

Resistance. Bacterium mallei is destroyed when taken from fresh cultures by an exposure at $55^{\circ} \mathrm{C}$. for 10 minutes. It is killed in a three per cent solution of carbolic acid in five minutes; by a 1 to 500 solution of mercuric chloride in from two to three minutes. Smears of the fresh cultures are destroyed by drying in the air for a few days. Smears made from glandered tissues will resist dessication for a longer time.

Pathogenesis. This organism is the cause of glanders in horses and the horse kind and in man. ${ }^{3}$ Guinea pigs are quite susceptible to inoculation. Dogs, ferrets, moles and field mice are said to be susceptible, while sheep, swine and rabbits are reported as less susceptible. Cattle are immune.

Isolating Bacterium mallei from lesions. In isolating the organism from lesions on the nasal septum or skin abscesses (farcy buds) considerable difficulty may be experienced on account of contaminating bacteria which may grow more vigorously on the media than Bacteria mallei. From lesions in the lungs or other organs, pure cultures can usually be obtained on acid-glycerin-agar or potato.

It is often necessary for the isolation of this organism to

${ }^{2}$ Kresling. Arch. de Soc. biol. 1892; Preuser. Berl. thierarzt. Woch., 1894.

${ }^{3}$ Many cases of glanders in man have been reported. Coleman and Ewing (Jour. of Medical Research, Vol. IX, n. s. IV (1903) p. 223 ) report a case with the study of the organism isolated. Robins (Studies from the Royal Victoria Hospital, Montreal, Vol. 2 No. 1, 1906) has gathered the litcrature and reported 156 cases in man. 
make animal inoculations with the suspected material. For this purpose guinea pigs are to be used. After death, the organism can be obtained in pure culture from the liver or spleen. If the suspected material is from the nasal ulcers or skin abscesses the inoculation should be made subcutaneously, to reduce the danger of death from sepsis. If the material is uncontaminated, more rapid results will follow an intraperitoneal inoculation.

Strauss pointed out that male guinea pigs should be employed, as this organism within a few days produces orchitis, when the guinea pig may be chloroformed and cultures made directly from the inflamed testicles. This is known as the Strauss method.

Bacteriological examination. (1) Cultures. By inoculating suitable media with the discharge from the nasal septum ulcers, contents of the skin abscesses or from the lesions found on post mortem in the lungs or other organs. The mieroscopic examination is helpful but can not be considered entirely positive in making the diagnosis, as Bacterium mallei does not possess differential morphological or staining properties. (2) Animal inoculation. By inoculating guinea pigs with the suspected material (Strauss method). In addition to these glanders is diagnosed in the living animal by several methods of which mallein was the first.

Preparation of mallein. Mallein is prepared by cultivating virulent Bact. mallei in acid glycerin bouillon, in flasks containing 250 cc. The culture is allowed to grow in an incubator at a temperature of 35 to $37^{\circ} \mathrm{C}$. for from four to six weeks. At the end of this time, the cultures are sterilized at $100^{\circ} \mathrm{C}$. for 30 minutes by boiling in a water bath or by steaming. They are then passed through a Berkefeld filter to remove the organisms. The filtrate is then evaporated one fifth (the original method was to evaporate the filtrate to one tenth its original volume and to give 0.25 cc. diluted to 2 ce. in a $0.5 \%$ carbolic acid solution as a dose) and $0.5 \%$ carbolic acid is added to preserve it. The dose is $2 \mathrm{cc}$. for the average size horse. 
The Bureau of Animal Industry, Washington, D. C., prepared mallein by growing the bacteria for five months at $37.5^{\circ} \mathrm{C}$. in glycerin-bouillon. This is then boiled for one hour and allowed to stand in a cool place for one week. The supernatant fluid is then decanted and filtered through clay filters by means of a vacuum pump. The filtrate is evaporated to one-third its original volume on a water bath, and the evaporated volume resupplied by a 1 per cent carbolic acid solution containing about 10 per cent of glycerin.

Mallein test. This consists in injecting subcutaneously the proper dose of mallein. If glanders is present, the following reaction will appear. The injection is followed in from six to eight hours by a quite sharp rise of temperature often reaching as high as $104^{\circ}$ to $106^{\circ} \mathrm{F}$. The high temperature continues from a few to several hours and then gradually subsides. The normal may be reached in a few hours, or it may require several days. At the point of injection, there appears a hot, diffuse swelling which gradually extends until it reaches a size of 20 to $30 \mathrm{~cm}$. in diameter. This swelling, which is very tender at first, lasts from three to four days. In some cases, there is what is called an "organic" reaction which consists in general depression, roughening of the hair, and sometimes shivering. This may or may not occur in conjunction with the other reaction and it may oceur in the absence of the rise of temperature and with slight local swelling. In testing horses with mallein it is very important to know whether this "organic reaction" is present. The rules for the use of mallein as recommended by the Bureau of Animal Industry are as follows: "Make the test, if possible, with a healthy horse, as well as with one or more infected or supposed to be infected with glanders. Take the temperature of all these animals at least three times a day for one or more days before making the injection.

"The injection is most conveniently made at 6 or 7 o'clock in the morning, and the maximum temperature will then usually be reached by or before 10 P. M. of the same day.

"Use for each horse one cubic centimeter of the mallein 
solution as sent out, ${ }^{*}$ and make the injection beneath the skin of the middle of one side of the neck, where the local swelling can be easily detected.

"Carefully sterilize the syringe after injecting each horse by flaming the needle over an alcohol lamp or, better, use separate syringes for healthy and suspected animals. If the same syringe is used, inject the healthy animals first and flame the needle of the syringe after each injection.

"Take the temperature every two hours for at least 18 hours after the injection. Sterilize the thermometer in a $5 \%$ solution of carbolic acid, or a $0.2 \%$ solution of corrosive sublimate, after taking the temperature of each animal.

"The temperature as a rule, will begin to rise from four to eight hours after the injection, and reach its maximum from ten to sixteen hours after injection. On the day succeeding the injection take the temperature at least three times.

"In addition to the febrile reaction, note the size, appearance, and duration of any local swelling at the point of injection. Note the general condition and symptoms of the animal, both before, during, and after the test.

"Keep the solution in the sealed bottle and in a cool place, and do not use it if it is clouded or if it is more than six weeks old. When it leaves the laboratory of the Bureau it is sterile."

Luedmersen and Glenny ${ }^{4}$ found after a careful investigation of this subject that a marked local swelling following the injection of mallein occurred in horses immunized to other bacterial products. This is important in considering the diagnostic value of local swellings where the.horses have been immunized against other bacteria such as diphtheria.

Agglutination. The agglutination method was first applied to glanders by M'Fadyean. ${ }^{5}$ Later it was recommended

* Mallein prepared and distributed by the Bureau of Animal Industry.

${ }^{*}$ Leudmersen and Glenny. The Jour. of Hygiene, Vol. VIII (1908).p. 36.

${ }^{5}$ M'Fadyean. Jour. Comp. Path. and Therap., Vol. IX (1896) p. 322 . 
for the control of glanders by Schütz and Miessner, ${ }^{6}$ and also Schnure. ${ }^{\top}$ recommended this method for the diagnosis of glanders.

The method as formulated by Schütz and Miessner for the eradication of glanders is as follows: ${ }^{8}$

Twenty to 50 ec. of blood are taken from the glandered or suspected horse, the date and history of the case being recorded and sent to the laboratory.

All horses whose blood agglutinates in dilutions of 1-1,000 or higher should be destroyed.

In the same way, all horses should be destroyed whose blood agglutinates in dilutions of only $1-500$ to $1-800$, if they show symptoms of glanders.

All other horses in which the agglutination is $1-500$ to 1-800 should be isolated and destroyed only when justified by a second test, in which the maximum dilution for agglutination is changed; on the other hand, they may be pronounced free from glanders if at the second test the dilution remains unchanged.

After glanders is established, the blood of horses in the same stable should be tested after three weeks; and this should be repeated until the last two tests show in all horses individually a uniform reaction.

In our work we have applied the general method recommended by Schütz and Miessner, with such slight modifications as seemed desirable. The method for the routine diagnosis which we have found to be very satisfactory is as follows :

Culture.-As pointed out by Schütz and Miessner, all cultures of 'B. mallei do not agglutinate satisfactorily. It was also shown by their work that a suitable culture when obtained is liable, at unexpected intervals, to lose its responsiveness to the agglutinin. This can be prevented by passing the organisms through a guinea pig at least once in three weeks. The organisms were grown for from 48 to 72 hours on acid-glycerin agar ( 5 per cent glycerin and with a reaction

${ }^{6}$ Schütz and Miessner. Archiv. f. wis. u. prak. Thierheilk., Bd. XXXI (1905) p. 353.

${ }^{7}$ Schnurer. Centralbl. f. Bakt., Bd. XXXIX (1905) p. 180.

${ }^{8}$ Moore and Taylor. The Jour. of Inf. Diseases, 1907, Sup. No. 3 , p. 85 . 
of +2.9 to phenolphthalein). In order to have a suitable culture on hand, subcultures should be made daily. A culture more than 72 hours old should not be used in preparing the test fluid.

Test-fluid.-The test-fluid is prepared by washing the growth from the agar culture by the aid of a sterile wire loop into distilled water containing 0.85 per c€nt sodium chloride and 0.5 per cent carbolic-acid crystals. This suspension is then placed in a thermostat at $60^{\circ} \mathrm{C}$. for two hours, which kills the bacteria. A temperature higher than $65^{\circ} \mathrm{C}$. or lower than $60^{\circ} \mathrm{C}$. should be avoided. After heating, the suspension is thoroughly triturated and filtered through sterile cotton. Thorough trituration of the emulsified growth is esiential before filtering. The filtrate thus prepared is diluted with the carbolized-salt solution until it is of a faintly clouded appearance. The proper dilution of the filtrate can only be determined by experience. The test-fluid gives the best results when made with freshly prepared carbolized-salt solutions.

Procuring the serum.-The serum is easily obtained. At least 10 cc. of blood are drawn from the jugular vein, under aseptic precautions, into a small sterile bottle, and sent to the laboratory. As soon as the clot forms, the supernatant serum is placed in a centrifuge and all the sediment thrown down, leaving the liquid perfectly clear. One cc. of the serum is then added to 39 cc. of a physiological salt solution, which makes a dilution of 1-40. It is desirable that the serum should be secured as soon as possible after the blood is drawn. If necessary to delay the test, the serum has given the best results if kept at about $10^{\circ} \mathrm{C}$. until used.

Making the test.-Three cc. of the "test-fluid" are placed in each of several small test-tubes. With a sterile pipette, the diluted serum is added to the tubes of test-fluid and thoroughly mixed. In making the different dilutions, the amount of diluted serum to be used is readily ascertained by the following table:

TABLE

\begin{tabular}{|c|c|c|c|}
\hline $\begin{array}{c}\text { Dilution of } \\
\text { Serum }\end{array}$ & $\begin{array}{c}\text { Amount of Di- } \\
\text { luted Serum }\end{array}$ & $\begin{array}{c}\text { Amount of } \\
\text { Test-Fluid }\end{array}$ & Dilution \\
\cline { 2 - 3 } $1-40$ & $1: 2$ cc. & 3 cc. & $1-100$ \\
$1-40$ & 0.6 & 3 & $1-200$ \\
$1-40$ & 0.405 & 3 & $1-300$ \\
$1-40$ & 0.3 & 3 & $1-400$ \\
$1-40$ & 0.24 & 3 & $1-500$ \\
$1-40$ & 0.195 & 3 & $1-600$ \\
$1-40$ & 0.15 & 3 & $1-800$ \\
$1-40$ & 0.12 & 3 & $1-1,000$ \\
$1-40$ & 0.105 & 3 & $1-1,200$ \\
$1-40$ & 0.09 & 3 & $1-1,500$ \\
$1-40$ & 0.06 & 3 & $1-2,000$ \\
$1-40$ & 0.03 & 3 & $1-4,000$ \\
$1-40$ & 0.015 & 3 & $1-8,000$ \\
& & & \\
\hline
\end{tabular}


Where dilutions greater than 1-1,000 are made, a serum diluted 1-80 may be used to better advantage, unless the pipette employed is very finely graduated. In this case the amount of diluted serum for a certain dilution must be double that indlcated in the table.

The mixture thus prepared is placed in an incubator at $37^{\circ} \mathrm{C}$. for 24-30 hours. A temperature higher than $37^{\circ} \mathrm{C}$. interferes with the agglutination.

Reaction.-The reaction consists of a layer of the agglutinated bacteria settling and covering the entire convexity at the bottom of the tube. This film-like sediment may become so dense that it rolls in at the periphery. The supernatant fluid becomes clear in the lower dilutions, but in the higher ones the clarification may not be complete, showing that all the bacteria have not become agglutinated. This is further evinced by the fact that the layer is less dense in the higher dilutions. The reaction may begin in six hours, but cannot be considered complete until 24 to 72 hours have elapsẹd. Often, however, a reaction appears in less than 24 hours.

After the agglutination is completed, further standing produces no visible change in the test-fluid.

A negative result shows a small round concentrated spot of sediment in the center of the convexity at the bottom of the tube, the test-fluid remaining apparently unchanged even after several weeks.

The agglutination test has been made by the microscopic method as in the Widal for typhoid fever. This laboratory has found that agglutination sufficient to be determined microscopically occurs often with very weak dilutions of the serum, and not infrequently with that of healthy horses. It is possible that the microscopic examination may be of assistance in diagnosing the disease in man. It has not been trustworthy in our hands with horses, although the method is used in certain laboratories.

Precipitation. According to Mohler ${ }^{9}$ the precipitin reaction of Konew is carried out in the following manner:

"The blood taken from the jugular vein of the horse to be examined is collected in a glass container and then allowed to remain at room or incubator temperature. The separated serum which is thus obtained serves as the second necessary fluid for the precipitation reaction. In order to produce the reaction one cubic centimeter

${ }^{9}$ Mohler. Proc. of the Amer. Vet. Med. Assn., 1910, p. 323. 
of the malleasa is poured into a glass test tube of three to four millimeters in diameter and fifteen centimeters long, so that the liquid in the tube is about three centimeters in height. Then about the same quantity of the blood serum from the suspected horse is taken in a Pasteur pipette which is introduced into the tube containing the malleasa in such a manner that the point of the Pasteur pipette reaches the bottom of the tube. Not until then is the serum allowed to pour very slowly under the malleasa. Inasmuch as the serum has a higher specific gravity it remains at the bottom, while the malleasa is forced up. The free end of the pipette is then covered with the finger and the pipette is carefully taken out, so that the serum is not mixed with the malleasa. Such a mixing should also be avoided during the introduction of the pipette into the serum. The two solutions must only come in contact at one point and then the reaction will be very marked.

"In case of a positive reaction, that is, when the serum is obtained from a horse affected with glanders, a ring of white cloudiness develops at the point of contact of the two clear solutions, as a result of the precipitin formation, which is particularly marked in good daylight when the tube is placed in front of a window against some dark object. According to the duration of the disease, the white ring develops at various times and in varying intensity. In severe and chronic cases of glanders the serum produces the ring immediately; in slight affections when the lesions are not very marked in the animal, the precipitation reaction appears in from five to fifteen minutes."

Malleasa. Malleasa is prepared by dissolving the glanders bacteria that appear on a two day old agar culture with an $8 \%$ antiformin solution using about $10 \mathrm{cc}$. for each agar culture. ${ }^{10}$ The antiformin dissolves the glanders growth in about two hours. A sufficient amount of culture should be added to require about two hours to dissolve the bacteria. The solution is strongly alkaline but should be neutralized by adding a $5 \%$ solution of sulphuric acid. It is then filtered first through filter paper and then a Berkefeld filter in order that the solution may be homogeneous. To this solution

10 The antiformin is the patented name of a disinfectant made by adding sodium hydrate to a solution of sodium hypochloride. It can be obtained in the market. Its activity seems to be due to an intense oxidation. 
Konew gave the name Malleasa. In this laboratory the precipitation method has not been satisfactory. ${ }^{11}$

Fixation of complement. For this method see chapter on specific bacterial products, tissue reactions and immunity.

BACTERIUM TUBERCULOSIS (KOCH) MigULA.

Synonyms. Bacillus tuberculosis Koch, Mykobacterium tuberculosis Lehmann and Neumann.

Place in nature. This organism is the cause of the disease known as tuberculosis. Tuberculosis is a disease of the bovine species most extensively but other mammalia are to a greater or a less extent affected by it. It also occurs in chickens and it has been described in certain species of fish. It is likewise one of the most serious diseases of the human family. Bact. tuberculosis was discovered by Robert Koch ${ }^{1}$ in 1882. The transmission of the disease by means of tuberculous material was shown to be possible by Klenke in 1843. In 1865, Villemin succeeded in transmitting the disease by inoculating tuberculous tissues into susceptible animals. Other observers contributing to the knowledge of the infectiousness of this disease were Van Zurn, Buhl, Klebs, Toussaint and others. ${ }^{2}$ Koch isolated the organism from tuberculous tissues from various sources. He produced characteristic lesions in guinea pigs and other animals by inoculating them with pure cultures of the bacterium.

At first the organisms obtained from tuberculous lesions of man and of cattle were thought to be identical. Those from fowls were different. This conclusion of Koch was confirmed by a number of workers and the belief that these organisms were identical was not questioned. In 1898, Theobald Smith ${ }^{3}$ pointed out three differences existing in the tubercle organ-

${ }^{11}$ Fitch. Report of the New York State Veterinary College, 1910-11.

${ }^{1}$ Koch. Berl. klin. Woch., No. 15, 1882.

Koch. Mittheilung a. d. Gesundheitsamte, Vol. II (1884).

${ }^{2}$ See Johne. Geschichte der Tuberkulose. Leipsic, 1883.

${ }^{3}$ Smith. Jour. of Exper. Med., Vol. III (1898) p. 45. 
isms isolated from man and from cattle. In 1901, Koch ${ }^{4}$ confirmed Smith's findings. This led to a number of special investigations to determine the relation between the human and bovine tubercle organisms. The conclusion of these numerous investigations ${ }^{5}$ is that the tubercle bacterium from man differs slightly in morphology, in its cultural characters and markedly in its virulence from the bovine variety. This gives us three distinct races of the tubercle bacterium, one in man, one in cattle and one in fowls.

Tubercle bacteria are found in nature in the tuberculous lesions of man, cattle and other animals suffering with the disease. They are highly parasitic and are not known to exist in nature except as parasitic bacteria. There is, however, a

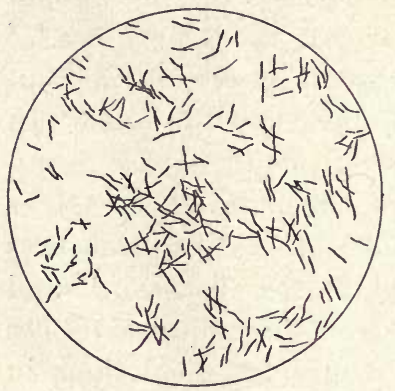

Fig. 54.

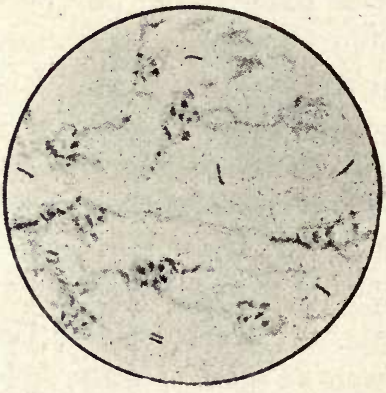

Fig. 55.

Fig. 54. Bacterium tuberculosis (human) highly magnified.

Fig. 55. Bacterium tuberculosis (bovine). Drawing from a coverglass preparation from tuberculous tissue of a guinea pig. $\times$ about 1000 .

large group of bacteria known as acid-fast or acid-proof organisms, which are found occasionally in the excreta of man and animals and also on timothy hay. They possess staining properties quite similar to the tubercle bacterium. There is

${ }^{4}$ Koch. Amer. Vet. Review, Vol. XXV (1901) p. 441.

${ }^{5}$ One of the most important investigations into the relation between human and bovine tubercle bacteria was by Park and Krumwiede Jr., Vol. V, Research Laboratory, Dept. of Health, City of New York, 1910.

Also, Jour. of Med. Research, Oct. 1910. 
also an organism resembling somewhat the tubercle that is parasitic for cattle, producing a very chronic catarrhal condition of the intestines (Johne's disease). It invades the intestines and is found in the tissues immediately beneath the mucous membrane.

Morphology. Bacterium tuberculosis appears as a slender rod 1.5 to $4.0 \mu$ in length and from 0.2 to $0.5 \mu$ in width. The ends are usually rounded. The organisms may be straight or slightly curved. As a rule, the curve is more pronounced in

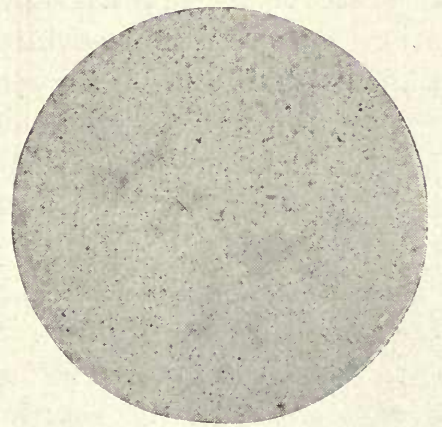

Fig. 56. Photograph from a preparation of tuberculous milk showing tubercle bacteria in the center. $\times 500$. the human variety. The diameters are quite uniform throughout. In the human variety, especially as found in tuberculous sputum, they are quite frequently beaded and stain somewhat irresularly. The unstained areas are regarded as vacuoles. The bovine variety is slightly shorter than the one from man. It is usually from 1.5 to $3 \mu$ in length and from 0.3 to $0.8 \mu$ in thickness when found in the tissues, milk or feces. They do not so frequently present irregularly stained areas. A number of observers have demonstrated branched forms of this organism. ${ }^{6}$

Staining. The tubercle bacterium does not stain readily with the ordinary aniline dyes. Once stained, however, the dye is retained, even after the application of alcohol and acids. It is for this reason that they are often spoken of as "acid fast" or "acid proof" bacteria. This property seems to depend upon the presence of fatty substances contained in the organism. The dyes that have been used successfully to

- Nocard and Roux. Annales de l'Inst. Pasteur, 1887.

Mafucci. Zeitschrift f. Hygiene, Bd. '

${ }^{7}$ Bienstock. Fort. d. Med., 1886. 
stain this organism are Ehrlich's solution of aniline-water gentian-violet and Ziehl's * earbol fuchsin solution. ${ }^{8}$ Much ${ }^{2}$ found a bacterium resembling that of tuberculosis morphologically but which did not retain the stain when treated with the decolorizing solutions. He refers to it as a non acid-fast tubercle bacterium. In staining Bact. tuberculosis, therefore, the preparation must be first deeply stained and then treated with a solution of a mineral acid such as nitric or sulphuric and thoroughly washed. The tubercle bacteria, if present, will remain deeply stained while the other bacteria and tissues will be decolorized. The preparations may be counterstained, in which case the other bacteria and tissues will be colored. Gabbett ${ }^{10}$ combined decolorization and counterstaining in one solution. This consisted of methylene blue 1 gram; conc. sulphuric acid 25 grams; and distilled water 100 ce. After staining in the earbol-fuchsin solution the preparations are covered with this decolorizer for a few seconds and washed in water. The tissues and other bacteria will be stained blue. It has been found that a large number of saprophytic acid-fast bacteria will become decolorized if treated with a $3 \%$ solution of hydrochloric acid in $95 \%$ alcohol. There are, however, a few non-pathogenic acid-fast bacteria that can not be differentiated from the tubercle bacteria by this method. ${ }^{11}$ The bacterium retains the stain when treated with the Gram method.

Cultivation. Bacterium tuberculosis is an aërobic organism, which is cultivated without difficulty on blood serum, egg medium, glycerin bouillon and potato, after it has been

* Kinyoun recommends the following formula:

Basic fuchsin

Carbolic acid c.,p.

Alcohol 95\%

Distilled water

Stain 3 minutes without heat.

${ }^{8}$ Ziehl. loc. cit.

Much. Beitr. z. Klinik der Tub., Bd. IX, p. 415.

${ }^{10}$ Gabbett. loc, cit.

${ }^{11}$ Peterson. Rept. of N. Y. State Vet. Coll., 1909-10, p. 65.
4 grams

8 grams

$20 \mathrm{cc}$.

$100 \mathrm{cc}$. 
accustomed to artificial cultivation. It is not readily obtained in pure culture from tuberculous tissues. Smith ${ }^{12}$ found that by inoculating guinea pigs with the suspected material and as soon as the disease had begun to develop chloroforming the pigs and transferring quite large pieces of the diseased organs, such as spleen or liver, directly to the surface of dog serum (coagulated at $72^{\circ} \mathrm{C}$.) and placing them in an incubator at $37.5^{\circ} \mathrm{C}$. in which there was considerable moisture, the multiplication of the organisins continues and in some days visible growth appears on the serum at the edges of the tissues. Some

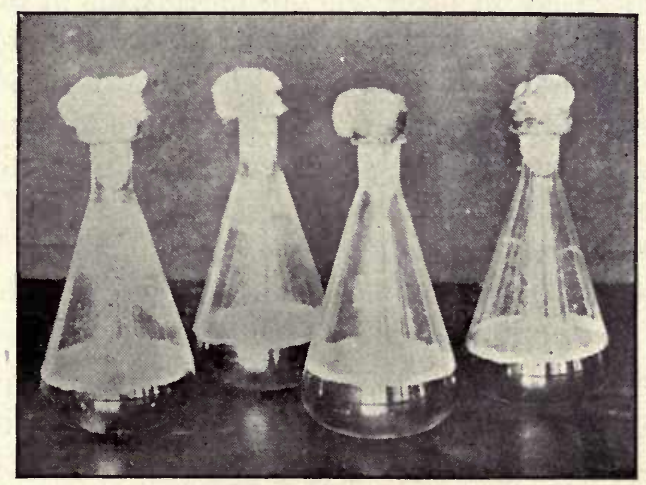

Fig. 57. Cultures of tubercle bacteria in flasks on glycerinated bouillon.

workers have little difficulty in the use of the ordinary beef serum.

Blood serum. On blood serum at $37.5^{\circ} \mathrm{C}$., colonies usually become visible at the end of eight to fourteen days. They appear at first as small, dry, grayish-white, scaly spots with corrugated surfaces. After three or four weeks' cultivation, these join together, covering the surface of the medium as a dry, whitish, wrinkled membrane. Coagulated dog serum is regarded by Theobald Smith ${ }^{13}$ as one of the most favorable media for the growth of tubercle bacteria.

${ }^{12}$ Smith. loc. cit.

${ }^{13}$ Th. Smith. Jour. Exp. Med., Vol. III (1898) p. 451. 
Glycerin agar. Upon glyeerin agar (glycerin 3 to 6 per cent) at $37.5^{\circ} \mathrm{C}$., colonies become visible at the end of from ten days to two weeks, at first as dry, white spots; later as delicately corrugated membranes. The colonies of the avian variety have a delicate spreading border about the thicker center.

Glycerin bouillon (made of beef or veal with peptone one per cent, glycerin 5 per cent, and rendered slightly alkaline) is an extremely favorable medium. The bouillon should be in shallow layers, in wide mouthed flasks, as the free access of oxygen is essential for growth. The inoculation of this medium should be made by carefully floating flakes of the growth upon the surface. In multiplying, the bacteria will spread out upon the surface, at first as a thin, opaque, floating membrane which rapidly thickens into a whitish wrinkled or granular layer, covering the entire surface of the fluid in from four to six weeks. Later, portions of the membrane may sink to the bottom. In old cultures, the membrane assumes a yellowish hue. These cultures emit a peculiar aromatic odor.

Pathogenesis. The pathogenesis of the different varieties of Bacterium tuberculosis varies. The human and bovine varieties appear to be equally virulent for guinea pigs. The lesions produced are quite characteristic and can be identified usually by the gross appearance or microscopic examination of the structure of the tissue changes. The human variety is not usually fatal to rabbits, cattle, or other animals and frequently the tissue changes which it produces are very slight and restricted to the point of inoculation. The bovine variety is usually fatal to rabbits and eattle. When fed milk containing tubercle bacteria horses frequently develop tuberculosis. Swine are very susceptible to the bovine variety. Sheep, goats, cats and dogs are less susceptible. The avian variety is virulent for fowls. Moore was unable to produce tuberculosis in guinea pigs with the avian culture or to produce tubereulosis in fowls with the human and bovine varieties by feeding or by subcutaneous inoculation of pure cultures or of tubercu- 
lous sputum or tissue. ${ }^{14}$ Both Nocard and Johne, however, report producing the disease in fowls with human and bovine tuberculous material. Natural infection seems to take place through the respiratory and digestive tracts. There is a pronounced difference of opinion ${ }^{15}$ as to the relative frequency of infection by these channels.

Toxin. Bact. tuberculosis produces what seems to be an endotoxin or bacterial protein. As the filtrate of the glycerin bouillon cultures possesses the property of causing a reaction when injected into tuberculous animals, it is possible that these organisms actually secrete one or more soluble toxins. It is supposed that the endotoxin or toxines give tuberculin its value.

Tuberculin. Tuberculin consists of the liquid (usually glycerinated bouillon) on which tubercle bacteria have grown for several weeks, after it has been heated to kill the bacteria and filtered to remove all of the organisms and properly concentrated. It was discovered by $\mathrm{R}$. Koch in $1890 .^{16}$ The original tuberculin was prepared by evaporating the filtrate of cultures of tubercle bacteria of sufficient age to one-tenth of the original quantity. This gave a thick syrupy fluid that had to be diluted before use. It is known as the crude tuberculin and was originally called Koch's "lymph." There are several modifications of the details in its preparation. It can be prepared either from the human or bovine variety of tubercle bacteria. Our experience has not pointed to any pronounced difference in the action of the tuberculin prepared with cultures from either source. In the preparation of tuberculin (old tuberculin of Koch) the following principles ${ }^{17}$ should be observed.

1. "The medium shall consist of bouillon prepared from

${ }^{14}$ Moore. Jour. of Med. Res., Vol. XI (1904) p. 521.

${ }^{15}$ See article by M'Fadyean. Jour. of Comp. Path. and Therap., 1910.

${ }^{16}$ Koch. Centralbl. f. Bakt., 1890.

${ }^{17}$ Report of Committee on the Standardizing of Tuberculin. Laboratory Section, Am. Public Health Association, 1908. 
meat (veal or beef) and not meat extract. The bouillon shall contain $1 \%$ peptone (Witte's), $0.5 \%$ sodium chloride or acid potassium phosphate, chemically pure glycerin $5 \%$ (this may vary from 3 to $7 \%$ ). The final reaction of the bouillon shall be 0.75 to 1.0 to phenolphthalein, the normal acidity of the broth being corrected by the addition of sodium hydrate solution.

2. "The culture of tubercle bacillus employed shall be of mammalian origin and shall produce an active tuberculin.

3. "The containers in which the cultures of tubercle bacilli are grown shall be in form similar to the Erlenmeyer flasks of the Jena pattern, preferably 300 ce. capacity, each flask to contain 100 ec. of bouillon.

4. "The cultures should be allowed to grow for four weeks after the surface of the medium is completely covered with the growth of the tubercle bacillus.

5. "In the preparation of the tuberculin the ripe cultures are shaken down, placed in a steam sterilizer and subjected to live steam for at least $2 \frac{1}{2}$ hours, filtered through paper, evaporated to one-tenth of original volume. Before being supplied to practitioners the tuberculin should be passed through Chamberland or Berkefeld filters.

6. "Tuberculin should be sent out from the laboratory so that the practitioner need not dilute it before using. The dilutions when exposed to the air should not for human practice be prepared for any great length of time before use. The diluent suggested is $0.25 \%$ phenol in physiological normal sodium chloride solution."

New tuberculin. In $1897^{\circ}$ Koch $^{18}$ described a new tuberculin, prepared by grinding in a mortar tubercle bacteria that had been dried in vacuo (this is done by machinery where large quantities are made). The grinding is continued until the microscopic examination fails to show unmutilated bacteria. One gram of the dry mass is shaken up in 100 ce. of sterile distilled water. This mixture is then centrifugalized at

${ }^{18}$ Koch. Deut. med. Woch., Bd. XIV (1897). 
high speed. The supernatant fluid, known as TO (TuberculinOberschicht), contains the water-soluble constituents of the bacterium, gives no precipitate on the addition of $50 \%$ glycerin, and has the same physiological action as the old tuberculin. The residue, TR (Tuberculin-Ruckstand) after pouring off $\mathrm{TO}$, is again dried, ground up, and again shaken in water and centrifugalized. This process is repeated several times, and eventually, after three or four repetitions, all the TR goes into emulsion. The total volume of water used for these TR extractions should not exceed 100 ec. All of the TR emulsions are then mixed together. This TR gives a precipitate with $50 \%$ of glycerin, and was supposed by Koch to contain substances important in producing an antibacterial immunity.

A number of other preparations of tuberculin have been made. Koch ${ }^{19}$ combined the TO and TR to form a tuberculinbacillary emulsion. It consists of 5 milligrams of pulverized tubercle bacteria in each cubic centimeter. Buchner and Halm prepared a tuberculoplasm by crushing the bacteria under a presure of 400 atmospheres. It possessed the properties of Koch's TR. There are several other preparations made but they are of no special value in veterinary work. The practical use of the tuberculins are (1) the old tuberculin to give a reaction for the purpose of the diagnosis of tuberculosis and (2) the new tuberculin for therapeutic value and to immunize animals against tuberculosis. The old tuberculin is also used to some extent in the treatment of tuberculosis. ${ }^{20}$ In veterinary practice the old tuberculin is used for diagnosis. A purified tuberculin is prepared by precipitating the old tubereulin with $95 \%$ alcohol and washing the sediment with $70 \%$ alcohol until the filtrate is clear and dry. A solution of from 0.05 to $0.1 \%$ of the dried precipitate is made in a sterile normal salt solution. This is employed for the Wolff-Eisner or ophthalmic test.

${ }^{19}$ Koch. Deut. med. Woch., 1901,

${ }^{20} \mathrm{~A}$ number of physicians have reported good results in the therapeutic use of old tubcrculin in selected cases. Its use for this purpose has not been successful in cattle. 
Application of tuberculin for diagnosis. The following precautions should be taken in the use of tuberculin. ${ }^{21}$ The old tuberculin is employed.

1. The tuberculin test for diagnosing tuberculosis should not be applied to an animal that is suffering from any other known infectious disease or other conditions giving rise to an elevated temperature, or an animal that is far advanced in pregnancy.

2. The animals to be tested should be kept during the test under perfectly normal conditions with the possible exception that it is necessary to keep them up in stables rather than to allow them to run in a pasture. Before injection the temperature of the animals should be taken. It is recommended that the temperature be taken every two hours for four to six hours preceding the injection of tuberculin. The real purpose of taking these preliminary temperatures is to ascertain whether or not the animals are suffering from any disorder that affects the temperature. It is required by some livestock sanitary boards that a definite number of temperatures should be taken before injecting the tuberculin. In practice two preliminary temperatures taken two hours apart before making an injection are quite sufficient.

3. The tuberculin is administered subcutaneously. It is usually injected under the loose skin in the neck or in the axilla. Care should be taken that the syringe is sterilized. It has been advised that the skin of the cow at the point of injection should also be disinfected. This is a safe precaution; but the difficulty of disinfecting the skin quickly and the infrequency with which cattle become infected with skin organisms suggest that this precaution is not necessary. If the syringe is sterilized in the beginning, the method recommended by Dr. Law, to insert the needle in pure (liquid) carbolic acid between each two injections, gives good results. This destroys any organisms that might become attached to the needle in withdrawing it from one animal, and the acid that adheres to

${ }^{21}$ Circular No. 1. N. Y. State Vet. Coll., 1908. 
it seems to be sufficient to prevent the introduction of organisms when the needle is inserted.

4. The dose of tuberculin that is ordinarily given to an adult animal of medium size is 0.25 cc. of the Koch tuberculin. The tuberculin from the laboratories in this country is usually sent out already diluted. Two cubic centimeters is the usual dose of the dilution.

5. Beginning six or eight hours after the injection, the temperature of the animals should be taken hourly or at least every two hours for eighteen hours after the injection, that is, five or six temperatures at intervals not longer than two hours. If at the end of this time the temperature of any animal appears to be rising it should be taken again and repeated at like intervals until it returns to the normal.

6. During the time that the test is being made the cattle should be kept quiet, free from all exposure or excitement, and fed and watered as usual. The water should not be too cold.

7. Reaction. The usual reaction consists in a rise of temperature, beginning about the sixth or eighth hour after injection and continuing for several hours. The rise varies from $1.5^{\circ}$ to $4^{\circ}$ or $5^{\circ}$ above the normal. A reaction, however, does not mean simply a rise of temperature for a brief time, but a gradual rise, a continued high temperature for a few ( 2 to 6 ) hours, and then a gradual decline. This is called the tuberculin curve, and it is more important in the interpretation than the simple rise of temperature. In eattle there is not infrequently a normal variation from $1^{\circ}$ to $2^{\circ}$ in the animal's temperature within twenty-four hours. Cold water, when drunk in considerable quantities, lowers the temperature from $2^{\circ}$ to $3^{\circ}$. A temporary excitement may cause an elevation of from $1^{\circ}$ to $1.5^{\circ}$. There are often marked variations in the temperature of the same animal on consecutive days.

In many animals there is an organic or constitutional reaction which consists in roughening of the coat, evidence of chill, dullness of the eye, indifference to food, and a general depressed appearance. In milch cows, in case of reaction there is a slight shrinking of the milk, due probably to the rise 
of temperature. In cows that do not react there is no effect upon the flow of milk.*

The interpretation of the reaction. When a tuberculin reaction occurs it indicates that the animal is suffering from a tuberculous infection and that most likely the process is active. This reaction may occur when the tuberculous focus is very small. It is possible that in those individuals where a reaction takes place and where no evidence of the disease is found in a gross examination of the viscera, a more careful examination of the organs and intermuscular and subcutaneous tissues as well as the bones and nervous system might reveal the presence of lesions.

In cases where there is no reaction the interpretation is more difficult. Tuberculin, however, does not give a reaction (1) during the pericd of incubation; (2) in many, if not all, cases where the disease is arrested; and (3) possibly not when it is very advanced. This means that the records of tested herds do not necessarily point out all the animals that are infected, or those which may subsequently develop an active form of the disease. The latent cases ean not be detected until the disease becomes active. To detect them as soon as they become active requires repeated tests. It is not known how long the tubercle bacteria will remain alive in latent lesions. We have cases where the lesions became active three and onehalf years after the animal ceased to react and also a case where an apparently healed calcified tubercle contained living, virulent tubercle bacteria three years after the animal ceased to react. It is such cases as these that have caused tuberculosis to reappear in many herds after the reacting animals have been destroyed. The owners of such herds are inclined to blame the tuberculin or the man who used it. The fault is not with the first application of this reagent, or with the

* Gilliland (Proceedings Am. Vet. Med. Asso., 1907, p. 371) made a careful study of the effect of the tuberculin test on lactation. He found it did not reduce the flow of milk of non-reacting cows and the slight reduction in the reacting ones he attributed to the rise of temperature. 
veterinarian who applied it, but in the failure to have subsequent tests made.

The skin and ophthalmic application of tuberculin. It has often been noted, especially in the human subject, that a considerable degree of local irritation occurs at the site of the injection of tuberculin in tuberculous patients. The significance of this phenomenon was not fully appreciated until the investigations of von Pirquet ${ }^{22}$ on so-called accelerated reactions in revaccinations against smallpox. This condition recalled the well-known experiments of Koch which led to the discovery of tuberculin; namely, that in a tuberculous guinea pig a second inoculation under the skin was followed by much more swelling than the first and a rapid formation of a slough without involvement of the surrounding lymph nodes as in the primary infection. Von Pirquet's attention was directed, in consequence of this, to the effect of tuberculin rubbed into searifications of the skin. In 360 tests on children in the Berlin and Vienna clinies it was found that a well-marked difference was obtained in the reaction hyperemia between tuberculous and non-tubereulous children under two years of age, but in older individuals this was slight. The diagnostic value, therefore, seemed to be limited to children. This method was tried by Arloing ${ }^{23}$ and Vallée ${ }^{24}$ in eattle, rabbits and guinea pigs, with uncertain results.

In order to overcome the danger of injecting too much tuberculin in making a diagnosis on the human subject a method was simultaneously proposed by Wolff-Eisner ${ }^{25}$ of Berlin and Calmette ${ }^{26}$ of Lille, France. The method consists in putting a drop of weak tuberculin solution (1\%) into the eye, whereby a conjunctival hyperemia is produced in tuberculous individuals. This is due to the increased sensitiveness of the tissues of tuberculous animals as compared with non-

${ }^{22}$ V. Pirquet. Berliner klin. Wochenschr., May 20, 1907.

${ }^{23}$ Arloing. Compte rendu de la Soc. de Biol., June 28-29, 1907,

${ }^{24}$ Vallée. Ibid. July 12, 1907.

${ }^{25}$ Wolff-Eisner. Berliner klin. Wochenschr., June 3, 1907.

${ }^{26}$ Calmette. Presse médicale, June 19 and July 13, 1907. 
tuberculous individuals, who should exhibit no signs of irritation from the same procedure. The recent tests of this method in the human subject have given a variety of results and reactions have been obtained in a considerable number of individuals who appeared to be perfectly healthy and who had no history of tuberculous infection. The view has been expressed that this reaction may take place in healed eases of tuberculosis as well as in active ones, due to the fact that the conjunctiva and possibly skin have been sensitized by some previous infection, however slight. If it is demonstrated that this reaction occurs simply as the result of anaphylaxis it would not indicate the presence of active tuberculosis.

This method of applying tuberculin has been tested in cattle by MeCampbell and White ${ }^{2 \tau}$ and others but it was found not to be very satisfactory.

Intradermal test. Moussu and Mantoux ${ }^{28}$ injected tuberculin into the skin and produced in tubereulous animals a loeal oedema and swelling which began in a few hours and reached its maximum in forty-eight hours; this indicated a reaction. This method eliminates the necessity of taking temperatures. Ward and Baker ${ }^{29}$ found this method to be aceurate in a large percentage of many cases tested by them and to be practicable for range eattle.

The subcutaneous injection of tubereulin is the only method at present that can be relied upon in testing dairy cattle. The other procedures are still in the experimental stage so far as cattle are concerned.

Theory for the reaction of tuberculin. The use of tuberculin has demonstrated three distinct and interesting phenomena: First, a marked sensitiveness of the tuberculous individual and a comparative indifference of the healthy body to it. Second, a distinct thermal reaction of the tuberculous

${ }^{27}$ McCampbell and White. Jour. Exp. Med., Vol. X (1908) p. 232.

${ }^{28}$ Moussu and Mantoux. Trans. 6th. International Congress on Tuberculosis, Vol. IV (1908) p. 821.

${ }^{20}$ Ward and Baker. Proceedings Am. Vet. Med. Asso., 1910, p. 291. 
individual, that is, a general effect. Third, a hyperemia of the tuberculous focus. These can be demonstrated in the tuberculous guinea pig. The extent of the hyperemia of the tuberculous focus in cattle does not seem to be as marked as in the guinea pig; but the explanation for the rise of temperature in the tuberculous body following the injection of tuberculin has not been so easy to determine. A number of explanations for the action of tuberculin have been offered, ${ }^{30}$ but the one first suggested by Eber ${ }^{31}$ and more recently modified by Theobald Smith ${ }^{32}$ seems to meet the conditions better than any of the others. It is as follows:

"In the tubercular tissue and its immediate vicinity the tubercle bacilli have induced certain tissue changes, and with them certain new functions of the tissue have been aroused, which are the result of immunization. These new properties are concentrated in the immediate neighborhood of the focus. The specific resistance is, as it were, chiefly focal and only secondarily generalized. When the tuberculin comes in contact with this focus, the former is acted on, with the result that the originally inocuous tubereulin becomes poisonous perhaps by the splitting off of some poisonous substance. An incomplete digestion I should prefer to call it. As a result of this action we have, first, the local hyperemia and, second, the constitutional effect. In other words, the tuberculin becomes poisonous by an immune reaction directed toward the tubercle bacillus. This reaction is defective and in so far dangerous to the host. The only way in which the danger can be met is for the body to produce an antibody to this second substance. So far there is little evidence to show that the body is able to produce this in any amount. The animal body has learned to

${ }^{30}$ Citron. (Berliner klin. Wochenschrift, 1907) expresses the opinion that the reaction to tuberculin consists in the multiplication of sessile cell receptors and free antibodies at the focus of infection, after which the latter disappear. He states further that in the last stage of the reaction there are numerous fixed cell receptors and free antibodies in the tuberculous foci and in the serum.

${ }^{31}$ Eber. Deutsche Zeitschrift fur Tiermedizin, Vol. 21, p. 34 .

sa Smith. The Harvey Lectures, 1905-6, p. 272. 


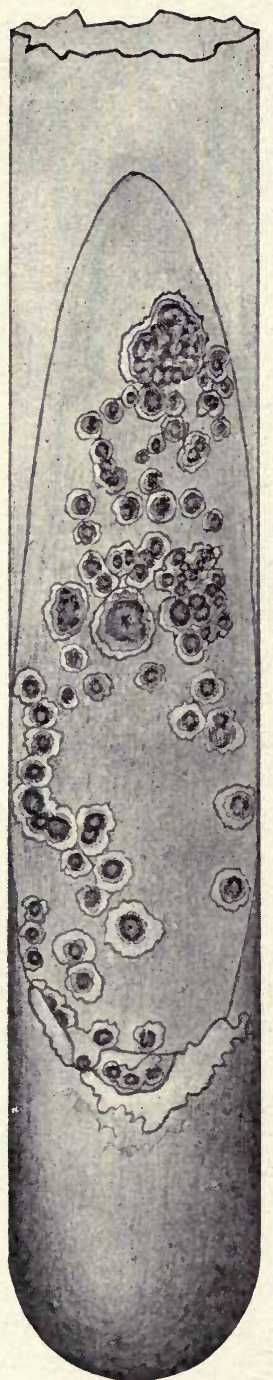

Fig. 58. A glycerin agar culture of avian tubercle bac. teria, showing colonies. Four weeks old. protect itself by suppressing multiplieation rather than by attempting to neutralize such poisons."

Bacterium of avian tuberculosis. This organism is more readily obtained in pure cultures directly from tissues than either the human or the bovine species. Moore ${ }^{33}$ obtained it in about $20 \%$ of the serum tubes inoculated directly from the organs. A measurement of over two hundred individual organisms in cover-glass preparations made directly from organs of fowls gave the following: In the liver the length varied from 1.2 to $3.5 \mu$, in the spleen and in the skin they varied from 1 to $4 \mu$ in length. A general average gave a length of $2.7 \mu$. They often appear in these preparations in dense masses. Chains made up of a number of short elements are rarely present. Granules are occasionally observed. In the preparations from the skin a considerable number of them contain polar granules and not infrequently three such bodies were noticed in a single individual. Perhaps the most striking feature concerning these organisms in the tissues is their enormous numbers: Sibley* has called attention to the similarity of avian tubercle bacteria to those of leprosy in that they multiply to such enormous numbers without a pronounced breaking down of the tissues.

Morphology. The morphology of

${ }^{33}$ Moore. loc. cit.

* Sibley (Jour. of Comp. Med. and Vet. Archives, 1890) pointed out the resemblance of avian tuberculosis to leprosy. 
the organisms varies with the media upon which it multiplies. On blood serum and egg media the organisms are nearly constant in form and size and slightly smaller than they usually appear in the tissues of the infected fowl. On glycerin agar they vary, excluding occasional long involution forms, from two to six $\mu$ in length, a large majority of the individuals ranging between two and five $\mu$. The average length of a large number was $3.9 \mu$, the width varied from 0.3 to $0.7 \mu$. In old cultures the variation in the size of the individuals is

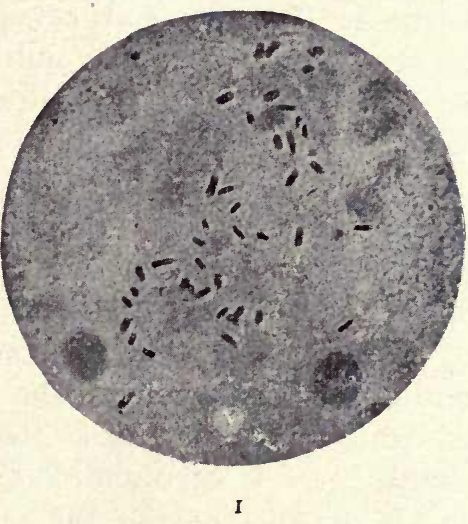
more marked. In cultures from three to six weeks old a large number of the individuals contain granules which stain deeply. When but two are present they are near the poles. Occasionally the longer rods contain three or more granules. If there is but one granule it usually appears near the middle of the organism. These granules are very similar in appearance to those described by Wolbach and Ernist ${ }^{31}$ in the human and bovine varieties. In old cultures involution forms are numerous.

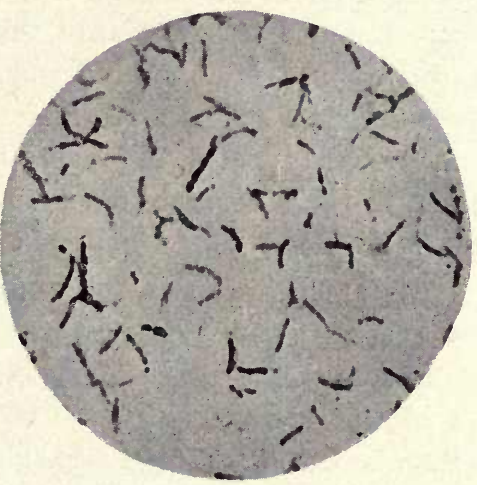

Fig. 59. Avian tubercle bacteria. 1 , bacteria in a cover-glass preparation from a tuberculous liver of a fowl; 2, photograph of a preparation from a glycerin agar culture.

Pure cultures were obtained by inoculating glycerin agar and blood serum tubes directly from tuberculous livers

"Ernst. loc. cit. 
and spleens. From the original cultures little difficulty is experienced in cultivating the organism on glycerin agar, fresh dog serum, Dorset's egg medium, potato, and glycerin bouillon. The first cultures in glycerin bouillon made from an original glycerin agar culture from the liver are characterized by a grayish, somewhat viscid mass that develops somewhat slowly in the bottom of the flask, but gradually clouds the liquid throughout. Later generations develop a thin, grayish, wrinkled pellicle which thickens and becomes a porcelain white, dense, but somewhat friable, membrane on the surface.

The colonies on glycerin agar may vary from one to three millimeters in diameter. The central portion is raised and of a slightly yellowish tint as observed under a hand lens. This central part is surrounded by a flat expansion, about twothirds the thickness of the center, varying from one-half to one millimeter in width, with ray-like projections radiating from it and extending into the outer and very thin band of growth with a lobulated margin. A pinkish tint to the growth has been described.

Nocard produced tubereulosis in fowls by inoculating them in the peritoneal cavity with a small quantity of caseous material taken from the bronchial gland of a tuberculous cow.

Bacterium of fish tuberculosis. This bacterium, isolated by Dubarre and Terre, ${ }^{34}$ resembles Bacterium tuberculosis in morphology and in a certain degree of acid-fastness. It grows at low temperature, $15^{\circ}$ to $30^{\circ} \mathrm{C}$. It is non-pathogenic for animals, but kills frogs within a month. Except for the acidfastness it has little in common with the organism of tuberculosis.

Vaccination against tuberculosis. A large number of men have tried to produce a vaccine with which to immunize cattle against tubereulosis but as yet their efforts have not been satisfactory. Individual animals may be made more resistant for a time by vaccination but the methods proposed can not

${ }^{34}$ Dubarre et Terre. Comp. rendu de la Soc. de Biol., 1897. 
be considered as practicable at present. M'Fadyean, ${ }^{35}$ von Behring, ${ }^{36}$ Pearson, ${ }^{37}$ Calmette and Guérin, ${ }^{38}$ T. Smith, ${ }^{39}$ and others have investigated this subject. The methods ${ }^{40}$ best known are those of Pearson and von Behring. They consist in inoculating calves with attenuated human tubercle bacteria. Haring, Sawyer and Morgan ${ }^{41}$ tested von Behring's method experimentally without satisfactory results. A few workers believe that it may be possible to obtain a practical method for vaccinating cattle against tuberculosis. The present knowledge of the nature of tuberculosis does not indicate the possibility of an efficient and practical vaccine for it being developed along the lines that have been followed.

OTHER PATHOGENIC ACID-FAST BACTERIA:

Johne's disease (chronic bacterial enteritis in cattle). In 1895, Johne and Frothingham ${ }^{1}$ described a chronic disease in eattle characterized by intestinal disturbances and pronounced wasting of flesh and a thickening of the mucous membrane of the intestine. Upon section, they found large numbers of acid-fast bacteria directly beneath the mucous membrane of the affected portions of the intestine. Morphologically, this organism resembles the tubercle bacterium. It varies in size from 1 to $2 \mu$ in length, although individuals of $4 \mu$ have been observed. The bacteria are not particularly intracellular but are found lying free single and in chains in the

${ }^{35}$ M'Fadyean. Jour. Comp. Path. and Therap., Jan. 1901.

${ }^{36}$ von Behring. Beiträge zur experimentellen Therapie, 1902.

${ }^{3 \pi}$ Pearson. Report Sixth International Congress on Tuberculosis, Washington, D. C., Vol. IV-ii, 1908, p. 1002.

${ }^{38}$ Calmette and Guérin. Ann. de l'Inst. Pasteur, Oct. 1905; May 1906; July, 1907.

${ }^{39}$ Smith. Jour. Med. Research, Vol. XVIII (1908) p. 451.

${ }^{40}$ For a review of methods for immunizing cattle against tuberculosis, see paper by Mohler and Schroeder, Proceedings of the Am. Vet. Med. Asso., 1910, p. 158.

${ }^{41}$ Haring, Sawyer and Morgan. Proceedings Am. Vet. Med. Asso., 1909, p. 252.

${ }^{1}$ Johne and Frothingham. Zeit. f. Tiermedizin, Bd. XXI (1894). 
spaces between the cells and fibers. In old lesions the bacteria are more numerous than in the early stages of the disease.

It was first thought to be a case of avian tuberculosis in cattle. M'Fadyean ${ }^{2}$ described this disease in England. It has been found a number of times in this country. A description of its artificial cultivation has not appeared. Olaf Bang ${ }^{3}$ found that cattle suffering with this disease gave a reaction to tuberculin prepared from the avian variety of tubercle bacteria.

Stockman ${ }^{4}$ has described acid-fast bacteria similar to those of Johne's disease, in the intestine of sheep. In scrapings from the intestine, bacteria appeared in great numbers and in dense clumps as in Johne's affection. They were also found in the mesentery lymphatic glands. Sections of the glands failed to show any tissue changes suggestive of the formation of tubercles.

\section{LEPROSY-LIKE BACTERIA IN ANIMALS.}

Dean ${ }^{1}$ investigated a disease of rats in England resembling leprosy in which he found enormous numbers of acid-fast bacteria in the cells which, however, he could not cultivate. This leprosy-like disease of rats was first described by Stefansky ${ }^{2}$ in 1903 . He pointed out two distinct types, one in which the skin and musculature were involved and the other where the lesions were confined to the lymphatic glands.

Wherry ${ }^{3}$ found in a study of the leprosy disease of rats that the organisms were taken up by flies that fed upon the carcasses of the leper rats. He showed that flies thus infected deposited the organisms with their feces. They did not mul-

${ }^{2}$ M'Fadyean. Jour. of Comp. Path. and Therap., Vol. XX (1907) p. 48 .

${ }^{8}$ Olaf Bang. Ninth International Vet. Congress, The Hague, 1909.

'Stockman. Jour. of Comp. Path. and Therap., Vol. XXIV (1911) p. 66.

${ }^{1}$ Dean. The Jour. of Hygiene, Vol. V (1905) p. 99.

${ }^{2}$ Stefansky. Centralbl. f. Bakt., Bd. XXXIII (1903) p. 481.

Wherry. Jour. of Inf. Dis., Vol. V (1908) p. 507. 
tiply in the intestine of the flies and they were practically eliminated within 48 hours. He experimented with the green bottle fly (Lucilia Caesar), blow fly (Caliphora vomitoria) and the house fly (Musca domestica). He calls attention to the value of rat leprosy in studying the role that parasitic insects may play in the transmission of leprosy bacteria.

SEPTICEMIA HEMORRHAGICA GROUP (HUEPPE) OR PASTEURELLA

General discussion of the group. The bacterium of chicken cholera, the bacterium of rabbit septicemia, bacterium of swine plague (Schweineseuche) and bacterium of hemorrhagic septicemia in cattle were found to be very closely related morphologically and in many if not all of their biological properties one to the other. The general resemblance in the effect of these organisms upon the animal body led Hueppe in 1886 to apply the name Bact. septicemiae hemorrhagicae to all of these organisms. Trevisan in honor of Pasteur proposed the general name Pasteurella for this group of bacteria. Lignières ${ }^{1}$ classified all of the diseases produced by this group of organisms as Pasteurelloses. He also reported saprophytic organisms as well as highly virulent forms belonging to this group. Moore ${ }^{2}$ found these organisms in the upper air passages of a large percentage of cattle, sheep, swine, dogs and cats. King ${ }^{3}$ found it on the conjunctiva of a healthy chicken. The evidence seems to warrant the conclusion that this group is widely distributed and that it can be found possessed of different degrees of virulence. The question as to the identity of the organisms isolated from cases of swine plague and from those of chicken cholera and the other diseases mentioned is difficult to answer. It seems well until the results of further investigations are recorded to look upon these bacteria as belonging to one group, but that for the present the organisms isolated from the different diseases should retain their original separate designations. Although the organisms from these

${ }^{1}$ Lignières. Ann. de l'Inst. Pasteur, Vol. XV (1901) p. 734.

${ }^{2}$ Moore. Bulletin No. 3. B. A. I., U. S. Dept. Agric., 1895.

${ }^{3}$ King. Loc. cit. 
different sources are closely related, the descriptions given by different workers vary to quite an extent. Until this entire group is carefully monographed, it seems necessary to refer to the different species. The species that have been described as pathogenic for domesticated animals are those of swine plague, chicken cholera, septicemia hemorrhagica, rabbit septicemia, and goose septicemia. Bacteria apparently belonging to this group have been isolated from a number of other morbid conditions in different animals, but unfortunately their descriptions are not sufficiently full to warrant their further consideration here.

\section{BACTERIUM CHOLERAE-GALLINARUM (FLUGGE) MigULA.}

Synonyms. Bacillus of fowl cholera; Bacillus cholerae gallinarum Flügge. ${ }^{1}$

Place in nature. This organism is the specific cause of the disease of fowls known as chicken cholera. It is the same morphologically as the bacterium that causes goose septicemia. $^{2}$ It is not known to exist in nature, except in infected fowls. As already stated, Lignières reports that members of this group exist as saprophytic organisms. Further investigations are necessary on this point. This bacterium was discovered independently by Perroncito, ${ }^{3}$ Toussaint ${ }^{4}$ and Pasteur. $^{5}$ It was first reported in this country by Salmon. ${ }^{6} \mathrm{Mi}$ gula identifies this organism with that of rabbit septicemia.

Morphology. The individual organisms are short, with rounded ends. They usually occur singly, but a few are seen

${ }^{1}$ Flügge. Die Mikroorganismen, 1886.

${ }^{2}$ Curtice. Bulletin No. 86, R. I. Agric. Exp. Station, 1902.

M'Fadyean. Jour. Comp. Path. and Therap., Vol. XV (1902) p. 162 .

${ }^{3}$ Perroncito. Arch. f. wiss. u. prakt. Thierheilkunde, 1879, p. 22.

${ }^{4}$ Toussaint. Compt. rendu de l'Acad. des Sci., Vol. XC (1890) p. 428 .

${ }^{5}$ Pasteur. Compt. rendu de l'Acad. des Sci., Vol. XC (1880) p. 239, 952 and 1030. Ibid., Vol. XCI (1881) p. 673.

'Salmon. Report U. S. Com. Agric., 1880-1882. 
in pairs. Spherical forms are numerous in actively growing eultures. The size varies from 0.5 to $0.7 \mu$ in width and from 1 to $2 \mu$ in length. A bipolar arrangement of the protoplasm is demonstrated when carbol fuchsin and alkaline methylene blue stains are used. The bipolar staining is more noticeable in smear preparations from tissues. The presence of a capsule is suggested by an unstained area surrounding each organism in smear preparations from tissues, especially the blood.

Staining. It stains readily with the aniline dyes. It is Gram negative.

Cultivation. This organism grows readily on alkaline agar or in bouillon made from meat.

Agar. The colonies on agar, after forty-eight hours at $37.5^{\circ} \mathrm{C}$. appear as round, smooth, thin, shiny disks, with entire border and measuring about $2 \mathrm{~mm}$. in diameter. Under a two-thirds objective they appear coarsely granular and show concentric circular markings. They appear smoky brown in color by transmitted light, and gray by reflected light. Colonies beneath the surface are usually lenticular in shape, and the granular appearance is more marked under a two-thirds objective than in the surface colonies. After twenty-four hours the growth on slant agar is flat, smooth, shining, grayish white by reflected light, and smoky brown by transmitted light. The condensation water becomes decidedly turbid. Growth upon glycerin agar presents no features distinguishable from that on agar slant.

Potato. No visible growth has been observed. Migula describes a feeble growth after some days.

Dog blood serum. After twenty-four hours at $37.5^{\circ} \mathrm{C}$. the path of the needle is covered with a smooth, shiny, raised growth. The condensation water is markedly turbid.

Bouillon. In from 24 to 48 hours the fluid becomes slightly clouded and does not clear up on standing. In young cultures no sediment is deposited, but in older cultures a viscous sediment accumulates. The reaction is alkaline to litmus and markedly so in old cultures. No pellicle is formed, but occasionally a circular bluish band of growth adheres to the 
tube at the level of the surface of the fluid. In acid bouillon the growth is less marked, and no accumulations of bacteria have been noticed at either surface or bottom of the liquid. Reaction becomes alkaline in old cultures. In bouillon containing one per cent glucose in the fermentation tube, the liquid throughout the tube becomes slightly clouded in twenty-four hours and remains so. The reaction becomes acid in two days. No gas is formed.

Life conditions and properties. It is an aërobe and facultative anaërobe. Its most favorable temperature for multiplication is $37.5^{\circ} \mathrm{C}$. It produces indol.

Resistance. It is destroyed at $57^{\circ} \mathrm{C}$. in ten minutes ${ }^{7}$ and by an exposure of one hour to direct sunlight in thin cover-glass preparations made from young ( 24 hour) cultures. It is quickly killed with 1 to 1000 solution of corrosive sublimate.

Pathogenesis. It is fatal to fowls inoculated with 1 cc. of a bouillon culture, subcutaneously or in the vein, in a short time. Smaller doses cause death in from 3 to 5 days. Rabbits die in from 15 to 36 hours after subcutaneous injection of a small quantity of a bouillon culture.

Cornil and Toupet $^{8}$ have described a bacterium as the cause of cholera in ducks which is very similar in all of its characteristics to the bacterium of fowl cholera. Migula has designated it Bacterium anatis.

Fiorentini ${ }^{9}$ has described an organism which he found to be the cause of an epizootic among swans. His description shows that it is very similar in its morphology and cultural characters to that of fowl cholera. Migula has designated it Bacterium cygni.

${ }^{7}$ Ward. Bulletin No. 156, Univ. of Calif. Agric. Exp. Station, 1904.

${ }^{8}$ Cornil and Toupet. Compt. rendu de l'Acad. de Sciences de Paris, Vol. CVI, p. 1747.

- Fiorentini. Centralbl. f. Bakt., Bd. XIX (1896) p. 932. 
BACTERIUM CUNICULICIDIA (FLUGGE) MIGULA.

Synonyms. Bacillus of rabbit septicemia; Bacterium septichaemiae Schröter.

Place in nature. In $1878 \mathrm{Koch}^{1}$ found an organism in decomposed albuminous matter that was fatal to rabbits. Later Gaffky ${ }^{2}$ found a similar one in contaminated water. Smith ${ }^{3}$ reported in 1887 a fatal disease in rabbits due to this organism. Thoinot and Masselin ${ }^{4}$ in 1888 studied a disease among the rabbits at the Alfort Veterinary College, and Moore and Kilborne ${ }^{5}$ reported an outbreak of a disease among the rabbits at the Experiment Station of the Bureau of Animal Industry, characterized by a localized inflammation of one or more serous membranes and due to the bacterium of rabbit septicemia. Beck ${ }^{6}$ has described a bacillus of lung plague in rabbits which was designated by Kruse as Bacillus cuniculi pneumonicus and deseribed by Migula as Bacterium cuniculi. This organism differs somewhat in its morphology and cultural characters from that of rabbit septicemia. Beck calls attention to the fact that fowls and pigeons are not susceptible. Several authors have considered this organism synonymous with the bacterium of fowl cholera.

Morphology. A short rod with rounded ends varying in length from 1.2 to $1.8 \mu$ and in width from 0.8 to $1.0 \mu$. Involution forms in which the contents seemed to be concentrated at one end of the elongated body, which assumed a sacklike appearance, have been observed.

Staining. It stains readily with the aniline dyes and it is Gram negative.

Cultivation. In its cultivation and cultural characters

${ }^{1}$ Koch. Loc. cit.

${ }^{2}$ Gaffky. Mitt. a. d. Kais. Gesundheitsamt., Bd. I (1881) p. 50.

${ }^{3}$ Smith. Jour. Comp. Med. and Surgery, Vol. VIII (1887) p. 24.

4 Thoinot and Masselin. Précis de Microbie, Third edition.

${ }^{5}$ Moore and Kilborne. Am. Vet. Review, Vol. XVII (1893) p. 285.

' Beck. Zeit. f. Hyg., Id. XV (1893) p. 363. 
on usual media it does not differ from the bacterium of fowl cholera.

Life conditions and properties. Here again it is not unlike fowl cholera except that phenol was detected in 18-day cultures. Soluble toxins have not been detected.

\section{BACTERIUM BOVISEPTICUM (KRUSE) MIGULA.}

Synonyms. Bacterium of Wild- und Rinderseuche Bollinger, ${ }^{1}$ Bacterium bipolare multocidum $\mathrm{Kitt}^{2}$; Bacillus bovisepticus Kruse ${ }^{3}$; Bacillus septicemia hemorrhagica Hueppe. ${ }^{4}$

Place in nature. This organism is the cause of septicemia hemorrhagica in cattle. It is also said to be the cause of a pleuropneumonia of calves (Pallas) and of a ealf septicemia $\left(\right.$ Jensen $^{5}$ ). It is found in the organs of animals suffering from the disease. It does not seem to differ from the bacterium found in the upper air passages of a eertain number of healthy cattle or from those found by Smith ${ }^{6}$ in a form of sporadic broncho-pneumonia in cattle. This organism was discovered by Bollinger in 1878. The disease caused by it has been investigated by Wilson and Brimhall, ${ }^{7}$ Rey; nolds ${ }^{8}$ and Fennimore ${ }^{9}$ in this eountry.

Morphology and cultural characters. Bacterium bovisepticum according to Migula does not differ in its morphology or cultural characters from the bacterium of fowl cholera. Aceording to Wilson and Brimhall the organisms take a deep 1878.

${ }^{1}$ Bollinger. Uber eine neue Wild- und Rinderseuche. München,

${ }^{2}$ Kitt. Sitzungsber. der Gesellsch. f. Morph. u. Phys. in München, Bd. I (1885) p. 240.

${ }^{3}$ Kruse. In Flüge's Mikroorganismen, Bd. II (1886) p. 421.

${ }^{4}$ Hueppe. Berliner klin. Wochenschrift, 1886.

${ }^{5}$ Jensen. Monatshefte f. praktische Thierheilkunde, Bd. II (1891) p. 1.

${ }^{6}$ Smith. Report B. A. I. 1895-96, p. 119.

${ }^{7}$ Wilson and Brimhall. Report State Board of Health of Minnesota, 1901.

${ }^{8}$ Reynolds. Bulletin No. 82, Minn. Agric. Exp. Station, 1903.

${ }^{\circ}$ Fennimore. Jour. of Comp. Med. and Vet. Archiv., Vol. XIX (1898) p. 625. 
polar stain in preparations from tissues and in cultures they may appear in short ehains. The marked polar stain often suggests a diplococeus. They state that it is destroyed at $58^{\circ} \mathrm{C}$. in 8 minutes and by a $1-5000$ solution of mereuric chloride in one minute. The method by which this organism is disseminated is not.known. The disease it produces appears at all seasons of the year. The specific bacteria are often found in smears made from the hemorrhagic foci and from the various organs and blood. It is pathogenic for the bovine species and by inoculation for rabbits and guinea-pigs. It seems to lose its virulence for cattle after it has been cultivated artificially for a few generations.

\section{BACTERIUM SUISEPTICUM (KRUSE) MIGULA.}

Synonyms. Bacillus of Schweineseuche Loeffler and Schütz ${ }^{1}$; Bacillus of swine plague Smith ${ }^{2}$; Bacillus suisepticus Kruse $^{3}$; Bacterium suicida Migula. ${ }^{4}$

Place in nature. Bacterium suisepticum is the cause of the disease in swine known as swine plague, or infectious pneumonia. This organism is found in the lungs, often in other organs of pigs suffering from this disease. An organism that ean not be differentiated from it is found in the mucus of the larynx in about 50 per cent of healthy pigs. This organism was first discovered by Loeffler and Schütz in 1885 as the eause of Schweineseuche. In 1886 Theobald Smith isolated it from cases of swine plague. It is not known to exist in nature outside of the infected animal and in the upper air passages of a certain percentage of healthy swine unless it is proved to be identical with the forms in the upper air passages of other animals.

Morphology. A rod-shaped organism varying from 0.8 to $2 \mu$ in length and from 0.4 to $1.2 \mu$ in breadth. The ends

${ }^{1}$ Loeffler and Schütz. Arbeit aus dem Kais. Gesundheitsamt., Bd. I (1886) p. 376.

${ }^{2}$ Smith. Special Report on swine plague, B. A. I., Washington, D. C., 1893 .

${ }^{3}$ Kruse. loc. cit. "Migula. loc. cit. 
are oval, and the shorter forms resemble micrococci. The size depends upon the medium and the stage of development of the individual bacteria. A capsule has not been demonstrated, although often in preparations made directly from tissues there appears to be one. It is not observed in cultures. Spores have not been seen. Involution forms are not uncommon in old cultures. The bacteria are especially numerous in the organs of a rabbit when it is allowed to lie for some hours after death before it is examined. It exhibits, when stained in cover-glass preparations made directly from animal tissues, a

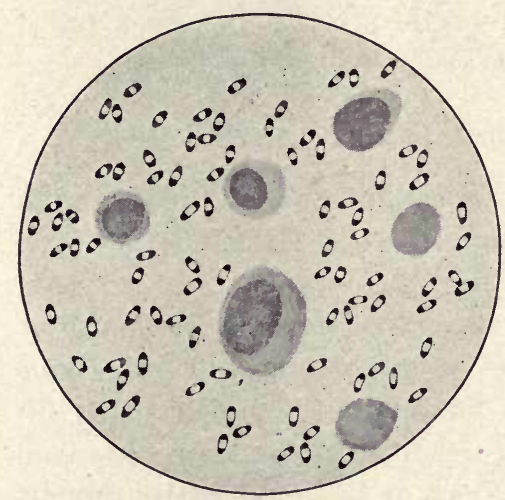

Fig. 60. Bacterium suisepticum from a cover-glass preparation of a rabbit's liver. light center with deeply stained extremities (polar stain). In preparations made directly from cultures this character is much less marked.

Staining. It $\mathrm{stains}$ readily with the basic aniline dyes. It does not stain by Gram's method.

Cultivation. This organism grows readily but not luxuriantly on the ordinary alkaline $\mathrm{media}$ made from meat infusions. It does not grow in media having a decided acid reaction.

Agar. The growth on this medium is not vigorous. It is of a neutral grayish color, with a glistening, moist appearing surface. It is slightly viscid and adheres to the agar surface. Isolated colonies vary from 1 to $2 \mathrm{~mm}$. in diameter, nearly round, convex, with smooth and sharply-defined margins. The condensation water becomes faintly clouded with a grayish sediment which becomes viscid. Within the agar the colonies appear as minute grayish dots. On agar, especially in plates (Petri dishes), it emits a peculiar, disagreeable, pungent odor. 
Gelatin. Ordinarily it does not grow in gelatin.

Potato. It does not grow on potato.

Serum. The growth is slight and often does not appear.

Bouillon. Alkaline peptonized bouillon becomes uniformly clouded in 24 hours when kept at a temperature of $36^{\circ} \mathrm{C}$. Occasionally cultures are obtained in which the growth appears in the form of flocculent masses, but usually after a few generations these disappear and the liquid becomes uniformly cloudy. If the bouillon contains any dextrose or muscle sugar, its reaction becomes acid in 24 to 48 hours, owing to the fermentation of the carbohydrate. With the virulent cultures the liquid usually clears within a few days. The small amount of grayish sediment becomes viscid after some days, and upon agitation it is forced up, appearing as a somewhat twisted, tenacious cone, with its apex at or near the surface of the liquid. Frequently a thin, grayish, somewhat viscid band composed of bacteria is found on the sides of the tube at the surface of the liquid. It will not grow in acid bouillon. If the bouillon contains from 1 to 2 per cent glucose, the growth is slightly more vigorous.

In the fermentation tube, alkaline bouillon containing sugars becomes uniformly clouded in both branches. Gas is not produced. In bouillon containing dextrose and saccharose the reaction becomes strongly acid in 24 hours, but the reaction of alkaline bouillon containing lactose is not changed.

Milk. Milk inoculated with this organism remains unchanged in appearance for several weeks. When boiled, after this period, the casein is not coagulated.

Life conditions and properties. Bact. suisepticum is aërobic and facultative anaërobic. It grows best at the temperature of $36^{\circ}$ to $37.5^{\circ} \mathrm{C}$. It multiplies slowly at room temperature. It does not produce a poisonous soluble toxin. Rabbits may be immunized by injecting them repeatedly with sterilized bouillon cultures.

Resistance. This organism is destroyed in bouillon at $58^{\circ} \mathrm{C}$. in ten minutes. A temperature of $56^{\circ} \mathrm{C}$. for this time did not destroy its vitality. They can not stand drying. The 
bacteria in a drop of bouillon dried on a cover-glass and kept at the room temperature are destroyed in 24 to 36 hours. In similar preparations made from agar cultures they resist drying from five to eight days. The difference in the time between the two cultures is probably due to the thicker layer in case of the agar preparations. It dies in water in test tubes in from nine to eleven days. In the soil it was not found after eight days. Smith states that it is destroyed in the soil after four days.

The bacterium of swine plague is very sensitive to the action of disinfectants. It is killed in lime water in 1 minute; by carbolic acid in 1 per cent solution in 5 minutes, and in a 2 per cent solution in 1 minute. Formalin in a solution of $1: 2000$ is fatal to it in 5 minutes.

Pathogenesis. This organism is pathogenic for rabbits, guinea pigs and mice among the smaller animals and for swine. With the virulent form rabbits inoculated either subcutaneously or in the vein with very small ( 0.001 ce.) doses, die of septicemia in from 16 to 24 hours. Guinea pigs are slightly less susceptible. When inoculated subcutaneously with 0.1 to 0.2 cc. of a bouillon culture, they die in from 30 to 72 hours. Mice succumb in about 24 hours when inoculated with a drop of the culture. Pigs inoculated intravenously usually die from acute septicemia in from 18 to 36 hours. If they live longer there may be decided lung lesions. Less virulent cultures cause peritonitis, pleuritis or pericarditis, killing in from 3 to 6 days. Still less virulent cultures produce extensive purulent local lesions.*

\section{BACTERIUM FELIS (KRUSE) MIGULA.}

Synonyms. Bacillus felis septicus Kruse.

Place in nature. Fiocea ${ }^{1}$ discovered this bacterium in the saliva of cats and dogs. It resembles morphologically and

* For a study of the variations in the lesions produced in rabbits partially immunized to this organism the student is referred to Bulletin No. 6, B. A. I., U. S. Dept. of Agric., 1894.

${ }^{1}$ Fiocca. Centralbl. f. Bakt., Bd. XI (1892) p. 406. 
in its cultural characters the bacterium of rabbit septicemia. Its distribution is not known, except in the mouths of cats and dogs. It was described as pathogenic for rabbits, guinea pigs, young rats and mice. It stains with the aniline dyes, often appearing in pairs as diplococei. It is Gram negative. It is presumed from the description given that this organism does not differ essentially from those found by Moore in the upper air passages of cats and dogs, and which could not be differentiated in the laboratory from the bacteria of swine plague and rabbit septicemia.

Bienstock obtained an organism from feces which morphologically and in its cultural characters resembled fowl cholera bacteria. It was pathogenic for white mice and rabbits. Bienstock ${ }^{2}$ designates it Bacillus coprogenes parvus.

BACTERIUM PULLORUM RETTGER.

Synonyms. Bacillus of white diarrhoea in chickens, or bacillary white diarrhea of growing chickens Rettger and Stoneburn. ${ }^{1}$

Place in nature. Bacterium pullorum is the cause of a serious epizootic disease of young chickens known as "bacillary white diarrhoea." It was described by Rettger first as the cause of a fatal septicemia and later called by him bacillary white diarrhoea. ${ }^{2}$ Jones ${ }^{3}$ designates it fatal septicemia or bacillary white diarrhoea. The organism exists in the infected fowl, i. e., in fowls that had the disease when chicks and recovered. It has been found in a certain number of the eggs laid by such fowls. Jones states that the organism is disseminated by the indiscriminate purchasing of eggs for hatching and of day old chicks. Rettger and Stoneburn found the

${ }^{2}$ Bienstock. Zeitsch. f. klin. Med., Bd. VIII.

${ }^{1}$ Rettger and Stoneburn. Bulletin No. 60, Storrs. Agric. Exp. Station, 1909.

${ }^{2}$ Rettger. New York Medical Journal, Vol. LXXI (1900) p. 803.

Ibid. Vol. LXXIII (1901) p. 267.

Rettger and Harvey. Journal Medical Research, Vol. XVIII (1908) p. 277.

${ }^{3}$ Jones. Report N. Y. State Vet. College, 1909-1910, p. 111. 
organism in the ova within the ovaries of hens, in the yolk of the fresh egg, in eggs incubated for varying lengths of time, and in yolk sacks of fully developed chicks still within the shell. This suggests that the source of infection is the adult and apparently healthy hen which was infected as a chick. ${ }^{4}$ Whether or not this organism has a habitat outside of the chicken body is not known.

Morphology. A somewhat slender organism varying from 2 to $3.5 \mu$ in length and from 0.3 to $0.5 \mu$ in breadth. The ends are rounded. It usually appears single, although pairs

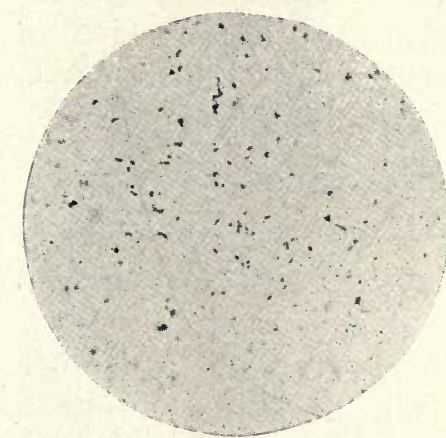

Fig. 61. Bacterium pullorum. Photograph of a preparation from an agar culture 36 hours old. $\times 400$. (Jones). and short chains are sometimes observed. It has a pronounced Brownian movement which in some cultures might be mistaken for motility. Spores and capsules have not been observed.

Staining. It stains readily with the usual bacterial stains. It does not take the Gram stain.

Cultivation. There is no difficulty in cultivating this organism on the ordinary media directly from the tissues and blood of the recently dead chick. It requires for rapid growth a temperature of $37^{\circ}$ to $38^{\circ} \mathrm{C}$.

Agar. On agar small grayish white glistening convex colonies appear in from 12 to 24 hours. In 48 hours they have reached their maximum development having a diameter of from 1 to $2 \mathrm{~mm}$. When magnified they are found to be finely granular. The growth does not become vigorous. The water of condensation becomes slightly cloudy.

Gelatin. Small whitish colonies appear in 48 hours. In stab cultures a delicate grayish growth appears along the

${ }^{4}$ Dr. F. S. Jones in this laboratory is making a thorough investigation of this point. 
needle puncture. It is distinctly granular in appearance. Growth does not spread over the surface of the gelatin. Liquefaction does not occur.

Potato. Frequently growth does not appear on potato. A narrow almost invisible growth along the line of inoculation has been described.

Serum. The growth on blood serum is like that on agar.

Bouillon. In alkaline bouillon the growth imparts a faint cloudiness to the liquid. A moderate quantity of rather viscid sediment forms in the tube. The reaction becomes acid. In bouillon containing lactose and saccharose gas is not formed. Dextrose and mannite bouillon become acid and usually gas is formed. In dextrose bouillon about $20 \%$ gas is formed in the closed branch of the fermentation tube. The gas formula is $\mathrm{CO}_{2}, 1$ part; $\mathrm{H}, 3$ parts. The action on mannite is practically the same as on dextrose. Some strains of this organism do not produce gas in any of the sugar media, but acid is formed.

Milk: Milk remains unchanged in appearance but after 48 hours it becomes slightly more acid although coagulation of the casein does not take place.

Life conditions and properties. Bacterium pullorum is an aërobe and facultative anaërobe. It develops slowly at room temperature but it grows well at a temperature from $36^{\circ}$ to $38^{\circ} \mathrm{C}$. Neither indol or nitrite is produced. A specific toxin has not been detected.

Resistance. It is very susceptible to disinfectants. A 1-1000 solution of mercuric chloride, a $1 \%$ solution of carbolic acid and $1 \%$ creolin emulsion destroy it in five minutes. It resists a temperature of $60^{\circ} \mathrm{C}$. for 30 minutes.

Pathogenesis. Bacterium pullorum is pathogenic for young chicks if inoculated orally within the first forty-eight hours after hatching. It is also pathogenic to chicks three days of age if injected subcutaneously. It causes death in from four days to three weeks and can be recovered from all organs. It is not pathogenic for adult fowls. Two cubic centimeters injected directly into the wing vein of adults produced marked depression which lasted for several days but no other 
bad effects were discovered. The same results were obtained when larger quantities were injected. No effect is produced by feeding large quantities of the culture to adults.

Half grown guinea pigs when injected subcutaneously with the culture die in from twenty-four to forty-eight hours. The essential lesion is a large edematous area beneath the skin of the abdomen. The organisms are recovered in pure culture from the internal organs. A rabbit weighing 1,660 grams injected subcutaneously with 3 cc. of a forty-eight hour bouillon culture died in seven days. The most pronounced lesions were enlargement, softening and congestion of the heart. The bacterium was recovered from all the internal organs in pure culture.

\section{BACTERIUM RHUSIOPATHIAE (KITT) MigULA.}

Synonyms. Bacillus of swine erysipelas Loeffler ${ }^{1}$; Bacillus rhusiopathiae suis Kitt ₹ ${ }^{2}$ Bacterium erysipeiatus suis, Migula. ${ }^{3}$

Place in nature. This organism is the cause of a disease in swine known in England as swine erysipelas, in Germany as Rotlauf and in France as rouget. Jensen ${ }^{4}$ deseribes five varieties of Rotlauf due to this organism that were previously considered as different diseases. Rotlauf or swine erysipelas is not known to exist in America. In 1894 Dr. Theobald Smith ${ }^{5}$ isolated and described an organism from rabbits that were inoculated with tissues from pigs sent to him from Minnesota which resembled Bacterium rhusiopathiae but which was not positively identified. This organism was discovered by Pasteur and Thuillier ${ }^{6}$ and later studied in pure culture and

${ }^{1}$ Loeffler. Arbeiten aus dem Kaiserl. Gesundheitsamt., Bd. I (1886) p. 46.

${ }^{2}$ Kitt. Bakterienkunde u. pathologische Mikroskopie, 1893, p. 284.

Loc. cit.

Jensen. Deutsche Zeitschr. f. Thiermed., Bd. XVIII (1892) p. 278.

- Smith. Annual Report B. A. I., U. S. Dept. Agric., 1895-1896.

- Pasteur et Thuillier. Compt. rendu de l'Acad. des Sci., Vol. XCV (1882) p. 1187. 
described by Loeffler. ${ }^{7}$ Kitt $^{8}$ has found long filament-forms resembling those of streptothrix.

Morphology. This organism is present in the heart blood and usually is abundant in the blood vessels of the skin. It is very slender, 1 to $2 \mu$ or more in length, 0.3 and $0.6 \mu$ in breadth. They sometimes appear as quite long slender filaments. They are straight or curved. In the blood they may appear in small clumps. They are often found in considerable numbers in the leucocytes. They do not produce spores. They do not seem to have a capsule.

Staining. They stain readily with the ordinary aniline dyes. They retain the color when treated by the Gram method.

Cultivation. The cultivation of this organism is best carried on in nutrient gelatin which gives a distinctly alkaline reaction to litmus paper.

Agar. At $35^{\circ} \mathrm{C}$. on the surface of agar there appear after twenty-four hours round, translucent, convex colonies varying from 0.3 to $0.5 \mathrm{~mm}$. in diameter. In the condensation water a very slight growth takes place. By the third day the colonies, if not crowded, will increase to $1 \mathrm{~mm}$. in diameter; they are round, grayish, with a glistening surface and sharply defined border. A slightly viscid deposit forms in the condensation water. Within the agar minute grayish colonies are developed. On glycerine agar the growth does not differ appreciably from that on the simple agar.

Gelatin. In needle cultures after twenty-four to thirtysix hours at the ordinary temperature there develops along the needle track a quite dense, grayish line, due to the crowding together of minute colonies. From the growth along the track of the needle faint, cloudlike processes extend laterally almost to the sides of the tube, giving the gelatin a clouded appearance, and to the growth a form resembling that of a "test tube brush." The gelatine is softened, but rarely liquefied. If the reaction is just right, slow liquefaction along the needle track takes place. The colonies, when not crowded, appear in

${ }^{7}$ Loeffler. loc. cit.

${ }^{8}$ Kitt. Centralbl. f. Bakt., Bd. XXII (1897) p. 726. 
reflected light as bluish-gray nebulous spots; by transmitted light they appear more distinctly as very delicate, bluish translucent areas. The colonies in general are round, but they have no sharp outline, gradually fading into the surrounding clear gelatin. After six days the colonies attain a diameter of 4-7 mm. with round, slightly more opaque centers, a few of which appear to be quite solid. Several days later the colonies are very indistinct and cloudlike. There is a small amount of liquefaction of the gelatin which does not seem, however, to be associated with the colonies. When crowded they present the appearance of two kinds of colonies, (1) those which have a simple nebulous appearance and (2) those which have a minute solid nucleus. The latter are much smaller than the former. The largest are about $2 \mathrm{~mm}$. in diameter. They are separated by a distance of 0.25 to $0.5 \mathrm{~cm}$. At the end of ten days about. one half of the colonies show the solid nucleus. The colonies are about 0.5 to $1 \mathrm{~mm}$. in diameter and consist of a central portion surrounded by a translucent band which is bounded externally by an opaque ring.

Potato. No growth.

Serum. On blood serum no growth.

Bouillon. The day following its inoculation the liquid is faintly but uniformly cloudy. When the tube is shaken this cloudiness has the appearance of clouds of dust. A few days later it is less marked, with a very slight deposit in the bottom of the tube. In bouillon containing $2 \%$ glucose in fermentation tubes at $36^{\circ} \mathrm{C}$., after twenty-four hours the liquid is usually uniformly clouded throughout. Occasionally, however, the liquid in the closed bulb remains clear for fortyeight hours. Gas is not produced.

Milk. At $36^{\circ} \mathrm{C}$. no appreciable change is produced in its appearance. Milk in which these organisms have multiplied may or may not coagulate on boiling. A microscopical examination shows a vigorous multiplication of the bacteria in this medium.

Life conditions and properties. It is an aerrobe and facultative anaërobe. It grows best at a temperature of $36^{\circ}$ to 
$38^{\circ} \mathrm{C}$. In the fermentation tube the closed bulb may become cloudy and the open one remain clear. It does not multiply in bouillon free from dextrose or lactose. It retains its virulence after several generations. Its virulence is increased by passing it through pigeons. It is rapidly attenuated at a temperature of $45^{\circ} \mathrm{C}$.

Resistance. It is destroyed at a temperature of $55^{\circ} \mathrm{C}$. in a few minutes. There seems to be little data relative to its resistance to disinfectants. Cultures that have been under eultivation for several generations are promptly killed by the ordinary disinfectants.

Pathogenesis. In addition to swine, this organism is pathogenic for rabbits, mice and pigeons. Death follows in from three to seven days after an intravenous (rabbit and pigeon) inoculation with a small (0.15 to 0.25 cc.) quantity of a culture. Pigeons are especially susceptible. Other animals seem to be immune.

Vaccine. Pasteur and Thuillier prepared a vaceine from attenuated cultures which gave very satisfactory results. Pigs that recover from an attack possess considerable immunity. Lorenz ${ }^{9}$ and Emmerich ${ }^{10}$ employed a blood serum for immunizing purposes.

BACTERIUM MURISEPTICUM (FLUGGE) MigULA.

Synonyms. Bacillus murisepticus Koch ${ }^{1}$; Bacillus murinus Schröter. ${ }^{2}$

Place in nature. The Bacterium murisepticum is the cause of a septicemia in mice. It was discovered by Koch in 1878. It has been found and described by Smith $^{3}$ and Moore ${ }^{4}$

' Lorenz. Deut. tierärtz. Wochensch., 1893, pp. 41 and 85 .

${ }^{10}$ Emmerich. Ibid, 1893, p. 127.

${ }^{1}$ Koch. loc. cit.

${ }^{2}$ Schröter. Kryptogamenflora von Schlesien, Bd. III (1886) p. 162.

${ }^{3}$ Smith. Second Annual Report B. A. I., U. S. Dept. Agric., 1885, p. 196.

${ }^{4}$ Moore. Jour. Comp. Med. and Vet. Archives, Vol. XIII (1892) p. 333 . 
in this country. It is closely related to swine erysipelas. In its morphology and cultural characters this organism does not seem to differ from that of swine erysipelas except in the following points. Morphologically, the bacteria of mouse septicemia are about one and one-half times as thick as those of rouget; the filaments are much shorter and less tortuous. On agar there is no appreciable difference in the character of the growth; the colonies are slightly smaller in cultures of the bacterium of rouget. In gelatin needle cultures the growth is more dense, and not so diffuse as that of mouse septicemia. In roll cultures the colonies of rouget bacteria consist of a central opaque nucleus with a hazy periphery, the whole about $3 \mathrm{~mm}$. in diameter, when the colonies are not erowded, and situated in a liquefied area of gelatin, extending slightly beyond the border of the colonies. The development in roll cultures is especially interesting, as the solid nucleus is observed in a considerable number of colonies of mouse septicemia. The bacterium of mouse septicemia is more virulent for mice than that of rouget. There seems to be a marked tendency on the part of both of these organisms to invade the white blood corpuscles.

It is interesting to note that in Europe where swine erysipelas is more or less common, mouse septicemia is not rare.

\section{BACTERIUM OF CASEOUS LYMPH-ADENITIS.}

Synonyms. Bacillus of pseudo-tuberculosis Preisz and Guinard ${ }^{1}$; bacillus of caseous lymph-adenitis Nörgaard and Mohler ${ }^{2}$; bacillus of Preisz.

Place in nature. This organism is supposed to be the cause of a disease known as caseous lymph-adenitis in sheep. Old sheep suffer most with it. It has been described as pseudotubereulosis by a number of writers. Nörgaard and Mohler give a full description of the disease, the bacterium and bibliography. The organism was first described by Preisz and

${ }^{1}$ Preisz and Guinard. Jour. de méd. vét. et de zoolich, Vol. XVI, p. 563 .

${ }^{2}$ Nörgaard and Mohler. Annual Report B. A. I., U. S. Dept. Agric., 1899, p. 638. 
Guinard and later by Preisz. ${ }^{3}$ The disease is found in Europe, Australia, South America and the United States. It is probably widespread in sheep-raising districts. In addition to its presence in this disease it has been found by Nocard ${ }^{*}$ in a case of ulcerative lymphangitis in horses. Kitt ${ }^{5}$ found it in a case of caseous broncho-pneumonia in cattle. The further distribution of the organism is not known.

Morphology. This bacterium. varies somewhat in size and shape according to the medium in which it has grown. It seems to be characterized by its variation in shape. It is short and thick with rounded ends. In tissues it is reported to appear often as nearly spherical bodies although dumb-bell or club-shaped forms may be present. They vary from 1.3 to $1.6 \mu$ in length. They are about $0.5 \mu$ thick. In young cultures longer forms are observed. The ends may be swollen and somewhat refractive and stain more deeply than the other part. In old agar cultures ovoid forms appear often in clumps. It does not form spores. Vacuoles and capsules have not been observed.

Staining. It stains well with carbol fuchsin and alkaline methylene blue. It takes the Gram stain.

Cultivation. It is readily cultivated on agar and in bouillon by inoculating tubes of these media with portions of the caseous lymph glands. The growth is very slow at first but subcultures develop more quickly.

Agar. The growth on slant agar is quite characteristic. If a loopful of the caseous material is drawn over the surface there will appear in the course of four or five days a limited number of well isolated colonies, showing at first as grayish white points. On about the twelfth day they will have attained their full size, that is, 4 to $6 \mathrm{~mm}$. in diameter, appearing as a thick white expansion, more or less rounded, with a shiny, waxlike, slightly granular surface marked by wavy concentric rings arranged parallel to the margin. The colonies have

${ }^{3}$ Preisz. Ann de l'Inst. Pasteur, Vol. VIII (1894) p. 231.

${ }^{4}$ Nocard. Compt. rend. de la Soc. de Biol., Vol. I (1899) p. 608.

'Kitt. Monatshefte f. prak. Thierheilkund, Vol. I (1890) p. 145. 
crenated borders and a papillated center. When a pure culture is used for inoculation on slant agar, the colonies appear in forty-eight hours, growing abundantly over the whole surface and becoming confluent. All cultures grown on agar are characteristic in being extremely dry and adherent to the medium. In cover-glass preparations the bacteria are found to be arranged in clumps. It grows •more slowly and not so abundantly on glycerine agar as on agar.

Gelatin. Gelatin at room temperature does not prove a desirable medium for the organism. When incubated at $37.5^{\circ} \mathrm{C}$. the growth is identical with that in bouillon.

Blood serum. On blood serum it grows more readily than on any other of the media although the cultures are not so characteristic as are those on agar. The growth is marked at the end of forty-eight hours by the appearance. of small pinpoint colonies, which increase slowly until the tenth day, when they have a diameter of 1 to $1.5 \mathrm{~mm}$. The border is slightly irregular with a dry, glistening, uneven surface of a color varying from deep yellow to grayish white. The colonies appear to send off lines of growth extending below the surface, and are surrounded by a cloudy zone which has to a greater or less degree the color of the colony. This outward radiation becomes more marked, until finally the contour of the colony is entirely effaced. The property of chromogenesis varies greatly, even under uniform conditions. The water of condensation contains a copious sediment of small granules which give it the tint of the colonies.

Potato. On potato the growth varies to a great extent. This is probably due to variations in its acidity. On potato with slight acidity a grayish white, slightly moist growth spreads irregularly over the surface. In some cases it is hardly visible to the naked eye, and, as a rule, it reaches its maximum growth at the end of the second week. With an acidity of 2.9 to 3.6 per cent no growth occurs, while the addition of a few drops of a $5 \%$ sodium hydroxide solution to the surface will cause the multiplication of the organisms.

Bouillon. In bouillon a general turbidity occurs in the 
course of 36 hours. Then the bouillon gradually becomes clear, while a granular sediment collects in the bottom of the tube. A scaly, grayish white, greasy looking pellicle forms on the surface and adheres closely to. the sides of the tube, but on agitation it is broken into flaky masses which settle to the bottom. A new pellicle is slowly formed, but it never becomes so strong as the original one. It will grow in both alkaline and acid broth ( $2 \%$ to phenolphthalein) but an acidity of $2.8 \%$ kills the organism. Old bouillon cultures give a pronounced alkaline reaction. Bouillon containing $1 \%$ dextrose in fermentation tubes becomes cloudy in 36 hours, and after 48 hours a pellicle is formed on the surface of the broth in the open bulb, while a sediment appears at the elbow. Fermentation occurs in the bulb, causing an acid reaction, while the contents in the closed tube remain unchanged (phenolphthalein test). Cultures in lactose are not so vigorous as in dextrose, and in saccharose they are still less abundant. The bacteria have no action upon the molecule of lactose or saccharose. Gas is not produced during growth in any of these sugar-containing media.

Milk. In milk growth takes place without visible change.

Life conditions and properties. The most favorable temperature is about $37^{\circ} \mathrm{C}$. Growth takes place slowly at room temperature. No growth occurs at $43^{\circ} \mathrm{C}$. It is an aërobe and facultative anaërobe. It does not produce indol and no specific toxin has been detected.

Resistance. A temperature of $65^{\circ} \mathrm{C}$. for 10 minutes proves fatal. Drying and sunlight kill it in 6 days' exposure. A $2.5 \%$ solution of carbolic acid destroyed life in one minute. A 1-2000 solution of mercuric chloride proved fatal in four minutes. Lime water was not effective after several hours. A $0.25 \%$ solution of formalin destroyed its vitality in six minutes.

Pathogenesis. This organism is fatal to guinea pigs, when inoculated intravenously or intraabdominally, in from four to ten days. The lesions are those of general infection with foci in the kidneys and liver. When inoculated subcu- 
taneously with 0.25 to $0.75 \mathrm{cc}$. of a bouillon culture the adjacent lymphatic glands become caseated. It proved fatal when fed but death occurred much later. Rabbits and mice are susceptible. Pigeons seem to be immune.

\section{BACTERIUM PYOGENES GRIPS.}

Synonyms. Bacillus pyogenes suis Grips ${ }^{1}$; Bacillus pyogenes bovis Künnemann. ${ }^{2}$

Place in nature. A number of investigators have found bacteria in suppurating lesions in different organs in cattle and swine. Lucet ${ }^{3}$ was the first to describe a bacillus in suppurating lesions in cattle. Grips and Künnemann have found them in suppurating lesions in swine and cattle and Poels found apparently the same organisms in arthritis. Glage ${ }^{4}$ pointed out the probable identity of these organisms. Its existence outside of the animal body is not known. The somewhat extensive literature on this organism has been summarized by Berger. ${ }^{5}$

Morphology. The bacteria appear as rods from 0.2 to $3.0 \mu$ in length with a breadth somewhat constant of from 0.2 to $0.3 \mu$. Spores do not form. Many of the individuals appear as micrococci, due to the shorter forms after division. The ends are often somewhat pointed.

Staining. It stains readily with carbol fuchsin and aniline gentian violet and less strongly with methylene blue. It does not always stain strongly with Gram's method although it is considered Gram positive, and this stain is considered of great value in differentiating this organism in exudates. Several of those who have worked with it have found that it stained very slightly by Gram's method.

${ }^{1}$ Grips. Inaug. Diss. Giessen, 1902. Also Zeit. f. Fleisch und Milch-hygiene, 1898.

${ }^{2}$ Künnemann. Archiv. f. Wissensch. u. Tierheilkunde, Bd. XXIX (1903) p. 128.

${ }^{3}$ Lucet. Ann. de l'Inst. Pasteur, Vol. VII (1893) p. 325.

"Glage. Deut. tierärtzliche Woch., No. 47, 1903.

${ }^{5}$ Berger. Zeit. f. Infektionskrankheiten ... der Haustiere, Bd. III (1908) p. 101. 
Cultivation. The media in which the most characteristic growth appears are blood serum, serum agar, bouillon and milk.

Agar. The growth on agar is very slow and scanty. This medium has been found unsuitable for the growth of Bact. pyogenes.

Gelatin. This is not a favorable medium for the isolation and cultivation of Bact. pyogenes, for it is soon crowded out by a growth of other microorganisms. In and upon serumgelatin, the growth is not much better than upon gelatin.

Blood serum. According to Berger a characteristic growth appears upon this medium. In twenty-four hours after inoculation, very small clear colonies appear. At first there are slight depressions in the surface; a day or two later a furrow forms along the line of inoculation which gradually becomes deeper as the serum liquefies. In this furrow, or near it, are sometimes found deeper depressions. In these, in old cultures in the vegetative form, are to be seen dull white, fine "kernels" of growth. The surface of the serum is moist and shiny. In the condensation water, a white precipitation forms, but the liquid itself remains clear. Soon the condensation water and the liquefied serum mix together. As the culture grows older, liquefaction increases, so that the culture medium divides and particles of serum float in the clear fluid. Finally, not very much remains of the solidified serum, but in its place is the clear liquid.

Potato. It does not grow on this medium.

Bouillon. Growth in bouillon is very slight.

Liquid serum. After 24 hours from the time of inoculation, a slight growth is visible in this medium. It forms a thick gray sediment which is easily stirred up by shaking the flask containing it. The liquid remains clear. The bacilli do not live long in this medium.

Serum bouillon. A thick, gray, flaky sediment forms. This medium was found to be more favorable than milk. For the best results, the quantity of serum should be less than that of bouillon. 
Milk. In twenty-four hours a luxuriant growth appears, but the milk itself is not changed. After two days, the milk begins to coagulate, and from the depth of the culture tube to the surface, the whey freely separates.

Life conditions and properties. In favorable media these bacteria were found to live 10 weeks at room temperature. Growth continued at $55^{\circ} \mathrm{C}$. but ceased at $59^{\circ} \mathrm{C}$. The bacteria have slight powers of resistance against drying. They are quickly destroyed by formaldehyde gas and sulphurous acid. The best temperature for growth is $37^{\circ} \mathrm{C}$. Slightly alkaline culture media are most favorable for their multiplication.

Pathogenesis. When rabbits are inoculated subcutaneously, abscesses form about the point of inoculation. It frequently happens that the pathogenic effect is slight; many of the animals which sicken after a single inoculation subsequently recover. Grips found that the culture with which he worked, when inoculated in comparatively large quantities, would kill rabbits and mice.

\section{BACTERIA OF PYELONEPHRITIS IN CATTLE.}

A number of investigations have been made to determine the etiology of abscess formation in the kidneys of cattle. A large number of bacteria have been found but those which seemed to be best described resemble very closely Bact. pyogenes. It is probable, however, that a number of varieties and possibly several species of bacteria stand in a causal relation to pyelonephritis in eattle. Ritzenthaler ${ }^{6}$ has summarized the literature on these lesions especially in relation to their etiology. Some of these investigators found a single organism while others found several species associated with the lesion.

\section{BACTERIUM SANGUINARIUM MOORE.}

Synonyms. Bacterium of fowl typhoid.

${ }^{6}$ Ritzenthaler. Jour. of Comp. Path. and Therap., Vol. XXIII (1910) p. 33. 
Place in nature. This organism was described by Moore ${ }^{1}$ from an outbreak of chicken disease thought at the time to be infectious leukemia but later identified as fowl typhoid. The organism is found in the blood and tissues of fowls dead of this disease. It is not known to have a habitat in nature outside of the infected fowls and material contaminated by them. It was isolated by Dawson ${ }^{2}$ from a large outbreak of the disease in Maryland and by Curtice ${ }^{3}$ in Rhode Island.

Morphology. Bacterium sanguinarium varies somewhat in size according to the medium in which it has developed. In tissues of fowls or rabbits it is from 1.2 to $1.8 \mu$ long and from 1 to $1.3 \mu$ broad. The ends are tapering or rounded in eul-

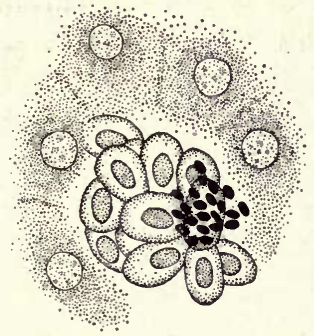

Fig. 62. Bacterium sanguinarium. A clump of organisms in a blood space in the liver of a fowl.

tures; in the short forms it could easily be mistaken for a micrococcus. In tissue it frequently appears in small clumps, but usually in pairs united end to end. Spores or vacuoles have not been discovered. Involution forms are common. In cultures on agar it is more slender than in tissues. When examined in a hanging drop preparation, especially at the edge, it frequently shows a marked polar arrangement of the cellular protoplasm. In these preparations there is observed a marked dancing motion of the organism. In old bouillon cultures short chains composed of these organisms united end to end are sometimes observed.

Staining. It stains with the aniline dyes ordinarily used,

${ }^{1}$ Moore. Bulletin No. 8, B. A. I., U. S. Dept. Agric., 1895, p. 63.

Report B. A. I., U. S. Dept. Agric., 1905-6, p. 185.

${ }^{2}$ Dawson. Annual Report, Bureau Animal Industry, 1898.

${ }^{3}$ Curtice. Bull. 87, R. I. Agric. Exp. Station, 1902. 
but retains the coloring matter very feebly, or not at all, when treated after the Gram method.

Cultivation. This organism is readily cultivated on the ordinary media. It is obtained in pure cultures from the heart blood or liver of a fowl just dead from the disease.

Agar. On this medium, at $37^{\circ} \mathrm{C}$, , the growth is moderately vigorous. It has a grayish glistening appearance. Isolated colonies are from 1 to $2 \mathrm{~mm}$. in diameter, convex, and with sharply defined borders. Agar plates emit a peculiar penetrating odor, which differs decidedly from the pungent odor given off by Bacterium suisepticum. The growth on this medium resembles very closely that of $B$. suipestifer.

Gelatin. In this medium the growth is less vigorous. In stick cultures it is more abundant along the line of inoculation than on the surface. Isolated colonies are about $0.25 \mathrm{~mm}$. in diameter, appearing to the unaided eye as homogeneous bodies, but slightly granular under low magnification. On the surface of the gelatin the colonies are granular and slightly spreading. They are not characterized by any distinctive markings. There is no liquefaction or softening of the medium.

Potato. On the surface of potatoes a delicate grayish yellow growth appears after forty-eight hours when kept at a temperature of $35^{\circ} \mathrm{C}$. Frequently there is no development, owing, presumably, to the acids in the potato.

Bouillon. In alkaline peptone bouillon at $36^{\circ} \mathrm{C}$. the growth imparts a uniform cloudiness to the liquid within twenty-four hours. If the bouillon contains much sugar the reaction becomes acid, otherwise it remains alkaline. A grayish friable sediment forms in the bottom of the tube. After several days' standing the growth settles, leaving a clear supernatant fluid. In a simple peptone solution containing one-half of 1 per cent sodium chloride the growth is less vigorous than in the one containing the meat juice. In meat extract bouillons the growth is likewise feeble. In acid peptone bouillon there is a very faint cloudiness imparted to the liquid. 
Alkaline bouillon containing 1 per cent dextrose in the fermentation tube becomes cloudy within twenty-four hours after inoculating and strongly acid in reaction. Similar tubes of bouillon containing saccharose and lactose become clouded throughout but they remain alkaline in reaction. The degree of alkalinity increases with age. Gas is not produced during the growth in bouillon containing these sugars.

Iife conditions and properties. This organism develops at a temperature from 20 to $41^{\circ} \mathrm{C}$. It does not grow well in acid media. It produces indol.

Resistance. It is destroyed at $50^{\circ} \mathrm{C}$. in fifteen minutes. A $1 \%$ solution of earbolic acid was fatal to it in 5 minutes. It resists drying when in films on cover-glasses for from 7 to 15 days.

Pathogenesis. This organism is fatal to fowls, pigeons, rabbits, guinea pigs, and mice. Other animals have not been tested. Excepting in intravenous injections, comparatively large quantities of a pure culture were required to produce fatal results. Fowls inoculated in the wing vein with 0.3 ce. of a fresh bouillon culture died in from three to thirteen days; usually on the fifth or sixth day. The temperature begins to rise on the second day after inoculation. It reaches 109 to $111^{\circ} \mathrm{F}$. a few days before death occurs. In cases where the fowls live from five to six days they appear perfectly well for at least three days, when the feathers begin to have a slightly ruffled appearance. Pigeons inoculated with 0.2 ce. of a bouillon eulture die in from four to five days. In rabbits the lesions resemble very closely those produced by attenuated hog cholera bacteria (B. suipestifer). Guinea pigs inoculated in the abdominal eavity with from 0.2 to 0.3 ec. of a bouillon culture die in from five to eight days.

BACTERIUM TRUTTAE MARSH.

Synonyms. The bacterium of a specific disease of brook trout.

Place in nature. Marsh ${ }^{1}$ discovered this organism as

${ }^{1}$ Marsh. U. S. Fish Commission Bulletin, 1902; p. 411. 
the cause of a serious disease affecting brook trout in certain parts of the country.

Morphology. This organism varies much in size when grown in different media. Marsh refers to it as pleomorphic, stating that on agar it is spherical, with a diameter of 0.5 to $1 \mu$. In liquid media it is elongated. In bouillon the predominating rods vary from 1 to $2.3 \mu$ in length and from 0.4 to $0.8 \mu$ in width. It appears frequently as a diplo-bacterium. In the blood of the diseased trout, it is from 0.5 to $1 \mu$ long, with rounded ends. It does not produce spores. A capsule has not been demonstrated.

Staining. It stains readily with the ordinary aniline dyes. Thionin and methylene blue give excellent results. By the Gram method it retains its stain in part. The iodine has some fixing power with the gentian violet.

Cultivation. This organism grows readily on the ordinary nutrient media, with a reaction of +0.5 to phenolphthalein. It grows slightly or not at all at +1.5 . It multiplies at a low temperature.

Agar. At +0.5 moderate abundant growth appears of a grayish white color which later becomes a grayish brown. A soluble pigment appears in about three days which diffuses in the medium but does not reside in the growth itself. It is of a reddish brown shade which becomes a dark brown in from two to three weeks.

Gelatin. In gelatin an abundant growth occurs accompanied by liquefaction. At first it is crateriform but later it becomes horizontal.

Blood serum. Blood serum liquefies along the line of visible growth. This becomes a dark brown color and the slanting portion liquefies.

Potato. No growth on acid potato. On neutralized potato there is a visible growth on the third day which appears as a faint growth elevated above the surface of the potato.

Bouillon. A marked growth appears after 18 hours, clinging to the sides of the tube. The liquid remains clear. In about 5 days, a delicate pellicle forms and floceuli are dis- 
tributed throughout the medium both of which sink upon agitation of the liquid. After 10 to 15 days a characteristic brown color makes its appearance, diffused throughout the medium, and the sediments become a deep brownish color. This deepens to a deep brown with age. In glucose bouillon the acidity is increased after some days and the characteristic brown color does not appear, probably due to the acid. Gas is not formed. Little or no change is produced in lactose or saccharose bouillon.

Life conditions and properties. This organism grows best at about $20^{\circ} \mathrm{C}$; $31^{\circ} \mathrm{C}$. inhibits its growth. It is an obligate aërobe. It does not produce indol. It reduces nitrates to nitrites and finally to ammonia.

Resistance. It is destroyed by an exposure of $10 \mathrm{~min}$ utes in bouillon cultures to a temperature between $42^{\circ}$ and $43^{\circ} \mathrm{C}$.

Pathogenesis. This organism is fatal to brook trout in a few days when injected either beneath the skin or in the peritoneal cavity. The fatal results occur after a longer time when the cultures are mixed with the food. It was not fatal to frogs.

BACTERIUM DIPHTHERIAE (LOEFFLER) MIGULA.

Synonyms. Corynebacterium diphtheriae Lehmann and Neumann; Klebs - Loeffler bacillus.

Place in nature. This bacterium is the cause of the specific disease in man known as diphtheria. It has been reported as the cause of a diphtheritic condition in cats and in the horse. Gerhardt ${ }^{1}$ reports the spread of diphtheria from fowls suffering from the disease to workmen attending them. There are numerous instances of this kind but the evidence is not conclusive that the organism was the same. Holmes ${ }^{2}$ reports diphtheria occurring in children in connection with an outbreak of disease in cattle and fowls. It is quite gen-

${ }^{1}$ Gerhardt. Rem. f. Thierheilkunde in Viehzucht, Bd. VI (1883) p. 180 .

${ }^{2}$ Holmes. Jour. Comp. Path. and Therap., Vol. XVII (1904) p. 1. 
erally believed that diphtheria in fowls is not caused by this organism. Klein ${ }^{3}$ studied the reaction produced in milch cows inoculated with the bacteria of human diphtheria. The inoculated cows developed a peculiar eruption on the teats and udder. Abbott ${ }^{4}$ failed to confirm the results of Klein. Dean and Todd ${ }^{5}$ more recently traced two cases of diphtheria to the consumption of milk from eows having a peculiar eruptive disease of the teats and udder.

Bacterium diphtheriae was first observed by Klebs ${ }^{6}$ in 1883 and the following year it was isolated and studied in pure culture by Loeffler. ${ }^{7}$ It is often called the Klebs-Loeffler bacillus in honor of its discoverers.

Morphology. The diameter of the Bact. diphtheriae varies from 0.3 to $0.8 \mu$, and the length from 1 to $6 \mu$. They occur singly and in pairs, and very infrequently in chains of three or four. The rods are straight or slightly curved, and usually are not uniformly cylindrical throughout their entire length, but are swollen in the middle portion. Their average length in pure cultures from different sources frequently varies greatly, and even from the same culture individual organisms differ much in their size and shape. They do not produce spores, but they have highly refractile bodies or granules.

Staining. The Klebs-Loeffler bacteria stain readily with ordinary aniline dyes, and retain fairly well their color after staining by Gram's method. With Loeffler's alkaline methylene blue, and to a less extent with Roux's and dilute Ziehl's solutions, they stain in an irregular and characteristic way, especially when grown on blood serum. They do not stain uniformly. In many cultures round or oval bodies, situated at the ends or in the central portions, stain much more in-

${ }^{3}$ Klein. 19 th annual report of the local Gov. Board, Supplemental report of the medical officer, 1889-90.

${ }^{4}$ Abbott. Jour. of Path. and Bact., Vol. II (1894) p. 35.

'Dean and Todd. The Jour. of Hygiene, Vol. II (1902) p. 194.

- Klebs. Kongress f. neue Medicine, 1883.

${ }^{7}$ Loeffler. Mitt. a. d. Kaiserl. Gesundheitsamt., Bd. 11 (1884) p. 421. 
tensely than the rest of the organism. Sometimes these highly stained bodies are thicker than the rest of the organism, and again they are small and surrounded by a more lightly stained portion. The bacteria stain in this peculiar manner at a certain period of their growth, so that only a portion of the organisms taken from a culture at any one time will show the characteristic staining. The granules which take the methylene blue more intensely than the remainder of the organism are brought out more distinctly by the Neisser stain.

Cultivation. Bacteria of diphtheria will grow on all the ordinary media made from meat infusion. Its most characteristic growth, however, is on Loeffler's blood serum.

Agar. On slightly alkaline, nutrient or glycerin-agar the growth is less eertain than upon blood serum; but the appearance of the colonies when examined under a low-power lens, though very variable, is often far more characteristic. For this reason, nutrient agar in Petri dishes is used to obtain pure cultures. The diphtheria organisms taken from cultures which have been under cultivation for some time grow fairly well on nutrient agar.

Gelatin. The growth on this medium is much slower, more scanty, and less characteristic than that on the other media.

Serum. The growth of diphtheria bacteria in pure culture on blood serum from eight to twelve hours will show small colonies which appear as pearl-gray, whitish-gray, or more rarely, yellowish-gray, slightly raised points. The colonies when separated from each other may increase in forty-eight hours to a diameter of $4 \mathrm{~mm}$. The borders are usually somewhat uneven. The colonies lying together become confluent when the serum is moist. During the first twelve hours the colonies are about equal in size to those of other pathogenic bacteria which are often present in the throat; but after this time the diphtheria colonies become larger than those of the streptococci and smaller than those of the staphylococci. Serum is not liquefied.

Bouillon. Diphtheria bacteria obtained from about one- 
half of the serum cultures grow readily in broth slightly alkaline to litmus; the other cultures grow very feebly. The characteristic growth in neutral bouillon is in fine granules. These deposit along the sides and bottom of the tube, leaving the broth nearly clear. Occasionally after twenty-four or fortyeight hours the bouillon becomes more or less diffusly clouded, and frequently a film forms over the surface of the broth. On shaking the tube this film breaks up and slowly sinks to the bottom.

Milk. Diphtheria bacteria grow readily in milk but do not change its appearance. As they begin to multiply at a comparatively low temperature $\left(20^{\circ} \mathrm{C}\right.$. $)$ milk that has become infected is a very favorable medium for the transmission of the virus.

Life conditions and properties. Bact. diphtheriae grows best in the presence of oxygen. It is a strong aërobe but it will multiply to a limited extent under anaërobic conditions. It grows best at a temperature of about $37^{\circ} \mathrm{C}$. but it is said to multiply between $19^{\circ}$ and $42^{\circ} \mathrm{C}$. This organism elaborates a very poisonous soluble toxin. It is this toxin which causes the general symptoms in case of infection. The production of toxin has been investigated very carefully by Madsen, ${ }^{8}$ Martin, ${ }^{9}$ Smith, ${ }^{10}$ and Park and Atkinson ${ }^{11}$ who have described their methods for preparing it. A very efficient therapeutic and immunizing serum is obtained from the horse after proper immunization with the toxin.

Resistance. Bact. diphtheriae is killed by boiling for one minute, by heating to $70^{\circ} \mathrm{C}$. for five minutes or $60^{\circ} \mathrm{C}$. for ten minutes. It resists drying in bits of the membrane removed from the throat, for several months. They are destroyed in a few minutes with a $1-1000$ corrosive sublimate or a 5 per cent carbolic acid solution.

Pathogenesis. The diphtheria bacterium through its

Madsen. Kraus und Levaditi. Handbuch d. Technic, etc., 1907.

- Martin. Ann de l'Inst. Pasteur, Vol. XII (1898) p. 26.

- Th. Smith. Jour. Exp. Med., Vol. IV (1899) p. 373.

:1 Park and Atkinson. Jour. Exp. Med., Vol. III (1898) p. 513. 
toxins is, when injected into their bodies, pathogenic for guinea pigs, rabbits, chickens, pigeons, small birds, and eats; also in a lesser degree for dogs, goats, cattle, and horses, but hardly at all for rats and mice. In spite of its pathogenic qualities for these animals true diphtheria occurs in them with extreme rarity. As a rule, so called diphtheritic inflammations that occur in these animals are due to other bacteria. According to Park, the eat is the only animal that has been known to contract true diphtheria.

Bacteria closely resembling Bact. diphtheriae. Bacillus Hoffmanni (Pseudodiphtheria bacillus). Hoffmann-Wellenhoff ${ }^{12}$ in 1888, and, at almost the same time, Loeffler ${ }^{13}$ described bacilli which they had cultivated from the throats of normal individuals and in several instances from those of diphtheritic persons, which were in many respects similar to true Bact. diphtheriae, but differed from it chiefly in being non-pathogenic for guinea pigs. These organisms were at first regarded by some observers as merely attenuated diphtheria bacteria. Nore recent investigations, however, proved them to be unquestionably a separate species, easily differentiated by proper methods. They differ from Bact. diphtheriae in so many important features that the term "pseudo-diphtheria bacillus" is hardly an appropriate one for them. Differentiation ean finally be made on the basis of animal pathogenicity, B. Hoffmanni being entirely innocuous to the ordinary laboratory animals. B. Hoffmanni forms no toxins, and animals immunized with it do not possess increased resistance to Bact. diphtheriae. The pseudo diphtheria bacteria do not, according to Smith, ${ }^{14}$ produce acids in bouillon containing dextrose.

Many bacilli have been described which have a slight morphological resemblance to the diphtheria organism but which have little or no pathological significance. Such organisms are met with in milk, air, and water, and as secondary

${ }^{12}$ Hoffmann-Wellenhoff. Wien. Med. Woch., Bd. III (1888).

${ }^{13}$ Loeffler. Centralbl. f. Bakt., Bd. II (1887) p. 524.

${ }^{14}$ Smith. 28th Annual Report State Bd. Health, Mass., 1897. 
invaders together with other bacteria in old discharging wounds. These bacteria are usually larger than that of diphtheria and rarely show polar granules or bodies. Culturally they show all the qualities of saprophytes. Inoculated into animals they produce at most a mild local reaction. In the literature these "organisms have often been loosely spoken of as "pseudo-diphtheria" bacilli, a term which is inappropriate since they have nothing in common with the Klebs-Loeffler bacillus except a certain morphological resemblance, and differentiation is not difficult.

SPECIES OF THE GENUS BACTERIUM WHICH CAUSE DISEASE IN THE HUMAN SUBJECT.

This genus contains a number of species such as Bact. anthracis, Bact. mallei and Bact. tuberculosis, that are pathogenic for both man and for one or more species of the lower animals. It also contains a number of species such as Bact. rhusiopathiae, and Bact. suisepticum, that are not known to infect the human subject at all. There are, however, a few species in this genus that are pathogenic for man and not for the lower animals, such as the bacterium of leprosy, and the bacterium of human diphtheria. The latter has been reported to cause disease in animals. 
A FEW SPECIES OF THE GENUS BACTERIUM WHICH ARE COMMONLY NOT PATHOGENIC.

\section{BACTERIUM AEROGENES (ESCHERICH) MIGULA.}

Synonyms. Bacterium lactis aerogenes Escherich ${ }^{1}$; Bacterium lacticum Babinsky; Bacillus aerogenes Kruse.

Place in nature. This is the type of a group of bacteria which are closely related in their biological properties to $B$. coli but quite distinct from it. It was discovered by Escherich in 1885 in the feces of infants. It is widely distributed in nature, being found in water and in sewage. It is a common cause of souring in milk.

Morphology. Bact. aerogenes is about 0.5 to $1.0 \mu$ in width and from 1 to $2 \mu$ in length. It has rounded ends. It rarely appears in chains except in milk where it is more common. When cultivated on suitable media, especially milk, a capsule is in evidence. It does not produce spores.

Staining. It stains with ordinary aniline dyes but it is Gram negative.

Cultivation. It is cultivated on the usual media without difficulty.

Agar. Upon this medium it develops a heavy white growth. The colonies when isolated have a tendency to confluence and are distinctly more mucoid in appearance than are those of Bacillus coli.

Gelatin. The growth on gelatin is quite vigorous. The medium is not liquefied.

Potato. The growth is heavy and gas is formed.

Bouillon. In bouillon, it causes a general clouding and a pellicle. The cultures have a slightly sour or cheesy odor. It ferments dextrose and lactose with the formation of gas. In the fermentation of dextrose there is 50 per cent gas $\mathrm{CO}_{2} 35, \mathrm{H} 65$. With lactose it is 62 per cent gas $\mathrm{CO}_{2} 38.5$ and II 61.5. According to Smith $^{2}$ saccharose is not attacked.

${ }^{1}$ Escherich. Die Darmbakterien des Säuglings, 1886, p. 57.

Fortschritte d. Medizin, Bd. III (1885) p. 237 and p. 515.

${ }^{2}$ Smith. The Wilder Quarter-Century Book, 1893, p. 209. 
Milk. There is rapid coagulation and acid formation. It is characteristic of this bacterium that it can produce a large amount of acids, chiefly lactic, without being injured by them.

Life conditions and properties. It is an aërobe and facultative anaërobe. It grows readily at temperatures between $24^{\circ}$ and $30^{\circ} \mathrm{C}$. It is not known to produce any specific toxin. It coagulates milk readily.

Pathogenesis. Different strains of this bacillus vary much in their pathogenicity for animals. Wilde claims that it is more pathogenic for white mice and guinea pigs than is the bacillus of Friedlander. He speaks of it as the most virulent member of this group. Kraus, writing in Flügge's "Mikroorganismen," rates its pathogenicity less high.

Closely related to this bacillus, as well as to those of the Friedlander group, is an encapsulated bacillus isolated from a case of broncho-pneumonia by Mallory and Wright ${ }^{3}$ which is extremely pathogenic for mice, guinea pigs, and rabbits.

\section{BACTERIUM ACIDI LACTICI (HUEPPE) MIGULA.}

\section{Synonyms. Bacillus acidi lactici Hueppe.}

Place in nature. This organism was studied in 1884 by Hueppe ${ }^{1}$ but it had previously been discovered by Grotenfelt $^{2}$ in sour coagulated milk. Esten quotes the following: "In the year 1877 Lister, by means of a capillary pipette to which was attached a screw-head so adjusted that he could force out 1-100 of a drop of a diluted solution of milk, obtained the first pure culture of a milk souring organism, which he named Bacterium lactis. Lister thus has the honor of being the first to discover and isolate as a pure culture this organism." The phenomenon of sour milk has been studied by a large number of bacteriologists. Esten ${ }^{3}$ has pointed out very clearly the large number of bacteria which have been

${ }^{3}$ Mallory and Wright. Zeit. f. Hyg., Bd. XX (1895) p. 220.

${ }^{1}$ Hueppe. Mittheil. a. d. Kaiserl. Gesundheitsamte, Bd. II (1884) p. 309.

${ }^{2}$ Grotenfelt. Fortschritte d. Medizin, 1889, p. 121.

3 Esten. Bulletin No. 59, Storrs Agric. Exp. Station, Storrs, Conn., 1909. 
described as the cause of this action. ${ }^{4}$ He has found this bacterium in corn meal, cow feces, and soil. He also found that it was present in the mouth of 17 out of 21 cows examined. $\mathrm{He}$ concludes that this bacterium is not a plant parasite but rather a harmless inhabitant of the cow's mouth and possibly of the stomach and intestines.

Morphology. According to Conn, Esten and Stocking, it is a rod varying from 0.7 to $1.2 \mu$ in length by 0.5 to $0.8 \mu$ in diameter. Sometimes it appears so short as to be described as a streptococcus when arranged in chains and as a micrococcus when it appears singly. Spores have not been found. Migula's description shows it to be a

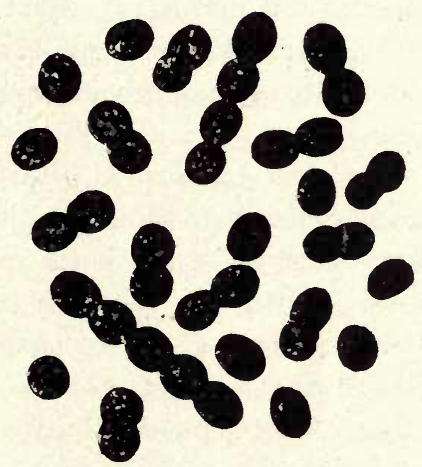

Fig. 63. Bacterium lactis acidi (Esten). $\times 5500$. much larger organism and it has been stated that the one

"The following table is taken from Esten's bulletin.

\begin{tabular}{lcl}
\hline Investigator & Date & $\begin{array}{l}\text { Names given to Bacterium lactis } \\
\text { acidi or Streptococcus lacticus. }\end{array}$ \\
\hline Lister & 1878 & Bacterium lactis. \\
Beyer & 1886 & Lactic acid organism. \\
Günther and & & Bacillus acidi lactici. \\
Thierfelder & 1894 & Bacillus acidi lactici. \\
Esten & 1896 & Bacterium lactarii. \\
Adametz & 1897 & Bacillus XIX. \\
Freudenreich & & B. acidi paralactis. \\
Günther & & Streptococcus acidi lactici. \\
Grotenfeld & & Streptococcus lacticus. \\
Kruse & & Bacterium lactis acidi. \\
Leichmann & Streptococcus acidi lactici. \\
Marpmann & & Lactic bacterium. \\
Kozai & & Lactic bacterium. \\
Utz & & Bacterium. \\
Schierbeck & Streptococcus. \\
Weigmann & &
\end{tabular}


studied by Hueppe was $B$. lactis aerogenes. Other descriptions show equal discrepancies.

Staining. It stains with the ordinary aniline dyes. It is Gram positive.

Cultivation. It is cultivated without difficulty on certain of the ordinary media.

Agar. There is no growth, or one that is scarcely visible. On milk agar it grows rather better, but at best it is very scanty.

Gelatin stab. A granular or linear needle growth, and no surface growth. Colonies are small points, rather opaque, not characteristic. They are almost wholly under the surface, and never grow typically on the surface. In litmus gelatin they are rather dense, strongly acid, and frequently, though not always, surrounded by minute, irregular spines along the edge. This type of colony can usually be detected with a little experience.

Bouillon. Frequently there is no sign of growth in this medium, but there is commonly a slight sediment. All three (dextrose, lactose and saccharose) sugar bouillons are rendered acid and there is commonly in the fermentation tube a growth in the closed branch.

Milk. Milk is rendered strongly acid and curdled in from six hours to two days. The eurd is smooth and hard, without gas bubbles. The coagulated casein is not digested.

Life conditions and properties. It grows best at about $20^{\circ} \mathrm{C}$. although it will multiply at the body temperature. It is a facultative aërobe, growing better without oxygen. No toxins are described. It is not pathogenic for animals. The above mentioned authors have deseribed four distinct varieties of this organism.

BACTERIUM (BACILLUS) BULGARICUM GRIGOROFF.

Synonyms. Bacillus of Massol; B. acidophilus; BoasOppler bacillus; Bacillus panis fermentati; Streptobacillus lebenis; Leptothrix buccalis.

Place in nature. This organism was discovered by 
Grigoroff ${ }^{1}$ who examined, in Massol's laboratory, "Yoghurt," the fermented milk of Bulgaria, and named the organism $B$. bulgaricus or the bacillus of Massol. Emmerling ${ }^{2}$ saw a long bacillus in Armenian fermented milk "Mazum" but was unable to cultivate it. A number of other investigators have found organisms which they have more or less fully described and which appear to be identical with Bact. bulgaricus. Heinemann and Hefferan ${ }^{3}$ have studied the distribution of this organism somewhat carefully and recorded its morphology and cultural characters. They found it in a number of samples of cow, horse, and human feces, saliva, in bran, ensilage and brewers' grains, in certain foods and spices, such as corn meal, sauerkraut, olive juice, dill pickles, and in the soil from a paddock where horses and cows were kept, and in garden soil.

Morphology. This bacterium usually is square cut at the ends. It often occurs in short chains and in milk in quite long filaments. Heinemann and Hefferan report true dichotomy, the organism appearing in the shape of the letter $Y$. According to these authors it exhibits a great variety of forms both in length and thickness. The morphology of the organism seems to be more characteristic when grown in milk where it appears as long irregularly stained filaments and single shorter rods, both showing unstained portions or vacuoles with often slightly enlarged ends.

Staining. It stains readily with the ordinary dyes and is Gram positive. It appears to be stained best by Weigert's modification of Gram's stain.

Cultivation. For the isolation of this organism the method employed by Heinemann and Hefferan is given. "The material to be examined is added to a tube of litmus milk and incubated at $42^{\circ} \mathrm{C}$. for 24 to 48 hours. Feces or other material eontaining large numbers of bacteria was added to acid

${ }^{1}$ Grigoroff. Révue Méd. de la Suisse, Rom. Genève, Vol. XXV (1905) p. 714 .

${ }^{2}$ Emmerling. Centralbl. f. Bakt., Bd. IV (1898) p. 418.

${ }^{3}$ Heinemann and Hefferan. Jour. of Inf. Diseases, Vol. VI (1909) p. 304 . 
broth eomposed of ordinary meat infusion or meat-extract broth with addition of 0.5 per cent glacial acetic acid and two per cent glucose. A transfer to litmus milk was made after 24 hours. The large amount of acid seems to restrain other bacteria from multiplying and interfering with the growth of Bact. bulgaricus. The litmus milk tubes were then used for plating in milk-serum agar, to which we also added 0.5 per cent glacial acetic acid. The plates were incubated at $42^{\circ} \mathrm{C}$. Microscopic colonies are usually visible in 24 hours, and are discernible to the naked eye after 48 hours. They are small and resemble colonies of streptococci, but may be distinguished from these under a hand lens by their slight irregularity of contour. Under the No. 3 objective they have the characteristic wooly appearance of Bact. bulgaricus. If present in the original material, they oceur on such a plate in nearly pure culture, other forms having been suppressed by the high temperature and by the acidity of the agar. The litmus milk tubes themselves are, after 48 hours, an indication of the presence of Bact. bulgaricus in the material added to then. The color of the litmus caused by Strept. lacticus is a light pink, but that caused by Bact. bulgaricus soon becomes a deep vivid pink, which is quite distinctive. We were soon able to tell at a glance from a series of milk tubes which were likely to prove positive for this organism. On whey-agar (one per cent acid to phenolphthalein) plates at $37^{\circ} \mathrm{C}$. to $42^{\circ} \mathrm{C}$. the 24-hour colonies are minute and almost indistinguishable to the eye from streptococcus colonies. If numerous they show on the plate like fine grains of sand. Under the microscope the edges of even the smallest colonies are seen to be broken or fringed and the 48-hour colonies are characteristically densely matted, wooly at the center, and branching at the edges. The colonies remain small and are mostly under the surface. On acetic-acid agar they appear readily and numerously, but remain minute and are smaller than streptococcus colonies. On plates from the gastric juice of a case of carcinoma two somewhat different types could be distinguished, one being the same as usual, the other more dense.

"On whey-agar slants the cultures show a good develop- 
ment both on the surface and in stabs. The surface growth consists of a large number of small colonies, often more or less confluent so as to form a delicate veil. The stab is fairly vigorous and granular. Milk, as mentioned above, is the most favorable medium. It is coagulated more slowly than by Strept. lacticus, usually not before 48 or 72 hours at $37^{\circ} \mathrm{C}$., often longer. Coagulation takes place more rapidly at $42^{\circ} \mathrm{C}$. than at $37^{\circ} \mathrm{C}$. and the power of acid-production is increased somewhat by reinoculation from tube to tube of milk at $42^{\circ}$ as soon as the curd is formed, i.e., the interval shortens. The coagulum is soft, smooth, and easily broken up. Whey is rarely separated. Some strains form sliminess of the milk, but this power is readily lost. Milk cultures have a peculiar cheesy butyric-acid odor and the taste after about 10 days is extremely acid and acrid.

"Ordinary laboratory media, such as plain agar, broth, potato or gelatin, allow little or no development. Some growth occasionally takes place on glucose agar. Gas is not formed in glucose media. The vitality of cultures decreases rapidly on any medium except milk. Even a whey-agar culture soon dies out. There is little or no growth below $37^{\circ} \mathrm{C}$. The optimum temperature appears to be about $42^{\circ}$ to $44^{\circ} \mathrm{C}$. By growing cultures in a hydrogen atmosphere in Novy jars we found that the organism grows anaërobically as well as aërobically.'

\section{BACTERIUM SUBVISCORUM MIGULA.}

Synonyms. Bacillus lactis viscosus Adametz.

Place in nature. This organism was discovered by Adametz ${ }^{1}$ to be the cause of a ropy condition of milk and cream. It is found in surface water. This organism is of considerable interest on account of the peculiar and objectionable condition it produces in milk.

Morphology. There is a great variation in size depending upon the medium and age of the culture. On an agar slant culture eight days old the spherical forms vary from 0.6 to $0.8 \mu$ in diameter, while the elongated forms which pre-

${ }^{1}$ Adametz. Landwirtsch. Jahrbücher, 1891, p. 185. 
dominate in numbers vary from 0.8 to $2.0 \mu$ in breadth and from 2 to $3 \mu$ in length. Ward ${ }^{z}$ found that in old cultures involution forms of considerable variation occurred. It possesses a very pronounced capsule. Spores have not béen de-

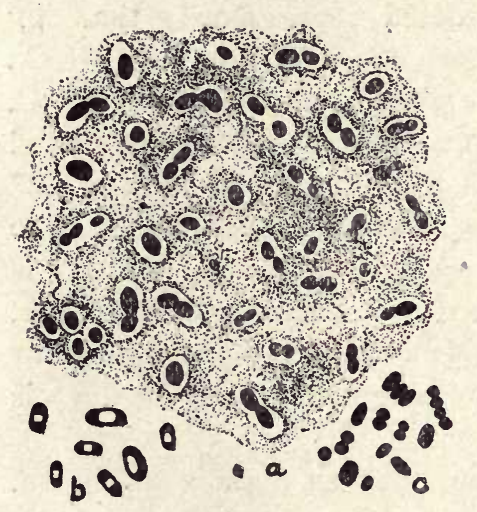

Fig. 64. Bacterium subviscorum:

(a) in milk showing capsule,(b) and (c) stained preparations from cultures (Ward)

tected. It occurs usually singly and more rarely in short chains. Ward thought that it possessed slight motility but he was unable to demonstrate flagella.

Staining. It stains readily with the aniline dyes. With carbol fuchsin it exhibits an irregular arrangement of the cellular protoplasm. This condition is most conspicuous in preparations made from bouillon cultures. It is Gram positive. The capsule can be demonstrated by the application of Welch's glacial acetic acid method and by the Gram stain.

Cultivation. It grows readily on the ordinary media in the presence of air. It grows most readily at room temperature.

Agar. The growth appears in agar plate cultures in 24 hours after inoculation as circular grayish colonies 1 to $2 \mathrm{~mm}$. in diameter. Young colonies are opalescent and exhibit the phenomenon of diffraction of light. Mature colonies may be irregular in contour, flat, with sharply defined borders, and grayish white in color. The growth is viscid. After several weeks, when the culture medium has dried perceptibly, the viscid character tends to disappear, and the colony becomes more pasty in consistency. In such old cultures, faint concentric markings are visible near the border. On the surface of slanted agar, the young growth is opalescent and usually consists of numerous small confluent colonies. The condensation

${ }^{2}$ Ward. Bulletin 165, Cornell University Agric. Exp. Station, Ithaca, N. Y., 1899. 
water becomes cloudy, viscid, and after considerable evaporation has occurred, brownish in color.

Gelatin. Surface colonies appear first as minute grayish points on the surface of the medium. Older colonies are nearly circular with a sharply defined border, and distinct circular markings. The colonies, at first whitish in color and opalescent, later become distinctly yellow. The growth is viscid like that on agar. The gelatin is not liquefied even after long standing.

Potato. A thin growth appears after 24 hours. It can be distinguished with difficulty, being of the same color as the potato. Later, the growth becomes more abundant and viscid, assuming a drab color.

Bouillon. In 24 hours, the bouillon becomes slightly clouded and somewhat viscid. A thin grayish growth adheres to the sides of the tube at the surface of the liquid. If the culture is undisturbed, a thick viscid pellicle forms after about a week. When the culture is agitated daily, the pellicle does not form and the liquid becomes uniformly viscid throughout. A quantity of white, tenacious sediment is deposited. The reaction is alkaline.

Milk. The cream on the milk becomes viscid in 12 hours after inoculation. The milk below, while ropy in young cultures; does not exhibit the maximum viscosity until several weeks have elapsed. In old cultures, the milk will spin out in opalescent, gossamer-like threads frequently a yard long. Only after considerable evaporation has occurred do milk cultures assume a semi-fluid consistency. The reaction, at first alkaline to litmus, becomes feebly acid after about two months.

Life conditions and properties. It is an aërobe and requires a low temperature for its best development. It does not grow in the incubator at all regularly. The indol reaction is not clear. Its peculiar property of producing ropy milk is supposed to be due to the gelatinous eapsule which surrounds it. It is not pathogenic for animals.

Resistance. It is destroyed by a temperature of $58^{\circ} \mathrm{C}$. for 10 minutes. Milk utensils that become infected can be properly cleansed if washed with boiling water. 


\section{CHAPTER XVIII.}

EACTERIACEAE.

\section{GENUS BACILLUS AND ITS SPECIES PATHOGENIC FOR ANIMALS.}

General discussion of the genus. The genus Bacillus was originally introduced by Cohn. ${ }^{1}$ The name bacillus has been used with different meanings in various classifications. Fischer ${ }^{2}$ includes under it non-motile rod-shaped organisms with or without spores. Lehmann and Neumann ${ }^{3}$ include in it rod-shaped organisms that form endospores centrally located without bulging, regardless of their motility. Migula ${ }^{4}$ includes in this genus all rod-shaped, motile bacteria with peritrichic flagella. The genus is often loosely employed to designate all rod-shaped bacteria regardless of their flagella or motility.

As defined by Migula, there are about nine hundred species of the genus Bacillus described, of which there are about twenty that are known to be pathogenic for domesticated animals. The species of this genus are widely distributed in nature and in certain instances it is difficult to fix differential specific or varietal characters. We have included a brief description of a very few of the more commonly encountered non-pathogenic bacilli such as Bacillus subtilis, B. vulgaris and B. prodigiosus.

${ }^{1}$ Cohn. Beiträge zur Biologie der Pflanzen, Bd. I (1872) p. 174.

${ }^{2}$ Fischer. loc. cit.

${ }^{3}$ Lehmann and Neumann. Atlas and Principles of Bacteriology, 1901.

${ }^{4}$ Migula. loc. cit. 
BACILLUS COLI ESCHERICH.

Synonyms. Bact. coli-commune Escherich ${ }^{1}$; B. Neapolitanus Emmerich ${ }^{2}$; B. pyogenes-foetidus Passet. ${ }^{3}$

Place in nature. Bacillus coli is found in the intestine of nearly all species of animals including man. It is not found elsewhere in nature except in soil, water or other substances contaminated with excrement. It was discovered by Emmerich in the stools of patients suffering with Asiatic cholera. Escherich later found it to be a common inhabitant of the normal intestine. The bacillus has often been found associated with various lesions in both man and the domesticated animals. Johnston ${ }^{4}$ has recently called attention to the possible etiological significance of this organism to a disease of the cocoanut palm. There are a number of varieties ${ }^{5}$ of this species and there are a number of species of bacteria so closely related to $B$. coli that they have been designated as the "colon" group of bacteria. These are B. coli, B. suipestifer, B. typhosus, B. icteroides, B. enteritidis, $B$. typhi murium, and others.

As there are well marked differences between $B$. coli, $B$. typhosus and B. suipestifer, it seems better, with our present knowledge, to consider these as distinct species and include in a group the species and its varieties. That is, the colon group should include $B$. coli and its varieties; the typhoid group, the varieties of $B$. typhosus; the intermediate group, the varieties of $B$. suipestifer and those species that ean not be clearly differentiated from it by their morphology and cultural characters.

In addition to the minor differences that may exist between different strains of $B$. coli there are two well defined varieties, one fermenting dextrose, lactose and saccharose with the formation of gas and the other not acting on saccharose.

${ }^{1}$ Escherich. Darmbak. des Säuglings. Stuttgart, 1886.

${ }^{2}$ Emmerich. Deut. med. Wochenschrift, 1884, No. 50.

${ }^{3}$ Passet. Aetiol. eiterigen Phlegmon des Menschen, Berlin, 1885.

4 Johnston. Phytopathology, Vol. I, No. 3, p. 97.

${ }^{5}$ Smith. The Amer. Jour. of the Medical Sciences, Sept. 1905.

Ford. Montreal Medical Jour., Nov. 1900. 
Examinations of the intestines of different species of animals show that there are no striking differences between $B$. coli obtained from these different sources, and that usually the two varieties exist in the same intestine. Moore and Wright ${ }^{6}$ did not obtain cultures of $B$. coli from the intestines of fowls that would ferment saccharose.

Morphology. Bacillus coli varies considerably in its morphology, according to the sources and the culture media from
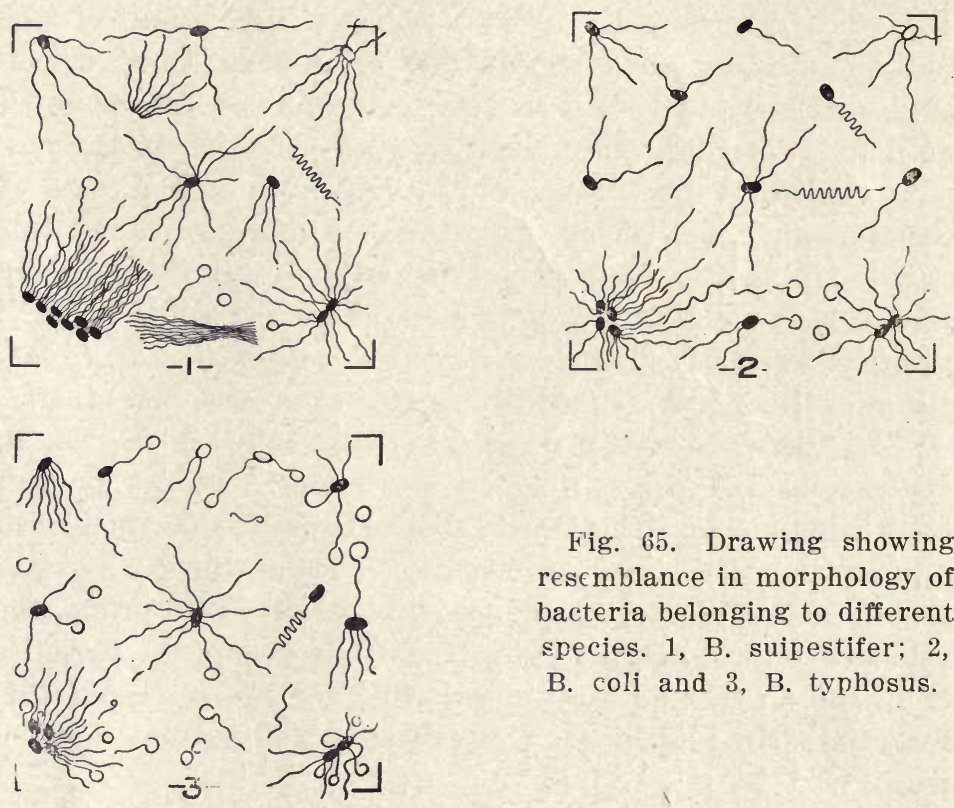

Fig. 65. Drawing showing resemblance in morphology of bacteria belonging to different species. 1, B. suipestifer; 2, B. coli and 3 , B. typhosus.

which it is studied. The more usual form is that of short rods with rounded ends, from 0.4 to $0.7 \mu$ in diameter by 1 to $3 \mu$ in length; sometimes, especially where the culture media are not suitable for their growth, the rods are so short as to be almost spherical, resembling micrococci in appearance, and, again, they are somewhat oval in form or are seen as threads of $6 \mu$ or more in length. The various forms may be associated 504.

'Moore and Wright. American Medicine, Vol. VIII (1902) p. 
in the same culture. The bacilli oceur singly or in pairs joined end-to-end, and more rarely in short chains. Under certain conditions the stained bacilli exhibit bipolar granules. Upon some varieties seven or eight peritrichic flagella have been demonstrated. ${ }^{\top}$

Staining. The colon bacillus stains readily with the ordinary aniline colors. It is always decolorized by Gram's method.

Cultivation. The colon bacillus develops on all the usual culture media. Its growth is usually more abundant than that of $B$. suipestifer or the typhoid bacillus but the difference is not sufficient for'a differential diagnosis. Although it grows best aërobically, yet it grows well anaërobically, especially in media containing sugars.

Agar. The surface colonies are mostly circular, finely granular, and rather opaque. The surface is glistening. The deep colonies are apt to have protuberances. In streak cultures an abundant, soft, white layer is quickly developed, but. the growth is not characteristic.

Gelatin. On gelatin, colonies develop in from 18 to 36 hours. When located in the depths of the gelatin and examined by a low-power lens they are at first seen to be finely granular, almost homogeneous, and of a pale yellowish to brownish color; later they become larger, denser, darker, and more coarsely granular. In shape they may be round, oval, or whetstone shape. The superficial colonies appear as small, dry, irregular, flat, blue-white points, that are commonly somewhat dentated at the margin. When the gelatin is not firm the margins of many colonies are broken by outgrowths, which are rather characteristic of colon bacilli. In stab cultures on gelatin the growth usually takes the form of a nail with a flattened head, the surface extension generally reaching out rapidly to the sides of the tube. Savage ${ }^{8}$ points out considerable variation in the surface colonies of $B$. coli on gelatin. He considers the variations to be influenced largely by the ma-

${ }^{7}$ Moore. The Wilder Quarter Century Book, p. 339.

${ }^{8}$ Savage. Jour. of Path. and Bact., Vol. IX (1903) p. 347. 
terial from which the organisms were isolated rather than the method employed in the isolation. He further calls attention to the fact that apparently typical $B$. coli gelatin colonies may be encountered which are not due to true $B$. coli.

Potato. On potato the growth is rapid and abundant, appearing after 24 to 36 hours in the incubator as a yellowishbrown to dark cream-colored deposit covering the greater part of the surface. But there are considerable variations from the typical growth on potato; there may be no visible growth at all, or it may be scanty and of a white color. These variations are due at times to the bacillus, but more often to variations in the potato.

Serum. The serum is not liquefied. On this medium grayish, uncharacteristic colonies are developed.

Bouillon. In bouillon Bacillus coli produces diffuse elouding with sedimentation; in some cultures a tendency to pellicle formation on the surface is occasionally seen. Ford ${ }^{9}$ considers the difference in the character of the growth in bouillon sufficient to form varieties. In one per cent solution in bouillon at $37^{\circ} \mathrm{C}$. in fermentation tubes the following gas production is obtained.

In dextrose, total gas about one-half the capacity of the closed branch, $\frac{\mathrm{H}}{\mathrm{CO}_{2}}=\frac{2}{1}$, reaction strongly acid.

In lactose, gas production, gas formula, and reaction practically the same as for dextrose.

In saccharose, total gas about two-thirds the capacity of the closed bulb, $\frac{\mathrm{H}}{\mathrm{CO}_{2}}$ approximately $\frac{3}{2}$; the final reaction may be slightly acid or alkaline, depending upon the time required for the evolution of the gas. One variety of $B$. coli does not ferment saccharose.

The time required for the production of the maximum quantity of gas varies as a rule from one to three days in case of the dextrose and lactose, and from five to twenty days in case of the saccharose.

- Ford. loc. cit. 
Milk. Milk coagulates in from four to ten days at $20^{\circ} \mathrm{C}$. and in from one to seven days at $37^{\circ} \mathrm{C}$. The coagulation is due principally but not altogether to acids. A ferment is produced which is capable of causing coagulation in the presence of lime salts, especially in acid solutions. It is evident also that the nature of this coagulation is more closely related to coagulation fermentation than to simple acid fermentation, from the fact that the colon coagulation forms a compact mass which is with difficulty soluble in alkalies, and contains much insoluble residue. In addition to albumose it has been shown that milk serum, after colon coagulation, contains a substance possessing the reaction of peptone, which is not contained in the original milk. Similarly albumin cleavage products are also formed in cultures of Bacillus coli in sugar-free ascitic fluid; it can not be assumed, therefore, that colon acidification of milk, as such, produces this proteolysis. Savage ${ }^{10}$ has studied the coagulation of milk by $B$. coli and concludes that the curdling is due in almost all cases to the formation of acid, and that the enzyme plays little or no part in the initial curdling, but it acts subsequently in converting the soluble caseinogen into insoluble casein. O'Hehir ${ }^{11}$ failed in isolating the enzyme but confirms the results of Savage.

Life conditions and properties. $B$. coli is an aërobe and facultative anaërobe. It multiplies slowly at room temperature, its optimum temperature is about $37^{\circ} \mathrm{C}$. It is capable of remaining alive for some time in water and soil. It produces indol. The toxic action is supposed to be due to the poisonous substances contained within the bodies of the bacteria. Culture filtrates show very little toxicity when injected into animals; whereas the injection of dead bacilli produces symptoms almost equal in severity to those induced by injection of the live microorganisms. Corroborative of the assumption of this endotoxic nature of the colon bacillus poison is the fact that, so far, no anti-toxic bodies have been demonstrated in serum resulting from immunization.

${ }^{10}$ Savage. Jour. of Path. and Bact., Vol. X (1904) p. 90.

${ }^{11}$ O'Hehir. Jour. of Path. and Bact., Vol. XI (1906) p. 405. 
It has the property of acting on certain carbohydrates producing acids and thereby it seems to be antagonistic to certain putrefactive bacteria in the intestine. This hypothesis has been quite clearly worked out, especially by Bienstock ${ }^{12}$ and Tissier and Martelly. ${ }^{13}$

Resistance. Colon bacilli are killed at a temperature of $60^{\circ} \mathrm{C}$. in from five to fifteen minutes. Many of them are destroyed by freezing but some individuals resist it for months. They resist drying for months. They will grow in stronger acid and alkali media than most bacteria. They are destroyed by $5 \%$ carbolic acid or 1-1000 solution of corrosive sublimate in about 2 minutes.

Pathogenesis. Many cultures of $B$. coli are fatal to guinea pigs of 900 grammes weight when inoculated subcutaneously in doses of 0.25 to 0.5 ce. of fresh ( 24 hour), bouillon culture. Other cultures require the peritoneal injection of a like quantity of the virus for fatal results. Some cultures do not produce morbid changes when injected in doses of 1 ec. into the peritoneal cavity. Mocre found that more of the cultures isolated from the intestines of dogs were virulent than those obtained from the normal viscera of other animals. Although the colon bacillus appears to have become localized in the digestive tract of living animals (including man) and to that extent become parasitic, it is not necessarily virulent as determined by animal inoculation. $B$. coli has been isolated from a large number of inflammatory lesions in animals. It is believed to be the cause of many intestinal and other disorders. It is apparently a frequent cause of localized inflammation and suppuration. Moore ${ }^{14}$ described an outbreak of disease among swine in which $B$. coli was apparently the etiological factor. It has been found that colon bacilli isviated from an inflamed intestine were more virulent than those

${ }^{12}$ Bienstock. Archiv. f. Hyg., Vol. XXXIX (1900) p. 390.

${ }^{13}$ Tissier and Martelly. Ann. de l'Inst. Pasteur, Vol. XVII (1902) p. 865 .

${ }^{14}$ Moore. Annual Report B. A. I., U. S. Dept. Agric., 1895-6, p. 218. 
taken from a perfectly normal one. 'This species is now considered important etiologically although there is no distinct disease for which it seems to be entirely responsible.

Identification of B. coli. Considerable difficulty is often experienced in positively identifying this species. According to Smith, ${ }^{15}$ "a type-species of $B$. coli includes those forms which grow on gelatin in the form of delicate bluish or more opaque whitish expansions with irregular margin, (2) which are actively motile when examined in the hanging drop from young surface-colonies taken from gelatin plates, (3) which coagulate milk within a few days, (4) grow upon potato either as a rich-pale or brownish-yellow deposit, or merely as a glistening, barely recognizable layer, (5) and which give a distinct indol-reaction. Their behavior in the fermentation tube must conform to the following scheme:

"Variety A. One per cent dextrose-bouillon (at $37^{\circ} \mathrm{C}$.).

"Total gas, approximately $1 / 2 ; \mathrm{H}_{/} / \mathrm{CO}_{2}$ approximately $2 / 1$; reaction strongly acid.

"One per cent lactose bouillon:

"As in dextrose-bouillon (with slight variation).

"One per cent saccharose-bouillon:

"Gas-production slower than in the preceding, lasting from seven to fourteen days. Total gas finally about $2 / 3$ $\mathrm{H} / \mathrm{CO}_{2}$ nearly $3 / 2$. The final reaction in the bulb may be slightly acid or alkaline, according to the rate of gas-production. Variety B. The same in all respects excepting as to its behavior in saccharose bouillon. Neither gas nor acids are formed in it." *

BACILLUS SUIPESTIFER KRUSE.

Synonyms. Bacillus of hog cholera Salmon-Smith; bacillus of swine plague Billings; bacillus of swine pest Selander; Bacillus cholerae suis; Bacillus cholerde suum

${ }^{15}$ Smith. loc. cit.

* Dunham has designated this variety of $B$. coli, B. coli communior because he believes it to be more common in the intestine than variety $\mathrm{A}$ or the colon bacillus as he designates it. 
Migula $^{1}$; bacillus of swine fever Klein ${ }^{2}$; Bacillus suipestifer Kruse. $^{3}$

Place in nature. This organism was discovered by Salmon ${ }^{4}$ and Smith in 1885 as the cause of the epizootic disease known as hog cholera. During the first three years of their investigation they examined about 500 hogs and obtained this organism from about 400 of them. Most of the cases came from outbreaks of the disease in the eastern part of the United States. The bacillus was thought to be parasitic and not to exist in nature except in infected hogs and material contaminated by them. Later de Schweinitz and Dorset ${ }^{5}$ found that the cause of the epizootic hog cholera was a filterable virus. Dorset; Bolton and McBride ${ }^{6}$ considered B. suipestifer to be a secondary invader of more or less pathogenic significance. Uhlenhuth ${ }^{7}$ and his associates found B. suipestifer in the intestine of 51 healthy swine out of 600 examined. The views at present seem to be that this organism is responsible for certain lesions in pigs but that it is not the cause of the epizootic disease known in this country as hog cholera. In his study of this organism T. Smith ${ }^{8}$ found seven varieties isolated from different outbreaks of swine disease, two bacilli bearing distinct names (viz. B. typhi murium Loeffler and $B$. enteritides Gaertner), a bacillus isolated from aborting mares, and the one described as the cause of the Danish swinepest, to belong to the same group. Later Reed and Carroll ${ }^{9}$

${ }^{1}$ Migula. loc. cit.

${ }^{2}$ Klein. Centralbl. f. Bakt., Bd. XVIII (1895) p. 105.

${ }^{3}$ Kruse. loc. cit.

"Salmon. Hog cholera, its history, nature, and treatment. U. S. Dept. of Agric., 1889.

${ }^{5}$ de Schweinitz and Dorset. Circular No. 41, B. A. I., U. S. Dept. of Agric., 1903.

${ }^{6}$ Dorset, Bolton and McBride. Bulletin No. 72, B. A. I., U. S. Dept. of Agric., 1905.

'Uhlenhuth. Arbeiten a. d. Kaiserlichen Gesundheitsamt, Bd. XXVII (1908) p. 425.

${ }^{8}$ Smith. Bulletin No. 6, B. A. I., U. S. Dept. Agric., p. 189.

- Reed and Carroll. The Medical News, Vol. LXXV (1899) p. 322. 
identified $B$. icteroides Sanarelli as belonging to this group. Cushing ${ }^{10}$ placed a number of other bacteria such as the paracolon and paratyphoid, the bacillus of psittacosis of Nocard and the "microbe de la septicemie des veaux" of Thomassen in this group which Durham ${ }^{11}$ designates "The Gaertner group." This group stands intermediate between B. coli and B. typhosus.

While these bacteria are very closely related, there seem to be quite distinct minor differences between certain of them. Others are not easily differentiated. In many instances it

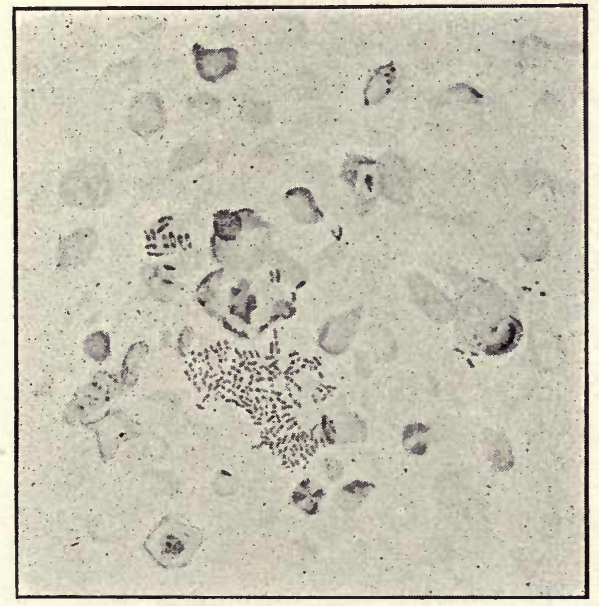

Fig. 66. Bacillus suipestifer in a smear preparation. (After Smith).

can not be positively done. Moore isolated a non-motile organism that could not be differentiated from $B$. suipestifer except by the absence of flagella. Smith has described a similar organism isolated by Prof. Burrill.

Morphology. A rod shaped organism varying in size according to the medium in which it has developed. From 156.

${ }^{10}$ Cushing. Johns Hopkins Hospital Bulletin,. Vol. XI (1900) p.

${ }^{11}$ Durham. The Lancet, Vol. I (1898) p. 154. 
agar cultures it is from 1.2 to $1.8 \mu$ long and from 0.5 to $0.8 \mu$ broad. The ends are rounded. Spores have not been observed. It is actively motile and a variable number, but usually from 3 to 5 , flagella have been demonstrated. The length of the flagella also vary. The average seems to be about $7 \mu$, although filaments $55 \mu$ with an average length of 35 to $40 \mu$ are reported. ${ }^{12}$

Staining. It stains readily with the aniline dyes. Preparations made from cultures usually stain uniformly; while in the preparations made from the tissue of inoculated animals there is frequently exhibited a light center with a deeply stained periphery. It is Gram negative.

Cultivation. This bacillus grows readily on all of the ordinary media used in bacteriological work at a temperature of 30 to $38^{\circ} \mathrm{C}$.

Agar. On the surface of inclined agar after 24 hours at a temperature of $37^{\circ} \mathrm{C}$. a grayish, glistening non viscid growth appears. When isolated the colonies are nearly round, convex, 0.5 to $2.0 \mathrm{~mm}$. in diameter. The edges are sharply defined and even. In stab cultures a grayish growth develops along the. needle track with a more vigorous growth on the surface about the needle puncture. The growth reaches its maximum in about 48 hours.

Gelatin. In this medium the growth is moderately feeble, the colonies appearing as grayish dots. When magnified they are finely granular and of a yellowish tint. The quantity and form of growth depends considerably upon the reaction of the gelatin. If decidedly alkaline there is often a tendency for the growth to spread. There is no softening or liquefaction of the medium.

Potato. The growth on potato takes the form of a very thin glistening layer. It is usually of a faintly yellowish color but this is subject to variation on different potatoes. If the reaction is strongly acid no growth appears.

Bouillon. In alkaline bouillon it imparts in 24 hours a

${ }^{12}$ Ferrier. Archives de Méd. Expér. et d'Anat. Patholog., Vol. VIII (1895) p. 58. 
uniformly cloudy appearance to the liquid. Ordinarily there is no membrane on the surface. After some days' standing the growth begins to settle, forming a grayish, friable sediment. If the bouillon contains muscle sugar the reaction will be changed to acid, in from 24 to 48 hours, due to the fermentation of the agar. Later, however, the liquid will become strongly alkaline, unless there was too much muscle sugar. In acid bouillon the growth is less vigorous. It grows better in a bouillon containing peptone than in a simple beef broth. In peptonized bouillon containing 1 per cent dextrose, gas appears within 24 hours and continues to form for from three to five days. During the first day from one-fourth to onehalf of the total quantity is produced. By the end of the second day the gas formation is nearly at an end. The total amount which collects in the closed branch of the fermentation tube is equivalent to about one-half of the capacity of this branch. The gas set free is composed of $\mathrm{CO}_{2}$ and an explosive gas which eonsists largely of $\mathrm{H}$. The ratio of $\mathrm{CO}_{2}$ to $\mathrm{H}$ is approximately as 1 to 2 . The reaction of the liquid becomes strongly acid, which condition checks the multiplication of the bacteria.

Gas is not produced in bouillon containing lactose or saccharose. These sugars are not fermented. Alkaline cultures containing them become more strongly alkaline as the growth continues.

Milk. When the milk is acid in the beginning it gradually becomes alkaline. There is no precipitation or coagulation of the casein. After standing for from two to three weeks in an incubator a gradually developing opalescence of the milk ean be observed. Later it becomes elear, then light brownish in color: If allowed to stand longer in the incubator the volume of the culture shrinks by evaporation and the opalescent liquid becomes quite thick and dark-colored but not viscid. When the opalescence appears the milk is strongly alkaline. The process seems to be a form of saponifieation of the fat globules due to the presence of the alkali produced by the action of the bacteria. 
Life conditions and properties. It is an aërobe and a facultative anaërobe. The most favorable temperature for its development is about $37^{\circ} \mathrm{C}$. It grows feebly at $20^{\circ} \mathrm{C}$. and ceases to multiply at $43^{\circ} \mathrm{C}$. A few cultures ${ }^{13}$ have given indol when grown in Dunham's solution. It apparently contains toxins (endotoxins), as immunity has been conferred on susceptible animals by the use of heated cultures.

Resistance. This organism is destroyed by a temperature of $60^{\circ} \mathrm{C}$. for ten minutes. It resists drying for variable lengths of time depending on the amount of protection it has. In drops of bouillon culture it resists drying for from five to six days while in smears from tissues it will live for from 20 to 40 days. It is destroyed after ten minutes in a $1 \%$ solution of carbolic acid, in $.25 \%$ sulphate of copper and 1 to 1000 solution of mercuric chloride.

Pathogenesis. Subcutaneous injections of from 1 to 3 ce. rarely produce fatal results in swine. An intravenous inoculation of 5 ce. usually produces a fatal bacteriemia. With smaller doses the "button ulcers," characteristic of hog cholera, have been produced (Welch). By feeding pigs with pure bouillon cultures the intestinal ulcers, typical of hog cholera, have also been obtained (Smith).

Rabbits inoculated subcutaneously with 0.1 ce. of the bouillon culture die in from 5 to 8 days. The essential lesions consist of necrotic foci (coagulation necrosis) in the liver and a very much enlarged and dark-colored spleen. Guinea pigs are affected similarly to rabbits, but death does not usually occur until from 7 to 12 days. Pure cultures of the bacillus can be obtained from the blood, liver or spleen of the inoculated animals. Moore ${ }^{14}$ found an organism that could not be differentiated from $B$. suipestifer in a fatal disease of pigeons in which the symptoms were referable to the nervous system. Smith ${ }^{15}$ found a similar organism to be apparently the cause of an infectious abortion in mares.

${ }^{13}$ Moore. Annual Report of the Com. of Agric. of N. Y. State, 1897.

${ }^{14}$ Moore. Bulletin No. 3, B. A. I., U. S. Dept. of Agric., 1893, p. 31.

${ }^{15}$ Smith. Ibid., p. 53. 
BACILLUS TYPHOSUS EBERTH.

Synonyms. Bacillus typhi abdominalis Eberth ${ }^{1}$; Bacillus typhosus; bacillus of Eberth; Eberth-Gaffky ${ }^{2}$ bacillus.

Place in nature. B. typhosus is the cause of typhoid fever in man. It is not demonstrated that it is pathogenic for domesticated animals but it is so closely related to certain bacteria that are of much significance in comparative pathology that it is mentioned here. B. typhosus was discovered by Eberth in 1880 and isolated by Gafflky in 1884 . This organism is not known to exist in nature excèpt in the bodies of infected people and in water, milk, sewage, ete., contaminated by the infected individuals. It has been clearly demonstrated that this organism remains in the body for a considerable time after recovery. In a few instances they have been found in the feces or urine several years after the patient has recovered. Such people are referred to as "bacilli carriers." This rondition probably holds in case of the disease caused by $B$. suipestifer.

Morphology. B. typhosus is a short rod, from 0.5 to $0.8 \mu$ in width and from 1 to $4 \mu$ in length. Its ends are rounded. It does not produce spores and capsules have not been observed. The flagella appear to be more numerous than in the coli and hog cholera groups.

Staining. The bacilli stain readily with the usual aniline dyes. They do not take the Gram stain.

Cultivation. B. typhosus is cultivated without difficulty on the usual culture media. It is not sensitive to the reaction of the media but will grow in media either slightly acid or alkaline.

Agar. Small grayish colonies at first transparent but later opaque appear on this medium in from 18 to 24 hours. On agar slants the growth is uniform, grayish, with a glistening surface.

${ }^{1}$ Eberth. Virchow's Archiv, Bd. LXXXI (1880) p. 58 and Bd. LXXXIII (1881) p. 489.

${ }^{2}$ Gaffky. Mitt. a. d. Kais. Gesundheitsamt., Bd. II (1884) p. 372. 
Gelatin. This medium shows colonies in from 24 to 36 hours at room temperature appearing as small, transparent, convex, round, or occasionally leaf-shaped colonies. The growth does not spread on the surface as is the usual habit of the colon bacillus. The gelatin is not liquefied. In stab cultures the growth extends along the entire length of the needle culture. With age the colonies become more opaque.

Potato. The growth on potato is somewhat distinctive. It was recommended by Gaffky as one of the means of identification. In from 24 to 48 hours the growth is hardly visible to the unaided eye. Sometimes this growth can not be seen except with the hand lens. If the potatoes are neutralized or made slightly alkaline the growth is much more abundant.

Bouillon. In bouillon the growth is rapid, imparting an even cloudiness throughout the liquid. The extent of the cloudiness varies somewhat. In some cultures the liquid becomes almost turbid. Rarely a pellicle is formed. In bouillon containing $1 \%$ dextrose, the liquid becomes acid but gas is not formed. This is true of levulose and mannite. In bouillon containing lactose and saccharose, the culture remains alkaline.

Milk. No appreciable change is produced in milk, although it is a good culture medium for this organism. In litmus milk the color becomes slightly reddish at first, due to the small amount of monnosaccharid present. Later the medium becomes deep blue due to the formation of alkali. The milk, however, is not saponified as in the case of $B$. suipestifer.

Life conditions and properties. B. typhosus is an aërobe and facultative anaërobe. It grows best at a temperature of about $37^{\circ} \mathrm{C}$. and in a neutral medium. It produces a toxin but there seems to be a difference of opinion as to whether the poisons produced by this organism are so-called endotoxins only or whether they are in part composed of soluble toxins comparable to those of diphtheria and tetanus. Besredka ${ }^{3}$

${ }^{3}$ Besredka. Ann. de l'Inst. Pasteur, Vol. XIX (1905) p. 477. Also Vol. XX (1906) p. 149. 
and others have shown that with endotoxic substances typhoid bacilli may produce a true toxin. In the blood of animals and of people this organism produces agglutinins. Kraus, Norris ${ }^{4}$ and others have demonstrated precipitins as a result of its growth.: The agglutination or Widal reaction for diagnosis is based on the presence of the aggultinins. This property holds with the bacillus of hog cholera, and for certain of the colon bacilli. B. typhosus does not as a rule produce indol. Peckham ${ }^{5}$ found indol to be quite commonly produced.

Pathogenesis. B. typhosus is the cause of typhoid fever in man. It is pathogenic for guinea pigs when inoculated in the abdominal cavity. Occasionally cultures are sufficiently virulent to cause death when injected subcutaneously.

Identification. B. typhosus has no morphological characters by which it can be identified. It is to be differentiated from $B$. suipestifer and the colon group by means of its growth on potato, its action on the sugars and its pathogenesis.

BACILLI BELONGING TO THE INTERMEDIATE OR GAERTNER GROUP.

Species in the group. In addition to B. suipestifer the following named bacilli have been found to belong to the intermediate or Gaertner group of bacteria as determined by their morphology and cultural characters. They are also considered as the meat poisoning bacteria.

B. enteritidis Gärtner. In 1888 Gärtner ${ }^{1}$ described a bacillus which he isolated from the flesh of a cow the eating of whose flesh had produced the symptoms of an acute intestinal catarrh in fifty-seven people-one of whom died and the bacillus was found in the spleen and blood of the patient. Gärtner found that the bodies of the bacilli were very toxic. Other occurrences of meat poisoning due to this or similar

${ }^{4}$ Norris. Jour. of Inf. Diseases, Vol. I (1904) p. 463.

${ }^{3}$ Peckham. The Jour. of Exp. Med., Vol. II (1897) p. 551.

${ }^{1}$ Gärtner. Correspondenz-Blätter des allgemeinen ärztlichen Vereins von Thüringen, No. 9, 1888. 
bacilli have been reported by Van Ermengem, ${ }^{2}$ Holst, ${ }^{3}$ Poels and Dhont, ${ }^{4}$ and Basenau. ${ }^{5}$ Schom ${ }^{6}$ found B. Gärtner in an outbreak of disease among rats and also found it in the living normal rats. He concludes that the rat is the "carrier" of this bacillus. Trautman ${ }^{7}$ had previously reported this organism as the cause of a disease in rats.

Bacillus icteroides Sanarelli. ${ }^{8}$ This organism was discovered by Sanarelli in the blood of yellow fever patients and was thought by him to be the cause of that disease. Reed and Carroll ${ }^{9}$ showed that it was closely related to if not identical with $B$. suipestifer. Later investigations showed that it bears no specific etiological relation to yellow fever.

Bacillus typhi murium Loeffler. ${ }^{10}$ This organism was discovered by Loeffler to be the cause of a fatal epizootic among field mice. Smith pointed out that it belonged to the $B$. suipestifer group of bacteria.

B. morbificans bovis Basenau. ${ }^{11}$ Basenau discovered this organism in meat. It seems to be identical with or at least very closely related to $B$. enteritidis.

B. paracolon Gwyn. In 1898 Gwyn ${ }^{12}$ reported the discovery of a bacillus in the blood of a patient who presented all the symptoms of typhoid fever but who did not give the usual blood reaction. He designated it as "paracolon."

Bacillus $O$ Cushing. Cushing ${ }^{13}$ isolated this bacillus from

${ }^{2}$ Van Ermengem. Bull. Acad. d. med. de Belgique, 1892.

${ }^{3}$ Holst. Centralbl. f. Bakt., Bd. XVII (1895) p. 717.

${ }^{4}$ Poels and Dhont. Holland Zeit. f. Tierheilkunde, Bd. XXIII (1894).

${ }^{5}$ Basenau. Arch. f. Hyg., Bd. XX (1894) p. 242.

${ }^{6}$ Schom. Arbeiten a, d. Kaiserl. Gesundheitsamte, Bd. XXX (1909) p. 575.

7 Trautman. Zeit. f. Hygiene, Bd. LIV (1906) p. 104.

${ }^{8}$ Sanarelli. The Medical News, Vol. LXXV (1899) p. 193.

${ }^{\circ}$ Reed and Carroll. The Medical News, Vol. LXXV (1899) p. 321 and 513.

${ }^{10}$ Loeffler. Centralbl. f. Bakt., Bd. XI (1893) p. 129.

${ }^{11}$ Basenau. Archiv f. Hyg., Bd. XX (1894) p. 242, also Bd. XXXII (1898) p. 219.

${ }^{12}$ Gwyn. Johns Hopkins Hospital Bulletin, Vol. IX (1898) p. 54.

${ }^{13}$ Cushing. The Johns Hopkins Hospital Bulletin, (1900) p. 156. 
a chronic lesion in a case that gave a history of a prolonged fever. He found that it was closely related to $B$. suipestifer.

The disorders or diseases caused by the Gärtner group consist of two types, (1) those in which there are gastroenteric symptoms following the ingestion of the meat, and (2) where the disease simulates a mild form of a continuous fever (paracolon). Buxton ${ }^{14}$ and Durham ${ }^{15}$ have made careful studies of this group based on cultural characters and the agglutination tests. Buxton gives the following scheme for identifying bacilli belonging to the colon, intermediate and typhoid groups.

Coagulation of milk

Production of indol

Fermentation of lactose with

gas

Fermentation of dextrose with

gas

Agglutination in typhoid im-

mune serum

B. coli Intermediate Typhoid
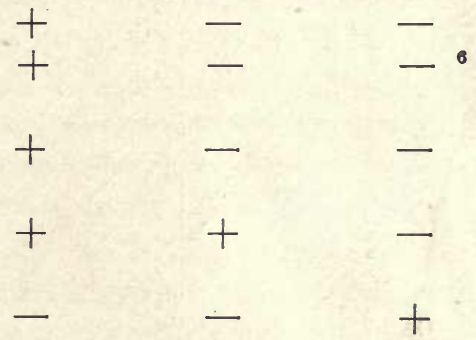

Peckham ${ }^{16}$ found indol to be quite commonly produced by $B$. typhosus and Moore found it in two different cultures of B. suipestifer.

In the bacteriological analyses of tissues, water, sewage, etc., that one is liable to make in the search for the specific bacterial cause or causes of animal diseases, organisms belonging to any of these three groups may be encountered. In order to simplify the identification the following table has been constructed.

${ }^{14}$ Buxton. Jour. Med. Research, Vol. VIII (1902) p. 201.

${ }^{15}$ Durham. Jour. Exp. Med., Vol. V (1901) p. 353.

${ }^{16}$ Peckham. Jour. Exp. Medicine, Vol. II (1897) p. 549. 
326

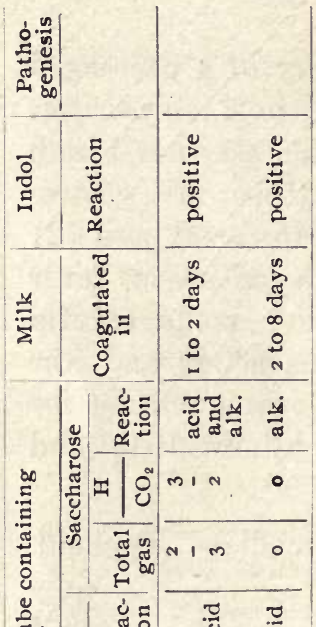

כี

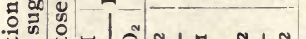

告

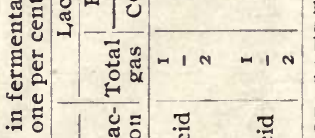

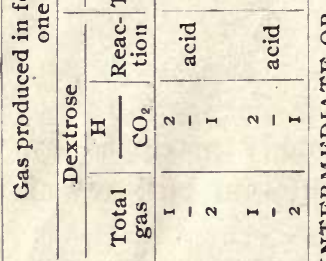

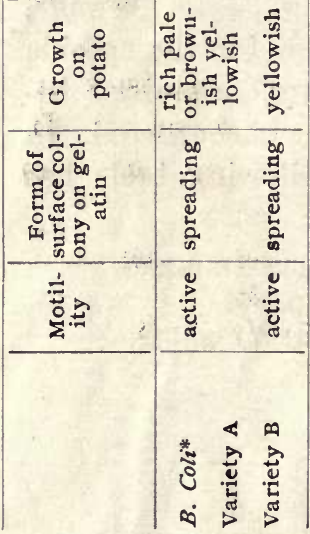

MICROBIOLOGY

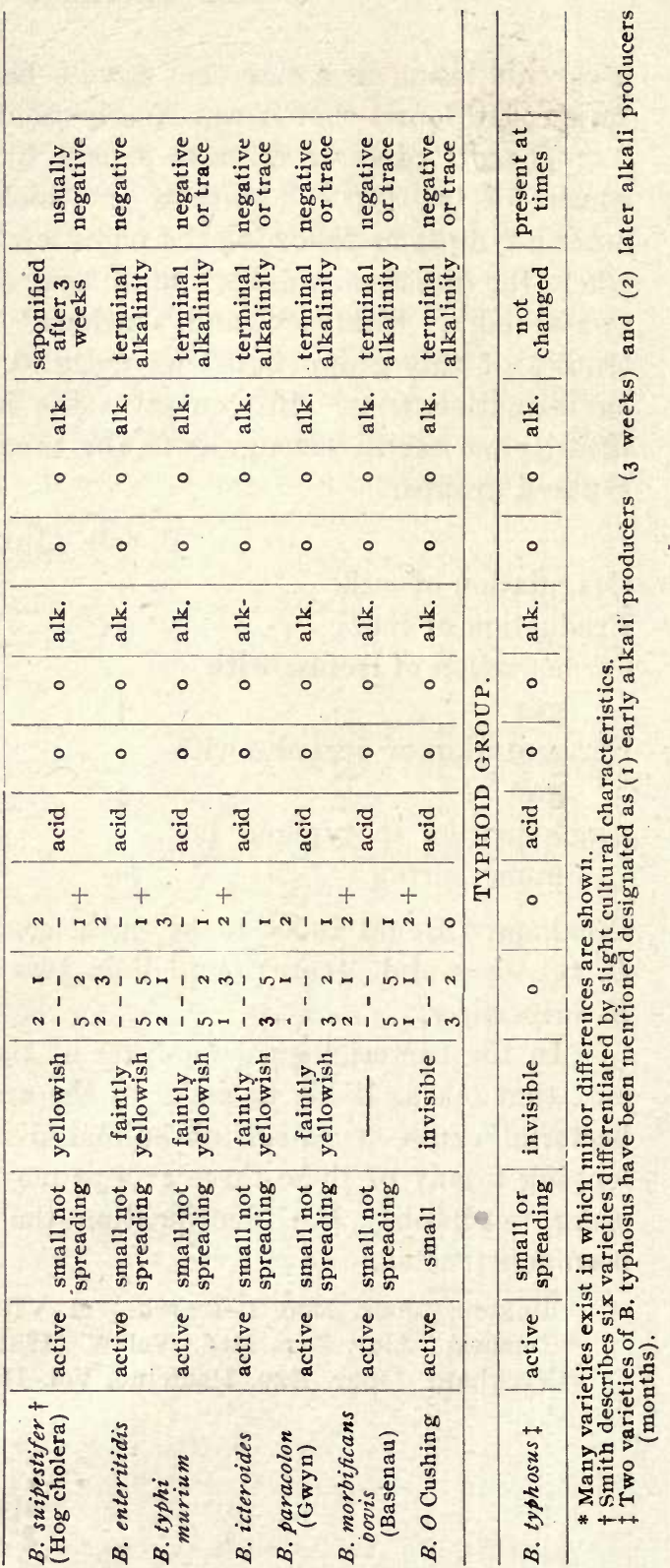


Bainbridge ${ }^{17}$ has divided the food poisoning bacilli into five sub-groups, namely :

(1) B. paratyphoid (A), which stands alone in both its cultural characters and its agglutination reactions.

(2) B. paratyphoid (B), which is indistinguishable from B. Aertryck and B. suipestifer in its cultural characters and (usually) in its agglutination reactions.

(3) B. Aertryck and B. suipestifer, which can not be differentiated from one another and which appear to be merely strains of the same micro-organism.

(4) B. enteritidis Gaertner and B. Danysz, which can be easily distinguished from the preceding sub-groups by their agglutination reactions, but which are indistinguishable from one another, and apparently also are only strains of the same organism.

(5) B. typhi murium has no existence as a definite organism, since different strains alleged to be $B$. typhi murium and obtained from accredited sources were found to differ greatly in their bacteriological characters.

Bainbridge has studied these organisms in connection with various viruses for the destruction of rats which he finds owe their potency to one of two bacilli that are indistinguishable from $B$. enteritidis. He concludes that phosphorus paste is much more efficient than viruses and he believes that a certain proportion of rats fed on the virus become immune and would therefore be unlikely to succumb to a second infection. Danysz ${ }^{18}$ considers that certain meat poisoning bacteria are quite efficient in the destruction of field mice and rats. He questions the poisonous effect of this group of bacteria on the human subject, as small and large quantities of food containing $B$. paratyphus or the Danysz virus have been eaten without the slightest evil effects and the paratyphus organism is often

${ }^{17}$ Bainbridge. Jour. Path. and Bact., vol. XIII (1908) p. 443.

${ }^{18}$ Danysz. Brit. Med. Jour., 1909-i, p. 209. 
found in perfectly healthy human beings.* Uhlenhuth ${ }^{19}$ and others have frequently found $B$. suipestifer or $B$. paratyphus $B$ in the normal contents of the intestines of pigs.

\section{BACILLUS TETANI NICOLAIER.}

Synonyms. Bacillus of lock jaw.

Place in nature. This bacillus is the cause of tetanus or lock jaw. All species of animals seem to be susceptible although horses and the human family suffer most from it. Tetanus has been recognized as a distinct affection for many centuries. In 1884 Carlo and Rattone produced tetanus in rabbits by inoculating them with pus from a cutaneous lesion of a human case. Nicolaier ${ }^{1}$ produced the disease by inoculating mice and rabbits with soil. In $1889 \mathrm{Kitasato}^{2}$ isolated the bacillus in pure culture and was able to reproduce the disease with it.

The bacilli of tetanus are widely distributed in the soil. It is stated by Park $^{3}$ that it is present in the intestines of about $85 \%$ of the horses and calves living in the vicinity of New York City. It is believed by some that its normal habitat is in the intestine of the herbivora. Joseph ${ }^{4}$ concluded from his investigations that $100 \%$ of old cattle have tetanus bacilli in their intestinal tract. It is much more numerous in the soil in some localities than others. There are areas in which tetanus in horses especially is very common after punc-

* Danysz states that in 1903-04 600,000 liters of cultures of the Danysz bacillus were distributed in France for the purpose of destroying field mice and for more than ten years some hundreds of liters of the virus have been distributed every week for the destrucition of rats and that among the large number of people who have thandled the virus no infection has been known to occur.

${ }^{19}$ Uhlenhuth. Berl. Militaer. Aerzliche Gesellschaft, May 21, 7908. Cited by Danysz.

${ }^{1}$ Nicolaier. Deut. Med. Woch., 1884, No. 52; Inaugural Diss,, Göttingen, 1885.

${ }^{2}$ Kitasato. Zeit. f. Hygiene, Bd. VII (1889) p. 225.

${ }^{3}$ Park. loc. cit., p. 235.

« Joseph. Zeit. f. Infektionsk. u. Hygiene der Haustiere, Bd. VII (1910) p. 97. 
ture wounds. It is stated that in the New Hebrides the natives poison (infect with tetanus bacilli) their arrow heads with dirt taken from erab holes in the swamps. As it produces spores it is quite resistant so that it has been found in old mortar, dried soils, and in the feces of horses and cattle.

Morphology. The bacillus of tetanus is a slender rod, 2 to $5 \mu$ in length, and 0.3 to $0.8 \mu$ in breadth. The vegetative

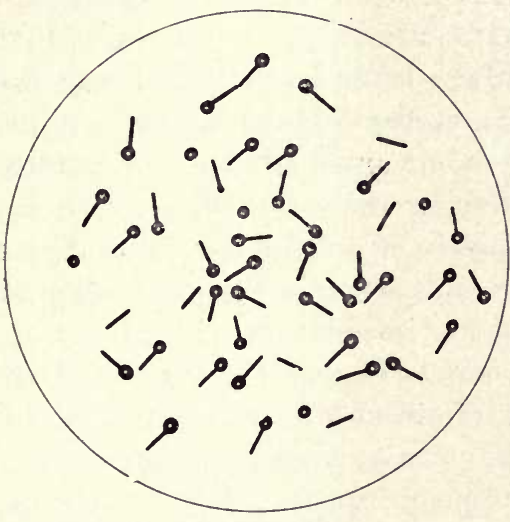

Fig. 67. Bacillus tetani. forms, which oceur chiefly in young cultures, are slightly motile and are seen to possess ${ }^{5}$ numerous peritrichial flagella, wh e $\mathrm{n}$ stained by special methods. After twenty-four to fortyeight hours of incubation, the length of time depending somewhat on the nature of the medium and the degree of anaërobiosis, the bacilli develop spores located at one end. Kanthack ${ }^{6}$ found in the study of the morphology of tetanus bacilli that they occasionally developed true branched forms.

As the cultures grow older the spore-bearing forms completely supersede the vegetative ones. Very old cultures contain spore-bearing bacilli and spores only.

Staining. The tetanus bacillus is easily stained by the usual aniline dyes, and reacts positively to Gram's stain. Flagella staining is successful only when very young cultures are used.

Cultivation. Bacillus tetani grows readily on ordinary media under anaërobic conditions. A slighty alkaline reaction is required. The addition of 1 to $1.5 \%$ glucose favors its growth. It develops sparingly at the point of introduction into the animal body and usually is accompanied by other

${ }^{5}$ Vottaler. Zeit. f. Hyg., Bd. XXVII (1898) p. 480.

' Kanthack. Jour. of Path. and Bact., Vol. IV (1896) p. 452. 
bacteria. For this reason it is difficult to isolate. Kitasato recommended the following method for isolating it:

Inoculate slightly alkaline nutrient agar or glucose bouillon with the tetanus-bearing material (pus or tissue from the inoculation wound), keeping the culture under anaërobic conditions for twenty-four to forty-eight hours at a temperature of $37^{\circ} \mathrm{C}$., and, after the tetanus spores have formed, heating it for one-half hour at $80^{\circ} \mathrm{C}$., to destroy the associated bacteria. The spores are able to survive this exposure, so that when anaërobic cultures are then made in the usual way the tetanus colonies develop. When the tetanus bacilli are the only spore-bearing bacteria present, pure cultures are readily obtained; when other spore-bearing anaërobes are present, the isolation of a pure culture may be a difficult matter. It can frequently be obtained in pure culture from the loeal lesion of a guinea pig dead of tetanus after inoculation.

Agar. In stick eultures, a growth occurs along the entire needle tract, resembling in its ramifications somewhat a miniature pine tree. On the surface, colonies present the appearance of light fleeey clouds. Under magnification, they seem to be a tangle of fine threads.

Gelatin. Along the needle track the growth exhibits the appearance of a cloudy linear mass, with prolongations radiating into the gelatin on all sides (arborescent growth). Liquefaction takes place slowly and generally with the production of gas. The colonies develop slowly and have a dense opaque center surrounded by fine diverging rays.

Potato. Growth is delicate and hardly visible.

Serum. Its growth appears on serum very much as it does on agar.

Bouillon. This medium becomes cloudy within twentyfour to thirty-six hours. Anaërobic conditions may be obtained by removing the air by boiling and covering the surface with a layer of sterile oil. It may be cultivated in ordinary bottles by filling them full and tightly corking. It ferments dextrose, producing acid and gas. The gas consists largely of $\mathrm{CO}_{2}$ but there are present volatile substances that give rise 
to a characteristic odor, resembling putrefying organic matter. This odor is due largely to $\mathrm{H}_{2} \mathrm{O}$ and methyl mercaptan. Milk. It grows readily in milk but does not produce any appreciable change.

Life conditions and properties. Bacillus tetani is an obligatory anaërobe although Ferran ${ }^{7}$ and others have succeeded in having subcultures grow under aërobic conditions. Smith, Brown and Walker ${ }^{8}$ found that by the addition of suitable carbohydrates and of fresh sterile liver tissue to the media its absolute anaërobiosis was weakened. It produces a soluble and one of the most powerful toxins known. It is stated that $0.000,005$ ec. of the filtrate of a broth culture will prove fatal to mice of ten grams weight. This toxin when in solution is very sensitive to heat. Two toxins have been named according to their action, tetanospasmin and tetanolysin. Tetanolysin was discovered by Ehrlich. ${ }^{9}$ It has the power to cause hemolysis of the red blood corpuscles of various animals and is an entirely separate substance from tetanospasmin which produces the familiar symptoms of the disease. Tetanolysin may be removed from cultures of tetanus by mixing red blood corpuscles with it. Tetanolysin when injected into animals produces an anti-hemolysin. Different cultures possess different ability to produce toxin. In the inoculated animal, the toxins are produced at the point of inoculation and are taken through the nerves to the motor cells of the anterior horn of the spinal column where the changes characteristic of tetanus occur, and which give rise to the symptoms.

Resistance. The vegetative forms of the tetanus bacillus are quite sensitive to heat or chemical agents. The spores, however, are quite resistant, but not so much so as those of anthrax. They are destroyed by exposure to live steam at $110^{\circ} \mathrm{C}$. They resist $5 \%$ solution of carbolic acid for many hours, but if $1 / 2 \%$ hydrochloric acid is added they are destroyed in two hours. They are killed when acted upon by

${ }^{7}$ Ferran. Centralbl. f. Bak., Bd. XXIV (1898) p. 28.

${ }^{8}$ Walker. Jour. of Med. Research, N. S. Vol. IX (1906) p. 173.

'Ehrlich. Ber. Klin. Woch., 1898. 
a solution of 1 to 1,000 bichloride of mercury for three hours.

Pathogenesis. This organism is fatal to mice, rabbits, guinea pigs, horses, goats and other animals. Rats and birds are less susceptible and fowls rarely contract the disease. Man is more susceptible than any of the animals that have been tested. A horse is about six times as sensitive as a guinea pig and 300,000 times as sensitive as a hen. If the experimental animal is inoculated with a non lethal dose, a local tetanus may be produced which lasts for some days or even weeks, after which recovery occurs.

Tetanus antitoxin. Like diphtheria, tetanus toxin when injected causes a reaction on the part of the animal tissues with the production of antitoxin. The tetanus antitoxin is produced by the injection into horses of tetanus toxin in increasing doses. The toxin is produced in bouillon cultures grown anaërobically in the laboratory. After 15 days, the culture is filtered through porcelain and the germ free filtrate is injected. The horses receive an initial dose of 5 ce. of the toxin with a sufficient amount of the antitoxin to neutralize it. In 5 days the dose is increased and then every 5 to 7 days larger amounts are given. The dose is increased as rapidly as the horses can stand it, until they support 700 to $800 \mathrm{cc}$. or more at a time. This amount should not be injected in a single place, or severe and perhaps fatal local tetanus may develop. After some months of this treatment the blood of the horse contains the antitoxin in sufficient amount for therapeutic use.

Tetanus antitoxin is used in certain localities very extensively for immunizing against tetanus horses that have received puncture wounds and in cases of operations where the healthy skin is incised. 'It is also used therapeutically in both man and animals. The results vary when it is administered after symptoms appear. It is very effective, however, as an immunizing agent. 


\section{BACILLUS PSEUDO-TETANI.}

Place in nature. In 1900 Bain ${ }^{1}$ isolated from a wound caused by a blank cartridge a tetanus-like bacillus which resembled very closely morphologically and in its anaërobic requirements the bacillus of tetanus. Because of the possibility of finding the tetanus organism by microscopic examination of the scrapings from the lesions when they can be located, it is important to recognize that forms resembling the tetanus organism very closely are sometimes encountered. Bain found that the bacillus which he isolated differed from the true tetanus organism in that it is not pathogenic for guinea pigs. It is Gram negative. It possesses less flagella. Among the cultural differences its growth in glucose gelatin and glucose agar is totally unlike that of tetanus in these media. It does not liquefy gelatin, as does the tetanus organism. It does, however, produce spherical spores situated at the ends of the rod, which would readily lead one to suspect tetanus from a simple microscopic examination. Bushnell ${ }^{2}$ found a bacillus in a case of fistulous withers that resembled morphologically that of tetanus, except that the spores were oval. After a few generations it grew in the presence of atmospheric oxygen. It was not pathogenic for experimental animals.

\section{BACILLUS NECROPHORUS FLUGGE.}

Synonyms. Bacillus of ealf diphtheria Loeffler; Bacillus diphtheriae vitulorum; Bacillus filiformis Schütz; Streptothrix cuniculi Schmorl; Nekosebacillus Bang.

Place in nature. This bacillus is the cause of a considerable variety of lesions in domesticated animals characterized by necrosis. It was first observed by Koch ${ }^{1}$ and later isolated and studied by Loeffler as the probable cause of the disease designated by Dammann as calf diphtheria. Bang ealled at-

${ }^{1}$ Bain. The Journal of the Boston Society of the Medical Sciences, Vol. V (1901) p. 505.

${ }^{2}$ Bushnell. Am. Vet. Review, Vol. XXVI (1902-03) p. 405.

${ }^{1}$ Koch. Mittheil. a. d. Kaiserl. Gesundheits., Bd. I (1881) p. 1. 
tention to its ability to produce a coagulation necrosis which led him to give it the name of Necrosebacillus. Schmorl ${ }^{2}$ found this to be the cause of a disease in rabbits. Mohler ${ }^{3}$ has described this organism from cases of necrotic stomatitis in calves and pigs. It has also been discovered in a number of diseases. The lip and leg ulceration of sheep is attributed to it. ${ }^{4}$ We have found it in a number of interesting cases of local necrotic areas in livers of cattle and in one case in the heart muscle of a horse. Bang ${ }^{5}$ found it to be associated with the necrotic processes found in the intestines of hogs. The results reported suggest that it may be an inhabitant of the normal intestine of swine and possibly of other animals. Its normal habitat in nature is not known, but from the many lesions attributed to it, it must be somewhat widespread.

Morphology. Flügge's name Bacillus necrophorus is retained although in the observation of several workers motility has not been observed. Mohler ${ }^{6}$ emphasizes the fact that he was unable to detect motility or to find flagella. It varies in size from short coccus-like forms to rods and filaments. Mohler states that they attain to $100 \mu$ in length and from 0.75 to $1.5 \mu$ in width. The rod forms are slender, sometimes beaded. In the tissues they appear more or less matted. The ends are club-shaped or tapering.

Staining. In smear preparations from tissues it does not stain as quickly with the usual dyes as most bacteria. Alkaline methylene blue and carbol fuchsin give good results. Mohler suggests alkaline toloidine blue * as a better stain for bringing out the beaded appearance.

Cultivation. The cultivation of Bacillus necrophorus is

${ }^{2}$ Schmorl. Deut. Zeit. f. Tiermed., Bd. XVII (1891) p. 375.

${ }^{3}$ Mohler. Bulletin No. 67, B. A. I., U. S. Dept. Agric., 1905.

${ }^{4}$ Melvin and Mohler. Circular No. 160, B. A. I., U. S. Dept. Agric., 1910.

${ }^{5}$ Bang. Review in Centralbl. f. Bakt., Bd. XIII (1893) p. 203.

${ }^{6}$ Mohler. loc. cit.

* He uses a $1 \%$ solution. The film preparation is dipped for from 2 to 5 seconds in the stain, immediately washed in water and mounted. 
attended with some difficulty. It is an obligatory anaërobe. It grows at a temperature between $38^{\circ}$ and $40^{\circ} \mathrm{C}$. The optimum temperature is about $35^{\circ} \mathrm{C}$. It does not grow readily on ordinary media although we have obtained fairly good cultures on agar. Agar-gelatin,* serum-agar and serum-agargelatin have been recommended. Several other media have been suggested.

Agar. Liborius cultures in from 36 to 48 hours show greyish white colonies in the depth of the medium. These have later a dense whitish or yellowish center with a more or less opaque cloudiness about them. Mohler refers to gas bubbles appearing in the medium. On serum agar the growth is similar to that on agar.

Gelatin. The growth is feeble on this medium. The gelatin is not liquefied.

Bouillon. This medium becomes turbid. The bacteria settle later in the form of whitish viscid flakes and the fluid becomes clear. Ernst has described the odor as being between that of cheese and glue. Mohler observed gas bubbles.

Milk. Milk is said not to be coagulated nor to become more acid.

Liquid serum. Mohler states that liquid serum is coagulated.

Life conditions and properties. B. necrophorus requires the absence of atmospheric oxygen. It produces indol. Its toxic production is not clearly determined. It has been thought by some that it elaborated a specific and important toxin because of the nature of the lesions it produces. The enormous number of bacilli present in the necrotic tissue suggests possibly that the excessive multiplication of the bacilli may be largely responsible for the result.

Resistance. P. necrophorus is destroyed after an exposure for 2 minutes in a $3 \%$ solution of carbolic acid. Corrosive sublimate and formalin destroy it in weak solutions.

Pathogenesis. This organism affects nearly all species of domesticated animals and it is reported as being found in

* Serum and agar equal parts. 
a few wild ones. It attacks nearly if not all tissues of the body producing necrosis which if not checked will eventually cause death. It is of much more importance in the production of morbid conditions than is generally supposed.

BaCillus CHAUVEaUi aRLOING, CORNEVIN AND THOMAS.

Synonyms. Bacillus charbonis Migula; Bacillus anthracis symptomatica Kruse; bacillus of black leg.

Place in nature. This organism is the cause of the disease known as black leg, black quarter, or symptomatic anthrax. This is a disease of eattle characterized by a peculiar emphysematous swelling of the subcutaneous tissues and muscles over
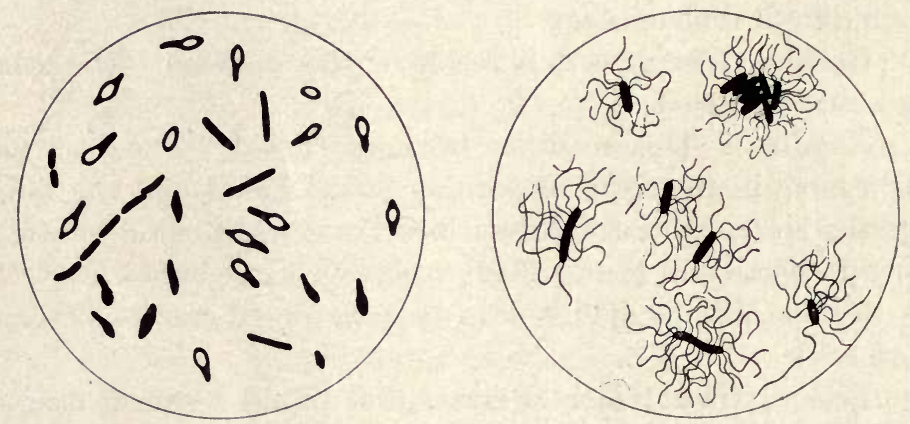

Fig. 68. Bacillus of blackleg showing spores and flagella. (Hutyra).

the quarter affected. The disease was formerly confused with anthrax. The bacillus is distributed in the soil and it is more or less common in certain localities. In the United States black leg is more prevalent in the Middle West than in the East. B. Chauveaui was discovered by Bollinger and Feser ${ }^{1}$ and later described by Arloing, Cornevin and Thomas. ${ }^{2}$

Morphology. Bacilli having rounded ends, from 0.5 to $1.0 \mu$ broad and from 3 to $5 \mu$ long. It often appears in pairs, joined end-to-end, but never growing out into long filaments, as the bacilli of malignant oedema are wont to do in the bodies

${ }^{1}$ Bollinger and Feser. Ber. thierärtzl. Woch., 1878.

${ }^{2}$ Arloing, Cornevin and Thomas. La charbon symptomatique du boeuf. Paris, 1887. 
of animals. In the hanging drop the bacilli are observed to be actively motile, and in stained preparations flagella may be demonstrated. Spores are formed. They are elliptical in shape, usually thicker than the bacilli, lying toward one extremity. This gives to the bacilli containing spores a somewhat spindle shape.

Staining. It stains readily with the ordinary aniline dyes. It stains feebly by Gram's method.

Cultivation: This organism grows readily on the ordinary cultural media in the absence of oxygen. It grows more vigorously, however, in media containing from 1 to $2 \%$ of glucose, or $5 \%$ of glycerine. It must be cultivated under strict anaërobic conditions.

Agar. In agar stick cultures growth. occurs along the needle track some distance below the surface after 24 to 48 hours. It has a peculiar disagreeable odor. A few gas bubbles form in the agar.

Gelatin. At room temperature colonies appear in from 24 to 48 hours. They are round or oval with somewhat dense centers about which fine radiating filaments form an opaque halo. The gelatin is liquefied.

Bouillon. Bouillon in the fermentation tube, containing $1 \%$ glucose, becomes deeply elouded in the elosed branch with the formation of a considerable quantity of gas.

Irife conditions and properties. The bacillus of symptomatic anthrax is an obligatory anaërobe and can not be cultivated under aërobic conditions. It grows best at a temperature of about $37^{\circ} \mathrm{C}$. although it multiplies more slowly at room temperature. This organism produces, according to Leclainche and Vallée, ${ }^{1}$ a soluble toxin, which they found to be formed in considerable quantities in broth containing blood and various animal fluids. According to these authors the best medium for obtaining the toxin is the bouillon of Martin ${ }^{2}$ made of equal parts of veal infusion and a peptone solution

${ }^{1}$ Leclainche and Vallée. Ann. de l'Inst. Pasteur, Vol. XIV (1900) p. 202 .

${ }^{2}$ Martin. Ann. de l'Inst. Pasteur, Vol. XII (1898) p. 26. 
obtained from the macerated tissues of the stomachs of pigs. The toxin contained in filtrates of such cultures is quite resistant to heat. Hanna ${ }^{3}$ studied the toxins of $B$. Chauveaui produced by the organism. He found that a culture medium consisting of blood plasma and peptone broth in the proportion of 1 to 5 gave the best toxins and that this toxin became attenuated. He observes that guinea pigs which had received the toxin appeared to be less sensitive to the toxin than fresh animals. He procured an antitoxin from the blood of rabbits that had received repeated doses of the toxins.

Pathogenesis. The bacillus of symptomatic anthrax is pathogenic for cattle six months of age or older, but rarely after they are six years old. It does not usually attack cattle under six months of age. Swine, horses, rabbits, dogs, eats and chickens are as a rule immune. The guinea pig is the most susceptible of the experimental animals. The lesions in the guinea pig consist of a blood stained serous exudate in the subcutaneous tissues extending from the point of inoculation over a considerable part of the abdomen. Naturally it is a disease of cattle, sheep and horses. Man has not been infected.

Resistance. Nörgaard states that a temperature of $110^{\circ} \mathrm{C}$. is necessary to destroy the dried spores. A 2 per cent solution of carbolic acid kills the vegetative forms after some hours. For disinfection purposes a 5 per cent carbolic acid solution or a 1 to 2000 corrosive sublimate solution is recommended.

Immunity. An active immunity against the bacillus of black leg is obtained by subcutaneously inoculating cattle with tissue extracts from infected animals. Several forms of vaccine have been prepared. The earlier ones required two vaccines. At present, however, the U. S. Bureau of Animal Industry prepares a single vaccine. The material used for the vaccine is obtained from a fresh blackleg tumor, by pounding the muscle tissue in a mortar with the addition of a little water and squeezing the pulp through a linen cloth. The

${ }^{3}$ Hanna. Jour. of Path. and Bact., Vol. IV (1896) p. 383. 
juice is spread in layers on plates and dried quickly at a temperature of about $35^{\circ} \mathrm{C}$. This temperature does not in the least affect the bacteria, and the dry virus obtained in this way retains a high degree of virulence for two years or longer.

When vaccine is to be prepared, the dried material is pulverized and mixed in a mortar with two parts water until it forms a semifluid homogeneous mass. This is spread in a thin layer on a suitable glass dish and placed in an oven, the temperature of which may be regulated with exactness. The reason for mixing the dried muscle with water is to insure a quicker and more uniform attenuation. The temperature of the oven is previously brought up to $95^{\circ}$ to $99^{\circ} \mathrm{C}$., and the virus is allowed to remain in it for six hours. When removed it appears as a brownish scale, which is easily detached from the dish. This scale is pulverized and put up in packages containing 10 doses each. Before it is used, it is mixed with 10 ce. water, filtered and the filtrate injected in doses of one cubic centimeter.*

The U. S. Bureau of Animal Industry finds that this vaccination is exceedingly helpful in preventing disease. Vaccine to the extent of hundreds of thousands of doses is sent out by the Bureau annually for this purpose.

\section{BACILLUS OEDEMATIS LIBORIUS.}

Synonyms. Bacillus oedematis maligni Koch; Vibrion septique Pasteur.

Place in nature. This organism is the cause of a malignant oedema in man and in certain animals. It is closely related to the bacillus of blackleg. It was isolated in pure culture by Liborius. ${ }^{1}$ It had previously been found by Pasteur and others, in putrid material. It was studied by Koch ${ }^{2}$

* Nörgaard. Blackleg in the United States and the distribution of vaccine by the Bureau of Animal Industry. Annual Report of the B. A. I., U. S. Dept. of Agric., 1898.

${ }^{1}$ Liborius. Zeit. f. Hyg., Vol. I (1886) p. 115.

${ }^{2}$ Koch. Mitt. a. d. Kais. Gesundheitsamt., Bd. I (1881) p. 52. 
in connection with anthrax. Gaffky ${ }^{3}$ found that this organism existed in the upper layers of garden soil and in dust. It has since been found to be somewhat widely distributed in external nature and it has also been reported from the intestines of animals and man.

Morphology. This bacillus is a long slender rod. It is about $1 \mu$ in width and from 3 to $8 \mu$ in length. They possess
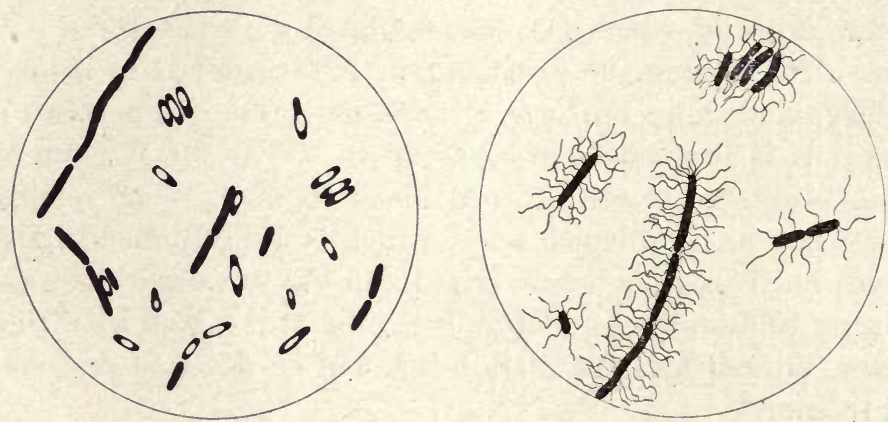

Fig. 69. Bacilius of malignant oedema showing flagella and spores (Hutyra and Marek).

numerous flagella. The motility is sluggish. It produces oval spores which appear irregularly, either in the center or near the ends of the organism. It does not have a capsule.

Staining. It is stained readily with the usual aniline dyes. It is Gram negative.

Cultivation. This organism is an obligatory anaërobe. It develops readily under anaërobic conditions on the usual media. It grows like the bacillus of black leg in media containing glucose.

Agar. Stab cultures in agar show a growth within 24 to 36 hours when kept at body temperature. In from 1 to 2 days the growth gives a clouded appearance extending from the line of inoculation. If sugar is present gas bubbles appear throughout the medium. Colonies or growths appear. Under the microscope the growth exhibits radial filaments.

${ }^{3}$ Gaffky. Mitt. a. d. Kais. Gesundheitsamt., Bd. I (1881) p. 80. 
Serum. On blood serum the growth is vigorous. The serum is rapidly liquefied with the production of gas.

Gelatin. The medium is liquefied.

Potato. Potato was used by Gaffky. The organism grows readily upon it.

Bouillon. In bouillon there is a uniform clouding of the liquid and a granular sediment is formed. No pellicle appears.

Milk. Milk is slowly coagulated.

Life conditions and properties. This organism requires for its development the absence of atmospheric oxygen. It develops at a temperature between $20^{\circ}$ to $37^{\circ} \mathrm{C}$. It produces gas with a peculiar disagreeable odor in all media containing sugars. The spores are very resistant, which is the explanation for the soil's being so extensively infected.

Pathogenesis. It is pathogenic for mice, guinea pigs, and rabbits. Horses, dogs, goats, sheep, pigs and chickens are susceptible. It is also virulent for man. Inoculated subcutaneously it causes an extensive hemorrhagic oedema of the subcutaneous tissue. It does not produce an odor like black leg and there is little if any gas. Animals become infected from the soil through wounds. This disease is confined naturally very largely to domesticated animals. It is stated that animals that recover from malignant oedema are subsequently immune to the disease. ${ }^{4}$

BACILLUS LACTIMORBI JORDAN AND HARRIS.

Place in nature. This organism was found by Jordan and Harris ${ }^{1}$ to be associated with the lesions in cattle that died of milk sickness or "trembles." It was thought to be the cause of this somewhat serious affection. They report finding it or an organism not distinguishable from it in the soil of regions where milk sickness has not occurred. They also found it but not in large numbers in the soil in localities where milk sickness appears, in normal cows' feces, on various

${ }^{4}$ Arloing and Chauveau. Ann. de médécine vét., 1884.

${ }^{1}$ Jordan and Harris. Jour. of Inf. Diseases, Vol. VI (1909) p. 401. 
grain and forage plants and in other localities. As it seems to be widely distributed, their suggestion is that the occurrence of the disease depends upon the presence of pathogenic races of the organism. The following description is taken from their exhaustive article which contains an extensive literature on milk sickness.

Morphology. In cover-glass preparations from the organs the bacilli are longer and more slender than the colon bacilli, and occasionally stain unevenly with methylene blue. In preparations made from cultures grown on agar at $37^{\circ} \mathrm{C}$. the organism is found to be a rod a little smaller than the anthrax bacterium, occurring singly and in pairs and in oceasional filaments.

Staining. In young cultures the bacilli are Gram positive but the granules are not differentiated by the Gram stain. The spores stain readily by any of the ordinary methods. The organism is motile and it is found on staining by van Ermengem's method to be possessed of 10 or 15 flagella disposed peritrichally, the flagella measuring in length about five times the length of the bacillus itself.

Cultivation. Jordan and Harris were able to cultivate this organism on ordinary culture media.

Agar. At $37^{\circ} \mathrm{C}$. at the end of 24 hours, the surface is more or less irregularly covered with a delicate veil-like growth, which is more profuse at the end of from 48 to 72 hours and eventually may take on a semiviscid character in some cultures. The color of the growth was grayish and surface moist, smooth and glossy. There was no pigmentation of the growth itself or of the medium. Gas was not produced. The condensation-water growth was heavy, grayish-white in color. No odor.

Gelatin. If the organism is grown in a petri dish of gelatin at $30^{\circ} \mathrm{C}$. it is found at the end of 24 hours that the whole of the medium is quite cloudy, with not infrequently several small islets of pellicular material scattered over the surface. The surface growth increases during the next four days but never forms a complete film over the surface. On 
blood agar serum colonies appear which resemble somewhat those of $B$. subtilis. A halo-like zone appears about the peripheral part of the colony. Jordan and Harris found certain agglutination reactions.

Potato. No growth was observed by Jordan and Harris on this medium. Luckhardt ${ }^{2}$ obtained a luxuriant growth on potato.

Blood serum. At the end of 48 hours there occurs along the needle track and confined to it an elevated, fairly vigorous, smooth, moist, yellowish, glossy growth, which later tends to spread but little. There is no discoloration of the medium, liquefaction, nor odor.

Bouillon. At the end of 24 hours there may not be any growth noticeable except sometimes a slight clouding of the broth at the surface. At the end of 48 hours there is seen on the surface a well-formed pellicle, which will sink if the tube is agitated; the rest of the medium is feebly clouded and there may be a fine semiflocculent sedimented growth at the bottom of the tube or along the dependent side, if the tube has been inclined.

Litmus milk. If not heavily seeded there may be no visible signs of growth. As a rule there is no change at the end of 48 hours; by 72 hours the cream ring will show a delicate green-blue color in the drier parts, and even in some instances the upper portion of the milk will show a slight alkaline reaction; this reaction daily increases until at the end of ten days the whole tube takes on an alkaline reaction which becomes more and more marked until as in cultures of $B$. suipestifer the medium may lose a part of its color, turning a dirty white, or even begin to turn opalescent. Coagulation has not been observed.

Life conditions and properties. The temperature best suited for the growth of this organism seems to be from $30^{\circ}$ to $37^{\circ} \mathrm{C}$. It is an aërobe, as it does not grow in the closed branch of the fermentation tube. Indol is not produced.

${ }^{2}$ Luckhardt. Jour. of Inf. Diseases, Vol. VI (1909) p. 492. 
Pathogenesis. Jordan and Harris found that rabbits were susceptible to injections intraperitoneally of 2 ec. of the heart blood of animals suffering with the disease, and from the peritoneal exudate and heart blood they obtained pure cultures of $B$. lactimorbi. Most of their experiments with rabbits, however, were negative. Luckhardt ${ }^{3}$ made a number of experiments to determine its effect on dogs. He was able to produce symptoms of milk sickness by feeding large quantities of the culture.

\section{BACILLUS ALVEI CHESHIRE AND CHEYNE. ${ }^{1}$}

Synonym. Bacillus of European foul brood. According to White ${ }^{2}$ this disease has been called the "New York bee disease" and "black brood."

Place in nature. This bacillus is the cause of the European "foul brood" of honey bees. This is a very serious affection of bees and the cause of heavy losses to the apiarist. It attacks the young larvae. The disease occurs most frequently in the spring and early summer. White ${ }^{3}$ found the greatest number of $B$. alve $i$ in the bodies of the dead larvae. They were found in the pollen and honey stored in the cells of the foul-brood combs. He also found them on the exterior of bees from infected colonies.

Morphology. It occurs singly and in pairs. When taken from the surface of agar cultures it varies from 1.2 to $3.9 \mu$ in length, and from 0.5 to $0.7 \mu$ in width. Involution forms are sometimes present. Spores are produced and occupy an intermediate position in the organism. They are oval and vary from 1.5 to $2 \mu$ in length and from 0.7 to $1 \mu$ in breadth;

${ }^{3}$ Luckhardt. loc. cit.

${ }^{1}$ Cheshire and Cheyne. Jour. Royal Mic. Society, Vol. V (1885) p. 581.

Harrison. Bulletin No. 112 Ontario Agric. College, 1900.

${ }^{2}$ Moore and White. Report N. Y. State Dept. Agric., Jan. 1903.

White. Bulletin No. 14 Technical Series, Bureau of Entomology, U. S. Dept. of Agric., 1906, p. 144.

${ }^{3}$ White. loc. cit. 
they exhibit polar germination. The few flagella are arranged about the organism.

Staining. It is colored with the ordinary bacterial staining solutions. It is Gram positive.

Cultivation. It can be cultivated on ordinary media. It grows at room temperature but better at $37^{\circ} \mathrm{C}$.

Agar. A gray layer spreads over the surface in 24 hours, which later takes on a slightly brown color. A heavy slightly viseid growth occurs in the condensation water. On agar plates, small, grayish, circular colonies form in 24 hours. When many are on the plate, they do not exreed $2 \mathrm{~mm}$. in diameter. Under low magnification they appear granular, with no definite margin.

Gelatin. It develops
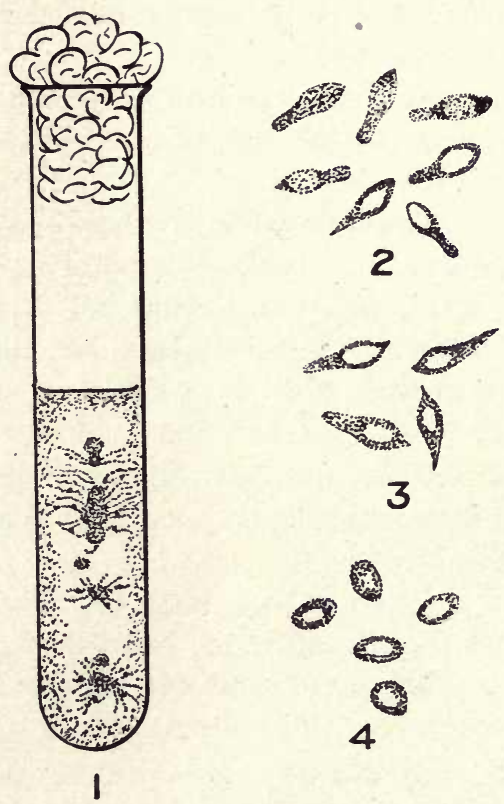

3

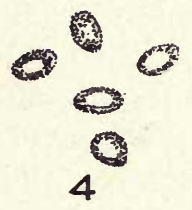

Fig. 70. Bacillus alvei. (1) Gelatin stab culture showing the character of the growth of colonies; (2) beginning of spore formation; (3) later stages in spore formation; and (4) free spores, 2, 3 and 4 much enlarged (White). slowly in gelatin. The colonies become very irregular in outline, owing to thread-like outgrowths which take place in curves from its border. Growth is better when $5 \%$ glycerin is added. From the small, white, spherical colonies which form along the line of puncture gray, threadlike growths shoot out through the medium. In about 2 months the gelatin is changed to a thick liquid, holding gray flocculent masses of organisms which gradually settle, forming a strong, slightly viscid sediment.

Potato. On this medium the bacillus grows rather slowly 
at first, but after 3 or 4 days a milky growth is observed which increases until a luxuriant growth is formed. It varies from lemon-yellow to a gray in color. In old cultures it has a brown color.

Serum. A slightly raised growth which is confined quite closely to the line of inoculation appears on the surface of solidified serum.

Bouillon. The medium becomes uniformly clouded in 24 hours; later it shows a tendency to clear by a settling of the organisms. A somewhat viscid sediment is thus formed in the bottom of the tube. In older cultures a slightly grayish band of growth adheres to the glass at the surface of the medium. The acidity is at first slightly increased, and a pellicle is sometimes formed. In bouillon containing lactose, dextrose and saccharose, the acidity is slightly increased but gas is not produced.

Milk. The acidity is increased. Coagulation usually takes place after the third day.

Life conditions and properties $B$. alve $i$ is a facultative anaërobe. Old cultures give a strong indol reaction.

Resistance. It is destroyed in the vegetative form with a $3 \%$ solution of carbolic acid and 1 to 2000 solution of bichloride of mercury in three minutes. A solution of bichloride of mercury 1-1000 kills the spores after 30 minuutes' exposure.

Pathogenesis. It is pathogenic for young honey bees.

BACILLUS LARVAE WHITE.

Synonyms. Bacillus of American foul brood; Bacillus $X$ White. ${ }^{1}$

Place in nature. This organism was discovered by White in the study of a bee disease now known as American foul brood. Its distribution seems to be similar to $B$. alvei.

Morphology. It is a slender rod, having a tendency to form in chains. This is especially true when grown in beelarvae bouillon. It is rather sluggishly motile. Spore forma-

${ }^{1}$ White. Report N. Y. State Dept. of Agric., Jan. 1904. 
tion takes place. This can be observed best in the different stages of the disease and decay of the larvae.

Staining. It stains with the usual aniline dyes.

Cultivation. It does not grow on any of the ordinary media made from meat infusion or peptone or in milk or on potato. It was discovered by White that it would grow on media prepared as follows:

Larvae are picked from the brood combs of a number of frames of a healthy brood and a bouillon (bee-larvae bouillon) is made from them following the same directions as when bouillon is made from meat. The first growth from these spores was secured in an agar (bee-larvae agar) made from this special bouillon when Liborius's method for cultivating anaërobes was used. Cultures are made from the dead larvae.

Agar. The inoculations must be made with the medium liquefied. The growth takes place near to but rarely on the surface. Cultures must pass through a few generations before a satisfactory surface growth can be secured.

Bee-larvae agar slant. On the surface of this medium a thin, gray, non-viscid growth develops.

Life conditions and properties. B. larvae is an anaërobe when first isolated but after a few generations it will grow in the presence of atmospheric oxygen. Indol has not been detected. White found in his study of the bacterial flora of the intestine of the honey bee the following bacteria which he isolated and studied:* Bacillus cloacae, Bacillus coli communis, Bacillus suipestifer, Bacillus subgastricus, Bacterium mycoides, Pseudomonas fluorescens liquefaciens, and two organisms referred to as Bacillus $E$, and Saccharomyces $F$.

* Ford has made an extensive study of the intestinal bacteria in man and reported their classification and distribution in the intestine. (Studies from the Royal Victoria Hospital, Montreal, Vol. I, No. 5, 1903.)

Dyar and Keith have published instructive notes on the normal intestinal bacilli of the horse and of other domesticated animals. Technological Quarterly, Vol. VI, No. 3, 1893. 


\section{A FEW COMMON NON,PATHOGENIC SPECIES.}

\section{BACILLUS SUBTILIS COHN.}

Synonyms. Vibrio subtilis Ehrenberg ${ }^{1}$; Bacillus subtilis Cohn ${ }^{2}$; hay bacillus.

Place in nature. This bacillus is widely distributed in external nature, especially on hay and straw and in the soil. Because of this it is liable to be found in or on almost any article or substance. It is very commonly encountered as a contamination in cultures. It does not possess any disease producing power but it has been reported as a secondary invader in suppurative lesions.

Morphology. Short thick rods with rounded ends. It sometimes appears as filaments and again as chains of long and short rods. It is from 0.8 to $1.2 \mu$ broad, 2.0 to $8.0 \mu$ long. It possesses from 6 to 8 flagella. The short forms are actively motile but the thread-like forms are immotile. Oval spores form in the presence of air and they germinate at right angles to long diameter. Spores are set free in about 24 hours. They are from 0.6 by $1.2 \mu$ in size.

Staining. The vegetative form stains readily with the aniline dyes and the spores by the methods for staining spores. It takes the Gram stain.

Cultivation. It multiplies readily on all ordinary media. It is an obligatory aërobe. There is considerable difference in the character of the growth especially in bouillon. This suggests that there are a number of varieties. The so-called potato bacillus (B. mesentericus) and a number of other aërobic, spore-bearing bacilli widely distributed in nature may belong to a group of bacteria including $B$. subtilis.

Agar. A grayish, dry, corrugated growth appears on the surface.

Gelatin. On this medium the colonies have granular centers and folded margins. Surface growth in stab cultures is

\footnotetext{
${ }^{1}$ Ehrenberg. Infusionsthierchen als volkommene Organismen.
} Leipsic, 1838.

${ }^{2}$ Cohn. Beiträge zur Biologie, Bd. I (1872) p. 175. 
whitish gray; colonies sink on liquefaction of medium; liquefaction progresses quite rapidly and a thick whitish scum is formed.

Potato. On potato a very vigorous grayish mealy or more membranous growth extends over the surface.

Bouillon. A thin membranous pellicle forms on the surface. In some cultures the liquid becomes cloudy and in others it remains elear beneath the membrane.

Milk. Milk becomes thickened, peptonized and slightly alkaline.

Life conditions and properties. It grows best at room temperature. It does not produce indol. A soluble toxin is not known.

Pathogenesis. It is not considered a disease producing organism. Charrin and de Nittis ${ }^{1}$ cultivated it on blood media and passed it through animals until it acquired some virulence. Silberschmidt ${ }^{2}$ and others have reported cases of its being pathogenic. In the earlier work, reference is made to the possibility of $B$. subtilis being a prototype of Bact. anthracis and some workers thought they had changed $B$. subtilis into virulent anthrax bacteria. Such results have not been recorded within recent years.

\section{BACILLUS PRODIGIOSUS (EHRENBERG) FLUGGE.}

Synonyms. Monias prodigiosa Ehrenberg ${ }^{1}$; Bacterium prodigiosum Schröter ${ }^{2}$; Micrococcus prodigiosus Cohn. ${ }^{3}$

Place in nature. This is a non-pathogenic microorganism. It is of interest in this connection simply because it may occur as a contamination and it is also interesting in the study of certain properties of bacteria, especially pigment produc-

${ }^{1}$ Charrin and de Nittis. Compt. rendu. de la Soc. de Biologie, Vol. XLIX (1897) p. 711.

'Silberschmidt. Ann. de l'Inst. Pasteur, Vol. XVII (1903) p. 268. Migula.

${ }^{1}$ Ehrenberg. Verhandl. der Berliner Akademie, 1839. Cited by

${ }^{2}$ Schröter. Cohn's Beiträge zur Biologie, 1872.

${ }^{3}$ Cohn. Untersuchungen iiber Bakterien, I, 1872. 
tion. It may be obtained from dust in the air, from water and from the soil. Klein ${ }^{4}$ describes contamination of meat and fish with $B$. prodigiosus, which gave rise to "pink" beef and fish. A thorough eleaning and disinfection of the place eliminated the trouble.

Morphology. B. prodigiosus appears sometimes perfectly spherical, sometimes oval or elliptical, and sometimes as short rods. They measure from $0.5 \mu$ to $1.0 \mu$ or more in diameter. It does not produce spores. There have been observed between the living cells masses of granules of different shapes, some much smaller, others much larger than the coccus, round or irregular in shape, and colored a very bright red. ${ }^{5}$

Cultivation. It grows especially well as an aërobe, but also, although more slowly, as an anaërobe. The most favorable temperature for its development seems to be from $23^{\circ}$ to $25^{\circ} \mathrm{C}$. At $35^{\circ}$ and above, the production of pigment decreases and soon ceases.

Agar. On slant agar the growth appears as thick bands of reddish color which become blood-red as they grow older and often show a metallic-like surface. The upper part of the thick shiny layer, directly in contact with the air, is alone highly colored.

Gelatin. On gelatin plates it forms in 24 hours, at $20^{\circ} \mathrm{C}$., small rounded colonies of a grayish color. The deep colonies come to the surface and have a bright color in the center. Liquefaction takes place rapidly. In twelve hours, the whole plate is liquefied. The liquid gelatin has a reddish color.

Potato. Growth is abundant on this medium. There appears after 24 hours a whitish layer which gradually spreads and forms a thick growth of a red color. The surface of the growth exhibits in some places a metallic green resembling that of fuchsin.

Serum. Serum is gradually liquefied. The growth resembles that on agar.

Bouillon. This medium quickly becomes turbid and takes

${ }^{4}$ Klein. The Jour. of Path. and Bact., Vol. II (1894) p. 214.

${ }^{5}$ Macé. Traité de Bactériologie. 
on a rosy color, which is often marked only in the upper portion, forming a thin superficial layer. Old cultures are slightly viscid.

Milk. It causes coagulation of the casein, without producing other changes. The coagulum according to Hueppe may later dissolve.

Life conditions and properties. The most interesting peculiarity of $B$. prodigiosus is the production of coloring matter. The pigment is formed only in the presence of oxygen, the colonies grown in the depths of gelatin or beneath a layer of oil remaining white. The coloring matter is insoluble

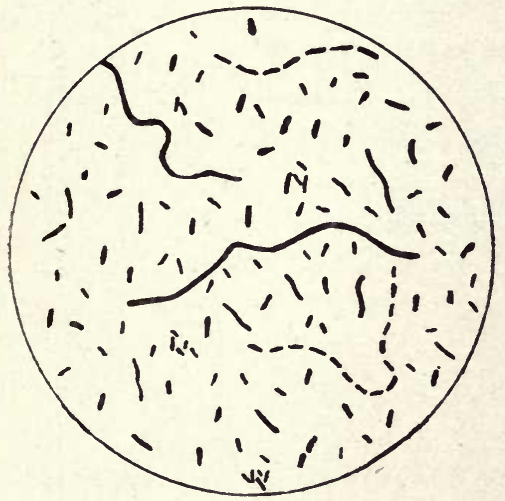

Fig. 71.

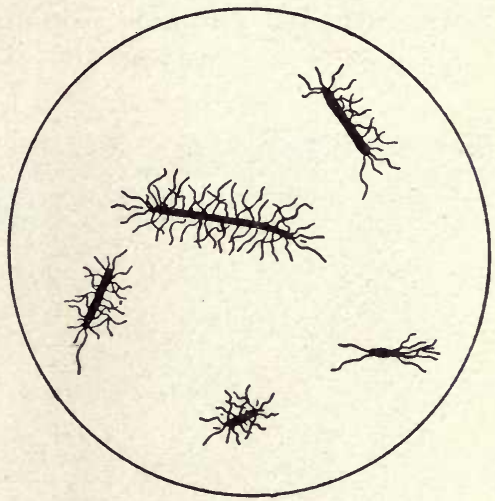

Fig. 72 .

Fig. 71. Bacillus vulgaris. Agar culture 36 hours old. $\times 510$. (Hauser).

Fig. 72. Bacillus vulgaris showing flagella from agar culture 12 hours old (Hauser). $\times 700$.

in water and slightly soluble in alcohol and ether. Light very quickly decolorizes the alcoholic solutions, but if they are kept in the dark, they will retain their color for years.

Pathogenesis. This bacillus does not appear to possess pathogenic properties. 
BACILLUS VULGARIS (HAUSER) MIGULA.

Synonyms. Proteus vulgaris Hauser; Bacillus proteus vulgaris.

Place in nature. This bacillus was first discovered by Hauser with other bacteria in putrefying substances. Bacillus (Proteus) Zenkeri belongs to this group. These putrefying bacteria belong to the organisms previously described as "Bacterium termo" referring to any motile bacteria found in putrefying infusions.

Morphology. Bacilli varying in size from 0.4 to $0.6 \mu$ broad and 1.0 to $1.4 \mu$ long. Shorter and longer forms have been observed and also flexible filaments which are sometimes more or less wavy or twisted like braids of hair.

Staining. It stains

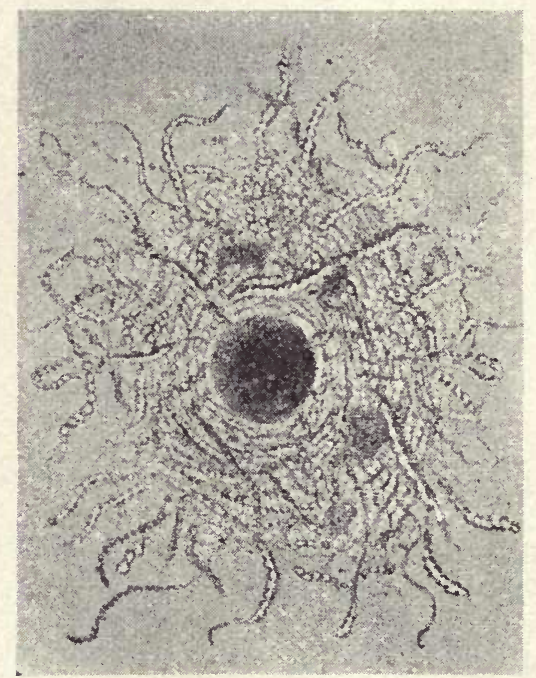

Fig. 73. Colony of Bacillus vulgaris four days old, cultivated at $20^{\circ} \mathrm{C}$. (Hauser). readily with fuchsin or gentian violet. It is Gram negative.

Cultivation. It grows readily on the ordinary media.

Agar. A rapidly spreading, moist, thin grayish-white growth appears.

Gelatin. The growth on gelatin plates is very characteristic. At the end of ten or twelve hours in a $5 \%$ gelatin at room temperature, small, round depressions are observed, which contain liquefied gelatin and a whitish mass consisting of bacilli in the center. Under a low-power lens these depressions are seen to be surrounded by a radiating zone composed 
of two or more layers, outside of which is a zone of a singlelayer, from which amoeba-like processes extend upon the surface of the gelatin. These processes are constantly undergoing changes in their form and position. The young colonies deep down in the gelatin are somewhat compact, and rounded. Later they form irregular, radiating masses, and simulate the superficial colonies. It is difficult to deseribe all the forms which the Bacillus proteus takes in the various stages of its growth on gelatin plates. When the consistency of the medium is more solid, as in $10 \%$ gelatin, the liquefaction and migration of surface colonies are more or less retarded. In gelatin-stick cultures the growth is less characteristic-liquefaction takes place rapidly along the line of puncture, and in a short time the entire contents of the tube are liquefied.

Potato. A dirty yellowish growth appears.

Serum. It is stated that some strains will liquefy congealed serum.

Bouillon. It produces a uniform cloudiness in the liquid. In some cultures a pellicle is formed. It ferments dextrose and saccharose with the formation of gas but it does not ferment lactose. ${ }^{1}$

Milk. Milk is coagulated.* The reaction becomes more acid.

Life conditions and properties. Bacillus proteus is an aërobe and facultative anaërobe. It grows at room temperature. Its maximum growth seems to occur at about $24^{\circ} \mathrm{C}$. but it multiplies readily at $37^{\circ} \mathrm{C}$. It produces a ferment which liquefies gelatin and dissolves coagulated casein. It produces indol and phenol. It multiplies in urine decomposing urea.**

${ }^{1}$ Smith. The Wilder Quarter Century Book, p. 212.

* There is a wide discrepancy in the findings of different workers on this point. It is possible that different strains may act differently.

** Horton Smith (Jour. of Path. and Bact.) has described an organism as Bacillus proteus urinae which he isolated from a case of cystitis. It grew aërobically on all the ordinary media and was also a facultative anaërobe. It grew more rapidly at a temperature of $37^{\circ} \mathrm{C}$. It resembles very closely $B$. vulgaris. It was pathogenic. for guines, pigs. 
Schnitzler ${ }^{2}$ speaks of its being the eause of meat poisoning. Wesenberg ${ }^{3}$ was able to isolate Bacillus proteus from decomposing meat which had caused serious illness in a large number of people. The poison may be a cleavage product resulting from the decomposition of the meat rather than a specific toxin elaborated by this bacillus.

Pathogenesis. Large doses injected into animals may give rise to localized abscesses. In man it has been found apparently as the etiological factor in cystitis and pyelonephritis.

${ }^{2}$ Schnitzler. Centralbl. f. Bakt., Bd. VIII (1890) p. 789.

${ }^{3}$ Wesenberg. Zeit. f. Hyg., Bd. XXVIII (1898) p. 484. 


\section{CHAPTER XIX.}

\section{BACTERIACEAE.}

\section{GENUS PSEUDOMONAS MIGULA.}

General discussion of the genus. The genus Pseudomonas includes the slender rod-shaped motile organisms which have polar flagella. The number of flagella at each pole varies from 1 to 10 or more. The species in this genus are included by the earlier writers in the genus Bacillus. Migula describes about 77 species under this genus only one of which is known to be of any pathogenic significance. The organisms belonging to the pseudomonas are widely distributed in nature, having been isolated from soil, water, and from the intestines of animals.

\section{PSEUDOMONAS PYOCYANEUTS MIGULA.}

Synonyms. Bacillus pyocyaneus Gessard; Bacterium acruginosum (Schroeter); bacillus of green or blue pus.

Place in nature. This organism, which is the cause of the occasional green or blue discoloration of surgical dressings, was isolated by Gessard. ${ }^{1}$ At first it was not thought to possess any pathogenic properties and was considered as a saprophyte. Ledderhose ${ }^{2}$ studied it experimentally on animals but its real etiological relation to definite morbid conditions was pointed out by Charrin. ${ }^{3}$ Lartigau ${ }^{4}$ has studied it in its relation to an epidemic of dysentery in man. It has often been found in the bacteriological examination of various lesions in different species of animals. In rabbits, even when subcutaneous inoculation is resorted to, the systemic symptoms pre-

\footnotetext{
${ }^{1}$ Gessard. La pyocyanine, Thèse de Paris, 1882.

${ }^{2}$ Ledderhose. Deutsche Zєit. f. Chirurgie, Bd. XXVIII (1888).

${ }^{3}$ Charrin. La maladic pyocyanique. Paris, 1889.

${ }^{+}$Lartigau. Jour of Exp. Med., Vol. III (1898) p. 595.
} 
dominate, and it is in this animal that the disease is presented in its most typical form. The symptoms generally noted are diarrhoea, albuminuria, fever, and in the most chronic cases, cachexia and paralysis, which Charrin considers of a perfectly characteristic type, and in which the hind quarters are the ones most frequently involved. The paralysis is essentially spastic in nature. At autopsy the animals show congestion of the mucous membrane of the intestine and usually small hemorrhages in the various viscera, but more constantly in the intestinal walls. Schaefer, ${ }^{5}$ who earried on his experiments with the dog, arrived at results not unlike those obtained by Charrin. Cadeac, ${ }^{6}$ shortly after the publication of Charrin's

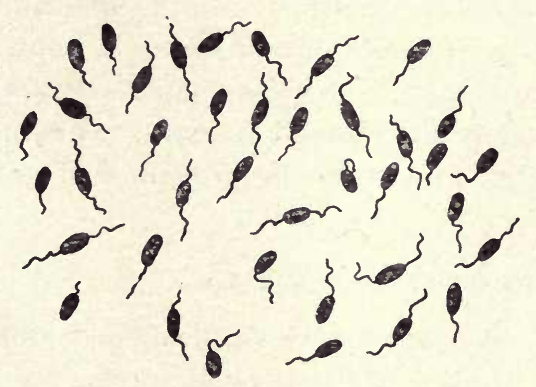

Fig. 74. Pseudomonas pyocyaneus. much enlarged. results, reported a case of spontaneous pyocyaneus infection in a dog. Since this there has been an abundance of experimental evidence which is essentially confirmatory of the conclusions of Charrin, Ledderhose and Schaefer. It has been found to be widely distributed in nature, occurring on the skin, in feces of animals and in purulent discharges.

Morphology. Slender rods from 0.3 to $1 \mu$ broad and from 2 to $6 \mu$ long; frequently united in pairs or in chains of four to six elements; occasionally growing out into long filaments and twisted spirals. It is actively motile, a single flagellum being attached to one end. It does not form spores.

Staining. It stains with the ordinary aniline colors; does not stain with Gram's solution.

${ }^{3}$ Schaefer. Inaug. Diss., Berlin, 1891.

${ }^{6}$ Cadeac. Comp. rendu de la Soc. de Biol., n. s. Vol. II (1890) p. 41. 
Cultivation. Pseudomonas pyocyaneus grows readily on the ordinary eultural media at the body temperature.

Agar. On the surface of agar a wrinkled, moist, slightly greenish-white layer is developed within 24 to 48 hours, while the medium itself becomes bright green. Later the color becomes much darker and is changed to a bluish green or almost black color.

Gelatin. In gelatin this organism develops colonies quite rapidly. The medium becomes a fluorescent green in color. The gelatin begins to liquefy in from 2 to 3 days and by the end of a week it is usually entirely liquefied. The surface colonies have a dark greenish center surrounded by a more delicate radiating zone. In stick cultures liquefaction begins at the surface in the form of a funnel and gradually extends downward. Later the liquid gelatin is separated from the solid by a horizontal plane. The gelatin near the surface has a greenish-yellow color.

Potato. On potato, a rusty brown growth appears, which is usually profuse. This changes later from a brown to a green color after lightly touching it. This has been referred to by Paul Ernst as the chameleon phenomenon.

Bouillon. This medium becomes a greenish color, especially near the surface. The growth appears as a more or less flocculent sediment. This medium gives off a peculiar sweetish odor.* In bouillon containing glucose, lactose or saccharose, the liquid becomes more alkaline and no gas is formed.

Milk. Milk becomes yellowish green in color. The casein is precipitated. In old cultures the casein may be digested.

Life conditions and properties. Pseudomonas pyocyaneus is an aërobe. In the presence of air it grows on the ordinary culture media at a temperature of from 20 to $37^{\circ} \mathrm{C}$. The blood temperature is more favorable. It liquefies gelatin and produces a very pronounced pigment. In old cultures this

* Because of this odor Sternberg designated this organism the "honey bacillus" in his report on yellow fever. The odor appears in cultures on all the media but it seems to be more pronounced in bouillon. 
is pronounced on the surface but upon agitation the brilliant color appears throughout. There.are two pigments produced, one a fluorescent green which is produced by other fluorescent bacteria. ${ }^{\top}$ It is soluble in water but not in chloroform. A second pigment, pyocyanin, which is of a bluish color, is also produced. It is soluble in chloroform. This pigment differentiates Pseudomonas pyocyaneus from other fluorescent bacteria. In addition to the ferment which causes liquefaction of gelatin there is also one which has been named "pyocyanase," and which has the power to dissolve bacteria. It has been stated that it insures some protective power when injected into animals. It has been used locally in case of diphtheria in children. Park does not consider it of greater value than other cleansing preparations in diphtheria.

Resistance. This organism does not produce spores. It is readily destroyed by the usual disinfecting solutions. It is killed at a temperature of $60^{\circ} \mathrm{C}$. for 10 minutes.

Pathogenesis. This organism is pathogenic for pigeons, guinea pigs and rabbits. Pigeons are especially susceptible.

${ }^{7}$ For a study of fluorescent bacteria, see Jordan, Botanical Gazette, Vol. XXVII (1899) p. 19. 


\section{CHAPTER XX.}

HIGHER BACTERIA AND FUNGI PATHOGENIC FOR ANIMALS.

General consideration. In the study of animal diseases a number of morbid conditions have been found which were produced as a result of the invasion of the tissues with certain organisms belonging to plant life more complex in structure than the lower bacteria. There is considerable confusion in the classification of these organisms. Some of the forms placed by Migula in the higher bacteria are classed by others among the fungi. Because of this confusion and the very few species that require consideration here, the organisms will be referred to in the genera under which they have been described without further attempt at classification.

The higher bacteria seem to stand in the process of development between the lower bacteria and the more highly developed fungi. In this connection it is important to recognize that certain bacteria such as those of tuberculosis, diphtheria, glanders and other forms in which branching sometimes occurs, are considered by a few writers as belonging to the streptothrices. The genera more commonly recognized as containing pathogenic forms are defined as follows:

\section{LEPTOTHRIX.}

This genus includes those forms which appear as simple threads without branches.

The leptothriches have been found in lesions of the mouth in the human subject. They have been cultivated only with difficulty. The genus seems to have little or no pathogenic significance for the lower animals.

\section{$\triangle$ CTINOMYCES.}

The actinomyces include those organisms which grow in the form of threads with true branching. They are charac- 
terized when growing in tissues by the formation of granules which are stellately arranged threads projecting outwardly with the ends club-shaped.*

The actinomyces are the most important of the higher bacteria. They produce the disease known as actinomycosis which affects a number of species of animals including man. Actinomyces seem to have been first observed by von Langenbeck in 1845 .

\section{CLADOTHRIX.}

This genus contains the threadlike forms in which false branching may be recognized. By false branching is meant an appearance resulting from the fragmentation of threads. The terminal cell breaks away from the main stem, is set at an angle by the elongation of the thread itself, and, as both continue dividing, the simulation of true branching is produced. "These forms occur largely in water and are not pathogenic for animals.

\section{ACTINOMYCES BOVIS BOLLINGER.}

Place in nature. This species was discovered in cattle by Bollinger** in 1877. It was given the name $A c$ tinomyces or "ray" fungus by the botanist Harz. Rivolta in 1878 described it as Discomyces bovis. In 1878, a similar organism was discovered by Israel $^{1}$ in

* Those forms which do not produce rosettes with club shaped rays in the tissues have been described as belonging to a separate genus, namely, Streptothrix or Nocardia. If it is considered that these forms constitute a different genus from actinomyces, Nocardia should be adopted. Streptothrix was given to a genus of hyphomycetes by Corda in 1839 and the name is still used.

** Bollinger, Deut. Zeit. f. Thi€rm€d., Bd. III (1877) p. 41. The disease produced in cattle by this organism had been known by a number of names, that of osteosarcoma being the most common. Bollinger, Perroncito and Johne made extensive investigations relative to the organism and the lesions it produces.

${ }^{1}$ Israel. Virchow's Archiv, Bd. LXXIV (1878) p. 15. 
the human subject. Bostroem ${ }^{2}$ has given detailed descriptions of the "ray fungus." Wolff and Israel, ${ }^{3}$ who have studied its biology most extensively, found that it grew sparingly under aërobic conditions, but more vigorously in the absence of atmospheric oxygen. Wright ${ }^{4}$ described cultures of actinomyces from 13 bovine and 2 human cases and concluded they were the same species. They grow as aërobes. Actinomyces bovis grows quite vigorously in glucose agar, a few millimeters below the surface. Its maximum growth is between 5 and $10 \mathrm{~mm}$. in the depth of the medium. It develops

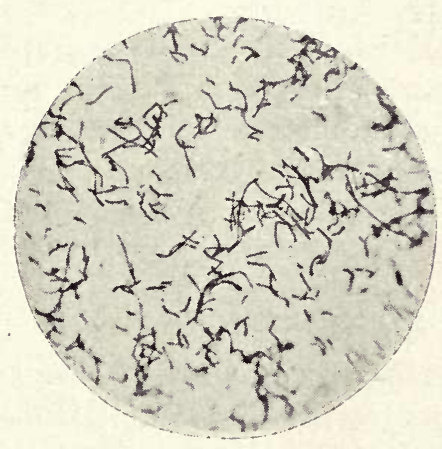

Fig. 75 .

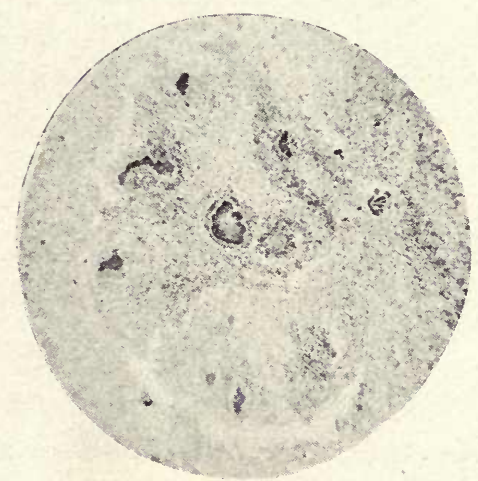

Fig. 76.

Fig. 75. Actinomyecs bovis. Photograph of filaments from an agar culture. $\times 410$ (Pickens).

Fig. 76. Actinomyces bovis. Photograph of a section of actinomycoltic tissue showing small clumps of the fungus.

somewhat feebly on the surface of agar. In alkaline bouillon heavy flocculent masses appear which settle to the bottom of the tube. It is not readily transmitted by inoculation. It

${ }^{2}$ Bostro€m. Beitr. z. path. Anat. u. allg. Path., Bd. IX (1891) p. 1.

${ }^{3}$ Wolff and Israel. Virchow's Archiv, Bd. CXXVI (1891) p. 11.

${ }^{4}$ Wright. Publications of the Mass. General Hospital, Vol. I (1905) p. 1. 
is stained by aniline gentian violet, carbol fuchsin and by Gram's method.

In the discharges of actinomycotic lesions the ray fungus may be detected as very fine yellowish granules. When examined microscopically, these appear as rosettes, sometimes showing central filaments with the terminal rays radiating apparently from a common center. They can be seen in the fresh preparation but frequently they appear with greater clearness if a few drops of a $10 \%$ caustic potash solution are added.

The natural habitat of Actinomyces bovis is thought to be on certain grasses, especially the barley (Hordeum murinum). It is quite widely distributed but the disease appears more frequently in some localities than in others. Its most common seats are in the jaw (lumpy jaw), in the tongue (wooden tongue) and in the lymph glands. The lesions, however, may occur in any organ. Assmann ${ }^{5}$ has collected 11 cases of generalized actinomycosis in cattle and hogs.

ACTINOMYCES PULMONALIS BURNETT.

Place in nature. In 1910, Burnett ${ }^{6}$ described an actinomyees (streptothrix) which he had isolated from the lesions in two bovine lungs which were thought by those making the post mortem to be tuberculous. He cbtained the organism in pure culture on potato. It grew, however, in bouillon, forming at first a delicate membrane on the surface and minute whitish spherical colonies in the depth and clinging to the sides of the tube. These are composed of long branched filaments. On agar minute translucent colonies appeared. The growth becomes thicker and finally presents a flat whitish raised mass. On glycerin agar its growth was less vigorous than on plain agar. On potato the young colonies are convex in form and translucent. Later they become confluent, the surface covered with a much convoluted, lemon yellow growth which later becomes chalky white, this being due to short threads growing

${ }^{5}$ Assmann. Deutsche tierärtz. Wochenschrift, 1904.

${ }^{6}$ Burnett. Ann. Rept. N. Y. State Vet. College, 1910, p. 167. 
into the air. These threads under the microscope are seen to consist of many spore-like bodies resembling streptococi. The growth becomes darker with time. Milk is coagulated in a few days and the coagulum completely digested. Litmus milk

Fig: 77. Actinomyces pulmonalis. A photogroph from a preparation from a colony in the condensation water of an agar culture, 5 days old. Stained with carbol fuchsin. $\times 365$ (Burnett).

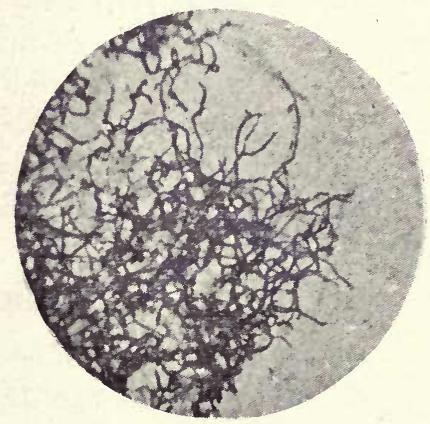

remains clear. The cultures especially those on potato have a pronounced musty odor.

It is not pathogenic for rabbits or guinea pigs inoculated in the ear vein or abdominal cavity.

This organism is exceedingly interesting inasmuch as the lesions which it produces in cattle are liable to be mistaken for tubercle and, as already stated, the two cases from which it was first isolated were first diagnosed as tuberculosis. In these cases the lungs were the only organs examined.

\section{ACTINOMYCES FARCINICA.}

Synonyms. Nocardia farcinica Trevisan 1889; Streptothrix farcinica Rossi-Doria 1891; bovine farcy.

Place in nature. In 1888 , Nocard ${ }^{7}$ discovered a disease of cattle in Guadaloupe, "Farcin du boeuf," to be due to an actinomyces (streptothrix). This organism has frequently been described from the lesions in the lungs which simulated tuberculosis. Flexner ${ }^{8}$ and Morris and Larkin ${ }^{9}$ have de-

${ }^{7}$ Nocard. Ann. de l'Inst. Pasteur, Vol. II (1888) p. 293.

${ }^{8}$ Flexner. Jour. Exp. Med., Vol. III (1898) p. 435.

${ }^{\circ}$ Morris and Larkin. Proc. of N. Y. Path. Soc., March 1899. 
scribed interesting cases of this kind. The organism of "bovine farey" has been studied in pure culture. On agar the colonies are small, whitish, opaque, raised and irregular. In bouillon it grows in floceulent masses which settle to the bottom leaving the liquid clear. It grows best at about $37^{\circ} \mathrm{C}$. Morphologically this organism is slender and extensively branched. In culture media the filaments are short and rather plump. It takes the Gram stain. In old cultures it is somewhat acid fast. It is pathogenic for guinea pigs in which nodules somewhat resembling tubercles are produced by intraperitoneal injections.

\section{ACTINOMYCES CAPRAE.}

Synonyms. Streptothrix caprae.

Place in nature. In 1899, Silberschmidt ${ }^{10}$ described an actinomyces which he isolated from a disease closely resembling tuberculosis in a goat. Morphologically, it resembles more closely bacteria than other forms of actinomyces. It grows readily upon the more common media. In bouillon, it develops on the surface, forming a pellicle which finally settles, the broth remaining clear. It is a facultative aërobe. In agar it develops in from two to three days. It grows more luxuriantly on glycerin agar. Lignières and Spitz ${ }^{11}$ describe three forms of actinomyces in cattle.

\section{ACTINOMYCES IN MAN.}

Actinomyces has been described in a number of eases in the human family. There does not seem, however, to be much if any difference in the ray fungus from the ordinary actinomyces of man and that of cattle. Vincent in 1894 cultivated an actinomyces from cases of madura foot disease in man. This disease occurs in certain tropical countries and has been termed Actinomyces madurae, ${ }^{12}$ or streptothricosis in man. MacCallum ${ }^{13}$ describes Actinomyces asteroides which causes

${ }^{10}$ Silberschmidt. Ann. de l'Inst. Pasteur, Vol. XIII (1899) p. 841.

${ }^{11}$ Lignières and Spitz. Actinobacillose. Buenos Aires, 1902.

${ }^{12}$ Vincent. Ann. de l'Inst. Pasteur, Vol. VIII (1894) p. 129.

${ }^{13}$ MacCallum. Centralbl. f. Bakt., Bd. XXXI (1902) p. 529. 
abscesses in man. A considerable number of non-pathogenic species have been described from air and water, some of which are chromogenic. Howard, ${ }^{14}$ in studying actinomyces isolated from the central nervous system, found that it may be both aërobic and anaërobic. He also found actinomyces in commercial vaccines.

\section{SACCHAROMYCES.}

The significance of the saccharomyces (yeasts) is largely restricted to their power of fermenting sugars, and they are of value in those arts requiring such fermentation. Few species are known to be parasitic or to produce lesions in the animal body.

\section{SACCHAROMYCES FARCIMINOSUS.}

Synonyms. Cryptococcus farciminosus; Blastomyces farciminosus.

Place in nature. This organism is the cause of the disease known as epizootic lymphangitis in horses..$^{15}$ It is found in the lesions of this disease both between the cells in the plasma, and partly enclosed in the pus cells. It measures from 3 to $4 \mu$ in diameter and in unstained preparations it can be seen with the oil immersion. It has been placed in numerous classifications. Tokishige ${ }^{16}$ was the first to place it among the saccharomyces. Rivolta deseribed it in 1873 . It can be stained with carbol fuchsin and other dyes. The disease which it produces is somewhat widely distributed in France, in Sweden (where it is known as Norlander Rotz), in Russia, Italy, Egypt and Japan. Pearson found it in the United States. This is important because the disease which it produces may be somewhat easily mistaken for farcy or skin glanders.

${ }^{14}$ Howard, Jour. of Med. Research, Vol. IX (1903) p. 301.

${ }^{15}$ Mettam. The Veterinary Record, Vol. XVI (1904) p. 834.

Pallin. Epizootic Lymphangitis. London, 1904.

Pearson. Circular No. 8, Penn. State Livestock Sanitary Board, 1907.

${ }^{16}$ Tokishige. Centralbl. f. Bakt., Bd. XIX (1896). 
Page, Frothingham and Paige ${ }^{17}$ have described a sporothrix they isolated from specimens taken from horses supposed to be suffering from epizootic lymphangitis. It differs markedly from Saccharomyces farciminosus described as the cause
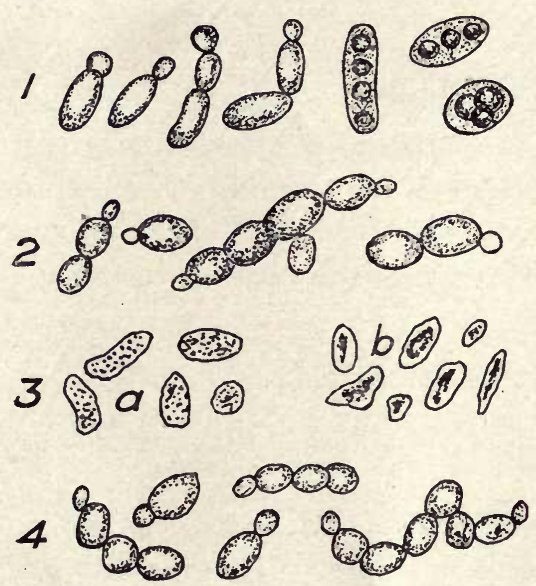

Fig. 78. Yeasts; 1, spore bearing yeast, $\mathbf{S}$. pasteurianus; 2 , yeast, $\mathbf{S}$. ellipsoidens; 3 , a, old form, b, dead forms; 4, S. cerevisiae. (After Marshall).

ganism, Sacharomyces dermatitidis, from a fatal case of dermatitis in man. Gilchrist, Ophuls, and others described similar organisms as the cause of lesions in the human subject.

\section{HYPHOM YCETES.}

The hyphomycetes are closely related to the higher algae. Perhaps as Jordan states they should be regarded phylogenetically as forms that have lost the chlorophyl they once possessed as the result of taking on a saprophytic or parasitic

${ }^{17}$ Page, Frothingham and Paige. Jour. Med. Research, N. S. Vol. XVIII (1910) p. 137.

${ }^{18}$ Busse. Centralbl. f. Bakt., Bd. XVI (1894) p. 175. 
mode of life. The group is characterized by a filamentous growth. The filaments are terminated by hyphae. The filaments growing together, more or less interlacing, form the mycelium. In this group belong the moles, and in their cultivation they prefer an acid to an alkaline medium.

Comparatively few of the members of this class are eapable of growing in living animal tissues. Plaut ${ }^{19}$ has divided the fungi pathogenic for man into three groups according to their pathogenic effects: 1 , the moles in their narrowest sense (mucor and aspergillus) ; 2 , fungus of thrush; and.3, the fungi attacking the skin. The disease in the mouth of children known as thrush is due to Oidium albicans. Favus, a disease attacking the hairy portions of man and animals, is due to Achorion Schoenleinii. Ringworm, a disease of the skin and hair, occurring most often in children, but also in animals, is caused by members of this family.

GENUS ASPERGILLUS.

The members of this genus are widely distributed and there are a number of species, several hundred having been described. Of these only two or three seem to be important in the production of animal diseases and of these fumigatus is the most important. It has been found to eause lesions in birds and it has also been found associated with morbid tissues in other animals. It grows readily on culture media. It produces conidiophores, the enlarged tip of which is hemispherical and varies from 8 to $20 \mu$ in diameter. It is readily isolated from the lesions in which it cecurs by cultivation on artificial media. It is an aërobe and according to Mohler and Buckley it grows best at a temperature of from 35 to $40^{\circ} \mathrm{C}$. Spores are not formed below $20^{\circ} \mathrm{C}$.

Pearson and Ravenel ${ }^{20}$ have described an interesting case of pneumonomycosis in a cow due to Aspergillus fumigatus. In their ease the aspergillus showed fruit hyphae and spores

${ }^{19}$ Plaut. Kolle and Wassermann's Handbuch, Bd. I, p. 549.

${ }^{20}$ Pearson and Ravenel. The University Medical Magazine, Aug. 1911. 
in the tissues. Pulmonary mycosis in birds has been described by Mohler and Buckley. ${ }^{21}$ Several observers have suspicion of the other species of the aspergillus, especially $A$.

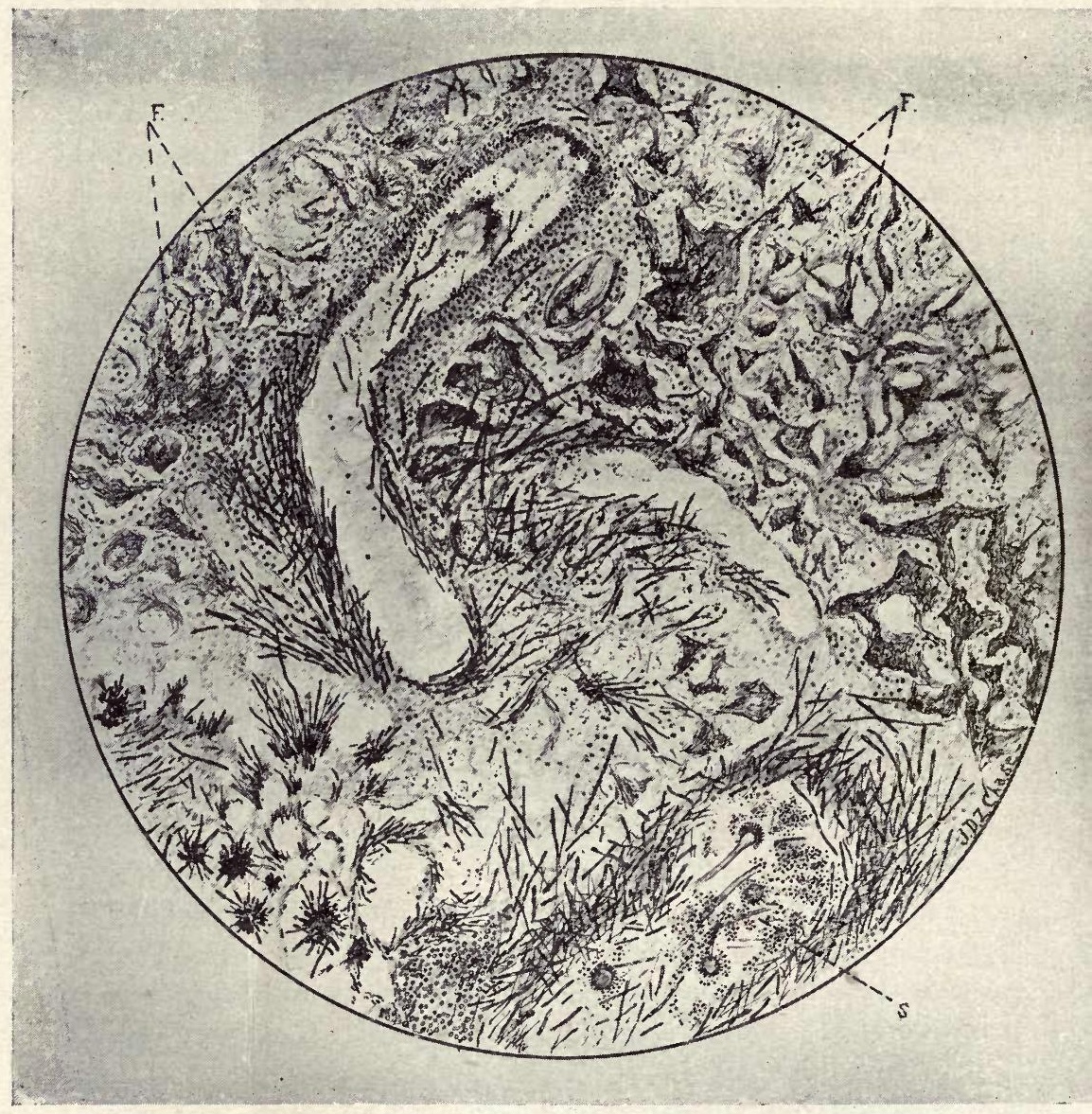

Fig. 79. Aspergillus fumigatus. A photograph of a section of a cow's lung showing A. fumigatus in fruit (Pearson \& Ravenel).

${ }^{21}$ Mohler and Buckley. Ann. Rept. B. A. I., U. S. Dept. Agric., 1903.

Renon. L'Etude sur l'aspergillose chez les animaux et chez l'homme, 1897. 
flavus and $A$. niger, as bearing some etiological relation to other diseases in animals, particularly certain forms of meningitis. Virchow ${ }^{22}$ described three cases of pneumonomycosis. The work of Grohe, ${ }^{23}$ Block, ${ }^{24}$ Grawitz ${ }^{25}$ and others has greatly extended our knowledge of the hyphomycetae in their relation to disease.

Rothwell ${ }^{26}$ found both Aspergillus niger and A. fumigatus are capable experimentally of producing lesions that resemble one another histologically, but that $A$. fumigatus caused the death of the animals whereas $A$. niger did not. He also found that both species were capable of germinating in the living tissues. He concludes that $A$. fumigatus is more pathogenic than $A$. niger but that the latter is capable of producing lesions in living animal tissues.

Torula infections. Frothingham ${ }^{27}$ discovered a tumorlike lesion in the lung of a horse caused by a torula. He describes the organism as follows.

"In wort gelatin there was an extensive and ever-increasing surface growth which sank with the gradual liquefaction of the medium.

"Wort is the best medium for growth.

"The organism is facultative anaërobic.

"No mycelia were observed.

“'There were many 'resting cells'.

"It was pathogenic for guinea pigs."

\section{TRICHOPHYTON TONSURANS.}

Place in nature. This is the cause of "ring worm" in man, horses, cattle and dogs. It rarely if ever occurs in sheep and hogs. It is said to be very common in calves. Morpho-

${ }^{22}$ Virchow. Virchow's Archiv, 1856.

${ }^{23}$ Grohe. Berliner klin. Woch., 1870.

${ }^{24}$ Block. .Zur Kennt. der Pilzbildung in der Geweben des thierschen Organismus. Inaug. Dis., Greifswald, 1870.

${ }^{25}$ Grawitz. Virchow's Archiv, Bd. LXXXI (1880) p. 355.

${ }^{28}$ Rothwell. Jour. of Path. and Bact., Vol. VII (1900) p. 34.

${ }^{27}$ Erothingham. The Jour. of Medical Research, Vol. VIII (1902) p. 31 . 
logically $T$. tonsurans consists of a mycelium about $4 \mu$ thick and spores (conidia), varying from 4 to $6 \mu$ in diameter which appear in short and longer chains. The mycelial filaments and the spores occur in the erusts on the skin and in the diseased hairs. The filaments branch at somewhat regular intervals. The spores are seen as rows of highly refractive round bodies. $T$. tonsurans is isolated with difficulty. It is cultivated according to Sabouraud more readily on a Beerwort medium composed of maltose 4 parts, peptone 2 parts, agar 1.5 parts and distilled water 100 parts. On this medium a vigorous growth appears. It liquefies gelatin forming a whitsh growth on the surface which is hard to break but beneath it has a yel-

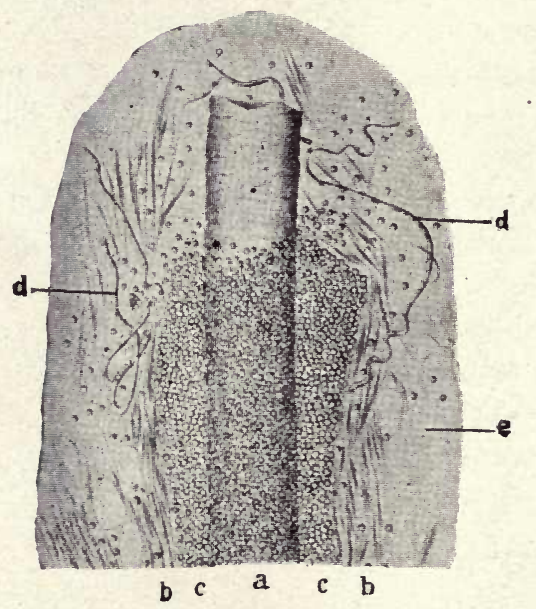

Fig. 80. Trichophyton tonsurans from a calf. a, hair; b, hair follicle; c, fungus about the hair; d, threads of fungus; e, epithelium. After Hutyra and Marek. guished as $T$. endothrix
or $T$. ectothrix, according as they are seen microscopically to occupy chiefly the interior or the exterior of the hair, respectively.

* Gruby described several varieties of fungi isolated from cases of ringworm. Comptes rendu, Paris, between the years 1841 and 1844 . a folded felty growth appears. It is either white, yellowish or reddish in color.

This species first described by Gruby * has been more or less subdivided. According to some writers, true ringworm is caused by moulds of two kinds, the first being the Microsporon Audouini, so called by Gruby, the other belonging to the family of the Trichophyt. The trichophyton fungi are distinlowish color. On potato 
Neumann ${ }^{28}$ has described the trichophytons eausing ringworm in domestic animals. In addition to these he found Microsporum Audouini Gruby to be one of the causes of ringworm. The trichophytons which he discovered as the cause of ringworm are briefly described as follows.

Trichophyton mentagrophytes (Ch. Robin). This is a pyogenic trichophyton, producing white cultures (Sabouraud). The mycelium may be divided into spores measuring 5 to $6 \mu$ in diameter but of very irregular length, particularly towards the periphery of the hair (from 2 to $3 \mathrm{~mm}$. up to 10 or 11 mm.).

Trichophyton flavum (Bodin). This tricophyton produces yellowish, wrinkled cultures (Sabourand). The mycelium may be divided into ovoid irregular cells from 5 to $6 \mu$ in size; occasionally some may be found to be $11 \mu$ in length.

Trichophyton equinum (Gedoelst). This consists of an intrapilary mycelium composed of oval spores of from 4 to $6 \mu$ in length and 2 to $4 \mu$ in width. Surrounding the hair are ramifying mycelial filaments with numerous septa and few spores.

Trichophyton verrucosum (Bodin) var. equi. This is a faviform trichophyton producing brown, heaped-up, irregular cultures (Bodin). The mycelium rapidly breaks up into spherical spores with a double contour. Endo-ectothrix.

Trichophyton verrucosum (Bodin) var. asini. This is a form of trichophyton producing gray cultures. The mycelium breaks up into regular chains of spherical cells.

Microsporum Audouini. The mycelium of this fungus found in the hair appeared as axial bundles of filaments, 2 to $2.5 \mu$ in diameter with well marked septa. These filaments give off at right angles fine branches which pass to the exterior where they produce conidia. They grow around the hair from its base to a height of from 1 to $3 \mathrm{~mm}$. They render the hair grayish in color and fragile.

${ }^{28}$ Neumann. Jour. of Comp. Path. and Therap., Vol. XVIII (1905) p. 193. 
Emery ${ }^{29}$ found that Microsporum Audouini acts both mechanically and chemically in the production of ringworm. The mechanical action is produced chiefly by the splitting apart of the component parts of the hair and by pressure exerted on the shaft and bulb. The chemical action is due to the effect of a toxin that causes slight folliculitis.

Trichophyton gypseum (Sabouraud). Sabouraud ${ }^{30}$ first isolated this organism from horses. It also has as its primary host the cow, dog, pig and possibly other animals. He cultivated it on beef wort agar and maltose peptone agar. The mycelial hyphae were divided transversely. In the young stage, septa are not visible near the ends which are rounded. The hyphae are irregularly branched. Many short branches are given off. Fitzgerald describes this organism in considerable detail and gives illustrations of the lesion it produced on the hand and also of the fungus. M'Fadyean ${ }^{31}$ studied the cultural characters of $T$. tonsurans and found it produced an enzyme which liquefied gelatin, and that the fungus would grow on a medium consisting entirely of keratin.

\footnotetext{
${ }^{29}$ Emery. Jour. of Path. and Bact., Vol. VII (1900) p. 400.

${ }^{30}$ Sabouraud. Les Trichophyties humaines. Paris, 1894.

${ }^{31}$ M'Fadyean. Jour. of Path. and Bact., Vol. III (1895) p. 176.
} 


\section{CHAPTER XXI.}

\section{PROTOZOA, THEIR CLASSIFICATION AND SPECIES PATHO- GENIC FOR ANIMALS.}

Historical sketch. Our knowledge of protozoa has developed simultaneously with that of bacteria. Nothing was known of either until Van Leeuwenhoek made his observation on the existence of microscopic organisms. They were called Animalculae for many years. With the development of better microscopes and technique for the study of mieroorganisms, the Schizomycetes, unicellular plants or bacteria, and the Protozoa (first animals), or unicellular animals, were recognized and differentiated. The bacteria seem to have been more extensively studied although the protozoa have been classified and many families, genera and species described.

The protozoa are quite widely distributed in external nature. They are found in largest numbers where the elimate is warm and moist. Their functions have not been defined but it is known that some of them live on and in the body tissues and that among these there are certain species that produce morbid ehanges or disease in the host. Here as with bacteria, the disease produced in the host is secondary to the development of the parasite. In an elementary text of this kind it is neither possible nor would it be profitable to take up a detailed discussion of the classification and life history of protozoa. The fact should be brought to the attention, however, that there is in the external world,-in soil and water and on the mucosae of animals, - a vast multitude of microscopic forms belonging to the animal kingdom and that certain of these are parasitic, and a few pathogenic, for domesticated animals and for man. For a more extended study of Protozoa the student is referred to the general and more specific 
treatises on that subject, ${ }^{i}$ and to the special literature, which is very large.

Characterization. Protozoa ${ }^{2}$ include all forms of animals which consist throughout their entire life of a single cell or of a colony of single cells. Of the protozoa as a class it may be said that the.individuals of each species are composed of a cytoplasm and a nucleus or nuclear substance. In the different species or groups of protozoa there are many variations through which the individual passes in its more or less complicated life-cycle. The cytoplasm varies in composition and structure according to its environment. It is essentially proteid in nature. It is more or less fluid but because of difference in the density and solubility of its substance it may appear granular, alveolar or exhibit distinct lines. These may be observed in properly fixed and stained preparations. There are usually an outer zone and a central part of the protoplasm. The pseudopodia extend from the outer layer. The organs of locomotion are flagella and cilia. There are many properties and variations associated with the cytoplasm that have been observed in the careful study of the life history of different species. Protozoa always have a nucleus or nuclear substance. This usually contains chromatin which consists largely of nuclein and which appears when stained as small granules, masses or rods. There are in the nucleus somatic and generative chromatin and in the flagellates another variety of chromatin which produces the locomotor apparatus and which is known as the locomotor nucleus.

${ }^{1}$ The following books are especially valuable for the study of protozoa.

Calkins. Protozoölogy, New York.

Doflein. Die Protozoen als Parasiten und Krankheitserreger, Jena.

Ziemann. Ueber Malaria und andere Blutparasiten, Jena.

Laveran and Mesnil. Trypanosomes and Trypanosomiasis. Trans. by Nobarro, Chicago.

${ }^{2}$ There is here, as with bacteria, difference of opinion among authors as to where these organisms should be placed. See foot note, page 8 . 
The protozoa possess the functions of irritability, nutrition, respiration and reproduction. They react in certain characteristic ways towards stimuli of a chemical, mechanical or electric nature. Protozoa receive nourishment by the ingestion or digestion of food and the exeretion of effete matter. Some species, especially the pathogenic forms, seem to absorb food in the liquid form directly through the body wall. Most of them, however, take solid food such as small animal or vegetable organisms or bits of organic matter, through more or less definite parts of the body. It is supposed that the contractile vacuole which protozoa contain has a respiratory as well as an excretory function. The interchange of gases is constantly going on either through this vacuole or by osmosis through a part of the cell wall. Protozoa reproduce themselves through cell divisions and its various modifications. The simplest variety is true cell division which may be either longitudinal or transverse by either the direct or indirect method. In some species there is a budding division which consists in a small piece breaking off from the body and forming a new individual. The reproduction by division or budding is interrupted at certain times in the history of each organism.

The development cycle of the protozoan consists in the changes that take place in its growth from one act of fertilization to another. ${ }^{3}$ According to Calkins, the developmental cycle as a whole should be considered the individual and should be made the basis for the whole rather than for any part or parts of it, for many protozoa pass through the sexual part of their life cycle in one host and the asexual part in another.

Cultivation of Protozoa. Certain protozoa may be cultivated en masse in aquaria jars containing in the water bacteria and the minute plants and animals usually kept in stock aquaria. Pure cultures have recently been obtained of cer-

${ }^{3}$ In conjugation when union is transient or when union is permanent and likened to the process of the fecundation of the ovum. 
tain protozoa. Novy and Knapp ${ }^{4}$ have cultivated flagellates, occurring in the blood in the condensation fluid of blood agar. According to Park, certain ameba may be cultivated in the following way: From the material containing ameba a loopful is removed with a platinum wire and drawn over the surface of the following medium poured in sterile petri dishes: Agar one part, tap water 90 parts, ordinary nutrient broth 10 parts, mixed and sterilized in the regular way.

Protozoa are studied microscopically in the fresh condition by spreading the material containing them on slides. The oil immersion objective is required. Permanent preparations are made by allowing smears to dry and then fixing in some fixing solution, rather than heat as for bacteria. Schaudinn recommended hot $\left(50^{\circ} \mathrm{C}\right.$. $)$ alcohol sublimate or saturated sublimate to which $5 \%$ glacial acetic acid has been added. The preparation should remain in it a few seconds and then it should be washed one-half hour in $60 \%$ iodine alcohol and then placed in $70 \%$ alcohol. They are then rinsed in water and stained. For this the bacterial stains may be used, also thin Delafield's hematoxin, picro-carmine, Mallory's eosin methylene blue and others.

Protozoa are affected injuriously by heat, electricity, light, moisture and chemical disinfectants. They may live in intense cold for a long time but most of them are destroyed by a moderate heat. Rather strong induction shocks will kill most protozoa. When protozoa are encysted while drying they will endure long periods of dessication. They are destroyed by disinfectants.

Pathogenesis. The diseases producing protozoa perform their harmful action either mechanically or by the direct destruction of the special tissues which they find suitable for food. As a rule, so far as known, they do not produce toxic substances. Infection with protozoa is often accompanied by some of the lower forms of animal life, acting as intermediate hosts or direct carriers of the organism.

${ }^{4}$ Novy and Knapp. Jour. Am. Med. Asso., Vol. XLVII (1906) p. 215. Also Science, Vol. XXV (1907) p. 815. 
Classification of Protozoa. In the classification of protozoa their morphology and their physiology are considered. Physiologically, they are grouped according to their ability to exist on dead or living organic matter into saprophytic and parasitic forms. The parasitic forms of the protozoa are again divided into commensals and pathogenic forms. The classification of protozoa morphologically is still in an unsettled stage. New discoveries are being made that result in constant changes in their classification. The following classification of protozoa is taken from Park's work, Pathogenic Bacteria and Protozoa, and is practically the same as Calkin's classification given in Osler's Modern Medicine. In the further discussion only those forms pathogenic for domesticated animals with brief references to a few affecting man will be considered.

\section{CLASSIFICATION.}

Phylum. Protozoa.-Unicellular animal organisms which reproduce by division or spore-formation; solitary or united in colonies; free-living or parasitic.

Sub-Phylum I. Sarcodina.-Protozoa with changeable protoplasmic processes or pseudopodia.

Class I. Rhizopodia.-Sarcodına with pseudopodia in the form of lobose or reticulose processes, with or without shells.

Sub-class. Amoebida.-Pseudopodia lobose.

Order 1. Gymnamoebida.-Naked amoeboid forms with lobose pseudopodia. Here are placed a few parasitic forms belonging to the genera Amoeba, Entamoeba, and Leydenia.

Order 2. Thecamoebida.-Shell-bearing amoeboid forms with lobose pseudopodia. One parasitic form, genus Allogromia, is placed in this order.

Sub-class. Foraminifera.-Divided into 10 orders; the various genera are salt water forms for the most part and are rarely parasitic.

Sub-class. Mycetozoa would be placed here were we to consider these forms as protozoa instead of fungi. Here are placed parasitic forms such as Plasmodiophora, Tetramyxa, Labyrinthula, and Nucleophaga. 
Class II. Heliozoa.-The genera are confined mainly to fresh water and are never parasitic. They are subdivided into four orders according to the nature of the skeleton.

Class III. Radiolaria.-Salt-water forms of protozoa, never parasitic.

Sub-phylum II. Mastigophora.-Protozoa with flagella.

Class I. Flagellata.-Small forms with from one to several flagella; with a strong tendency to form colonies.

Order 1. Monadida.-Minute forms with from one to three flagella. There is no definite mouth-opening and nutrition is holozoic, saprophytic, or parasitic. The parasites and commensals which belong to this order are species belonging to the genera Cercomonas, Herpetomonas, Piroplasma, Leishmania, and Trypanosoma (appendix Spirocheta).

Order 2. Choanoflagellida.-With collar-like processes surrounding the base of the flagellum; not parasitic.

Order 3. Heterommastigida.-With two or more flagella of dissimilar length; the genus Bodo is parasitic.

Order 4. Polymastigida.-The flagella are numerous and of similar or dissimilar size. Here are several ecto- and endo-parasitic forms belonging to the genera: Costia, Tetramitus, Trichomonas, Monocercomonas, Hexamitus, Lamblia, Polymastix, Lophomonas, Trichonympha, Pyrsonympha and Joenia.

Order 5. Euglenida.-Occasional parasites as Copromonas in frogs.

Order 6. Phytoflagellida.-Flagellates with coloring matter in the form of green, yellow or brown chromatophores. Frequently colonial. Here belong the most frequent sources of odors in drinking waters, the following genera being especially noteworthy: Dinobyron, Synura, and Uroglena, all colonial forms, with yellow chromatophores.

Order 7. Silicoflagellida.-A single genus of salt water mastigophora with latticed skeleton. Distephanus, parasitic on radiolaria.

Class II. Dinoflagellata.-Never parasitic.

Class III. Cystoflagellata.-Two genera of characteristic form. One, Noctiluca, is remarkable for the vivid phosphorescence which it causes. 
Sub-phylum III. Infusoria.-Protozoa with cilia.

Class I. Ciliata.-Cilia present at all times.

Order 1. Holotrichida.-The cilia are distributed over the surface, and there is no specialized oral apparatus known as the "adoral zone" consisting of cilia fused into "membranelles." Here are found some parasites belonging to the genera Ichthiophthirius, Buetschlia, Anophrys, Isothrica, Dasytricha, Opalina.

Order 2. Heterotrichida.-With cilia distributed over the general surface, and, in addition, a speclalized zone in the mouth-region. Here are several well-known parasitic forms belonging to the genera Nyctotherus, Balantidium, Entodinium, Ophryoscolex and Cycloposthium.

Order 3. Hypotrichida.-The cilia are limited to the ventral surface, and are frequently fused into specialized organs of motion and touch, the cirri. There are no strictly parasitic forms.

Order 4. Peritrichida.-The cilia are greatly reduced, in some cases to the adoral zone, but additional rings may be present. Several ecto-parasites belong here, especially the genera Spirochona, Kentrochona, Lichnophora, Cyclochaeta and Trichodina.

Class II. Suctoria.-Infusoria.-Infusoria with suctorial tentacles in the place of cilia in the young phases. They are frequently ectoparasites and the young of some genera, e. g., Sphaerophyra, are internal parasites in other infusoria.

Sub-Phylum IV. Sporozoa.-Protozoa without motile organs; reproduction by sporulation; always parasites.

Class I. Telosporidia.-Sporozoa in which the act of reproduction ends the individual's life, the entire protoplasm being used in forming spores.

Order 1. Gregarinida.-The young stages alone are cell parasites, the adult organisms living in fluids within the cavities of animal hosts. There are no human parasites.

Order 2. Coccidia.-Intracellular parasites, mainly in the epithelial cells of vertebrate and invertebrate hosts. Human parasites have been traced mainly to the genus Coccidium. Here also we should place Cyclasterion scarlatinale Mallory.

Order 3. Haemosporidia.--Sporozoa of small size living in the blood corpuscles of vertebrates. Human parasites belong to the genera Laverania and Plasmodium. 
Class II. Neosporidia.-Sporozoa in which the entire cell is not used at one time in forming spores, the latter developing while ordinary processes are carried on.

Order 4. Myxosporidia.-Neosporidia with spores containing polar capsules and anchoring threads. Here belong several genera of note, in that serious epidemics of lower animals are caused by them, e. g., Nosema-causing pébrine diseases in silkworm, Myxobolus, Myxidium, etc.

Order 5. Sarcosporidia.-Neosporidia in which the initial stages are passed in muscle cells of vertebrates. Cysts are formed with double membranes in which kidneyshaped reproductive elements are produced. The one genus occasionally parasitic in man is Sarcocystis.

Protozoan infection. The exogenous life of protozoan parasites is the life of the parasite outside of the usual host whether it is the primary or "intermediate" host. This is the most critical period in the entire life cycle of the parasite and the success of infection depends largely upon two of several factors, (1) dissemination of the spores and (2) infection of new hosts. In regard to the latter, many and diverse adaptations have arisen. The same general conditions hold with pathogenic protozoa affecting animals as with those attacking man. The environmental conditions which protozoan parasites have to meet and overcome are well stated in a principle by Manson ${ }^{5}$ and are quite as applicable for protozoa pathogenic for animals as they are for those affecting man. "The pathogenic protozoa are responsible probably for a very large number of diseases. Many appear to be able to pass directly from host to host, unaffected apparently by the atmospheric conditions they encounter on the passage; that of smallpox and of most of the exanthematous fevers probably belong to this category. Others, on the contrary, demand special climatic conditions. Such are the germ of scarlet fever, which does not spread in the tropies, and the germ of dengue which, conversely, does not spread in cold climates. That of the first is

'Albutt and Rolleston's System of Medicine, Vol. II, Part II, 1907. 
killed or paralyzed by heat; that of the latter by cold. Or, it may be, they do not find appropriate transmitters except in special climatic conditions. Many of the protozoa acquire the power of successfully invading the human body only after certain developmental changes, which take place after they leave their first host. Thus, according to Schaudinn, the germ of amebic dysentery has to pass through a sporulating stage before it becomes infective, and this stage is accomplished outside of the body and in conditions of tropical heat. Hence, amebic dysentery is a tropical disease. Other protozoan disease germs, notably those of malaria, yellow fever, trypanosomiasis, and relapsing fever, require an animal intermediary to remove them from the body of their original host, foster them during a necessary stage of development, and reimplant them in the human host. These animal intermediaries being tropical, the diseases they disseminate are also necessarily tropical.",

\section{GYMNAMOEBIDA.}

Although in man a number of disease producing ameba have been found, for example Ameba coli, ${ }^{*}$ but one species seems to have been discovered pathogenic for domesticated animals, namely Ameba meleagridis.

\section{AMEBA MELEAGRIDIS SMITH.}

This organism was discovered by Theobald Smith $^{6}$ in 1895 to be the cause of the very destructive disease of turkeys popularly known as blackhead and deseribed by him as infectious enterohepatitis. Smith found this organism in the diseased tissues of the caeca and liver.

Morphology. The most frequent appearance of the organisms is that of round homogeneous bodies with a sharply defined single contoured outline. They vary in size from 8 to $15 \mu$ in diameter. The difference in size may be due to the shrinkage caused by the fixing agents. In the tissues in the

* Cause of dysentery in man.

${ }^{6}$ Smith. Bulletin No. 8, B. A. I., U. S. Dept. of Agric., 1895. 
crushed preparations they appear free although occasionally they are found engulfed by giant cells. As found in sections of the fixed and stained tissues they appear as spherical or slightly oval bodies, varying from 6 to $10 \mu$ in diameter. In
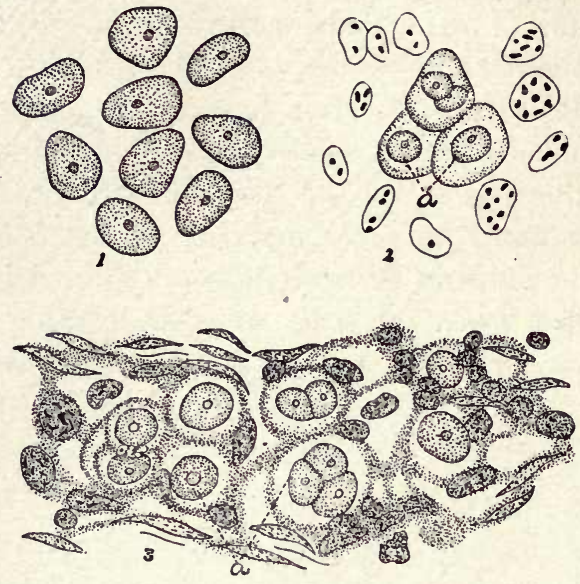

Fig. 81. Ameba meleagridis. 1, Isolated organisms; 2, single parasites; 3 , groups of the parasites (a) of the ameba in the mucous membrane of a turkey's celium. (After Smith.)

most of them, nuclear bodies appear centrally or somewhat to one side which are about $2 \mu$ in diameter.

These organisms differ from the ameba of dysentery in being more uniform and varying but slightly in size and in being free from vacuoles.

Moore ${ }^{7}$ was able to transmit the disease caused by it by feeding the excreta and infected livers and caeca to healthy turkeys. Chester ${ }^{8}$ reports this disease in chickens, and Milks ${ }^{9}$ described the disease and the organism in chickens in Louisiana.

'Moore. Cir. No. 5, B. A. I., U. S. Dept. Agric., 1896.

${ }^{8}$ Chester. Rept. of the Bacteriologist, Delaware Coll. Agric. Exper. Station, 1899-1900.

${ }^{9}$ Milks. Bulletin No. 108, Loulsiana Agric. Exp. Station, 1908. 
THE FLAGELLATA.

General description. The flagellates are motile protozoa. Their organs of locomotion are flagella or whip-like processes which arise as a rule from the anterior part of the organism. In motion the larger ones (primary flagella) are directed forward while the smaller ones (secondary ones) are directed backward.

There is a great variety of these forms. As a rule, their structure is more fixed in outline than ameba. It is stated that this is due to the fact that they usually have a somewhat definite but delicate membrane containing elastic fibers. They reproduce either in the free motile state or after they are eneysted. In the first case as a general thing they divide longitudinally. The basal ganglia and flagella divide with the nuclei. Multiple division is also observed. In the second case, they may or may not conjugate before they encyst. Division forms occur in the cyst by a process similar to that in the amebae. It has been stated by Schaudinn that certain of these forms pathogenic for man require a second host for the development of their sexual cycle.

The orders of flagellates which possess species pathogenic for domesticated animals are the Monadida, which contain the genera Piroplasma, Trypanosoma and the Spirochaete.

\section{GENUS PIROPLASMA (BABESIA) SMITH AND KILBORNE.}

In 1888, Babes ${ }^{1}$ described bodies in the red blood cells in Roumanian cattle affected with a somewhat fatal disease that up to that time had not been understood, but which was similar to that known in the United States as Texas fever. $\mathrm{He}$ described these bodies somewhat indefinitely. His inference seemed to be that they were micrococci. In 1893, Smith and Kilborne ${ }^{2}$ described the organism of Texas fever, and named

${ }^{1}$ Babes. Compt. rendu de l'Acad. de Sci., Vol. CVII (1888) p. 692.

${ }^{2}$ Smith and Kilborne. Texas fever Bulletin No. 1, B. A. I., U. S. Dept. of Agric., 1893. 
it Pyrosoma bigeminum.* Species of this genus have been found and described in nearly all of the domesticated animals.

PIROPLASMA (PYROSOMA) BIGEMINUM SMITH AND KILBORNE.

Synonym. Babesia bovis Starcovici. ${ }^{3}$

Place in nature. Smith and Kilborne discovered this organism to be the cause of the disease of cattle existing in the southern part of the United States known as "Texas fever." It was found by Lignières ${ }^{4}$ in the disease of cattle in Brazil known as "tristeza" or bovine malaria, and Hunt and Collins ${ }^{5}$ found it in the malady known as tick fever in Australia.

It was first reported by Smith and Kilborne that this organism was transmitted from the infected animal to the uninfected one through the medium of the cattle tick Boophilus annulatus. ${ }^{*}$ They also found that this organism passed through the egg and into the young ticks that were hatched from the eggs of ticks that had grown on infected cattle or on those immunized to the disease such as are found in the tick-

* The generic name Pyrosoma was assigned because of its pearshaped form and the specific name bigeminum was selected because the organism usually appeared in pairs in the blood corpuscles. The generic name Pyrosoma had already been given to a well-known Ascidian genus and consequently it was changed to Piroplasma by Patton in 1895. In the meantime Starcovici (1893) had given the name Babesia bovis to the form described by Babes; and as this form seems to be identical with that described by Smith and Kilborne the correct name of the genus would appear therefore to be Babesia and the species parasitic in cattle should be called, according to Starcovici, Babesia bigeminum.

${ }^{3}$ Starcovici. Centralbl. f. Bakt., Bd. XIV (1893) p. 1.

* It is also known as Spanish fever, bloody murrain, tick fever, bovine malaria and hemoglobinuria.

"Lignières. "La Tristeza." Buenos Ayres, 1890.

${ }^{5}$ Hunt and Collins. Rept. on Tick Fever. Brisbane, Australia, 1899.

* This genus was first described by Riley in 1868 as Ixodes bovis. Curtice in 1891 (Jour. Comp. Med. and Vet. Arch., Vol. XII (1893) p. 3-13, also Vol. XIII (1892) p. 1,) changed the generic name to Boophilus (ox-loving). Recently Karsch's genus Margoropus has been adopted as the correct name of the genus. 
infested territory and that the young ticks were able to transmit the parasite to healthy or uninfected cattle. Further than this the life history of this organism does not seem to be known. As an etiological factor Piroplasma bigeminum depends for its transmission upon the cattle tick.

Morphology. As described by Smith, Piroplasma bigeminum appears in the red blood corpuscles of cattle suffering from the acute form of the disease known as Texas fever as
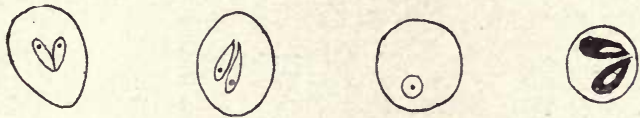

Fig. 82. Piroplasma big€minum in the red blood corpuscles.

double pear-shaped forms and single rounded or more or less irregular bodies; in size the average is from 2 to $4 \mu$ in length and from 1.5 to $2.0 \mu$ in width, the broad end tapering to a point. In the double form the tapering ends come together. In the fresh blood the small forms are quite homogeneous while the larger ones often exhibit in the broad end a somewhat rounded body from 1 to $2 \mu$ in diameter which is glistening and stains darker than the rest of the organism. Ameboid movements have been observed in the central bcdy.

Some differences occur in the description of the organism by different writers. Smith describes in the mild or chronic form of the disease coccus-like bodies. These bodies seem to be those described by Theiler $^{6}$ as $A n a$ plasma marginale. In films made from the blood of acute cases of Texas fever dried in the air and fixed either by heat or by a fixa-

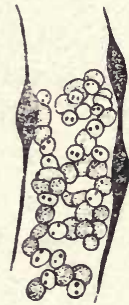

Fig. 83. Blood in a capillary of the heart showing Piroplasma bigeminum in the red corpuscles. (A f t e r Smith and Kilborne. ) tive, the organisms stain readily with alkaline methylene blue or gentian violet. Smith found in the acute cases that they were most numerous in the blood from the capillaries of the

' Theiler. Report of the Government Bacteriologists. Pretoria, South Africa, 1908-09. 
heart muscle and kidney. They were, however, much in evidence in films from the peripheral circulation. The presence of this organism is generally considered diagnostic of Texas fever. It does not appear as yet to have been cultivated on artificial media.

\section{PIROPLASMA OVIS.}

Synonym. Babesia ovis Stareovici.

Place in nature. Babes found this organism to be the cause of the disease known as "carceag", or ictero-hemoglobinuria of sheep in Roumania. It was later described by Bonome $^{\tau}$ in an epizootic of a similar kind in Italy. This parasite is described as being very similar to that of Piroplasma bigeminum except that it is somewhat smaller.

PIROPLASMA EQUI LAVERAN.

Place in nature. This organism was discovered by Guglielmi ${ }^{1}$ in horses. It is the cause of a febrile disease (Piroplasmosis) accompanied by an acute anemia. It was found by Theiler ${ }^{2}$ that it could be inoculated from immune horses into mules and from mules into susceptible horses. The organisms are readily found in the blood of the horse during the febrile stage of the disease. Theiler ${ }^{3}$ showed that they were transmitted from horse to horse by means of Rhipicephalus everst. It does not seem to have been reported in the United States.

Morphology. Piroplasma equi as found in infected blood appears as spherical or elongated, oval or rarely pyriform bodies. They are nearly always within red corpuseles. It is net common to find them free in the plasma. The parasites are from 0.5 to $2.5 \mu$ in diameter, the most common being 1.0 to $1.5 \mu$. The following forms of the parasite are deseribed by

${ }^{7}$ Bonome. Virchow's Archiv, Bd. CXXXIX (1895) p. 1.

${ }^{1}$ Guglielmi. La clinica veterinaria, 1899, p. 220.

${ }^{2}$ Theiler. Ann. Rept. of the Director of Agriculture, Transvaal, 1904-1905, p. 94.

${ }^{3}$ Theiler. Schweitzer-Arch. f. Tierheilk., Bd. XLVII (1901) p. 253. 
Bowhill ${ }^{4}$ : (1) large and small spherical forms, karyosome, situated at edge of parasite; (2) large and small pyriform parasites single and in pairs; (3) large and small rod-like bodies, some of them extending aeross the entire diameter of the corpusele, sometimes in pairs; (4) rosette form, consisting of four bodies connected in the center by fine threads, each body usually containing a karyosome at its extremity; (5) flagellate forms.

Laveran found multiplying forms more common in the spleen than in peripheral blood. They multiply by direct division, usually into two, sometimes into four bodies. The karyosome elongates, then divides into two parts; these separate, followed by division of the cell body. The two parasites often divide, giving four, within the red corpusele. Sometimes the karyosome divides into four parts before the protoplasm divides. The disposition in fours is one of the most striking morphological characters of Piroplasma equi (Laveran).

The number of parasites in the peripheral blood varies a great deal. They are present during febrile stages but disappear after the fall of temperature. During the stage of high fever they are numerous. Theiler found them in unstained blood as abundant as one parasite in from 5 to 40 red corpuscles. Williams states that the number of parasites in the peripheral blood is proportional to the severity of the disease and that from 1 to 10 per cent or up to 30 per cent of the corpuscles may be infected. Baruehello and Mori state that the parasites are found most easily during the early stages of the disease. The "rosette" form is present in varying numbers. Sometimes the parasites are so searce as to be found only after a long search. After the administration of quinine the rosettes are very scarce (Theiler). With the fall of temperature the number of parasites decreases from day to day; by the time the temperature has fallen they ean be found only with diffieulty.

${ }^{4}$ Bowhill. Jour: of Hyg., Vol. V (1905) p. 7. 
Staining. Stained by Romanowsky's or Laveran's method the cell body takes a bluish tint and the karyosome a red-violet color.

PIROPLASMA CANIS.

Place in nature. Piroplasma canis was first described in Italy by Piana and Galli-Valerio ${ }^{1}$ who found it in the blood of a dog suffering from jaundice and fever after living in a marshy locality. The disease caused by this organism was recognized by Hutchin in South Africa as malignant jaundice or bilious fever of the dog. It was recognized in France by Le Blane of Lyons in 1900. Because of certain differences in the symptoms it has been suggested that possibly there are two forms or species of the parasite of canine piroplasmosis. The parasite is transmitted by means of a tick (Haemophysalis laechi).

Morphology. In morphology, it differs from Piroplasma bigeminum in that it is larger and is not so constantly bigeminate, but appears quite frequently single. Nuttall and Graham Smith ${ }^{2}$ show from 1 to 16 parasites in a single corpuscle and also extra cellular forms. There are, therefore, many minor differences in the descriptions of the different authors.* $P$. canis described in Italy measured from 2.5 to $3.5 \mu$ in their largest diameter; those observed in France from 2 to $4 \mu$. Nocard and Motas state that the parasites are larger in young dogs and that in adult dogs near the close of the disease they appear very much smaller. Nuttall and Graham Smith mention the smallest specimens observed in South Africa 0.7 to $1.2 \mu$; the largest $3.6 \mu$, rarely pyriform bodies measured $5 \mu$. The pyriform bodies are not so common in these species as in $P$. bigeminum. Nocard and Motas state that they are best observed immediately after the fall of the fever, the only

${ }^{1}$ Piana and Galli-Valerio. Il moderno Zooiatro (1895) p. 163 (cited by Burnett).

${ }^{2}$ Nuttall and Smith. Jour. of Hygiene, Vol. V (1905) p. 237.

* Nuttall and Smith (Loc. cit.) have brought together these differences and a perusal of their article on canine piroplasmosis is especially recommended. 
time when they are numerous and motile. The parasites are irregular and have a dark contour in the somewhat large and pale blood corpuscle. Corpuscles are not appreciably enlarged when they contain from but one to six parasites but when the number is greater than this they are somewhat enlarged.

Staining. A number of staining solutions have been recommended. Marchoux used Laveran's stain which colors the chromatin violet red. Nocard and Motas use Nicole's carbol-thionin to stain films dried in the air, fixed in absolute alcohol and stained for 30 seconds. With this the corpuscles appear a pale green, the parasites a dark blue and sharply defined, their central portion remaining unstained or staining a pale blue.

Graham Smith ${ }^{3}$ described in detail the morbid anatomy of piroplasmosis in dogs. In this he gives the percentage of corpuscles infected in smears made from the different organs. These vary from less than 1 to 50 per cent or more. His examination shows that over 91 per cent of all infected corpuseles contain either 1 or 2 parasites only and that 98 per cent contain from 1 to 4 . Even numbers of parasites were present in 97.11 per cent of all infected corpuscles containing more than one parasite and odd numbers were present in only 2.88 per cent of the infected corpuscles.

\section{PIROPLASMA PARVUM THEILER.}

Synonyms. Theileria parva; Babesia parva.

Place in nature. $P$. parvum is the cause of the East Coast fever of Southern Africa. This name was given to the socalled Rhodesian redwater by Koch in 1903. Certain authorities in Asia Minor have assigned to it the more scientifically correct name of tropical piroplasmosis. This is a specific disease affecting cattle, characterized by a high temperature, the presence of a specific piroplasma ( $P$. parvum) in the red blood corpuseles, a heavy mortality and by not being directly trans-

\footnotetext{
${ }^{3}$ Graham Smith. Jour. of Hyg., Vol. V (1905) p. 250.
} 
missible from animal to animal. According to Robertson, ${ }^{1}$ who distinguished it from $P$. bovis because of the frequent occurrence of bacillary forms and the minute size of the parasite, the red blood corpuseles are not diminished in number. The organism was described by Theiler. A similar disease due to a like parasite has ben reported in Tunis. ${ }^{2}$ The organisms appear in large numbers in the blood. In the early stages of the disease they appear as rods or in ring forms. Miyajima, ${ }^{3}$ in his work on the cultivation of trypanosomes, indicates that Piroplasma parvum represents a stage in the life cycle of the

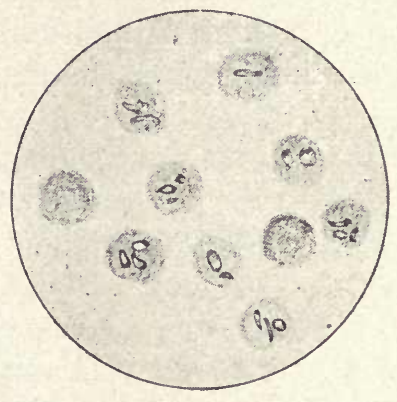

- Fig. 84. Piroplasma parvum. (After Theiler). trypanosome. The work of other observers does not confirm this conclusion. Bettencourt ${ }^{4}$ changed its genus to Theileri on grounds not considered sufficient by Gonder ${ }^{5}$ on account of the variation in the size of the parasites. It is transmitted by means of a tick (Rhiphicephalus appendiculatus) and it can not be transmitted by the injection of blood. Recovery. from the disease assures complete immunity and the animals are not subject to a relapse. This has been taken as an indication that the parasites are destroyed after a certain period. Gonder has made observations on the development of the parasite in the tick. The student of piroplasmosis will find his article of much interest.

- ${ }^{1}$ Robertson. Jour. Comp. Path. and Therap., Vol. XVII (1904) p. 214.

${ }^{2}$ Ducloux. Compt. renđu de la Soc. de Biol., Vol. LVII (1905 ii) p. 461.

${ }^{3}$ Miyajima. Philippine Jour. of Sci., Manila, cited by Crawley, Bulletin 119, B. A. I.

"Cited by Gonder.

'Gonder. Rept. of the Government Bacteriologist, Pretoria, South Africa, 1909-1910, p. 69. 
Nuttall, Fantham and Porter ${ }^{b}$ observed the movements of this parasite within the blocd corpuseles. The following is taken from their conclusions on the "omnibus hypothesis," which is based on the assumption that the invasion of the red blood corpuscles may take place in the spleen or bone marrow and that the corpuseles act chiefly as vehicles for parasites destined solely to gain an entry into ticks for the purpose of undergoing further development: "The corpuscles are penetrated by parasites as the blood cireulates through the internal organs; the parasites multiply in these organs but not in the corpuscles. As the disease progresses more and more protozoal passengers board the transporting vehicles, the corpuseles. This hypothesis offers an explanation of the fact that (1) the disease is not communicable by blood inoculation; (2) that the percentage of infected corpuscles not only increases steadily, but that the percentage of corpuscles containing many parasites grows as the disease advances; (3) that the parasites do not persist in the blood after recovery. It is, of course, conceivable that intracorpuseular multiplication may take place; if it occurs the process must be very slow.

"The assumption appears justified that the parasites obtain nutriment from the corpuseles they inhabit. The discovery recently made by Meyer ${ }^{\tau}$ that East Coast Fever may be communicated by transplantation of the affected spleen or pieces of that organ goes to support the hypothesis here advanced, for doubtless the transplanted splenic tissue lived on for a time in the peritoneal cavity of the experimental animals and served as a nidus wherein the parasites continued to multiply. Meyer's experiments demonstrate that the spleen, and possibly other internal organs, serve as the primary seats of the invasion of the blood corpuseles by the parasites.

"Summarizing our observations on the living parasite, we would state that they show active movements within the cor-

${ }^{6}$ Nuttall, Fantham and Porter. Parasitology, Vol. II (1909) p. 325 .

'Meyer. Jour. Comp. Path. and Therap., Vol. XXII, p. 213. 
puscles and at times in living parasites. We have not obtained any conclusive evidence that the parasites multiply within the infected corpuscles, but at times appearances were observed suggesting this possibility. In several cases the parasites seemed to grow slightly in size during the period of observation. When infected corpuscles lost their haemoglobin the parasites were distinctly seen for a time, after which they degenerated and died. The escape of parasites from infected corpuscles was witnessed on six occasions; it was accomplished without injury to the corpuscle. On two occasions the escaped parasites appeared to reenter fresh corpuscles.'

\section{PIROPLASMA MUTANS THEILER}

\section{Synonyms. Babesia mutans.}

Place in nature. This piroplasma was discovered by

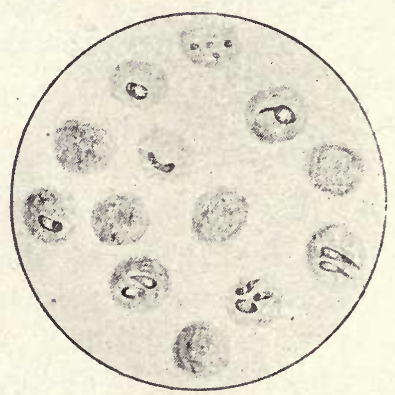

Fig. 85. Piroplasma mutans (after Theiler). Theiler. ${ }^{1}$ It was found in a disease (gall sickness) of cattle in South Africa and often associated with other species of the same genus, especially $P$. parvum. Theiler found that this disease had a period of incubation in cattle varying from 13 to 42 days. Animals immune to $P$. bigeminum are susceptible to $P$. mutans. Likewise $P$. mutans does not protect against $P$. bigeminum. In earlier work this species has apparently been confused with other piroplasmae. It exists in South Africa and Madagascar.*

${ }^{1}$ Theiler. Jour. Comp. Path. and Therap., Vol. XIX (1906) p. 292 ; Vol. XX (1907) p. 1; Vol. XXII (1909) p. 115.

* It corresponds to the species described by Holmes in the Indian hill cattle at Muktesar; Stephens and Christophers in Madras; MiYajuma and Shibayama in Japan; Shein in Annam; Bettencourt in a deer in Portugal; Boevet on the Gold Coast of Africa; Martini in Peychile, in China; Lichtenheld in German East Africa; and Balfour in the Sudan. 
The essential lesion caused by $P$. mutans is anemia with poikilocytosis. According to Theiler, it does not as a rule produce fatal results. It is not, according to the same author, transmitted by the blue tick (Margoropus annulatus).

Morphology. P. mutans is very similar to $P$. parvum in its morphology.

ANAPLASMA MARGINALE THEILER.

Place in nature. Theiler has differentiated from Piroplasma bigeminum, $P$. parvum and $P$. mutans, a fourth parasite which he designates Anaplasma marginale, the parasitic nature of which still requires further investigation. According to Theiler, A. marginale, hitherto known as "marginal points," causes a severe anemia frequently ending in death. He also holds anaplasma to be an organism reduced by parasitism, having lost its "originelles" and its plasma so that phylogenitically it represents one of the oldest piroplasmatae. This also needs further elucidation. According to Theiler ${ }^{1}$ this organism is the cause of "gall-sickness," a type of disease in cattle which is rarely observed spontaneously in a pure state but more commonly occurs as a mixed infection with other piroplasma and possibly trypanosomes. The period of incubation is shorter (from 16 to 40 days) after an experimental injection of blood containing the parasite than after a spontaneous infection (which varies from 60 to 80 days). It is transmitted by the tick Boophilus decoloratus. According to Sieber ${ }^{2-}$ there can be little doubt of the parasitic nature of these bodies. Theiler ${ }^{3}$ points out that it is identical with the coceus-like forms of Piroplasma bigeminum deseribed by Smith and Kilborne and states that anaplasmosis is undoubtedly identical with the South African gall sickness.

${ }^{1}$ Theiler. Dept. of Govt. Bacteriologist, Transvaal, 1908-09; Jour. Comp. Path. and Therap., Vol. XXIII (1910) p. 98.

${ }^{2}$ Sieber. The Govt. Vet. Bacteriologist, Report, 1909-10, Pretoria, p. 104. Also 1911, p. 104.

${ }^{3}$ Theiler. Zeit. f. Infektionskrankheiten u. Hyg. der Haustiere, Bd. VIII (1910) p. 39. 
Miorphology. In the case of intravenous injection this organism appeared first on the eighteenth day in the red blood corpuscles of the spleen pulp, there usually being but one parasite in a corpusele. Free forms were seen. The number of infected corpuscles was small, varying from 2 to $4 \%$. Smaller forms were found with the others.

From the descriptions given it appears that there were several piroplasmoses affecting cattle in the tropies and that many of the diseases caused by them exist as mixed infections. The student is referred to the reports of Dr. Theiler and his co-workers for further details concerning these organisms and their effect upon animals.

Dschunkowsky and Luhs ${ }^{4}$ described a piroplasma in the blood of diseased cattle in Transcaucasia which they believe to be a distinct species. Theiler looks upon it as Anaplasma marginale.

\section{TRYPANOSOMA.}

History and general characteristics of the genus. The genus trypanosoma was introduced by Gruby who described trypanosomes in frogs in 1840. This genus of protozoa was studied at intervals and in various species by different workers from 1843 to 1880 . Lewis in 1878 deseribed trypanosomes in rats. A little later, Evans described them as the cause of surra among horses and camels in India. In 1894 Bruce discovered the trypanosome of nagana among the horses and cattle in Zululand. Later, other species were discovered and are believed to be the cause of the disease with which they are associated. It has also been found that these organisms are more or less prevalent in the blood of many healthy domesticated and wild mammals, birds and cold blooded animals.*

${ }^{*}$ Dschunkowsky and Luhs. Centralbl. f. Bakt, Bd. XXXV (1904) p. 486. Also Eighth International Veterinary Congress, Budapest, Vol. III (1905).

* For a summary of the literature and a detailed list of the discoveries concerning trypanosomes in different species of animals and birds the student is referred to the work of Laveran and Mesnil on Trypanosomes and Trypanosomiases. 
Methods of study. The trypanosomes may be studied in the fresh (living) state and in a fixed and stained condition. In the fresh condition a drop of blood from the infected individual is placed on a slide and a cover-glass placed over it. To study the structure of the organisms the blood must be in a thin layer. The movement of the corpuseles caused by the parasite enables one to locate them with a low magnification (100 diameters). When they are rare it has been recommended to centrifuge the blood after adding a small quantity of sodium eitrate solution to prevent coagulation. The trypanosomes are found to be more numerous in the leucocytic layer. The organisms can be studied for a considerable time in a hanging drop preparation.

In stained preparations, the following process was recommended by Laveran. ${ }^{1}$

The blood is spread in a thin layer on a glass slide, dried very rapidly, and fixed in absolute alcohol for five to ten minutes. The following solutions should be prepared beforehand:

1. Methylene-blue with silver oxide or Borrel blue. Take 50 or $60 \mathrm{cc}$. distilled water in a flask of about 150 cc. capacity, and add some crystals of silver nitrate. When these are dissolved, fill the flask with a concentrated solution of caustic soda and shake. A precipitate of silv $\epsilon \mathrm{r}$ oxide is formed. This is washed several times with distilled water, so as to get rid of any silver nitrate or excess of soda. A saturated watery solution of methylene blue ("medicinal methylene blue," Hoechst) is then poured on to the silver oxide and allowed to remain for a fortnight, the flask being shaken from time to time.

2. Watery solution of eosin, 1 per 1,000 ('water-soluble' eosin, Hoẹchst).

3. Solution of tannin, 5 per cent, or better, a solution of tanninorange, which can be obtained ready made up.

The staining mixture is prepared at the time of using, according to the following formula:

$\begin{array}{ll}\text { Solution of eosin ( } 1 \text { per } 1,000) & 4 \mathrm{cc} . \\ \text { Borrel blue } & 1 \mathrm{cc} . \\ \text { Distilled water } & 6 \mathrm{cc} \text {. }\end{array}$

The mixture is at once poured into a flat dish, such as a Petri

${ }^{1}$ Laveran. Compt. rendu de la Soc. de Biol., Vol. LII (1900) p. 549. 
dish, or better, a square or oblong dish with sloping bottom. The slide on which the blood-film has been spread and fixed is placed film downwards in the staining solution (a piece of glass rod or a projection from the bottom of the dish preventing the slide from touching the bottom, where a precipitate nearly always forms), and left there for five to twenty minutes. Five to ten minutes' staining is long enough for most trypanosomes, especially for the mammalian parasites; twenty minutes' staining is necessary for certain species -e.g., T. Lewisi-particularly when undergoing reproduction. After removal from the staining solution the slide is well washed in a large quantity of water (or by blowing a strong stream of water on the film with a wash-bottle), then treated with the solution of tannin for several minutes, again wash€d in excess of water, and finally in distilled water, and dried. If a precipitate is formed, which would render microscopical examination difficult, wash the film with oil of cloves, then with xylol, and gently rub the surface of the preparation with a piece of soft linen soaked in xylol.

The preparations keep better uncovered than if covered with balsam or cedar-wood oil, in which case they rapidly lose their stain. When the staining has been successful, the protoplasm of the parasite is pale blue; the nucleus, fiagellum, and edge of the undulating membrane are purplish; the centrosome is deep violet-a little different from the nucleus; the undulating membrane is unstained, or stained a very pale blue. The red corpuscles are pink, the nuclei of the leucocytes dark purple.

TRYPANOSOMA EVANSI STEELE.

Place in nature. Trypanosoma Evansi is the eause of the disease in horses, eattle and oceasionally in dogs, elephants and other wild animals, known as surra. The name "cachectie" was given by natives to this disease which in horses is characterized by a profound eachexia and has been known for a great many years. It closely resembles nagana in that its essential lesion is that of anemia with remittent and intermittent fever; edema of the limbs and abdomen, great muscular weakness and terminal paresis. This disease lasts from one to several months. Occasionally it runs its course more quickly. This trypanosome was diseovered by Evans ${ }^{1}$ in 1880 . In 1885 Steele ${ }^{2}$ identified the one found in transport mules in

'Evans. Report on Surra, Military Dept., Dec. 1880.

${ }^{2}$ Steele. Report on an obscure and fatal disease in transport mules, etc., 1885. 
British Burma with that described by Evans and named it Trypanosoma Evansi. Tr. Evansi is the cause of a very destructive disease of animals in Africa, India and Indo-China. The species susceptible to this parasite are the horse and the horse kind, cattle, camels, elephants and dogs. Dogs are especially easily infected with surra by subcutaneous inoculation. Rabbits and guinea pigs are also susceptible. When the latter are inoculated subcutaneously, trypanosomes appear in the blood on the sixth or seventh day. Apart from the enlargement of the spleen, the morbid changes are not well marked.

Morphology. Tr. Evansi has an average length of about $25 \mu$ and about $1.5 \mu$ in width. The free flagellum measures about $6 \mu$. In length it varies from 25 to $30 \mu$. It reproduces by simple division as the centrosome nucleus and flagellum divide into two parts and finally the protoplasm itself divides. Laveran and Mesnil ${ }^{3}$ attempted to cultivate the organism after Novy's method but succeeded only once in six experiments.

The means by which surra is transmitted are not definitely determined. A large horse fly, probably Tabanus, has been thought to be a possible carrier. Deixonne in a letter to Laveran, referring to an outbreak of surra in Mauritius, said that it occurred simultaneously with the appearance of stomaxys. According to Schat, Stomaxys calcitrans is chiefly concerned in the propagation of surra in Java. This fly attacks cattle as well as horses. Rogers ${ }^{4}$ shows that the horse flies in India can convey surra to the dog
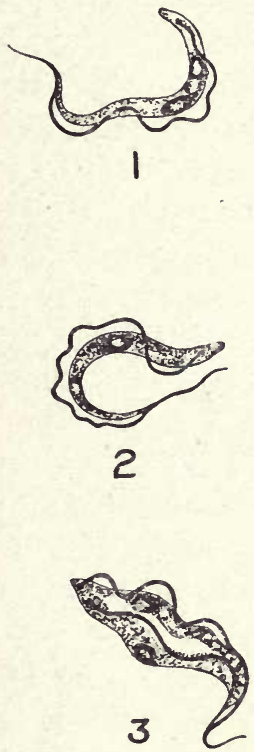

Fig. 86. Trypanosoma Evansi from rat's blood. (After Nocht and Mayer). and rabbit. He points out that the latent eases of surra in

${ }^{3}$ Laveran and Mesnil. loc. cit.

4 Rogers. Brit. Med. Jour., 1904-ii, p. 1454. 
cattle may in this way often become sources of infection. The evidence that has been accumulated during recent years tends to disprove Lingard's hypothesis that surra was transmitted by infected water or food.

TRYPANOSOMA EQUIPERDUM DOFLEIN.

Place in nature. Tr. equiperdum is the cause of the venereal disease of horses and asses known as dourine,${ }^{1}$ which occurs naturally in breeding horses and asses but which is readily transmitted to others by inoculation. Dourine is characterized by (1) an irregular period of incubation varying from thirty or forty days to a year or more after primary infection (Lingard), (2) by the localization of the primary lesions in the organs of reproduction and later by the appearance of placques, (3) by a chronic course, (4) by the production in the later stages of the disease of a paralysis of the posterior extremities and (5) by its terminating fatally in from a few months to two years or longer. The disease has occurred in many places in Europe. It was discovered in the United States by Williams ${ }^{2}$ in 1882 . Since that time it has been reported from several western states and in 1911 Mohler* found $T r$. equiperdum. The disease was discovered in the Canadian Northwest and studied experimentally at Ottawa by Higgins ${ }^{3}$ who found the specific organism. This trypanosome seems to have been first observed by Rouget ${ }^{4}$ in 1894 . In 1901 Doflein $^{5}$ gave it the name Tr. equiperdum. It is found in the blood taken from the regions of the oedematous swellings and placques. Laveran and Mesnil state that they have rarely

${ }^{1}$ French, Mal du coit; German, B€schalkrankh€it.

${ }^{2}$ Williams. Annual Report of the Board of Livestock Commissioners for the State of Illinois, 1887.

* For a summary of the appearance and study of dourine in the United States see report by Mohler. Bulletin No. 142, B. A. I., U. S. Dept. of Agric., 1911.

${ }^{3}$ Higgins. Special Report on Maladie du coit or Dourine, Dept: of Agric., Ottawa, 1907.

${ }^{4}$ Rouget. Ann. de l'Inst. Pasteur, Vol. X (1896) p. 716.

${ }^{5}$ Doflein. Die Protozoen, etc., Jena, 1901, p. 66. 
found it in the blood taken from other parts of the body. They state that the best time to find the parasite in the placques is on their first appearance. As the cutaneous lesions spread the parasite becomes more difficult to find. Mohler ${ }^{6}$ concludes that $T r$. equiperdum are fewer in number and not so virulent in the dourine of the United States as they are in countries where the disease is indigenous. Watson ${ }^{7}$ in a study of dourine concludes that it is in the early stages of infection that the trypanosomes are most active and numerous in the genital organs and that as the disease advances or as the animal becomes tolerant or indifferent to it the parasites disappear from these regions.

Morphology. Tr. equiperdum when examined in fresh blood from infected animals is quite actively motile. It is somewhat spindle shaped. It -varies in size from 22 to $30 \mu$ in length and from 1.2 to $2.0 \mu$ in width. The posterior extremity is bluntly truncate. The head end is prolonged into a wavy
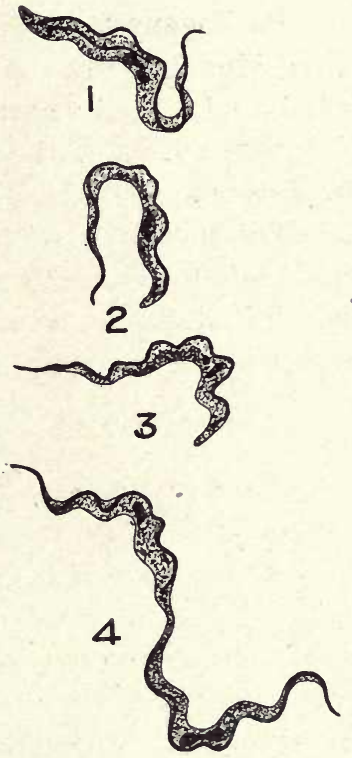

Fig. 87. Trypanosoma equiperdum from guinea pig. (After Nocht and Mayer). whip-like flagellum, giving it the appearance of a tail. Along one side is a wavy, undulating membrane terminating in a flagellum. The nucleus is rather large and located centrally. The centrosome from which the undulating membrane and the flagellum start is in the posterior part. It is readily stained with Borrel's blue, or by Giemsa's azur-eosin stain.

${ }^{6}$ Mohler, loc. cit.

'Watson. Rept. of the Vet. Director-General and Livestock Commissioner, Dept. of Agric., Ottawa, Canada, for the year ending Mar. 31, 1910, p. 60. 
Mohler succeeded, after many efforts, in cultivating this trypanosome on a medium composed of defibrinated rabbit's blood 3 parts and agar 1 part. The medium was allowed to congeal in the slanting position. The condensation water was inoculated.

Pathogenesis. Tr. equiperdum oceurs naturally in the horse kind but dogs and rabbits are very susceptible when inoculated. In the horse kind it is transmitted by copulation. No other means of dissemination are known. Rats and mice are less susceptible. Birds are immune.

The diseovery of the Trypanosoma equiperdum by Higgins and Mohler and the quite wide distribution of dourine in the United States as indicated by Mohler ${ }^{8}$ point to its importance economically as well as etiologically in this country.

TRYPANOSOMA BRUCEI PLIMMER AND BLANDFORD.

Place in nature. Trypanosoma Bruce $i$ is the cause of the disease known as nagana or "tsetse" fly disease in South Africa. It was first discovered by Bruce in Zululand. An infected dog was sent to England by Bruce in 1896 where a careful study of the organism was made by Kanthack, Durham and Blandford ${ }^{1}$ in London and Cambridge. Plimmer and Blandford continued the study of the organism and assigned the specific name in honor of Bruce, its discoverer. The disease exists in the Transvaal and its immediate vicinity. This organism thrives better in the blood of some animals than it does in that of others. It can not resist a long exposure at a temperature of $40^{\circ}$ to $41^{\circ} \mathrm{C}$. When the temperature of the infected animal is raised above $40^{\circ}$ to $41^{\circ} \mathrm{C}$. the parasites diminish in number and when the temperature falls the parasites begin to multiply again in the blood. The high temperature of birds seems to render them refractory. This parasite is transmitted by the "tsetse" fly. According to Bruce, it affects cattle, horses, and to a less extent sheep and goats and

${ }^{8}$ Mohler, loc. cit.

${ }^{1}$ Kanthack and others. Pro. of the Royal Soc., Vol. LXIV (1898) p. 109 . 
the wild ruminants of Zululand. The parasites become inactive and soon die after the death of the host.

Morphology. Tr. Brucei appears in fresh blood as a small very motile organism, with a spiral like body having an undulating membrane and flagellum. It usually moves with the flagellar end foremost, so that this is regarded as the anterior extremity. The organism has approximately the same size in the rat, mouse, guinea pig and dog, i. e. from 25 to $27 \mu$ long and from 1.5 to $2.5 \mu$ wide. In the horse and donkey it is longer, measuring from 28 to $33 \mu$ in length. When the blood is centrifuged, the parasites are found most abundantly in the upper part of the layer formed by the red corpuscles. This method is recommended in searching for trypanosomes when they are present in small numbers. Small bodies have been observed in the lymph glands, in the bone marrow and in the spleen which vary from 1 to $2 \mu$ in diameter.

Staining. For staining fresh preparations of this species neutral red, toluidin blue, and methylene blue stain the
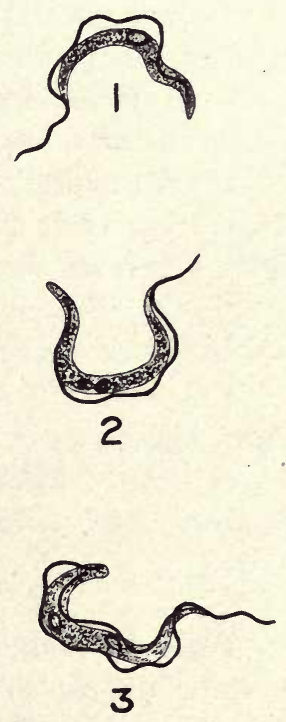

Fig. 88. Trypanosoma Brucei from rat's blood. (After Nocht and Mayer).

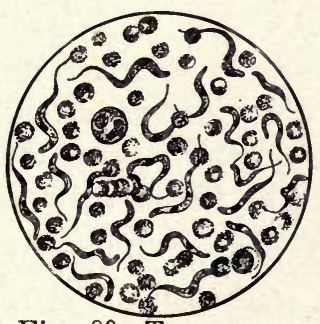

Fig. 89. Trypanosoma Brucei in blood of a rat. (After Nocht and Mayer).

granules in the interior of the living trypanosome. The stain becomes more general with preparations of dead organisms.

Novy and $\mathrm{McNeal}^{2}$ succeeded in cultivating Trypanosoma Brucei and $\operatorname{Tr}$. Lewisi. The former is more sensitive and more exacting in its cultural requirements than $T r$. Lewisi. $T r$. Lewisi will grow on a medium containing one-half or less of its own

${ }^{2}$ Novy and McNeal. Jour. of Inf. Diseases, Vol. I (1904) p. 1. 
quantity of blood, whereas $\operatorname{Tr}$. Brucei will not develop under such conditions. $\operatorname{Tr}$. Brucei in actively growing cultures possess a virulence nearly the same as that of the original nagana blood.

Trypanosoma Lewisi ${ }^{3}$ varies greatly in size, when grown on blood media, in cultures. There are minute forms which, not counting the flagellum, are but 1 to $2 \mu$ in length. Others, typical in form, are not much longer than the diameter of the red blood corpuscles while most of the spindle shaped cells range from 15 to $20 \mu$. Some trypanosomes can be found which are from 50 to $60 \mu$ in length. The small forms may explain how Novy and McNeal succeeded in infecting rats with infected blood that had passed through a Berkefeld filter.

Trypanosoma Brucei when grown in blood media show slight variations in size. As a rule, they measure from 15 to $17 \mu$ in length. It is longer and proportionately narrower than $\operatorname{Tr}$. Lewisi and its flagellum is not so long or distinet.

TRYPANOSOMA EQUINUM VOGES.

Place in nature. Tr. equinum is the cause of the fatal epizootic disease among horses in South America known as Mal de caderas. This trypanosome was discoveerd by Elmassian in 1901. This discovery was promptly confirmed by Voges ${ }^{1}$ and others. The disease is quite widespread in Brazil and other South American countries. It is more prevalent in the dry season. It is essentially a disease of horses although the mule and donkey are susceptible. Mice, rats, dogs, rabbits and monkeys are affected when inoculated with the infected blood. Swine, sheep, goats and cattle are resistant but their blood will, according to Laveran and Mesnil, harbor the trypanosome for some time. It is reported by Elmassian and Migone ${ }^{2}$ that the rodent, Hydrochaerus capybara, is the "res-

${ }^{3}$ This is the Trypanosome of rats. It has been alleged to be closely related to $T r$. Evansi.

${ }^{1}$ Voges. Berlin€r tierärztl. Woch., 1901.

${ }^{2}$ Elmassian and Migone. Ann. de l'Inst. Pasteur, Vol. XVIII (1904) p. 587. 
ervoir" of this parasite. They report the disease in dogs that have devoured the infected capybara. The direct carriers of the parasite from the capybara to horses are not definitely determined. The disease caused by this parasite is characterized by rapid wasting (although the appetite is good), rise of temperature and weakness in the hind quarters. Later the animal can not stand. There may be swellings especially over the joints but not pronounced and persistent edematous areas as in nagana. The skin, especially about the neck, shoulders and hind quarters, may be the site of slight eruptions 3 to 4 centimeters in diameter from which the hair has fallen and over which scabs form.

Morphology. According to Laveran and Mesnil, Tr. equinum is 22 to $24 \mu$ long, by about $1.5 \mu$ wide; but parasites undergoing division may be 28 to $30 \mu$ long, by 3 to $4 \mu$ wide. In the ordinary forms the flagellum measures about $5 \mu$. The parasite has the same length in different species of animals. The measurements given that were made of the parasites taken from the mouse, rat, monkey, guinea pig, dog, and horse are identical.

In fresh blood $T r$. equinum very closely resembles $T r$. Evansi and $T r$. Brucei; it is only in preparations which are well fixed and stained that one is able to distinguish between them. T'r. equinum is very active when the blood is drawn, but in ordinary fresh preparations it loses its motility fairly quickly. In animals with many trypanosomes in their blood the movements of the parasites usually become sluggish during the
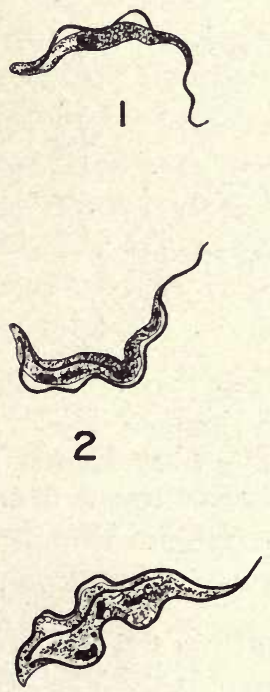

3

Fig. 90. Trypanosoma equinum from blood of a mouse. (After Nocht and Mayer). few hours immediately preceding death, probably owing to the asphyxial condition present. 
The duration of the disease is from 1 to 4 months. Experimentally in the horse Lignières found the shortest duration of the disease to be 34 and the longest 134 days. The trypanosomes appear in the blood in from five to eight days.

TRYPANOSOMES IN THE BLOOD OF HEALTHY CATTLE.

Crawley ${ }^{1}$ describes a trypanosome which he found in the

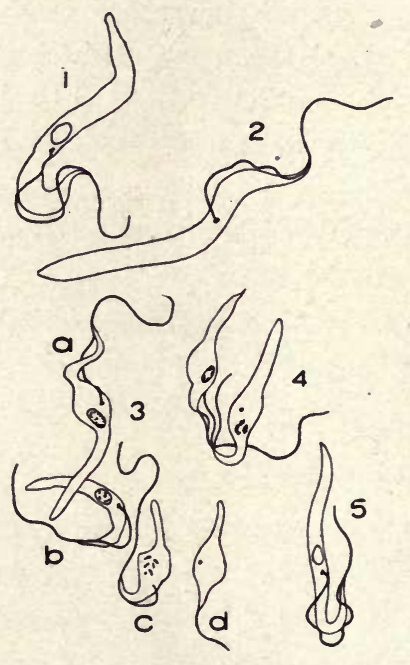

Fig. 91. Trypanosoma Americanum. Nos. 1 and 2, from a 6 day bouillon culture; 3,4 and 5 from a 10 day bouillon culture. (After Crawley). blood of seven American eattle, and which he names Tr. Americanum, a new species. Crawley's work was done to repeat Miyajima's ${ }^{2}$ cultural observation in which he found that the trypanosomes were derived from the piroplasma. Crawley used the blood of American cattle in which no trypanosomes could be found on microscopic examination. By following the method of cultivation he procured trypanosomes from each of the seven cases. $\mathrm{He}$ was able to show, however, that the trypanosomes which he cultivated had no connection with the piroplasma. Crawley found the largest specimen to measure about $38 \mu$ in length, which did not include all of the flagella. He estimates that the total length is not unlikely $75 \mu$. It has a very short undulating membrane. The kinetonucleus may be in front of, along side of or behind the trophonucleus, but the two are always close together. The short undulating membrane is explained

${ }^{1}$ Crawley. Bulletin 119, B. A. I., U. S. Dept. Agric., 1909. Also reprinted in Jour. of Comp. Path. and Therap., Vol. XXIII (1910) p. 17.

${ }^{2}$ Miyajima. Philippine Jour. of Science, Manila, 1907. 
on the ground that the nuclear system is pushed forward at the junction of the anterior and middle thirds. Crawley concludes that $T r$. Americanum lives in all probability as a typical trypanosome in the blood of perhaps $75 \%$ of adult and yearling cattle, but that it is not present in young ealves. He found that the removal of the trypanosomes from the circulating blood stimulates their multiplicative energy, presumably as the result of a cooler environment. $\mathrm{He}$ found that this trypanosome could be cultivated in ordinary bouillon made from either beef or mutton and that the average time required for the trypanosomes to be readily detected in the tubes was about $3 \frac{1}{2}$ days. He found seasonal fluctuation, trypanosomes being more abundant in the spring and summer than they are in the autumn. Recently, Stockman ${ }^{3}$ has found trypanosomes in the blood from 6 of 10 animals in England that were going to South Africa and were being immunized against piroplasmosis. The evidence of Crawley and Stockman indicates the distribution of trypanosomes in cattle. Frank and Frosch, ${ }^{4}$ in 1909, found living specimens in the spleen pulp of an ox which had died from what was thought to be anthrax or blackleg. Pathogenic bacteria were not found. Frosch ${ }^{5}$ described this parasite and named it Tr. Franki. Knuth, ${ }^{6}$ who studied the same material, describes the trypanosome as from 20 to $40 \mu$ in length with a breadth of about $2 \mu$ and that it resembles $\mathrm{Tr}$. Theileri more closely than any other species. Frank and Frosch considered it to be pathogenic. Mayer ${ }^{7}$. considers it a trypanosome that had previously been found exclusively in the tropical or sub-tropical countries. $\mathrm{He}$ quotes from a number of authors who have found trypanosomes occurring sporadically in cattle, mostly, however, in Asia and Africa.

${ }^{3}$ Stockman. Jour. Comp. Path. and Therap., Vol. XXIII (1910) p. 189 .

${ }^{4}$ Frank and Frosch. Zeit. f. Infektionskrankheiten. . . der Haustiere, Bd. V (1909) p. 330.

${ }^{5}$ Frosch. Ibid., p. 316.

${ }^{6}$ Knuth. Ibid., Bd. VI (1909) p. 39.

${ }^{7}$ Mayer. Ibid., p. 46. 
TRYPANOSOMES AFFECTING MAN.

In 1802 Winterbottom reported the occurrence among the negroes on the west coast of Africa of a disease characterized by a tendency to sleep. Since that time it has been known as "Sleeping Sickness." In 1901, Dutton examined with Dr. Forde a patient affected with this disease. He found that the small worm-like bodies previously observed by Forde were trypanosomes. Dutton ${ }^{1}$ named it Trypanosoma gambiense. It was found that this parasite was transmitted largely by an insect, Glossina palpalis. It was observed as early as 1907 by Koch that it could be transmitted by contact. Hindle ${ }^{2}$ has shown experimentally that this parasite will pass through the mucous membrane of the vagina and also through the skin in the absence of any lesion.

TREPONEMA ANSERINA.

Synonyms. Spirochaeta gallinarum; Spirochaeta Marchouxi; Treponema gallinarum.

Place in nature. Sakharoff ${ }^{1}$ in 1891 demonstrated that this organism was the cause of a septicemia in geese. Although the disease is a septicemia Levaditi has shown that the organisms invade the intercellular spaces of various organs. The disease usually runs an acute course in young fowls. The virus is transmitted by the tick Argas persicus and possibly by $A$. miniatus and reflexus. In 1903 Marchoux and Salimbeni ${ }^{2}$ described a spirochaete ( $S p$. gallinarum) as the cause of a disease of fowls in Brazil. It has not been determined whether these two organisms are identical or represent independent species as first described. Spirochaetosis, or the disease produced by them in fowls, has been reported from Russia and various parts of Northern and Southern Africa, Southern Asia and South America. Whether this species has a habitat outside of

${ }^{1}$ Dutton and Ford. Jour. Trop. Med., Sept. 1, 1902.

${ }^{2}$ Hindle. Parasitology, Vol. IV (1911) p. 24.

${ }^{1}$ Sakharoff. Ann. de l'Inst. Pasteur, Vol. V (1891) p. 564.

${ }^{2}$ Marchoux and Salimbeni. Ann. de l'Inst. Pasteur, Vol. XVII (1903) p. 569. 
the bodies of geese (and in case it is identical with Treponema (Spirochaeta) gallinarum, of fowls) has not been determined.

Morphology. This organism is a spiral, varying from 10 to $18 \mu$ in length. It is reported to be actively motile, although flagella have not been demonstrated. According to Balfour, it undergoes changes, in the body of the intermediate host (Argas persicus). It can be demonstrated by carbol fuchsin, Leishmann's and Giemsa's stains. It has not been cultivated on artificial media. Geese, ducks, fowls and sparrows have been inoculated. Rabbits, guinea pigs, horses and man are not susceptible.

The genus Treponema is without undulating membrane but with flagella. This genus includes the following species.

Treponema pallidum Schaudinn, 1905. Found in lesions of frambesia or yaws.

T. anserinum Sakharoff, 1890. Found in the blood of geese suffering from a certain disease.

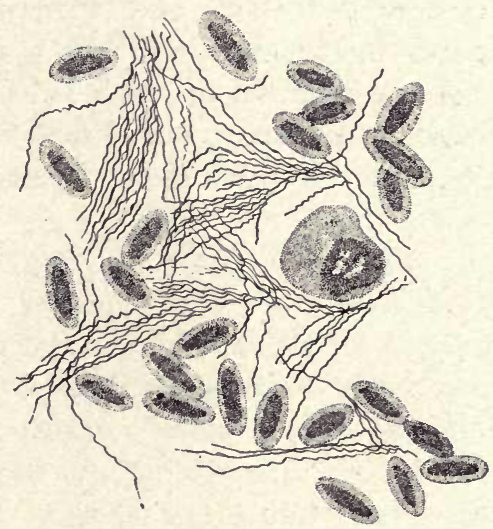

Fig. 92. Treponema anserina from the blood of a goose. (After Cantacuzène).

T. gallinarum Marchoux and Salimbeni, 1903. Discovered in the blood of chickens.

T. Theileri Laveran and Vallée, 1904. Discovered in the blood of cattle.

T. muris Wenyon (Tr. Laverani Breini and Kinghorn). Found in the blood of mice.

\section{SPIROCHAETA.}

Classification and place in nature. Spirochaetes are still considered by some writers as bacteria and by others as protozoa. They were first deseribed by Ehrenberg in 1838 . 
Schaudinn's discovery that the cause of syphilis is an organism belonging to the Treponema (Spirochaeta) pallidum revived interest in this group of organisms. Novy and Knapp ${ }^{1}$ concluded that the spirochaeta are bacteria. The best known, morphologically, of these forms is the type genus spirochaeta with undulating membrane and without flagella. According to Calkins, ${ }^{2}$ there are two genera of these organisms, namely, Spirochaeta and Treponema. To the spirochaeta belong Sp. plicatilis of Ehrenberg and Sp. balbianii found by Cretes in oysters and clams and a number of forms referred to this genus but which are not fully deseribed. A number of these have been found in the blood of horses, sheep and other animals, in tumors, pustules and on normal mucous membranes. Spirochaeta Obermeieri of relapsing fever in man belongs to this genus.

The spirochaetes are largely spiral in form and some of them have transverse bands of chromatin. The nuclear apparatus is of the "diffuse" type which represents an intermediate condition between the "distributed nucleus" of bacteria and the morphological nucleus of higher cells. The flagella of the genus treponema may be the attenuated ends which remain after the longitudinal division. The spirochaetes seem to divide longifudinally. Many of these organisms seem to be intracellular parasites, others live in the lymph and blood and others are neither parasitic nor commensal in their mode of life. Treponema gallinarum is said to frequently leave the blood plasma and to penetrate the blood corpuscles of the chick. $T$. Duttoni penetrates the egg of the tick. These organisms are often transmitted by insects. Nuttall showed experimentally that bed bugs transmit $S p$. recurrentis from man to man, $T$. Duttoni is conveyed by a tick (Ornithodorus manbata), Treponema gallinarum is transmitted by a tick (Argas miniatis) and T. Theileri by Rhipicephalus decoloratus. It has also been shown that multiplication of the parasites occurs in the

Novy and Knapp. Jour. of Infect. Diseases, Vol. III (1906) p. 291.

¿ Calkins. loc. cit. 
bodies of the insects and that the eggs may be infected and may carry the organisms.

The spirochaetes stain in smear preparations with Giemsa's stain. They do not stain in sections of tissue with the ordinary staining methods. Levaditi's ${ }^{3}$ method is highly recommended for staining these bodies.

The fresh tissue is cut into small pieces which should not be thicker than 2 to 4 millimeters.

Fix in ten-per-cent formalin (four per cent formaldehyde) for twenty-four hours.

Wash in water.

Dehydrate in 96-per-cent alcohol twenty-four hours.

Wash in water.

Place in a 3-per-cent silver-nitrate solution at incubator temperature $\left(37.5^{\circ} \mathrm{C}\right.$.) and in the dark for three to five days.

Wash in water for a short time.

Place in the following solution (freshly prepared):

Pyrogallic acid

Formalin

2-4 grams.

Distilled water

5 cc.

$100 \mathrm{cc}$

Leave in this for twenty-four to forty-eight hours at room temperature.

Wash in water.

Dehydrate in graded alcohols.

Embed in paraffin and cut thin sections.

The sections may be examined without further staining, or, if desired, may be weakly counterstained with Giemsa's solution or hematoxylin.

There are several other methods for demonstrating these organisms.

A disease of the pig due to spirochaetes. Dodd ${ }^{4}$ has recently described a spirochaete which he found in a pig sent to the government laboratory in Pretoria. The examination showed very few morbid changes in the tissues but the skin was sprinkled with dark, hemorrhagic-like spots. From scrapings of these lesions he was able to find the organism. It is

${ }^{3}$ Levaditi. Compt. rendu de la Soc. de Biol., Vol. LVIII (1906) p. 67.

${ }^{4}$ Dodd. A disease of the pig, due to spirochaeta. Jour. Comp. Path. and Therap., Vol. XIX (1906) p. 216. 
described as long and very slender, its length varying from 9 to $26 \mu$. Both extremities are pointed. The spiral forms predominate but in the same preparation curved or simply long straight threads were observed. They appeared singly,

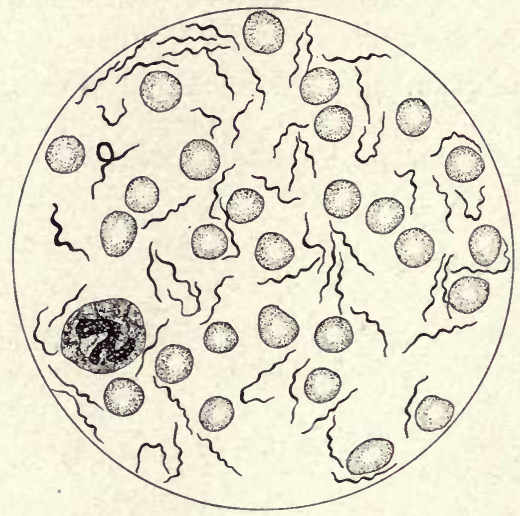

Fig. 93. Spirochaetes from the lesions in the diseased skin of a pig. (After Dodd). in pairs and in clumps. It was difficult to distinguish it in the unstained preparation. It stains well with any of the ordinary aniline dyes but does not retain the coloring matter after being treated by the Gram method.

Hindle ${ }^{5}$ has studied the life cycle of Treponema gallinarum. He worked with spirochaetosis brought from Brazil by Prof. Marchoux. Hindle demonstrated that this parasite multiplied by transverse division as shown in Fig. 94. He also showed the life cycle of the parasite in the fowl and tick (Argas). Figure 95 is taken from his article. The various steps in the life cycle of $S p$. gallinarum are summarized by Hindle as follows:

"One end of a long spirochaete (a) doubles back (b), the reflexed portion being closely applied to the main part of the parasite. The reflexed part gradually increases in length (c), all the time being closely wound round the other portion of the spirochaete (b, c), and thus the two ends approach each other and finally appear in juxtaposition (d). The appearance now presented by the parasite is that of two spirochaetes tightly coiled together, except that at one end of the coil the two threads are continuous, being flexed through an angle of $180^{\circ}$.

"After having passed through this process, which takes

${ }^{5}$ Hindle. Parasitology, Vol. IV (1911) p. 463. 
place with considerable rapidity, the two halves of the spirochaete uncoil from each other ( $f, g)$ and separate at the point of flexion $(\mathrm{g})$, thus producing two parasites. Sometimes the spirochaete breaks in two, before the daughter parasites have uncoiled from each other (e). In the former case the parasites may remain connected together for some time before finally

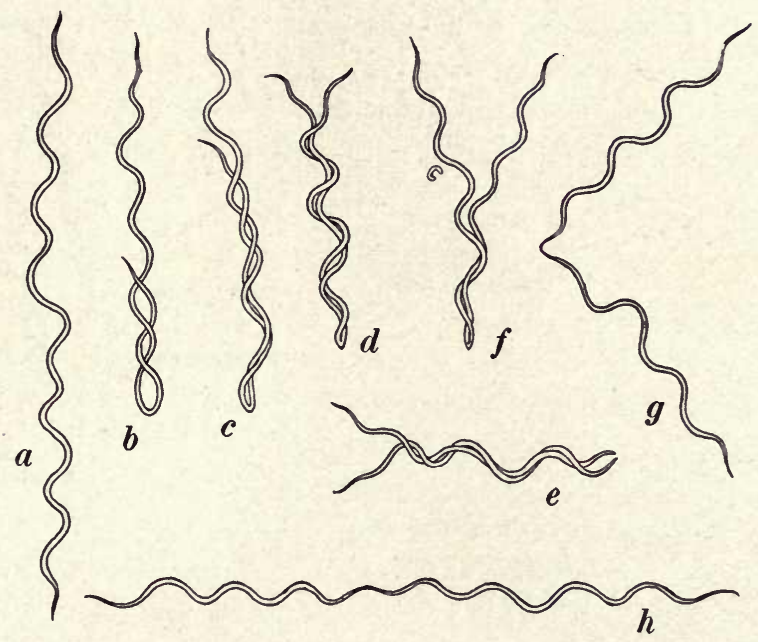

Fig. 94. Various stages in the flexions and transverse divisions of Treponema (Spirochaeta) gallinarum. (After Hindle).

separating $(\mathrm{h})$ and in this case exactly resemble the forms of transverse division previously recorded for these parasites.

"Commencing with the ordinary parasite in the blood of the fowl, the spirochaete grows until it reaches a certain length $(16 \mu-19 \mu)$ and then divides by the peculiar mode of transverse division described above. This process is repeated and is probably the only method of multiplication of the parasite within the blood. When the spirochaetes disappear from the circulation some of them break up into coccoid bodies which, however, do not usually redevelop in the fowl. When the spirochaetes are ingested by Argas persicus, some of them pass through the gut wall into the coelomic fluid. From this medium they bore their way into the cells of the various organs 


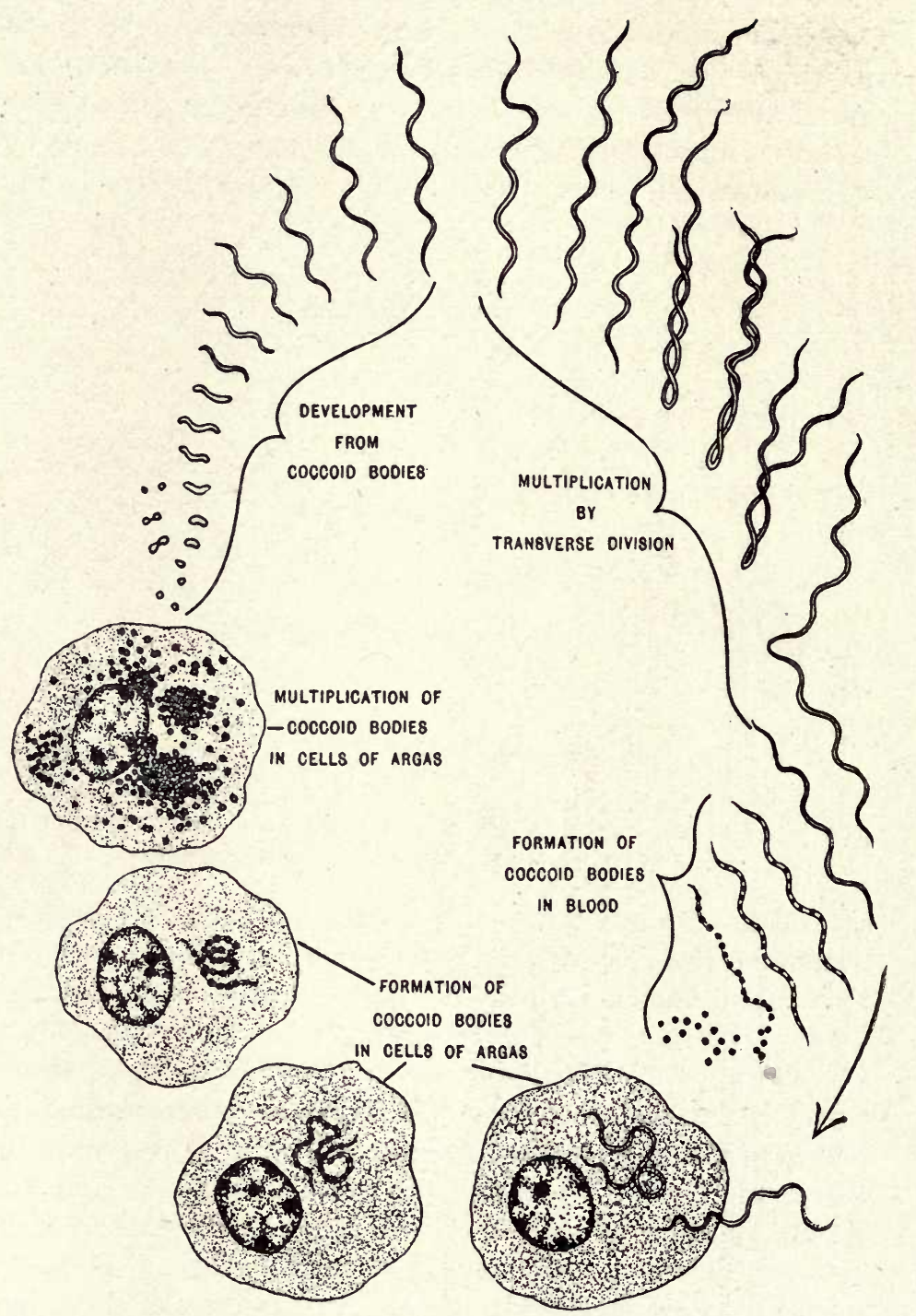

Fig. 95. The life-cycle of Treponema (Spirochaeta) gallinarum illustrated diagrammatically. (After Hindle). 
of the tick and there break up into a number of coccoid bodies. These intracellular forms multiply by ordinary fission in the cells of the Malpighian tubules and gonads. Some of the coccoid bodies are formed in the lumen of the gut and Malpighian tubules. The result is that some of the coccoid bodies may be present in the Malpighian secretion and excrement of an infected tick and when mixed with the coxal fluid may gain entry into another fowl by the open wound caused by the tick's bite. They then elongate and redevelop into ordinary spirochaetes in the blood of the fowl, and the cycle may be repeated.',

TREPONEMA (SPIROCHAETA) THEILERI.

Synonyms. Spirillum ovina; Spirillum Theileri; Spirochaeta ovis; Spirochaeta equi.

Place in nature. This organism was discovered by Theiler ${ }^{1}$ in 1902 in the blood of cattle and sheep. Theiler reports the occurrence of spirochaetes in sheep in the Transvaal which resemble very closely the one in question and it is possible they are identical. He also discovered spirochaetes associated with a disease of horses in South Africa and later it was reported from the west coast of South Africa. Novy and Knapp have designated this latter one Spirochaeta equi. Todd believes that spirochaetes from cattle and sheep belong to the same species.

Morphology. It resembles morphologically Treponema anserina. It varies from 0.25 to $0.4 \mu$ in width and from 10 to $30 \mu$ in length.

SPIROCHAETA MICROGYRATA LOWENTHAL VARIETY GAYLORDI.

Calkins ${ }^{2}$ describes the spirochaeta of mouse cancer discovered by Gaylord and which appears to be identical with the Spirochaeta microgyrata of Lowenthal ${ }^{3}$ found in ulcerated human carcinoma, in a dog tumor and in feces. Calkins' de-

${ }^{1}$ Theiler. Jour. Comp. Path. and Therap., Vol. XVII (1904) p. 48.

${ }^{2}$ Calkins. Jour. of Inf. Diseases, Vol. IV (1907) p. 171.

${ }^{3}$ Lowenthal. Berlin. klin. Woch., Bd. XLIII (1906) p. 43. 
scription is as follows. "As it ordinarily appears, the organism measures from 2.5 to $7.8 \mu$ in length, and it is made up of from 4 to 13 nodes. The average length of the node in a great many measurements is $0.6 \mu$, and the organism is $0.6 \mu$ wide. The nodes therefore are characteristically crowded and the undulations steep. Compared with Sp. Obermeieri, Sp. refringens, and Sp. pallida, this form is much shorter, has more crowded nodes and a greater diameter both relatively and absolutely.",

The ends of Spirochaeta microgyrata Gaylordi are blunt and rounded and there is no evidence of tapering at the extremities, nor of undulating membrane, nor of flagella.

Treponema (Spirochaeta) muris. Wenyon ${ }^{4}$ found in the blood of a brown mouse affected with $T$. dimorphon very active spirals. This spirochaete varies from 3 to $7 \mu$ in length and about $0.2 \mu$ in width. They always appeared in the spiral form. It produces a definite infection in mice with an incubation period of 5 to 6 days. An interesting fact was the discovery of identical organisms in the lice which infested the mice. It has not been cultivated.

SPIROCHAETA AFFECTING MAN.

SPIROCHAETA OBERMEIERI.

Place in nature. This organism, which bears the name of its discoverer, was found by Obermeier in 1873 to be the cause of relapsing fever. They appeared in the blood only and were detected there during the fever, not during the intermissions.

Morphology. The spirochaeta of Obermeier is a delicate spiral thread measuring from 7 to $9 \mu$ in length (Novy), and about $1.0 \mu$ in thickness. While this is its average size, it may, according to some observers, be considerably longer than this, its undulations varying from 4 to 10 or more in number. Compared with the red blood cells among which they are seen, the microorganisms may vary in length from one-half to 9 or 10

${ }^{4}$ Wenyon. The Jour. of Hygiene, Vol. VI (1906) p. 580. 
times the diameter of the corpuscle. In fresh preparations of the blood, very active corkscrew motility and definite lateral oscillation are observed. In stained preparations no definite cellular structure can be made out, the cell body appearing homogeneous, except in degenerated individuals, in which irregular granulation or beading has been observed. Flagella have been described by various observers. Novy and Knapp ${ }^{1}$ believe that the organisms possess only one terminal flagellum. Zettnow, ${ }^{2}$ on the other hand, claims to have demonstrated lateral flagella by special methods of staining. Norris, Pappenheimer, and Flournoy, ${ }^{3}$ in smears stained by polychrome methods, have described long, filamentous tapering ends which they interpreted as bipolar, terminal flagella, never observing more than one at each end. Spores are not found. It has not been successfully cultivated artificially but Novy and Knapp kept it alive in original blood for forty days.

TREPONEMA (SPIROCHAETA) PALLIDA SCHAUDINN.

T. pallida, the cause of syphilis, is the most important spirochaeta affecting man. It was discovered by Schaudinn ${ }^{4}$ in 1905. It is found in preparations made from lesions of that disease.

Morphology. Treponema pallida is an extremely delicate undulating filament measuring from four to ten $\mu$ in length, with an average of seven $\mu$, and varying in thickness from an immeasurable delicacy to about $0.5 \mu$. It is thus distinctly smaller and more delicate than the spirochaete of relapsing fever. Existing in fresh preparations it is distinctly motile, its movements consisting of a rotation about the long axis, gliding movements backward and forward, and, occasionally, a bending of the whole body. Its convolutions, as counted by Schaudinn, vary from 3 to 12 and differ from those observed

${ }^{1}$ Novy and Knapp. Jour. of Infec. Diseases, Vol. III (1906) p. 291.

${ }^{2}$ Zettnow. Deut. med. Woch., Bd. XXXII (1906).

${ }^{3}$ Norris, Pappenheimer and Flournoy. Jour. of Inf. Diseases, Vol. III (1906) p. 266.

${ }^{4}$ Schaudinn and Hoffman. Arb. a. d. Kais. Gesundheitsamte, Bd. XXII (1905) p. 529. 
in many other spirochaetae by being extremely steep, or, in other words, by forming acute, rather than obtuse, angles. The ends of the microorganism are delicately tapering and come to a point. In his first investigations, Schaudinn was unable to discover flagella and believed that he saw a marginal undulating membrane similar to that noticed in the trypanosomes. Later observations by this observer, as well as by others, revealed a delicate flagellum at each end, but left the existence of an undulating membrane in doubt. Uncertain, in his later investigations, whether the microorganisms described by him could scientifically be classified with the spirochaetae proper, Schaudinn suggested the name of "Treponema pallida."'

SPIROCHAETA DUTTONI.

This spirochaete was found by Dutton in 1905 to be the cause of African tick fever. It resembles very closely $S p$. Obermeieri.

Several other spirochaeta have been found in the human body but those mentioned are the most important etiologically.*

\section{NEGRI BODIES.}

Synonyms. Bodies associated with the brain cells in cases of rabies.

Place in nature. Negri bodies are minute structures that were discovered by Negri of the University of Parva in 1903 in the brain cells of cases of rabies or hydrophobia. The cause of this disease has been the object of many researches but it defied the efforts of investigators until Negri made the discovery of bodies which he believed stood in a causal relation to the disease. They have been thought by some workers, however, to be a specific degeneration associated with the cause. They can be found in the brain of practically every animal

* The student is referred to the papers of Uhlenhuth and Haendel, Fritz Schaudinn, and Prowazek for details relative to the Spirochaetes of recurrent fever, and those closely allied to Treponema pallida. (Arbeiten a. d. Kais. Gesundheitsamte, Bd. XXVI (107). 
that dies of rabies. Negri bodies appear in smear and impression preparations and in sections of the brain. Ammon's horn seems to be the most satisfactory part to examine for these bodies. There is a very large literature on this subject. The work of Williams and Lowden ${ }^{1}$ indicates that these bodies belong to the Protozoa. The following are their conclusions.

"The smear method of examining the Negri bodies is superior to any other method so far published for the following reasons: (a) It is simpler, shorter, and less expensive; (b) The Negri bodies appear much more distinct and characteristic. For this reason and the preceding one, its value in diagnostic work is great; (c) The minute structure of the Negri bodies can be demonstrated more clearly; (d) Characteristic staining reactions are brought out.

"The Negri bodies as shown by the smears as well as by the sections are specific to hydrophobia.

"Numerous 'bodies' are found in fixed virus.

" 'Bodies' are found before the beginning of visible symptoms-i. e., in rabbits on the fourth day in fixed virus, on the seventh day in street virus-and evidence is given that they may be found early enough to account for the appearance of infectivity in the host tissues.

"Forms similar in structure and staining qualities to the others, but just within the limits of visible structure (at 1,500 diam. magnification) have been seen. Such tiny forms, considering the evidence they give of plasticity, might be able to pass the coarser Berkefeld filters.

"The Negri bodies are organisms belonging to the class protozoa. The reasons for this conclusion are: (a) They have a definite, characteristic morphology; (b) This morphology is constantly cyclic, i. e., certain forms always predominate in certain stages of the disease, and a definite series of forms indicating growth and multiplication can be demonstrated; (c) The structure and staining qualities, as shown especially by

${ }^{1}$ Williams and Lowden. Jour. of Inf. Diseases, Vol. III (1906) p. 452 . 
the smear method of examination, resemble those of certain known protozoa, notably of the rhizopoda.

"If the 'Negri bodies' are living organisms they are the cause of hydrophobia; a single variety of living organisms found in such large numbers in every case of disease, and only in that disease, appearing at the time the host tissue becomes infective, in regions that are infective, and increasing in these infective areas with the course of the disease can be no other, according to our present views, than the cause of that disease."

Morphology. The largest forms measured are about $18 \mu$ and the smallest about $0.5 \mu$.* They are round, oval, oblong, triangular or ameboid. The latter are more numerous in the fixed virus of rabbits and guinea pigs. They vary in number according to the stage of the disease and to the infectivity of the part.

They are situated chiefly in the cytoplasm and along the fibres in the branches of the large nerve cells of the central nervous system. In parts of smears which are more broken up the bodies may appear as if lying free, and it is these bodies, if the pressure be not too great in smearing, that show the structure best. In some cases the bodies are distinctly localized in small scattered areas of the central nervous system. This is shown especially well in smears. Whatever the variety or species of animal infected, the bodies preserve the same general characteristic structure, i. e., a hyaline-like cytoplasm with an entire margin, containing one or more chromatin bodies having a more or less complicated and regular arrangement.

Their structure varies to a certain extent with their size. In fixed virus, with an occasional exception, only tiny forms are found.

* Remlinger (Ann. de l'Inst. Pasteur, Vol. XVII (1903) p. 834) found that the virus of rabies would not pass through the closegrained Chamberland $\mathrm{B}$ and $\mathrm{F}$ filters but that under certain conditions it would go through the more open textured Berkefeld filter. To produce the disease with the filtrate from 0.5 to 1 cc. was necessary to be injected under the dura-mater. 
These are rounded, or sometimes wavy in outline, as if possessing slight amoeboid motion, sometimes elongated, ex-

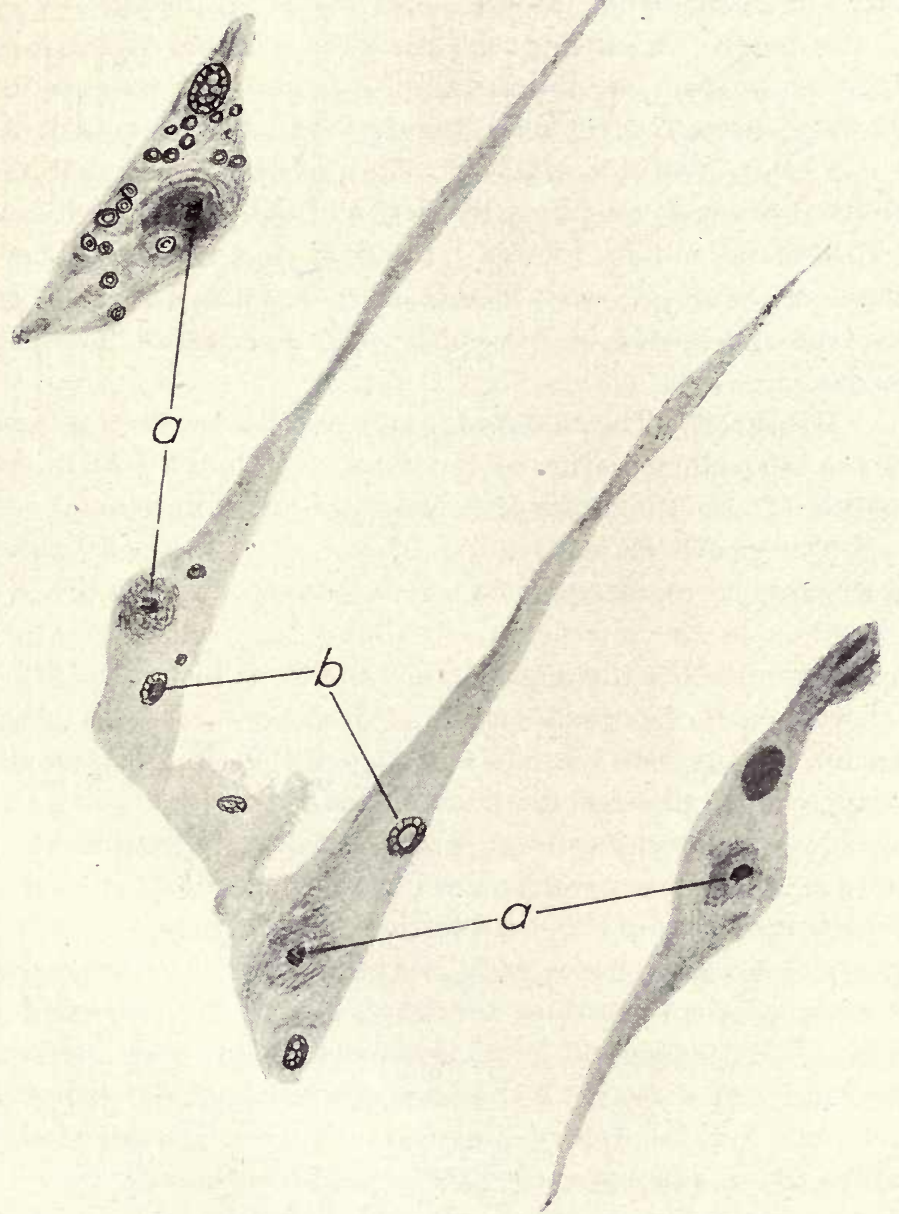

Fig. 96. Negri bodies in nerve cells: a, nuclei of cells; b, Negri bodies. (After Frothingham). 
tending along the rim of the host-cell nucleus, or along one of the nerve fibrils, as if moving there; with eosin and methylene-blue they take a delicate light magenta stain, very similar to that taken by the small serum globules in the blood vessels. Many of the organisms, however, show a small chromatin granule, situated more or less eccentrically, sometimes on the very rim of the body. In the larger forms the granule is large, in the smaller it can not always be seen; some of the larger forms show from two to several granules and oceasionally they show a definite central body and the small granules about it.

In this laboratory rabbits were inoculated with the brains of 60 suspected cases (mostly dogs) of rabies in which Negri bodies could not be found. In every case the results were negative. On the other hand, every animal that has been inoculated with the brains containing these bodies has died of rabies.

Diagnosis. The methods recommended by the committee of the laboratory section of the American Public Health Association for the diagnosis of rabies ${ }^{2}$ are given in detail.

The most striking feature of rabies, in the dead animal, is the absence of recognizable gross changes. This restricts the diagnosis to the microscopic findings or to other laboratory methods. As the diagnosis of the disease is to be made in the laboratory, the method consists of two parts: (1) the procuring of the suspected animals in a condition suitable for diagnosis and (2) the technique employed.

(1) The results of the numerous investigations into the nature and diagnosis of rabies have demonstrated that all the structures necessary for a positive diagnosis are included in the brain and the nerve ganglia of the head. This necessitates sending to the laboratory the head only of the suspected animal. The head should be removed close to the body, packed in $i c e$, and sent directly to the laboratory as quickly as possible.

(2) The laboratory diagnosis of rabies is restricted, for all practical purposes, to three procedures, namely:

a. Inoculation of experimental animals.

${ }^{2}$ Jour. Am. Pub. Health Asso., Vol. I (1911) p. 420. 
b. The determination of the changes in the ganglia as described by Van Gehuchten and Nelis. ${ }^{3}$

c. The presence of Negri bodies.

Inoculation. In the animal inoculation method rabbits are to be preferred, although guinea pigs may be used. They should be inoculated with the suspected brain, preferably subdurally, although intraocular and intramuscular inoculation eannot be entirely excluded. The diagnosis by this method is not recommended, except in case of failure by the other methods, and where a late determination will be of value.

Van Gehuchten and Nelis method. The diagnosis by means of the changes in the Gasserian ganglia, described by Van Gehuchten and Nelis, has proved to be very satisfactory where the suspected animal has died or was killed in the late stages of the disease, or when Negri bodies cannot be found, or cannot be looked for because of destruction of brain, putrefaction, ete. When sections are made from the ganglia removed during the first stages of the disease, the apparently specific lesions are often absent or not sufficiently well marked to warrant a diagnosis. The technique required for this procedure is simply that of ordinary pathological histology. The changes may be of two kinds:

The typical, or focal lesions. These are characterized by the partial or complete destruction of the ganglion cells, their place being occupied by cells of the endothelial type. The foci may consist almost entirely of cells of the endothelial type, but often associated with them are mast cells, lymphocytes, plasma, and connective tissue cells, and polymorphonuclear leucocytes.

The atypical, or diffuse lesions. These are characterized by a more or less general infiltration between the ganglion cells and nerve fibres of cells of an endothelial origin and the various cells which are associated with chronic inflammatory processes. These changes are usually associated with the typical lesions.

The lesions in the ganglia may be very extensive, involving

${ }^{s}$ Van Gehuchten and Nelis. Ann. de Méd. Vet., Vol. XLIX (1900) p. 234 . 
the entire ganglion, or they may be restricted to a single ganglion cell here and there in the organ. The lesions may be present in one ganglion and not in the other. It is sometimes necessary to examine a number of sections before finding the changes.

Negri bodies. The diagnosis by the presence of Negri bodies: The numerous examinations and investigations that have been made since 1903 to confirm the discovery of Negri that the bodies which he described possessed a diagnostic, if not causal, relation to rabies, have been practically unanimous in their affirmative findings. We feel justified, therefore, in asserting that the presence of Negri bodies is sufficient evidence on which to diagnose the disease. The results of the different investigations also indicate that the Ammon's horn is the place where these Negri bodies are most constantly present, and therefore the part of the brain to be first examined for them. If they are not found there, an examination should be made of the cerebrum and cerebellum. Those who have worked with these bodies have found that they are not especially diffcult to stain or to detect on microscopic examination. Several methods of preparing the material for examination have been suggested, and in the different laboratories where the diagnosis of rabies is being made, slightly different technique is employed.

In formulating a method to be recommended to all laboratories, it does not seem within the province of this Committee to accept or to reject any of the technical methods which are giving excellent results in the hands of certain workers, but which are not employed by others. The failure of any of the procedures about to be given depends apparently more upon the worker than upon the method.

Because of the excellent results obtained by different technique, the Committee recommended as a procedure in diagnosing rabies from suspected animals sent to laboratories for that purpose, the following: namely,

1. Examine for Negri bodies, and, if they are found, report the disease as positive. 
2. If Negri bodies cannot be found, examine the Gasserian ganglia for cellular lesions.

3. If the results from the examination for Negri bodies and ganglion changes are negative, rabbits should be inoculated in those cases where a late diagnosis will be of value. Otherwise, animal inoculations should be omitted.

Examination for Negri bodies. At least four preparations from each of the hippocampi, four from each of the cerebra, and four from the cerebellum, should be carefully examined before pronouncing the ease negative. In making the preparations for examination any one of the following three methods may be employed.

Smear preparations as described by Williams, of the New York City Board of Health Research Laboratory.

Impression preparations as described by Frothingham, of Harvard University.

Fixing the tissue and making sections.

Either of the first two methods is preferable to the last, although occasionally the Negri bodies seem to be more clearly differentiated in the section. Zenker's fluid is recommended for fixing the tissue. It does not seem to be necessary to fix for more than from four to six hours when the tissues are cut in thin pieces.

The stain to be employed for smear or impression preparations should be either Van Giessen's, or eosin and methylene blue. If the tissue is fixed in acetone and sectioned, the staining method recommended by Mann or that proposed by Lentz gives excellent results. If the tissue is fixed in Zenker's fluid, eosin and methylene blue should be used.

It is understood that in the application of any of these methods, the greatest care should be taken relative to the preparation, stain, the time of staining, and the variation in the number and location of the Negri bodies in the brain. Experience has shown that cases of rabies are exceedingly rare which eannot be diagnosed accurately by the search for Negri bodies. As a precaution, all reports that are negative on microscopical and histological examination should state that 
if the animal was believed from its action to have had rabies, the persons bitten should be warned of their possible danger, in order that they may take the preventive treatment if they so desire.

\section{SARCOSPORIDIA.}

Place in nature. This order of protozoa is very little known. The sarcosporidia are parasites found in the striped muscle and in connective tissue of certain mammais and birds. The parasite belonging to this order appears, according to Calkins, ${ }^{1}$ in its earliest stages as a minute white body embedded in the material of a muscle fiber, in which condition it is known as Miescher's tube, a name applied to the vegetative forms of the mouse parasite Sarcocystis muris. As the young trophozites grow, the nuclei increase in number, a definite saclike membrane develops around the protoplasmic body, while in the centre groups of spores begin to form. The ripening spores (merozoites, gymnospores) gradually encroach upon the more peripheral unused protoplasm of the tube until the ends only appear to be active, and capable of vegetative functioning, and even these, finally, are used in spore formation. In Sarcocystis tenella of sheep such eysts may grow to a length of two inches in the muscle bundles, where they ultimately burst, the spores being scattered or carried by blood to new regions, where development begins anew (auto-infection). In some cases the entire body may be overrun by such parasites, mice especially often being killed in this manner.

In all cases there is every reason to believe that this method of endogenous multiplication can not be continued indefinitely any more than a paramecium can continue to divide indefinitely, and there is reason to suppose that the potential part of vitality gives out at the end of a more or less definite cycle of generations. In many cases, the organisms seem to have devised a means of counteracting this senile process and of being stimulated to renewed activity in much

${ }^{4}$ Calkins. Protozoology, p. 185. 
the same way that the paramecium * can be stimulated by artificial means. It is a recognized fact that many of the blood diseases are characterized by relapses in which the organisms reappear after having disappeared from the circulation.

Pathogenesis. The extent of the effect of sarcosporidia upon living animals is not fully known.

In some cases the cyst wall calcifies and the contents of the eyst degenerate, with apparently no harm to the host, in other cases the cysts burst and their contents spread into the surrounding tissue, producing abscesses and tumors as with many myxosporidia and sometimes causing the death of the host.

The symptoms of sarcosporidiosis in the pig are described as paralysis of the hind extremities, a skin eruption, and general systemic symptoms, such as increased temperature and pulse.

In sheep especially, the disease often causes fatal epizootics. In the mouse, Sarcocystis muris is a deadly parasite.

Laveran and Mesnil claim to have extracted a toxin (Sarcocystin) by means of glycerine or a salt solution, which they have found extremely toxic for experimental animals $(0.0001$ gm. kills $1 \mathrm{kgm}$. of rabbit). The dried and powdered extracts are also virulent. These extracts will remain virulent for a long time in the ice box but will not withstand heating above $60^{\circ} \mathrm{C}$. for any time.

Minchin and Fantham ${ }^{2}$ have described a new species, Rhinosporidium kinealyi, to be the apparent cause of a tumorlike growth of connective tissue in the nasal cavities of the natives of India. Watson ${ }^{3}$ finds that sarcosporidia may become a grave menace to the life of their hosts. He calls at-

* By changing the food the cultures of paramecium that had almost lost vitality were restored by feeding beef broth for several days, and another cycle of cell generations produced.

${ }^{2}$ Minchin and Fantham. Quarterly Jour. of Mic. Science, Vol. XLIX (1905) p. 521.

${ }^{3}$ Watson. Jour. of Path. and Therap., Vol. XXII (1909) p. 1. 
tention particularly to the presence of these parasites giving rise to the disease and death of eattle suspected of loco-poisoning. In cattle that died he found enormous numbers of sareosporidia. They were very numerous in the heart and muscles. $\mathrm{He}^{4}$ reported that his work in and about Lethbridge showed
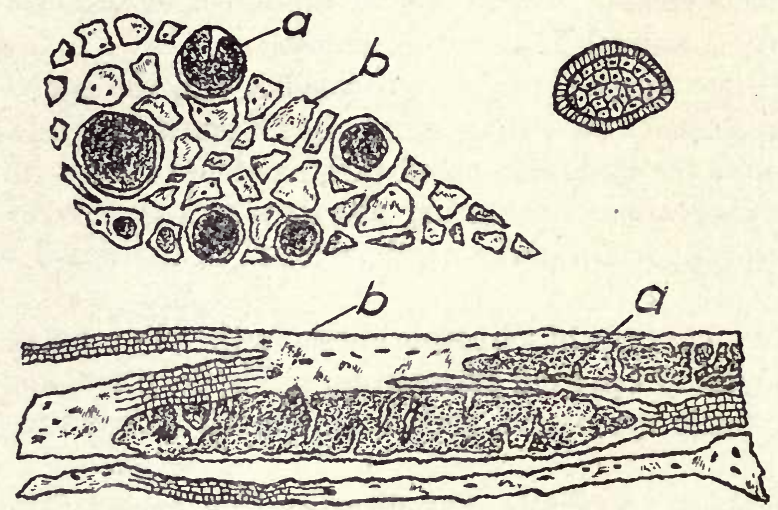

Fig. 97. Sarcocysts in muscle. A, sarcocyst, b, muscle. The upper figure shows the sarcocysts in cross section of muscle and the lower one in longitudinal section. (After Watson).

that sarcosporidiosis may be closely associated with and is probably a very frequent sequel to the disease of cattle known as loco-disease. He feels that this form of parasitism may complicate the diagnosis in both loco-poisoning and dourine. Foelger $^{5}$ calls attention to the presence of eosinophiles in the muscles infested with sarcosporidia.

\section{LEUCOCYTOZOON CANIS BENTLEY.}

Bentley ${ }^{6}$ found what he believed to be a parasite in the white blood corpuseles. It is accompanied by a marked

${ }^{4}$ Watson. Appendix No. 10. Rept. of the Veterinary DirectorGeneral and Livestock Commissioner, Dept. of Agric., Canada, for the year ending Mar. 31, 1909. Issued 1911.

${ }^{5}$ Foelger. Zeit. f. Infekionsk. u. Hyg. der Haustiere, Bd. IV (1908) p. 102.

${ }^{6}$ Bentley. British Med. Jour., 1905-i, p. 988. 
eosinophilia. Gessard ${ }^{\top}$ describes a protozoan parasite which he bclieves to be identical with the protozöon described by Bentley in the polymorphonuclear leucocytes of a dog that was evidently in poor health. He deseribes it as follows.

"The parasites are oblong bodies with a smooth regular outline; they are colorless, motionless and contain no pigment. When stained with Leishman's method a nucleus, protoplasm, and a capsule can be readily made out. The nucleus in some instances is horse-shoe shaped, in others irregularly spherical. The measurements of the body are very uniform, 11 to $12 \mu$ by 4.2 to $5.2 \mu$."

\section{COCCIDIA.}

General discussion. Of the sporozoa that oceur as parasites, in the higher animals, coccidia are perhaps of first importance. In their young state they exist as non-encapsulated inhabitants of epithelial cells, particularly in those of the intestinal canal and its adnexa, especially the liver, and more rarely in those of the organs of excretion. Some of the mature forms surround themselves with a capsule and become changed into round or oval permanent cysts or oocysts (Schaudinn), which leave their resting-place and usually their host, and under certain conditions form sickle-shaped sporozoites through the repeated division of their cell body (sporogony). Through the taking-up of sporozoite-containing oöcysts into a new host there is produced an infection of the latter, in that the sporozoites are set free and seek out epithelial cells for their further development.

Besides this form of multiplication there occurs within the infected organ also a reproduction by schizogony - that is, there are developed from mature but non-encysted individuals, by means of segmentation, a large number of new sickle-shaped individuals, the so-called.merozoites, which seek out epithelial cells, and develop further in the same.

'Gessard. The Jour. of Hygiene, Vol. VI (1906) p. 229. 
Recently Tyzzer ${ }^{1}$ has reported a study of coccidiosis in the rabbit in which he points out that they attack only the epithelial cells and that at the termination of the process of growth of the parasite, the cell is reduced to simply a sac containing the parasite having on one side a deeply stained crescent.*

Several species of coccidia have been described. They have been found in many animals and occasionally as the cause of serious parasitism. The following species are more commonly encountered. The condition resulting from the invasion of coccidia is known as coccidiosis. Rabbits affected with coccidiosis exhibit livers with nodules which frequently have been mistaken for tuberculosis. The hepatic parenchyma is studded or literally filled with whitish yellow cysts varying in size from a millet seed to that of a pea or even larger. They are globular or elongated in shape. They may be present in very large numbers in which ease the liver is enlarged and covered with nodular protuberances. The cysts contain a thick, yellowish, grumous or caseous matter chiefly composed of the encysted coccidia, epithelial cells in the state of fatty degeneration, free nuclei and fat globules. The membrane lining these nodules is simply the altered wall of a hepatic canal which under the influence of irritation has developed a somewhat thick capsule of connective tissue.

${ }^{1}$ Tyzzer. Jour. of Med. Research, Vol. II (1902) p. 235.

* Calkins has pointed out very clearly the well recognized biological principle that degeneration is an inevitable outcome of continued parasitism (Lankaster degeneration). While the degeneration of the usual vegetative organs is the result of parasitism, the restricted mode of life of the parasite may require certain conditions which may lead to structural adaptations on its part. This tends to decrease the chances of the parasite. In order to overcome this, the biological fact has been observed that the number of offspring of an animal is in inverse proportion to the chances of reaching maturity and that the number is great enough to maintain the species. With the great group of protozoa it is expected that some of them would have acquired a parasitic mode of life. 


\section{COCCIDIUM OVIFORME LEUCKART.}

Synonyms. Coccidium cuniculi Rivolta (Anat. physiol. 1878).

Morphology and development. In the encysted state, as it may be found in the biliary canals of infested rabbits, the parasite is an ovoid body $-30 \mu$ to $50 \mu$ long by $14 \mu$ to 28 $\mu$ broad-enclosed in a double contoured shell (cyst), with a depression (micropyle) at one of its poles. At first the eyst is filled with protoplasm; very soon the latter separates from the wall and contracts into a nucleated spherical mass. It is the last phase of parasitic development observed in the liver; the coccidia pass with the bile from the liver into the intestine,

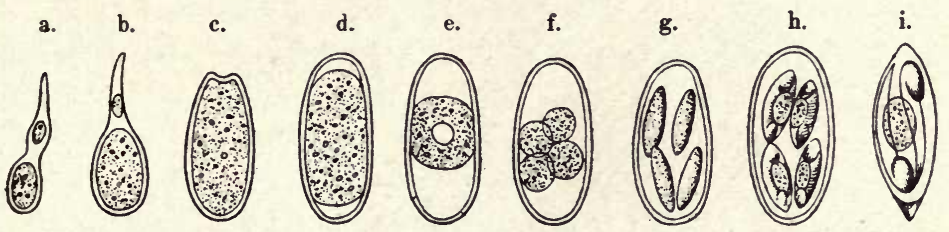

Fig. 98. Coccidium oviforme from a rabbit's liver. a and b, young stages in the epithelial cells of the bile duct; c, d and e, oocysts; $\mathrm{f}$, $\mathrm{g}$ and $\mathrm{h}$, spore formation; i, spore with sporozoite. (After Doflein).

and are carried out with the excreta. Their ulterior evolution takes place in water or in moist earth. If some of the ripe cysts from an infested liver are placed under a thin layer of water, on damp sand, or on a piece of charcoal in a moist chamber, their development may be followed. The rapidity of their evolution depends upon the conditions of temperature and oxygenation in which they are placed. The process may be completed in from ten to fifteen days (Balbiani), or in four or five days according to $R$. Pfeiffer. Segmentation divides the protoplasmic sphere into two, then into four smaller spheres or sporoblasts; each of these elongates, surrounds itself with a double membrane, and becomes a sporocyst. The division of the contents of each sporocyst results in the formation of two nucleated comma-shaped protoplasmic bodies (sporozoites) 
placed in inverse direction-the rounded extremity of cne being in contact with the pointed extremity of the cther-and between them may be seen the remains of the granular mass. In this state the eysts may exist without alteration for a very long time in external media. Introduced into the intestine with the food or water, the ripe cysts are dissolved by the pancreatic juice; the sporocysts, set free, open and liberate the sporozoites which more or less rapidly gain the biliary canals and invade their epithelial cells.

The multiplication of Coccidium oviforme, within the

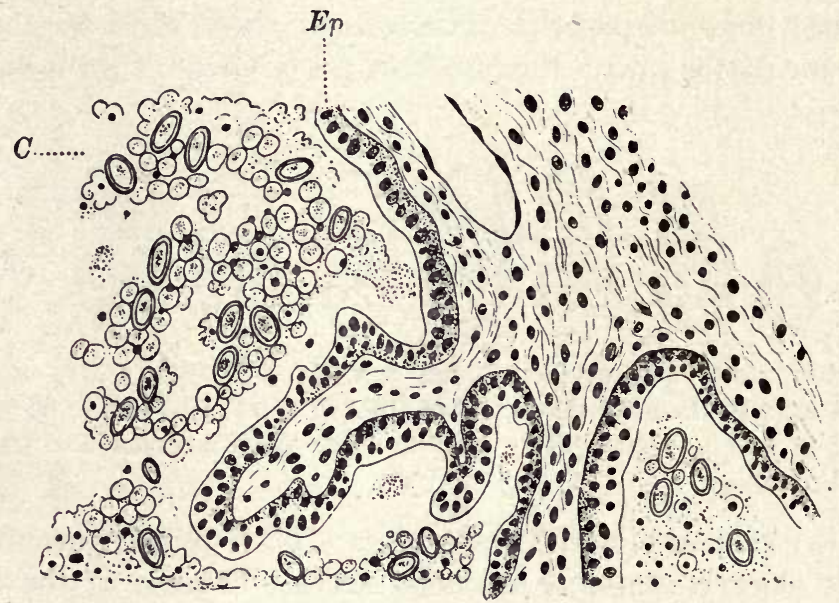

Fig. 99. Coccidium oviforme in the section of a rabbit's liver. Ep, epithelial cells; C, coccidia. (After Thoma and Kitt).

epithelial cells, is accompanied by fecundation and by schizogenesis after the manner already indicated. Feeundation has not been observed in Coccidium, but probably it is identical with that which has been seen in allied species. Influenced by chemotactic attraction, several microgametes come in contact with the macrogamete; one of them penetrates by the micropyle, which is then closed. The male nucleus blends with the female nucleus, and together they constitute the oöcyst: it is the encysted coccidium or sporont, which by sporogenesis will produce sporoblasts, then sporozoites. 
The coecidia in the liver show themselves in two principal forms-free or encysted. The free coccidia (schizonts, merozoites, or young macrogametes) are most frequently spherical or slightly elongated, and measure $11 \mu$ to $14 \mu$ broad, and $17 \mu$ to $22 \mu$ long. Some are almost homogeneous and very refrangent, with a darker central point; the others are altogether granular, without a central point; they resemble cells undergoing fatty degeneration; their volume varies from $6 \mu$ and $8 \mu$ to $30 \mu$. They are often included in epithelial cells, and solitary or grouped in small masses in the same cell. The encysted coccidia (oöcyst) may also exist in the interior of a cell; and like the preceding, they are sometimes lodged in large giant-cells.

It is not rare to find white particles floating in the bile, similar to the contents of the tumors, and almost exclusively formed of coccidia. Rivolta once found numerous encysted coceidia in the epithelium of a dilated gall-bladder.

A number of observers have recorded the presence of coccidia that were not distinguishable from Coccidium oviforme in the intestinal epithelium of lambs and other animals such as horses, cattle, goats and swine.* In a few eases they have been recorded in the livers of men who had to do with the handling of rabbits. Other species have been found, one in particular affecting the epithelial intestine of salmon and house mice. In addition to the coccidia other closely related genera of animal parasites have not infrequently been found in animal tissues.

Sjöbring, ${ }^{1}$ who studied a coceidium in the birds of Sweden, describes forms belonging to two genera of coccidia. One was found in pheasants and the other in many different species of birds. He states that he did not find coceidia in the liver. More recently Morse ${ }^{2}$ has found coccidia in the intestine of small chicks suffering from a disease popularly known as white diarrhea. He designates the organism as Coccidium tenellum.

* Quoted by Doflein, Die Protozoen.

${ }^{1}$ Sjöbring. Centralb. f. Bakt., Bd. XXII (1897) p. 675.

${ }^{2}$ Morse. Circ. 128, B. A. I., U. S. Dept. of Agric., 1908. 
This he also referred to as Coccidium avium. Cole and Hadley ${ }^{3}$ have ascribed the disease of turkeys known as blackhead to an invasion by a coccidium. Hadley ${ }^{4}$ describes the morphology of this coccidium, accepting the generic term Eimeria, deseribing it under Eimeria avium. Later, Cole and Hadley ${ }^{5}$ described their findings that coccidia are the cause of the disease known as blackhead in turkeys."

Raillet and Lucet ${ }^{6}$ described a "renal coccidiosis" in geese caused by a coccidium designated Coccidium truncatum.

Smith ${ }^{7}$ reported finding eysts of sporozoa in the intestine of eattle but he did not identify them. They appeared as homogeneous and knobbed crescents within the cysts.

${ }^{3}$ Cole and Hadley. Sciєnce, N. S. Vol. XXVII (1908) p. 994.

${ }^{4}$ Hadley. Archiv. f. Protistenkunde, Bd. XXIII (1911).

${ }^{5}$ Cole and Hadley. Bulletin 141, Agric. Exp. Station of the Rhode Island State College, 1910.

* The disease known as blackhead was described by Theobald Smith (see p. 381) as being due to Amoeba melegridis. In Science for Oct. 14, 1910, Smith replies to some of the publications of Cole and Hadley in which he points out that after a careful review of the slides which he had prepared in his original study of blackhead he finds no evidence that the disease is due to coccidia.

${ }^{6}$ Raillet and Lucet. Compt. rendu de la Soc. de Biol., Vol. XLII (1890) p. 293.

${ }^{7}$ Smith. Bulletin No. 3, B. A. I., U. S. Dept. Agric., 1893, p. 73. 


\section{CHAPTER XXII.}

\section{EPIZOOTIC DISEASES OF UNDETERMINED ETIOLOGY (FILTERABLE VIRUSES).}

General statement. Although microbiology has revealed the definite cause of many of the infectious diseases of man and the lower animals, it has failed thus far to demonstrate the cause of a number of important maladies that can be inoculated from affected individuals to healthy ones or that can be prevented by rigid quarantine of the infected. Diseases of this class exist among lower animals and in man. The more important of the epizoötic diseases of this class are "foot and mouth" disease, contagious pleuro-pneumonia, rinderpest, cow, horse and sheep pox, horse sickness, epithelioma contagiosum of fowls, chicken pox (of fowls), dog distemper, influenza, infectious cerebro-spinal meningitis of horses and epizootic hog cholera. ${ }^{1}$ The literature on these different affections shows that for each disease one or more observations have been made which have caused the announcement of the discovery of the specific cause. For the diseases mentioned, however, reported discoveries relative to the causal factors have not been satisfactorily confirmed and consequently they remain in the class of unknown etiology. In the human subject such diseases as scarlet fever, measles, variola (small pox), chicken pox, yellow fever, typhus fever and Rocky Mountain spotted fever are still included in this class.

The cause of rabies, which attacks all species, is believed by some pathologists to be undetermined, although there are investigators who believe the bodies discovered by Negri are protozea and the eause of the malady. For this reason the Negri bodies are included temporarily among the pathogenic protozoa.

${ }^{1}$ M'Fadyean reviews the literature on the ultravisible viruses in a series of articles in the Jour. of Comp. Path. and Therap., Vol. XXI (1908) pp. 58, 168 and 232. 
Probable etiology. Many opinions exist concerning the etiology of these affections. Bacteria, protozoa and enzymes have each been thought to be their cause. Although the specific infectious agent is not known it has been found that whatever it is, it resides in certain tissues or organs of the infected individual from which at some time and by some means it is transmitted to others.

Reasons for failure to discover the cause. All of these diseases have been carefully studied by the methods that have been effective in revealing the cause of many of the infectious maladies. Many other methods have also been tried. The failure to find the cause may rest in a number of conditions concerning the nature of the infective agent among which the following may be mentioned:

Their incultivability. It is possible that the cause of these diseases can not be cultivated outside of the body of their host or perhaps hosts. They are possibly obligatory parasites.

Mixed or symbiotic infections. It has been thought that possibly these maladies were the result of a mixed infection.

Unstainability. It has been thought that possibly the causal factors could not be stained by known methods and because of their refractive nature could not be detected in the fresh state microscopically.

Ultramicroscopic size. This was Pasteur's explanation for not finding the cause of rabies. Helmholtz showed that on account of dispersion of light, organisms less than $0.2 \mu$ in size could not be rendered visible to the usual eye. Many of the known microorganisms are so small that they are on the border line between the visible and invisible.

Filtration experiments. Various forms of mineral filters - porcelain (Pasteur), infusorial earth (Berkefeld)-have been of much service in securing filtrates free from known bacteria. This method has been brought into use with the diseases of unknown etiology by which it has been found that the virus, whatever it is, of certain diseases can be removed 
from the infecting material while that of others will pass through them.*

Contagious pleuro-pneumonia. The virus of contagious pleuro-pneumonia in cattle does not pass through the Chamberland filter B. Nocard and Roux ${ }^{2}$ inoculated collodion capsules containing bouillon with the "lymph" exudate of contagious bovine pleuro-pneumonia, sealed and placed them in the abdominal eavity of rabbits. In from 15 to 20 days the liquid became cloudy and with a magnification of 2000 diameters and a brilliant illumination, they detected minute bodies in the liquid. With this culture they produced the same disease in cattle that follows the inoculation of the exudate. Nocard ${ }^{3}$ found that the pulmonary exudate was rendered harmless by passing it undiluted through a Berkefeld or a Chamberland filter, but when diluted from 60 to 80 times its volume with water or bouillon and passed through a Berkefeld or Chamberland F. filter it was infective. The eloser grained filters such as Kitasato's or Chamberland B. kept the virus back.

Foot and mouth disease. Loeffler and Frosch ${ }^{4}$ found that the virus of foot and mouth disease when diluted passed through a Berkefeld filter that refused to pass Ps. fuorescence. The Kitasato filter of finer pores kept back the virus. This was the first among the diseases* of animals to have its virus demon-

* In filtering the substance containing the virus it is important that the filter $\mathbf{r}$ mployed is perfect and is capable of keeping back known bacteria. There is considerable difference in the density of filters of the same make. Secondly, the conditions under which the filtration takes place should be such that the virus can not grow through the filter.

${ }^{2}$ Nocard and Roux. Ann de l'Inst. Pasteur, Vol. XII (1898) p. 240.

${ }^{3}$ Nocard. Handbuch der pathogenen Mikroorganismen, Kolle and Wassermann, Bd. III (1903) p. 704.

${ }^{4}$ Loeffler and Frosch. Centralbl. f. Bakt., Bd. XXIII (1898) p. 371.

* The mosaic or spotted disease of the tobacco plant was the first infectious disease to furnish experimental evidence that there was a virus that would pass through such a filter. Iwanowski in 1892 determined that the filtered juice of this plant was infective. In 1899 Beigerinck independently rediscovered the same fact. 
strated in the filtrate after passing through a Berkefeld filter. This discovery led to many investigations along this line with infective fluids from animals suffering with the diseases of undetermined etiology. In their investigations Loeffler and Frosch (loc. cit.) made the following determinations regarding the destruction of the virus.

It was killed (1) by drying for twenty-four hours at summer temperatures (maximum $31^{\circ} \mathrm{C}$. at mid-day); (2) by heating at $37^{\circ} \mathrm{C}$. for twelve hours (the effect of a shorter exposure at the same temperature was not tried) ; (3) by heating for half an hour at $70^{\circ} \mathrm{C}$.; and (4) by heating for half an hour at $60^{\circ} \mathrm{C}$. In one case, however, an animal inoculated with a large dose of lymph which had been thus heated developed a typical attack of the disease.

Lymph stored in eapillary tubes and kept in an ice chest for fourteen days was always infective. After three weeks it was sometimes inactive, but even after eight or nine weeks many samples proved active when large doses were employed for inoculation.

Fowl pest. In 1901 Centanni and Savonuzzi ${ }^{5}$ investigated a disease which oceurred among fowls in the province of Ferrara, in Italy, and to which they gave the name fowlplague (peste aviaria).* The disease had apparently existed for a long time in Italy, and although it closely resembles fowlcholera, it had been differentiated by Perroncito and others from the latter affection by minor clinical and pathological characters, and by the absence of the easily recognized fowlcholera bacteria in the blood. The two diseases appear to have been frequently confounded until Centanni and Savonuzzi showed that the cause of fowl-plague is an ultravisible virus, not arrested when a mixture of blood and saline solution is passed through a Berkefeld filter.

At a later date a very exhaustive study of the disease was

${ }^{5}$ Centanni and Savonuzzi. La peste aviaria. Referred to by Maggiora and Valenti. Belgium.

* This disease has since been reported in Austria, Germany and 
made by Maggiora and Valenti ${ }^{6}$ who, in thirty experiments, found that dilute mixtures of blood and water ( 1 in 40 or 60) were still infective when passed through Berkefeld or Chamberland F. filters, which were proved to be efficient for the arrest of such small visible organisms as the pyogenic staphylococci. On the other hand, the filtrate furnished by a Chamberland $\mathrm{K}$. filter under a pressure of not more than one and a half atmospheres, was non-infective.

Other diseases of fowls and birds. Schiffmann ${ }^{7}$ found in the brains of pigeons and young geese in which the disease is not acute well defined corpuscles which present a certain resemblance to the Negri bodies of rabies. All attempts to induce the virus of fowl plague to multiply outside the body have failed. Maggiora and Valenti found that the blood kept in hermetically sealed tubes in a cool place and in the dark retained its virulence for at least 45 days. Dried blood kept under similar conditions retained its virulence for 22 days. When exposed to the air in diffuse sunlight it remained virulent for 15 days. According to Lode ${ }^{8}$ pieces of the organs such as the liver placed in glycerine retained their virulence for from four to five months.

Marx and Stickner ${ }^{9}$ found that the virus of the affection of birds known as epithelioma contagiosum would pass through a filter. Juliusberg ${ }^{10}$ confirmed the results of Marx and Stickner and showed that the virus of this disease in pigeons was also filterable. Burnet ${ }^{11}$ obtained varying results in his experiments with the pigeon virus.

Maggiora and Valenti found that the Chamberland filter K. under a pressure of one and one-half atmospheres held back the virus of exudative typhus of chickens or chicken pest.

Rinderpest (cattle plague). Nicolle and Adil-Bey ${ }^{12}$

'Maggiora and Valenti. Zeit. f. Hyg., Bd. XLII (1903) p. 185.

${ }^{7}$ Schiffmann. Zeit. f. Hyg., Bd. LII (1903) p. 185.

${ }^{8}$ Lode. Centralbl. f. Bakt., Bd. XLIII (1906) p. 355.

'Marx and Stickner. Deut. med. Woch., 1902, p. 893.

${ }^{10}$ Juliusberg. Deut. med. Woch., Oct. 1904.

"Burnet. Ann. de l'Inst. Pasteur, Vol. XX (1906) p. 742.

${ }^{12}$ Nicolle and Adil-Bey. Ann. de l'Inst. Pasteur, Vol. XVI (1902) p. 56 . 
were the first to show that the virus of rinderpest may pass through a filter which arrests the smallest visible bacteria. With a thin walled Berkefeld filter the results vary, the filtrate sometimes being infective and sometimes the inoculated animals remaining well. The Chamberland $F$ filters kept back the virus. Wooley ${ }^{13}$ states that whether or not the virus passes through the pores of a Chamberland depends largely on the condition of the material used in the experiment. Semner ${ }^{14}$ found that the filtrate of infective material passed through a Chamberland filter was not virulent. Kolle and Turner ${ }^{15}$ obtained similar results. Todd ${ }^{16}$ concludes that the filterable nature of the virus is not fully determined.

Hog cholera. In 1903 de Schweinitz and Dorset ${ }^{17}$ found that in certain outbreaks of epizootic hog cholera the blood serum of the diseased hogs when diluted with water and passed through a porcelain filter was still capable of producing the disease in healthy pigs. They found that the virus passed through the Berkefeld or Chamberland $\mathrm{F}$ or $\mathrm{B}$ filters. This is the disease that was thought to be due to B. suipestifer or the bacillus of hog cholera. The findings of de Schweinitz and Dorset were confirmed by Ostertag ${ }^{18}$ in Germany. The virus of this disease in serum or organ juice is killed when exposed for one hour at $78^{\circ} \mathrm{C}$. It is also found to be destroyed in one week in buried organs undergoing putrefaction. Uhlenhuth, ${ }^{19}$ Huebner and others have found that the English swine fever, American hog cholera and German Schweinepest, are caused by a filterable virus.

Sheep-pox. In 1902 Borrell $^{20}$ demonstrated that material

${ }^{13}$ Wooley. The Philippine Jour. of Science, 1906, p. 581.

${ }^{14}$ Semner. Deut. Zeit. f. Tiermed. u. vergl. Path., Bd. XXII (1897) p. 32.

${ }^{15}$ Kolle and Turner. Zeit. f. Hygiene, Bd. IX (1898) p. 309.

${ }^{16}$ Todd. The Jour. of Hygiene, Vol. VII (1907) p. 570.

${ }^{17}$ de Schweinitz and Dorset. Circular 44, B. A. I., U. S. Dept. Agriculture, 1903.

${ }^{18}$ Ostertag. Zeit. f. Infek. der Haustiere, Bd. II (1907) p. 250.

${ }^{19}$ Uhlenhuth. loc. cit.

${ }^{20}$ Borrel, Compt. rendu de la Soc. de Biol., Vol. LIV (1902) p. 59. 
from pustules from cases of sheep-pox when diluted with water and passed through a Berkefeld filter retained its virulence.

Cow-pox. The virus of cow-pox was shown by Remlinger (Bull. de l'Inst. Pasteur) to pass through the Chamberland filter. His results have been confirmed by several other workers. Likewise the cause of the equine pernicious anemia is looked upon by some as being due to a filterable virus.

Accorảing to Carré, canine distemper should be added to the list of diseases caused by a virus that will pass through the Berkefeld filter.

Ellermann and Bang ${ }^{22}$ have recently described a leucocythaemic disease of fowls in Denmark in which they consider the cause to be an ultravisible virus.

Epizoötic cerebro-spinal meningitis. Joest and Degen ${ }^{23}$ have described in the nerve cells of horses suffering from epizöotic cerebro-spinal meningitis intranuclear bodies resembling somewhat the Negri bodies found in rabies. They appeared in the nucleus of the ganglion cells and never in other cells or lying between cells and fibres. They vary in size from fine points to about the size of the red blood corpuseles. They take stains quite similarly to the Negri bodies. They also stain after the Gram-Weigert method, using eosin as a counter-stain. They also stain after Giemsa's method in which the bodies have a pale blue appearance while the nucleolus is stained a deep dark blue. Safrenin stains them a pale yellowish brown while the nucleus is an intense yellowish brown.

Their observations were based on 27 cases of the disease in 24 of which the bodies were found. The findings of Joest and Degen suggest that these bodies may be of value in diagnosing cerebro-spinal meningitis from other diseases that might be confused with it.

${ }^{22}$ Ellermann and Bang. Centralbl. f. Bakt., Bd. XLVI (1908) p. 595 .

${ }^{23}$ Joest and Degen. Zeit. f. Infekt. *** der Haustiere, Bd. VI (1909) p. 348. 
Blue tongue. Spreull ${ }^{25}$ describes the disease known in South Africa among sheep as malarial catarrhal fever and which is known among the natives as "blue tongue." It is an inoculable disease of sheep characterized usually by fever and by lesions in the mouth and feet. He showed that it could be transmitted to cattle and to goats by inoculation. Its cause has not been ascertained.

This interesting disease of sheep known as blue tongue has been shown by Robertson and Tyler to be due to a virus that passes through a Berkefeld filter. It is destroyed, according to Tyler, by drying but it resists advanced putrefaction of the blood containing it.

Infectious anemia of horses. Hempel, ${ }^{26}$ after a careful investigation of infectious anemia of horses, concludes that its cause is an ultravisible virus, that animals which recover have no immunity and that it is impossible to artificially immunize horses against this disease. Mack ${ }^{27}$ found intracellular bodies in a small number of red corpuscles.

African horse sickness. As early as 1900 M'Fadyean ${ }^{28}$ showed that the cause of horse sickness in South Africa was an ultravisible virus that would freely pass through a Berkefeld filter and that was not entirely arrested by the closegrained Chamberland F and B filters. He showed that the virus remained infective when the plasma containing it was heated to $75^{\circ} \mathrm{C}$. and that it was highly resistant to the effect of putrefaction occurring in the blood in which it was present.

${ }^{25}$ Spreull. Jour. of Comp. Path. and Therap., Vol. XVIII (1905) p. 321 .

${ }^{28}$ Hempel. Zeit. f. Infekt. * * * der Haustiere, Bd. V (1908) p. 381.

${ }^{27}$ Mack. Proceedings Am. Vet. Med. Asso., 1911.

${ }^{28}$ M'Fadyean. Jour. Comp. Path. and Therap., Vol. XIII (1900) p. 1; also Vol. XIV (1901) p. 59. 


\section{CHAPTER XXIII.}

\section{SPECIFIC BACTERIAL PRODUCTS, TISSUE REACTIONS AND IMMUNITY.}

The first efforts in the study of the relation of bacteria to animal diseases were directed to the discovery of the infecting organisms. To find the specific cause and learn its life history for each of the infectious and communicable diseases was the task of the bacteriologist. Working with the methods introduced by the earlier investigators the bacteria that cause a number of the infectious diseases were found, isolated, and carefully studied. This was closely followed and partially aceompanied by a study of the products of bacterial growth and their effect upon the tissues of the animal body. The researches of Pasteur ${ }^{1}$ in the production of immunity against anthrax and chicken cholera, of Salmon and Smith ${ }^{2}$ in the immunizing of pigeons to hog cholera, the discovery of tubereulin, diphtheria and tetanus toxins, were findings of interest in the physiological properties of bacteria. These were followed by a still more complicated line of investigations, namely, that of the response of the body tissues to the stimulus of the products of bacterial growth or toxins and the determination of the nature of the specific substances that are given off by the tissues as a result of such stimulus. As the result of this latter study we are in possession of much theoretical knowledge concerning the mechanism by which the tissues of the body adjust themselves to the injuries inflicted by these invading organisms or their products. The results of this work have developed a large literature on the subject and many new terms have been introduced to indicate the newly discovered substances that have been found and the resulting

${ }^{1}$ Pasteur, Chamberland and Roux. Compt. rendu de l'Acad. des Sci., Vol. XCVII (1881).

${ }^{2}$ Salmon and Smith. Hog Cholera, B. A. I., U. S. Dept. Agric., 1889, p. 155. 
phenomena in the animal body. In the study of this subject it is important to recognize and to keep clear and distinct two phenomena, namely: (1) that many bacteria elaborate during their multiplication either in the body or in culture media poisonous substances known as toxins and (2) that these poisons produce when in the animal body a reaction on the part: of the tissues which results in their (tissues) giving off certain reactionary bodies or substances known as antitoxins, or antibodies.

The products of bacterial growth. The more important of the bacterial products at least so far as they have been analyzed and determined are the "bacterial proteins" and" toxins.

Bacterial proteins. These substances are bacterial poisons which are not as a rule specific. They excite fever, inflammation and suppuration and withstand heating to a temperature of $100^{\circ} \mathrm{C}$. Vaughan and Novy ${ }^{3}$ classify the bacterial proteids as follows: (1) those which constitute an integral part of the bacterial cells; and (2) those which have been assimilated by the cells, but which have been formed by the fermentative or cleavage action of the bacteria on the proteid bodies in which they are growing. Tuberculin and mallein are the most important of this group of bacterial products. According to Buchner and Roemer, all bacterial proteins are very similar in their action. It has been stated that deuteroalbumose, which is obtained by the action of pepsin on albumin and has no connection with bacteria, has an effect on tuberculous guinea pigs somewhat similar to tuberculin.

Toxins. Toxins are poisonous synthetical products of bacterial growth.

Although the exact composition of the toxin of any species has not as yet been determined, it is believed that they are of proteid character. At first all the toxins were supposed to be albumins, but recently some of the most important, such as those produced by the tetanus and diphtheria bacteria, havebeen shown to possess characters which separate them from.

\footnotetext{
${ }^{3}$ Vaughan and Novy. Cellular toxins, Fourth edition, p. 32.
} 
that class. Toxins are formed during the growth of bacteria in media containing no proteid, but more abundantly when it is present. Toxins are divided into two classes, namely, extracellular and intracellular. The toxins produced by certain bacteria such as the tetanus and diphtheria organisms during their multiplication either in the tissues of the body or in culture media are largely given up to the medium in which they are growing while the toxins of the bacteria of tuberculosis, glanders, and the colon group and many other species are largely retained in the bodies of the organisms.

Extracellular toxins. The extracellular toxins are, so far as known, uncrystallizable. They are soluble in water and they are dialyzable; they are precipitated along with proteids by alcohol, and also by ammonium sulphate; if they are proteids they are either albumoses or allied to the albumoses. They are relatively unstable. The degree of heat and the resistance to chemical manipulation varies much with the toxins from different species. Among the precipitants employed to procure them in a pure state ammonium sulphate seems to have the least harmful effect. The most important of the extracellular toxins are those produced by the diphtheria and tetanus bacteria. These bacteria may produce several entirely distinet toxins; thus, according to Madsen and Ehrlich, the specific tetanus poison consists of two toxins, tetanospasmin and tetanolysin. To the first of these the tetanic convulsions are due, while the second has a hemolytic action.

In case of several of the pathogenic bacteria, if it is not -true of them all, there are several toxins produced: the specific or perhaps most characteristic product or toxin and other products or toxines. Thus in case of the soluble products of Bacterium diphtheriae there is the toxin or the only poison capable of causing acute death ${ }^{4}$ and the toxone which causes the late manifestation or paralysis. The toxin is modified by various influences such as light, heat, moisture, etc., and is thereby converted into a toxoid. D. C.

${ }^{4}$ Rosenau. Bulletin No. 21, Hygienic Laboratory, Washington, 
Intracellular toxins. These are toxins more intimately associated with the bacterial cell. Little is known of their nature, although some of them are not so easily injured by heat as others. In the case of all toxins the fatal dose for an animal varies directly with the species, body.weight, age, and previous condition as to food, temperature, etc. In estimating the minimum lethal dose of a toxin these factors must be carefully considered.

Vegetable and animal poisons resembling toxins. Within recent years it has been found that the bacterial poisons belong to a group of toxic bodies presenting very similar properties; and which occur widely in the vegetable and animal kingdoms. Among plants the best known examples are the ricin and abrin poisons, obtained by making water emulsions of the seeds of the Ricinus communis and the Abrus precatorius (jequirity) respectively. The chemical reactions of ricin and abrin correspond to those of the bacterial toxins. They are soluble in water; they are precipitated by strong alcohol; and they are less easily dialyzed than the albumoses. They have been called toxalbumins. Their toxicity is impaired by boiling. They are among the most powerful poisons known, ricin being the more fatal.

It is also stated with certainty that the poisons of scorpions and of poisonous snakes belong to the same group. The poisons derived from the latter are usually called venoms, and a considerable number of such venoms derived from different species have been studied. It may be stated that there is obtainable from the natural secretions of the poison glands of certain snakes venoms which have all the reactions of the poisonous bodies derived from bacteria. Like ricin and abrin, the venoms are not so easily dialyzed as the bacterial toxins, and therefore they have also been classed as toxalbumins.

Tissue response or specific products given off by the body cells as a result of stimulation with protoplasmic alien substances. Perhaps the most striking reaction of the body tissues when acted upon by toxins is the production of antibodies or a.substance that will neutralize the effect of the 
toxins. The large amount of work that has been done on this subject has pointed to but not fully explained certain fundamental laws underlying the production of antitoxins and antibodies of various kinds. Thus it has been shown that the body cells in adapting themselves to alien substances of protoplasmic origin may elaborate specific substances (antibodies or antitoxins, eytolysins and agglutinins) which tend to neutralize or destroy the alien substance eausing their production. This is illustrated with tetanus. By the injection of an animal (guinea pig or horse) with a non-lethal dose of the toxin of the tetanus bacillus (i. e. filtered bouillon culture) and repeating the injection with steadily increasing quantities, the condition will be reached where the blood serum of the injected animal will neutralize the poisonous effect of the tetanus toxin. The substance given off by the cells of the body that neutralizes or renders the tetanus toxin harmless is known as tetanus antitoxin. A similar result is obtained with the bacterium of diphtheria. The early works of Roux and Yersin ${ }^{5}$ and v. Behring ${ }^{6}$ on diphtheria and Kitasato's ${ }^{\top}$ experiments with toxins should be read in further explanation of this subject. Bordet $^{8}$ and others found that by the injection of the blood corpuseles of an animal of one species (A) into an animal of another species (B) the blood serum of (B) will acquire the ability to dissolve the red blood corpuscles of $(\mathrm{A})$. That is, the action of the corpuscles of (A) upon the body cells of (B) causes the throwing off of a substance (hemolysin) into the serum which will dissolve the corpuscles of (A). The solution of the red blood corpuscles is known as hemolysis.

Other tissues are capable of producing antibodies that will cause lysis. These are termed cytolysins and the process of dissolving the cells is known as cytolysis. When applied to endothelial cells for example the process is referred to as endotheliolysis.

${ }^{5}$ Roux and Yersin. Ann. de l'Inst. Pasteur, Vol. II (1888) p. 629.

${ }^{6}$ V. Behring. Deut. med. Woch., Bd. XVI (1890) p. 1113.

${ }^{7}$ Kitasato. Zeit. f. Hyg., Bd. X (1891) p. 267.

${ }^{8}$ Bordet. Ann. de l'Inst. Pasteur. Vol. XII (1898) p. 688. Ibid., Vol. XIII (1899) p. 273. 
An antitoxin against venoms was found by Phisalix and Bertrand ${ }^{\circ}$ and demonstrated to be of therapeutic value by Calmette. ${ }^{10}$ It is prepared by the injection of the modified venom of the cobra or other poisonous serpents into an animal whose blood later will neutralize the poisonous effect of the venom. ${ }^{11}$ The antibodies causing this action are designated antivenene or antivenom serum.

In 1894 , Pfeiffer ${ }^{12}$ made an observation in the study of cholera microspira which has been designated "Pfeiffer's phenomenon" and which explains somewhat clearly the effect of certain of the intracellular toxins. He found that when he injected the living virulent microspira into the abdominal cavity of a guinea pig which had been immunized to these bacteria by repeated inoculations with non-lethal doses, or when he injected a susceptible guinea pig with the organisms simultaneously with the serum of an immune guinea pig, that the organisms lost their motility, became spherical and then underwent granular degeneration and finally complete dissolution while the inoculated animal remained apparently unaffected. In this case there was a destruction of the bacteria themselves or bacteriolysis.

One experiment after another, therefore, has demonstrated the existence of specific antibodies that are given off by the body cells in response to the stimulation by extracellular and intracellular toxins, animal tissues, vegetable proteids and venoms.

In addition to the specific reaction products described, there are several other substances produced by the body cells that seem to be quite as specific in their origin and nature as the cytolysins. These substances, which seem to be products directed toward immunity, possess certain properties which

${ }^{9}$ Phisalix and Bertrand. Compt. rendu de l'Acad. des Sci. de Paris, Vol. CXVIII (1894) p. 356.

${ }^{10}$ Calmette. Comp. rendu de la Soc. de Biol. de Paris, Vol. I (1904) p. 120.

${ }^{11}$ For further study of the antitoxins of venoms see work of Flexner and Noguchi, Jour. Exp. Med., Vol. VI, p. 277.

${ }^{12}$ Pfeiffer. Zeit. f. Hyg., Bd. XVII (1888) p. 355. 
have been availed of in both diagnosis and therapeutics. The more important of these are agglutinins, precipitins and opsonins.

Agglutinins.* Agglutinins are substances produced in the body by the stimulation of the cells by certain agents known as agglutinogens. These are cultures of living bacteria, heated or killed cultures and in some cases culture filtrates. They may be introduced subcutaneously, intravenously or into the abdominal cavity. It has been shown that certain animal tissues like red blood corpuscles seem to cause the production of agglutinins specific for the injected corpuscles. The agglutinins are present to a limited degree in the normal serum. These are known as the "normal agglutinins" but they seem to have the same nature as the immune agglutinins. It is possible that their presence in normal serum is traceable to the action of certain parasitic bacteria. ${ }^{13}$

The action of the agglutinins is specific in that they clump the bacteria (agglutinogens) which cause their production. Thus the serum of a glandered horse will clump the free glanders organisms when suspended in physiological salt solution or

* The first observations on agglutination were made by Gruber and Durham (Munisch. Med. Woch., Bd. XLIII (1896) p. 285). Later 'Charrin and Roger (Compt. rendu de la Soc. de Biol., Vol. I 9 série (1889) p. 667) in experiments made with Pseudomonas pyocyaneus observed the clusters of bacteria which settled to the bottom of the fluid. A number of other workers observed the clumping of bacteria when brought in contact with immune sera. Widal (Soc. Med. des Hopitaux, 1896) showed that the agglutination had an important application in diagnosis. He applied it to typhoid fever, and the method is now known as the Widal or the Gruber-Widal test. The same principle was applied by M'Fadyean (Jour. Comp. Path. and Therap., Vol. IX (1896) p. 322), Bonome (Centralbl. f. Bakt., Bd. XXXVIII (1905) p. 601), Kleine (Zeit. f. Hyg., Bd. XLIV (1903) p. 183), Schütz and Miessner (Arch. f. wiss. u. prak. Tierheilk., Bd. XXXI (1905) p. 353), and Schnurer (Centralbl. f. Bakt., Bd. XXXIX (1905) p. 180) in the diagnosis of glanders, the first work being done by M'Fadyean. (See diagnosis of glanders). The literature on the subject of agglutination as a means of diagnosis is extensive.

${ }^{13}$ Hoffman. Hyg. Rundschau, Bd. XIII (1903) p. 114. 
bouillon but it will not clump other bacteria. The phenomenon of agglutination therefore is a specific combination between the agglutinin and the agglutinin-stimulating substance or agglutinogen. It is very probable that the process follows certain ehemical laws, as definite quantitative relations exist between the agglutinogen and the agglutinins so that the agglutination reaction will vary in different tests in its degree of completeness with the quantities of agglutinin and agglutinogen present. This requires that a certain uniformity in the density and quantity of the culture used should be maintained. Although the agglutination test is specific there are groups of bacteria that may be agglutinated by the serum containing the agglutinin resulting from a single culture in the group. Whenever an immune serum agglutinates a number of members of the group closely related to the specific organism used for its production, the reaction is spoken of as "group agglutination."

The agglutinins are stable substances that resist drying and can be kept dry and active for years. Widal and Sicard found that they pass with difficulty through a porcelain filter and do not dialyze. They are precipitated in part by 15 per cent sodium chloride, which throws down fibrinogen, and further precipitated with magnesium sulphate, which throws down globulins. It is thought that they are intimately related to the globulins and to fibrinogen. A temperature of $60^{\circ} \mathrm{C}$. diminishes their activity, but some of them are not destroyed below $70^{\circ} \mathrm{C}$. Sunlight has no effect upon them.

Smith ${ }^{14}$ has shown that there are two kinds of agglutinins produced with certain motile bacteria, one of which acts upon the bacteria directly, the other upon the flagella. The occurrence of these two bodies explains some of the incompatible results of earlier experiments.

The practical application of the agglutination test may be made for diagnosis in any infectious bacterial disease if the etiological organism is at hand, or the test may be made for the

${ }^{14}$ Smith. Jour. Med. Research, Vol. XII (1904). 
identification of the microorganisms provided specific serums are at hand.*

Precipitins. Precipitins were first discovered by Kraus. ${ }^{15}$ They are antibodies believed to be specific and given off by the body cells as the result of stimulation by various microorganisms. When animals are inoculated with certain bacteria such as typhoid bacilli there appears in the blood serum some days later a substance which causes a specific precipitate when mixed with a germ free culture fluid of that organism. This peculiar reaction was found to hold true for a number of bacteria. The phenomenon of precipitation, however, is not limited to bacterial precipitation. Bordet ${ }^{16}$ found the blood

${ }^{15}$ Kraus. Wiener klin. Woch., (1897) p. 736.

${ }^{16}$ Bordet. Ann. de l'Inst. Pasteur, Vol. XIII (1889) p. 225.

* McFarland (Text book upon the Pathogenic Bacteria) gives the following method of making the tests.

"If possible, a culture of the microorganism grown upon agaragar is to be selected for the purpose. A good-sized platinum loopful of the culture is taken up and distributed as uniformly as possible throughout a few cubic centimeters of distilled water. This is best done by placing the water in a test tube and then rubbing the culture upon the glass just above the level of the fluid, until it is thoroughly emulsified, permitting it to enter the water little by little and, finally, washing it all down into the fluid. This gives a distinctly cloudy fluid, too concentrated to use. Of this one adds enough to each of a series of watch-glasses or test tubes, each containing an equal volume of distilled water (say 2 cc.) to make the fluid opalescent by reflected light though transparent by transmitted light. The same quantity should be added to each so that they form a uniform series. The serum is next diluted or otherwise added to the tubes, so that they receive different concentrations in a series from the blood of a patient running, say $1: 10,1: 20,1: 30,1: 40,1: 50,1: 60$, $1: 80,1: 100,1: 150,1: 200,1: 300$, or a laboratory series with artificially prepared serums of high value, running, perhaps, 1:1000, $1: 2000,1: 5000,1: 10,000$, and $1: 100,000$ or many times higher dilutions.

"If watch-glasses are used, they are stood upon a black surface, covered, and examined in fifteen, thirty, and sixty minutes by simply looking at the dark surface through the fluid. If agglutination occurs, the original opalescence gives place to a slightly curdy appearance, as the uniformly suspended bacteria aggregate in clumps. 
serum of rabbits treated with the serum of chickens gave a specific precipitate when mixed with chicken serum. This investigation has been extended to other substances. Wasserman ${ }^{17}$ produced an antibody which precipitated the casein of the particular variety of milk employed for immunization.

The precipitins, like the agglutinins, are inactivated by heating from $60^{\circ}$ to $70^{\circ} \mathrm{C}$. and they are not reactivated by the addition of normal serum.

The precipitins are supposed to be specific. They are being used quite extensively for the differentiation of animal proteids. Precipitation, as with agglutination, brought about by bacterial stimulation, has to a certain extent, "group" reaction.

Opsonins. Denys and Leclef ${ }^{18}$ called attention to the fact that blood serum aided phagocytosis by its action upon the bacteria rather than upon the leucocytes. They procured experimental evidence that substances which alter bacteria in

"If test tubes are employed, they are best observed by tilting them and looking through a thin layer of the contained fluid at a dark surface or at the sky. In either case the flocculent collections of agglutinated bacteria can be seen.

"The test can also be made and observed under the microscope by the hanging-drop method, but in working with such small quantities much of the accuracy of the technic is apt to be lost.

"Some knowledge is required in order to form correct deductions from the experiments. Thus, with typhoid blood, the agglutination of the typhoid bacillus usually occurs within an hour in dilutions of 1:50, but the agglutinability of the culture employed should be known before the experiment is undertaken.

"Similarly, when the method is employed for the differential treatment of bacteria, the value of the serum should be known at least approximately."

For a detailed method for the agglutination test for the diagnosis of glanders, see $B$. mallei. It will be noted that there are two distinct methods for observing the agglutination for diagnosis (1) macroscopic and (2) microscopic.

${ }^{17}$ Wasserman. Deut. med. Woch., Bd. XXIX (1900).

${ }^{18}$ Denys and Leclef. La cellule, Vol. XI (1895) p. 198. 
such a way as to enhance their ingestion by the leucocytes exist in the blood serum of immunized rabbits.*

In 1897 , Mennes ${ }^{19}$ showed that the immunity of guinea pigs inoculated with toxins or cultures of pneumococei depends upon a modification of their serum whereby an active phagoeytosis is produced and that this is not due to any special activity of the leucocytes. Wright and Douglas ${ }^{20}$ introduced the word opsonin (opsono, to prepare food for) to characterize the substance in normal blood which they believed prepared the bacteria for ingestion by the phagocytes. They were able to show that this substance exists in the serum and that it is partly thermolabile. It acts on the bacteria and not on the

* These authors found in the study of phagocytosis that the leucocytes in an immunized rabbit obtained their power of engulfing the bacteria from some other substance than the serum. The immunized animal fights the bacteria, first, by the direct action of the serum, second, by its leucocytosis. Their conclusions were as follows:

"(a) The serum of normal rabbits exercises no bactericidal action on the Streptococcus pyogenes.

"(b) The serum of a rabbit on whom a certain degree of immunity to streptococcus has been conferred by vaccination, will delay the development of streptococcus for several hours and will sometimes exhibit a true bactericidal power.

"(c) Leucocytes from a normal rabbit added to the serum of a normal rabbit exhibit only a feeble phagocytic power to streptococcus. The leucocytes die before their usual term of life.

"(d) Leucocytes from a normal rabbit added to the serum of a vaccinated rabbit energetically destroy streptococcus. The leucocytes preserve their normal duration of life.

“(e) Leucocytes from a vaccinated rabbit added to its own serum act the same as above (d).

"(f) Leucocytes from a vaccinated rabbit added to the serum of a normal rabbit act as above (c).

"(g) If a dose of streptococcus, lethal for a normal rabbit, is injected into the pleura of a vaccinated rabbit, the serum prevents the development of a pleurisy.

"(h) If a dose of streptococcus capable of producing erysipelas in a normal rabbit is injected under the skin of a vaccinated rabbit the infection is prevented especially by leucocytes."

${ }^{19}$ Mennes. Zeit. f. Hyg., Bd. XXV (1897) p. 413.

${ }^{20}$ Wright and Douglas. Proc. of the Royal Society, Vol. LXXII (1904) p. 357. 
leucocytes. Neufeld and Rimpau ${ }^{21}$ discovered a third element in blood serum which they claimed sensitized the bacteria but did not act on the leucocytes. They proposed the name bacteriotropic for these sensitizing substances.

Opsonin is a substance elaborated by the tissues and which sensitizes bacteria for leucocytes thereby increasing phagocytosis. This substance exists, to a certain extent, in normal serum, and can be increased by active immunization with dead bacteria or bacterial products. The question at present is to determine whether the normal opsonins and those found in immune animals are identical. As phagocytosis is one of the essential agencies in the production of immunity, and as this process is intensified by the introduction of the bacteria causing the infection, autogenic vaccines for various infections were introduced. A special technique for determining the increased phagocytosis in the blood of the infected individual has been introduced.* Hektoen ${ }^{22}$ found in a careful study of

${ }^{21}$ Neufeld and Rimpau. Deut. med. Wochenschrift, Bd. XL (1904) p. 1458.

${ }^{52}$ Hektoen. Jour. of Inf. Dis., Vol. V (1908) p. 249.

* This method as described by Hiss and Zinnser taken from Wright is as follows: "The three factors necessary for the performance of an opsonic test are (1) the blood serum to be tested; (2) an even emulsion of bacteria and (3) leucocytes.

“.1) Blood serum is obtained by bleeding from the finger and receiving the blood into glass capsules. These are sealed at both ends; the blood is allowed to clot; and the separation of serum is hastened by a few revolutions of a centrifuge.

"(2) The bacterial emulsion is obtained by rubbing up a few loopfuls of a twenty-four-hour slant agar culture with a little physiological salt solution ( $0.85 \mathrm{per}$ cent) in a watch-glass. A very small amount of salt solution is used at first and more is gradually added, drop by drop, as the emulsion becomes more even. The final breaking up of the smaller clumps is best accomplished by cutting off very squarely the end of a capillary pipette, placing it perpendicularly against the bottom of the watch glass, and sucking the emulsion in and out through the narrow chink thus formed.

"Emulsions of tubercle bacteria are more difficult to make. The bacteria filtered off in the manufacture of old tuberculin are commonly used. These are washed in salt solution on the filter, and are 
normal opsonins that "normal human serum may contain bactero-opsonins with marked specific affinities. The results of experiments indicate that the bactero-opsonins and hemopsonins in human, rabbit and dog serum may be distinct substances, at least in part, and that normal serum may contain several more or less distinct opsonins for alien red corpuscles.' The opsonic index, however, is not considered by many pathologists trustworthy, but the efficiency of autogenic vaccine, in certain cases at least, has been well established. How generally it can be applied with success is not known. Vaccine treatment is still in the experimental stage.

then scraped off and sterilized. They are then, in a moist condition, placed in a mortar and thoroughly ground into a paste. While grinding, salt solution (1.5 cent) is gradually added until a thick emulsion appears. This emulsion may be diluted and larger clumps separated by centrifugalization.

“(3) The leucocytes are obtained by bleeding from the ear or finger directly into a solution containing eighty-five hundredths per cent to one per cent of sodium chlorid and five-tenths to one and five-tenths per cent of sodium citrate. Ten or fifteen drops of blood to 5 or $6 \mathrm{cc}$. of the solution will furnish sufficient leucocytes for a dozen tests. This mixture is then centrifugalized at moderate speed for five to six minutes. At the end of this time, the corpuscles at the bottom of the tube will be covered by a thin grayish pellicle, the buffy coat, consisting chiefly of leucocytes. These are pipetted off with a capillary pipette (by careful superficial scratching movements over the surface of the buffy coàt).

"There being, of course, no absolute scale for phagocytosis, whenever an opsonin determination is made upon an unknown serum, a parallel control test must be made upon a normal serum. This normal is best obtained by a "pool" or mixture of the sera of five or six supposedly normal individuals.

"The three ingredients-serum, bacterial emulsion, and leucocytes-having thus been prepared, the actual test is carried out as follows: Capillary pipettes of about six or seven inches in length and of nearly even diameter throughout, are made. These are fitted with a nipple and a mark is made upon them with a grease-pencil about 2 to $3 \mathrm{~cm}$. from the end. Corpuscles, bacteria and serum are then successively, in the order named, sucked into the pipette up to the mark, being separated from each other by small air-bubbles. Equal quantities of each having thus been secured, they are mixed thoroughly by repeatedly drawing them in and out of the pipette 
Aggressin. Bail ${ }^{23}$ in studying the problems of virulence and immunity for the purpose of explaining the so-called "phenomenon of Koch" * found that if tubercle bacteria were injected, together with sterilized tuberculous exudate, into healthy guinea pigs they died within 1 to 2 days. When the exudate was injected alone it produced no appreciable effect and when the tubercle bacteria were injected alone they produced death from tuberculosis in the usual time. His conclusion was that there is something in the exudate that allows the bacteria to become more aggressive and to this substance he assigned the name aggressin. He believed this substance to be an endotoxin liberated by the bacteria and that its effect is to paralyze the polynuclear leucocytes thereby inhibiting phagoeytosis. Heating the exudate to $60^{\circ} \mathrm{C}$. increased rather than diminished its aggressive properties. According to Bail, several of the pathogenic bacteria such as Micrococcus pyogenes, the bacterium of chicken cholera, and the typhoid bacillus, produce aggressins which can be found in the exudates occurring

upon a s'ide. The mixture is then drawn into the pipette; the end is sealed; and incubation at 37.5 degrees is carried on for an arbitrary time, usually fifteen to thirty minutes. The control with normal serum is treated in exactly the same way. After incubation the end of the pipette is broken off, the contents are again mixed, and smears are made upon glass slides in the ordinary manner of blood smearing. Staining may be done by Wright's modification of Leishman's stain, by Jenner's, or by any other of the usual blood stains. In these smears, then, the number of bacteria contained in each leucocyte is counted. The contents of about eighty to one hundred ceıs are usually counted and an average is taken. This average rumber of bacteria in such leucocytes is spoken of as the "phagocytic index.' The phagocytic index of the tested serum, divided by that of the 'normal pool' (control) serum, gives the 'opsonic index'.",

${ }^{23}$ Bail. Arch. f. Hyg., Bd. LII, p. 272, 411.

Zeit. f. Hyg., (1905 i.) No. 3.

* Koch observed in his early investigations on tuberculosis that tuberculous animals when inoculated intraperitoneally with fresh cultures of tubercle bacteria died quickly from an acute attack of the disease and the resulting intraperitoneal exudate was composed almost exclusively of lymphocytes. 
about the site of inoculation. Hiss and Zinsser ${ }^{24}$ state that the production of aggressins by pathogenic bacteria is probably absent in test tube cultures, but is called forth in the animal body by the effect of the germicidal or other influences encountered by the organisms after inoculation. Aggressins, therefore, are the substances present in sterilized exudates resulting from the infection with several if not all of the pathogenic bacteria and which when injected with the specific virulent organisms, cause them to produce death in an unusually brief time. The theory that the aggressins consist of endotoxins liberated by the bacteria has been attacked by Wassermann and Citron ${ }^{25}$ and by Wolf. ${ }^{26}$ These investigators claim that much of the aggressive power of the exudates is due to their containing liberated bacterial poisons.

It has been found possible to immunize animals against certain infections by repeated injections of aggressins in the form of exudates, which results in the formation of "antiaggressins," which inhibit the action of the aggressin thereby permitting phagocytosis to take place. Bail divided the bacteria according to their power to produce an aggressin and consequently to their ability to invade the animal body into "pure parasites," "half parasites" and "saprophytes," the last being unable to live in the animal tissues because of the total absence of aggressins. Further investigations on the nature of aggressins are necessary before any very definite conclusions can be drawn concerning them. The theory as put forth by Bail is of assistance in explaining the phenomenon of virulence or difference in the degrees of pathogenesis of many bacteria.

Anaphylaxis. Hericourt and Richet ${ }^{27}$ found that repeated injections of eel-serum into dogs gave rise to an in-

${ }^{24}$ Hiss and Zinsser. loc. cit. p. 293.

${ }^{25}$ Wassermann and Citron. Deut. med. Woch., Bd. XXXI (1905) p. 573 .

${ }^{26}$ Wolf. Centralbl. f. Bakt., Bd. XXXVII (1904) pp. 390, 566, 684.

${ }^{2 \tau}$ Hericourt and Richet. Comp. rendu de la Soc. de Biol.., 10 série Vol. V (1898) p. 137. 
creased susceptibility toward this substance instead of immunizing the dogs against it. Richet applied to this phenomenon the term anaphylaxis (ava, against, $\phi v \lambda a \xi ı$, protection) in contradistinction to prophylaxis. It has been observed that occasionally sudden death has followed the injection of horse serum into animals and into man. In a certain number of cases the injection of horse serum into man is followed by urticarial eruptions, joint pains, fever, swelling of the lymph nodes, edema and albuminuria. This reaction, which appears after an incubation period of 8 to 13 days, was termed by v. Pirquet and Shick ${ }^{28}$ "the serum disease." $\mathrm{T}$. Smith found that guinea pigs injected with diphtheria toxinanti-toxin mixtures in the course of anti-toxin standardization would succumb after a short interval if they were given a subcutaneous injection of normal horse serum. Otto, ${ }^{29}$ in working on this hypersusceptibility, has referred to it as "Theobald Smith's phenomenon." Arthus ${ }^{30}$ confirmed the observation of Richet and his observations are frequently referred to as the "phenomenon of Arthus." Rosenau and Anderson $^{31}$ confirmed the observations of v. Pirquet, Smith, Richet and others and showed conclusively that the horse serum had no relationship to its toxin or anti-toxin constituents and that the sensitization of the guinea pigs became more marked after a definite incubation of about 10 days. Vaughan ${ }^{32}$ and others showed that the reaction was not limited to animal sera but could be produced by peptone, egg albumen, milk and other proteids. Anaphylaxis may be defined therefore as the result, consisting in restlessness, rapid breathing, often staggering and convulsions, and possibly death following in from five minutes to a few hours after the second injection of these proteid substances, when the first injection was made from

${ }^{28}$ v. Pirquet and Shick. Die Serum Krankheit. Wien, 1905.

${ }^{29}$ Otto. Leuthold-Gedenl:schrift, Bd. I (1905).

${ }^{30}$ Arthus. Compt. rendu de la Soc. de Biol., Vol. LV (1903) p. 817.

${ }^{31}$ Rosenau and Anderson. Public Health and Marine Hospital Service, Bulletin 29 (1906) and 36 (1907).

${ }^{2}$ Vaughan. Assn. of American Physicians (1907). 
8 to 13 days previously. Rosenau and Anderson found that guinea pigs could be thus sensitized with 0.004 ce. of serum and that the poisonous symptoms could be produced with 0.1 ce. injected into the peritoneal cavity of a half-grown guinea pig and that 0.1 ce. of horse serum injected subcutaneously was sufficient to produce serious symptoms. This hypersensitization of the animal tissues by a small quantity of the proteid substance is of much significance in explaining the serious and often fatal results following later injections of the same substance.

Complement. In the study of the germicidal action of blood serum it has been found that the forces which are able to hinder the development of bacteria in the blood or to destroy them depend upon the presence of an anti-bacterial substance which Buchner ${ }^{33}$ designated alexin and which is made inactive by heating to a temperature of $55^{\circ} \mathrm{C}$. This substance was designated "mycosozins" by Hankin and "cytase" by Metchnikoff. Ehrlich called this substance complement (from the Latin complementum, that which fills up completely). It is defined as that constituent of normal and immune serums which is thermolabile, that is, destroyed by heating to $55^{\circ} \mathrm{C}$., and which unites with the immune body or amboceptor to produce lysis.

The production of antitoxins or antibodies. The facts have been established (1) that certain bacteria (especially those of diphtheria and tetanus) produce during their multiplication in culture media poisonous substances or toxins and (2) when these toxins are repeatedly injected in non-lethal doses into the animal body the blood serum of the injected animals will contain a substance (antitoxin) that will neutralize the action of the toxins. This laid the foundation for the application of serum therapy in a practical way. The necessity of some method by which to standardize the antitoxin and to determine the dose to be used was apparent. The investigations along this line taken up by Ehrlich have yielded the most satisfactory results and his explanations and con-

${ }^{33}$ Buchner. Centralbl. f. Bakt., Bd. V (1889) p. 817. 
clusions are quite widely if not generally accepted not only in connection with the production of antitoxin and its standardization but also in explaining the phenomenon of lysis as exhibited in hemolysis, cytolysis and bacteriolysis.

According to Ehrlich, toxins and antitoxins neutralize each other after the manner of chemical reagents. This belief is largely based on the observations that neutralization takes place more rapidly in concentrated than in weak solutions, and that warmth hastens and cold retards neutralization. From these observations Ehrlich concluded that toxins and antitoxins act as chemical reagents in the formation of double salts, a molecule of the poison requiring an exact and constant quantity of the antitoxin in order to produce a neutral or harmless substance. This implies that a specific atomic. group in the toxin molecule combines with a certain atomic group in the antitoxin molecule.

He also found that the toxins are not simple bodies, but easily split or modified into other substances which differ from each other in the avidity with which they combine with antitoxin. These derivatives of toxin he calls prototoxins, deuterotoxins, and tritotoxins.

Ehrlich's studies of the toxin-antitoxin reaction were directed along the line of his former investigations into the manner of cell-nutrition, ${ }^{*}$ namely, that as nutritious substances are brought into workable combination with the cell by means of the atom-groups corresponding to side chains, so toxins exert their deleterious action only because the cells possess side chains by means of which the toxin ean be chem-

* Ehrlich ("Das Sauerstoffbedürfniss des Organismus," Berlin 1885) held the opinion, that for the cells to be nourished, the nutritive substance must enter into chemical combination with some elements in the cell protoplasm. The large number of chemical substances which act as nutriment led him to believe that the complex prot plasmic molecules of the cells were made up of a central atomgroup (Leistungs-Kern) upon which depended the activities of the cell and a great variety of side chains which enabled the cell to enter into combination with food and other substances that were brought to it in the circulation. This can be illustrated graphically by the 
ically bound to the cell. Later Ehrlich called the side chains "receptors."

All forms of toxins are supposed to consist of two groups of atoms, which combine in an equally energetic manner with antitoxin or with suitable receptors in the cells, but differ in their resistance to heat and other destructive agents. The less resistant form passes readily into a modified toxin or toxoid substance which has the same affinity for the antitoxin or the cell receptors as the original toxin but is not so poisonous. Ehrlich believed that the facts were best explained on the supposition that the toxic molecule contains two independent groups of atoms one of which he designated the haptophorous (combining) and the other as the toxophorous (poisonous) group. It is by the action of the haptophorous group that toxin unites with antitoxin or the cell receptors. * The toxophorous group is unstable, but after its destruction the molecule still unites with the antitoxin or the sensitive molecule through its retained haptophorous group.

chemical conception from which the term side chain was borrowed. The formula given is that of salicylic acid in which the<smiles>O=C(O)C1CCCCC1O</smiles>

benzol ring represents the "Leistungs-Kern," or radicle, while $\mathrm{COOH}$ and $\mathrm{OH}$ are side chains by means of which other substances may be brought into relation with the "radicle."

* Bordet believed, contrary to Ehrlich, that toxin unites in different multiples with antitoxin, so that the toxin molecule may have its affinity slightly, partly or wholly satisfied by antitoxin. Slightly satisfied, it is still feebly toxic; combined with a larger amount of antitoxin, it is not toxic; but still may, when absorbed into the system, lead to the production of antitoxin. Fully saturated, it has no poisonous properties, and no ability to stimulate the production of antitoxin. 
The receptors or side chains present in the cells may have a specific affinity for a given toxin and when united with the toxin the receptor loses its normal physiological function. If the effect of the toxin destroys the cells further activities cease, but if the effect on the cell is less severe, the reparative forces presumably cause the neutralized receptor to be cast off and the regenerative powers of the body cause new "receptors" to appear. As pointed out by Weigert ${ }^{34}$ the regenerative processes rarely stop when the tissue is replaced but tend to an overproduction-" the profligate habit of nature" - so that many receptors may be given off by the cells and set free in the circulation. These free receptors constitute the active principle in antitoxin. They possess in this free state the same specific affinity for the toxin or antigen as they do when attached to the body of the cells.

In explaining the production of antitoxins or antibodies and their action on the toxins or antigens it was necessary because of a lack of knowledge of their chemical nature to represent graphically chemical combinations. When the chemical formulae of these substances are determined the graphic figures will undoubtedly be replaced by specific chemical formulae.

Ehrlich assumes that the body cells possess receptors of different kinds and that the toxins or other substances that come to them which have a specific affinity for any of the receptors will combine with them. It is through these receptors that the toxins come in combination with the cytoplasm of the cells.

When the toxin attacks the cell through the receptor there is produced an excess of receptors which in case of excessive stimulation by toxin are thrown off from the cells and circulate free in the blood plasma. These free receptors possess a single combining group of atoms and may combine with the toxin in the circulation before it comes in contact with the cells themselves. The toxoids are modified toxins which have

${ }^{34}$ Weigert. Verhandl. d. gesund. Deut. Naturf. Aertze, Frankfort, 1896. 
less poisonous effect upon the cells but which combine with the antitoxin equally.

The liberation and action of bacterial endotoxins or proteids. The bacterial poisons which reside in the bodies of the bacteria are mostly yielded up only after the death of the organism. Here, in the invaded animal, the disease processes are more closely associated with the actual presence of the bacteria in the immediate vicinity than in the case of the extracellular toxins. The endotoxins are extracted by crushing or grinding the bacteria in a moist or dried condition. In this way a large series of impure bacterial proteids is obtained. The immunization processes produced by the cell substances of bacteria seem to have nothing to do with the toxic action of the cell proteids, but rather depend upon the introduction of suitable receptors which give rise to the bactericiảal protective powers-lysin, precipitin, and agglutinin.

Bacteria have been grouped according to their toxin and proteid producing power as follows. (1) Those bacteria which produce as free secretions true toxins, such as the bacteria of diphtheria and tetanus. (2) Those bacteria which possess apparently only endotoxins, true toxins which are more or less closely bound to the living cell, and which are only in a small degree separable in unchanged condition perhaps outside of the body. On the death of the organism they become partly free, partly remain united, or become secondary poisonous modifications no longer of the nature of toxins. The microspira of cholera and the colon bacillus are examples of this group. (3) Bacteria which yield perhaps no true toxins, not even intraplasmatically. The cell plasma contains poisons of another kind which obscures the typical proteid action. The bacterium of anthrax and of tuberculosis are examples of this group.

The pyogenic action of the bacterial proteids common to all bacteria depends principally upon their being extraneous albuminous substances. Pyogenic effects may be produced in a like manner by extraneous albumins of non-bacterial origin. That extraneous albuminous substance is harmful to the or- 
ganism which seeks to resist its action is shown by those specific precipitating ferments, such as precipitants, which are produced in the organism after the introduction of extraneous albumin.

The immune body. In taking Ehrlich's side chain theory
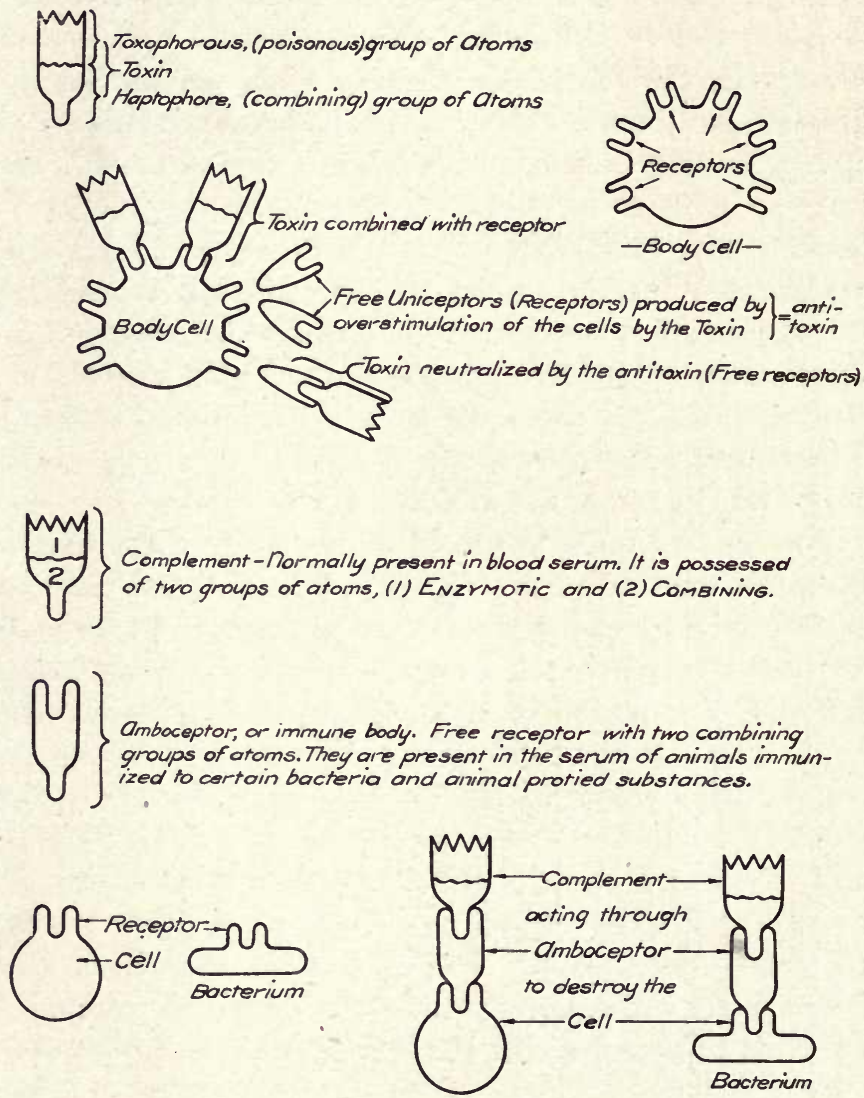

Ehrlich's conception of the formation of Antitoxin, the production of Toxic ana Bacterial Iminunity.

Fig. 100. Diagrams illustrating the production of antitoxin and lysis. to explain bacteriolysis and cytolysis it is found that it is necessary to assume that when an animal becomes immune to 
certain bacteria, for example the guinea pig to cholera microspira (see Pfeiffer's phenomenon), there is thrown off from the cells of the body as a result of the stimulation of the cholera organisms free receptors which possess two combining groups of atoms, one specific for the antigen or in this case the cholera microspira, the other adapted to the haptophore group of atoms of the complement. These free receptors possessing two combining groups of atoms are known as immune bodies, intermediary bodies or amboceptors. Specific amboceptors are necessary for the production of bacteriolysis, hemolysis and cytolysis.

The antitoxins, agglutinins and precipitins are specific antibodies possessing but one combining group of atoms or uniceptors. These combine with the toxin. The immune bodies are specific antibodies possessing two combining groups of atoms or amboceptors. These unite one group of combining atoms with the specific antigen, the other group of combining atoms with the complement. In the production of hemolysis or bacteriolysis Emil Fischer has likened the receptor of the corpuscle or bacterium to a lock, the amboceptor to the key, and the complement to the hand that turns the key. There must be the definite key for the definite lock and when in place any hand can turn it. The amboceptor is the specific body through which the normal complement can work.

The subject of toxins, antitoxins and immunity is so large that the student is referred to the studies of Ehrlich, Morgenroth, Sachs, Bordet, Metchnikoff and others for a more exhaustive study of the subject. There is a large current literature and several volumes have been published concerning it. Of these the following are recommended: Collected Studies un Immunity, by Paul Ehrlich, translated by Ch. Boldman; Immunity, by E. Metchnikoff; Handbuch der Technik u. Methoden der Immunitätsforschung, by Kraus and Levaditi, two volumes. The small volume, Immune Sera by Wassermann, translated by Boldau and Handbuch der Serumtherapie, by WolffEisner. 


\section{CHAP'TER XXIV.}

\section{SERUM DIAGNOSIS.}

The discovery of the complement in normal blood serum and the various bodies such as agglutinins and precipitins resulting from stimulation of the tissues by alien proteid substances has led to the development of methods for utilizing these bodies in making specific diagnoses. The recognition of the existence of these bodies was accompanied by the work of Bordet and Gengou ${ }^{1}$ who found that the red blood corpuseles of animals when put in contact with many different substances are so altered that their hemoglobin is set free. This phenomenon of solution is now generally known as hemolysis. The first utilization of this knowledge as a sero-diagnostic agent was made in 1906 by Wassermann ${ }^{2}$ who used it in the "complement fixation" method to detect the presence or absence of syphilis. His method has been modified somewhat by Noguchi ${ }^{3}$ and other workers. Schütz and Schubert ${ }^{4}$ applied this method of serum diagnosis to glanders and in this country Mohler and Eichhorn ${ }^{5}$ have reported good results from its use. The method that is followed in this laboratory for diagnosing glanders and which was taken from Mohler and Eichhorn and Noguchi with slight modifications made by Dr. C. P. Fitch is giving very good results. It is as follows:

The diagnosis of glanders by the complement fixation method. The test requires five different substances: (1) washed red blood corpuscles of a sheep, (2) hemolytic ambo-

\footnotetext{
${ }^{1}$ Bordet and Gengou. Ann. de l'Inst. Pasteur, Vol. XV (1901) p. 289.

${ }^{2}$ Wassermann and Bruck. Klin. Med., 1905.

${ }^{3}$ Noguchi. Serum diagnosis of syphilis, 1911.

${ }^{4}$ Schütz and Schubert. Arch. f. wissenschaftliche und praktische Tierheilkunde, Bd. XXXV (1909) p. 44.

${ }^{5}$ Mohler and Eichhorn. Bulletin No. 136 , B. A. I., U. S. Dept. of Agriculture, 1911.
} 
ceptor, (3) complement, (4) antigen (bacterial extract), (5) serum from the blood of the suspected animal to be tested.

1. Red blood cells. The washed red blood corpuscles of a sheep are obtained by bleeding a vigorous sheep from the jugular vein under antiseptic precautions. The blood is preferably collected in a sterile flask containing a few glass beads. The blood is shaken, defibrinated and filtered through sterile gauze into a glass tube. The tube is then filled with* physiological salt solution and the mixture centrifuged. The supernatant fluid is poured off and the process repeated until all the serum is removed from the corpuscles. Enough salt solution is added to the sedimented corpuscles to make the volume of blood equal the original amount filtered into the tube.

2. Hemolytic amboceptor. The hemolytic amboceptor is obtained from the serum of a rabbit which has been immunized to the washed red blood corpuscles of a sheep. A strong vigorous rabbit is selected and injected with the washed red corpuscles. The injections are preferably made intraperitoneally and at intervals of 4-5 days. Two ec., 4 ec., 8 ec., and $12 \mathrm{cc}$. of the corpuscles are respectively used for each injection. In seven or eight days after the last injection a small amount of blood is taken from the rabbit (by bleeding from an ear vein) and the serum titrated to determine whether its hemolytic action is sufficient; that is, whether it will readily dissolve the hemoglobin from the corpuscles of a sheep. If it is found satisfactory the animal is bled from the carotid and the serum collected and stored in small bottles. It is preferable not to put more than 2 cc. in each bottle. The serum may be preserved by adding 0.5 per cent of carbolic acid in a 5 per cent dilution. If the carbolized serum is not used for three days after adding the carbolic acid it will not require inactivation (heating at $56^{\circ} \mathrm{C}$. for $1 / 2$ hour). Noguchi prefers adding 2 drops of ehloroform to each 2 ce. of hemolytic serum

* For hemolytic work 0.85 per cent (Ehrlich) to 0.9 per cent (Madsen) salt solution is universally employed. We prefer the latter concentration. 
and in this case in order to get the best results the serum should be inactivated before using. Serum preserved in this way can be kept in the ice box for from three months to a year. It must, however, be titrated at intervals of a few weeks as the titre may change.

Titration of Hemolytic Rabbit Serum. Dilutions of the hemolytic serum are made in eight test tubes, according to the following table. It is best to use pipettes to measure the required amounts.

TABLE NO. I.

DiLUtions OF HEMOLYTiC AMBOCEPTOR (RABBit SERUM).

\begin{tabular}{|c|c|c|c|c|}
\hline $\begin{array}{l}\text { Tube } \\
\text { No. }\end{array}$ & $\begin{array}{c}\mathrm{NaCl} \\
\text { Solution }\end{array}$ & Serum & $\begin{array}{c}\text { Gives } \\
\text { Dilution }\end{array}$ & Remarks \\
\hline I & gcc. & I cc. & I-10 & This is a I-ro basic dilution \\
\hline 2 & $9 \mathrm{cc}$. & $\begin{array}{l}\text { I cc. of I-IO } \\
\text { dilution }\end{array}$ & I-100 & \\
\hline 3 & $8 \mathrm{cc}$. & $\begin{array}{l}2 \text { cc. of } \\
\text { I-100 dil. }\end{array}$ & I-500 & \\
\hline 4 & $9 \mathrm{cc}$ & $\begin{array}{l}\text { I cc. of } \\
\text { I-100 dil. }\end{array}$ & $1-1000$ & \\
\hline 5 & I cc. & $\begin{array}{l}2 \text { cc. of } \\
\text { I-1000 dil. }\end{array}$ & $I-1500$ & \\
\hline 6 & I cc. & $\begin{array}{l}\text { I cc. of } \\
\text { I-1000 dil. }\end{array}$ & $I-2000$ & \\
\hline .7 & $3 \mathrm{cc}$ & $\begin{array}{l}\text { I cc. of } \\
\text { I-IOco dil. }\end{array}$ & $I-4000$ & \\
\hline 8 & $8 \mathrm{cc}$ & $\begin{array}{l}2 \mathrm{cc} \text {. of } \\
\text { I-1000 dil. }\end{array}$ & $I-5000$ & \\
\hline
\end{tabular}

The titration proper is then made in the following manner: Eight additicnal test tubes are each filled with 2.5 ce. of salt solution to which is then added the hemolytic serum (amboceptor) in quantities of 1 ce. of the different dilutions (Table No. I) to each tube. Afterwards the complement of the guinea pig serum is added in quantities of 0.5 cc. of a $10 \%$ dilution to each tube, and finally 1 ce. of a five per cent suspension of washed sheep corpuscles in salt solution is placed in each tube.

Besides these eight tubes there are also three control tubes, 
one to show that the complement alone will not produce hemolysis (without the amboceptor), the second that the amboceptor alone without the complement will not produce hemolysis, and the third that the salt solution alone will not produce hemolysis. Thus in the first control tube we add 3.5 cc. of salt solution, 0.5 cc. of complement, and 1 ce. suspension of sheep corpuseles. In the second control tube we add 3 ec. salt solution, 1 ce. of the $1-100$ dilution of the amboceptor and 1 cc. suspension of sheep corpuseles. In the third control tube we add 4 ce. salt solution and 1 ce. sheep corpuscles. A test tube rack with two rows of holes is very convenient for holding the tubes for these tests.

TABLE NO. II.

TITRATION OF RABBIT SERUM (HEMOLYTIC AMBOCEPTOR).

\begin{tabular}{|c|c|c|c|c|c|}
\hline $\begin{array}{l}\text { Tube } \\
\text { No. }\end{array}$ & $\begin{array}{l}\text { (a) } \mathrm{NaCl} \\
\text { solutiou }\end{array}$ & Amboceptor & $\begin{array}{l}\text { (b) Com- } \\
\text { plement }\end{array}$ & $\begin{array}{l}\text { (c) Blood } \\
\text { corpuscles }\end{array}$ & Remarks \\
\hline 1 & $2.5 \mathrm{cc}$. & I cc. of I-Io dil. & $0.5 \mathrm{cc}$. & I cc. & - \\
\hline 2 & $2.5 \mathrm{cc}$. & I cc. of I-Ico dil. & $0.5 \mathrm{cc}$. & I cc. & \\
\hline 3 & $2.5 \mathrm{cc}$. & I cc. of I-500 dil. & $0.5 \mathrm{cc}$ & I cc. & - \\
\hline 4 & $2.5 \mathrm{cc}$. & I cc. of I-I000 dil. & $0.5 \mathrm{cc}$ & I cc. & \\
\hline 5 & $2.5 \mathrm{cc}$. & I cc. of $1-1500$ dil. & $0.5 \mathrm{cc}$. & I cc. & \\
\hline 6 & $2.5 \mathrm{cc}$. & I cc. of I- 2000 dil. & $0.5 \mathrm{cc}$. & I cc. & \\
\hline 7 & $2.5 \mathrm{cc}$. & I cc. of $\mathrm{I}-4000 \mathrm{dil}$. & $0.5 \mathrm{cc}$. & I cc. & \\
\hline 8 & $2.5 \mathrm{cc}$ & I cc. of I $50 c 0 \mathrm{dil}$. & $0.5 \mathrm{cc}$ & I cc. & \\
\hline 9 & $3.5 \mathrm{cc}$. & controls & $0.5 \mathrm{cc}$. & I cc. & $\begin{array}{l}\text { complement control } \\
\text { (no hemolysis should } \\
\text { occur) }\end{array}$ \\
\hline 10 & $3.0 \mathrm{cc}$ & I-100 dil. & $0.5 \mathrm{cc}$. & I cc. & $\begin{array}{l}\text { amboceptor control } \\
\text { (no hemolysis should } \\
\text { occur) }\end{array}$ \\
\hline I1 & $4.0 \mathrm{cc}$. & & & I cc. & $\begin{array}{l}\text { salt solution control (no } \\
\text { hemolysis should occur) }\end{array}$ \\
\hline
\end{tabular}

a. $0.9 \% \mathrm{NaCl}$ solution.

b. 0.5 cc. of a $10 \%$ solution of the complement.

c. $5 \%$ suspension of washed sheep corpuscles in salt solution. 
As ean be seen from Table II, the final volume in each tube is always uniformly 5 ec. Thus the different amounts of the blood derivatives used are always made up to 5 ce. by adding salt solution.

After adding the substances to the test tubes in the order given, the tubes are well shaken, placed in the test tube rack, and put in an incubator at $37^{\circ} \mathrm{C}$. for two hours. Then the tubes are removed from the incubator and the results read.*

The highest dilution in which complete hemolysis has taken place represents the titre of the hemolytic amboceptor. Thus if complete hemolysis has taken place up to and including the tube where the dilution of the rabbit serum was 1-2000 (Tube No. 6, Table II), the hemolytic titre of this serum is represented by 1-2000. This dilution, however, is not used in the glanders test; but rather its double strength, which would be 1-1000. The titre of the hemolytic amboceptor for use in the diagnosis of glanders should not be less than 1-1000 and therefore if the rabbit serum should prove to be of a lower titre it should be discarded. It often happens that some rabbits are found to be unsuited for the production of amboceptor and the titre of their serum ean not be raised high enough even after repeated inoculations with washed sheep corpuscles.

It is advisable to preserve the hemolytic amboceptor in small vials containing 1 to 2 ce. of the rabbit serum, and seal the corks with paraffin or sealing wax.

3. Complement. The complement which is contained in the blood serum of a normal guinea pig is employed. The complement should be titrated to determine its efficiency to act with the hemolytic amboceptor.

Titration of Complement. By titration of the complement there is aimed to be established a complement unit which is the smallest quantity of complement necessary to produce complete hemolysis in the presence of one amboceptor unit

* If the tubes are placed in a water bath kept at $37^{\circ} \mathrm{C}$. the time here may be shortened to one half hour. 
and a suspension of sheep corpuscles.* The serum from each guinea pig should be titrated in the following manner before it is used. A basic dilution of 1-10 is made of the complement by adding $0.3 \mathrm{cc}$. of the complement to $2.7 \mathrm{cc}$. of salt solution in a test tube.

TABLE NO. III.

TITRATION OF COMPLEMENT.

\begin{tabular}{|c|c|c|c|c|}
\hline $\begin{array}{l}\text { Tube } \\
\text { No. }\end{array}$ & $\begin{array}{l}\text { NaCl } \\
\text { solution } \\
\text { (a) }\end{array}$ & $\begin{array}{l}\text { Complement } \\
\text { from I-ro di- } \\
\text { lution (b) }\end{array}$ & $\begin{array}{l}\text { Ambocep- } \\
\text { tor (c) }\end{array}$ & Blood corpuscles (d) \\
\hline I & $2.5 \mathrm{cc}$. & $0.5 \mathrm{cc}$. & I cc. & I cc. \\
\hline 2 & $2.6 \mathrm{cc}$ & $0.4 \mathrm{cc}$. & I cc. & I cc. \\
\hline 3 & $2.7 \mathrm{cc}$. & $0.3 \mathrm{cc}:$ & I cc. & I cc. \\
\hline 4 & $28 \mathrm{cc}$ & $0.2 \mathrm{cc}$. & I cc. & I cc. \\
\hline 5 & $2.9 \mathrm{cc}$ & $0.1 \mathrm{cc}$. & I cc. & I cc. \\
\hline 6 & $3.5 \mathrm{cc}$ & $0.5 \mathrm{cc}$. & & $\begin{array}{l}\text { I cc. complement control } \\
\text { (no hemol ysis should occur) }\end{array}$ \\
\hline 7 & $3.0 \mathrm{cc}$ & & I cc. & $\begin{array}{l}\text { I cc. amboceptor control (no hemo- } \\
\text { lysis should occur) }\end{array}$ \\
\hline 8 & $4.0 \mathrm{cc}$ & & & $\begin{array}{l}\text { I cc. salt solution control (no hemo- } \\
\text { lysis should occur) }\end{array}$ \\
\hline
\end{tabular}

a. $0.9 \% \mathrm{NaCl}$ solution.

b. Guinea pig serum in diminishing quantities.

c. Of previously titrated hemolytic serum, double dissolving quantity.

d. $5 \%$ suspension of washed sheep blood corpuscles in salt solution.

From this dilution certain definite amounts are added to each of five other tubes according to Table III. To the complement thus distributed to each tube, is added 1 cc. of hemolytic amboceptor of which the titre has already been deter-

* The serum is obtained by bleeding a strong vigorous guinea pig by cutting the throat. The pig is first anesthetized and the ventral portions of the neck shaved and disinfected. The blood is collected preferably in a Petri dish. 
mined * and likewise 1 cc. of a $5 \%$ solution of sheep blood corpuscles. The amount of fluid in each tube is made up to 5 ce. by the addition of salt solution. Three controls are used. The first control tube contains $3.5 \mathrm{cc}$. salt solution, $0.5 \mathrm{cc}$. of the $10 \%$ basic dilution of complement and 1 ce. of a suspension of sheep corpuscles. In the second control $3 \mathrm{cc}$. salt solution, 1 ce. of the amboceptor dilution and 1 ec. of the suspension of corpuscles; in the third control $4 \mathrm{cc}$. of salt solution and 1 ce. of the suspension of sheep's corpuscles are used. The order of adding each product and the amount of each are given in Table III.

After shaking each tube, they are placed in a rack and then in an incubator at $37^{\circ} \mathrm{C}$. for two hours.* After the expiration of this time they are removed and the results noted. The highest dilution of complement in the tube in which the hemolysis is complete indicates the titre of the complement. For example, if hemolysis is complete in the tube where $0.3 \mathrm{cc}$. of the $10 \%$ basic dilution of the complement was used (Tube 3 , Table III) and the hemolysis is incomplete in the tube in which 0.2 ce. of the same dilution was employed (Tube 4 , Table III) then the titre of the complement is 0.3 cc., inasmuch as a $10 \%$ basic dilution of the complement was employed. Thus, in the tests using this complement it would be necessary to employ a $3 \%$ complement dilution, that is, 3 ce. of the serum of the guinea pig in $97 \mathrm{ce}$. of salt solution.

The amboceptor used in this titration should be inactivated when fresh, or when preserved with chloroform. The carbolized ambocepter may be used without inactivation after it is 3 days old.

4. Antigen. In testing for glanders this consists of an extract of Bact. mallei prepared as follows. Cultures are made on acid glycerine agar and allowed to incubate for 48-72 hours.

* That is, if the titre was found to be 1-3000 by the previous titration you would add 1 cc. of a $1-1500$ dilution, as double the quantity of amboceptor is added which has been stated before.

* Here again the time may be shortened to one-half hour by the use of a water bath at $37^{\circ} \mathrm{C}$. 
The growth is then washed off with salt solution. This salt solution suspension of the organisms is kept at $60^{\circ} \mathrm{C}$. for four hours in order to kill the bacteria. The suspension is then placed in a shaking machine and shook at frequent intervals for four days. It is then centrifuged at high speed (3000-5000 revolutions per minute), the clear supernatant liquid drawn off and ten per cent of a $5 \%$ solution of carbolic acid added. Before use the antigen must be titrated to obtain its anticomplementary action. It would be well also to determine its antigenic and hemolytic properties as well. However, this may be left until the test proper.

Titration of the Extract or Antigen. The titration of the extract is carried out in order to determine the quantity of the extract which no longer prevents hemolysis (the anti-complementary action). A 1-10 dilution of the extract is first made by adding $1 \mathrm{cc}$. of the extract to $9 \mathrm{cc}$. of salt solution. From this 1-10 dilution other dilutions are prepared as follows.

TABLE NO. IV.

DILUTIONS OF THE ANTIGEN.

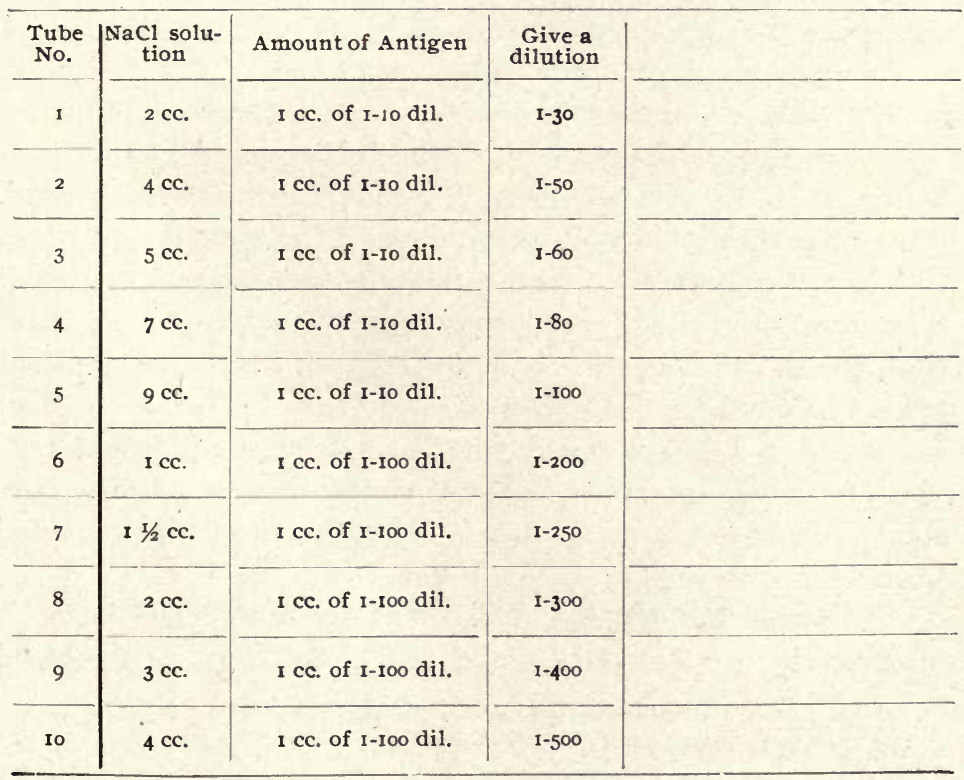


The titration proper is carried out as follows. Eleven test tubes and three for controls are used. To each tube 1 ce. of salt solution is added, then 1 ce. of the complement of the previously determined smallest quantity established by the titration done before. To each tube add $1 \mathrm{cc}$. of the different dilutions (1-10, 1-30, 1-50, etc.) of the extract as obtained in Table IV. The tubes are shaken, placed in a rack and the rack placed in an incubator at $37^{\circ} \mathrm{C}$. for one hour.* The tubes are then removed and 1 ce. of a double quantity of the previously titrated amboceptor is added to each tube, and finally 1 ce. of a $5 \%$ suspension of washed sheep blood corpuscles. Three control tubes are used. The first serves for a control to show that the complement alone (without the amboceptor) does not produce hemolysis, the second to show that the amboceptor alone does not produce hemolysis and the third that the salt alone does not produce hemolysis. In the first control tube 3 ce. of salt solution, 1 ec. of complement and 1 ec. of blood corpuseles are added. The second tube contains 3 cc. of salt solution, 1 ce. of amboceptor and 1 ec. of blood corpuscles, while the third contains 4 ce. of salt solution and 1 ce. of suspension of sheep blood corpuscles. The following table (Table V) gives a summary of the foregoing method.

Each tube is shaken and all the tubes placed in the incubator at $37^{\circ} \mathrm{C}$. for two hours. $t_{\text {t }}$ The results are then read. The tube in which hemolysis is no longer prevented represents the titre of the extract. In the glanders test, however, one-half that quantity is used. For example, if the results of the titration should be that the first tube which does not prevent hemolysis contains a dilution of $1-80$ (tube 5 , Table V), then a dilution of 1-160 of the extract is used for the glanders test. Antigen which possesses, too much anti-complementary substance should not be used ; that is, where hemolysis is prevented in as high dilutions as $1-300,1-400,1-500$, etc.

5. Suspected serum. The suspected glandered horse is bled usually through the jugular and about 20 cc. of the blood

* May place in water bath at $37^{\circ} \mathrm{C}$. for $1 / 2$ hour.

† Or water bath at $37^{\circ} \mathrm{C}$. for one hour. 
is collected in a small bottle. The blood is then allowed to coagulate and the serum to collect. If the.blood came from an animal affected with glanders, the serum contains the specific glanders bacteriolytic amboceptor or immune bodies.

TABLE NO. V.

TITRATION OF GLANDERS BACTERIA EXTRACT.

\begin{tabular}{|c|c|c|c|c|c|c|}
\hline $\begin{array}{l}\text { Tube } \\
\text { No. }\end{array}$ & $\underset{\text { tion (a) }}{\mathrm{NaCl} \text { solu- }}$ & $\begin{array}{l}\text { Comple- } \\
\text { ment (b) }\end{array}$ & Extract (c) & $\begin{array}{l}\text { Ambocep- } \\
\text { tor (d) }\end{array}$ & $\begin{array}{l}\text { Blood cor- } \\
\text { puscles (e) }\end{array}$ & - \\
\hline I & I cc. & I cc. & I cc. of I-10 & ì cc. & I cc. & \\
\hline 2 & I cc. & I cc. & I cc. of I-3o & I cc. & $1 \mathrm{cc}$. & \\
\hline 3 & I cc. & I cc. & I cc. of I-so & I cc. & : I cc. & \\
\hline 4 & I cc. & I cc. & I cc. of $1-60$ & I cc. & I cc. & \\
\hline 5 & I cc. & I cc. & I cc. of I -80 & I cc. & I cc. & \\
\hline 6 & I cc. & I cc. & I CC. of I-100 & I cc & I cc. & \\
\hline 7 & I cc. & I cc. & I cc. of $I-200$ & I $\mathrm{cc}$ & I cc. & \\
\hline 8 & I cc. & I cc. & I cc. of $I-250$ & I cc. & I cc. & \\
\hline 9 & I cc. & $1 \mathrm{cc}$. & I cc. of $I-300$ & I cc. & I cc. & \\
\hline I0 & I cc. & I cc. & I cc. of $1-400$ & I cc. & I cc. & \\
\hline II & I cc. & I cc. & I cc. of $I-500$ & I cc. & I cc. & , \\
\hline 12 & $3 \mathrm{cc}$. & I cc. & controls & I cc. & I cc. & $\begin{array}{l}\text { Comp. control } \\
\text { (no hemolysis } \\
\text { should occur) }\end{array}$ \\
\hline 13 & $3 \mathrm{cc}$. & & & I cc. & I cc. & $\begin{array}{l}\text { Ambocep. con- } \\
\text { trol (no hemoly- } \\
\text { sis should occur) }\end{array}$ \\
\hline 14 & $4 \mathrm{cc}$ & & & & I cc. & $\begin{array}{l}\text { Salt solu. control } \\
\text { (no hemolysis } \\
\text { should occur) }\end{array}$ \\
\hline
\end{tabular}

a. $\mathrm{NaCl}$ solution.

b. The determined smallest quantity established according to the primary test.

c. Dilutions made according to Table IV.

d. Double the quantity previously determined by titration.

e. $5 \%$ suspension of washed sheep blood corpuscles. 
The amount of these immune bodies in the blood of glandered horses is not uniform and probably depends to some extent on the degree of infection present, therefore it is advisable to use in the test such quantities of the serum as will prove sufficient for the reaction to take place.

TABLE NO. VI.

THE FINA1, TEST FOR GLANDERS.

\begin{tabular}{|c|c|c|c|c|c|c|c|}
\hline $\begin{array}{l}\text { Tube } \\
\text { No. }\end{array}$ & $\begin{array}{l}\mathrm{NaCl} \\
\text { solu- } \\
\text { tion } 1\end{array}$ & $\begin{array}{c}\begin{array}{c}\text { Suspected } \\
\text { horse } \\
\text { serum } 2\end{array} \\
\end{array}$ & $\mid \begin{array}{c}\text { Glanders } \\
\text { bacteria } \\
\text { extract } 3\end{array}$ & $\begin{array}{c}\text { Com- } \\
\text { ple- } \\
\text { ment } 4\end{array}$ & $\begin{array}{c}\text { A mbo- } \\
\text { ceptor } \\
5\end{array}$ & \begin{tabular}{|} 
Blood \\
corpus- \\
cles 6 \\
\end{tabular} & Remarks \\
\hline I & cc. & $\begin{array}{l}\text { cc. } \\
0 . \mathrm{I}\end{array}$ & $\begin{array}{c}\text { Cc. } \\
\text { I }\end{array}$ & $\begin{array}{c}\mathrm{cc} . \\
\mathrm{I}^{*}\end{array}$ & cc. & $\begin{array}{c}\text { cc. } \\
1\end{array}$ & $\begin{array}{l}\text { Test tube for the dose } \\
\text { o. cc. of suspected } \\
\text { serum }\end{array}$ \\
\hline 2 & 2 & O.I & $-+-\infty$ & I & I & I & $\begin{array}{l}\text { Serum control for the } \\
\text { dose o. I cc. of sus- } \\
\text { pected serum }\end{array}$ \\
\hline 3 & 1 & 0.2 & I & I & I & I & $\begin{array}{l}\text { Test tube for the dose } \\
0.2 \mathrm{cc} \text {. of suspected } \\
\text { serum }\end{array}$ \\
\hline 4 & 2 & 0.2 & & I & I & I & $\begin{array}{l}\text { Serum control for the } \\
\text { dose } 9.2 \text { cc. of sus- } \\
\text { pected serum }\end{array}$ \\
\hline 5 & I & - & I & I & I & I & $\begin{array}{l}\text { Control for the quan- } \\
\text { tity of extract used } \\
\text { (hemolysis) }\end{array}$ \\
\hline 6 & & & 2 & I & I & I & $\begin{array}{l}\text { Control for the double } \\
\text { quantity of ext. for } \\
\text { gr. accuracy (hemo.) }\end{array}$ \\
\hline 7 & 2 & & & I & I & I & $\begin{array}{l}\text { Control of the hemoly- } \\
\text { tic system (hemoly- } \\
\text { sis) }\end{array}$ \\
\hline 8 & 3 & & & I & & I & $\begin{array}{l}\text { Control of the comple- } \\
\text { ment (no hemoly- } \\
\text { sis) }\end{array}$ \\
\hline 9 & 3 & & & -...- & I & I & $\begin{array}{l}\text { Control of amboceptor } \\
\text { (no hemolysis) }\end{array}$ \\
\hline 10 & 4 & & & & & I & $\begin{array}{l}\text { Control of salt solution } \\
\text { (no he molysis) }\end{array}$ \\
\hline
\end{tabular}

1. 0.9 per cent $\mathrm{NaCl}$ solution.

2. Suspected horse serum to be inactivated for 30 minutes at $56^{\circ}-57^{\circ}$ C. in water bath, in order to destroy the complement which is present in the serum of every horse.

3. One-half of the quantity which does not prevent hemolysis and estab'ished by titration (See Table V).

4. The determined smallest quantity established according to the preliminary test (See Table III).

5. Double the quantity previously determined by titration (See Table II).

6. $5 \%$ suspension of washed sheep blood corpuscles.

* Place for 1 hour in incubator or one-half hour in water bath at $37^{\circ} \mathrm{C}$. 
The necessary quantity has been established by Schütz and Schubert as 0.2 and 0.1 cc. placed in two different tubes. In some instances the tube containing $0.2 \mathrm{cc}$. may show a fixation of the complement, while the tube containing $0.1 \mathrm{cc}$. of the same serum may show only a partial fixation or hemolysis. In the majority of cases, however, the fixation is usually manifested in both tubes.

Method of performing test. Four tubes are employed for testing the serum of each animal. Two tubes are used for the test proper and two for controls. The tubes are numbered $1,2,3$, and 4 . One ce. of a physiological salt solution is added to tubes Nos. 1 and 3. Two ec. is placed in tubes 2 and 4. The serum of the suspected horse is then added. This serum has previously been rendered inactive, that is, the complement has been "inactivated" by heating for one-half hour at $56-57^{\circ} \mathrm{C}$. One-tenth ce. of this inactivated serum is added to tubes 1 and 2. Two-tenths ce. is added to tubes ${ }^{\circ} 3$ and 4. The antigen (glanders bacteria extract) is now added to tubes Nos. 1 and 3. One ce. of an established dilution is used. Tubes 2 and 4 are controls to see whether the suspected horse's serum will influence hemolysis.

To each tube is now added 1 cc. of a dilution of the complement (blood serum of normal guinea pigs). The proper dilution has been determined by titration as mentioned before.

A series of six controls should be made in connection with each series of tests carried out. One set of controls will do for a single day's testing as long as the same substances (antigen, complement, amboceptor) are used in each test. It is also well to set what are called "positive" and "negative" controls in connection with each series of tests made. That is, the blood from a known glandered animal and likewise the blood from a healthy animal should be tested in connection with the blood from the suspected animals.

The six controls mentioned above are made according to Table VI beginning with tube No. 5 .

Each tube is shaken carefully and placed in an incubator 
for 1 hour (or water bath at $37^{\circ} \mathrm{C}$. for $1 / 2$ hour). This is done in order to allow the union or fixing of the complement which will become locked up with the antigen and the bacteriolytic amboceptor in case the suspected serum came from a glandered
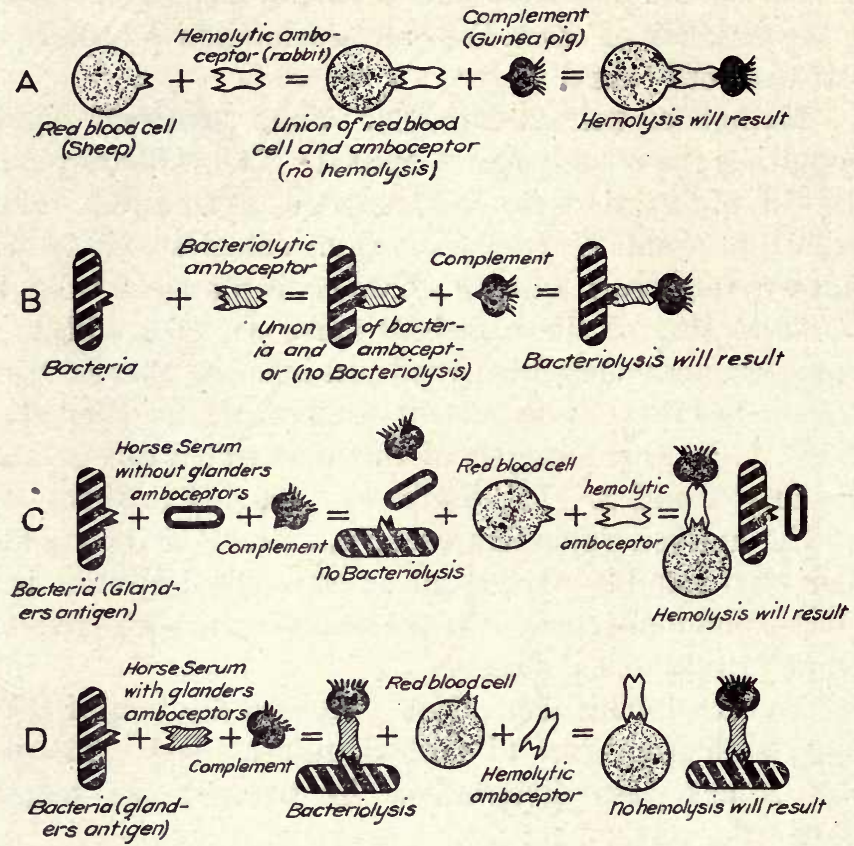
A -Hemolytic System
B - Bacteriolytic System
C -llegative reaction, normal horse serum
D -Positive reaction, glandered horse serum

\section{- Diagrammatic Representation of Complement Fixation-}

Fig. 101. A scheme illustrating the complement fixation method devised by Noguchi and modified slightly by Mohler and Eichhorn for diagnosis of glanders.

animal. If the bacteriolytic amboceptor is not present or the suspected serum was from a healthy animal the complement will not become locked up or fixed. 
After the required incubation period the tubes are removed from the incubator and to each tube is added 1 ec. of the previously titrated rabbit serum (hemolytic amboceptor). This serum has previously been inactivated by heating to $56^{\circ}-57^{\circ} \mathrm{C}$. for one-half hour, provided it has not been earbolized and kept for three days. Finally 1 ce. of a $5 \%$ suspension of the washed red corpuscles of a sheep is added to each tube. The tubes are now replaced in the incubator and left for 10 hours, when the results may be read. If put in a water bath at $37^{\circ} \mathrm{C}$. and left for 1 hour and then removed and kept at room temperature for from 3-5 hours the results may be read. Some workers prefer reading the results as soon as removed from the water bath. If the horse was affected with glanders, that is, the serum of the animal contained bacteriolytic amboceptor, no hemolysis will have taken place in tubes 1 and 3 . The red corpuscles will have settled to the bottom and the upper liquid will be clear. The controls Nos. 2 and 4 should show complete hemolysis, that is, the fluid in the tubes should be uniformly red. If, however, the suspected serum came from a healthy horse and did not contain the bacteriolytic amboceptor, hemolysis should take place in tubes Nos. 1 and 2. Mohler gives the following advice in the interpretation of the results of the test.

1. "Horses in which the serum produces a complete fixation of the complement in the quantities of $0.1 \mathrm{ec}$. and $0.2 \mathrm{ec}$. should be considered as glandered.

2. "Horses in which the serum gives a complete fixation in the quantity of 0.2 ec. and an incomplete fixation in the quantity of $0.1 \mathrm{ce}$. should likewise be considered glandered.

3. "Horses in which the serum produces an incomplete fixation of the complement in the quantities of 0.1 cc. and 0.2 ce. should also be considered as glandered.

4. "Horses in which the serum shows no fixation of the complement in either tube should be considered free of glanders."

In order to reduce the possibility of error to a minimum the agglutination test may be applied to the latter cases, and 
if this shows a value of 1 to 1,000 or over, the animal should be considered as glandered. However, such cases are extremely rare.

The diagnosis of infectious abortion. The method of complement fixation for detecting infection with Bact. abortionis was first used by M'Fadyean ${ }^{6}$ and more recently Sven Wall ${ }^{7}$ has reported it to be very trustworthy. He used it in conjunction with the agglutination test. In this laboratory we are testing out the complement fixation method for diagnosis or picking out cattle infected with this organism in the control of infectious abortion. M'Fadyean and Stockman ${ }^{8}$ have recently used the agglutination test in the diagnosis of bovine contagious abortion. In conclusion they state that the test has now passed beyond the probationary stage and deserves to be adopted as the method of diagnosis. They state that the discovery of such a reliable method of diagnosis removes what was hitherto the greatest obstacle in successfully combating the disease.

${ }^{6}$ M'Fadyean. loc. cit.

"Sven Wall. Zeit. f. Infektionsk. u. Hygiene der Haustiere, Bd. X (1911).

${ }^{8}$ M'Fadyean and Stockman. Jour. Comp. Path. and Therap., Vol. XXV (1912) p. 22. 


\section{CHAPTER XXV.}

\section{IMMUNITY AND VACCINE THERAPY.}

General consideration.* It has long been recognized that certain species of animals do not suffer from certain infectious diseases. It has also been noticed that when animals or man recovered from certain infections that they did not readily contract that disease again. This resistance to the invasion of certain microorganisms has been termed immunity. It is, however, relative, for in many instances it can be overcome either by excessive infection or by changing the physical condition of the host. The resistanee or immunity found to exist against infection is divided into two quite distinct classes (1) natural, i. e. where the individuals of a species do not contract the disease and (2) acquired, i. e. where they become resistant to a specific infection after having recovered from one attack.

* For the further study of the facts and principles concerning the production of immunity and immune bodies the student is referred to the following works on this subject:

Citron. Immunity, methods of diagnosis and therapy and their practical application, 1912.

Ernst. Modern Theories of Bacterial Immunity. Boston, 1903.

Kraus and Levaditi. Handbuch der Technik und Methodik der Immunitätsforschung, 1909.

Metchnikoff. Immunity in Infective Diseases. Cambridge, 1905.

Much. Die Immunitätswissenschaft, 1911.

Müller. Vorlesungen über Infektion und Immunität, 1910.

Nuttall. Blood Immunity and Blood Relationship. Cambridge, 1904.

Sternberg. Immunity, Protective Inoculations in Infectious Diseases and Serum-Therapy. New York, 1895.

Sobernheim. Zeit. f. Hyg., Bd. XXV (1897) p. 301.

Vaughan and Novy. Cellular Toxins or the Chemical Factors in the Causation of Disease.

Wassermann. Immune Sera, Haemolysins, Cytotoxins, and Precipitins. New York, 1904. 
Natural immunity. Every species of animals possesses resisting powers against certain disease producing microorganisms. Occasionally this natural resisting power is present with certain races only. Thus the Algerian sheep are immune to anthrax while other sheep are very susceptible to it. Cattle are immune to glanders and horses do not suffer from black quarter. A satisfactory explanation for this natural immunity has not been recorded.

Acquired immunity. Acquired immunity is a resistance brought about in the individual by several means, namely : (1) by recovering from a naturally contracted attack of the disease; (2) by inoculating the individual with non-lethal doses of the virulent organisms; (3) by the injection of the individual with attenuated virus as in vaccination; (4) by injecting dead (killed) bacteria or the product resulting from their multiplication in culture media; and (5) by the injection of the blood serum of animals that have recovered from the disease or that have been immunized by any of the above mentioned methods. This form of immunity varies in its completeness and duration according to the disease and the extent to which the immunizing agents have been applied.

Explanation of acquired immunity. A number of ingenious explanations have been offered for acquired immunity. The only ones that have withstood the test of their objectors are those of Metchnikoff, representing the cellular theory, and of Ehrlich, representing the humoral theory. The results from different lines of investigation indicate that the factors involved in securing immunity against infectious diseases are multiple in number and varied in character. As pointed out by Meltzer it is difficult to explain immunity as being due to one or even to a few anti-bacterial properties of the animal body. In the struggle against bacteria the defence of the body is carried on by the united action of each and every resisting influence. However, a number of theories have been proposed.

1. The exhaustion theory. This theory was suggested in 1880 by Pasteur, who thought that the microorganisms growing in the body used up some substance essential to their 
further existence and died out leaving the body unsuited for future occupation. The theory could not apply to passive immunity produced by the injection of antitoxin.

2. The retention theory. This was proposed by Wernich and Chauveau. This theory is based on the supposition that bacteria elaborate some metabolic product that inhibits their further development and the future invasion of the tissues by the same species. This theory is illustrated by the facts shown in the cultivation of bacteria in artificial media. The bacteria often die apparently from the accumulation of metabolic products long before the nutriment is exhausted.

3. The phagocytosis theory. Metchnikoff has supposed that acquired immunity is brought about because of the action of the phagocytes upon the invading organisms. He has shown that in cases of infection with the Vibrio Metchnikovi, the phagocytes of unprotected animals do not take up the bacteria, but that in vaccinated animals they do. It appears from all the work that has been done on this subject that the phagocytes are active in proportion to the degree of immunity possessed by the individual. It has not been demonstrated, however, whether they are active because the animal is immune, and the bacteria harmless to it, or whether the animal is immune because the phagocytes are destructive to the bacteria.

4. The humoral theory. This theory is based on the observations of Buchner, Nuttall and others that blood serum has the power of destroying a certain number of bacteria when introduced into it. Nuttall showed in addition to this that the bacteriolytic power ceased if the blood was heated to $55^{\circ} \mathrm{C}$. It is found, however, that the bacteriolytic serums occur only in cases where there is a high degree of forced immunity, their activity being in proportion to the degree of immunity obtained. An explanation for the action of these serums upon bacteria is given by Ehrlich in his lateral-chain theory.

5. Ehrlich's side-chain theory. According to Ehrlich, in every living cell there must exist an active central body and a number of other chemical groups or side chains. These 
groups have the greater variety of functions, especially those of nutrition and assimilation. This theory teaches that immunity depends upon the presence or absence of certain substances which he calls receptors or lateral chains which certain of the cells possess. These receptors are concerned in the normal nutrition of the cells and have affinities for various complex albuminous substances. Among these substances are the molecules of the toxin produced by certain bacteria and possibly other poisons. Every toxin has affinities described as haptophorous and toxophorous, that is, every molecule of the toxin is composed of two different groups of atoms, the one the toxophore or poisonous group, the other the haptophore, or combining group of atoms. The haptophorous molecules of the toxin combine or unite with the receptors of those cells for which they have special affinity and through the haptophore group the toxophore part of the molecule is able to act upon the eell. In some cases the cells are destroyed and in others additional receptors seem to be produced because of the stimulation. These receptors may pass out of the cell into the serum, where they act as free receptors or immune bodies to lock up or neutralize the toxin. The free receptors are the active part of the antitoxin.

Toxic and bacterial immunity. Investigations have shown that there are two distinct types of acquired immunity against bacterial diseases, namely : (1) toxic immunity and (2) bacterial immunity. Toxic immunity is where the disease is caused by the elaboration of an extracellular toxin such as. exists in diphtheria and tetanus and where the individual is immunized either by the production of an antitoxin within the body due to an attack of the disease or where the antitoxin has been injected into the body. Bacterial immunity is where amboceptors or immune bodies are present, having been produced in the body by the infecting organisms (Pfeiffer's phenomenon), or introduced from without. Toxic immunity is easily acquired against the toxic diseases such as diphtheria and tetanus but the production of bacterial immunity against the diseases in which the bacteria destroy the tissues such as 
tuberculosis and glanders has not been generally successful. The subject needs much additional investigation.

Active and passive immunity. Most authors recognize an active and a passive immunity. The active immunity includes those cases in which the specific antitoxin or immune bodies (amboceptors) are produced within the body as a result of the stimulation of the tissues by the antigen (either the specific organism or its toxin). Thus a horse that recovers from an attack of tetanus or has been made resistant to it by repeated injections of tetanus toxin possesses an active immunity to tetanus. Passive immunity is where the individual receives from without a sufficient quantity of antitoxin or amboceptors with which to neutralize the toxin or destroy the invading bacteria should they appear in the tissues. The horse that receives a quantity of tetanus antitoxin is made passively immune to the disease. As a rule active immunity is of much longer duration than the passive variety.

Immunity against protozoan diseases and filterable viruses. The work on immunity has been largely in connection with bacterial diseases. Experimental work has shown, however, that immunity can be established against several of the protozoa. Whether the same classifications can be applied here as in bacterial immunity is doubtful. Our knowledge of the tissue response to protozoa is not sufficient to warrant the discussion of the question. It is a fact, however, that cattle can be made immune to Texas fever ${ }^{1}$ by injecting subcutaneously from one to two cubic centimeters of the blood serum or defibrinated blood of immune cattle. If the injection is made in young calves and in cool weather the loss is very slight. The work of de Schweinitz and Dorset ${ }^{2}$ and others has shown that immunity can be conferred against hog

${ }^{1}$ Schroeder. Report U. S. Bureau Animal Industry, 1898, p. 273. Connaway. Bulletin No. 37, Mo. State Bd. of Agric., 1897.

Francis and Connaway. Bulletin No. 35, Texas Agric. Exper. Station, 1899.

${ }^{2}$ de Schweinitz and Dorset. Circular No. 41, U. S. Bureau of Animal Industry, 1903. 
cholera with the serum of hyperimmunized hogs. Like results have been obtained with several other diseases more common in the tropics. See References on immunity.

\section{VACCINES.}

Vaccines, vaccination and vaccine therapy. As originally used, vaccine meant an attenuated virus, that is, a virus capable of producing a reaction of the body tissues that tended to protect them against a later attack of the virulent virus. It had for its purpose the production of immunity. The vaccine of small pox is perhaps the best known example of this, although those for anthrax and black leg have long been recognized. The use of these vaccines is prophylactic in that they were given before actual infection had taken place, and for the purpose of protecting the individual. In 1885 Pasteur brought forward a new idea with the introduction of his antirabic vaccination. This vaccine is administered after infection has taken place and immunity is induced so rapidly that it prevents the more slowly developing attack of the strong virus. Wright and Douglass ${ }^{3}$ still further advanced the methods of vaccination for therapeutic purposes by injecting dead bacteria into the body of patients suffering with various chronic affections due to these organisms. At first Wright seems to have limited the application of his vaccine to chronic conditions with well marked and usually external localization of the infectious processes. More recently the practice of injecting dead bacteria (cultures of bacteria heated sufficiently to kill the organisms) has been extended to the more acute diseases such as typhoid in man and glanders in horses and even to diseases of short duration such as pneumonia and to infections in which there is a general systemic intoxication and in bacteriaemia.

The meaning of the term vaccine has been changed through the development of vaccine therapy from an attenuated virus to one in which the life of the organism has been

${ }^{3}$ Wright and Douglass. Proceedings of the Rcyal Society, Vol. LXXII (1903) p. 357. 
entirely destroyed. The term is also applied with questionable accuracy to such substances as tuberculins and antitoxins* when they are injected for therapeutic or immunizing purposes.

The term vaccination is generally applied to the injection of vaccines for prophylaxis or prevention.

The term vaccine therapy is applied to the injection of vaccines for the purpose of rapidly immunizing an individual after infection has taken place. Vaccine therapy or therapeutic vaccination is simply an offshoot from prophylactic vaccination. One shades insensibly into the other. The boundaries between what is called health and disease are clinically undefinable. In health the body may harbor disease germs and the supposed healthy may be slightly infected without being aware of it. The principles underlying prophylactic vaceination are thus applicable to vaccine therapy.

Vaccine therapy is being very generally employed for a great variety of both acute and chronic affections. The principle underlying it seems to be the rapid production of immunity. According to Wright, this is accomplished through the agency of opsonins which increase the phagocytosis. It has not been demonstrated that therapeutic vaccination can be generally applied with success. At present it is in the experimental stage and the efficiency of the method for diseases generally is not as yet known. $\dagger$

Three kinds of vaccines are used. (1) Autogenic vaccines which consist of heated (killed) cultures of the organism which is causing the trouble and which was isolated from the case. (2) Stock vaccines consisting of dead organisms of certain species like Micrococcus pyogenes, Streptococcus pyogenes or other bacteria, and which are used in cases where the

* For information concerning the properties of immune sera and their bearing upon the question of immunity the student is referred to the articles by Bordet (Ann. de l'Inst. Pasteur, Vol. XVIII (1904) p. 593) and Muir and Browning (The Journal of Hygiene, Vol. VI (1906) p. 1).

† The current veterinary literature contains many articles on the use of vaccines in the treatment of animal diseases. Most of these point to success in their use. 
changes are or are supposed to be caused by one or the other of these species. And (3) mixed or polyvalent vaccines eomposed of the killed organisms of several species. In addition to these, various serums, culture filtrates and tissue extracts such as leucocyte extract are used and sometimes called vaccines.

In measuring the dose of dead bacteria to be injected Wright employed the opsonic index. It has been found, however, that reliance can not be placed upon it for that purpose and consequently the dose must be determined experimentally. From 500,000 to $25,000,000$ organisms or even more are usually given as an initial dose.* This practical appreciation of bacteria in therapeutics is in the process of demonstration. At present, the indications are that many of the vaccines (killed bacteria) will be of great assistance in the treatment of numerous infections.

* For a discussion of this subject the student is referred to the small volume by $R$. W. Allen, 3rd. edition, on vaccine therapy and its theory and practice. Also Wolff-Eisner's Handbuch der Serumtherapie und experimentellen Therapie, 1910. 


\section{AUTHOR INDEX.}

\section{A}

Аввотт, 294.

Ada Metz, 183, 301, 305.

AdIL-BEy, 437.

Albutt, 380.

AlleN, 486.

Anderson, 456, 457.

ANDREWs, 190, 191.

Arloing, 257, 336.

ARNold, 60.

Arthus, 456.

Assmann, 362.

Atrinson, 296.

\section{B}

BAAs, 231.

BABES, 383, 386.

BABINSKY, 299.

BAGINISKY, 58, 106.

BAIL, 454, 455.

BAIN, 333.

BAINBRIDGE, 231, 327.

BAKER, 258.

BalbianI, 6, 429.

BALfour, 407.

BANG, 93, 216-218, 220, 333, 334, 439.

Bang, Olaf, 264.

BARBER, 227.

BARRIE, 152.

BARUCHELLO, 387.

Basenau, 324, 326.

BAUMANN, 231.

Baumgarten, 29.

BECK, 269.

von Behring, $6,72,223,263,445$.

BeIgeriNCK, 435.

Bentley, 426, 427.

Berger, 286, 287.

BERGEY, 188.

Bertrand, 446.

BesRedKa, 322.

BetTencourt, 390.

BEYER, 301.

BEYERINCK, 152.

Bienstock, 247, $275,314$.

Billings, 315.

Billroth, 33, 189, 206.
BLACK, 369.

BLANDFORD, 400.

BoAs, 302.

BopIN, 371.

BOLDAU, 463.

Boldman, 463.

BOLLINGER, 206, 270, 336, 360 .

Bolton, 316.

BONGERT, 231.

BoNome, 386, 447.

BoRdet, 445, 449, 459, 463, 464, 485.

BoRRELL, 438.

Bostrokm, 361.

BoWHILL, 387.

BRACKEN, 70.

BRAUELL, 222.

BREINI, 407.

BrIEger, 148, 149.

BRIMHALL, 270.

BRown, 331.

Browning, 485.

BRUCE, 394, 400.

BRUCK, 464.

Brugiere, 3.

BUCHNER, 27, 107, 143, 146, 442. $457,481$.

BUCKLEY, 367, 368.

BuHL, 245.

Bullard, 11.

BURNET, 437.

BURNETT, 362, 363.

BURRI, 230.

BURRILL, 317.

Busey, 186.

BushNel, 333.

Busse, 366.

Butschli, 6, 20.

Buxton, 90, 325 .

Cadeac, 356

Calkins, 213，374, 375, 377, 498, $424,428$.

Calmette, 257, 263, 446.

Campbell, 188.

Canestrini, 231.

CARLO, 328.

Carre, 439. 
Carroll, 316, 324.

Centanni, 436.

Chamberland, 226, 441.

СНамот, 176.

Charrin, 349, 355, 356, 447.

Chauveau, 481.

Ches hire, 344.

Chester, 39, 109, 115, 382.

Cheyne, 344.

Citron, 259, 455, 479.

Cohn, 4, 6, 29, 33-35, 88, 308, 348, 349.

Cole, 432.

Coleman, 90, 237.

Collins, 384.

Cons, 181, 207, 301.

Connaway, 483.

Conradi, 90.

Corda, 360.

Cornevin, 336.

Cornil, 268.

Crawley, 404, 405.

Cretes, 408.

Curtice, 266, 289.

Cushing, 317, 324, 326.

\section{D}

DALLiNger, 22.

DAMMANN, 333.

DANYSZ, 327, 328.

Davaine, $1,4,5,222$.

Dawson, 232, 289.

Dean, 264, 294.

De BARY, 6, 29, 30 .

Degen, 439, 440.

Deixonne, 397.

Dennmane, 203.

DenYs, 450.

DHONT, 324.

DoAne, 188.

Dond, 409, 410.

Doflein, 374, 398, 429, 431.

Doremus, 105.

DORIA, 363.

Dorset, 73, 96, 316, 438, 483.

Douglas, 451.

Douglass, 484.

Drysdale, 22.

DschunkowsKy, 394.

DubarRe, 262.

Dubois, 204.

Ducloux, 390.

DUJARDIN, 3, 5, 29.

DUNHAM, 315.

DurhaM, $86,317,325,400,447$. vor Dusch, 5.

DutTon, 406, 416.

DYAR, 347.

\section{$\mathbf{E}$}

EBer, 259.

EBerth, 321.

Ehren berG, 3, 5, 29, 34, 35, 215, $348,349,407,408$.

Ehrlich, 7, 127, 128, 331, 443, $457-460,462,463,465,481)$, 481.

EichHоRN, 464, 476.

EICHORN, 105.

EllermanN, 439.

Elmassian, 402.

EMERY, 371.

EMMERICH, 281, 309.

EMMERLING, 303.

VAN ERMENGeM, 134, 324.

ERrst, 28, 261, 335, 357, 479.

ESCHERICH, 193， 299, 309.

ESMARCH, 102.

Esten, 181, 207, 300, 301.

Evans, 394, 396, 397.

EwING, 235, 237.

\section{$\mathbf{F}$}

Fantham, 391, 425.

Fehleisen, 189.

FenNimore, 270.

Fermi, 94.

FERRAN, 331.

Ferrier, 141, 318.

FESER, 336.

Froced, 274.

Fiorentint, 268.

Fischer, 8, 12, 13, 20, 23, 32-35, $215,308,463$.

Fitch, 229, 245, 464.

FitzGERAID, 372.

FleXNer, 363, 446.

FlourNoY, 415.

FlueGGe, 39, 266, 269, 281, 300, $333,334,349$.

Foelger, 426.

Ford, 9, 309, 312, 347, 406.

FORDE, 406.

FraNCIS, 483.

Frank, 405.

Frankel, 89.

FrankLaNd, 174.

FreudeNREICH, 181, 301. 
Frosch, 405, 435, 436.

FrothinghaM, 263, 366, 369, 419, 423.

\section{G}

GabBett, 136, 248.

GaertNer, 316, 317, 323, 325, 327.

GAFFKY, $269,321,322,340,341$.

GAGE, 120, 125.

Galli-Valerio, 388.

GAYLORD, 413.

Gedoelst, 371.

vaN Gehuchten, 421.

GeNGou, 464.

GerhaRDT, 293.

GerNhARDT, 178.

GESSARD, 355, 427.

Giemsa, 137.

GILChRIST, 366 .

GillillaND, 256.

GilRuth, 205.

GLAGE, 286.

GLEN Ny, 240.

GoNDER, 390.

GoodsIR, 33.

GordoN, 190, 192, 193.

GorhaM, 89.

Gottstein, 231.

GouillebeaU, 204.

Grai, 129, 130.

Grawitz, 369 .

GRIGOROFF, 302, 303.

GrimberT, 153.

GrIPs, 286, 28 r.

Grohe, 369 .

GrotenfELT, 300, 301.

GRUBER, 447.

GRUBY, 370, 371, 394.

GueriN, 263.

Guglielmi, 386.

GUINARD, 282, 283.

GUNTHER, 301.

GWYN, 324, 326.

\section{H}

HADLEY, 89, 432.

HAECKEL, 6, 8.

HAENDEL, 416.

HANKIN, 457.

HANNA, 338.

HARING, 263.

HARRIS, 341-344.

HARRISON, 344.

HARTLEB, 230.
HARVEY, 275.

HARZ, 360.

HAUSER, 351, 352.

HeFFERAN, 303.

HeinemanN, 303.

Hektoen, 366, 452.

HeLlRIEGEL, 152.

HelmaN, 237.

Helmholz, 434.

HeMPEL, 440.

HeNle, 5.

HericourT, 455.

Herter, 11.

Higgins, 398, 400.

HiLl, 28, 121, 155, 202.

HiNDLE, 400, 410-412.

Hiss, 22, 85, 95, 132, 196, 452, 455.

HofFMANN, 297, 415, 447.

Holmes, 293.

HoLsT, 324.

HoLTH, 220.

HORDER, 190, 191.

HOWARD, 365.

HUEBNER, 438.

HUEPPE, 144, 230, 265, 270, 300, 302,351 .

Hunt, 384.

HUNZIKER, 107, 183.

HUTChIN, 388.

HUTYRA, 336, 340, 370.

ISRAEL, 360,361 .

IWANOW, 226 .

JAEGER, 78 .

JEFFERS, 113, 114.

JeNNER, 138, 139.

Jensen, 200, 270, 278.

JoEsT, 439, 440.

JoHNe, 245, 251, 263, 360.

JoHnson, 132.

JoHNSTON, 309.

JoNEs, 275, 276.

JoRDAN, 142, 174, 181, 341-344, $358,366$.

JoSEPH, 328.

JULIUSBERG, 437.

\section{K}

KAESEWURM, 231.

KALNIG, 237.

KANTHACK, $329,400$. 
KARSCH, 384.

KEITH; 347.

KERR, 217.

KilboRne, 6, 269, 383-385, 393.

KING, 11, 265.

KINGHORN, 407.

Kinyoun, 248.

Kitasato, 328, 330, 445.

Кıтт, 204, 270, 278, 279, 283, 430.

KLeBS, 245, 293, 294.

KLeIN, 294, 316, 350.

KLEINE, 447.

KLENKE, 245.

KNAPP, 376, 408, 413, 415.

KNUTH, 405.

KOBER, 186.

Косн, 5, 6, 72, 114, 159, 189, 206, $221,226,230,245,246,251$ $253,257,269,281,333,339$, 406,454 .

Kolle, 438.

Konew, 243, 245.

KozaI, 301.

KraUs, 210, 300, 323，449，463, 479.

KRESLiNG, 237.

KrUMwiede, JR., 246.

Kruse, 36, 269-271, 274, 299, 301, $315,316,336$.

Kunnemann, 286.

Kunstler, 6.

KURTh, 191.

LAMARCK, 3 .

VON LANGENBECK, 360.

LARKIN, 363.

LARTIGAU, 355.

LAVERAN, 6, 374, 386, 387, 394 , $395,397,398,402,403,407$, 425 .

LAW, 254.

Le Blanc, 388.

LECLAINCHE, 337.

LECLEF, 450.

VAN LeEUWENHOEK, $1,2,373$.

LehmaNN, 151, 193, 198, 215, 245 , $293,308$.

LEHRMANN, 31.

LEICHMAN N, 301.

LENTZ, 423.

LEUCKART, 429.

LEVADITI, 406, 409, 463, 479.

LEVY, 231.

LEWANDOWSKI, 213.
LEWIS, 394.

LiboRIUS, 104, 218, 335, 339, 347.

LigNIERES, 202, 265, 266, 364 , $384,404$.

LINDNER, 33.

LINGARD, 398.

VON LiNGELSHEIM, 190, 196.

Lister, 5, 300, 301.

LOBER, 11.

LODE, 437.

LoEB, 209.

LOEFFLER, 5, 34, 89, 92, 126, 128 , $133,134,136,234,271,278$, $279,293,294,297,316,324$, $333,435,436$.

LORENZ, 281.

LOWDEN, 417.

Lowenthal, 413.

LUCET, 286, 432.

LUCKHARDT, 343, 344.

LUEDMERSEN, 240.

LuHs, 394.

LUKSCH, 22.

LUPKE, 200.

\section{M}

McBride, 316.

McCallum, 364 .

MCCAMPBELL, 258.

MACE, 350 .

M'FADYEAN, 216, 218, 220, 221, $223,228,240,251,263,264$, $266,372,433,440,447,478$.

MCFARLAND, 230, 449.

MACK, $132,440$.

McNeal, 216, 217, 220, 401, 402.

MADSEN, 296, 443, 465.

MafUCCI, 247.

MAGGIORA, 437.

Magnusson, 202.

MALLORY, 300.

MANEGOLD, 203.

MANN, 423.

Manson, 380.

Mantoux, 258.

MARChOUX, 389, 406, 407, 410 .

MAREK, 370 .

MARMOREK, 85.

MaRPMANN, 301.

MARSH, 291, 292.

MARSHALL, 366 .

Martelly, 314.

MARTIN, 296, 337.

MARX, 437.

Masselin, 127, 269. 
MAssol, 302, 303.

MATZuschita, 39.

MAYER, 397, 399, 401, 405.

Meltzer, 480.

MeLvin, 334.

MenNes, 451.

MesNil, 374, 394, 397, 398, 402, 403,425 .

Messea, 22, 29, 30, 140.

METCHNIKOFF, $7,457,463,479$ 481.

Mettam, 365.

MeYer, 391.

Miessner, 241, 447.

Migone, 402.

Migula, 30-33, 39, 195, 215, 216, $221,234,245,266-271,274$, $278,281,293,299-301,30$, $308,316,336,352,355,359$.

MilKs, 382.

Minchin, 425.

Miyajima, 390, 404.

MOELLER, 131.

Mohler, 200, 201, 211, 213, 243, $263,282,334,335,367,368$, $398-400,464,476$.

Moore, 68, 90, 158, 159, 179, 188, $190,199,229,241,250,251$, $260,265,269,275,281,288$, $289,310,311,314,317,320$, $325,344,382$.

Morgan, 263.

MoRgENROTH, 463.

MoRI, 387.

MORRIS, 363 .

MoRse, 431.

Moussu, 258.

MUCH, 248, 479.

Mueller, 2, 3, 5, 34, 210, 479.

Muir, 485.

\section{$\mathbf{N}$}

NAEgeli, $4,8$.

NAKANISHI, 20.

NeELSon, 136.

Negri, 416, 422.

NeIsser, 211.

NELIS, 421.

NeNCKI, 148.

Nessler, 87, 150.

Neufeld, 452.

Neumann, 31, 151, 193, 198, 215 , $245,293,308,370$.

Newman, 188.

Nicolaier, 328.
Nicolle, 437.

DE NitTis, 349.

NobarRo, 374.

NOCARD, 9, 247, 251, 262, 283, 317, $363,388,389,435$.

Noснт, 397, 399, 401, 403.

Noguchi, 446, 464, 465, 476.

NorgaARD, 200, 282, 338, 339.

NoRRIS, 323, 415.

Novy, 57, 106, 149, 376, 401, 402, $408,413-415,442,479$.

Nowak, 216, 217.

Nuttall, 388, 391, 408, 479, 481.

OBERMEIER, 414.

Ogston, 189, 206.

O'HeHIR, 313.

OPHULS, 366.

OPPLER, 302.

OSLER, 377.

Ostertag, 203, 204, 438.

Отто, 456.

\section{$\mathbf{P}$}

PAGE, 366.

PAige, 366.

Pallas, 270.

Pallin, 365.

PALMer, 190.

Paltauf, 130.

PAPPENHeIMER, 415.

PARK, 77, 114, 145, 172, 181, 199, $210,246,296,297,328,358$, $376,377$.

Pasquale, 191.

PAsset, 190, 211, 309.

Pasteur, 1, 4-6, 155, 206, 228, 229 , $266,278,281,339,434,441$, $480,484$.

Pearson, 263, 365, 367, 368.

Peckham, 323, 325.

Perez, 157.

Perkins, 366.

Perroncito, 266, 360, 436.

Perrone, 196.

Peterson, 137, 248.

Petrusky, 86.

PFeiffer, 429, 446, 463, 482.

Pfeiler, 202.

Pheiffer, 143.

Phisalix, 446.

Piana, 388.

Pickens, 361. 
voN Pirquet, 257, 456.

Plaut, 367.

Plim Mer, 400.

Poels, 200, 286, 324.

Polla NDER, $1,4$.

Pollender, 221, 222.

Porter, 391.

Prazmowski, 34.

Preisz, 282, 283.

Pr-WazeK, 416.

Pruden, 197.

\section{$\mathbf{R}$}

RABE, 206.

RABENHORST, 6.

RAILLET, 432.

RATTONE, 328 .

RAVENEL, 367, 368.

REDFIELD, 176.

REED, 179, 204, 316, 324.

REMLINGER, 418, 439.

ReNon, 368.

RETTGER, 275.

REYNOLDS, 270.

RICHET, 455, 456.

RIDEAL, 70.

RILEY, $384^{\circ}$.

RIMPAU, 452.

RItZenthaleR, 288.

Rivolta, 360, 365, 429, 431.

Robertson, 390, 439.

RoBin, 371.

RoBins, 237.

RoEMer, 442.

Rogers, 397, 447.

Rolleston, 380 .

Romanowsky, 137.

Rosenau, 70, 443, 456, 457.

RosenbaCH, 189, 206, 207, 211.

Rosishaur, 231.

Rossi, 363.

Rотсн, 179.

ROTHWELL, 369.

Rouget, 398.

Roux, 6, 226, 247, 435, 441, 445.

RUBNER, 150.

Russell, 186.

\section{S}

Sabouraud, 370, 372.

SACCARDO, 112.

SACHS, 463.

Saint-Vincent, 3.

SAKHAROFF, 406, 407.
Salimbeni, 406, 407.

SALMON, 266, 315, 316, 441.

SANARELLI, 317, 324 .

SAND, 200.

SANFElice, 105.

SAVAGE, 311, 313.

SAvonuzzi, 436.

SAW YER, 263.

SCHAEFER, 356 .

Schat, 397.

Schaudine, $376,381,383,407$, $408,415,416,427$.

ScheNK, 366.

SchierbeCK, 301.

SCHIFFMANN, 437.

SCHMEIDEBERG, 149.

SCHMORL, 333, 334.

SCH NEIDER, 142.

SCHNITZLER, 354.

SchNuRER, 241, 447.

SсHОM, 324.

SCHROEDER, 5, 263, 483.

Schroeter, 269, 281, 349, 355.

SChubert, 464, 475 .

Schultz, 178.

SCHULz, 231.

Schutz, 200, 202, 234, 241, 271, $333,447,464,475$.

DE Schweinitz, 316, 438, 483.

Sclavo, 232.

SEDILLOT, 6.

Selander, 315.

SEMNer, 438.

SHICK, 456.

Siblex, 260.

SICARD, 448.

Sieber, 393.

Silberschmidt, $349,364$.

SJobRING, 431.

SMITH, ERWIN, 59.

Smith, GrahaM, 388, 389.

Smith, Horton, 353.

Smith, Theobald, 6, 59, 68, 83, $92,105,152,154,156,158$, $245,246,249,259,263,269$ $271,278,281,296,297,299$, $309,315-317,320,324,331$, $353,381,383-385,432,441$, $448,456$.

SobernheinI, 22, 479.

SPITZ, 364.

SPREULL, 440.

Starcovici, 384, 386.

SteEle, 396.

STEFANSKY, 264. 
Sternberg, 72, 196, 210, 357, 479.

STICKNER, 437.

STOCKING, 181, 207, 301.

Stockman, 216, 218, 220, 221, $264,405$.

StONEBURN, 275.

STRAHL, 143.

Strauss, 238.

Stribolt, 93, 217, 218.

STRUTZER, 230.

Swithinbank, 188.

\section{$\mathrm{T}$}

TAVEL, 17, 22.

TAYLOR, 241.

TERRE, 262.

THeIleR, 385-387, 389, 390, 392$394,413$.

THIERFELDER, 301.

ThoINOT, 127, 269.

THOMA, 430 .

Thomas, 336.

Thomassen, 317.

THUILLIER, 278, 281.

Thuм, 142.

TISSIER, 314.

ToDD, 294, 413, 438.

ToKishige, 365 .

TOUPET, 268.

Toussaint, $245,266$.

Trautman, 324 .

Trevisan, 35, 363.

Trombetta, 157.

TURNER, 438.

TYLER, 439.

TYzzen, 428.

\section{U}

UHLENHUTH, 316, 328, 416, 438.

UsCHINSKY, 88.

UTz, 301.

\section{V}

VALENTI, 437.

VALleE, 257, 337, 407.

VAUGHAN, 148, 149, 442, 456, 479.

VILLEMIN, 245.

Vincent, 177, 364.

Virchow, 369.

VoGES, 89, 402.

VotTALER, 329.

\section{W}

WAHRLICH, 230.

WALKER, 331.

WALL, 220, 478.

WARD, 11, 179, 183, 188, 204, 207, $258,268,306$.

WASHBURN, 211.

WASSERMANN, $450,455,463,464$, 479.

Watson, 399, 425, 426.

WECHSBERG, 211.

WeIGERT, 5, 128, 130, 460.

WeigmaN N, $181,301$.

WELCH, 320.

WELFARTH, 152.

WELLENHOFF, 297.

WENYON, 407, 414.

WERNICH, 481.

WESENBERG, 354 .

WEYL, 213.

WHERRY, 264.

WHIPPLE, 178.

WHITE, 258, 344-347.

WIDAL, 447, 448.

WILDE, 300.

WILlaCH, 230.

Williams, 85, 387, 398, 417, 423.

WILson, 270.

WINOGRADSKY, $35,94$.

WiNSLOW, 190.

WINTERBOTTOM, 406.

Wolbach, 28, 261.

WOLF, 455.

WOLFF, 361.

WOLFF-EISNER, 257, 463, 486.

WOLFFHUGEL, 114.

WooD, 230.

WoOLEY, 438.

Wright, 58, $139,300,310,361$, $451,452,484-486$.

\section{Y}

YERSIN, 445.

Youxg, 70 .

\section{Z}

Zetтxow, 20, 415 .

ZIEHL, 128, 133, 136, 248.

ZiemaNN, 74 .

ZINSSER, 452, 455.

Zорн, 29, 30 .

VAN ZURN, 245. 


\section{GENERAL INDEX.}

A

abortin, 220 .

abortion, 216,478 .

abscess, 207, 213, 288.

Achorion Schoenleinii, 367.

acid agar, 91.

fast bacteria, 135-137, 263, 264.

production, 152, 153.

acquired immunity, 480-482.

actinomyces, 359,360 .

asteroides, 364 .

bovis Bollinger, 360-362.

caprae, 364.

farcinica, 363, 364 .

madurae, 364.

in $\operatorname{man}, 364,365$.

pulmonalis Burnett, 362, 363.

actinomycosis, 360 .

active immunity, 483 .

adenitis, lymph, 282-286.

African horse sickness, 440.

tick fever, 416.

agar, used for cultures, see various organisms.

-gelatin-raw serum, 218-220.

-gelatin-serum, 93.

inoculation of tubes, $100,101$. preparation, $90,91$.

agglutination test, 240-243.

agglutinin, 447-449, 461, 463, 464 .

agglutinogen, 447, 448 .

aggressin, 454, 455 .

albumose, 443 .

alcoholic stains, 128.

alexin, 457.

algae, 5 .

allococcaceae, 33 .

amboceptor, 463-468.

ameba, 381 .

American foul brood, 346 .

amoebida, 377.

amphitricha, 30 .

anaerobic bacteria, 37, 103-107.

analysis, watēr, 176-178.

anaphylaxis, $455-457$.

Anaplasma marginale, 385.

marginale Theiler, 393, 394. anaplasmosis, 393 . anemia, 386, 393, 440 .

anesthetics, 166,167 .

aniline dyes, 5, 127, 128.

animal inoculation, 165-173.

animalcula, $2,373$.

animals, experimental, 163-173.

anthrax, 172, 221.

bacterium, see Bacterium anthracis.

immunization, 229, 232.

-like organisms, 229-231.

serum, 232.

symptomatic, 336 .

vaccine, 229.

anti-aggressin, 455 .

antibody, 442, 444-447, 450, 457461.

antigen, 460, 470-472.

antiseptic, 71 .

antitoxin, $6,165,332,442,444-$ $447,457-463$.

antivenene, 446 .

apoplectiform septicemia, 200202.

apparatus, 52-63.

aqueous stains, 129.

arthrospore, 23,30 .

asepsis, 71 .

Asiatic cholera, 309.

aspergillus, 367-370.

autoclave, 60,67 .

autogenic vaccine, 485 .

avian tuberculosis, $260-262$.

\section{B}

babesia, 383 .

bovis Starcovici, 384 .

mutans, 392.

ovis Starcovici, 386.

parva, 389.

bacillary white diarrhoea, 275 .

bacilleae, 33 .

bacillus, 18, 29-34, 308-354.

abortus, 216.

acidi lactici Hueppe, 300, 301.

acidi paralactis, 301.

acidophilus, 362.

aerogenes Kruse, 299..

Aertryck, 327. 
bacillus alvei Cheshire and Cheyne, 344-346.

American foul brood, 346. anthracis-similis McFarland, 230.

anthracis symptomatica Kruse, 336.

anthracoides Bainbridge, 231.

anthracoides Hueppe and

Wood, 230.

black brood, 344 .

black leg, 336 .

blue pus, 355 . -

Boas-Oppler, 302.

bovisepticus Kruse, 270.

buccalis maximus, 2.

bulgaricus, 303.

of calf diphtheria Loeffler, 333 . carriers, 180.

of caseous lymph-adenitis Nörgaard and Mohler, 282.

charbonis Migula, 336.

Chauveaui Arloing, Cornevin and Thomas, 336-339.

cholerae gallinarum, 266.

cholerae suis, 315.

cholerae suum Migula, 315.

cloacae, 347.

coli, 299, 317, 325, 326.

coli communis, 347.

coli Escherich, 309-315.

colon, 326.

of contagious abortion in cattle Bang, 216.

coprogenes parvus, 275.

cultivation, $311-313,318,319$, $321, \quad 322, \quad 329-331, \quad 333-335$, $337,340-343,345-353$.

cuniculi pneumonicus, 269.

Danyz, 327.

diphtheriae vitulorum, 333.

$E, 347$.

of Eberth, 321.

Eberth-Gaffky, 321.

enteritidis, 309, 326.

enteritidis Gaertner, 316, 323, $324,327$.

European foul brood, 344.

felis septicus Kruse, 274.

filiformis Schütz, 333.

food poisoning, 327,328 .

fowl cholera, 266-268.

Friedlander, 300.

Gaertner, 323-328.

green pus, 355 . bacillus hay, 348 .

Hoffmanni, 297.

hog cholera, 326.

of hog cholera Salmon-Smith, 315.

icteroides, 309, 326.

icteroides Sanarelli, 317, 324 .

identification, 315,323 .

intermediate, 323-328.

Klebs-Loeffler, 293, 298.

lactimorbi Jordan and Harris, 341-344.

lactis aerogenes, 302 .

lactis viscosus Adametz, 305.

larvae White, $346,347$.

life conditions, $313,314,320$, $322,323,331,335,337,338$, $341,343,346,347,349,351$, 353,354 .

lock jaw, 328 .

mallei Loeffler, 234.

of Massol, 302, 303.

mesentericus, 348 .

morbificans bovis Basenau, $324,3 \dot{2} 0^{\circ}$.

morphology, 310, 311, 317, 318, $321,329,334,336,337,340$, $342,344-348,350,352$.

murinus Schröter, 281.

murisepticus Koch, 281.

neapolitanus Emmerich, 309.

necrophorus Flügge, 333-336.

New York bee disease, 344 .

non-pathogenic, 348-354.

$O$ Cushing, 324-326.

oedematis Liborius, $339-34 \ldots$.

oedematis maligni Koch, 339 .

panis fermentati, 302.

paracolon Gwyn, 324, 326.

paratyphoid, 327. *

pathogenesis, $314,315,320$, $323,332,335,336,338,341$, $344,346,349,351,354$.

place in nature, $309,310,316$, $317,321,328,329,333,334$, $336,339-342,344,346,348-$ $350,352$.

potato, 348 .

of Preisz, 282.

prodigiosus (Ehrenberg)

Flügge, 349-351.

properties, see life conditions. proteus vulgaris, 352.

(proteus) Zenkeri, 352. pseudoanthracis Wahrlich,230. 
bacillus pseudodiphtheria, 297, 298.

pseudo-tetani, 333.

of pseudotuberculosis Preisz and Guinnard, 282.

pus, 355 .

pyocyaneus Gessard, 355.

pyogenes bovis Künnemann, 286.

pyogenes-foetidus Passet, 309.

pyogenes suis Grips, 286.

rabbit septicemia, 269.

resistance, $314,320,331,332$, $335,338,346$.

rhusiopathiae suis Kitt, 278.

of Schweineseuche Loeffler and

Schütz, 271.

septicemia hemorrhagica $\mathrm{Hu}$ eppe, 270.

staining, $311,318,321,329,334$, $337,340,342,345,347,348$, 352.

subgastricus, 347.

subtilis, 25.

subtilis Cohn, 348, 349.

suipestifer, 22, 290, 291, 309, 324-327, 347.

suipestifer Kruse, 315-320.

suisepticus Kruse, 271.

of swine erysipelas Loeffler, 278.

of swine fever Klein, 316.

of swine pest Selander, 315 .

of swine plague Billings, 315 .

of swine plague Smith, 271.

tetani Nicolaier, 328-332.

tuberculosis Koch, 245.

typhi abdominalis Eberth, 321.

typhi murium, 309, 326, 327.

typhi murium Loeffler, 316, 324.

typhoid, 325 .

typhosus, 309, 317, 321.

typhosus Eberth, 321-323.

viscosus, 21.

vulgaris (Hauser) Migula, 352-354.

white diarrhoea, 275 .

$X$ White, 346 .

$X I X, 301$.

bacteria, acid fast, $135,137,263$, 264.

acid production, 152, 153.

activities, 12, 13 .

aerobic, 37.

aєrogenic, 36 . bacteria anaerobic, 37, 103-107.

chemical action, 144, 145.

chemotaxis, 143.

chromogenic, 36 .

classification, $3,16,29-37$.

color, 16.

cultivation, 97-107.

definition, 8.

denitrification, 152 .

differentiation, 164, 165 .

and disease, 156-162.

distribution, 9-12, 216.

examination, 120-129, 238.

fat decomposition, 151.

in feces, 174.

and fermentation, 5, 145, 146.

fission, $26,27$.

food, 97.

gas production, 153-155.

genera, 29-35.

growth, y, 10, 12, 97-107.

habitat, 9-12.

heat production, 144 .

higher, 16, 17, 359-372.

history, 215.

infection, 15ช-162, 187.

intermediate, 323-328.

isolation, 55-59, 101, 237, 238.

longevity, 27, 28.

lower, 16, 17, 26, 27.

mesaphilic, 37.

metatrophic, 12.

milk, 178-188.

monomorphous, 30 .

morphology, 16-28, 217, 222.

motility, 22, 140, 141.

multiplication, 12.

in nature, 8-15.

nitrifying, 37, 152.

non-pathogenic, $180,299-307$, 348-354.

parasitic, $12,35,36,156-158$.

paratrophic, 12 .

pathogenic, $12,14,15,36,156$ -

$162,180,186$.

phosphorescent, 143.

photogenic, 36 .

physiology, 4 .

pigment production, 141, 142.

pleomorphous, 30.

products, 441-463.

psychrophilic, 37 .

putrefactive, 151.

reduction power, 150,151 .

reproduction, $16,17,26,27,29$. 
bacteria saprogenic, 36 .

saprophytic, $12,13,35,36$, 137.

size, 16 .

soil, 174 .

sporulation, 24-26.

thermophilic, 37 .

vegetative forms, 17 .

vital activities, 140-155.

water, 174-178.

bacteriaceae, 30-32, 215-358.

bacterial immunity, 482, 483 . products, 441-463.

bacteriological examination, 238 . bacteriology, agricultural, 13.

beginning, 1 .

dairy, 14.

definition, 9.

divisions, 13-15.

history, 1-7.

industrial, 14.

bacteriolysis, 446 .

bacterium, 18, 29, 31, 32, 209-307. abortionis Bang, 216-221.

acidi lactici (Hueppe) Migula, $300,301$.

aerogenes (Escherich) Migula, 299,300 .

aeruginosum (Schroeter), 355. agglutination, 240-243.

anatis, 268.

anthracis, 1, 4, 23, 24, 225-232, $298,349$.

anthracis Koch, 230.

anthracis (Koch) Migula, 221. 229.

anthrax, see anthracis.

anthrax-like, 229-231.

astheniae Dawson, 232-234.

avian tuberculosis, 260-262.

bipolare multocidum Kitt, 270.

bovisepticum (Kruse) Migula, $270,271$.

bulgaricum Grigoroff, 302-3vo. caseous lymphadenitis, 282-286. cholerae-gallinarum, 266-268. coli-commune Escherich, 309.

cultivation, $217-220,224-226$, $233-236,241,248-250,267-$ $273,276,277,279,280,283-$ $285,287,288,290-293,295$, $296,299,300,302-307$.

cuniculi, 269.

cuniculicidia (Flügge) Migula, 269,270 . bacterium cygni, 268.

diphtheriae (Loeffler) Migula, 293-298.

erysipelatus suis Migula, 278.

felis (Kruse) Migula, 274, 275.

of fish tuberculosis, 262 .

of fowl typhoid, 288 .

Johne's disease, 263, 264.

lactarii, 301 .

lacticum Babinsky, 299.

lactis, $300,301$.

lactis acidi, 301.

lactis aerogenes, 299.

leprosy-like, $264,265$.

life conditions, $220,221,226$, $234,236-238,268,270,273$, $277,280,281,285,288,291$, $293,29 \dot{0}, 300,302,307$.

lymph adenitis, 282-286.

mallei, 298, 470 .

mallei (Loeffler) Migula, 234245.

morphology, 223, 232, 234, 247, $260-262,266,267,269-272$, $276,279,283,286,289,292$, $294,299,301-303,305,306$.

murisepticum (Flügge) Migula, $281,282$.

mycordes, 347.

pathogenesis, 221, 226-229, 234, $237,250,251,268,274,277$, $278,281,285,286,288,291$, $293,296,297,300,363$.

place in nature, $216,217,221$, $222,232,234,245-247,266$, $269-271,274,275,278,279$, 281-283, 286, 289, 291-294. 299-303, 305, 360-372.

prodigiosum Schröter, 349.

properties, see life conditions.

pullorum Rettger, 275-278.

pyelonephritis, 288.

pyogenes Grips, 286-288.

resistance, $23,161,221,234$, $237,268,273,274,277,281$, $285,291,293,296,307$.

rhusiopathiae, 298.

rhusiopathiae (Kitt) Migula, 278-281.

sanguinarium Moore, 288-291.

septicemiae hemorrhagicae. $265,266$.

septichaemia Schröter, 269. 
staining, $123-139,217,223,232$, $233,235,247,248,267,269$, $272,276,279,283,286,289$, $290,292,294,295,299,302$, $303,306$.

subviscorum Migula, 305-307.

suicida, 271.

suisepticum, 273, 274, 290, 298. suisepticum (Kruse) Migula, 271-274.

termo, 352.

trout disease, 291.

truttae Marsh, 291-293.

tuberculosis, 92, 93, 298.

tuberculosis (Koch) Migula, 245-251.

of Wild- und Rinderseuche Bollinger, 270.

zymogenic, 36 .

bactridium, 34 .

bactrillum, 34 .

bactrinum, 34 .

Baginisky's apparatus, 58 .

bee disease, 344 .

bee-larvae agar slant, 347 .

beggiatoa, $5,16,35$.

beggiatoaceae, 32 .

bichloride of mercury, 72 .

bile medium, 90 .

bilious fever, 388 .

black brood, 344 .

blackhead, 381 .

black leg, 336 .

immunity, 338, 339.

vaccine, 338,339 .

black quarter, 336 .

Blastomyces farciminosus, 365 .

blood cells, 465 .

cultures, 122, 123.

preparations, 138, 139.

serum, see serum.

blue tongue, 440 .

Boas-Oppler bacillus, 302 .

Botryococcus ascoformans Bollinger, 206.

bottles, 55 .

bougie, 60 .

bouillon cultures, 99, 100; see also various organisms. examination, $116,120-122$. preparation, $81-84,87,91$. serum, 85.

bovine farcy, 363 .

\section{C}

calcium carbonate broth, 84 .

compounds, 74 .

compounds, 74 .

calf diphtheria, 333 .

cancer, mouse, 413.

canine piroplasmosis, 388 .

capsule, $18,21$.

staining, 132.

carbohydrates, 153-155.

carbol fuchsin, 124, 128, 133.

carbolic acid, 73, 76 .

gentian violet, 129.

carceag, $38 b$.

caseous lymph-adenitis, 282.

catarrh, 213.

intestinal, 323 .

catarrhal fever, 440 .

cattle disease, 383 .

plague, 437.

tick, 6 .

cell content, $19,20$.

division, $26,27$.

wall, $19,20$.

centrifuge, 59 .

cerebro-spinal meningitis, 213, 439.

chicken pest, 437 .

chlamydobacteriaceae, 16, 31, 22.

chlorophyl, 8.

choanflagellida, 378 .

cholera, Asiatic, 309.

fowl, 266-268.

hog, $172,315,326,438$.

ciliata, 379.

cladothrix, $32,35,360$.

cladotricheae, 30 .

classification, see protozoa, streptococcus.

cleaning mixtures, 80 .

clostridieae, 34 .

clostridium, 34 .

coccaceae, 30,33 , 189-214.

coccidiosus, $428-432$.

coccidium, $379,427-432$.

cuniculi Rivolta, 429.

oviforme Leuckart, 429-432.

coccoceae, 31 .

coccus, $2,17,33,207$.

Cohn's solution, 88 .

colon bacillus, 326 .

colonies, 98, 99, 109-116.

complement, 457, 463, 464 .

titration, $468-470$. 
conidia, 16, 17.

contagious abortion, 216.

pleuropneumonia, 435 .

copper sulphate, 132.

corrosive sublimate, 72 .

Corynebacterium diphtheriae Lehmann and Neumann, 293.

counterstains, 136.

counting colonies, 112-114.

cover-glass, 54 .

preparations, 122-124.

cow pox, 439.

crenothrix, 32,35 .

cultivation, see bacillus, bacterium, micrococcus, protozoa, pseudomonas, streptococcus. cultures, 99-102.

Bact. mallei, 241.

blood, 122, 123.

examination, 108-123.

media, 5, 55-59, 79-101, 114-116, $120,122,163,164,218-220$.

plate, $102,108-114$.

test tube, 114-116.

cystitis, 354 .

cystoflagellata, 378 .

cytase, 457.

cytolysis, 445 .

cytoplasm, 19

\section{D}

decoloring agents, 135, 136 .

decomposition, fat, 151 .

degeneration forms, 28 .

denitrification, 152.

deodorant, 71 .

dermatitis, 366 .

deuteroalbumose, 442 .

deuterotoxin, 458 .

diagnosis, 420-424.

by animal inoculation, 168 .

serum, 464-478.

tuberculosis, 254-260.

diarrhoea, 275 .

differentiation of species, 164 , 165.

dinoflagellata, 378 .

diphtheria, $6,172,173,293,333$. calf, 333 .

pseudo-, 297, 298.

diplococcus, 17.

diseases caused by bacteria, 156162.

disinfection, 70-78. distribution, see bacterium, micrococcus, streptococcis.

dog distemper, 205.

dourine, 398.

dyes, aniline, 5, 127, 128.

dysentery, 355 .

\section{E}

East Coast fever, 389 .

Eberth-Gaffky bacillus, 321.

ectoplasma, 22.

egg medium, 96.

Ehrlich's side-chain theory, 481, 482.

endospore, 23, 30.

endotoxin, 461, 462.

englenida, 378 .

enteritis, 263, 264.

enterohepatitis, 381 .

entoplasm, 20.

epithelioma contagiosum, 437.

epizootic cerebro-spinal meningitis, 439 .

lymphangitis, 365,366 .

mouse, 324 .

erysipelas, 197.

swine, 278.

exhaustion theory, 480 .

experimental animals, 163-173.

extracellular toxin, 443.

exudative typhus, 437.

\section{F}

farcy, 363,365 .

fat decomposition, 151.

fecal bacteria, 174 .

fermentation, 5, 177.

bacteria, 145, 146 .

tubes, 56, 59 .

ferments, 146-148.

Fermi's solution, 94.

fever, bllious, 388 .

catarrhal, 440 .

East Coast, 389.

malarial catarrhal, 440.

Malta, 213.

relapsing, 414.

swine, 316.

Texas, 6, 383, 384 .

tick, 416.

typhoid, 321.

yellow, 324 .

filament, $16,17,27$.

film preparations, 123 .

filter, 67. 
filterable virus, $7,433-440,483$, 484.

filtration, 434,435 .

fission, $26,27$.

fixing bath, 134 .

flagellata, $6,378,383-416$.

flagellum, 18, 21, 22, 29, 30 . motility, 140, 141.

staining, 132 .

flasks, 55,56 .

flora, bacterial, 10, 11.

food poisoning bacilli, 327, 328 .

foot and mouth disease, 435 .

foraminifera, 477 .

forceps, 54 .

formaldehyde gas, 74, 75 .

formalin, 74 .

foul brood, $3,344,346$.

fowl cholera, $266-268$.

pest, 436 .

plague, 436, 437.

typhoid, 288.

frambesia, 407 .

Friedlander bacillus, 300 .

fungi, $8,178,359-372$.

\section{G}

Gaertner bacillus, 323-328.

gall sickness, 392, 393.

gas in cultures, 117.

formation, 153-155.

gelatin, cultures, see various organisms.

inoculation, 100, 101.

preparation, 91, 92.

gentian violet, 128, 129.

germ theory, 5 .

germicide, 5, 71 .

milk as, 182.

Giemsa's stain, 137, 138.

glanders, $169,170,234,365,464-$ 478.

glycerine agar, 91, 250.

bouillon, 250 .

"going light," 232.

gonorrhea, 213.

goose septicemia, 266, 406.

Gram's solution, 129, 130.

granular venereal disease, 203, 204.

granule, 18, 26.

grape-coccus, 207.

gregarinida, 379 .

gymnamoebida, 377,381 .

gymnobacterium, 30 .

\section{H}

haemosporidia, 379 .

hanging block, 121.

drop, 121.

haplobacterinae, 33 .

haptophore, $459,482$.

hay bacillus, 348 .

heat production, 144 .

heliozoa, 378.

hemoglobinuria, 386 .

hemolysis, $210,211,445,464-478$.

hemolytic amboceptor, 465-468. serum, 466-468.

heterommastigida, 378 .

heterotrichida, 379 .

higher bacteria, 16, 17, 359-372.

history, see bacteria, micrococcus, streptococcus.

Hiss's medium, 95.

serum, 85.

hog cholera, 172, 315, 326, 438. bacillus, 315,326 .

holotrichida, 379 .

homococcaceae, 33.

horse sickness, 440.

humoral theory, 481.

hydration, 144 .

hyphomycetes, 366,367 .

hypotrichidia, 379 .

\section{I}

ictero-hemoglobinuria, 386 .

identification of species, 38-51.

immune body, 462,463 .

immunity, 6, 444-447, 457-463, $479,484$.

active, 483 .

anthrax, 229, 232.

bacterial, 482,483 .

black leg, 338, 339 .

natural, 480 .

passive, 483 .

protozoan, $483,484$.

toxic, $482-484$.

incubator, 57, 58, 61, 62 .

incultivability, 434 .

infection, 158-162, 187.

mixed, 434.

protozoan, 380,381 .

symbiotic, 434.

infectious abortion, 478 .

anemia, 440.

enterohepatitis, 381.

pneumonia, 202, 271 .

inflammations, 197, 314. 
infusoria, $3,6,30,379$.

inoculation, $5,103,421$. gelatin, 100,101 .

test animals, 165-173.

intermediary body, 463 .

intermediate bacteria, 323-328.

intestinal catarrh, 323.

obstruction, $177,178$.

intracellular toxin, 444.

intradermal test, 258.

involution, $18,28$.

isolation, 55-59, 101, 237, 238.

\section{J}

jaundice, 388 .

Jeffers' plate, 113.

Jenner's stain, 138, 139.

Johne's disease, 263, 264.

\section{K}

Klebs-Loeffler bacillus, 293, 298.

\section{L}

lactic acid organism, 301 .

lateral, see side chain theory.

leprosy, 264.

-like bacterium, 264, 265.

leptitricheae, 30 .

leptothrix, 359.

buccalis, 302.

Leucocytoon canis Bentley, 426, 427.

life conditions, see bacillus, bacterium, micrococcus, pseudomonas, streptococcus.

lime, 74 .

liquid media, 116. serum, 287, 335.

litmus media, 86 . milk, 343.

liver diseases, 429-432.

lock jaw, 328 .

Loeffler's blood serum, 89, 90, 92. mordant, 133, 134. stain, 133.

lophotricha, 30 .

lower bacteria, 16, 17, 26, 27.

lymph-adenitis, 282-286.

lymphangitis, $365,366$.

lysin, 461 .

lysis, 445, 458, 462 .

\section{M}

mal de caderas, 402.

malaria, 6 .

malarial catarrhal fever, 440.

malignant jaundice, 388 .

oedema, 339 .

malleasa, 244, 245.

mallein, 237-240, 442 .

Malta fever, 213.

mastigophora, 378 .

mastitis, 204.

meat-poisoning, 323-328.

media, see cultures.

meningitis, $213,369,439$.

mercury bichloride, 72 .

mesaphilic bacteria, 37 .

metatrophic bacteria, 12 .

methylene blue, $123,124,126$, 128.

microbe, 6 .

micrococcus, 17, 18, 27, 29-31, 33, 206-214.

botryogenes Rabe, 206.

caprinus, 211-213.

catarrhalis, 213.

cultivation, 208, 209, 211-213.

distribution, 207.

gonorrhoea, 213.

hemolysis, $210,211$.

history, 206.

intracellularis meningitis, 213.

lanceolatus, 21, 213.

life conditions, 209, 213.

melitensis, 213.

morphology, 207, 211.

pathogenesis, $210,213$.

place in nature, 207, 211.

prodigiosus Cohn, 349.

properties, see life conditions.

pyogenes, 206.

pyogenes aureus, 208.

pyogenes (Rosenbach) Migula, 207-211.

resistance, $210,213$.

staining, 207, 211.

tetragenes, 213.

microorganism, 6 .

microscope, 53, 120.

microspira, 32.

Microsporon Audouini, 370.

Microsporum Audouini, 371.

milk, bacteria, 178-188.

as culture medium, see various organisms. 
examination of cultures, 116, $117,120$.

as germicide, 182 .

impurities, 187, 188.

pasteurization, 187.

preparation, 86 .

sickness, 341.

sterilization, 187.

mixed infection, 434 .

vaccines, 486 .

monadida, 378,383 .

monas, 3,6 .

prodigiosa Ehrenberg, 349.

monotricha, 30 .

mordant, 133-135.

morphology, 53-55, see also bacillus, bacterlum, micrococcus, protozoa, pseudomonas, streptococcus.

motas, $388,3 \diamond 9$.

motility, 22, 140, 141.

moulds, 6 .

mouse cancer, 413 .

epizootic, 324 .

septicemia, 281.

mycetozoa, 377 .

mycosis, 368 .

Mykobacterium tuberculosis Lehmann and Neumann, 245. myxosporidia, 380 .

\section{$\mathbf{N}$}

nagana, 400 .

natural immunity, 480 .

Negri bodies, 416-424, 433.

nekrosebacillus Bang, 333.

neosporidia, 380 .

neutral red, 87.

New York bee disease, 344 .

nitrate bouillon, 87 .

nitrifying bacteria, 37, 152.

nitrogen combinations, 152.

Nocardia farcinica Trevisan, 363.

non-pathogenic bacteria, 180, 299$307,348-354$.

Novy's apparatus, 57.

nuclear substance, 20.

nucleus, $19,20,27$.

nutrient agar, 90.

gelatin, $91,92$.

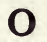

oedema, malignant, 339 .

Oidium albicans, 367 . ophthalmic reaction, 257,258 .

opsonic index, 486.

opsonin, 450-453.

oscillaria, 5.

oxidation, 144

\section{$\mathbf{P}$}

paraform, 76 .

parasite, $12,35,36,156-158$.

passive immunity, 483 .

pasteurella, 265, 266.

pasteurization of milk, 187.

pathogenesis, see bacillus, bac-

terium, micrococcus, protozoa, pseudomonas, streptococcus.

pathogenic bacteria, $12,14,15$, $36,156-162,180$.

in milk, 186.

pathology, 4, 14 .

pediococcus, 33 .

peptone solution, 84 .

peritricha, 30 .

peritrichlda, 379 .

Petri dish, 56.

Pfeiffer's phenomenon, 446, 463, 482.

phagocytosis, $450-455,481$.

phenomenon of Arthus, 456.

of Koch, 454.

Pfeiffer's, 446, 463, 482.

Theobald Smith's, 456.

phosphorescence, 143.

phragmidiothrix, 32 .

phytoflagellida, 378 .

pigment production, 141, 142.

piroplasma, 6 .

bigeminum Smith and Kilborne, 384-386.

canis, $388,389$.

equi Laveran, 386-388.

mutans Theiler, 392, 393.

ovis, 386.

parvum Theiler, 389-392.

Smith and Kilborne, 383, 384.

piroplasmosis, 386 .

canine, 388 .

tropical, 389.

place in nature, see bacillus, bacterium, micrococcus, protozoa, pseudomonas, streptococcus.

plague, swine, $171,172,271,315$.

planococcus, 31,33 .

planosarcina, 31,33 .

plasmodium, 6 . 
plasmolysis, 19, 26.

plate cultures, $102,108-114$.

platinum loop, 57.

plectridieae, 34 .

plectridium, 34 .

pleomorphism, $\mathbf{z 8}$.

pleuropneumonia, $270,435$.

pneumonia, 213.

infectious, 202, 203, 271.

pleuro-, 270, 435.

pneumonomycosis, 367 .

polymastigida, 378 .

polymerization, 144 .

polyvalent vaccine, 486 .

potato, as culture medium, see various organisms.

precipitation test, 243,244 .

precipitin, 449, 450, 461, 463, 464.

products, bacterial, 441-463.

properties, see bacillus, bacterium, micrococcus, protozoa, pseudomonas, streptococcus.

proteids, 461, 463 .

-free media, 88,89 .

protein, 442.

Proteus vulgaris Hauser, 352.

protista, 6,8 .

protoplasm, 19, 20, 23, 26 .

prototoxin, 458.

protozoa, 6, 373-432.

classification, 377-380.

cultivation, $375,376$.

immunity, 483, 484.

infection, 380 , 381 .

morphology, 381, 382, 385-389, $393,394,397-401,403,404$,

$407,409-416,418-420,429-432$.

pathogenesis, $376,400,425,426$.

place in nature, $384-386,388$ $392,396-409,413,414,416$ $418,424,425$.

staining, 388, 389, 401, 402.

Pseudoanthracis Burri, 230.

pseudodiphtheria, 297, 298.

pseudomonas, 32, 355-358.

cultivation, 357.

fluorescens liquefaciens, 347.

life conditions, 357,358 .

morphology, 356 .

pathogenesis, 358 .

place in nature, 355,356 .

properties, see life conaliions.

pyocyaneus Migula, 355-358.

resistance, 358 .

staining, 356 . pseudotetanus, 333.

pseudotuberculosis, 282.

ptomains, 148, 149.

purification of water, 178 .

pus bacillus, 355 .

coccus, 207.

examination, 123.

putrefaction, 151.

pyelonephritis, 288, 354 .

pyocyanase, 358 .

pyocyanin, 149 .

Pyrosoma Smith and Kilborne, 384-386.

\section{$\mathbf{R}$}

rabbit septicemia, 269 .

rabies, $170,171,416-424$; see also Negri bodies.

radiolaria, 378 .

rat disease, 324 .

reaction, Bact. mallei, 243.

ophthalmic, $257,258$.

skin, $257,258$.

tissue, 441-463.

tuberculin, 254-260.

reagent, 87.

receptor, 459-461, 463.

red blood cells, 465 .

reducing bath, 135 .

reduction power of bacteria, 150 , 151.

relapsing fever, 414.

reproduction, bacteria, 16,17 , $26,27,29$.

resistance, 6 ; see also bacillus, bacteria, bacterium, micrococcus, pseudomonas, streptococcus.

retainer, 79,80 .

retention theory, 481 .

rhizopodia, 377 .

ring worm, 369 .

Rotlauf, 278.

rouget, 278.

\section{$\mathbf{S}$}

saccharomyces, 365,366 .

F, 347.

farciminosus, 365,366 .

in $\operatorname{man}, 366$.

safety burner, 63 .

saprophyte, $12,13,35,36,137$.

sarcina, $17,27,31,33$.

sarcocyst, 426 . 
sarcodina, 377

sarcosporidia, 380, 424-426.

sarcosporidiosis, 425 .

schizomycetes, 8,373 .

Schweineseuche, 271.

segmentation, 19, 27.

sensitizing bath, 135 .

septa, 16.

septicemia, apoplectiform, 200 .

goose, 226, 406.

hemorrhagica, 265, 266, 270.

mouse, 281.

rabbit, 269 .

serum, agar-gelatin, 93, 218-220.

anthrax, 232.

blood, $89,90,92,93,249,250$.

bouillon, 85 .

complement, 457 .

as culture medium, see various organisms.

diagnosis, 464-478.

disease, 456.

hemolytic, $466-468$.

Hiss', 85.

liquid, 287, 335 .

preparation, $85,89,90,92,93$.

sterilization, 86 .

titration, 466-468, 472-475.

for tubercle bacteria, 92,93 .

water, 85.

side chain theory, 459-462, 481, 482.

silicate jelly, 94 .

silicoflagellida, 378 .

silk worm, 4.

skin glanders, 365 .

reaction, 257,258 .

sleeping sickness, 203, 406.

slides, 54 .

soil bacteria, 174 .

solid media, 90, 114-116, 120, 122.

solution, Fermi's, 94.

Gram's, 129, 130.

peptone, 84 .

Uschinsky's, 88, 89.

Ziehl's, 125.

species, identification, 38-51.

spirillaceae, $31,32,34$.

spirillum, 18, 27, 29, 30, 32, 34 . ovina, 413.

sputigenum, 2.

'Theileri, 413.

spïrochaeta, $29,32,35,406-416$. Duttoni, 416. equi, 413.

gallinarum, 406, 410-412.

Marchouxi, 406.

microgyrata Lowenthal, 413, 414.

muris, 414.

Obermeieri, 414, 415.

ovis, 413.

pallida, 415, 416.

staining, 137.

Theileri, 413.

spirosoma, 32 .

spore, 17-20, 23-25, 29.

germination, 24,25 .

staining, 131.

sporozoa, 379 , 427-432.

sporulation, 24-26.

sputum, examination, 123.

staining, see bacillus, bacterium, capsule, micrococcus, protozoa, pseudomonas, spirochaeta, spore, streptococcus, tubercle bacterium.

stains, 123-139.

alcoholic, 128.

aqueous, 129.

Giemsa's, 137, 138.

Jenner's, 138, 139.

Loeffler's, 133.

Wright's, 139.

staphylococcus, $17,33$.

pyogenes aureus, 213.

pyogenes aureus Rosentach, 207.

starch-jelly, 95.

sterilization, 64-69, 79, 80.

of milk, 187.

of serum, 86 .

sterilizer, 60, 65, 152.

stock vaccines, 485 .

strangles, 200.

Strauss method, 238.

strengthening bath, 135 .

Streptobacillus lebenis, 302.

streptococcus, 18, 31, 33, 189-205.

acidi lactici, 301.

agilactae, 204.

anginosus, 192.

of apoplectiform septicemia in

fowls Nörgaard, 200-202.

biologic properties, 195 .

brevis, 190.

capsulatus gallinarum, 203.

classification, 190-193.

conglomeratus Kurth, 197. 
contagiosi, 204.

coryzae contagiosae equorum Eisenberg, 200.

cultivation, $195,196,198,200$, $201,203$.

distribution, 193, 194.

equi Schütz, 200.

erysipelatos Rosenbach, 197.

faecalis, 192.

flexuosi, 191.

gracilis, 193.

of granular venereal disease of cattle, 203, 204.

history, 189, 190.

of infectious pneumonia of horses, 202, 203.

lacticus, 301, 304, 305.

life conditions, 198, 199, 201.

longus, 190.

longus von Lingelsheim, 197.

mastitis, 204, 205.

mitis, 192.

morphology, 195, 198, 200, 203. pathogenesis, 199, 202, 203.

place in nature, 197, 200, 202205.

properties, see life conditions. pyogenes, 192.

pyogenes Rosenbach, 197-200.

resistance, 196, 199, 201.

rigidi, 191.

salivarius, 192.

septopyaemicus Biondi, 197.

staining, 198, 200, 203.

streptothrix, 32.

cuniculi Schmorl, 333.

farcinica Rossi-Doria, 363.

Stribolt's medium, 218-220.

suctoria, 379 .

sulfurairer, 5 .

sulphur, 76 .

sulphuretted hydrogen, 149 .

sulphuric acid, 76 .

suppuration, 207, 286, 314.

surra, 396.

swine erysipelas, 278.

fever, 316 .

pest, 315 .

plague, $171,172,271,315$.

symbiotic infections, 434 .

symptomatic anthrax, 336.

synthesis, 144.

syphilis, 415 .

\section{$\mathbf{T}$}

takosis, 211.

telosporidia, 379 .

terminology for colonies, 109-112, $115,116$.

test, agglutination, 240-243.

animals, 165-173.

fluid, 242.

intradermal, 258.

mallein, 239, 240 .

precipitation, 243, 244.

tube, 55, 56, 114-116.

tube cultures, 114-116.

tetanolysin, $331,443$.

tetanospasmin, 331, 443.

tetanus, 6, 328, 445 .

antitoxin, 332 .

pseudo-, 333.

tetracoccus, 17.

tetrad, 27.

Texas fever, $6,383,384$.

thallophyte, 8 .

thecamoebida, 377.

Theileri parva, 389.

Theobald Smith's phenomenon, 456.

theory, Ehrlich's side chain, 481, 482 .

exhaustion, 480 .

germ, 5 .

humoral, 481.

retention, 481 .

therapy, vaccine, 7, 484-486.

thermoregulator, 63 .

thermostat, 58,59 .

thiothrix, 32,35 .

tick, cattle, 6 .

fever, 416.

tissue reactions, 441-463.

titration, antigen, $471,472$. complement, $468-470$.

serum, 466-468, 472-475.

titre, 468-472.

Torula tonsurans, $369,370$.

toxalbumin, 444 .

toxic immunity, 482-484.

toxin, 156-158, 442-447, 456-463.

Bact. tuberculosis, 251.

extracellular, 443.

intracellular, 444.

toxoid, $443,460,461$.

toxone, 443 .

toxophore, $459,482$.

trembles, 341 .

Treponema anserina, 406. 407. 
anserinum Sakharoff, 407. gallinarum, 406, 410-412. gallinarum Marchoux and Salimbeni, 407.

Laverani Breini and Kinghorn, 407.

muris, 414.

muris Wenyon, 407.

pallida, $415,416$.

pallidum Schaudinn, 407.

Theileri, 413.

Theileri Laveran and Vallée, 407.

trichobacteria, 30 .

trichobacteriaceae, 35 .

trichobacterinae, 35 .

trichophyta, 370 .

Trichophyton tonsurans, 370-372.

tricresol, 73 .

tritotoxin, 458

tropical piroplasmosis, 389 .

trout disease, 291.

trypanosoma, 6, 394-406.

Americanum, 404, 405.

Brucei, 402.

Brucei Plimmer and Blandford, 400-402.

equinum Voges, 402-404.

equiperdum Doflein, 398-400.

Evansi Steele, 396-398.

gambiense, 406.

Lewisi, 402.

tsetse fly disease, 400 .

tube, $55,56,114-116$.

tubercle bacterium, 251, 260-262.

serum culture, 92, 93.

staining, 136, 137 .

tuberculin, 6, 251-260, 442

reaction, $254-260$.

tuberculosis, 5, 169, 245.

animal inoculation, 169.

avian, $260-262$.

diagnosis, 254-260.

pseudo-, 282.

vaccination, $262,263$.

tumor, 413.

typh̄oid bacillus, 325 .

fever, 321.

fowl, 288.

typhus, exudative, 437.

\section{U}

uniceptors, 463.

unstainability, 434.

ultramicroscopic bodies, 434 .

Uschinsky's solution, $88,89$.

\section{V}

vaccination, 484-486.

against tuberculosis, 262, 263.

vaccine, $281,453,484-486$.

anthrax, 229.

apparatus for making, 60-63.

autogenic, 485 .

blackleg, 338, 339 .

mixed, 486 .

polyvalent, 486 .

stock, 485 .

therapy, 7, 484-486.

vacuole, 26.

vaginitis, 203.

vegetative forms, 17

venereal disease, 203, 204.

venom, 444.

vibrio, $3,29,34$.

buccalis, 2.

subtilis Ehrenberg, 348.

Vibrion septique Pasteur, 339.

vibrionia, 3.

virus, filterable, $7,433-440,483$, 484.

vital activities, 140-155.

\section{W}

water, analysis, 176-178.

bacteria, 174-178.

bath, 66 .

purification, 178.

white diarrhoea, 275 .

wound infection, 158, 161, 162 ,

Wright's device, 58.

stain, 139.

\section{Y}

yaws, 407.

yeast, 6 .

yellow fever, 324 .

\section{Z}

Zenker's fluid, 125.

Ziehl's solution, 125. 


\title{
SHOR'T TITLE CATALOGUE
}

\author{
oF \\ VETERINARY PUBLICATIONS.
}

The Pathology and Differential Diagnosis of Infectious Diseases of Animals. Moore.............\$4.00

The Principles of Microbiology. Moore........\$3.50

Veterinary Obstetrics. Williams............\$8.00

Surgical and Obstetrical Operations. Williams...... $\$ 2.50$

Veterinarian's Hand-Book of Materia Medica and Therapeuties. Udall.................... Press

General Surgery-Fröhner. Translated by Udall..... \$3.00

Veterinary Doses and Prescription Writing. Fish.....\$1.50

Examination of the Urine of the Horse and Man. Fish. .\$1.50

Elementary Exereises in Physiology. (Laboratory Manual.) Fish.................... $\$ 1.50$

Elementary Exercises in Materia Medica and Pharmacy.

(Laboratory Manual.) Fish..........\$1.50

The Clinical Pathology of the Blood of Domesticated Animals. Burnett................. \$2.50

Fure Milk and the Public Health. Ward.........\$2.00

CARPENTER \& CO.

SUCCESSORS TO THE PUBLISHING DEPARTMENT OF

TAYLOR \& CARPENTER

ITHACA, NEW YORK 









\section{YD 23380}

- U.EA u

1

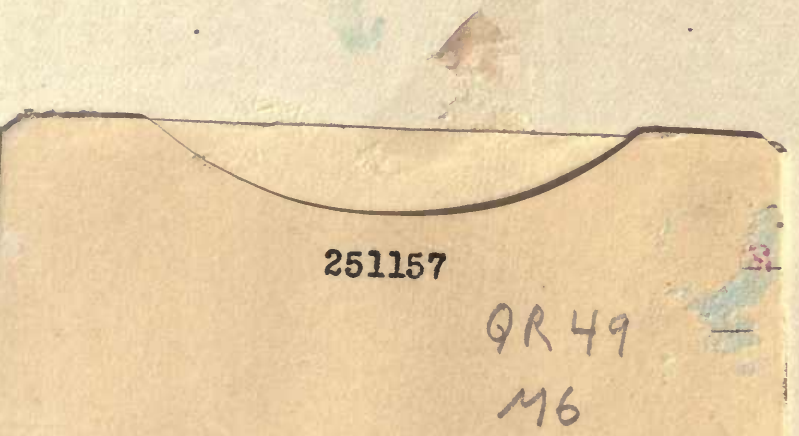

BIOLOGY

LIBRARY

THE UNIVERSITY OF CALIFORNIA LIBRARY 
